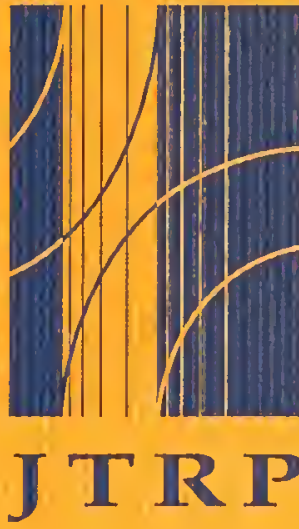

Joint

Transportation

Research

Program

FHWA/IN/JTRP-99/2

Final Report

FLEXIBLE PAVEMENT DRAINAGE MONITORING, PERFORMANCE, AND STABILITY

Aiwen Feng

Jianfeng Hua

Thomas D. White

May 1999

Indiana

Department

of Transportation

Purdue

University 

Final Report

FHWA/IN/JTRP-99/2

\title{
FLEXIBLE PAVEMENT DRAINAGE MONITORING, PERFORMANCE AND STABILITY
}

\author{
By \\ Aiwen Feng \\ and \\ Jianfeng Hua \\ Research Associates \\ and \\ Thomas D. White \\ Professor \\ School of Civil Engineering \\ Purdue University \\ Joint Transportation Research Program \\ Project No: C-36-15N \\ File No: 6-9-14 \\ Prepared as Part of an Investigation \\ Conducted by the \\ Joint Transportation Research Program \\ Purdue University \\ In Cooperation with the \\ Indiana Department of Transportation \\ And the \\ U.S. Department of Transportation \\ Federal Highway Administration
}

The contents of this report reflect the views of the authors who are responsible for the facts and the accuracy of the data represented herein. The contents do not necessarily reflect the official views or policies of the Federal Highway Administration and the Indiana Department of Transportation. The report does not constitute a standard, specification or regulation.

Purdue University

West Lafayette, Indiana 47907

May 1999 
Digitized by the Internet Archive in 2011 with funding from

LYRASIS members and Sloan Foundation; Indiana Department of Transportation 
TECHNICAL REPORT STANDARD TITLE PAGE

\begin{tabular}{|c|c|c|}
\hline $\begin{array}{l}\text { 1. Report No. } \\
\text { FHWA/N/JTRP-99/2 }\end{array}$ & 2. Government Accession No. & 3. Reciplent's Catalog No. \\
\hline \multirow{2}{*}{\multicolumn{2}{|c|}{$\begin{array}{l}\text { 4. Title and Subtitle } \\
\text { Flexible Pavement Drainage Monitoring, Performance and Stability }\end{array}$}} & $\begin{array}{l}\text { 5. Report Date } \\
\text { May } 1999 \\
\end{array}$ \\
\hline & & 6. Performing Organization Code \\
\hline \multicolumn{2}{|c|}{$\begin{array}{l}\text { 7. Author(s) } \\
\text { Aiwen Feng, Jianfeng Hua and Thomas D. White }\end{array}$} & $\begin{array}{l}\text { 8. Performing Organization Report No. } \\
\text { FHWA/LN/JTRP-99/2 }\end{array}$ \\
\hline \multirow{2}{*}{\multicolumn{2}{|c|}{$\begin{array}{l}\text { 9. Performing Organization Name and Address } \\
\text { Joint Transportation Research Program } \\
\text { 1284 Civil Engineering Building } \\
\text { Purdue University } \\
\text { West Lafayette, Indiana 47907-1284 }\end{array}$}} & 10. Work Univ No. \\
\hline & & $\begin{array}{l}\text { 11. Contract or Grant No. } \\
\text { HPR-2035 }\end{array}$ \\
\hline \multicolumn{2}{|c|}{ 12. Sponsoring Agency Name and Address } & 13. Type of Report and Period Covered \\
\hline \multirow{2}{*}{\multicolumn{2}{|c|}{$\begin{array}{l}\text { Indiana Department of Transportation } \\
\text { State Office Building } \\
100 \text { North Senate Avenue } \\
\text { Indianapolis, IN } 46204\end{array}$}} & Final Report \\
\hline & & 14. Sponsoring Agency Code \\
\hline
\end{tabular}

\section{Supplementary Notes}

Prepared in cooperation with the Indiana Department of Transportation and Federal Highway Administration.

\section{Abstract}

The current study is a continuation of the study FHWA/IN/JTRP project HPR-2078, "Locating the Drainage Layet for Flexible Pavements". In this previous study, three test sections were constructed in a new pavement on a by-pass around Fort Wayne, Indiana. These test sections were instrumented to record temperatures, moisture, frost penetration, rainfall and subdrainage system outflow. Collected data and Finite Element Method (FEM) analysis indicate the subdrainage systems are performing satisfactorily. However, concern developed over the stability and rutting characteristics of the open-graded drainage layers. As a continuation study, longet term environmental and subdrainage performance data was collected. Additional data was collected from FWD tests, condition surveys and roughness measurements. Laboratory triaxial tests were also conducted on all asphatt mixtures, unbound aggregate materials and subgrades. Tests of asphatt mixtures were conducted at two loading speeds and both wet and dry. Asphalt mixture tests were conducted at the recorded seven-day high field temperature. These data were used in FEM analysis of the stability and ruting characteristics of the test sections.

The three subdrainage systems continue to be effective. There is no change in the ranking of performance. Section 1 (open-graded asphalt drainage layer over a dense asphalt base filter/separator layer) continues to drain significantly faster than section 2 and 3 (open-graded asphalt drainage layer over a dense aggregate filter/separator layer). Water infiltration through the surface has decreased significantly. The pavement sections are in excellent condition.

\begin{tabular}{|l|l|l|l|}
\hline \hline $\begin{array}{l}\text { 17. Key Words } \\
\text { flexible pavement, drainage, triaxial test, stability, rutting }\end{array}$ & $\begin{array}{l}\text { 18. Distribution Statement } \\
\text { No restrictions. This document is available to the public through the } \\
\text { National Technical Information Service, Springfield, VA 22161 }\end{array}$ \\
\hline \hline 19. Security Classif. (of this report) & 20. Security Classif. (of this page) & $\begin{array}{c}\text { 21. No. of Pages } \\
\text { 309 }\end{array}$ & 22. Price \\
\hline
\end{tabular}




\section{TABLE OF CONTENTS}

Page

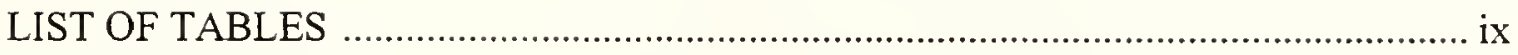

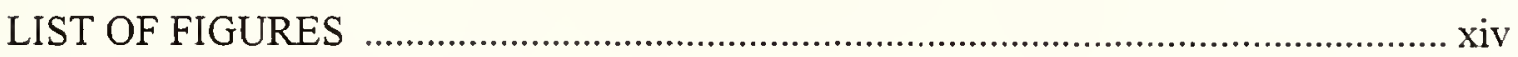

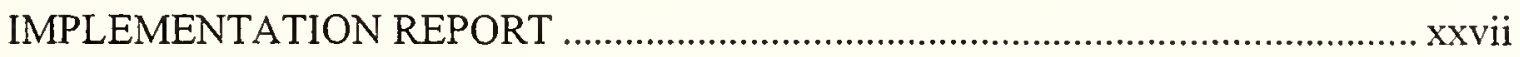

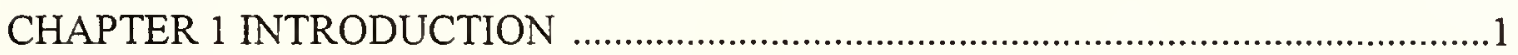

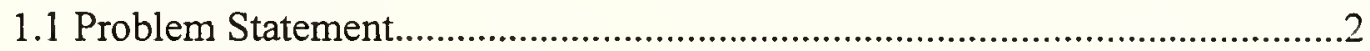

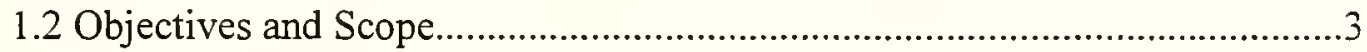

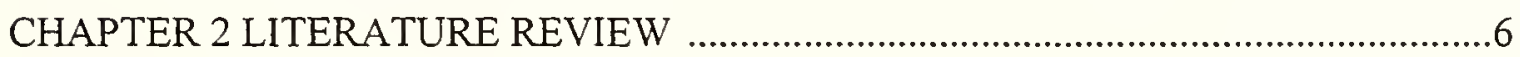

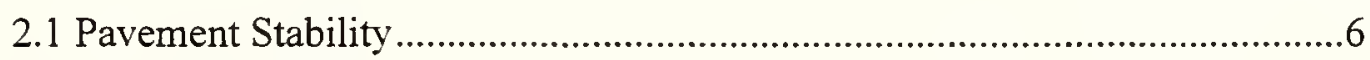

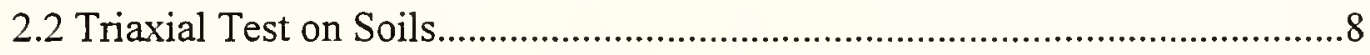

2.3 Typical Strength Parameters of Clay and Gravel ........................................11

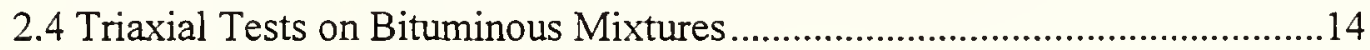

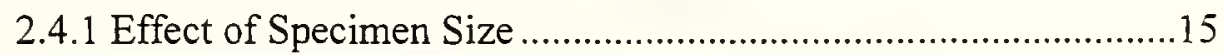

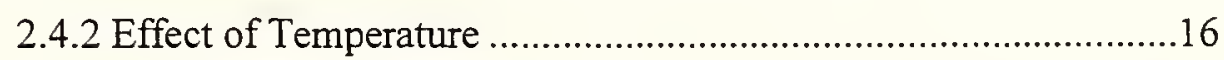

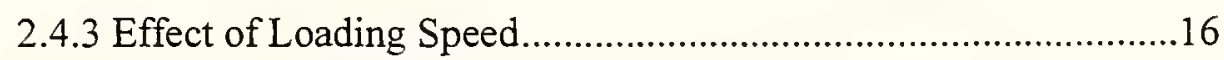

2.5 Application of Triaxial Test to Pavement Design .........................................17

2.6 Laboratory Compaction of Asphalt Samples................................................18

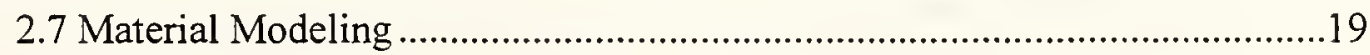




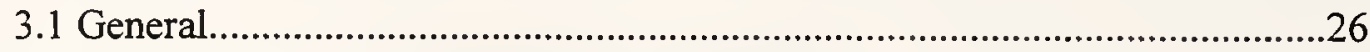

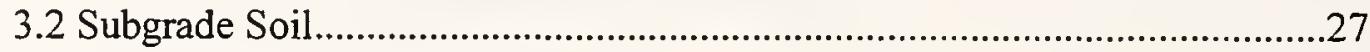

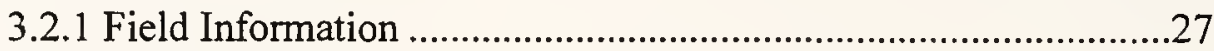

3.2.2 Test Specimen Preparation...........................................................

3.2.3 Saturation, Consolidation and Loading........................................32

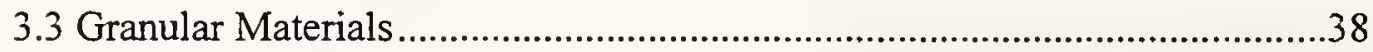

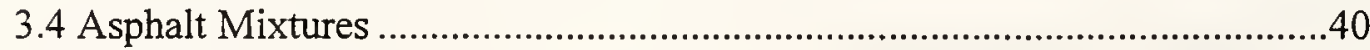

3.4.1 Asphalt Mixture Specimen Preparation ...........................................40

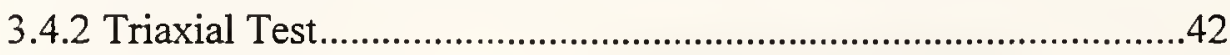

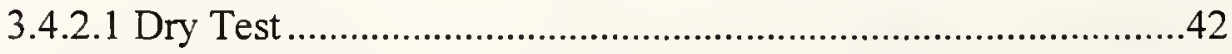

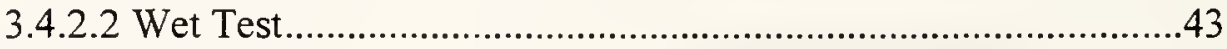

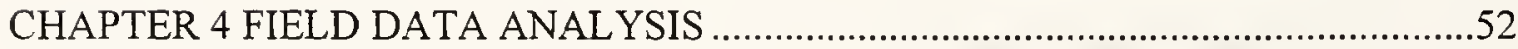

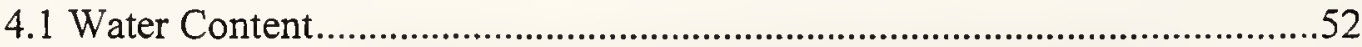

4.2 Field Temperature Data and Analysis ......................................................... 71

4.2.1 Field Data ...............................................................................

4.2.2 Comparison with SHARP Predictions .........................................74

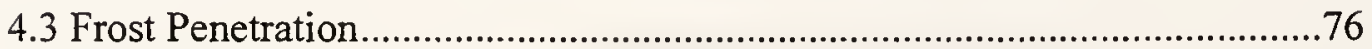

4.4 Rainfall and Outflow Analysis ................................................................82

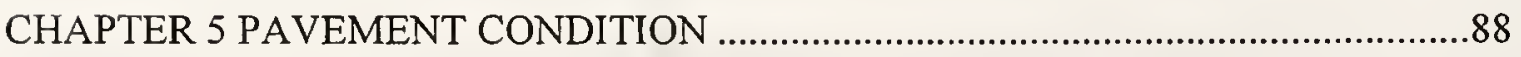

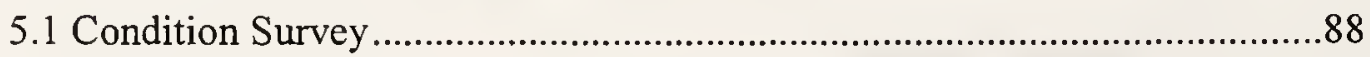


5.2 Falling Weight Deflector Test .90

\section{CHAPTER 6 LABORATORY TESTS ON SUBGRADE AND GRANULAR}

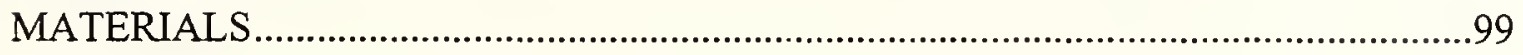

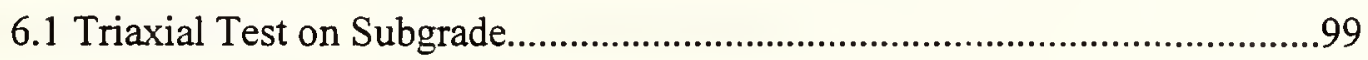

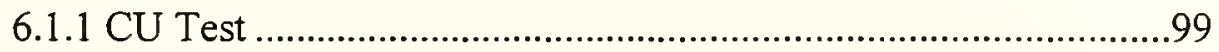

6.1.2 Partial Saturated Triaxial Test ................................................101

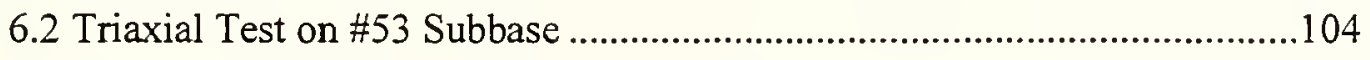

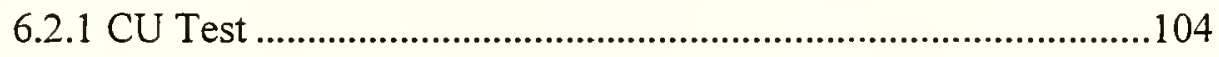

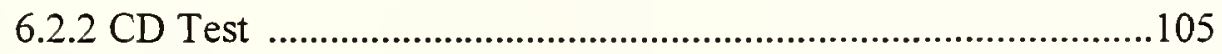

6.3 Triaxial Test on \#8 Trench Aggregate.........................................................106

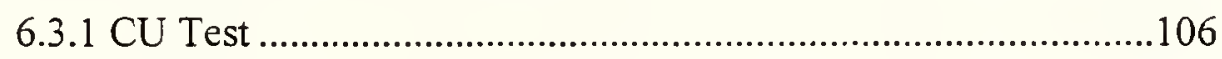

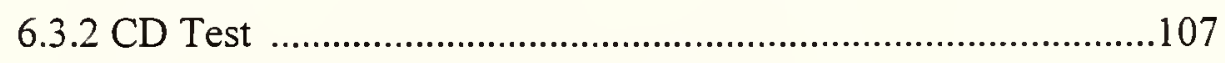

CHAPTER 7 TRIAXIAL TESTS OF ASPHALT MIXTURES ..................................126

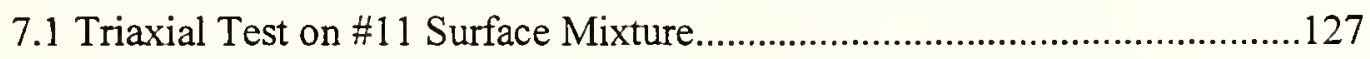

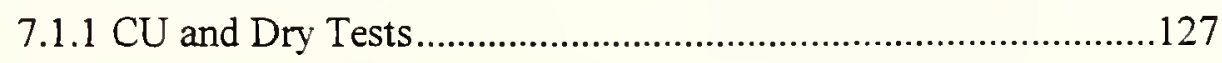

7.1.2 ANOVA and Regression Analysis.........................................130

7.2 Triaxial Test on \#9 Binder Mixture ..........................................................133

7.2.1 CU Test and Dry Test ........................................................133

7.2.2 ANOVA and Regression Analysis ............................................135

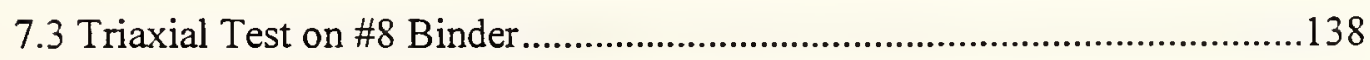

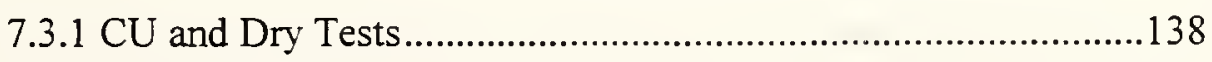


7.3.2 ANOVA and Regression Analysis. 141

7.4 Triaxial Tests on 5C Open-Graded Mixture ..............................................144

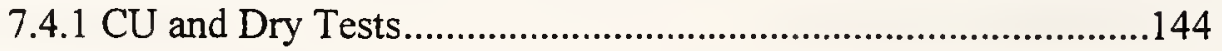

7.4.2 ANOVA and Regression Analysis..........................................146

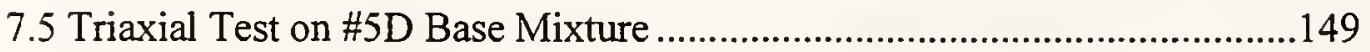

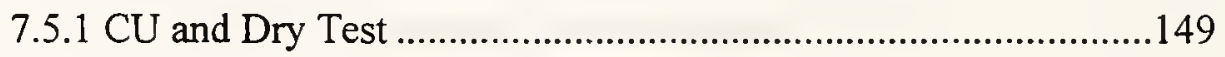

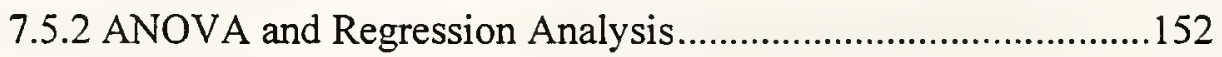

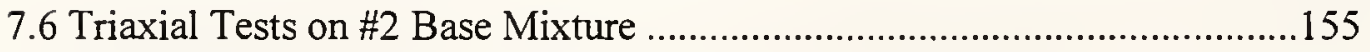

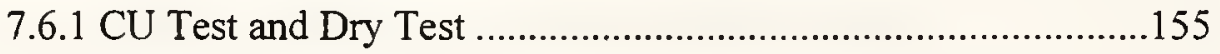

7.6.2 ANOVA and Regression Analysis..........................................157

CHAPTER 8 STABILITY AND DEFORMATION ANALYSIS …............................185

8.1 Model Geometry and Finite Element Mesh ............................................185

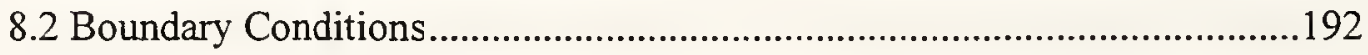

8.3 FWD Tests and Model Verification ..........................................................192

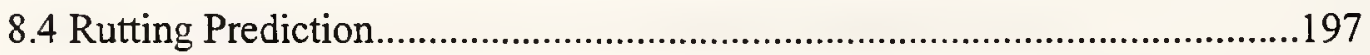

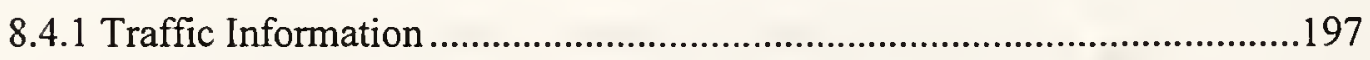

8.4.2 Creep Rate Model Calibration ...........................................................198

8.4.3 Test Sections Rutting Analysis..........................................................202

8.5 Strength and Stability Analysis.............................................................209

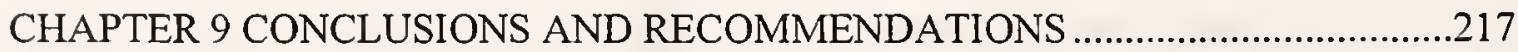

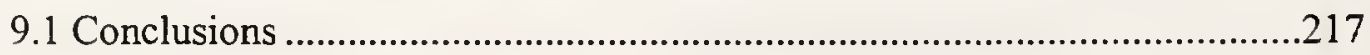


9.1.1 Subdrainage Performance and Pavement Condition............................................217

9.1.2 Shear Strength

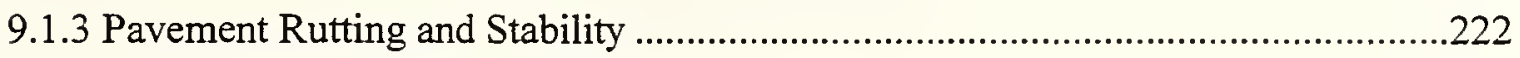

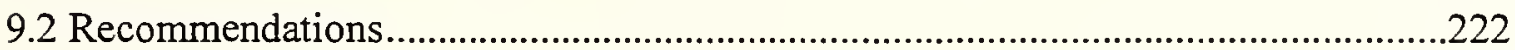

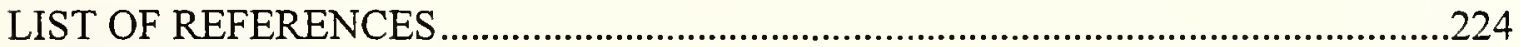

APPENDICES

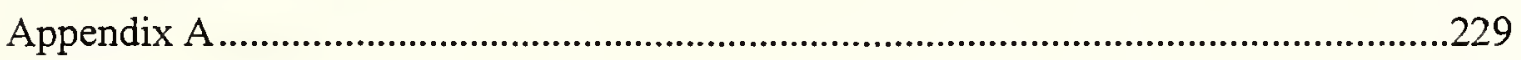

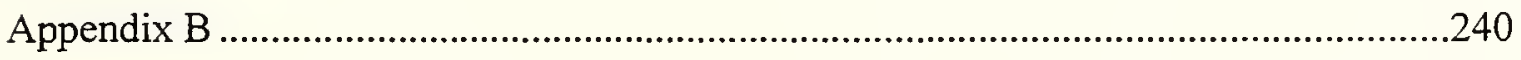

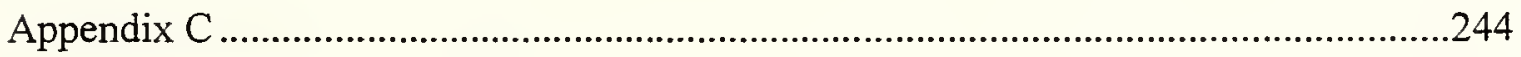

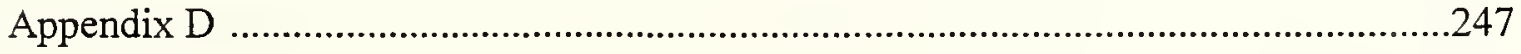

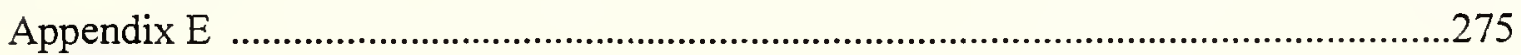




\section{LIST OF TABLES}

Table

2.1 Typical Properties of Compacted Soils 13

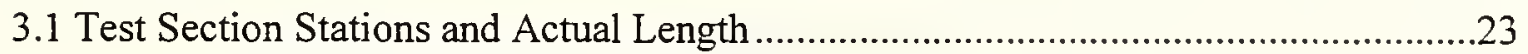

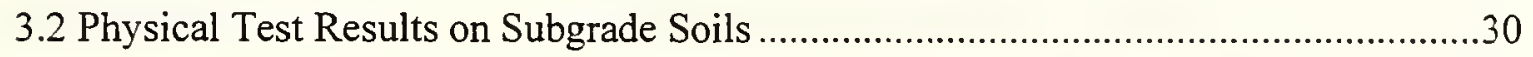

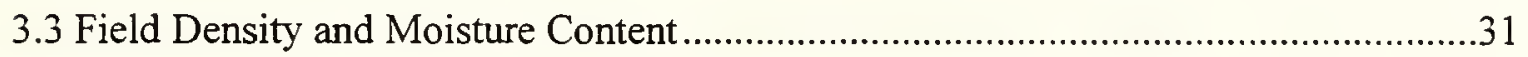

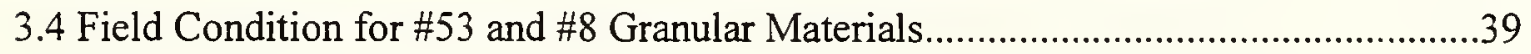

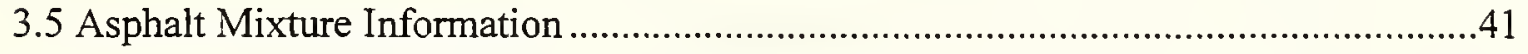

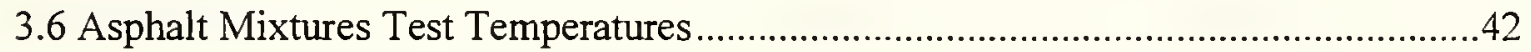

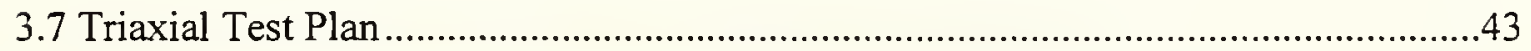

4.1 Estimated Volumetric Moisture and Degree of Saturation in Pavement Layers .........54

4.2 Hottest and Coldest Pavement Surface Temperature ( $25 \mathrm{~mm}$ Below Surface) ...........74

4.3 Comparison of Observed Temperature and Predicted Temperature ............................75

4.4 Summary of COE Frost Penetration Estimation........................................................

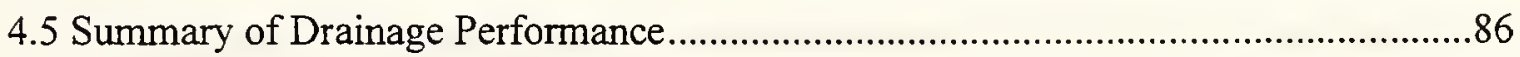

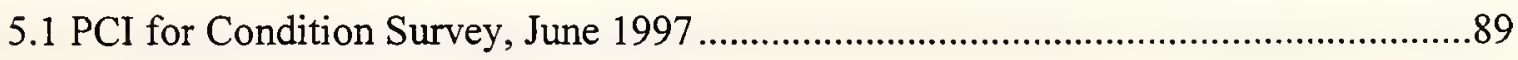


Table

5.2 PCI for Condition Survey, September 1998 .90

6.1 Subgrade Triaxial Test Results 101

6.2 Young's Modulus Predicted from Janbu Equation 102

6.3 Partial Saturated Triaxial Test Results on Subgrade 103

6.4 Analysis on Subgrade 103

6.5 CU Test Results on \#53 Dense Aggregate Base 104

6.6 CD Test Results on \#53 Dense Aggregate Base 105

6.7 Quantitative Results on \#53 Dense Aggregate Base. 106

6.8 CU Test Results on \#8 Trench Aggregate 106

6.9 CD Test Results on \#8 Trench Aggregate. 107

6.10 Quantitative Results on \#8 Trench Aggregate 107

7.1 CU Test Results for \#11 Surface Mixture. 129

7.2 Dry Test Results for \#11 Surface Mixture. 129

7.3 ANOVA for \#11 Surface Mixture Young's Modulus in CU Tests .130

7.4 ANOVA for \#11 Surface Mixture Yield Stress in CU Tests 131

7.5 ANOVA for \#11 Mixture Surface Young's Modulus in Dry Test .131

7.6 ANOVA for \#11 Surface Mixture Yield Stress in Dry Test.

7.7 Young's Modulus, log (E), Regression Results for \#11 Surface Mixture CU Tests.132 7.8 Yield Stress, $\log (Y)$, Regression Results for \#11 Surface Mixture CU Tests 132

7.9 Young's Modulus, $\log (\mathrm{E})$, Regression Results for \#11 Surface Mixture Dry Tests .132

7.10 Yield Stress, $\log (Y)$, Regression Results for \#11 Surface Mixture Dry Tests. .133 
Table

7.11 CU Test Results on \#9 Binder Mixture. .134

7.12 Dry Test Results on \#9 Binder Mixture 135

7.13 ANOVA for \#9 Binder Mixture Young's Modulus in CU Tests. 136

7.14 ANOVA for \#9 Binder Mixture Yield Stress in CU Tests .136

7.15 ANOVA for \#9 Binder Mixture Young's Modulus in Dry Tests .136

7.16 ANOVA for \#9 Binder Mixture Yield Stress in Dry Tests.

7.17 Young's Modulus, E, Regression Results on \#9 Binder Mixture CU Tests.

7.18 Yield Stress, Y, Regression Results on \#9 Binder Mixture CU Tests 137

7.19 Young's Modulus, E, Regression Results on \#9 Binder Mixture Dry Tests 138

7.20 Yield Stress, Y, Regression Results on \#9 Binder Mixture Dry Tests 138

7.21 CU Test Results on \#8 Binder Mixture. 139

7.22 Dry Test Results on \#8 Binder. 140

7.23 ANOVA for \#8 Binder Mixture Young's Modulus in CU Test 141

7.24 ANOVA for \#8 Binder Mixture Yield Stress in CU Test

7.25 ANOVA for \#8 Binder Mixture Young's Modulus in Dry Tests 142

7.26 ANOVA for \#8 Binder Mixture Yield Stress in Dry Tests. 142

7.27 Young's Modulus, $\log (E)$, Regression Results on \#8 Binder Mixture CU Tests....142 7.28 Yield Stress, $\log (Y)$, Regression Results on \#8 Binder Mixture CU Tests 143

7.29 Young's Modulus, $\log (\mathrm{E})$, Regression Results on \#8 Binder Mixture Dry Tests ...143

7.30 Yield Stress, $\log (Y)$, Regression Results for \#8 Binder Mixture Dry Tests 143

7.31 CU Test Results on \#5C OG Mixture 144 
7.32 Dry Test Results on \#5C OG Mixture .145

7.33 ANOVA for \#5C OG Mixture Young's Modulus in CU Tests .146

7.34 ANOVA for \#5C OG Mixture Yield Stress in CU Tests. 147

7.35 ANOVA for \#5C OG Mixture Young's Modulus in Dry Tests 147

7.36 ANOVA for \#5C OG Mixture Yield Stress in Dry Tests

7.37 Young's Modulus, $\log (E)$, Regression Results for \#5C OG Mixture CU Tests ....148

7.38 Yield Stress, Log(Y), Regression Results on \#5C OG Mixture CU Tests .148

7.39 Young's Modulus, $\log (\mathrm{E})$, Regression Results on \#5C OG Mixture Dry Tests ....148

7.40 Yield Stress, Log(Y), Regression Results on \#5C OG Mixture Dry Tests. 149

7.41 CU Test Results on \#5D Base Mixture 150

7.42 Dry Test Results on \#5D Base Mixture. 151

7.43 ANOVA for \#5D Base Mixture Young's Modulus in CU Tests 152

7.44 ANOVA for \#5D Base Mixture Yield Stress in CU Tests 152

7.45 ANOVA for \#5D Base Mixture Young's Modulus in Dry Tests 153

7.46 ANOVA for \#5D Base Mixture Yield Stress in Dry Tests. 153

7.47 Young's Modulus, $\log (\mathrm{E})$, Regression Results on \#5D Base Mixture CU Tests...153

7.48 Yield Stress, $\log (Y)$, Regression Results on \#5D Base Mixture CU Tests 154

7.49 Young's Modulus, Log(E), Regression Results on \#5D Base Mixture Dry Tests ..154

7.50 Yield Stress, Log(Y), Regression Results on \#5D Base Mixture Dry Tests 154

7.51 CU Test Results on \#2 Base Mixture. 156

7.52 Dry Test Results on \#2 Base Mixture 
7.53 ANOVA for \#2 Base Mixture Young's Modulus in CU Test 158

7.54 ANOVA for \#2 Base Mixture Yield Stress in CU Test.

7.55 ANOVA for \#2 Base Mixture Young's Modulus in Dry Tests

7.56 ANOVA for \#2 Base Mixture Yield Stress in Dry Tests.

7.57 Young's Modulus, Log(E), Regression Results for \#2 Base Mixture CU Tests .....159

7.58 Yield Stress, $\log (Y)$, Regression Results on \#2 Base Mixture CU Tests ...............160

7.59 Young's Modulus, $\log (E)$, Regression Results on \#2 Base Mixture Dry Tests .....160

7.60 Yield Stress, $\log (\mathrm{Y})$, Regression Results on \#2 Base Mixture Dry Tests ... 160

8.1 Material Properties for FEM Analysis 191

8.2 Statistical Data for the FWD on Section 1 193

8.3 Statistical Data for the FWD on Section 2

8.4 Statistical Data for the FWD on Section 3 194

8.5 PURWheel Test Information .200

8.6 Back Calculated Creep Rate Model Parameters 203

8.7 Predicted Rutting Depth under 10,000 Truck Applications. .208

9.1 Summary of Subgrade Triaxial Test Results .219

9.2 Summary of Triaxial Test Results on $\# 53$ and $\# 8$ 220

9.3 Summary of Asphalt Mixture Strength Parameters .221 


\section{LIST OF FIGURES}

Figure

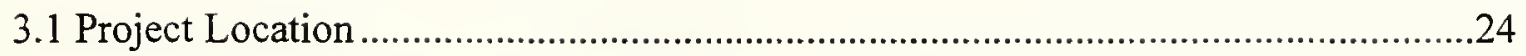

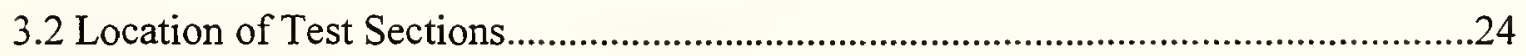

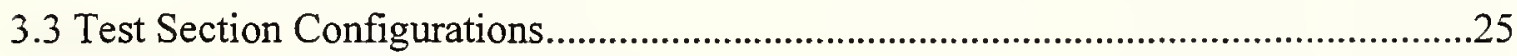

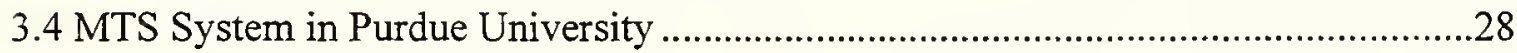

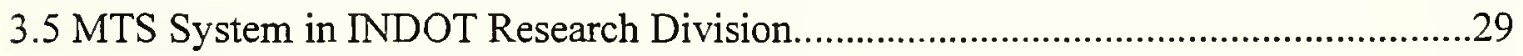

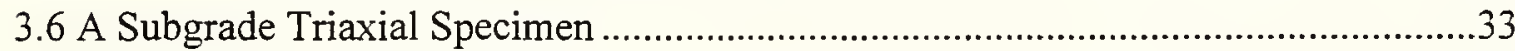

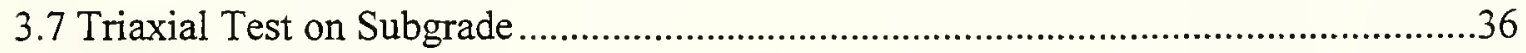

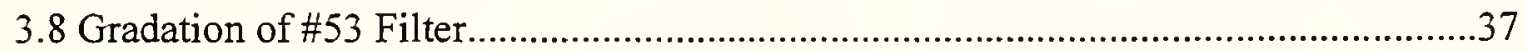

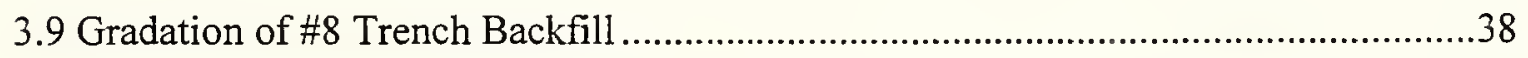

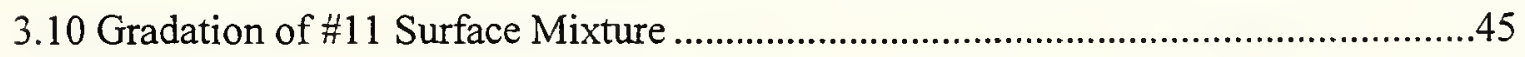

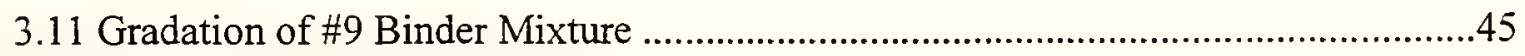

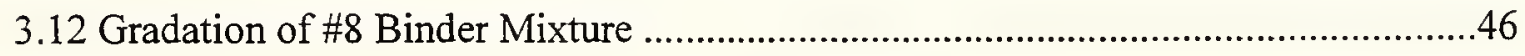

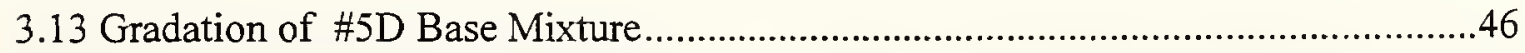

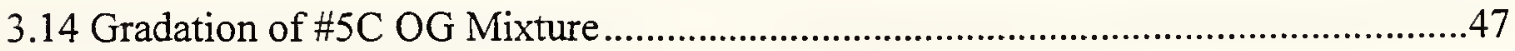

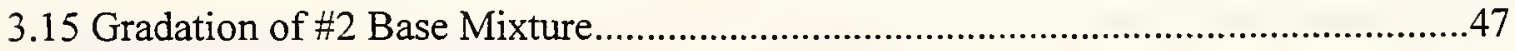

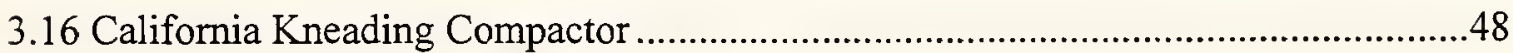


Figure

3.17 Mold and Kneading Foot .49

3.18 Environmental Chamber and Triaxial Cell .50

3.19 Heating System and Water Pump .51

4.1 Laboratory Moisture Retention Curve for Subgrades 55

4.2 Laboratory Moisture Retention Curve for Binder and Surface. 56

4.3 Laboratory Moisture Retention Curve for Base Layers. .57

4.4 Laboratory Moisture Retention Curves for Subbase and Trench Gravel. .58

4.5 SWP in Subgrade, Section 1 59

4.6 SWP in Base, and Drainage Layer, Section 1 .60

4.7 SWP in Subgrade, Section 1 61

4.8 SWP in Base, and Drainage Layer, Section 1 .62

4.9 SWP in Subgrade, Section 2. .63

4.10 SWP in Base, and Drainage Layer, Section 2...... .64

4.11 SWP in Subgrade, Section 2 .65

4.12 SWP in Base and Drainage Layer, Section 2 .66

4.13 SWP in Subgrade, Section 3 .67

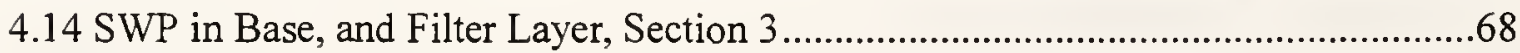

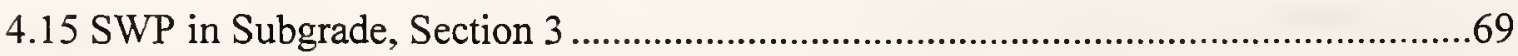

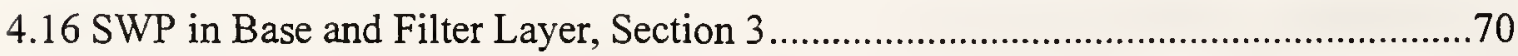

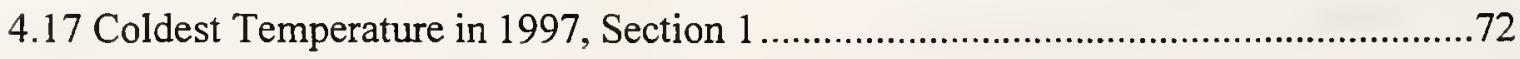

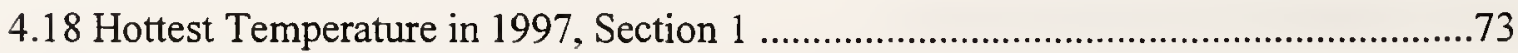


4.19 Resistance and Temperature in January 1997, Section 1 . .77

4.20 Resistance and Temperature in January 1997, Section 1 ..........................................78

4.21 Resistance and Temperature in January 1997, Section 1 1.........................................79

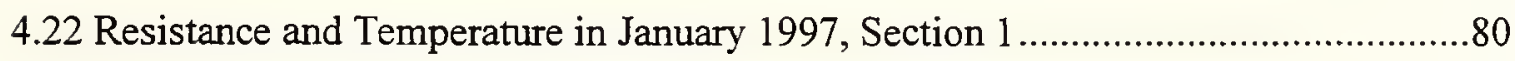

4.23 Resistance and Temperature in January 1997, Section 1 .......................................81

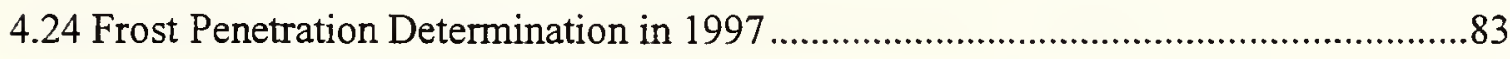

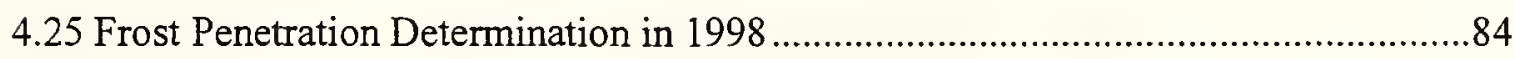

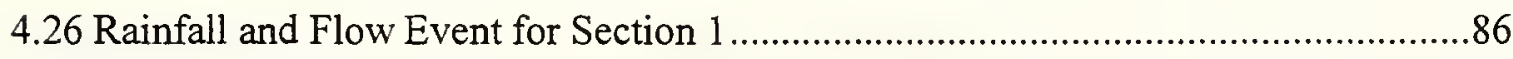

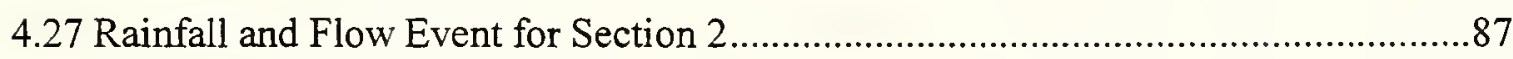

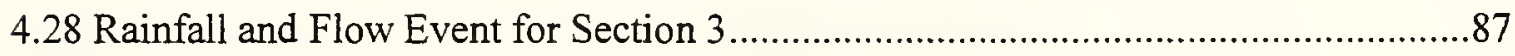

5.1Longitudinal Construction Joint Crack ....................................................................

5.2 Shoulder Crack

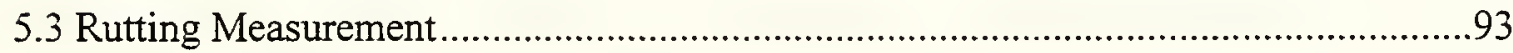

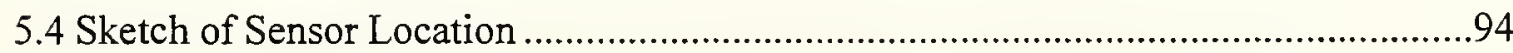

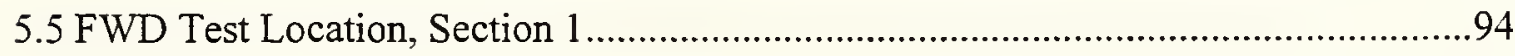

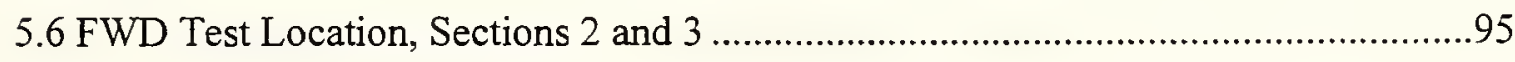

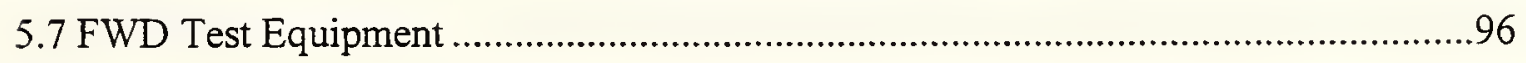

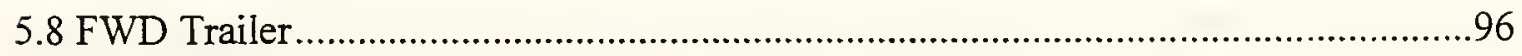

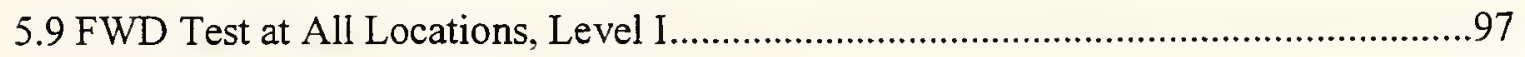

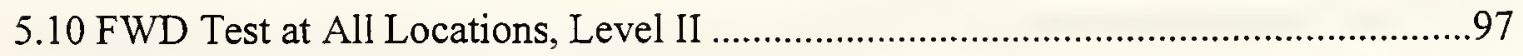

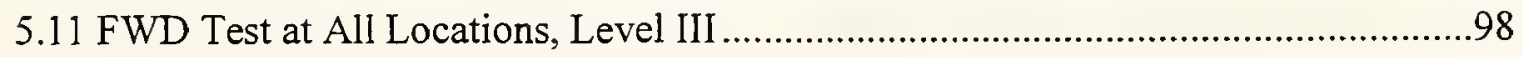


6.1 Stress-Strain Results for CU Tests on Section 1 Subgrade 108

6.2 Pore Pressure Results for CU Tests on Section 1 Subgrade .108

6.3 Stress-Strain Results for CU Tests on Section 2 Subgrade. 109

6.4 Pore Pressure Results for CU Tests on Section 2 Subgrade 109

6.5 Stress-Strain Results for CU Tests on Section 3 Subgrade. 110

6.6 Pore Pressure Results for CU Tests on Section 3 Subgrade .110

6.7 Mohr's Circles for Section 1 Subgrade CU Tests.....

6.8 Mohr's Circles for Section 2 Subgrade CU Tests.

6.9 Mohr's Circles on Section 3 Subgrade CU Test.

6.10 Young's Modulus vs. Confining Pressure (CU Test), Subgrade

6.11 Yield Stress vs. Confining Pressure (CU Test), Subgrade.

6.12 Stress-Strain Results for Partially Saturated Test on Section 1 Subgrade 113

6.13 Stress-Strain Results for Partially Saturated Tests on Section 2 Subgrade 114

6.14 Stress-Strain Results for Partially Saturated Test on Section 3 Subgrade..... 114

6.15 Mohr's Circles for Section 1 Partially Saturated Tests 115

6.16 Mohr's Circles for Section 2 Partially Saturated Tests 115

6.17 Mohr's Circles for Section 3 Partially Saturated Tests 116

6.18 Young's Modulus vs. Confining Pressure on Partially Saturated Test, Subgrade...116

6.19 Yield Stress vs. Confining Pressure on Partially Saturated Test, Subgrade 117

6.20 Stress-Strain Results on \#53 CU Tests 117

6.21 Pore Pressure Results on \#53 CU Tests. 118 
Figure

6.22 Mohr's Circles for the \#53 CU Tests.

6.23 Stress-Strain Results on \#53 CD Tests

6.24 Volumetric Strain Vs Axial Strain for the \#53 CD Tests

6.25 Mohr's Circles for the \#53 CD Tests. 120

6.26 Young's Modulus vs. Confining Pressure for the \#53 CD Tests. 120

6.27 Yield Stress vs. Confining Pressure for \#53 Tests

6.28 Stress-Strain Results for the \#8 Trench Aggregate CU Test 121

6.29 Pore Pressure Results for the \#8 Trench Aggregate CU Tests 122

6.30 Mohr’s Circles for \#8 Trench Aggregate CU Tests 122

6.31 Stress-Strain Results for \#8 Trench Aggregate CD Tests 123

6.32 Volume Change for \#8 Trench Aggregate CD Tests 123

6.33 Mohr's Circles on \#8 Trench Aggregate CD Tests. 124

6.34 Young's Modulus vs. Confining Pressure for \#8 Trench Aggregate .124

6.35 Yield Stress vs. Confining Pressure for \#8 Trench Aggregate 125

7.1 Mohr's Circles for the \#11 Surface Mixture CU Tests at Loading Speed of $1.25 \mathrm{~mm} / \mathrm{min}$ 161

7.2 Mohr's Circles for the \#11 Surface Mixture CU Tests at Loading Speed of $12.5 \mathrm{~mm} / \mathrm{min}$. 161

7.3 Young's Modulus vs. Confining Pressure on \#1 1 Surface Mixture CU Tests 162

7.4 Yield Stress vs. Confining Pressure for \#11 Surface Mixture CU Tests 162 
Figure

7.5 Mohr's Circles for \#11 Surface Mixture Dry Tests at Loading Speed

of $1.25 \mathrm{~mm} / \mathrm{min}$

7.6 Mohr's Circles for \#11 Surface Mixture Dry Tests at Loading Speed

of $12.5 \mathrm{~mm} / \mathrm{min}$

7.7 Young's Modulus vs. Confining Pressure for the \#11 Surface Mixture Dry Tests ..164

7.8 Yield Stress vs. Confining Pressure on \#11 Surface Mixture Dry Tests 164

7.9 Mohr's Circles for \#9 Binder Mixture CU Tests at Loading Speed of

$1.25 \mathrm{~mm} / \mathrm{min}$

7.10 Mohr's Circles for \#9 Binder Mixture CU Tests at Loading Speed of

$12.5 \mathrm{~mm} / \mathrm{min}$ .165

7.11 Young's Modulus vs. Confining Pressure for the \#9 Binder Mixture CU Tests.....166

7.12 Yield Stress vs. Confining Pressure for the \#9 Binder Mixture CU Tests .166

7.13 Mohr’s Circles for \#9 Binder Mixture Dry Tests at Loading Speed of

$1.25 \mathrm{~mm} / \mathrm{min}$ 167

7.14 Mohr's Circles for \#9 Binder Mixture Dry Tests at Loading Speed of

$12.5 \mathrm{~mm} / \mathrm{min}$ 167

7.15 Young's Modulus vs. Confining Pressure for the \#9 Binder Mixture Dry Tests ....168

7.16 Yield Stress vs. Confining Pressure for the \#9 Binder Mixture Dry Tests.. 168

7.17 Mohr's Circles for \#8 Binder Mixture CU Tests at Loading Speed of

$1.25 \mathrm{~mm} / \mathrm{min}$ 
7.18 Mohr's Circles for \#8 Binder Mixture CU Tests at Loading Speed of $12.5 \mathrm{~mm} / \mathrm{min}$ 169

7.19 Young's Modulus vs. Confining Pressure for the \#8 Binder Mixture CU Tests.....170

7.20 Yield Stress vs. Confining Pressure for the \#8 Binder Mixture CU Tests 170

7.21 Mohr's Circles for \#8 Binder Mixture Dry Tests at Loading Speed of $1.25 \mathrm{~mm} / \mathrm{min}$ 171

7.22 Mohr’s Circles for \#8 Binder Mixture Dry Tests at Loading Speed of $12.5 \mathrm{~mm} / \mathrm{min}$ 171

7.23 Young's Modulus vs. Confining Pressure for the \#8 Binder Mixture Dry Tests ....172

7.24 Yield Stress vs. Confining Pressure for the \#8 Binder Mixture Dry Tests .172

7.25 Mohr Circles for \#5C OG Mixture CU Tests at Loading Speed of

$1.25 \mathrm{~mm} / \mathrm{min}$ 173

7.26 Mohr Circles for \#5C OG Mixture CU Tests at Loading Speed of $12.5 \mathrm{~mm} / \mathrm{min}$ 173

7.27 Young's Modulus vs. Confining Pressure for the \#5C OG Mixture CU Tests 174

7.28 Yield Stress vs. Confining Pressure on \#5C OG Mixture CU Tests 174

7.29 Mohr Circles for \#5C OG Mixture Dry Tests at Loading Speed of $1.25 \mathrm{~mm} / \mathrm{min}$ .175

7.30 Mohr Circles for \#5C OG Mixture Dry Tests at Loading Speed of

$12.5 \mathrm{~mm} / \mathrm{min}$

7.31 Young's Modulus vs. Confining Pressure for the \#5C OG Mixture Dry Tests.......176 
Figure

Page

7.32 Yield Stress vs. Confining Pressure for the \#5C OG Mixture Dry Tests 176

7.33 Mohr's Circles for \#5D Base Mixture CU Tests at Loading Speed of

$1.25 \mathrm{~mm} / \mathrm{min}$

7.34 Mohr's Circles for \#5D Base Mixture CU Tests at Loading Speed of

$12.5 \mathrm{~mm} / \mathrm{min}$ 177

7.35 Young's Modulus vs. Confining Pressure for the \#5D Base Mixture CU Tests .....178

7.36 Yield Stress vs. Confining Pressure for the \#5D Base Mixture CU Tests. 178

7.37 Mohr's Circles for \#5D Base Mixture Dry Tests at Loading Speed of

$1.25 \mathrm{~mm} / \mathrm{min}$ 179

7.38 Mohr's Circles for \#5D Base Mixture Dry Tests at Loading Speed of

$12.5 \mathrm{~mm} / \mathrm{min}$ 179

7.39 Young's Modulus vs. Confining Pressure for the \#5D Base Mixture Dry Tests.....180

7.40 Yield Stress vs. Confining Pressure for \#5D Base Mixture Dry Tests 180

7.41 Mohr Circles for \#2 Base Mixture CU Tests at Loading Speed of

$1.25 \mathrm{~mm} / \mathrm{min}$ 181

7.42 Mohr Circles for \#2 Base Mixture CU Tests at Loading Speed of

$12.5 \mathrm{~mm} / \mathrm{min}$ 181

7.43 Young's Modulus vs. Confining Pressure for \#2 Base Mixture CU Tests 182

7.44 Yield Stress vs. Confining Pressure for \#2 Base Mixture CU Tests 182

7.45 Mohr’s Circles for \#2 Base Mixture Dry Tests at Loading Speed of $1.25 \mathrm{~mm} / \mathrm{min}$ .183 
7.46 Mohr's Circles for \#2 Base Mixture Dry Tests at Loading Speed of

$12.5 \mathrm{~mm} / \mathrm{min}$

7.47 Young's Modulus vs. Confining Pressure for \#2 Base Mixture Dry Tests 184

7.48 Yield Stress vs. Confining Pressure for \#2 Base Mixture Dry Tests 184

8.1 Plane View of the Model and FEM Mesh (x-y Plane) 187

8.2 Cross Section of the Model and FEM Mesh (x-z Plane) ….......................................188

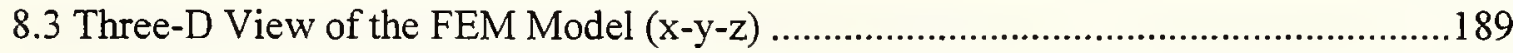

8.4 Predicted Rutting Profile in the Full Driving Lane Model (Without Wander)..........190

8.5 A Typical FWD Loading and Sensor Deflection Histories 195

8.6 Comparison of FWD and Predicted FEM Deflections, Section 1 195

8.7 Comparison of FWD and Predicted FEM Deflection, Section 2 ............................196

8.8 Comparison of FWD and Predicted FEM Deflection, Section 3 .............................196

8.9 Loading Time Distribution of the Dual Tire 198

8.10 Rut Depth vs. Number of Load Passes of PURWheel Tests of Indiana \#11

Surface Mixture .201

8.11 Predicted Pavement Cross Section after 3 Years, Section 1 ..................................204

8.12 Predicted Pavement Cross Section after 3 Years, Section 2 .................................205

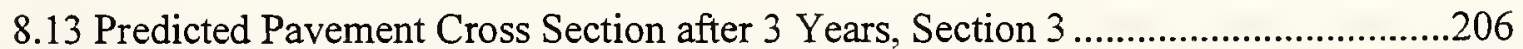

8.14 Measured Surface Deformation after 10,000 Applications, Section 1...................207

8.15 Measured Surface Deformation after 10, 000 Applications, Section 2...................207

8.16 Measured Surface Deformation after 10, 000 Applications, Section 3...................208 
Figure

8.17Stress and Strength Distribution in Surface Layer, Section 1 .211

8.18 Stress and Strength Distribution in Top of the Drainage Layer, Section 1..............211

8.19 Stress and Strength Distribution under the Wheel Path, Section 1 .........................212

8.20 Stress and Strength Distribution in the Trench, Section 1 ....................................212

8.21 Stress and Strength Distribution in Surface Layer, Section 2 ................................213

8.22 Stress and Strength Distribution at Top of the Drainage Layer, Section 2 ..............213

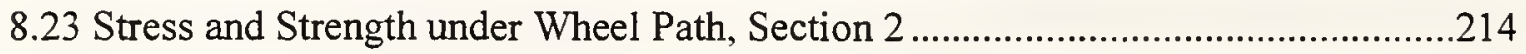

8.24 Stress and Strength Distribution in the Trench, Section 2 ................................214

8.25 Stress and Strength Distribution in the Surface Layer, Section 3 ..........................215

8.26 Stress and Strength Distribution at Top of Drainage Layer, Section 3..................215

8.27 Stress and Strength Distribution under Wheel Path, Section 3 ............................216

8.28 Shear Stress and Strength Distribution in Trench, Section 3 $\ldots \ldots \ldots \ldots \ldots \ldots \ldots \ldots \ldots \ldots \ldots \ldots . .216$

Appendix Figure $\quad$ Page

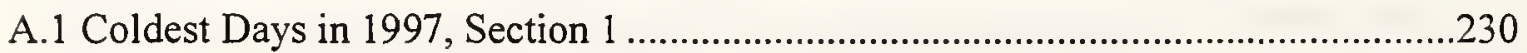

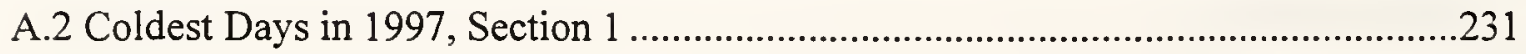

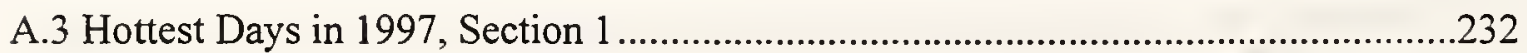

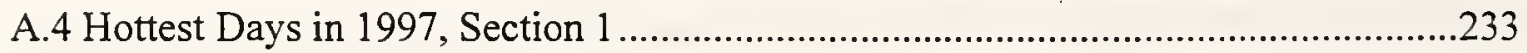

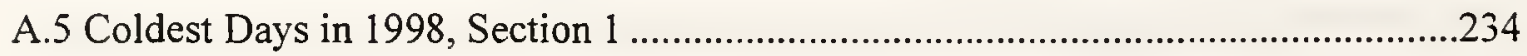

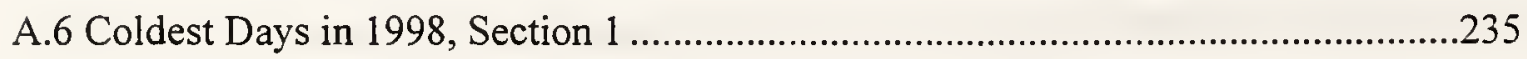

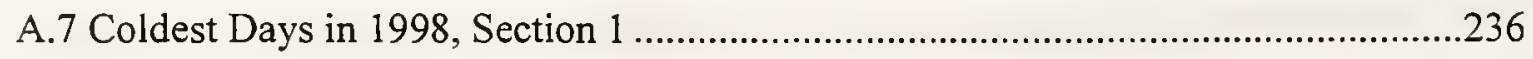

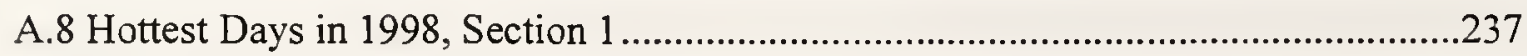




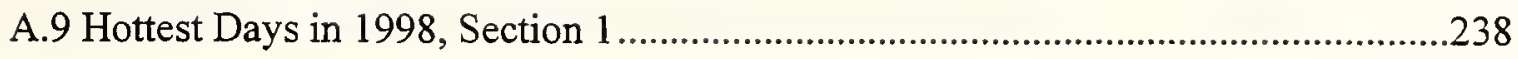

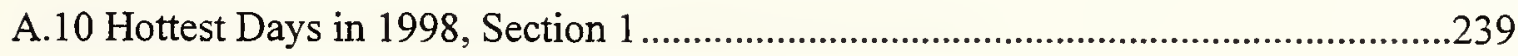

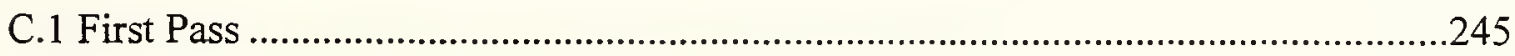

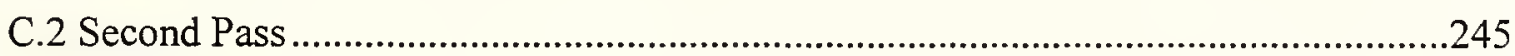

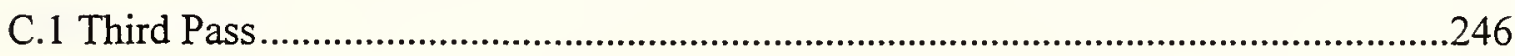

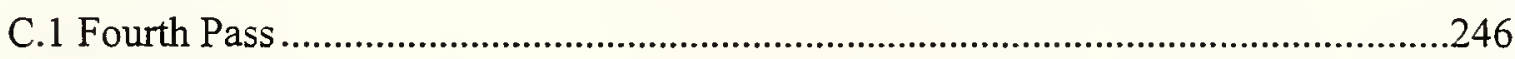

D.1 Stress-Strain on \#11 Surface Mixture Dry Test ...................................................248

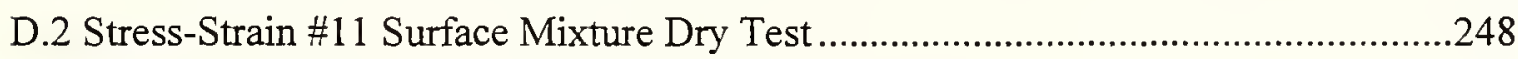

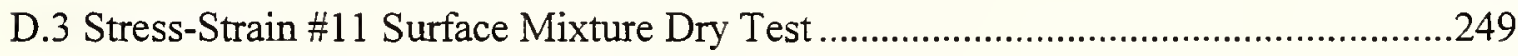

D.4 Stress-Strain on the \#11 Surface Mixture CU Test..................................................249

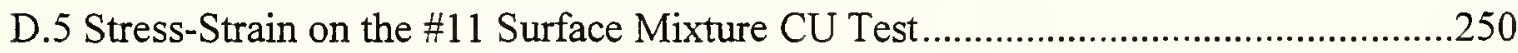

D.6 Stress-Strain on the \#11 Surface Mixture CU Test.................................................250

D.7 Pore Pressure vs. Axial Strain on the \#11 Surface Mixture CU Test .......................251

D.8 Pore Pressure vs. Axial Strain on the \#11 Surface Mixture CU Test ........................251

D.9 Pore Pressure vs. Axial Strain on the \#1 I Surface Mixture CU Test ........................252

D.10 Stress-Strain \#9 Binder Mixture Dry Test ......................................................252

D.11 Stress-Strain \#9 Binder Mixture Dry Test .........................................................253

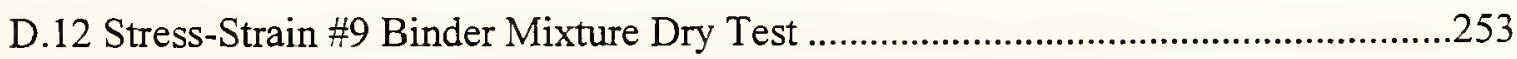

D.13 Stress-Strain on the \#9 Binder Mixture CU Test ...................................................254

D.14 Stress-Strain on the \#9 Binder Mixture CU Test ..............................................254

D.15 Stress-Strain on the \#9 Binder Mixture CU Test ..................................................255 
D.16 Pore Pressure vs. Axial Strain on the \#9 Binder Mixture CU Test........................255

D.17 Pore Pressure vs. Axial Strain on the \#9 Binder Mixture CU Test.......................256

D.18 Pore Pressure vs. Axial Strain on the \#9 Binder Mixture CU Test........................256

D.19 Stress-Strain on \#8 Binder Mixture Dry Test ............................................257

D.20 Stress-Strain \#8 Binder Mixture Dry Test .................................................257

D.21 Stress-Strain \#8 Binder Mixture Dry Test ..................................................258

D.22 Stress-Strain on the $\# 8$ Binder Mixture CU Test .............................................258

D.23 Stress-Strain on the $\# 8$ Binder Mixture CU Test ..............................................259

D.24 Stress-Strain on the \#8 Binder Mixture CU Test .............................................259

D.25 Pore Pressure vs. Axial Strain on the \#8 Binder Mixture CU Test........................260

D.26 Pore Pressure vs. Axial Strain on the \#8 Binder Mixture CU Test......................260

D.27 Pore Pressure vs. Axial Strain on the \#8 Binder Mixture CU Test.......................261

D.28 Stress-Strain on the \#5C OG Mixture Dry Test................................................261

D.29 Stress-Strain on the \#5C OG Mixture Dry Test..................................................262

D.30 Stress-Strain on the \#5C OG Mixture Dry Test.............................................262

D.31 Stress-Strain on the \#5C OG Mixture CU Test................................................263

D.32 Stress-Strain on the \#5C OG Mixture CU Test................................................263

D.33 Stress-Strain on the \#5C OG Mixture CU Test............................................264

D.34 Pore Pressure vs. Axial Strain on the \#5C OG Mixture CU Test ..........................264

D.35 Pore Pressure vs. Axial Strain on the \#5C OG Mixture CU Test .........................265

D.36 Pore Pressure on the \#5C OG Mixture CU Test .................................................265 
Appendix Figure $\quad$ Page

D.37 Stress-Strain on the \#5D Base Mixture Dry Test................................................266

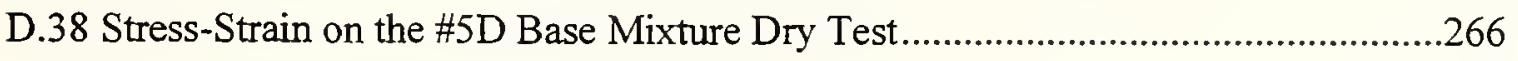

D.39 Stress-Strain on the \#5D Base Mixture Dry Test..................................................267

D.40 Stress-Strain on the \#5D Base Mixture CU Test ...............................................267

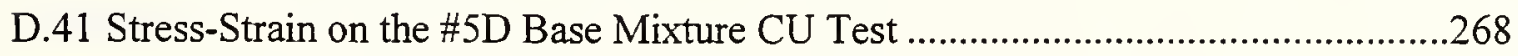

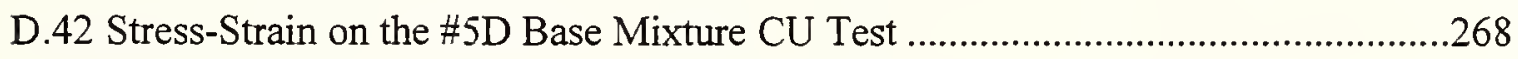

D.43 Pore Pressure vs. Axial Strain on the \#5D Base Mixture CU Test........................269

D.44 Pore Pressure vs. Axial Strain on the \#5D Base Mixture CU Test ........................269

D.45 Pore Pressure vs. Axial Strain on the \#5D Base Mixture CU Test .........................270

D.46 Stress-Strain on the \#2 Base Mixture Dry Test...................................................270

D.47 Stress-Strain on the \#2 Base Mixture Dry Test.....................................................22

D.48 Stress-Strain on the \#2 Base Mixture Dry Test....................................................271

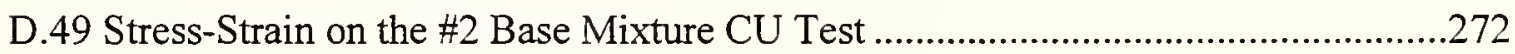

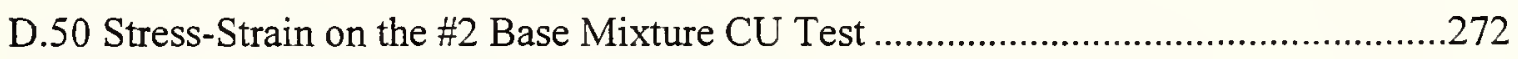

D.51 Stress-Strain on the \#2 Base Mixture CU Test ..................................................2.273

D.52 Pore Pressure vs. Axial Strain on the \#2 Base Mixture CU Test...........................273

D.53 Pore Pressure vs. Axial Strain on the \#2 Base Mixture CU Test...........................274

D.54 Pore Pressure vs. Axial Strain on the \#2 Base Mixture CU Test...........................274 


\section{IMPLEMENTATION REPORT}

Results of this current study should be considered along with results of a previous study, HPR-2078, "Locating the Drainage Layer for Flexible Pavements". The two studies together provide three years of performance data for three subdrainage test sections on I-469 at Fort Wayne, IN. The long term monitoring has provided data for recommendations on the most efficient drainage section, effect of subdrainage on moisture conditions in the pavement layers and subgrades, appropriateness of the SHRP temperature prediction equations, and recommended approach for predicting frost penetration. In addition, techniques have been developed for using the PURWheel laboratory test device results in combination with a finite element analysis to evaluate the rutting potential of mixtures and combinations of asphalt layers.

Protocals have been developed for triaxial testing of asphalt mixtures. Utilization of these results is demonstrated in modeling FWD tests of the test sections, predicting inservice rutting and evaluating stability of pavement materials.

It is clear that section 1 is the most efficient subdrainage section. Drainage occurs from this section in about two-thirds the time of the other two sections. This section has a dense asphalt base as a separator/filter under the drainage layer and on top of the subgrade. Water infiltrating the surface reaches the top of this rather impenetrable layer and then drains laterally. The dense base does not store moisture and its use has not led to an increase in moisture in the subgrade. 
The SHRP equations for predicting high and low temperatures for application in selecting performance graded asphalts are valid. This continued evaluation indicates they are accurate for the extremes of the temperature regime in Indiana.

A procedure was developed for using PURWheel tests to predict asphalt mixture rutting characteristics. The results of tests on asphalt mixtures were utilized to predict rutting of the drainage sections. The results were reasonably close. Further use and development of these techniques are recommended. Two areas of further work include evaluation of the effect of PURWheel test slab preparation on rutting and incorporation of temperature variation in the analysis.

Triaxial tests were conducted on subgrades, unbound aggregates and asphalt mixtures used in the three test sections. Testing protocals for the subgrades and unbound aggregates were based on existing test standards or were modified slightly. Protocals for preparing and tesing asphalt mixtures were largely undocumented in current test standards or recent literature. The protocals developed are recommended but need further evaluation. In the tests conducted, air was used as the pressurizing medium. Air has been used for this purpose and the specific test apparatus used in this study is designed for air confinement. However, test results may be affected by air permeating the membrane encapsulating the specimen. This issue needs to be addressed. Also, triaxial tests of unbound aggregates were limited by the maximum load that could be applied. It is recommended that future tests of unbound aggregate be conducted in equipment with a load capacity at least two times that used in the current study.

Theoretical analysis indicates that materials in the various layers of the test sections are stable. This means that shear failure would not occur at an early date. 
Tension zones were predicted in the unbound aggregate trench backfill material and at the surface of the shoulder. Cracking in the shoulder parallel to the traffic direction provides some confirmation of this theoretical result. It is recommended that a binder (asphalt or cement) be used to provide cohesion in the trench backfill material. High quality hot mix asphalt should be used in shoulder pavement.

Both theoretical predictions and in-service performance indicates that the pavement materials are stable. Measured rutting is minimal which confirms the stability and rutting analysis. Section 1 which was recommended for its drainage efficiency is predicted to have slightly higher rutting than the other two sections. A recommendation is made that its performance continue to be monitored. Also, further study is recommended to optimize drainage and rutting performance of drainage layers.

In this study, laboratory determined material properties were combined with a model of pavement sections and a dynamic load representing the falling weight deflectometer. The predicted surface deflections were in surprisingly good agreement with measured surface deflections. This represents a new area of research that would be beneficial in pavement evaluation. This approach suggests a very direct way of tieing design and evaluation together. 



\section{CHAPTER 1 - INTRODUCTION}

An important component of pavement design is provision for subsurface drainage. Significant effort has been expended to find effective ways to remove free water from pavements as quickly as possible. One way to achieve this objective is to use high permeability open-graded unbound aggregate or asphalt concrete as a drainage layer in the pavement structure. The drainage layer combined with an edge collection system and outlet will effectively drain a pavement system.

In 1995 three drainage test sections on I-469 at Fort Wayne, IN were instrumented. These test sections were part of new construction. Details of the instrumentation and initial data collection are reported by Hossam and White [1996]. Mostly, the instrumentation has continued to function well and data collection has continued as part of the current study. Over all, data has been collected for variations in pavement moisture condition, temperature and frost penetration. Also, unique data has been collected for the pavement subdrainage performance. The drainage function of pavement drainage layers is achieved by use of aggregate gradations with limited sizes. Such gradations have high permeability. However, this kind of gradation may not be stable, particularly when used in pavements carrying substantial truck traffic. As a result, the current study also includes tasks for laboratory testing of materials in the pavement 
and investigation of the stability of the open-graded drainage layers as well as the test sections in general.

Anticipation was that the stability and rutting analyses would be conducted with a finite element method (FEM). And to quantify the parameters for the material models used in the analyses, triaxial tests would be conducted on the pavement materials, trench material and subgrades. Triaxial testing is a common geotechnical engineering test. It has been shown to be a reliable way to characterize the mechanical properties of soils. Duncan, et al [Duncan, 1980] illustrated that all of the parameters for the "Duncan Model" were obtained through triaxial testing. Numerous studies have shown the Drucker-Prager model is appropriate for granular materials [Low, et al, 1995]. In the ABAQUS USERS MANUAL [ABAQUS, 1997] the recommendation is that: "The extended Drucker-Prager plasticity model in ABAQUS is often used to model granular materials such as soils as well as other materials which exhibit pressure dependent yield". Also "Data for geological materials are most commonly available from triaxial compression testing" [ABAQUS, 1997]. Triaxial testing has been applied in the past for testing asphalt mixtures (Smith [1951], Mcleod [1951], Wood [1951], and Goetz and Chen [1957]. However, unlike with soils, the triaxial test did not become a common test for asphalt mixtures.

\subsection{Problem Statement}

The Indiana Department of Transportation (INDOT) adopted a new set of typical pavement sections for construction and reconstruction in 1993. Most of these sections include a drainage layer, which is intended to carry water to collector edge drains. 
Bituminous bases $\# 5 \mathrm{C}$, $\# 2$, and $\# 5$ are being used as drainage layers for these sections. Coarse aggregate $\# 53$ and bituminous base $\# 5 \mathrm{D}$ are being used as filter layers under the drainage layer. The definitions of the above materials can be found in "Indiana Department of Transportation Standard Specifications" [1995].

In the study HPR-2078, "Locating the Drainage Layer for Flexible Pavement", three drainage test sections were included as part of I-469 construction at Fort Wayne, Indiana [Hossam and White, 1996]. Sensors were installed in the pavement and subgrade to measure temperature, moisture, frost penetration, and suction. The sensors and associated data collection system continue to perform well. There was a stated desire by INDOT to continue data collection. In addition, the drainage function of pavement drainage layers is achieved by use of aggregate gradations with limited sizes. Such gradations have high permeability. However, this kind of gradation may not be stable, particularly when used in pavements carrying substantial truck traffic. For this reason, it was anticipated that the stability and rutting analyses would be conducted with a finite element method (FEM). And to quantify the parameters for the material models used in the analyses, triaxial tests would be conducted on the pavement materials, trench material and subgrades.

\subsection{Objectives and Scope}

This study provides for continued data collection from the test sections as well as estimates of elastic modulus, yield stress, cohesion and angle of internal friction. ABAQUS analysis of the stability and rutting characteristics of the drainage layers in the test sections will use these parameters directly. The stability and rutting study can be 
divided into three parts: laboratory testing, field distress survey, and finite element analysis.

The laboratory testing includes triaxial testing of subgrades, coarse base and trench unbound aggregates, and bituminous mixtures. The purpose of triaxial testing is to generate material properties for the finite element analysis. The properties obtained from the triaxial test are Young's modulus, yield stress, friction angle, and cohesion.

For the clay subgrade, both consolidated, undrained and partially saturated tests are to be conducted. Both consolidated drained and consolidated undrained tests are to be conducted on the unbound $\# 53$ coarse base and $\# 8$ trench materials. These tests will be conducted at three confining pressures and one loading speed.

Asphalt materials are visco-elastic-plastic materials. In addition to moisture, asphalt mixtures are affected by temperature and loading speed. Triaxial tests of asphalt mixtures will be conducted at the measured, average 7-day high temperature, at two loading speeds and in dry and consolidated undrained conditions. Superpave binder grade is selected based on the average, 7-day high temperature [Superpave Asphalt Binder Specification, 1995]. It is on this basis the triaxial test temperature for asphalt mixtures was selected.

Though collected data indicates that the pavement system is in a partially saturated state. The purpose of $\mathrm{CU}$ and partially saturated tests on subgrade clay, $\mathrm{CU}$ and $\mathrm{CD}$ tests on unbound aggregate, $\mathrm{CU}$ and dry tests on asphalt mixtures is to provide first hand information about the effect of water. 
A part of this project involved continuation of the data collection from instrumentation installed for the three drainage sections. In addition, pavement profile and nondestructive structural tests were conducted.

Finite element analysis was used to evaluate stability and rutting characteristics of the drainage sections. Triaxial tests were conducted to obtain material properties for the FEM analysis.

This report consists of nine chapters. The literature review is presented in Chapter two. Materials and laboratory tests are discussed in Chapter three. Instrumentation data are presented in Chapter four. Distress survey, Falling Weight Deflectormeter tests and profiles are presented in Chapter five. Triaxial test results are presented in Chapter six for the subgrade, base, and trench aggregates. Triaxial test results on bituminous mixtures in the test sections are presented in Chapter seven. Application and results of the finite element analysis are presented as Chapter eight and conclusions are presented in Chapter nine. 


\section{CHAPTER 2 LITERATURE REVIEW}

A fundamental engineering approach to bituminous pavement structural design is desired. One step toward its establishment is use of tests that realistically characterize pavement layer and foundation materials. A combination of fundamental pavement structural and mechanical models will provide a means of accurately predicting pavement response. More importantly, pavement sections and material combinations not tested can be analyzed. This is not possible with empirical or mechanistic - empirical based design procedures. It is believed that the triaxial compression test offers the best solution to the material testing and modeling problem [Smith, 1951, McLeod, 1951, Wood, 1956, Goetz and Chen, 1957, Morris, et al., 1974, Low, et al., 1995].

\subsection{Pavement Stability}

Pavement rutting is manifested by a surface depression in the wheel path. Typically, a pavement system consists of several different layers of materials, subgrade, subbase, base, binder, and surface course. Instability of one or more of the layers can contribute to the surface rutting.

Three basic types of rutting can develop in bituminous mixes: 
Wear rutting is caused by the progressive loss of coated aggregate particles from the asphalt pavement surface. It is caused by a combination of environmental and traffic effects.

Structural rutting is caused by permanent vertical deformation of the pavement structure under repeated traffic loading. Permanent vertical deformation can be caused by continued densification due to insufficient initial compaction and by plastic deformation and co-lateral uplift in one or more of the pavement layers. Because of the "flexible" surface of asphalt pavement materials, rutting of any layer is measured in the surface deformation.

Instability rutting is caused by lateral movement of materials within an asphalt concrete layer. It primarily results from plastic flow [ Dawley et al, 1990].

Eisenmann and Hilmer [1987] showed that densification is largely completed after an initial stage of traffic. Continued rutting is caused by plastic flow of asphalt mixtures.

Roberts, et al [1990] point out that it is quite common for the air voids of HMA surfaces to be reduced from 7 or 8 percent to 4 or 5 percent after 2 or 3 summers of traffic due to densification. Rutting from densification is generally not significant [Huang, 1995]. More significant rutting is associated with shear failure. Shear failure may occur in the HMA layer, underlying layers, or the subgrade soil. Shear failure occurs when the shear stress equals or exceeds the shear strength at a "point". However, shear failure is progressive, expanding to encompass material around the "point". One or more pavement layers may be involved. Shear flow is associated with shear failure. With shear flow, 
material flows from laterally underneath the wheel path. This leads to significant rutting [White, et al. 1993].

There are two principal causes for rutting described in Superpave [1995]. One is that the subgrade, subbase, or base is over stressed. As a result deformation occurs in these layers rather than in bituminous layers. This is normally considered a structural problem. The other principal cause of rutting is that the shear strength of the asphalt layers is too low to resist traffic loads. In this case deformation can occur in the asphalt layer [Superpave, 1995].

Rutting is evidence that a mixture has low shear strength. Shear deformation is characterized by a downward and lateral movement of the mixture. The Mohr -Coulomb equation $\tau=c+\sigma \tan \phi$ ( $\tau$ is shear strength, $\mathrm{c}$ is internal cohesion, $\phi$ is internal friction angle, and $\sigma$ is normal stress) can be used to evaluate the shear strength of asphalt mixtures [Superpave, 1995].

It is well known that the triaxial test is the most appropriate test to characterize the shear strength of granular materials. The triaxial test is widely used in geotechnical engineering, but has not been used often to test asphalt mixtures.

\subsection{Triaxial Test on Soils}

Soil shear strength is a significant property in geotechnical engineering. "The shear strength can be defined as the maximum shear stress the soil can withstand (peak strength) or as the final shear stress the soil can withstand (ultimate strength)" [Holtz, $1981]$. 
There are several ways to determine soil shear strength. The in situ method such as with the vane shear test or penetrometer devices avoids some of the problems of disturbance associated with the extraction of soil samples from the ground. Laboratory tests, on the other hand, yield the shear strength directly. The most common laboratory tests to determine shear strength are the direct shear test and triaxial tests.

The direct shear test is inexpensive, simple, and fast, especially for granular materials. The disadvantages are: it is hard to control drainage, the failure is forced to occur on a specific plane, and there are serious stress concentrations at the sample boundaries.

In contrast, the triaxial test is more complicated than the direct shear test. However, in the triaxial test, the drainage can be strictly controlled, "there is no rotation of $\sigma_{1}$ and $\sigma_{3}\left(\sigma_{1}\right.$ is the major principal stress, $\sigma_{3}$ is the minor principle stress $)$ and there is less stress concentration than in the direct shear test." The failure plane is not restricted and the stress paths can be controlled until failure [Holtz and Kovacs, 1981].

In a triaxial test, the specimen is always encased in a rubber membrane to allow for confinement to be applied. Axial load is applied through a piston contacting a platen on the end of the cylindrical specimen. Confining pressure is applied all around the specimen. Various types of confinement medium have been used including gases, water, and oils [Lambe, 1951]. However, there is concern that gases and water would permeate a membrane. In the current study two membranes were used with some light greasing. The triaxial cell used for unbound aggregate materials and asphalt mixture tests only provided for a gas (air) medium because of electronic components inside of the pressure 
chamber. Equipment and protocols for soil tests were adopted from those of Karim [1997].

There are several ways to run the triaxial test. For example, in the unconsolidatedundrained test (UU ) cell pressure (confining pressure) is applied and water is not allowed to drain from the specimen while the axial load is applied. In the consolidated-undrained test (CU), the specimen is first consolidated under a predetermined cell pressure. After consolidation is completed, all valves are closed and load is applied. The consolidated drained test $(\mathrm{CD})$ is a test in which the specimen is first consolidated but then drainage is allowed during loading [Bowles, 1994].

Which triaxial test to run depends on the soil type and in situ loading conditions. In particular, the confining pressure, loading speed, and drainage condition should match in situ conditions.

There are certain triaxial test specimen conditions considered desirable. For example, the specimen height-to-diameter ratio should be between 2 and 2.5. The largest particle size should be smaller than 1/6 the specimen diameter. However, the specimen may be an undisturbed or disturbed. The undisturbed specimen is obtained from large undisturbed samples or from samples secured in accordance with ASTM D 1587, "Standard Practice for Thin-Walled Tube Sampling of Soils". Disturbed samples may be prepared by compacting material in layers using a static or kneading compaction. Such laboratory prepared specimens can be prepared with the desired use of a cylindrical, split mold to facilitate sample preparation. The material should be batched by thoroughly mixing soil with sufficient water to produce the desired water content. After batching, the 
material is stored in a covered container for at least sixteen hours. This allows the sample moisture to equilibrate. Procedures for achieving the desired density are given in ASTM D4767-88, "Standard Test Method for Consolidated-Undrained Triaxial Compression Test on Cohesive Soils".

In saturated triaxial tests, the objective of the saturation is to fill all the voids in the specimen with water. Saturation is usually accomplished by applying back pressure to the specimen pore water to drive air into solution. The degree of saturation is evaluated by the pore pressure parameter $B=\Delta u / \Delta \sigma$ ( $\Delta \sigma$ is the change of confining pressure, $\Delta u$ is the change of pore pressure induced from the change of confining pressure for undrained conditions). The specimen shall be considered saturated if B is equal to or greater than 0.95 [ASTM D4767 -88].

In a drained test, the pore-fluid drain valve of the triaxial cell is opened, and the rate of strain should be low to minimize excess pore pressure. It is almost impossible to obtain reliable results from drained tests of clay because of the low permeability. The usual range of loading rate is $0.5 \mathrm{~mm}$ to $1.25 \mathrm{~mm} / \mathrm{min}$ [Bowles, 1994].

\subsection{Typical Strength Parameters of Clay and Gravel}

Parameters obtained from typical triaxial tests are soil shear strength parameters $\phi$ and $\mathrm{c}$, the elastic modulus, $\mathrm{E}$, and Poisson's ratio, $\mu$. Typically, Poisson's ratio is not determined because it is difficult to determine accurately. It was not measured in this study.

Shear strength can be determined from Coulomb's shear strength equation: 


$$
\begin{aligned}
& \tau=c+\sigma \tan \phi \\
& c=\text { soil cohesion or interparticle adhesion } \\
& \sigma=\text { intergranular pressure } \\
& \phi=\text { angle of internal friction }
\end{aligned}
$$

When used directly, the parameters are total stress parameters. If, instead, pore pressure is removed from the total stress $\sigma$ and the effective stress $\sigma^{\prime}$ is used $\left(\sigma^{\prime}=\sigma-u\right)$, then these parameters are called effective stress parameters. The shear strength of soil depends only on the effective stress [Holtz, Kovacs, 1981].

For a saturated or partially saturated cohesionless soil, the $\mathrm{CD}$ test will yield about the same $\phi$ angle as for a dry soil unless the material is very fine-grained (low coefficient of permeability) and /or the test is performed at an extremely rapid rate of strain, i.e. in the case that excess pore pressure is generated [Holtz, 1981]. For any saturated, cohesive soil, the results are highly dependent on the type of test and whether the soil is normally consolidated, overconsolidated, or remolded. Soil parameters will range from $\phi \cong 0$ and $\mathrm{c}$ $>0$ in the $\mathrm{UU}$ test to $\phi=$ true value and $\mathrm{c} \cong 0$ in the $\mathrm{CD}$ test. For any partially saturated cohesive soil, the results depend on both the degree of saturation, $\mathrm{S}$, and the type of test performed. In either the UU test or CU test $0<\phi<$ true value for $\mathrm{S}<100 \%$. Cohesion will vary with type of test, degree of saturation, S, and whether the soil is normally consolidated or over consolidated [Bowles, 1994]. Some typical values of strength parameters are shown in Table 2.1 . 
Table 2.1 Typical Properties of Compacted Soils [Hunt, 1986]

\begin{tabular}{|c|c|c|c|c|c|}
\hline \multirow[b]{2}{*}{ Soil type } & \multicolumn{2}{|c|}{ Typical values of compaction } & \multicolumn{3}{|c|}{ Typical values of strength } \\
\hline & $\gamma_{\mathrm{dry}}, \mathrm{pcf}$ & $\begin{array}{l}\text { Optimum Water } \\
\text { Content } \varpi(\%)\end{array}$ & $\begin{array}{c}\text { Cohesion } \\
\text { (Compacted) } \\
\mathrm{kPa}\end{array}$ & $\begin{array}{c}\text { Cohesion } \\
\text { (Saturated) } \\
\mathrm{kPa}\end{array}$ & $\begin{array}{c}\phi \\
\text { (degree) }\end{array}$ \\
\hline $\begin{array}{l}\text { GW Well graded clean } \\
\text { gravels, gravel sand mixture }\end{array}$ & $125-135$ & $11-8$ & 0 & 0 & $>38$ \\
\hline $\begin{array}{l}\text { GP Poorly graded clean } \\
\text { gravels, gravel sand mixture }\end{array}$ & $115-125$ & $14-11$ & 0 & 0 & $>37$ \\
\hline $\begin{array}{l}\text { GM Silty gravels, poorly } \\
\text { graded gravel sand silt }\end{array}$ & $120-135$ & $12-8$ & N/A & N/A & $>34$ \\
\hline $\begin{array}{l}\text { GC Clayey gravles, poorly } \\
\text { graded gravel-sand-clay }\end{array}$ & $115-130$ & $14-9$ & N/A & N/A & $>31$ \\
\hline $\begin{array}{l}\text { SW Well graded clean sands, } \\
\text { gravelly sands }\end{array}$ & $110-130$ & $16-9$ & 0 & 0 & 38 \\
\hline $\begin{array}{l}\text { SP Poorly graded clean } \\
\text { sands, gravelly sands }\end{array}$ & $100-120$ & $21-12$ & 0 & 0 & 37 \\
\hline $\begin{array}{l}\text { SC Clayey sands, poorly } \\
\text { graded sand clay mixture }\end{array}$ & $105-125$ & $19-11$ & 75 & 10.9 & 31 \\
\hline $\begin{array}{l}\text { ML Inorganic silts and } \\
\text { clayey silts }\end{array}$ & $\begin{array}{c}95-120 \\
24-12 \\
\end{array}$ & $24-12$ & 66 & 9 & 32 \\
\hline $\begin{array}{l}\mathrm{CL} \text { Inorganic clays of low } \\
\text { to medium plasticity }\end{array}$ & $95-120$ & $24-12$ & 85 & 12.9 & 28 \\
\hline $\begin{array}{c}\text { MH lnorganic clayey silts, } \\
\text { elastic silts }\end{array}$ & $70-95$ & $40-24$ & 70.8 & 19.8 & 25 \\
\hline $\begin{array}{c}\mathrm{CH} \text { Inorganic clays of high } \\
\text { plasticity }\end{array}$ & $75-105$ & $36-19$ & 101.5 & 10.9 & 19 \\
\hline
\end{tabular}

In considering results of the triaxial test, soil moduli $\mathrm{E}$ are generally low. Also, it is not practical (or easy) to measure Poisson's ratio in any current soil test. As a result, Poisson's ratio is usually estimated. Commonly used values for Poisson's ratio range from 0.25 to 0.4 for all cohesionless materials and dry cohesive soils. Typical values of 
Poisson's ratio for partially saturated and saturated cohesive soils range from 0.35 to 0.50 [Bowles, 1994].

Factors that influence shear strength of granular materials are: void ratio, particle shape, grain size distribution, particle surface roughness, moisture, intermediate principal stress, maximum particle size, and degree of overconsolidation. Holtz [1981] states that an artificial, well-graded mixture of gravel with sand has a $\phi$ angle of 57 and, a wellgraded, compacted crushed rock has a $\phi$ angle of $60^{\circ}$.

Holtz [1981] also reports that average values of effective friction angle $\phi^{\prime}$ for undisturbed clays range from around $20^{\circ}$ for normally consolidated high plasticity clays up to $30^{\circ}$ or more for silty and sandy clays. The value of $\phi^{\prime}$ for compacted clay is typically $25^{\circ}$ or $30^{\circ}$ and occasionally as high as $35^{\circ}$. There is not much difference between $\phi^{\prime}$ determined on undisturbed or remolded clay samples. The angle of internal friction from CU tests is typically $0^{\circ}-3^{\circ}$ less than that from the CD tests.

\subsection{Triaxial Tests on Bituminous Mixtures}

The usual volumetric components of field asphalt mixtures are aggregate, bitumen, water and air. Volume occupied by air may also be occupied by water. These components are analogous to soils, which are composed of soil particles, water and air. Because of the similarities, the triaxial test has been applied to asphalt mixtures. A number of studies using the triaxial test for asphalt mixtures were conducted in the 1940s and 1950s. Triaxial testing has had limited application in the evaluation of asphalt mixtures due to what is perceived as complexity of the test. 
The strength of asphalt mixtures in the triaxial test is due partly to the friction and interlocking of aggregates, which increases with increasing normal stress, and partly to cohesion or viscous resistance, which increases with increasing shear rate [Superpave, 1995].

\subsubsection{Effect of Specimen Size}

Researchers conducting triaxial tests of asphalt mixtures seem to have accepted a specimen height to diameter ratio of 2 to 1 . for example, Hveem [1951] recommended that triaxial test specimens have a H/D ratio of 2.0 or more. Smith [1951] stated that $101.6 \mathrm{~mm}$ (4 in.) diameter by $203.2 \mathrm{~mm}$ ( 8 in.) high specimens can be tested with excellent reproductibility for asphalt mixes with particle size not exceeding $25.4 \mathrm{~mm}$ (1 in.). Also, asphalt mixtures with particle sizes up to $50.8 \mathrm{~mm}(2 \mathrm{in}$.) can be tested with sufficient accuracy and reproducibility for most design and control purposes. Low, et al. [1995] and Goetz and Chen [1950] also used specimens $101.6 \mathrm{~mm}$ (4 in.) in diameter by $203.2 \mathrm{~mm}(8 \mathrm{in}$.$) high in their triaxial tests.$

In contrast, the requirement in ASTM D4767-88 "Standard Test Method for Consolidated Undrained Triaxial Compression Test on Cohesive Soils", is that specimens have a diameter of six times larger that the largest particle size. Also, the height to diameter (H/D) ratio should be between 2 and 2.5 .

A decision was made in this study to use specimens $150 \mathrm{~mm}$ (6 in.) in diameter and $300 \mathrm{~mm}$ (12 in.) high. This is a two to one ratio. The specimen size was used for all asphalt mixtures. 


\subsubsection{Effect of Temperature}

The strength of asphalt mixtures is also dependent on the viscosity of the binders.

These binders are affected markedly by changes in temperatures. A temperature of $60^{\circ} \mathrm{C}$ has been considered a reasonable maximum for asphalt pavement and many tests have specified this temperature [Smith, 1951]. Low, et al. [1995] used a temperature of $60{ }^{\circ} \mathrm{C}$ to obtain asphalt mixture properties. Wood [1956] concluded that the temperature effect is more pronounced than rate of deformation.

As noted above, the test temperature selected for this study utilized the more realistic Superpave high temperature criteria. This temperature is the average, 7-day high temperature. Temperatures for other asphalt mixtures in the pavement were predicted from the average, 7-day high temperature using a temperature prediction program by White [1981].

\subsubsection{Effect of Loading Speed}

Static truck loads represent the severest condition imposed on an asphalt pavement. Such loading can result in accumulation of significant pavement deformation.

Endersby [1951] found that in the triaxial test, the cohesion increases with increasing loading speed. McLeod [1951] showed that when the loading speed is changed from $1.3(0.05 \mathrm{in})$ to $10.2 \mathrm{~mm}(0.4 \mathrm{in})$ per min., the cohesion doubled from $136 \mathrm{kPa}$ to $272 \mathrm{kPa}$ and the friction angle decreased several degrees. Goetz and Chen [1957] reported that the angle of internal friction was not affected by the rate of strain, but the cohesion increases steadily as the rate of strain was increased from 1.27 to $50.8 \mathrm{~mm}$ per 
min. Worley [1951] reported use of a strain rate of $0.254 \mathrm{~mm}(0.01 \mathrm{in}$.) per min. for asphalt mixtures. Low and Fwa [1995] used a loading speed of $25.8 \mathrm{~mm}$ per min.

The above research has shown loading speed has significant effect on asphalt mixture shear strength. An initial loading speed of $1.25 \mathrm{~mm} / \mathrm{min}$ was selected for this study. To incorporate the effect of speed in the test results a second loading speed of 12.5 $\mathrm{mm} / \mathrm{min}$ was utilized.

\subsection{Application of Triaxial Test to Pavement Design}

Smith [1951] developed a design chart to evaluate asphalt pavement rutting potential based on what was termed the "closed triaxial testing system" results of $\phi$ and c. In the test, the triaxial cell is filled with water. No external pressure is applied. Vertical load is applied and the deformation of the specimen results in a change in the cell pressure. Various asphalt mixtures are divided into stable regions and unstable regions based upon their strength determined in this fashion. The two regions are related to real world pavement performance.

McLeod [1951] used $\phi$ and $\mathrm{c}$ from triaxial tests to evaluate the maximum vertical load a pavement can carry. Worley [1951] showed that the triaxial test could be applied to flexible pavement design. The triaxial test was used as a quasi-fundamental method of examining soils and related materials and was correlated to flexible pavement performance.

Morris, et al, [1974] evaluated various laboratory tests and concluded that triaxial tests can best be used to simulate the stress, temperature and strain conditions occurring 
in the field. Yoder, et al [1951] also suggested that the triaxial test offers a good means of evaluating pavement design.

Low and Fwa [1995] used results of triaxial tests to characterize asphalt mixtures in conjunction with the Drucker-Prager model. They concluded that the approach links empirical mix design concepts with mechanistic pavement analysis and design procedures.

\subsection{Laboratory Compaction of Asphalt Specimens}

One of the primary problems in the general field of asphalt mixture testing is fabrication of test specimens that have the same properties as field mixes. In static compaction, the orientation of aggregate particles are random, while in rolling compaction, the particles are aligned in the direction of least resistance. As a result, mode of compaction affects stability [Endersby, 1951]. It is pointed out that only by "kneading action" can a cylindrical test specimen acquire the particle orientation which is produced in the pavement by rolling [Hennes, 1951].

Smith compared the compaction effect of the double plunger method and the California Kneading Compactor method. He pointed out that kneading-type compaction yields specimens with particle orientation and mixture stability approximating that obtained in actual field construction [Smith, 1951].

As a result, laboratory test specimens prepared in this study utilized the California kneading compactor. This was possible because previous work had produced a modified 
compaction foot for compacting specimens up to $200 \mathrm{~mm}$ ( 8 in.) diameter. Further modification was made to compact the $300 \mathrm{~mm}$ (12 in.) tall specimens.

\subsection{Material Modeling}

Materials in a pavement system such as subgrade soil, unbound aggregate, and asphalt concrete are hydrostatic pressure dependent. The mechanical models available and common for these largely granular materials are the Mohr-Coulomb model, cam-clay model, Drucker-Prager model, creep model and extended Drucker-Prager model.

In the Mohr-Coulomb model the maximum shear stress is used as a response failure criteria. The shear strength is a function of the normal stress acting on the shear plane. The associated flow rule predicts volume dilatancy. The flow rule defines magnitudes of the plastic strain increment tensor. In turn the associate flow rule defines a relation between plastic flow and a yield criteria [Chen, 1995].

The Drucker-Prager model uses the octahedral stress as failure criteria. Shear strength is a function of the hydrostatic stress. For the negative hydrostatic or compression case, the dilatancy behavior is always predicted [Chen, 1995].

Saturated clays are effectively modeled with the Cam-Clay model. In the model, the pore pressure is predicted using the equation $\Delta \mathrm{u}=\mathrm{B}(\mathrm{A} \Delta \tau+\Delta \sigma)$. Both hardening and softening behavior of clay is represented by the model [Wood, 1990]

Asphalt concrete is known to be a nonlinear, viscous-elastic-plastic material. Its properties are temperature and strain rate dependent [Huang, 1993]. Low, et al, [1995] suggested that the post-yield stress-strain behavior of asphalt concrete is of little practical 
interest to pavement engineers and only the material behavior up to ultimate load is important. They also pointed out that triaxial test-based characterization of bituminous mixtures, used in conjunction with Drucker-Prager model, can provide a link between the empirical mix design concepts and mechanistic pavement analysis and design procedures. Huang, [1997] used a creep rate model in predicting asphalt concrete rutting for accelerated pavement tests. The analysis was made using a finite element method of analysis [ABAQUS, 1998]. The creep model is defined as:

$$
\begin{aligned}
& \dot{\varepsilon}=A \sigma^{\mathrm{n}} \mathrm{t}^{\mathrm{m}} \\
& \text { where } \quad \dot{\varepsilon}=\text { creep strain rate } \\
& \sigma=\text { the uniaxial equivalent deviator stress } \\
& \mathrm{t}=\text { the total time }
\end{aligned}
$$

$\mathrm{A}, \mathrm{m}, \mathrm{n}=$ parameters related to material properties

In this model, the instantanteous plastic deformation is neglected [ABAQUS, 1998].

In an analysis of a test section failure resulting from shear flow in a granular base, White, et al, [1995] used the extended Drucker-Prager in ABAQUS. This model is suitable to model granular materials, such as soils, as well as other materials. The rate dependent characteristics may be addressed in this model. The isotropic hardening is used as the hardening rule. Strain-softening behavior can also be modeled by using a nonassociated flow rule. The yield surface is defined as:

$$
\mathrm{t}-\mathrm{p} \tan \beta-\mathrm{d}=0 \text {, }
$$


Where

$$
\mathrm{t}=\frac{1}{2} \mathrm{q}\left[1+\frac{1}{\mathrm{~K}}-\left(1-\frac{1}{\mathrm{~K}}\right)\left(\frac{\mathrm{r}}{\mathrm{q}}\right)^{3}\right]
$$

$\mathrm{p}=$ equivalent pressure stress

$\mathrm{q}=$ the Mises equivalent stress

$r=$ the third stress invariant

$\mathrm{d}=$ measures the cohesion of the material, it is usually a function of plastic strain to provide isotropic hardening or softening. $d=(1-1 / 3 \tan \beta) \sigma_{c}{ }^{0}$.

$\beta=$ the angle of internal friction

$\mathrm{K}=$ the ratio of yield stress in triaxial tension to triaxial compression, $\mathrm{K} \geq 0.778$ to ensure yield surface to be convex.

$\sigma_{\mathrm{c}}^{0}=$ uniaxial compression yield stress.

The parameters of these models can be obtained directly from triaxial test,

$$
\begin{gathered}
\tan \beta=\frac{3 \sin \phi}{3-\sin \phi} \\
\mathrm{K}=\frac{3-\sin \phi}{3+\sin \phi} \\
\sigma_{\mathrm{c}}^{0}=2 \mathrm{c} \frac{\cos \phi}{1-\sin \phi}
\end{gathered}
$$

$\phi=$ friction angle from triaxial test

$\mathrm{c}=$ cohesion strength from triaxial test 
The requirement that $\mathrm{K} \geq 0.778$ predicts a high tension strength for materials. This could potentially be a problem where the system will experience large tension stresses. However, in a flexible pavement system, any tension stress is small. As a result, this limitation should not affect analysis results. Some applications [Low, et al., 1995], [White, et al., 1993] etc. have shown the Drucker-Prager model is effective in modeling flexible pavements. 


\section{CHAPTER 3 MATERIALS AND LABORATORY TESTS}

Drainage test sections are located on I-469 near Fort Wayne, Indiana, as shown in Figure 3.1 and 3.2. Interstate 469 is a four-lane divided highway. The project was let in January 1995 and completed in October 1995. The three test sections are located between Brooks Road and Leo Road (Bridge) and lie between Stations $150+05$ and $173+40$ in the eastbound lane. Section station limits are shown in Table 3.1. Figure 3.3 shows the configuration of the three test sections.

Table 3.1 Test Section Stations and Actual Length

\begin{tabular}{|c|c|c|c|c|c|c|}
\hline $\begin{array}{c}\text { Section } \\
\#\end{array}$ & \multicolumn{4}{|c|}{ Section } & \multicolumn{2}{c|}{ Drainage pipe (actual section) } \\
\hline & From & To & Length & From & To & Length \\
\hline 1 & $150+05$ & $158+05$ & $242 \mathrm{~m}$ & $150+15$ & $157+95$ & $236 \mathrm{~m}$ \\
& & & $(800 \mathrm{ft})$ & & & $(780 \mathrm{ft})$ \\
\hline 2 & $158+05$ & $166+05$ & $242 \mathrm{~m}$ & $158+15$ & $165+95$ & $236 \mathrm{~m}$ \\
& & & $(800 \mathrm{ft})$ & & & $(780 \mathrm{ft})$ \\
\hline 3 & $166+05$ & $173+40$ & $223 \mathrm{~m}$ & $166+13$ & $173+40$ & $220 \mathrm{~m}$ \\
& & & $(735 \mathrm{ft})$ & & & $(727 \mathrm{ft})$ \\
\hline
\end{tabular}




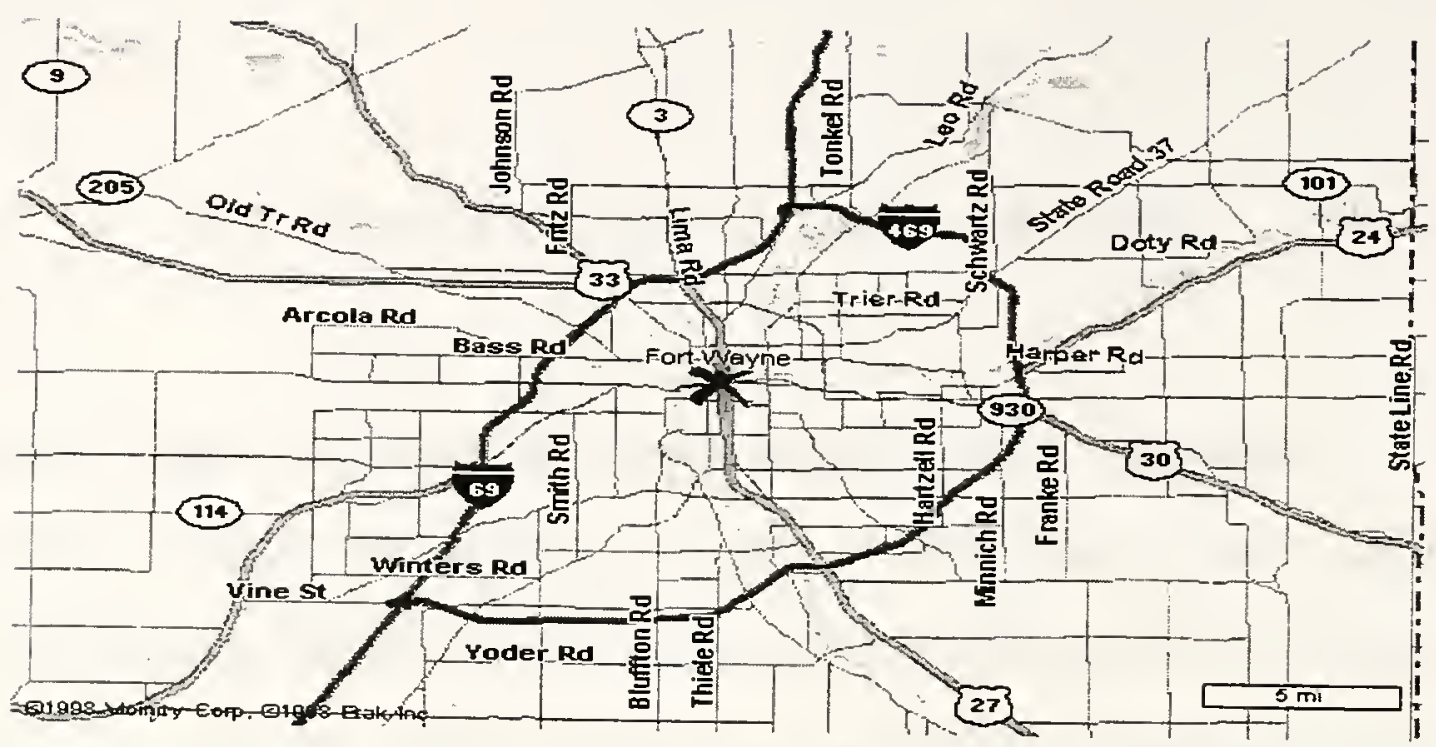

Figure 3.1 Project Location

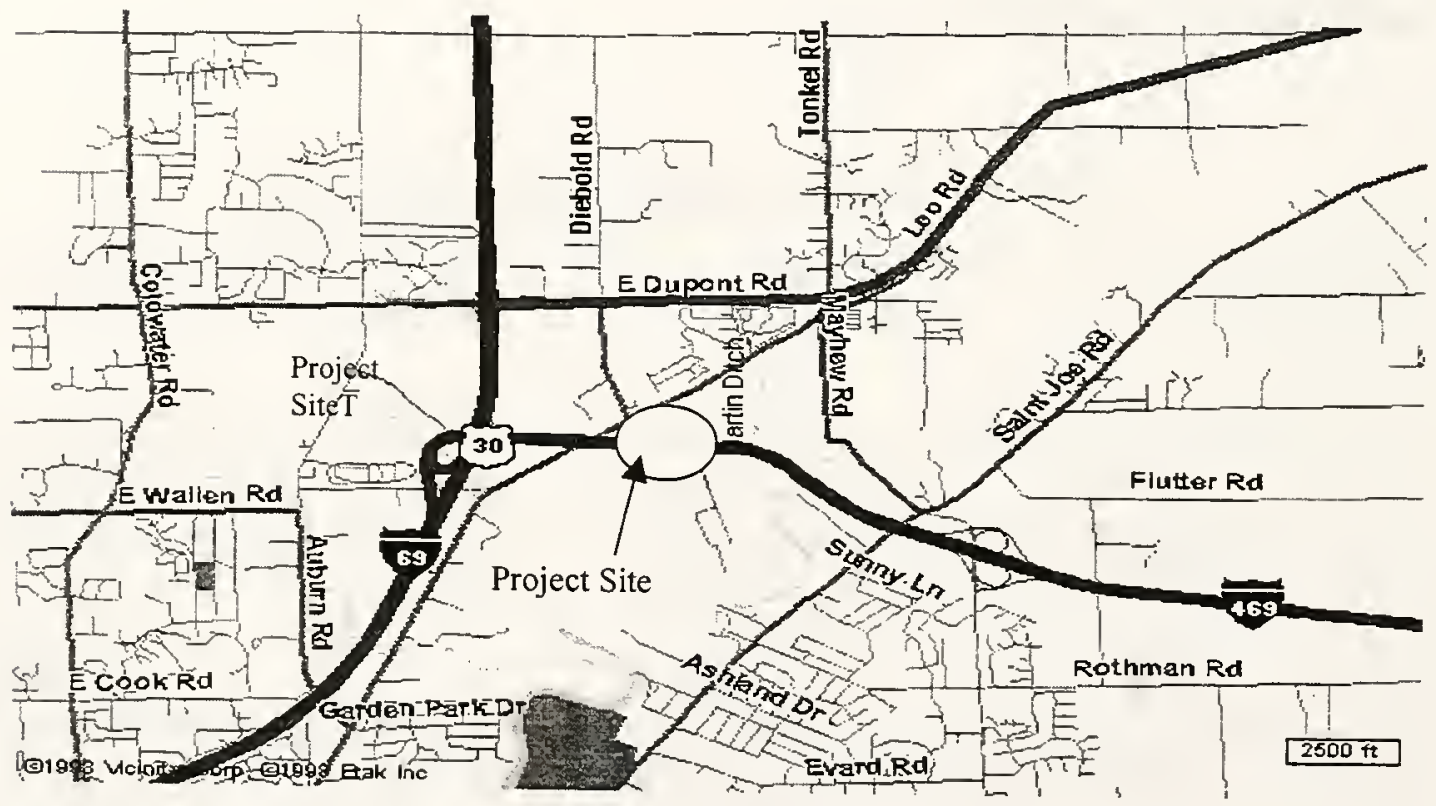

Figure 3.2 Location of Test Sections 


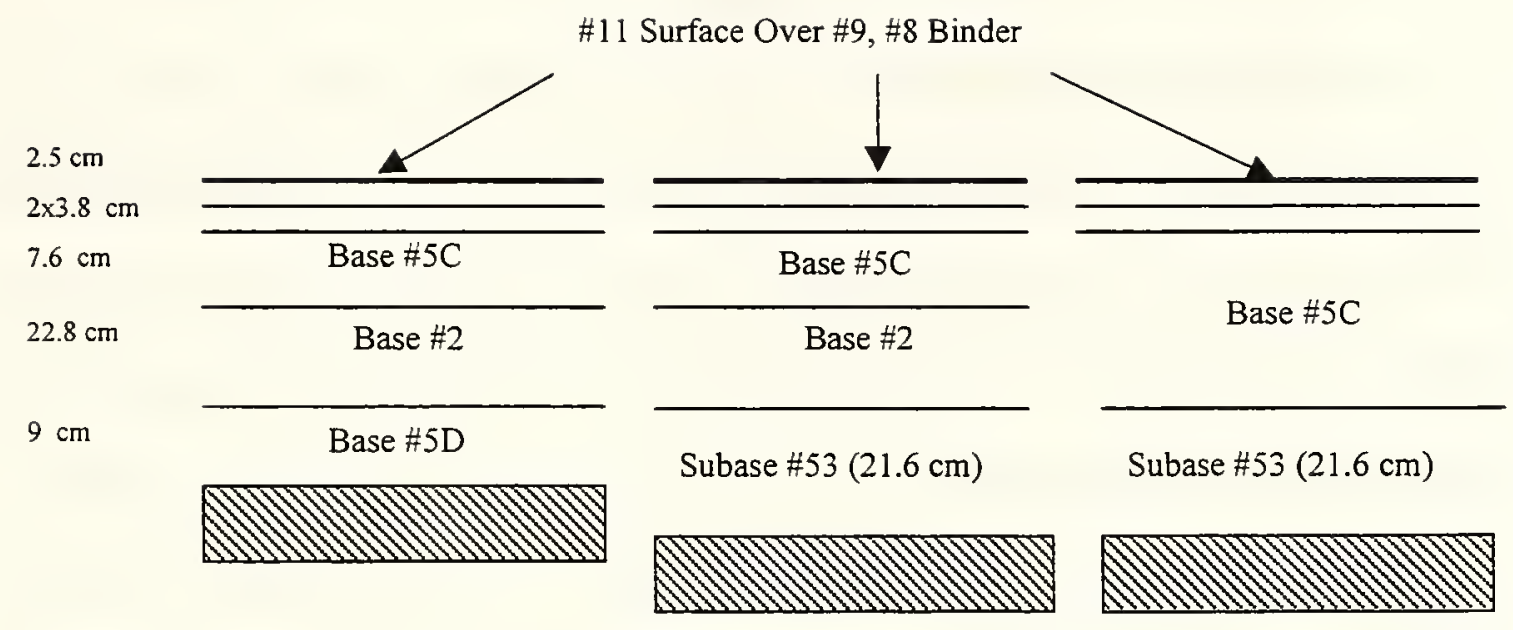

Section 1

Section 2

Section 3

Figure 3.3 Test Section Configurations ( Hossam, 1996) 
Materials tested and reported in this chapter include subgrade soils, Indiana \#11, $\# 9$, \#8, \#5D, \#5C, \#2 asphalt mixtures, \#53 granular subbase, and \#8 gravel trench backfill material.

\subsection{General}

As discussed in Chapter 2, the purpose of conducting triaxial tests on the pavement materials, trench backfill material and subgrades was to obtain material model parameter values for use in the FEM analysis of test section stability and rutting. Triaxial testing is recommended for this purpose (ABAQUS, 1995). Data from triaxial tests provides estimates of elastic modulus, yield stress, cohesion and angle of internal friction. These are used directly in material models in ABAQUS. It is recognized that the triaxial test as conducted in this study does not represent all of the stress paths pavement materials will experience. But laboratory resources were not available to conduct "true" triaxial tests. The triaxial tests that were conducted followed the practice in ASTM D4767 -88 "Standard Test Method for Consolidated Undrained Triaxial Compression" and the procedure in Bowles Laboratory manual [Bowles, 1993] except for the Indiana \#2 asphalt mixture which has a maximum particle size of $63 \mathrm{~mm}$. The apparatus and protocols were checked to be in agreement with other researchers conducting triaxial tests in the Geotechnical Laboratory at Purdue University.

Tests on asphalt mixtures included modifications of apparatus and protocols. For example, a means was developed to provide heated water for saturating asphalt mixtures. These tests as well as tests on the unbound aggregate materials were limited because of MTS equipment load capacity of $45 \mathrm{KN}$. Significance of the limited load capacity is that 
the maximum test confining pressure was lower than desired. Literature on triaxial tests of asphalt mixtures dates to the 1950s. These literature sources were reviewed as the test conditions were selected.

Triaxial tests were conducted with two MTS electro-hydraulic testing systems. In tests on both systems, a control board was used to manually control confining pressure, back-pressure and specimen saturation. Tests on asphalt mixtures with temperature control utilized an environmental chamber. The subgrade and $\# 8$ trench aggregate were tested on the MTS system in the Geotechnical Laboratory, Purdue University. The load capacity of this equipment is $25 \mathrm{KN}$. Components of the test apparatus are shown in Figure 3.4. The \#53 filter material and all asphalt mixtures were tested on the MTS system at the INDOT Research Division. Load capacity of this test equipment is $45 \mathrm{KN}$. The system components and environmental chamber are shown in Figure 3.5. In planning tests, the confining pressures were estimated for the various materials from a preliminary FEM analysis. A range of confining pressures was selected to bracket these estimated values.

\subsection{Subgrade Soil}

\subsubsection{Field Information}

Subgrade specimens were obtained after the subgrade was brought to grade and compacted. Physical test results and permeability characteristics are summarized in Table 3.2. 


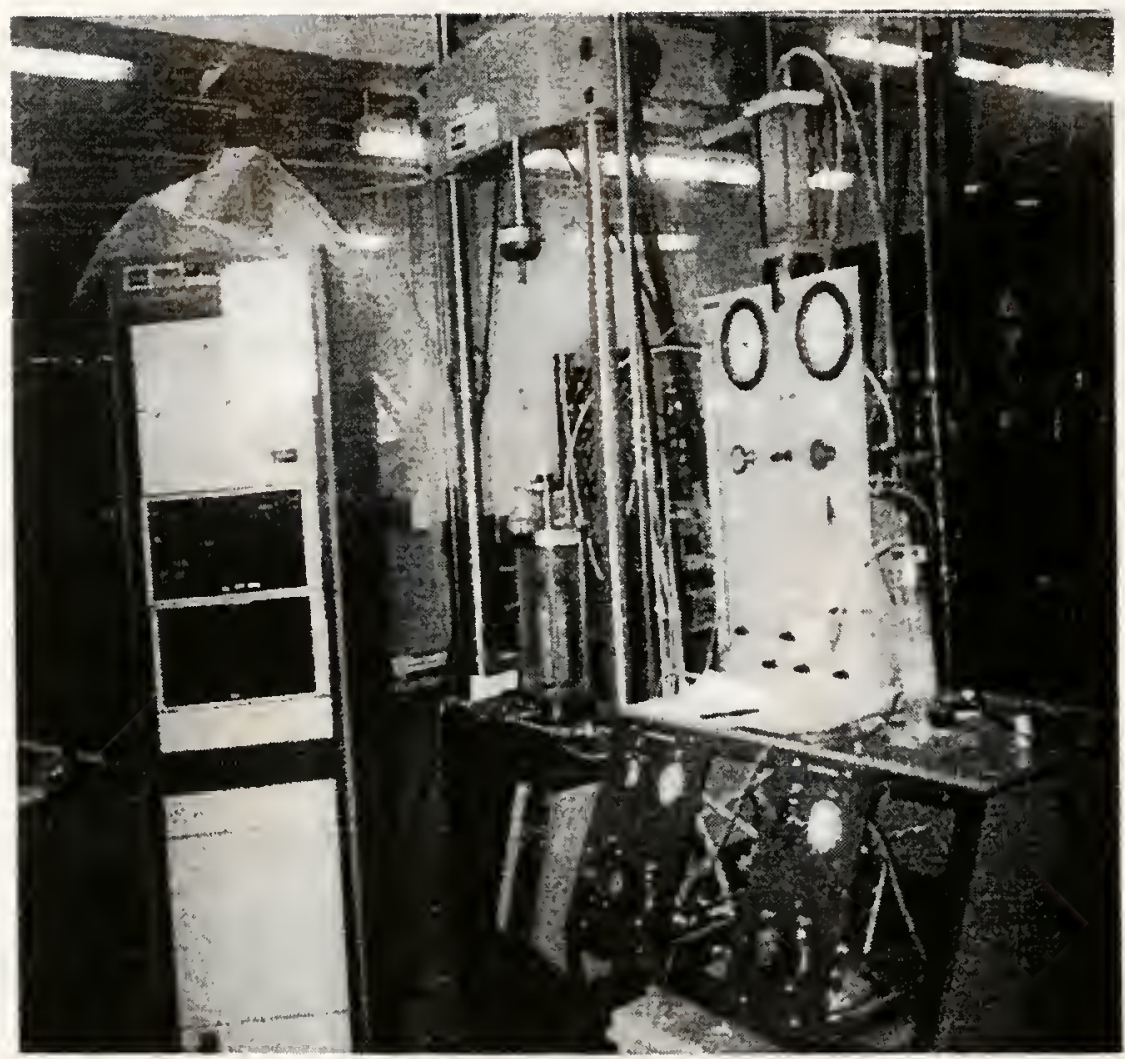

Figure 3.4 MTS System in Purdue University 


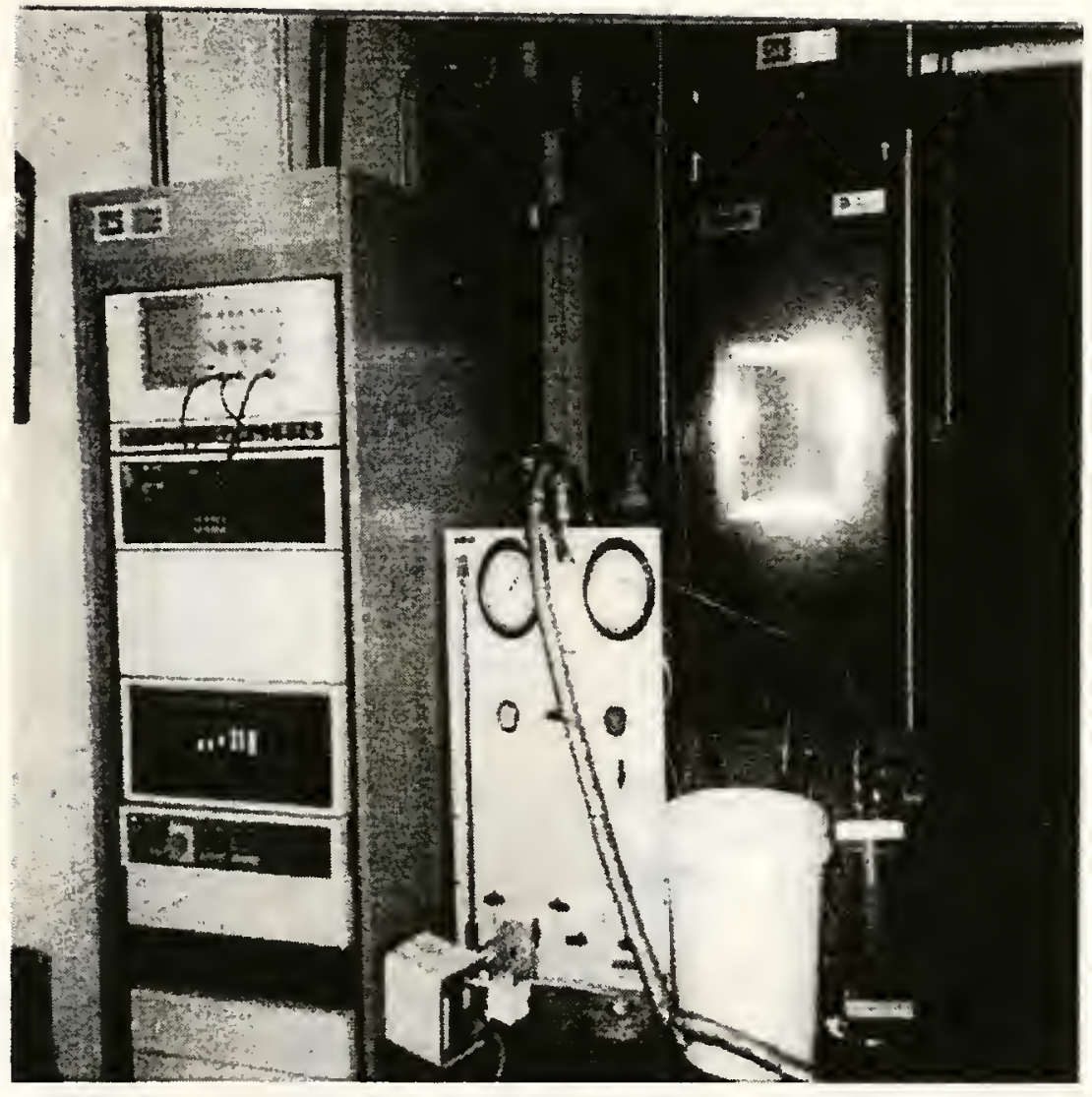

Figure 3.5 MTS System in INDOT Research Division 
Table 3.2 Physical Test Results on Subgrade Soil (Hossam, 1996)

\begin{tabular}{|c|c|c|c|c|c|c|c|c|c|c|}
\hline Section & \multicolumn{5}{|c|}{1} & \multicolumn{2}{|c|}{2} & \multicolumn{3}{|c|}{3} \\
\hline Location & 1 & 2 & 3 & 4 & 5 & 1 & 2 & 1 & 2 & 3 \\
\hline $\begin{array}{c}\text { USCS Soil } \\
\text { Classification }\end{array}$ & $\mathrm{CL}$ & $\mathrm{ML}$ & $\mathrm{CL}$ & $\mathrm{CL}$ & $\mathrm{SC}$ & $\overline{C L}$ & $\mathrm{CL}$ & $\overline{\mathrm{SM}}$ & $\overline{C L}$ & $\mathrm{ML}$ \\
\hline $\begin{array}{c}\text { Permeability } \\
\text { (constant head), } \\
\mathrm{cm} / \mathrm{sec}\end{array}$ & N/A & $\begin{array}{c}2.4 \mathrm{E}- \\
08\end{array}$ & $\begin{array}{c}3.9 \mathrm{E}- \\
08\end{array}$ & $\begin{array}{c}5.8 \mathrm{E}- \\
08\end{array}$ & $\begin{array}{c}3.9 E- \\
08\end{array}$ & $\begin{array}{c}2.4 \mathrm{E}- \\
08\end{array}$ & $\begin{array}{c}6.2 \mathrm{E}- \\
08\end{array}$ & $\begin{array}{c}8.5 \mathrm{E}- \\
08\end{array}$ & N/A & N/A \\
\hline $\begin{array}{c}\text { Permeability } \\
\text { (rising, falling) } \\
\mathrm{cm} / \mathrm{sec}\end{array}$ & N/A & $\begin{array}{c}3.7 \mathrm{E}- \\
08\end{array}$ & $\begin{array}{c}2.4 \mathrm{E}- \\
08\end{array}$ & $\begin{array}{c}7.4 \mathrm{E}- \\
08\end{array}$ & $\begin{array}{c}3.8 \mathrm{E}- \\
07\end{array}$ & $\begin{array}{c}6.4 \mathrm{E}- \\
08\end{array}$ & $\begin{array}{c}7.5 \mathrm{E}- \\
08\end{array}$ & $\begin{array}{c}7.1 \mathrm{E}- \\
08\end{array}$ & N/A & N/A \\
\hline $\begin{array}{c}\text { Bureau of } \\
\text { Reclamation } \\
\text { (FHWA,1982), } \\
\mathrm{cm} / \mathrm{sec}\end{array}$ & $\begin{array}{c}7.73 \mathrm{E} \\
-08\end{array}$ & $\begin{array}{c}5.7 \mathrm{E}- \\
07\end{array}$ & $\begin{array}{c}7.73 \mathrm{E} \\
-08\end{array}$ & $\begin{array}{c}7.73 E \\
-08\end{array}$ & $\begin{array}{c}2.89 \mathrm{E} \\
-07\end{array}$ & $\begin{array}{c}7.73 E \\
-08\end{array}$ & $\begin{array}{c}7.73 \mathrm{E} \\
-08\end{array}$ & $\begin{array}{c}7.25 E \\
-06\end{array}$ & $\begin{array}{l}7.73 \\
\text { E-08 }\end{array}$ & $\begin{array}{r}5.7 \mathrm{E} \\
-07\end{array}$ \\
\hline
\end{tabular}

There was some variation in the subgrade soil type. As shown in Table 3.2, the subgrade unified soil classifications included CL, ML, and SM.

In situ moisture content is an important factor in subgrade performance. Hossam, [1996] reported the subgrade water contents to be relatively uniform year round. Additional readings in the current study show that the soil moisture remains uniform. There are some differences between the sections, which will be discussed below.

Subgrade density, which was measured at the time of construction by Hossam, 1996, is another important parameter in subgrade performance. That data is shown in Table 3.3. 


\subsubsection{Test Specimen Preparation}

As noted above, triaxial tests on subgrade specimens were conducted in accordance with ASTM D4767-88 "Standard Test Method for Consolidated Undrained Triaxial Compression". The test requires that the specimen diameter be six times larger than the maximum particle size and the specimen height should be $2 \sim 2.5$ times the diameter. In this study, the specimens were compacted in the laboratory and are therefore remolded specimens. Target moisture content and density of the specimens were those measured in situ. Since the clay subgrade has a very low permeability, consolidated, undrained (CU) and partial saturated triaxial tests were conducted. These tests were conducted on specimens $71.1 \mathrm{~mm}$ ( $2.8 \mathrm{in}$.) in diameter by $177.8 \mathrm{~mm}$ (7 in.) high.

Table 3.3 Field Density and Moisture Content (Hossam, 1996)

\begin{tabular}{|c|c|c|c|c|c|}
\hline Section & Station & $\gamma_{\text {dry }}(\mathrm{gm} / \mathrm{cc})$ & $\gamma_{\text {wet }}(\mathrm{gm} / \mathrm{cc})$ & $\mathrm{w} / \mathrm{c}, \%$ & Saturation \\
\hline 1 & $150+85$ & 1.67 & 2.02 & 20.5 & 0.87 \\
\hline 2 & $158+67$ & 1.91 & 2.18 & 14.3 & 0.84 \\
\hline 3 & $166+60$ & 2.07 & 2.28 & 10.3 & 0.86 \\
\hline
\end{tabular}

The field moisture data was collected from October 1995 to February 1996. The moisture content for preparing specimens uses the data from this period, which is shown in Table 3.3.

An appropriate amount of soil is dried in an oven overnight. The required amount of soil for a specimen is separated and mixed to the field moisture content. The soil is placed in a plastic container, which is covered tightly for overnight equilibration to make sure the moisture is uniform. 
In preparation for compaction, a $71.1 \mathrm{~mm}$ (2.8 in.) diameter split mold is assembled with a membrane inserted. Soil is placed and compacted in six layers. Each layer has the same mass. The desired mass density is achieved by compacting each layer to a predetermined volume. Each layer was scarified prior to adding the subsequent layer. After compaction, the specimen was removed from the split mold and the net weight and dimensions of the specimen determined. Water content is determined from residual material. A prepared specimen is shown in Figure 3.6.

The first membrane used in specimen preparation not only facilitates removal from the split mold but also provide additional protection against possible membrane penetration. Cross section area used in calculation is corrected for membrane thickness using the membrane manufacture's supplied thickness values.

\subsubsection{Saturation, Consolidation and Loading}

A dry mounting method [ASTM D4767-88] was used to remove air from the specimen. The specimen drainage system is dried by a flow of dry air. Assembly for testing involves placing a dry porous disc and a filter paper on top of the base plate. The specimen is placed on the filter paper. In reverse order a filter paper and dry porous disc are placed on top of the specimen. Another membrane is applied on the outside of the specimen using an expander. Connections are made. 


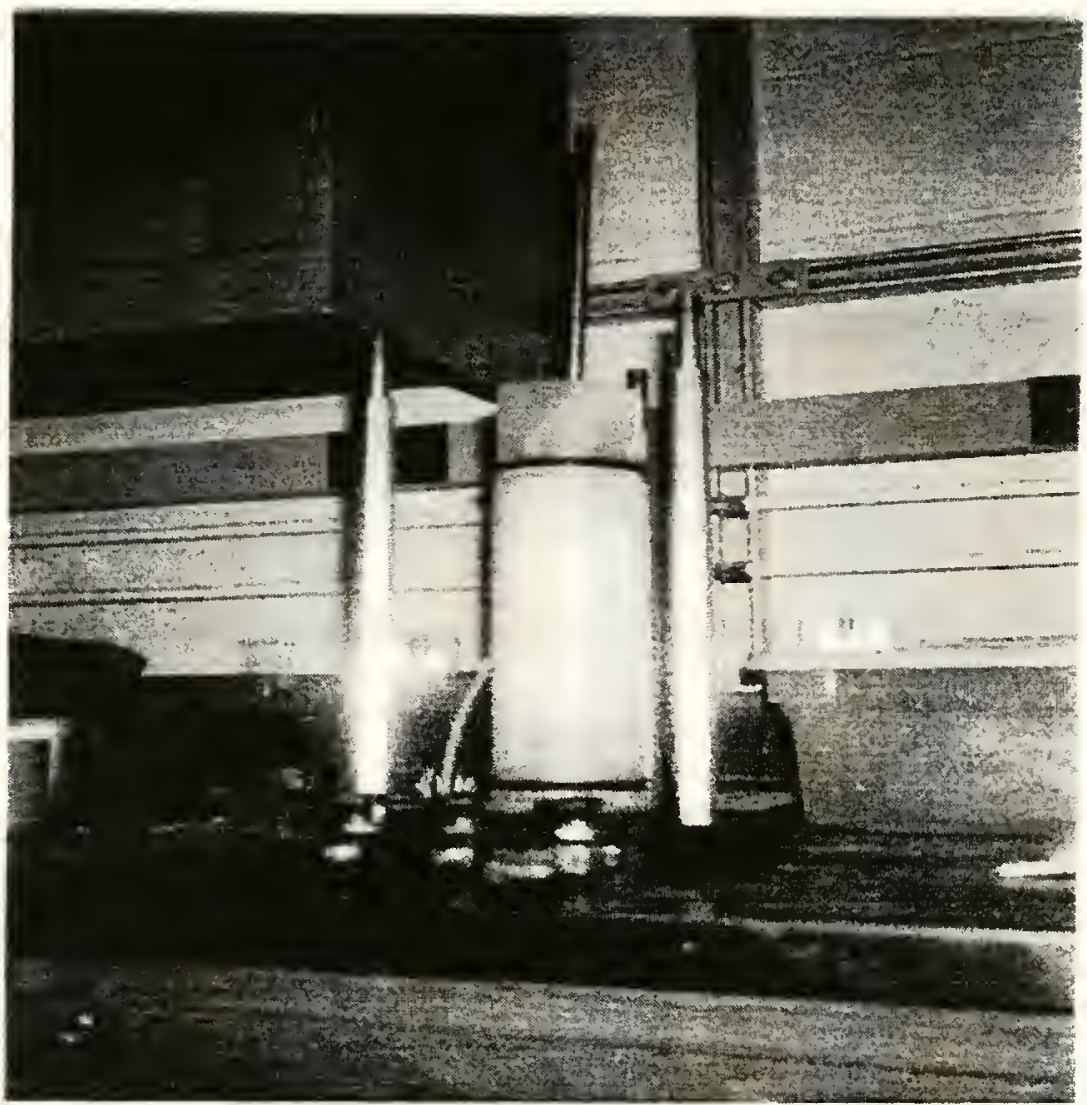

Figure 3.6 A Subgrade Triaxial Specimen 
Because the subgrade soil permeability is on the order of $10^{-7} \mathrm{~mm} / \mathrm{sec}$, it was difficult to fully saturate the specimens. Carbon dioxide was employed to purge and to replace air in the specimens. In this process, a confining pressure of about $10 \mathrm{kPa}$ is applied, then the carbon dioxide is pushed through the bottom of the specimen with a pressure less than the confining pressure. The air is exhausted out of the top drain port and through a water reservoir, air bubbles can be observed from the top port connected to the water reservoir. Carbon dioxide is applied for a period of about two hours. The two hours is based on experience with other, current research. When the $\mathrm{CO}_{2}$ valve is closed, the air bubbles will disappear after some time. Then, when the valve is reopened, air bubbles will reappear in the tank. This means $\mathrm{CO}_{2}$ is circulating in the specimen. Backpressure is then applied at the top and bottom of the specimen simultaneously. The backpressure is increased in increments of about $69 \mathrm{kPa}$. Confining pressure will increase automatically with the backpressure to maintain a constant confining pressure. After a period of time, the B parameter is evaluated to check whether the specimen is saturated. The parameter B is an indicator of degree of saturation and is defined as:

$$
\mathrm{B}=\Delta \mathrm{u} / \Delta \sigma_{3}
$$

For evaluation of the $\mathrm{B}$ parameter a $69 \mathrm{kPa}$ increment of confining pressure $\left(\Delta \sigma_{3}\right)$ is applied and the resulting increment of pore pressure $(\Delta \mathrm{u})$ read. If $B$ is below 0.95 , the backpressure is increased until B is close to or above 0.95 . Generally, the specimens required a high backpressure (above $345 \mathrm{kPa}$ ) to achieve saturation.

After the specimen is saturated, the confining pressure is increased until the difference between the pore pressure and confining pressure is the desired consolidation 
pressure. Drainage valves of the top and bottom platens are opened. The amount of drained water is read using a burret. There are two ways to check whether consolidation has been completed: a) plot the consolidation curve or b) after some time, no excess water is coming out of the specimen. Method a) was used in this study.

After consolidation is completed, the MTS equipment and computer are turned on, a $0.2 \mathrm{kN}$ seating load is applied to the specimen and load is applied immediately at a rate of $0.001 \%$ of the height of the specimen per second. This loading rate is about the lowest loading rate possible for the MTS equipment in the Geotechnical Laboratory. The purpose of such a low loading rate is to avoid generating excess pore pressure. Total displacement is about $30 \mathrm{~mm}$. Figure 3.7 shows a specimen being tested.

Air was the lateral confinement medium used for tests with equipment in the Geotechnical Laboratory, Purdue University. Air was also used as the confining medium on tests at INDOT Division of Research. The apparatus at INDOT has electronic components mounted inside the confining cell. There is concern that the air would penetrate the rubber membrane. Both water [Bernal, 1996] and air [Karim, 1997] have been used as the confining medium. No problem with using air was noted. A double membrane with light "greasing" was used in the current research. There was not significant change in pore pressure over time. However, the B parameter was not checked after consolidation. It is recommended that future research address the issue of air penetrating the doubled membrane used in this research. 


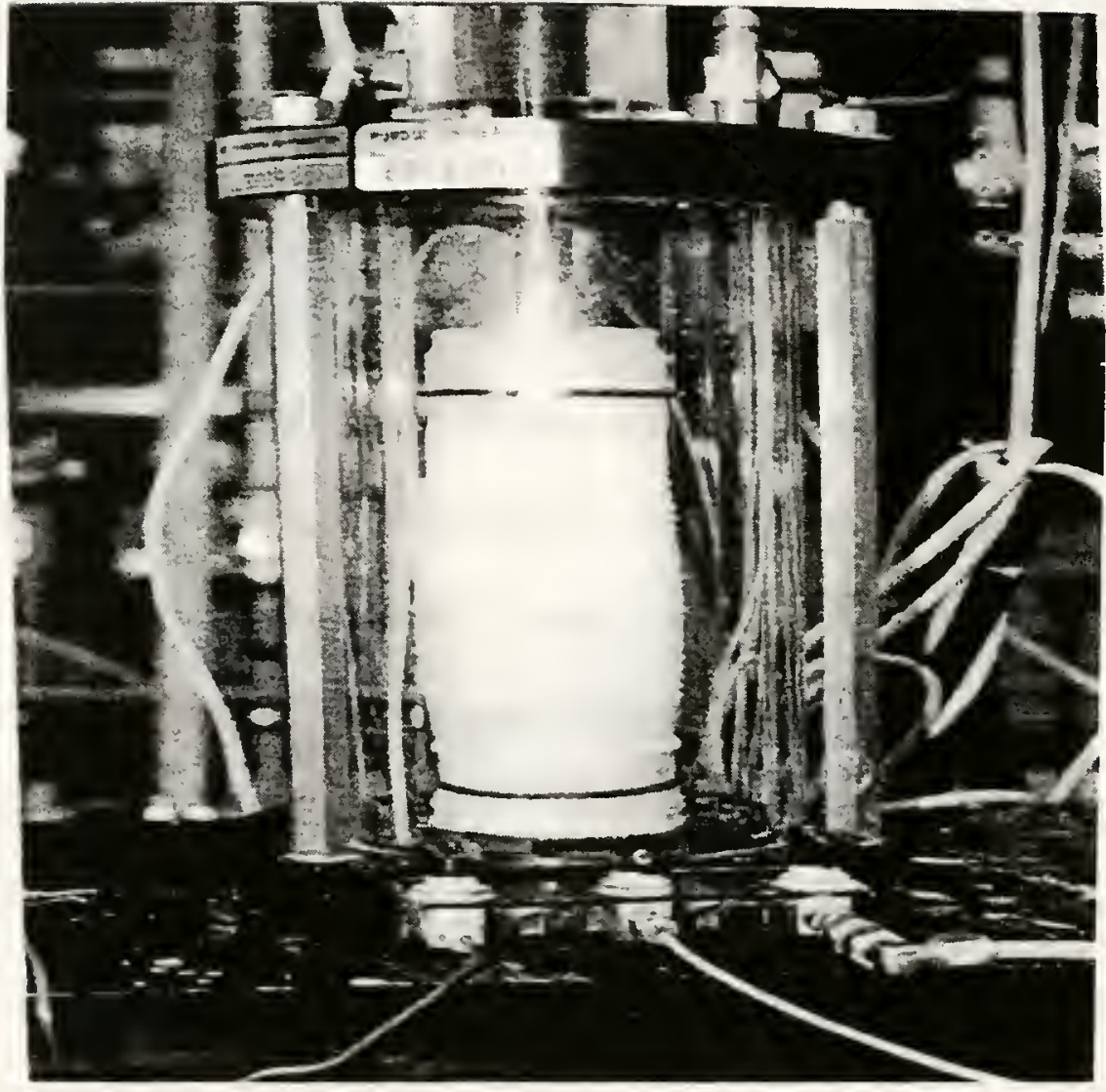

Figure 3.7 Triaxial Test on Subgrade 


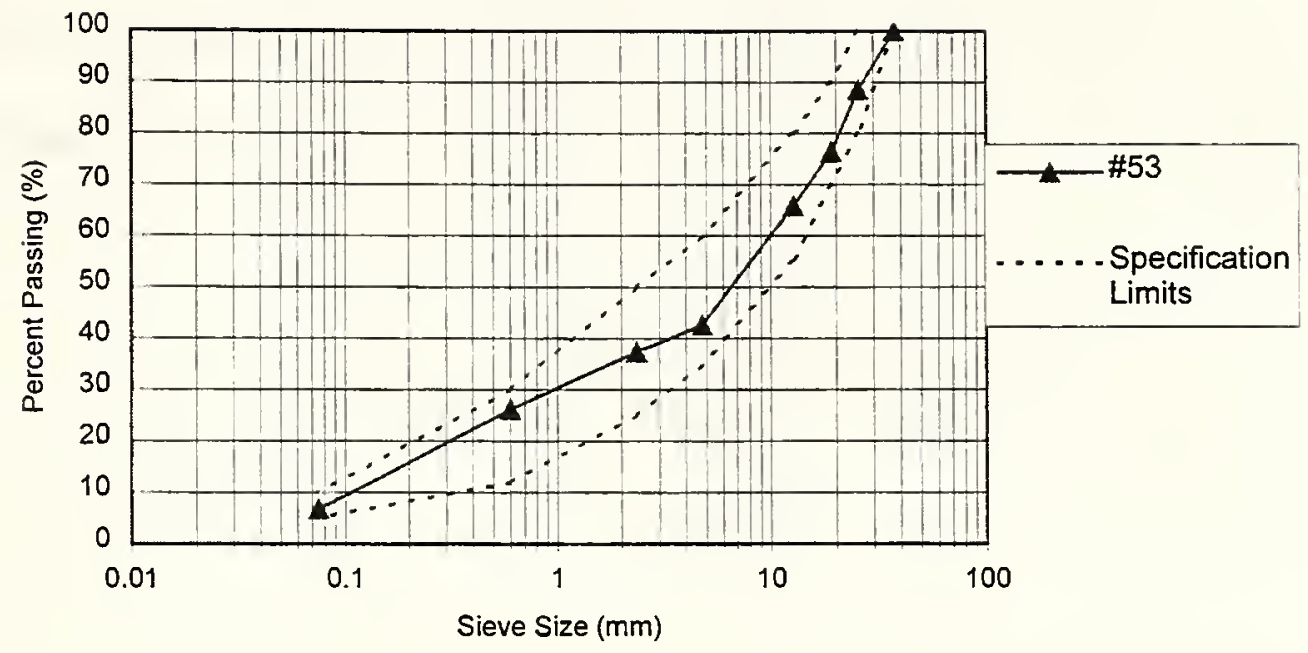

Figure 3.8 Gradation of \#53 Filter 


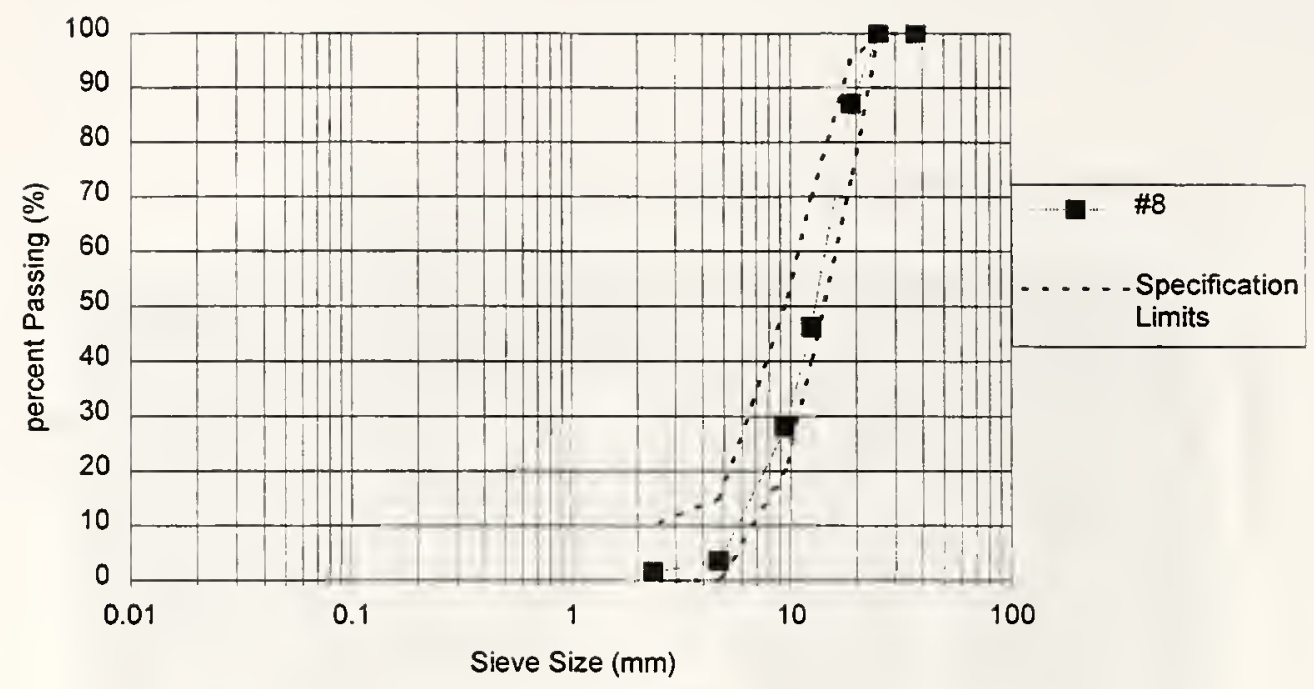

Figure 3.9 Gradation of \#8 Trench Backfill

\section{$\underline{3.3 \text { Granular Materials }}$}

Granular materials subjected to triaxial tests included \#53 and \#8 unbound aggregates. In the drainage test sections, \#53 and \#8 materials were used as filter/subbase and trench backfill, respectively. Figure 3.8 shows the gradation of the \#8 trench backfill. Figure 3.9 shows the gradation of the \#53 aggregate. Field moisture contents of the \#53 and \#8 materials were low, approximately equal and vary in the same way. Initial volumetric moisture content of the \#53 material from TDR measurements was about eight percent on average. The field conditions are summarised in Table 3.5.

Specimen size for the \#53 and the \#8 aggregate for triaxial testing was $152.4 \mathrm{x}$ $304.8 \mathrm{~mm}$ (diameter $\mathrm{x}$ height). Specimen preparation is similar to that for the subgrade 
soil. Materials are dried and then water added to obtain the desired moisture content. A Marshall hammer was used to compact the \#53 subbase. Two membranes were used in specimen preparation. The second membrane was used because the aggregate was prone to damage the membranes. The doubled membrane also helps against possible air penetration.

Because of the low in situ density, unbound \#8 trench aggregate was just poured into the mold to form the specimen. In field installations, the aggregate is placed into the trench without compaction. The triaxial testing procedures are similar to those for the subgrade soil.

Consolidated, undrained (CU) and consolidated, drained (CD) tests were conducted on the $\# 53$ unbound aggregate materials. However, $\mathrm{CU}$ and partially saturated tests were conducted on the $\# 8$ trench backfill material. Although the trench material may

Table 3.4 Field Condition for \#53 and \#8 Granular Materials (Hossam, 1996)

\begin{tabular}{|c|c|c|c|}
\hline Material & Density $\left(\mathrm{kg} / \mathrm{cm}^{3}\right)$ & Moisture content $(\%)$ & Saturation \\
\hline$\# 53$ aggregate & 2.30 & 8 & 0.29 \\
\hline$\# 8$ trench backfill & 1.26 & N/A & N/A \\
\hline
\end{tabular}

have significant moisture, the high moisture is a transient condition because of the high permeability. The laboratory tests were selected so that the specimens after consolidation would have a moisture content close to the initial field conditions. 


\subsection{Asphalt Mixtures}

Triaxial tests were conducted on the \#11 surface, \#9 and \#8 binders, \#5C open graded base and \#5D and \#2 dense base asphalt mixtures. Table 3.5 shows the constituents of these mixtures. Figures 3.10 through 3.15 show the material gradations.

\subsubsection{Asphalt Mixture Specimen Preparation}

As discussed in Chapter 2, the California Kneading Compactor was used to prepare the asphalt mixture triaxial specimens. Figure 3.16 shows a picture of the California Kneading Compactor. Figure 3.17 shows the mold and modified kneading foot. The steel mold has a total height of $330.2 \mathrm{~mm}$ (13 in.), and an inner diameter of $152.4 \mathrm{~mm}(6 \mathrm{in}$.$) . Thickness of the top and bottom steel plates is 65.3 \mathrm{~mm}(1 / 4 \mathrm{in}$.$) .$ Compacted specimen height is approximately $317.7 \mathrm{~mm}$ (12.5 in.).

A mechanical mixer was used to prepare the asphalt mixtures. In preparation for compaction, the foot and mold is heated in an oven at $165^{\circ} \mathrm{C}$. The asphalt mixtures were cured for two hours at $135^{\circ} \mathrm{C}$. A heated trough was used to feed the mixture into the mold. Two factors control specimen density. One is the total number of tamps or compaction time. Another factor is the foot pressure. Density can be reached in a short period of time by increasing the foot pressure. However, there is a practical limit on the foot pressure. The compaction process should not crush the aggregate during compaction. Trials were conducted to determine the correct foot pressure. In compacting specimens, the heated mixture is pushed into the mold uniformly and continuously from the trough in 
order to achieve a uniform density through the specimen height. After compaction, a load was applied to a circular steel plate on top to level the specimen.

Table 3.5 Asphalt Mixture Information (Hossam, 1996)

\begin{tabular}{|c|c|c|c|}
\hline $\begin{array}{c}\text { Asphalt } \\
\text { Mixture }\end{array}$ & Stockpile Blending Formula & $\begin{array}{c}\text { Asphalt Content } \\
(\%)\end{array}$ & $\begin{array}{c}\text { Bulk } \\
\text { Density } \\
\left(\mathrm{gm} / \mathrm{cm}^{3}\right)\end{array}$ \\
\hline $\begin{array}{c}\# 11 \\
\text { surface }\end{array}$ & $\begin{array}{c}25 \% \# 11 \mathrm{LS}, 24 \% \# 11 \mathrm{Slag}, \\
51 \% 24 \mathrm{NS}\end{array}$ & 5.8 & 2.21 \\
\hline$\# 9$ binder & $\begin{array}{c}51 \% \# 9 \mathrm{LS}, 15 \% \# 11 \mathrm{LS}, \\
34 \% 24 \mathrm{NS}\end{array}$ & $4.8 \%$ & 1.98 \\
\hline$\# 8$ binder & $58 \% \# 8 \mathrm{LS}, 42 \% 24 \mathrm{NS}$ & $4.3 \%$ & 2.16 \\
\hline$\# 5 \mathrm{D}$ base & $\begin{array}{c}58 \% \# 5 \mathrm{LS}, 10 \% \mathrm{RAP}, \\
32 \% 24 \mathrm{NS}\end{array}$ & $4.1 \%$ & 2.24 \\
\hline$\# 5 \mathrm{C}$ & $92 \% \# 5 \mathrm{LS}, 8 \% 24 \mathrm{NS}$ & $3.5 \%$ & 2.03 \\
\hline$\# 2$ & $\begin{array}{c}60 \% \# 2 \mathrm{LS}, 20 \% \# 5 \mathrm{LS}, \\
10 \% \# 11 \mathrm{LS}, 10 \% 24 \mathrm{NS}\end{array}$ & $2.3 \%$ & 2.24 \\
\hline
\end{tabular}

\section{( LS - Lime Stone, NS - Natural Sand, RAP --- Recycled Asphalt Pavement )}

After the specimen and mold cooled to about $40^{\circ} \mathrm{C}$, the specimen is jacked from the mold. When the specimen reaches room temperature, $6.35 \mathrm{~mm}(0.25 \mathrm{in}$.) of each end is sawn off. The final specimen height is $304.5 \mathrm{~mm}$ (12 in.).

Test temperatures for the different asphalt layers were selected based on attenuation of temperature with depth into the pavement. Surface mixture test temperature was the measured average seven-day high temperature. This temperature is used in selecting the Superpave PG asphalt grade. Temperature attenuation into the pavement 
was predicted using a model by White [1981]. Specimens were conditioned over night in an oven at the desired test temperature. Table 3.6 shows test temperatures for various pavement layers.

Table 3.6 Asphalt Mixtures Test Temperatures

\begin{tabular}{|l|l|l|l|l|l|l|}
\hline Asphalt layer & $\# 11$ & $\# 9$ & $\# 8$ & $\# 5 \mathrm{C}$ & $\# 5 \mathrm{D}$ & $\# 2$ \\
\hline Temperature $\left({ }^{\circ} \mathrm{C}\right)$ & 41.1 & 39.4 & 38.3 & 36.1 & 32.8 & 33.9 \\
\hline
\end{tabular}

\subsubsection{Triaxial Test}

Asphalt mixture triaxial tests were conducted with the MTS system at the Indiana Department of Transportation Research Division. This system is shown in Figure 3.5. Figure 3.18 shows the triaxial cell and environmental chamber. Figure 3.19 shows the water pump system used in cycling hot water to the specimen.

All of the asphalt mixtures were tested at the field average seven-day high temperature. Both dry and saturated undrained tests were performed to evaluate the effect of moisture on mixture properties. Two loading speeds, $1.25 \mathrm{~mm} / \mathrm{min}$ and 12.5 $\mathrm{mm} / \mathrm{min}$ were investigated. Table 3.7 shows the tests conducted.

\subsubsection{Dry Test}

For dry tests the environmental chamber is turned on and allowed to heat to the test temperature. The specimen is put between the top and bottom end caps. Two membranes were applied and the specimen transferred to the base; The triaxial cell is 
installed and confining pressure applied. A seating load of about $0.8 \mathrm{KN}$ is applied and then the test is started.

Table 3.7 Triaxial Test Plan

\begin{tabular}{|c|c|c|c|c|}
\hline \multirow{2}{*}{$\begin{array}{c}\text { Confining } \\
\text { Pressure }\end{array}$} & \multicolumn{4}{|c|}{ Loading Speed } \\
\cline { 2 - 5 } & \multicolumn{2}{|c|}{$1.25 \mathrm{~mm} / \mathrm{min}$} & Dry & Wet \\
\cline { 2 - 5 } & Dry & Wet & $\mathrm{x} \mathrm{x}$ & $\mathrm{x} \mathrm{x}$ \\
\hline 1 & $\mathrm{x} \mathrm{x}$ & $\mathrm{x} \mathrm{x}$ & $\mathrm{x} \mathrm{x}$ & $\mathrm{x} \mathrm{x}$ \\
\hline 2 & $\mathrm{x} \mathrm{x}$ & $\mathrm{x} \mathrm{x}$ & $\mathrm{x} \mathrm{x}$ & $\mathrm{x} \mathrm{x}$ \\
\hline 3 & $\mathrm{x} \mathrm{x}$ & $\mathrm{x} \mathrm{x}$ & \multicolumn{2}{c}{} \\
\hline
\end{tabular}

\subsubsection{Wet Test}

Dry and wet test procedures were similar except in the wet test, two porous stones were used at both ends of the specimen. Before the test, a reservoir of water was heated to the test temperature. Hot water was circulated through a hose system to maintain a constant temperature water source during the saturation process. Both the supply and return water lines for the triaxial specimens were bound together and insulated. A vacuum was applied to draw the pre-heated, deaired water into the control panel tank. The tank was submerged in a larger reservoir to maintain the temperature constant. The specimen was transferred to the cell base, and a vacuum was supplied to remove air from the specimen. De- 
aired water was supplied to purge the specimen until no air bubbles were observed. Backpressure was held until the pore pressure was the same as the backpressure and no water was flowing into the specimen. With this condition, the specimen was considered to be saturated. The confining pressure was adjusted to obtain the target effective confining stress. Subsequently, the valve was opened to dissipate excess pore pressure (consolidation). A seating load about $0.8 \mathrm{KN}$ was applied and the test started.

In the wet test, a porous stone is very helpful in speeding up the purging, saturation and consolidation processes. It was also important in quickly dissipating excess pore pressure during loading. 


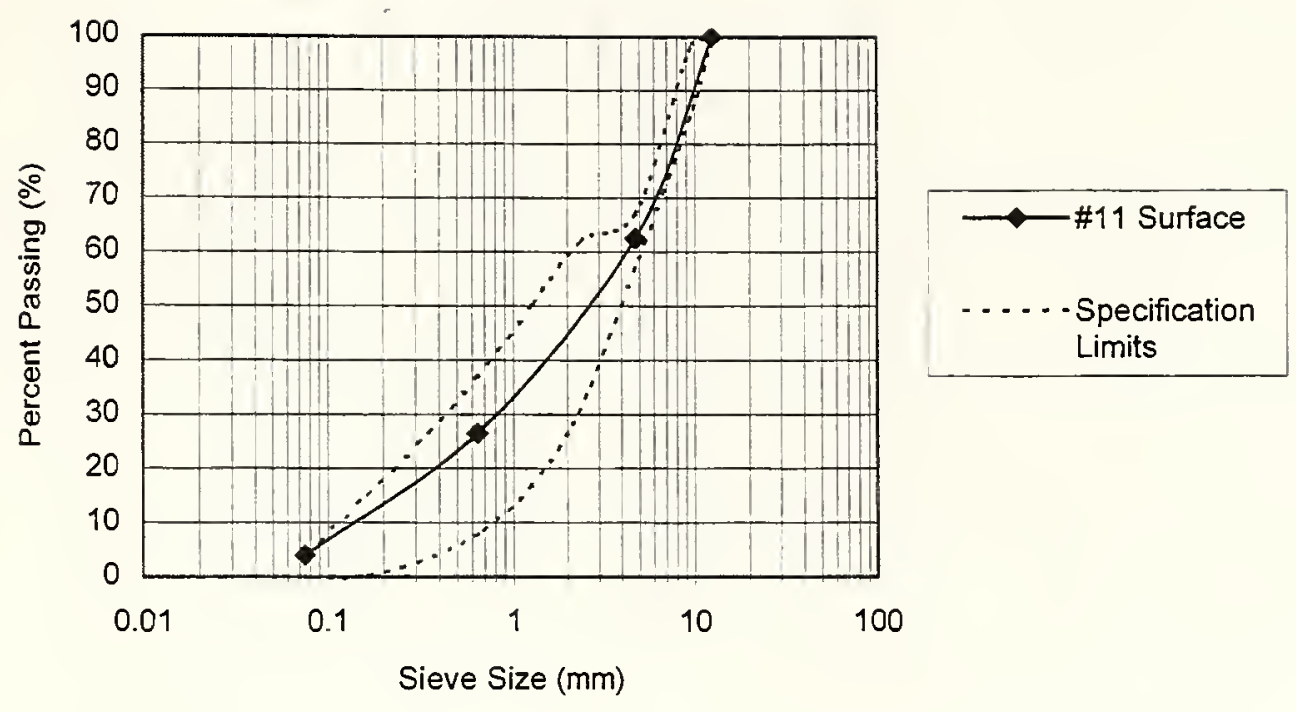

Figure 3.10 Gradation of \#11 Surface Mixture

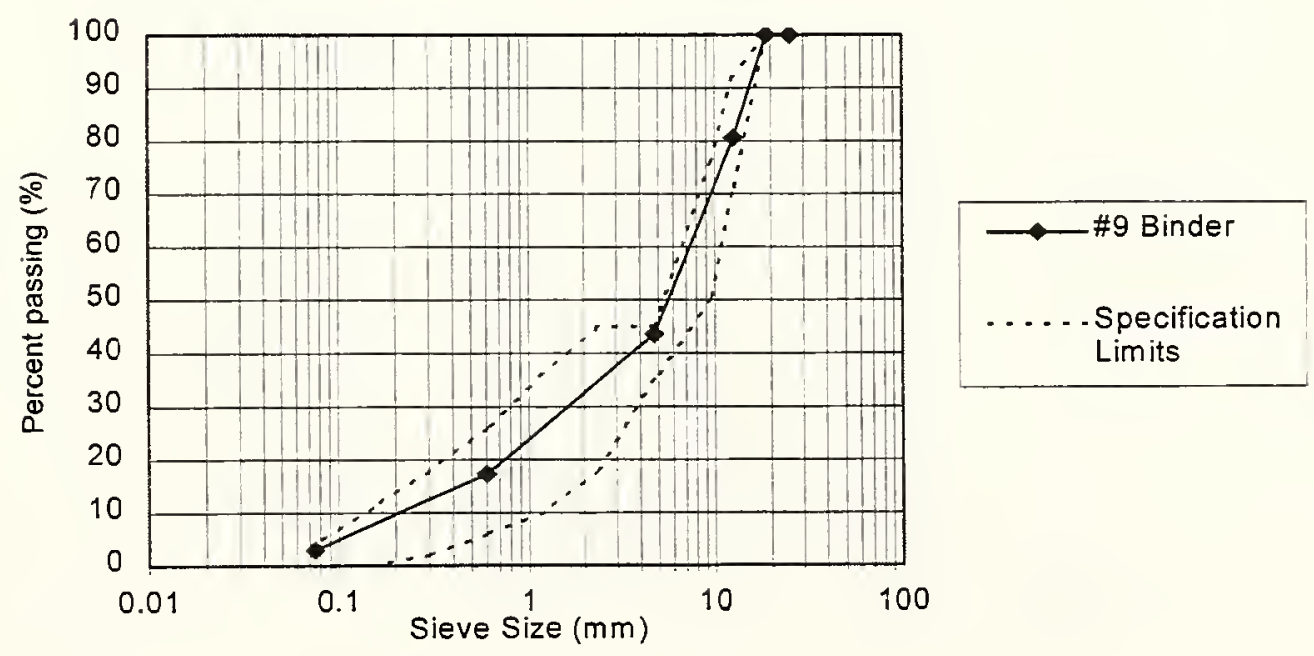

Figure 3.11 Gradation of \#9 Binder Mixture 


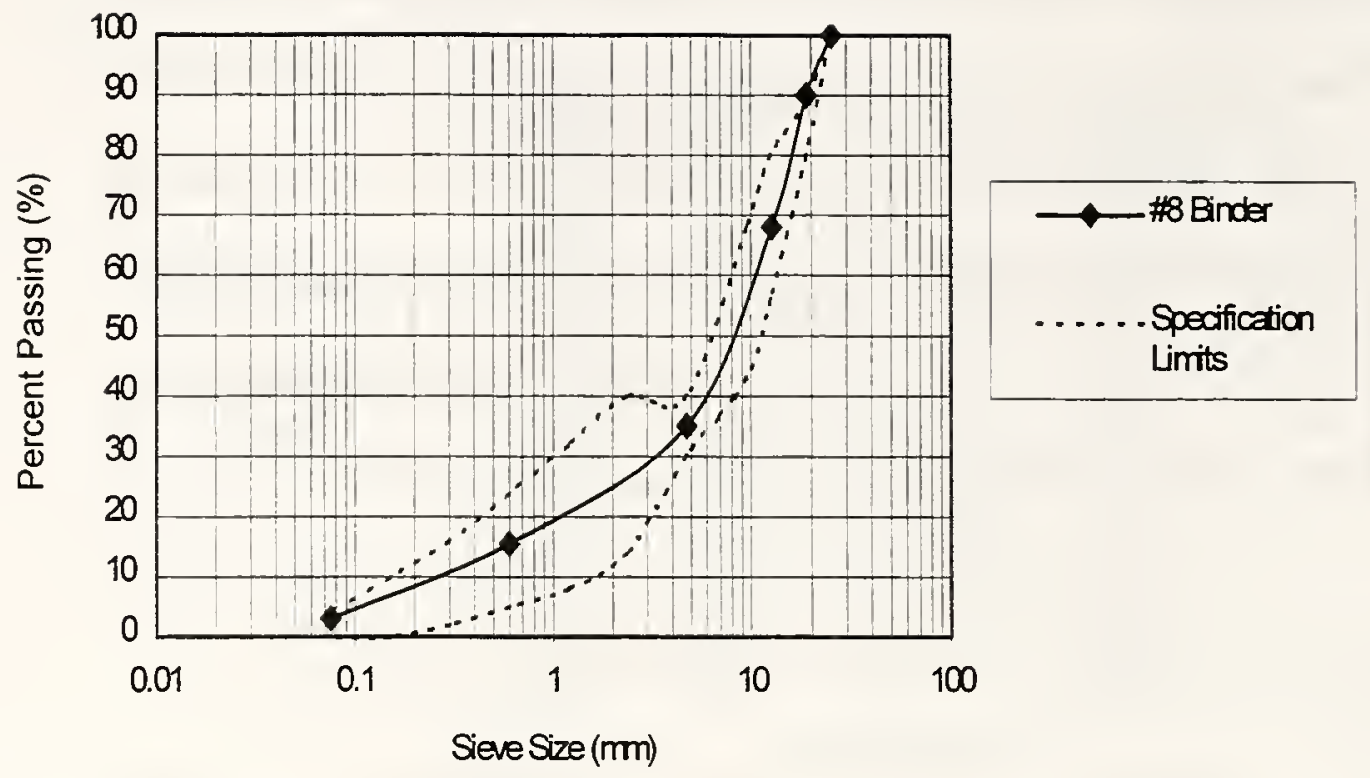

Figure 3.12 Gradation of \#8 Binder Mixture

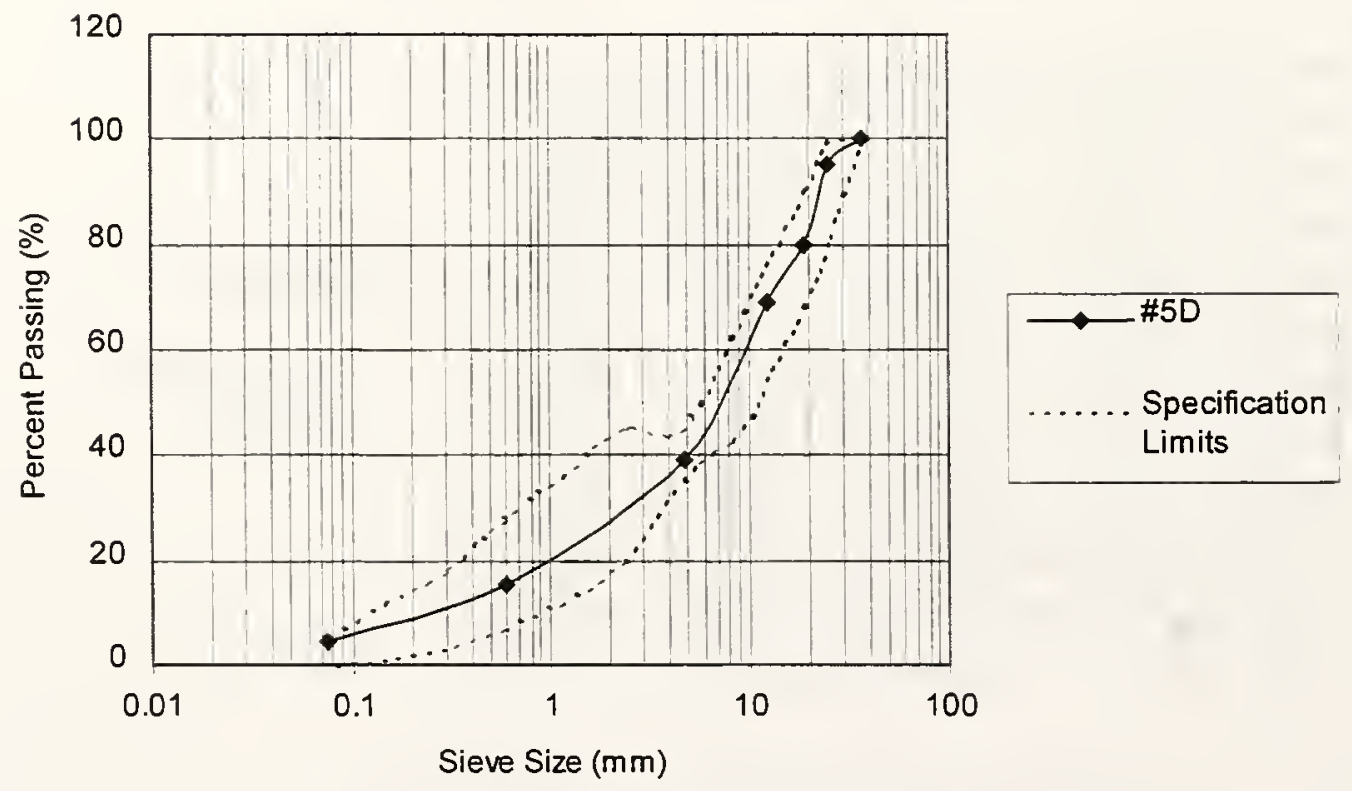

Figure 3.13 Gradation of \#5D Base Mixture 


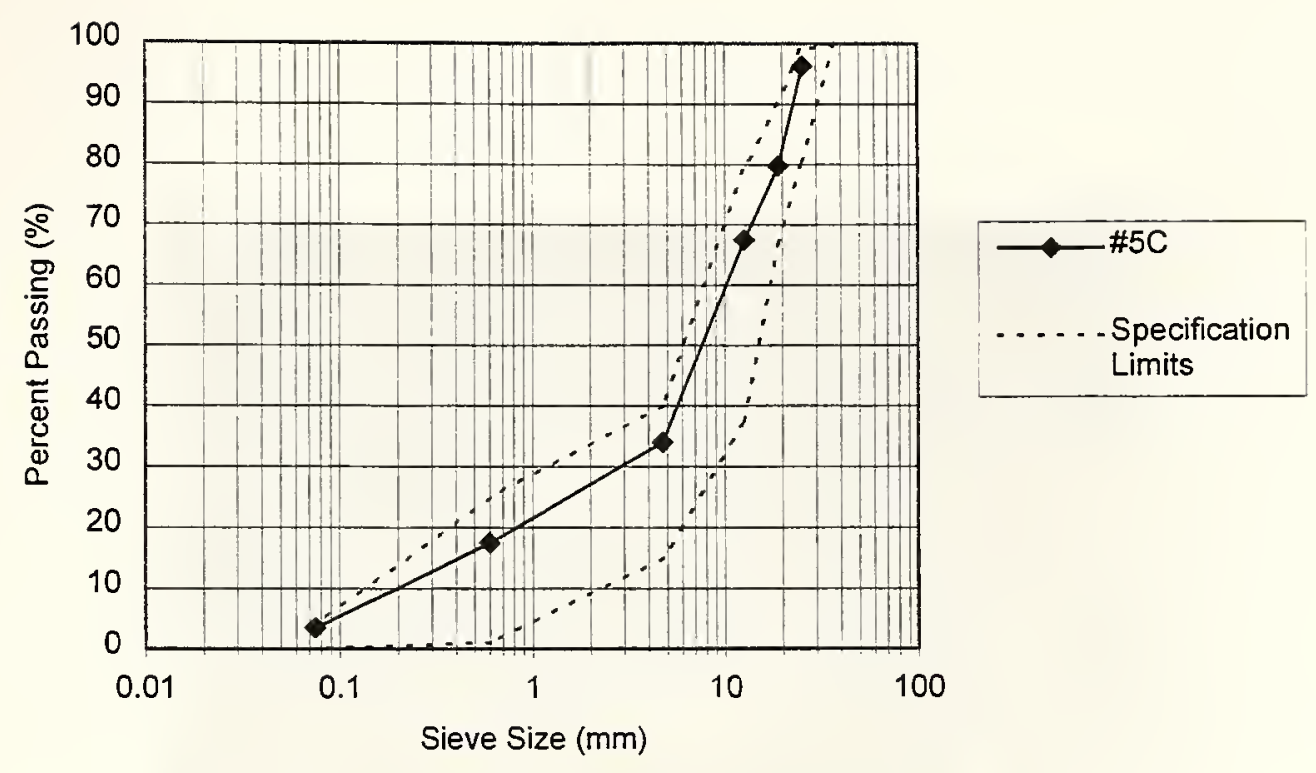

Figure 3.14 Gradation of \#5C OG Mixture

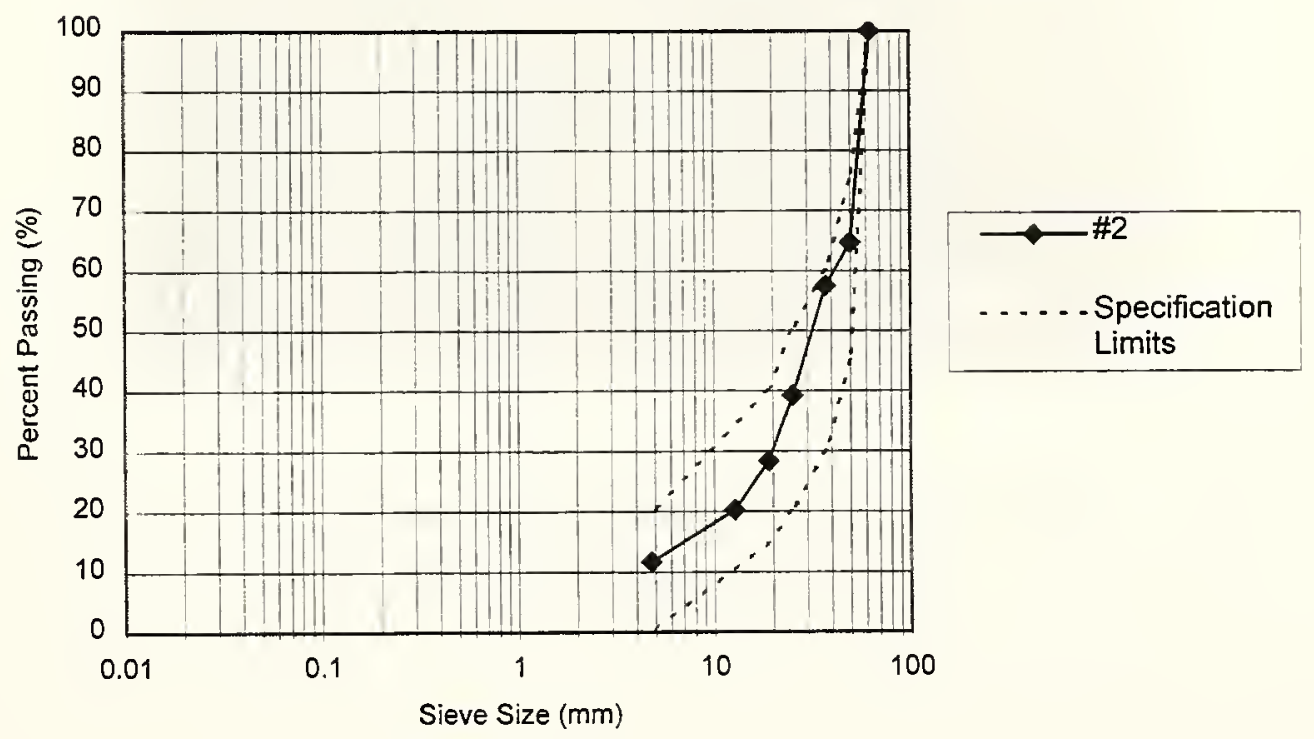

Figure 3.15 Gradation of \#2 Base Mixture 


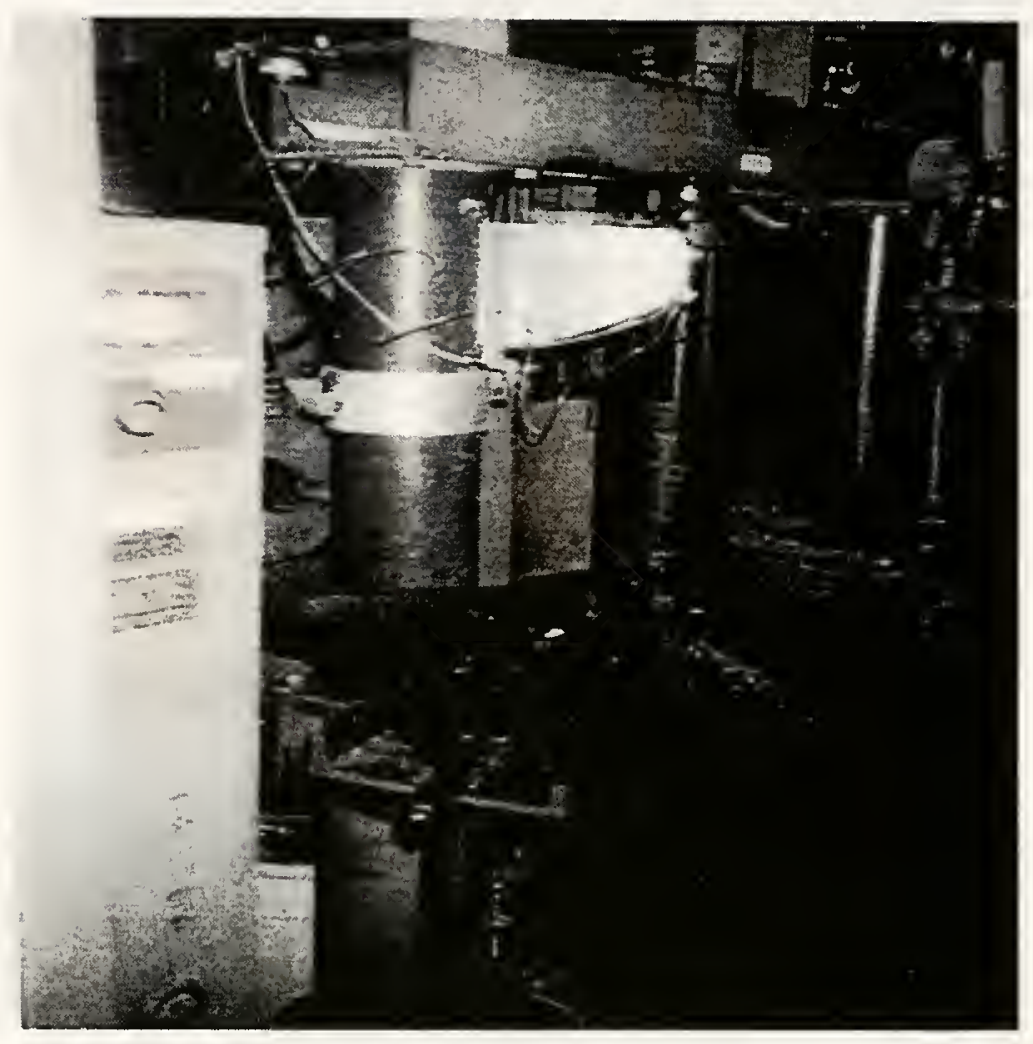

Figure 3.16 California Kneading Compactor 


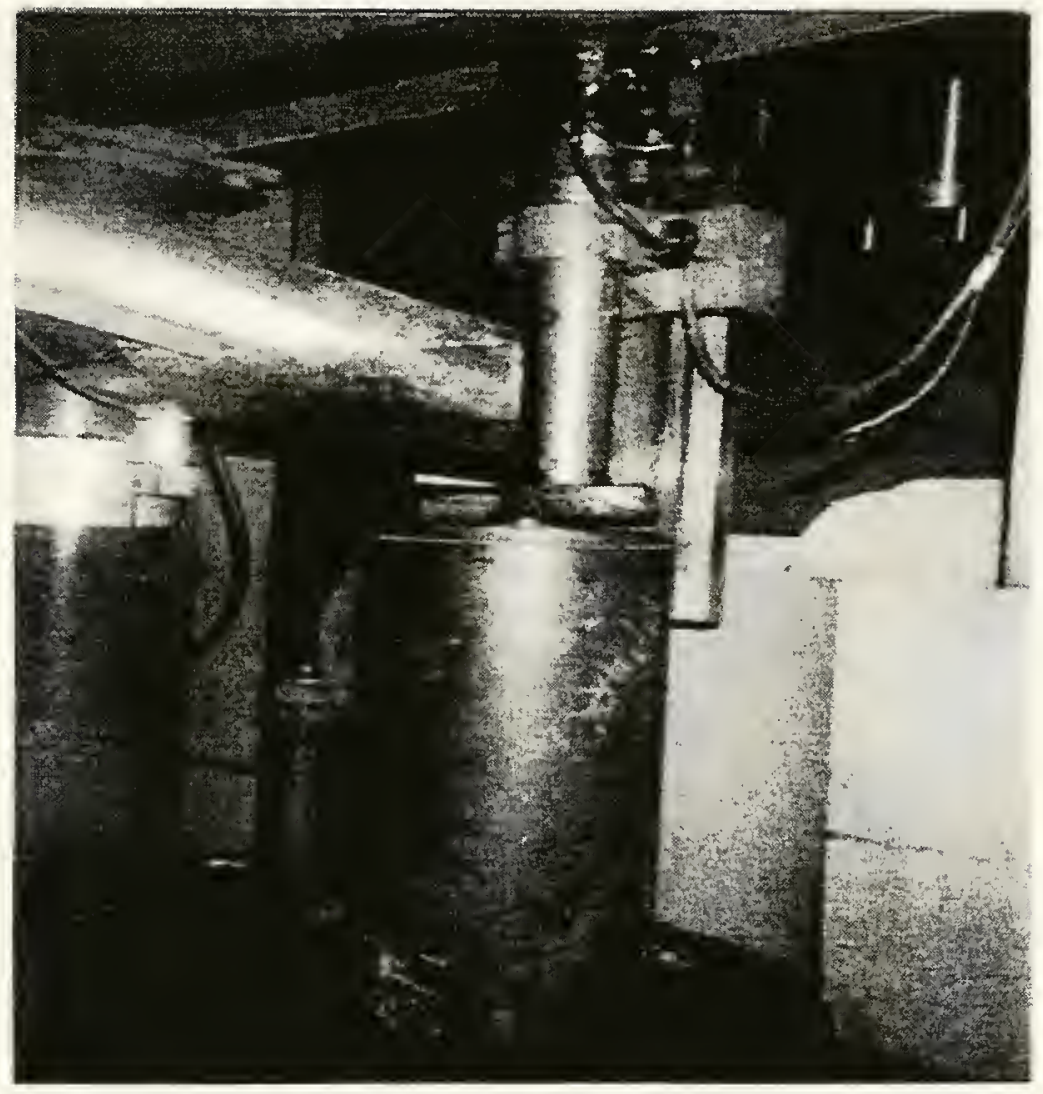

Figure 3.17 Mold and Kneading Foot 


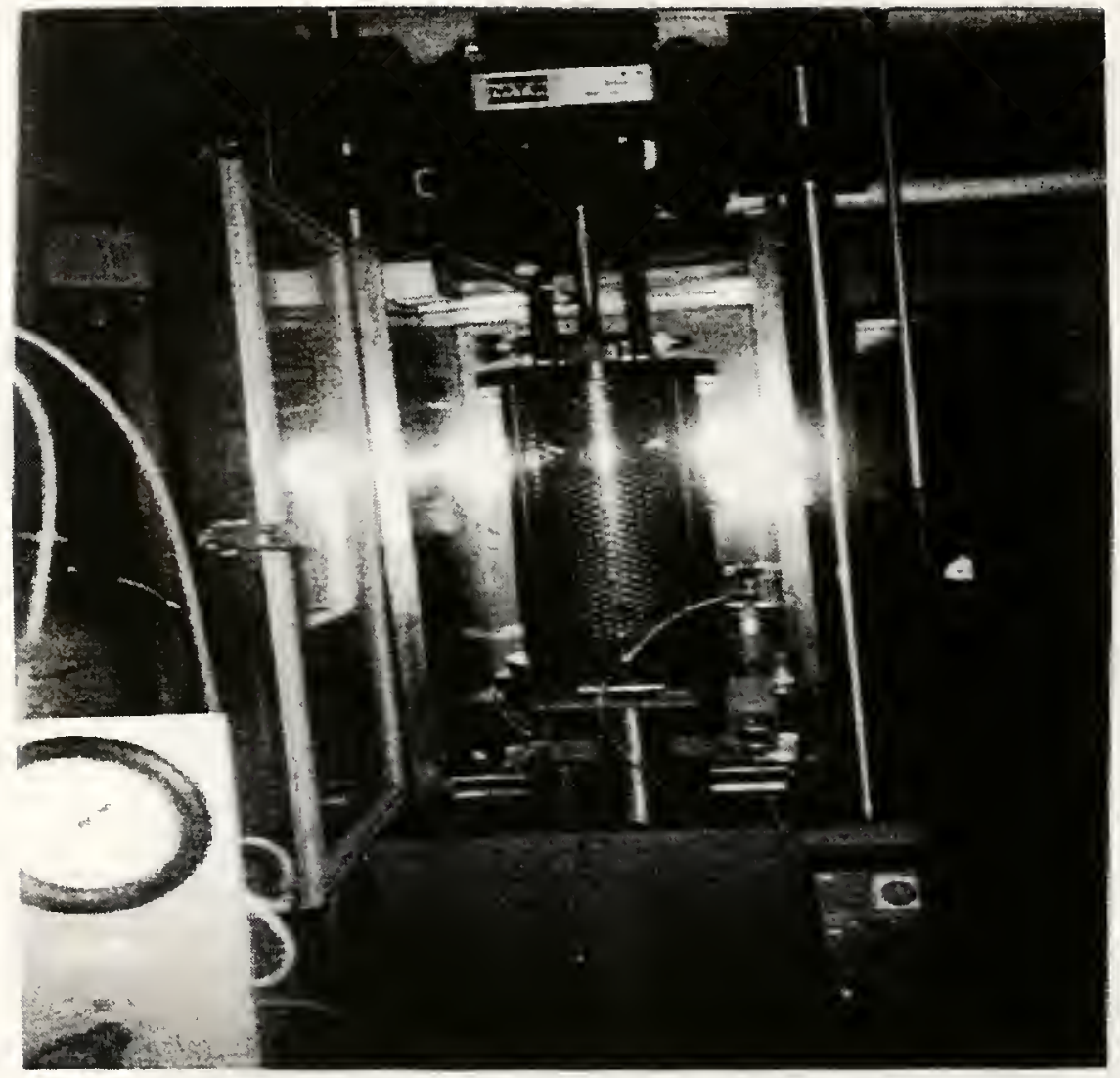

Figure 3.18 Environmental Chamber and Triaxial Cell 


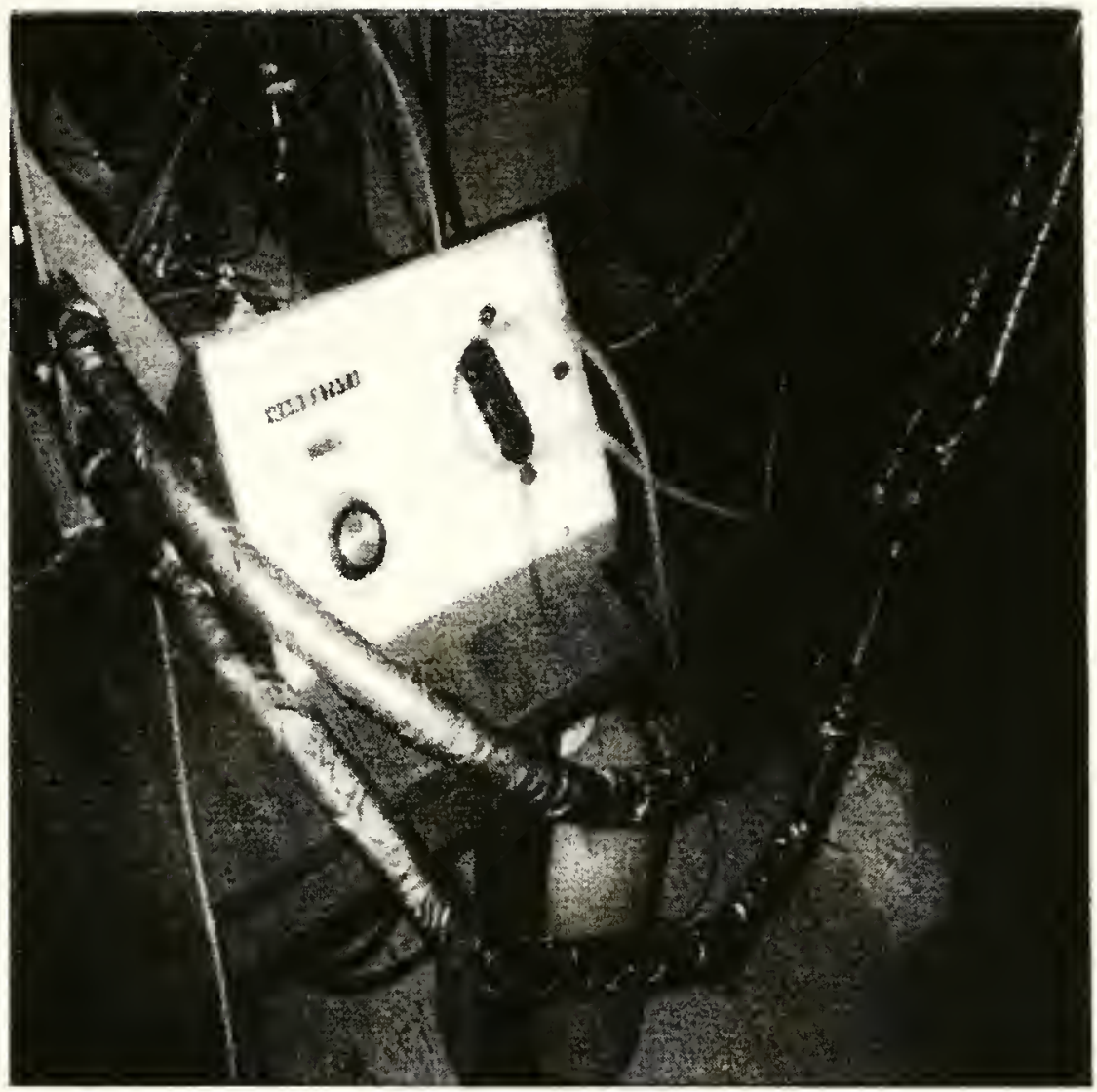

Figure 3.19 Heating System and Water Pump 


\section{CHAPTER 4 FIELD DATA ANALYSIS}

Field instrumentation in this study was used to obtain moisture, soil water potential, degree of saturation, air temperature, pavement and subgrade temperatures, rainfall, subdrainage, and frost depth. The data reported covers the period from August 1996 to October 1998.

\subsection{Water Content}

Water content was determined using a soil moisture sensor (Watermark 200, Model 257). The functionality and calibration of the moisture sensor are described by Hossam, 1996.

In application, the soil moisture sensor resistance $R_{s}$, is measured in the field. This value is used in the following equation to obtain the soil water potential (SWP).

$S W P=\frac{R s}{0.01306\left[1.062\left(34.21-T_{s} \div 0.01060 T_{s} T_{s}\right)-R_{s}\right]}$

Where, SWP -.- soil water potential $(\mathrm{kPa})$

$R_{s}$-- sensor resistance ( $\mathrm{kOhms}$ )

$I_{s}$... soil temperature $\left({ }^{\circ} \mathrm{C}\right)$ 
Subsequently, the SWP is used with a laboratory determined moisture retention curve for asphalt mixtures, unbound aggregate materials and subgrades to estimate the field moisture. Moisture retention curves for subgrades, surface and binder asphalt mixture, base asphalt mixtures, and unbound aggregate materials are shown in Figures 4.1, 4.2, 4.3 and 4.4, respectively. The SWP is denoted as suction in the figures.

Variation in SWP for section 1 is shown in Figures 4.5 to 4.8. Figures 4.5 and 4.7 show the SWP variation in the subgrade at different depths. The SWP is higher in winter but in general shows little variation. The average non-winter volumetric moisture content of the subgrade can be found from Figure 4.1, and is roughly $30 \%$, which represents a 0.67 degree of saturation. This number is consistent with what Hossam observed by TDR. The SWPs of asphalt base layers (\#5C, \#5D and \#2) are shown in Figure 4.6 and 4.8. Their moisture content can be found from Figure 4.3. The moisture contents of the $\# 2$, $\# 5 \mathrm{D}$, and $\# 5 \mathrm{C}$ are about $5 \%, 3 \%$ and $10 \%$ respectively. These moisture contents represent a degree of saturation of roughly $.67, .22, .01$ and .31 for the subgrade, the \#5D filter, the $\# 2$ base and the $\# 5 \mathrm{C}$ base, respectively.

Variation in SWP for section 2 is shown in Figures 4.9 to 4.12 . Figures 4.9 and 4.11 show the SWP variation in the subgrade at different depths. Three sensors are reading over-range. The WBs at subgrade depth of $178 \mathrm{~mm}$ and $940 \mathrm{~mm}$ show over limit. And, the WB at $330 \mathrm{~mm}$ in the subgrade started to show over-limit in December 1997. There is little variation in SWP. The average non-winter volumetric moisture content in the subgrade can be found from Figure 4.1 , which is roughly $33 \%$ or a degree of saturation of 0.7 . This number is also consistent with what Hossam observed by TDR. The base and filter layers (\#5C, \#53 and \#2) SWP variations are shown in Figures 4.10 
and 4.12. Their moisture content can be estimated from Figure 4.3. The estimated average non-winter moisture contents for the $\# 2, \# 53$ and $\# 5 \mathrm{C}$ bases are $5 \%, 9 \%$ and $10 \%$, respectively. Corresponding degrees of saturation are $0.01,0.26$, and 0.31 .

Similar results are found for section 3. The SWP data is shown in Figures 4.13 to 4.16. Estimated average non-winter moisture contents for the section subgrade and \#53 and $\# 5 \mathrm{C}$ bases are about $33 \%, 9 \%$ and $10 \%$, respectively. Corresponding degrees of saturation are $0.7,0.26$ and 0.31 .

Generally speaking, the moisture contents in all layers are almost constant, and show little variation. The moisture content in the filter and base layers is low. This suggests the effect of the drainage layer. The estimated non-winter moisture contents are summarized in Table 4.1.

Table 4.1 Estimated Volumetric Moisture and Degree of Saturation in Pavement Layers

\begin{tabular}{|c|c|c|c|c|c|c|}
\hline \multirow{2}{*}{ Pavement Layers } & \multicolumn{2}{|c|}{ Section 1 } & \multicolumn{2}{c|}{ Section 2 } & \multicolumn{2}{c|}{ Section 3 } \\
\cline { 2 - 7 } & $\omega(\%)$ & Saturation & $\omega(\%)$ & Saturation & $\omega(\%)$ & Saturation \\
\hline Subgrade & 30 & 0.67 & 33 & 0.7 & 33 & 0.7 \\
\hline$\# 5 \mathrm{D}$ & 3 & 0.22 & $\mathrm{~N}$ & $\mathrm{~N}$ & $\mathrm{~N}$ & $\mathrm{~N}$ \\
\hline$\# 53$ & $\mathrm{~N}$ & $\mathrm{~N}$ & 9 & 0.26 & 9 & 0.26 \\
\hline$\# 2$ & 5 & 0.01 & 5 & 0.01 & $\mathrm{~N}$ & $\mathrm{~N}$ \\
\hline$\# 5 \mathrm{C}$ & 10 & 0.31 & 9 & 0.31 & 10 & 0.31 \\
\hline
\end{tabular}

( $\mathrm{N}-$ Material is not implemented in this section $\omega--$ volumetric moisture content) 


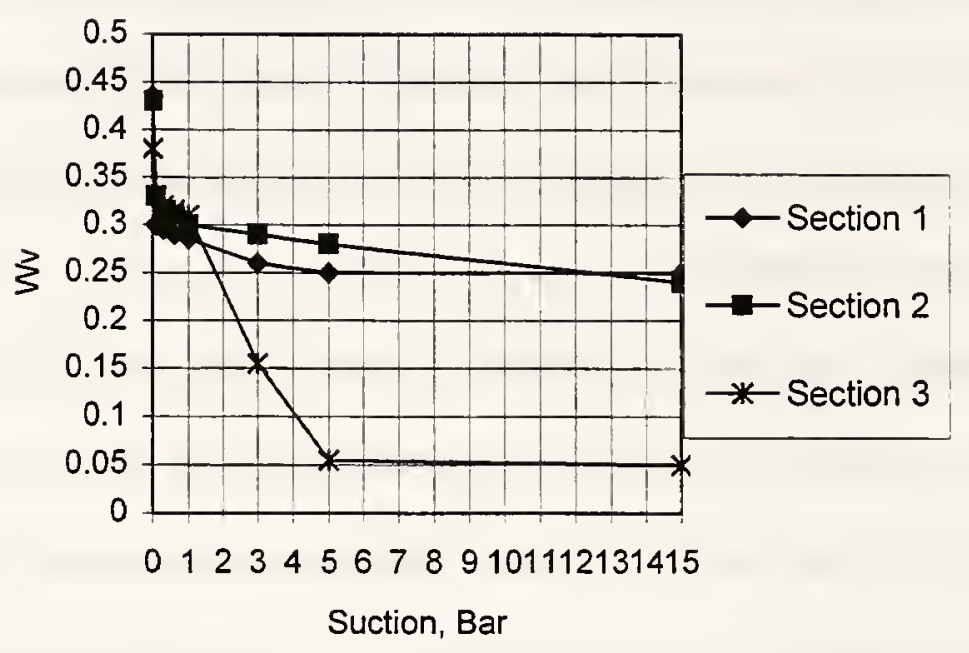

$(1 \mathrm{Bar}=100 \mathrm{kPa})$

Figure 4.1 Laboratory Moisture Retention Curve for Subgrades [Hossam, 1996] 


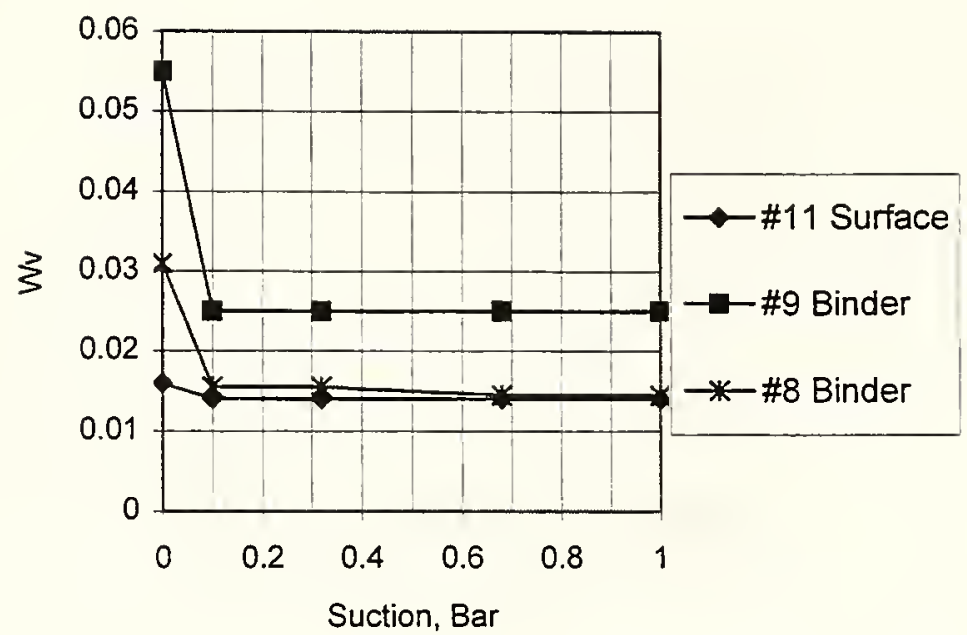

(1 $\mathrm{Bar}=100 \mathrm{kPa})$

Figure 4.2 Laboratory Moisture Retention Curve for Binder and Surface [Hossam, 1996] 


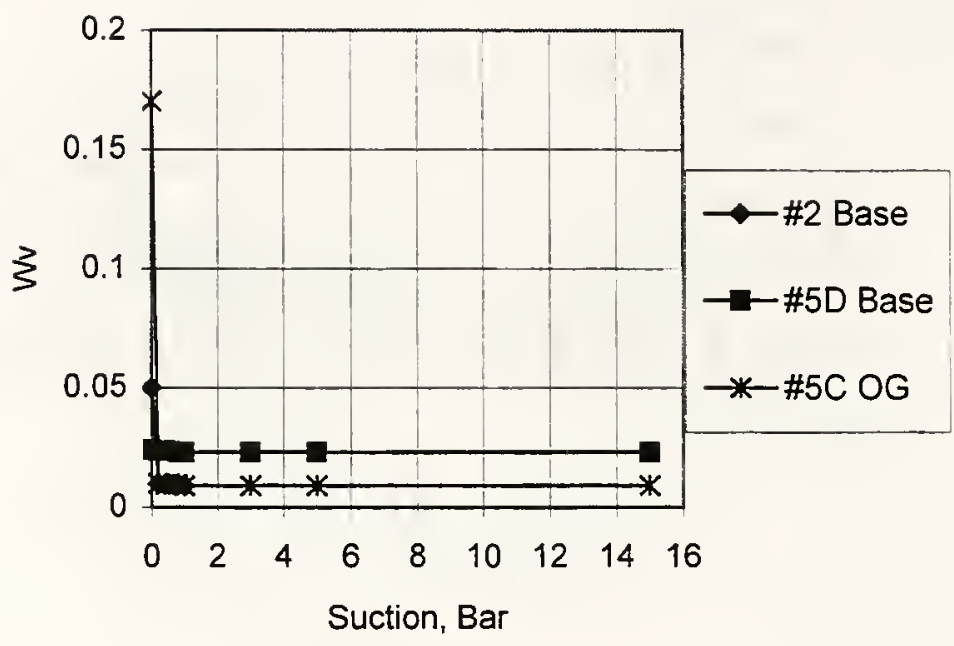

$(1 \mathrm{Bar}=100 \mathrm{kPa})$

Figure 4.3 Laboratory Retention Curve for Base Layers [Hossam, 1996] 


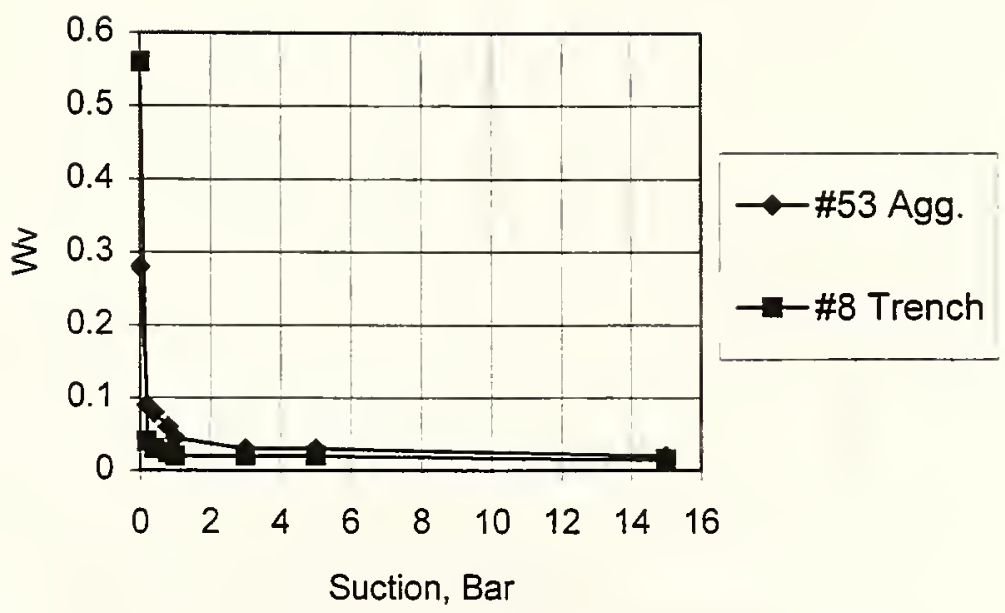

$$
\text { ( } 1 \mathrm{Bar}=100 \mathrm{kPa})
$$

Figure 4.4 Laboratory Moisture Retention Curves for Subbase and Trench Gravel [Hossam, 1996] 


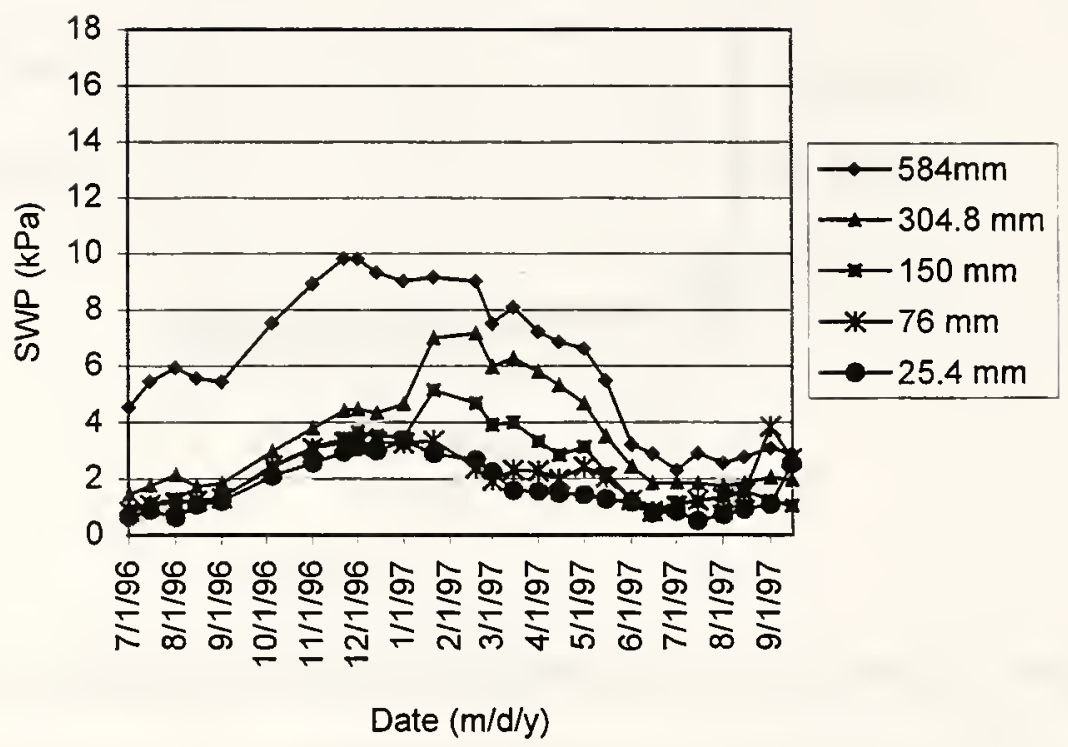

Figure 4.5 SWP in Subgrade, Section 1 


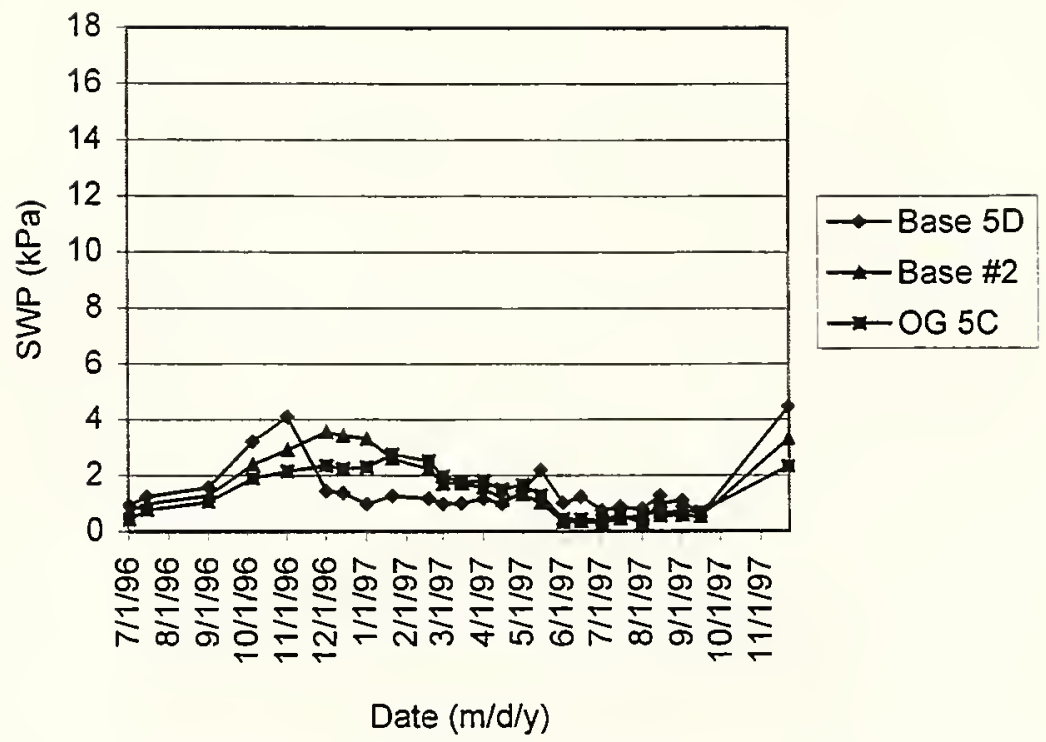

Figure 4.6 SWP in Base and Drainage Layer, Section 1 


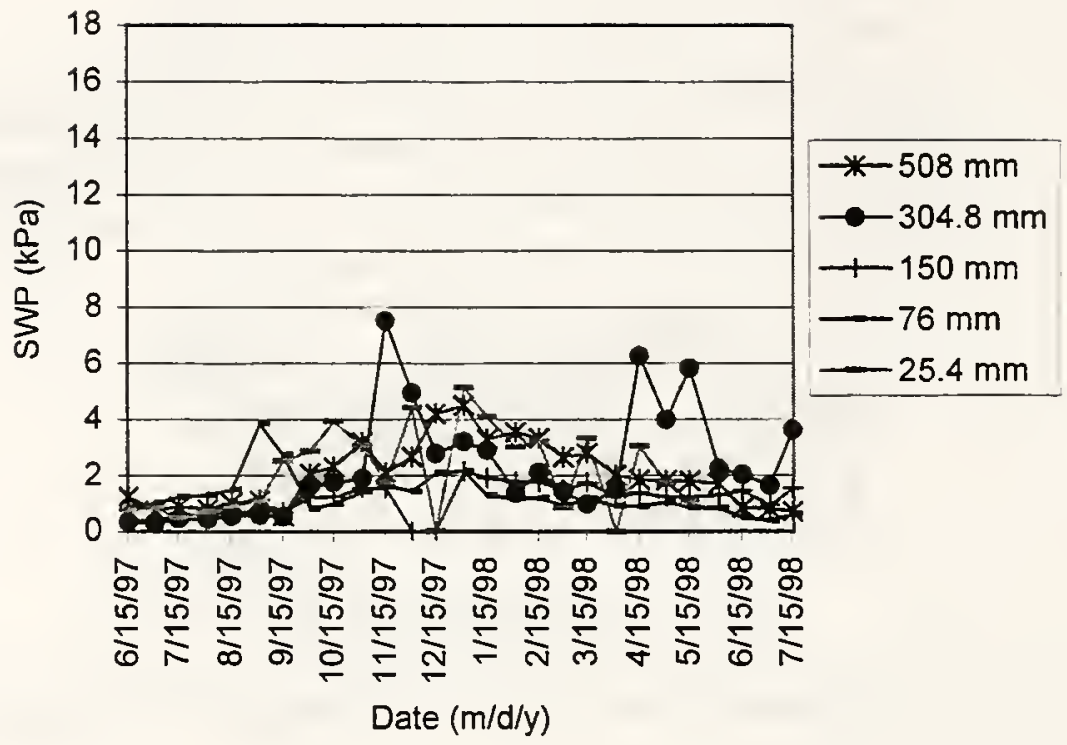

Figure 4.7 SWP in Subgrade, Section 1 


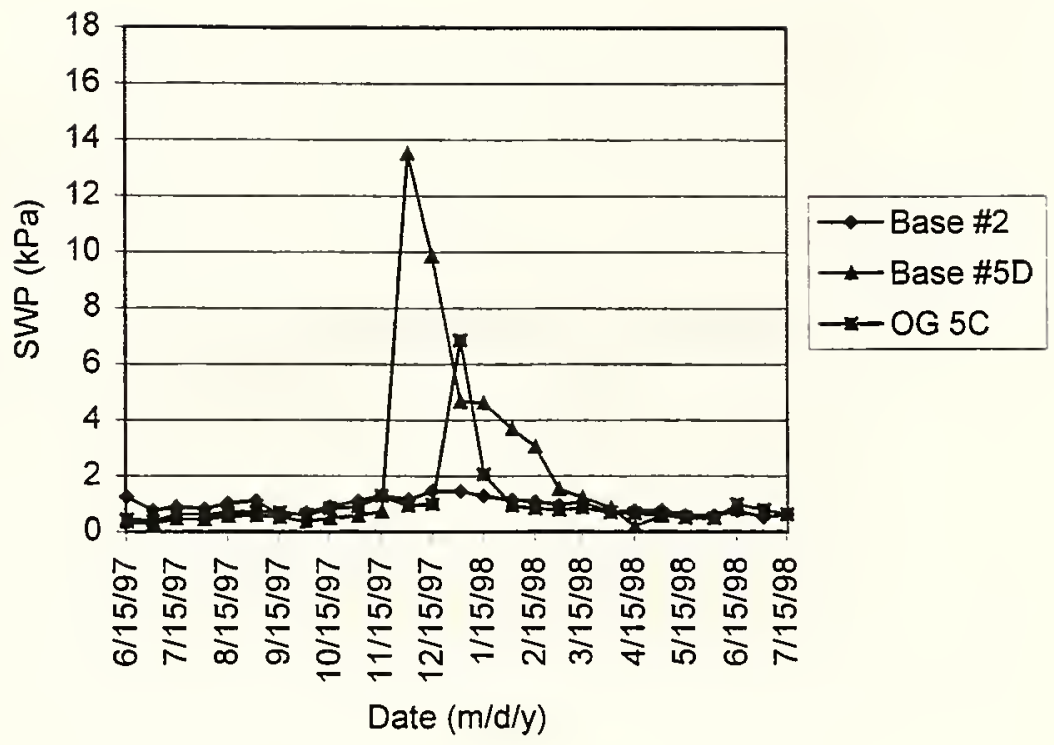

Figure 4.8 SWP in Base, and Drainage Layer, Section 1 


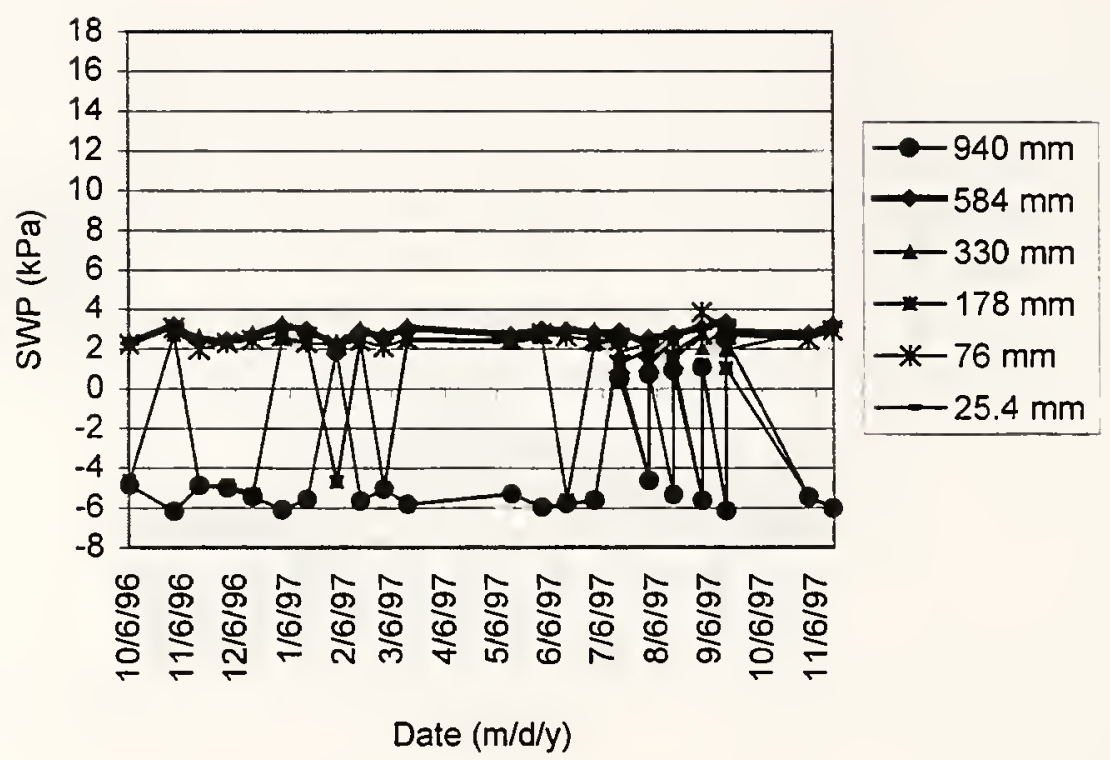

(Sensor at $178 \mathrm{~mm}$ and $940 \mathrm{~mm}$ are reading over limit)

Figure 4.9 SWP in Subgrade, Section 2 


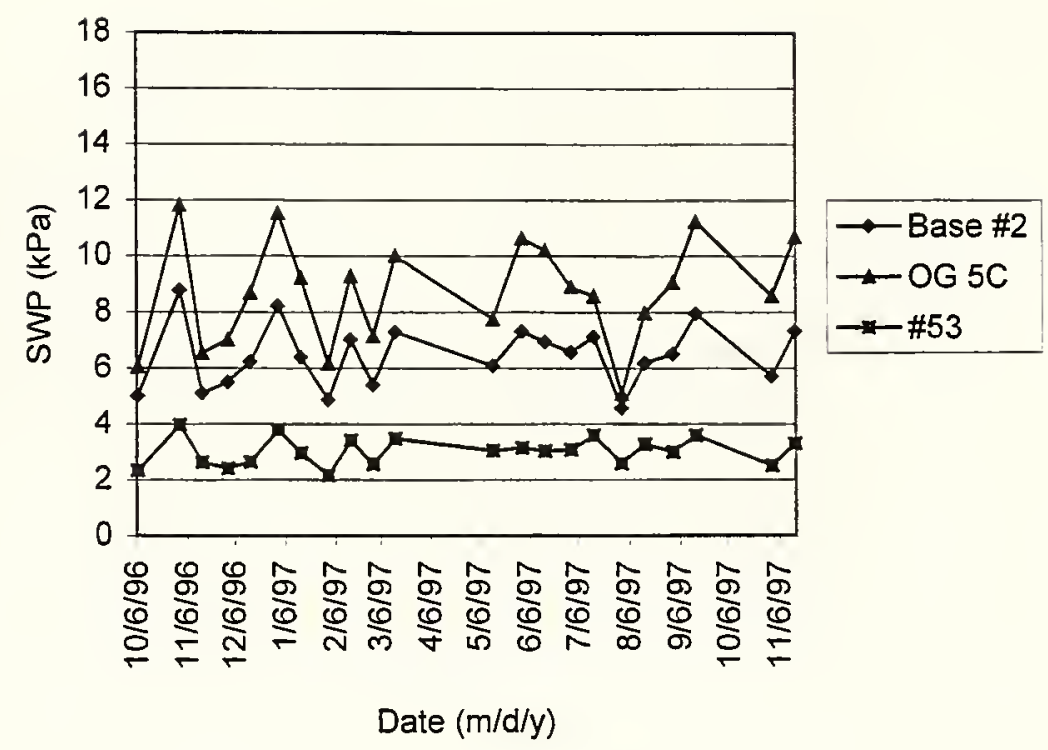

Figure 4.10 SWP in Base, and Drainage Layer, Section 2 


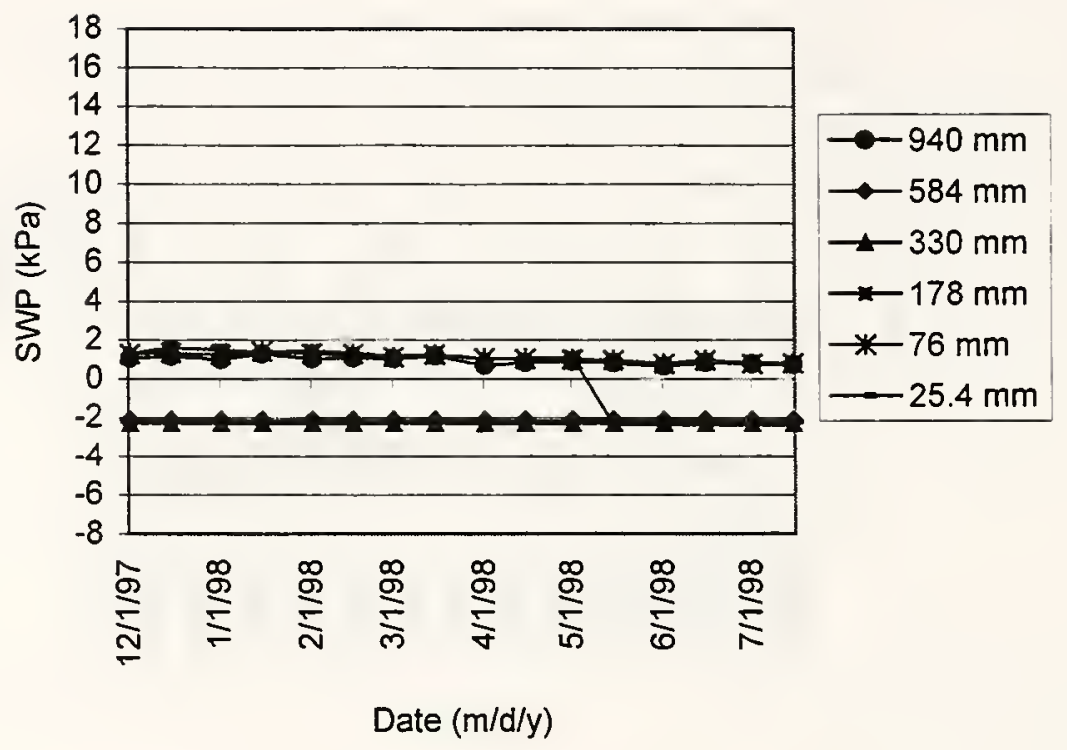

(Sensor at 178, 330, $940 \mathrm{~mm}$ failed)

Figure 4.11 SWP in Subgrade, Section 2 


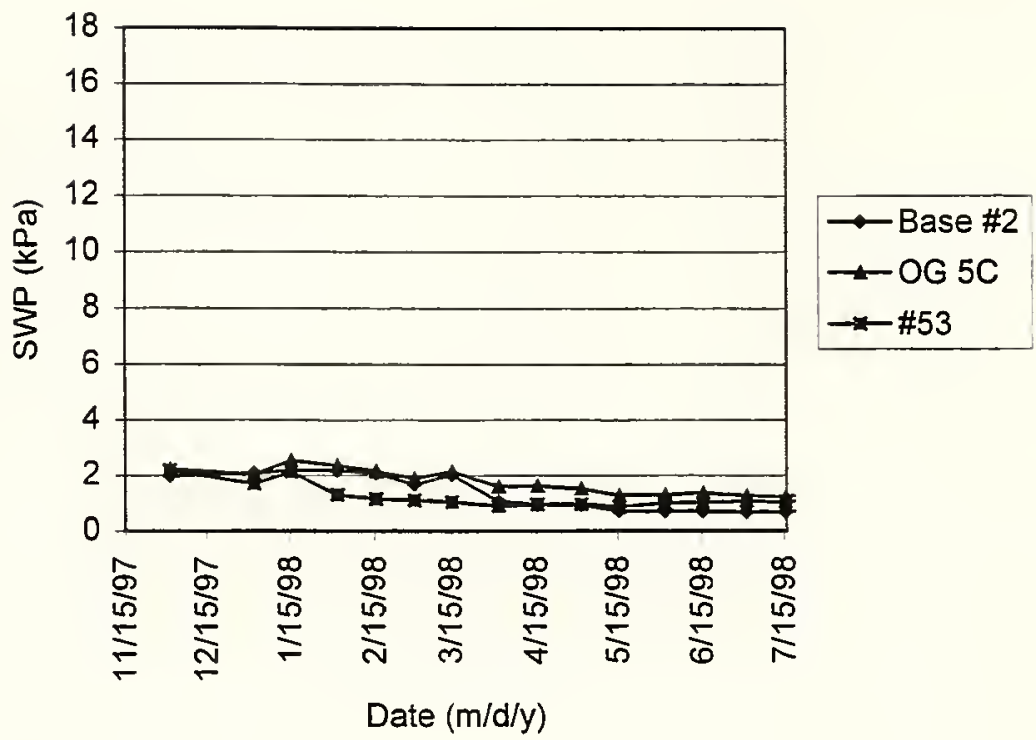

Figure 4.12 SWP in Base and Drainage Layer, Section 2 


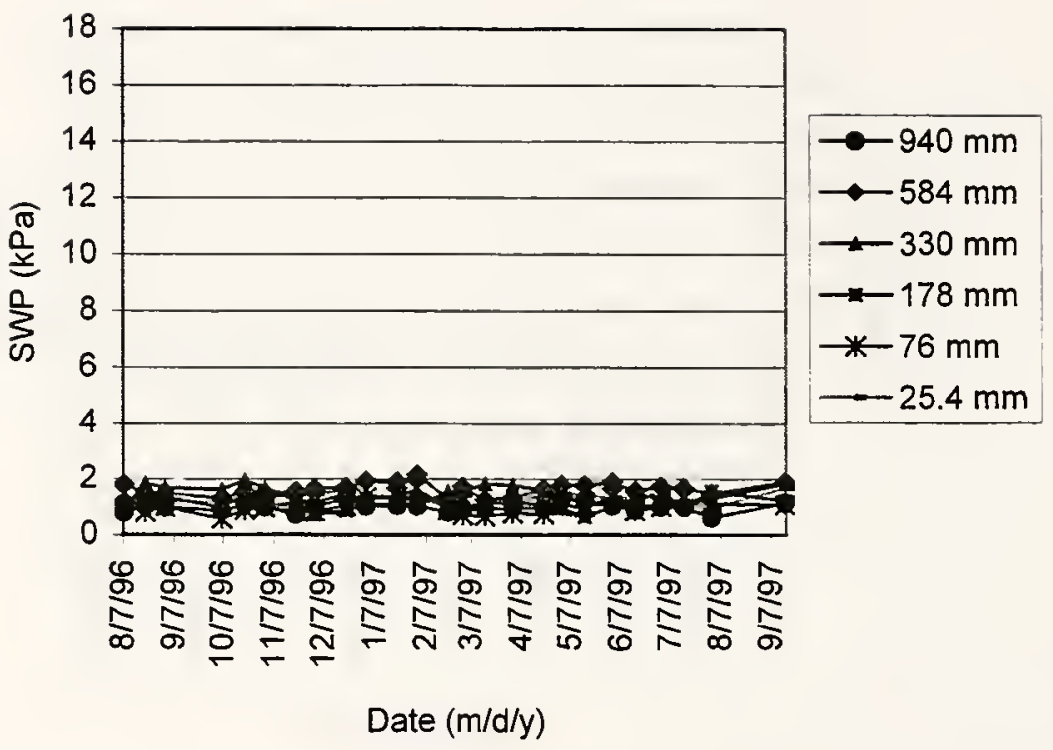

Figure 4.13 SWP in Subgrade, Section 3 


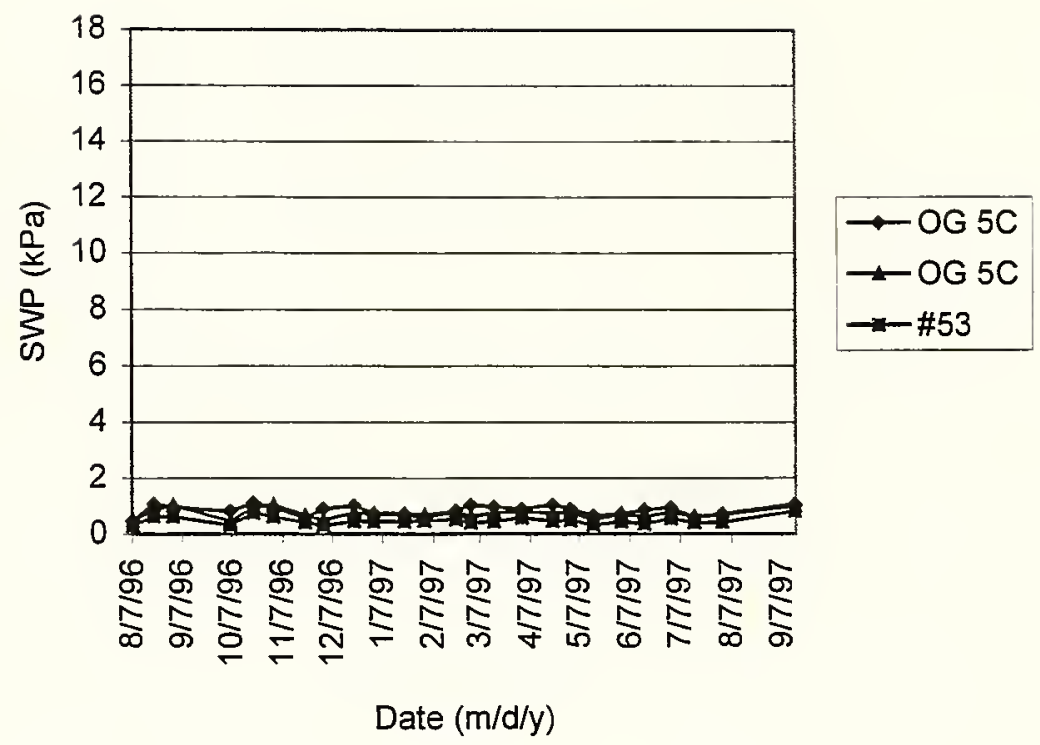

Figure 4.14 SWP in Base, and Filter Layer, Section 3 


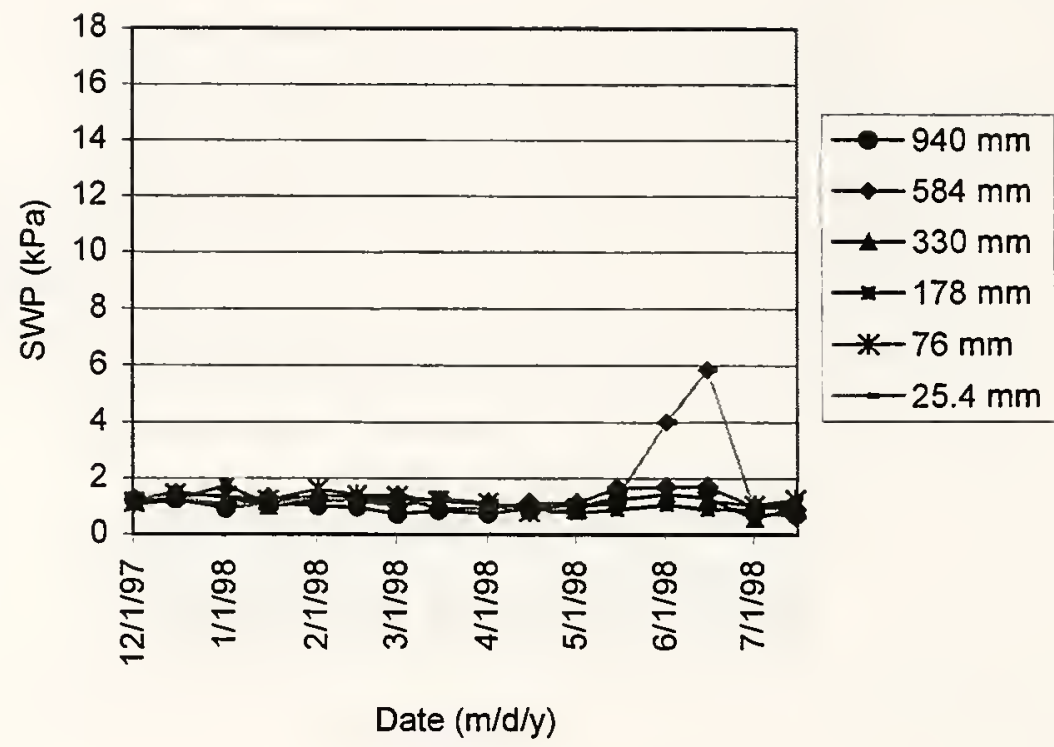

(Sensor at $254 \mathrm{~mm}$ depth reads a little larger in June)

Figure 4.15 SWP in Subgrade, Section 3 


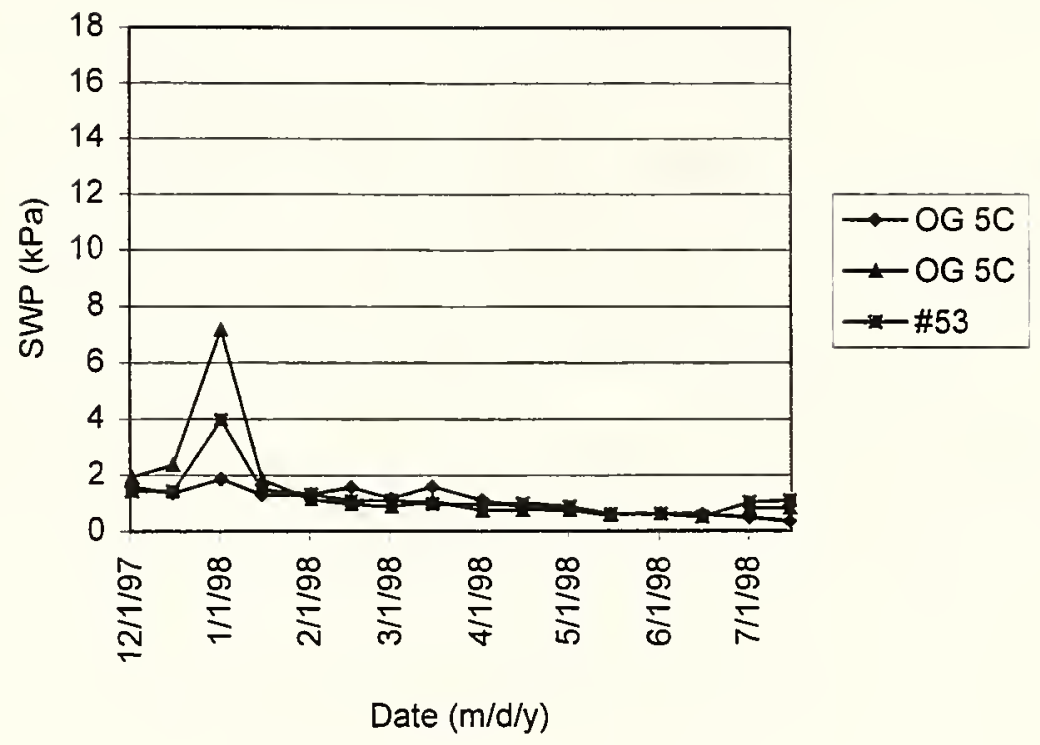

Figure 4.16 SWP in Base and Filter Layer, Section 3 


\subsection{Field Temperature Data and Analysis}

\subsubsection{Field Data}

Volume of temperature data is significant. However, the hottest and coldest temperature is of primary interest. The coldest temperature event in the winter of 19961997 occurred in the period of January 27-29. For the winter of 1997-1998, this event occurred in the period of January 11-14. The hottest temperature event of 1997 occurred in the period of July 14-21. In 1998, this event occurred in the period of June 22-28. The temperature results are very similar for all three sections. In this chapter only temperatures for section 1 are presented. The complete temperature data for section 1 is presented in Appendix A. Temperature data for section 2 and 3 are very similar to that of section 1 . As a result, they are not presented separately.

Figure 4.17 shows data for the coldest event in the winter of 1997 for section 1. The hottest event in the summer of 1997 for section 1 is shown in Figure 4.18. It is observed that there is very little variation in temperature at a depth of $584 \mathrm{~mm}$ into the subgrade.

The coldest and hottest surface temperatures ( $25 \mathrm{~mm}$ below surface) for the three sections are summarized in Table 4.2. 
Coldest Days (Jan 27, 28, 29, 1997)

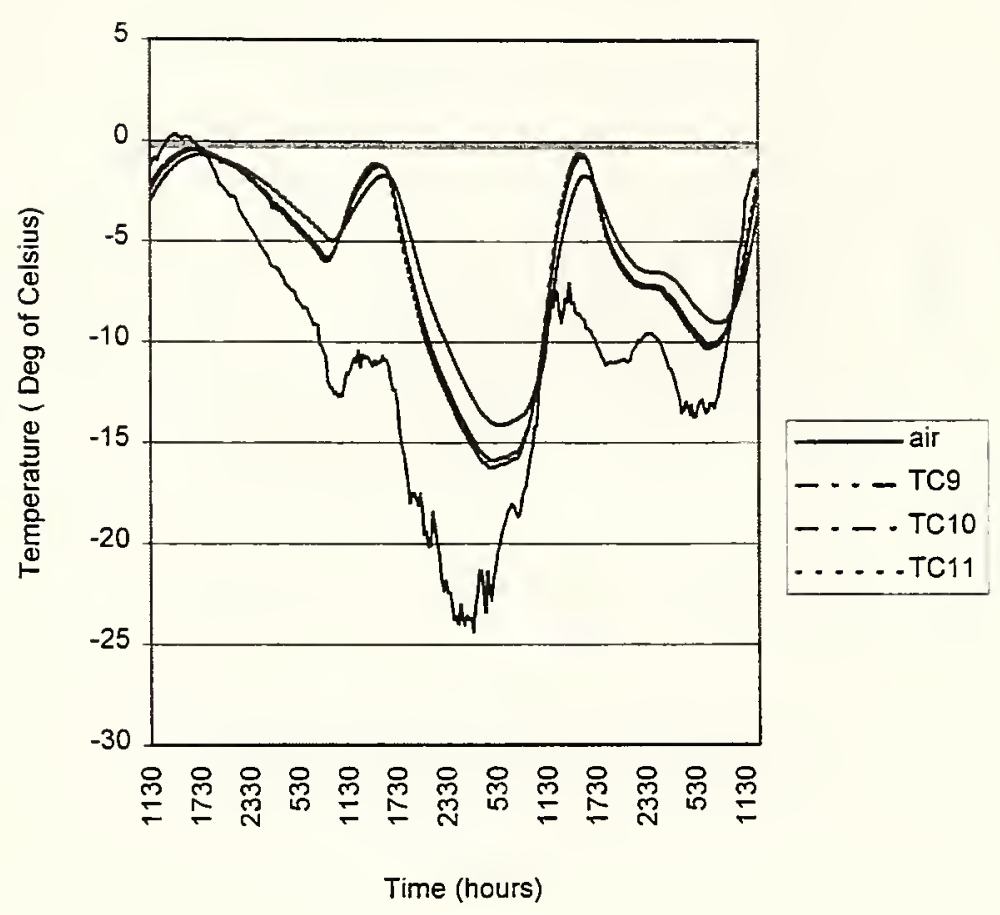

Figure 4.17 Coldest Temperature in 1997, Section 1 
Hottest Days (July 14-21, 1997 )

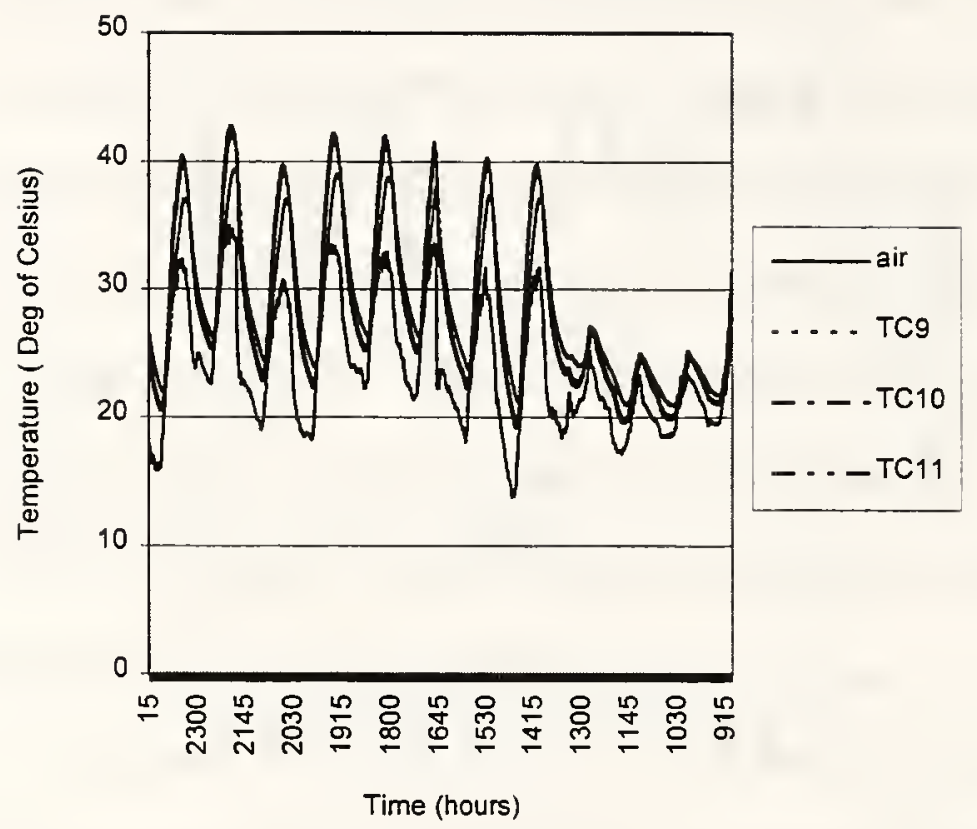

Figure 4.18 Hottest Temperature in 1997, Section 1 
Table 4.2 Hottest and Coldest Pavement Surface Temperature (25 mm Below Surface)

\begin{tabular}{|c|c|c|c|c|c|}
\hline & & \multicolumn{2}{|c|}{1997} & \multicolumn{2}{c|}{1998} \\
\hline \multirow{4}{*}{\begin{tabular}{c} 
Temperature \\
\cline { 2 - 6 }
\end{tabular}} & Sections & Air $\left({ }^{\circ} \mathrm{C}\right)$ & $\begin{array}{c}\text { Pavement } \\
\left({ }^{\circ} \mathrm{C}\right)\end{array}$ & Air $\left({ }^{\circ} \mathrm{C}\right)$ & $\begin{array}{c}\text { Pavement } \\
\left({ }^{\circ} \mathrm{C}\right)\end{array}$ \\
\cline { 2 - 6 } & $\operatorname{Sec} 1$ & -24.36 & -16.23 & -9.98 & -6.46 \\
\cline { 2 - 6 } & $\operatorname{Sec} 2$ & -23.11 & -15.41 & -9.58 & -5.16 \\
\hline \multirow{2}{*}{$\begin{array}{c}\text { Surface } \\
\text { Temperature }\end{array}$} & $\operatorname{Sec} 3$ & -22.64 & -15.46 & -9.46 & -7.35 \\
\cline { 2 - 7 } & $\operatorname{Sec} 1$ & 34.94 & 42.78 & 32.72 & 39.78 \\
\cline { 2 - 7 } & $\operatorname{Sec} 2$ & 33.56 & 41.44 & 34.22 & 39.39 \\
\hline
\end{tabular}

\subsubsection{Comparison with SHRP Predictions}

The highest and lowest pavement temperatures are critical in the Superpave binder grade selection. The lowest temperature is the historical one-day lowest pavement surface temperature. The highest temperature is taken at $20 \mathrm{~mm}$ below the surface and is the historical highest average seven-day temperature.

If only air temperature data is available, two empirical equations can be used to predict the high and low temperature. The equation (Superpave Asphalt Binder Specification) is as follows:

$$
\begin{aligned}
\mathrm{T}_{20, \mathrm{~mm}} & =\left(\mathrm{T}_{\text {air }}-0.00618 \mathrm{Lat}^{2}+0.2289 \mathrm{Lat}+42.2\right) 0.9545-17.78 \\
\mathrm{~T}_{\text {surf }} & =0.859 \mathrm{~T}_{\text {air }}+1.7
\end{aligned}
$$$$
\mathrm{T}_{20 \mathrm{~mm}}=\text { high pavement design temperature at a depth of } 20 \mathrm{~mm} \text { depth }
$$$$
\mathrm{T}_{\text {air }}=\text { historical average seven day high temperature in Equation } 4.1 \text { and one day }
$$ 
minimum air temperature in Equation. 4.2.

Lat $=$ geographic latitude of the project in degrees

Table 4.3 shows the comparison results. The latitude at Fort Wayne is 41.07 degrees North of the equator.

Table 4.3 Comparison of Observed Temperature and Predicted Temperature

\begin{tabular}{|c|c|c|c|c|c|c|c|}
\hline & & \multicolumn{3}{|c|}{1997} & \multicolumn{3}{|c|}{1998} \\
\hline & & $\begin{array}{l}\text { Air } \\
\left({ }^{\circ} \mathrm{C}\right)\end{array}$ & $\begin{array}{l}\text { Superpave } \\
\text { Predicted } \\
\left({ }^{\circ} \mathrm{C}\right)\end{array}$ & $\begin{array}{l}\text { Measured } \\
\qquad\left({ }^{\circ} \mathrm{C}\right)\end{array}$ & $\begin{array}{l}\text { Air } \\
\left({ }^{\circ} \mathrm{C}\right)\end{array}$ & $\begin{array}{l}\text { Superpave } \\
\text { Predicted } \\
\left({ }^{\circ} \mathrm{C}\right)\end{array}$ & $\begin{array}{l}\text { Measured } \\
\qquad\left({ }^{\circ} \mathrm{C}\right)\end{array}$ \\
\hline Coldest & Section 1 & -24.36 & -22.49 & -22.23 & -9.98 & -10.14 & -8.46 \\
\hline \multirow[t]{2}{*}{ Temperature } & Section 2 & -23.11 & -21.22 & -20.41 & -9.58 & -9.79 & 8.04 \\
\hline & Section 3 & -22.64 & -21.01 & -19.76 & -9.46 & -9.68 & -7.95 \\
\hline Hottest & Section 1 & 34.94 & 42.78 & 42.78 & 32.72 & 42.28 & 41.78 \\
\hline \multirow[t]{2}{*}{ Temperature } & Section 2 & 33.56 & 42.11 & 41.44 & 34.22 & 43.22 & 42.39 \\
\hline & Section 3 & 35.67 & 42.56 & 41.89 & 32.67 & 42.33 & 41.67 \\
\hline
\end{tabular}

(Measured temperature is at $20 \mathrm{~mm}$ depth)

Since the Superpave equation is for a pavement temperature at $20-\mathrm{mm}$ depth and the sensor of TC11 is at 25.4-mm depth, a program by White [1984] is used to determine the field temperature at $20 \mathrm{~mm}$ depth. From the above table, it is seen that the Superpave equation gives excellent prediction of temperature for the winter and summer of 1997 and summer of 1998 . There is a difference between the predicted and measured temperature for the winter of 1998 . This suggests that the Superpave equation may not be adequate for 
moderate winters at the project latitude. Since the key temperatures are related to the historical cold temperature, the Superpave equation is satisfactory for selecting PG asphalt grades.

\section{$\underline{4.3 \text { Frost Penetration }}$}

Watermark blocks measure the resistance between two electrodes, the resistance is expected to increase when water inside the block freezes. This substantial increase in resistance is an indicator of frost penetration. For comparison, predicted frost penetration using the U.S. Army Corps of Engineers (COE) is shown in Table 4.4

Table 4.4 Summary of COE Frost Penetration Estimation (Hossam, 1996)

\begin{tabular}{|c|c|c|}
\hline Period & $\begin{array}{c}\text { Freezing index } \mathrm{F}, \\
\text { (deg. }{ }^{0} \mathrm{~F} \text { days) }\end{array}$ & Frost Penetration (mm) \\
\hline Mean of 30 years & 346 & 685 \\
\hline Avg. 5 coldest in 30 years & 691 & 826 \\
\hline Avg. 3 coldest in 30 years & 746 & 959 \\
\hline Coldest in 30 years & 850 & 1067 \\
\hline
\end{tabular}

Figure 4.19 to 4.23 show typical measured resistance and corresponding temperatures at different depths in section 1 for January 1997. The sharp increase in resistance is obvious. The increase is inversely proportional to pavement temperature. The pavement temperature has to be below freezing several hours before the water freezes. 
$163 \mathrm{~mm}$ Depth in Subgrade

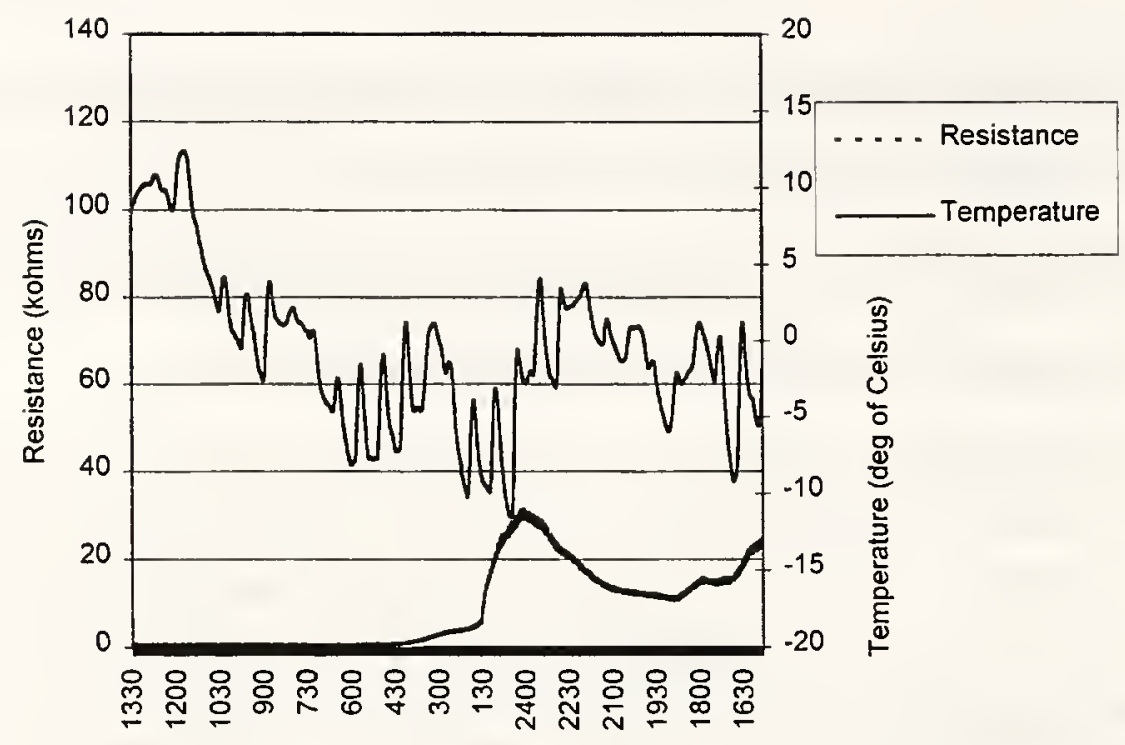

Time (hours)

Figure 4.19 Resistance and Temperature in January 1997, Section 1 
$25.4 \mathrm{~mm}$ Depth in Subgrade

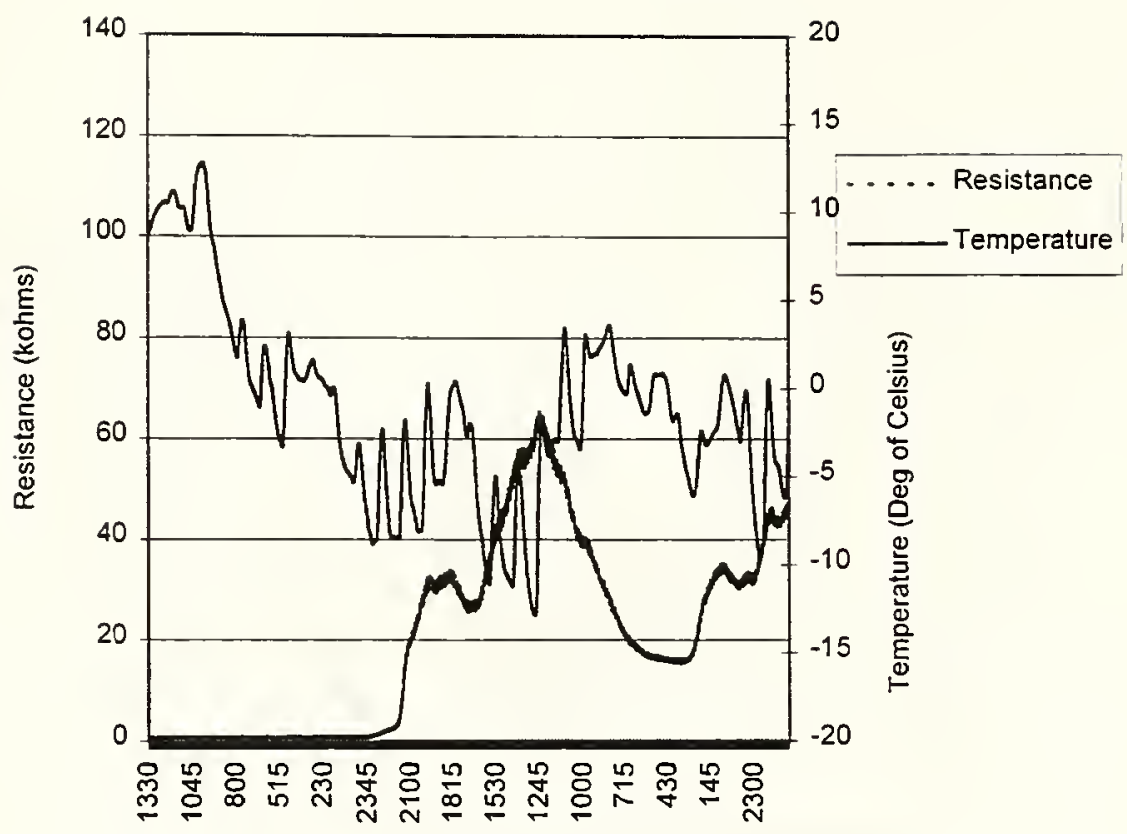

Time (hours)

Figure 4.20 Resistance and Temperature in January 1997, Section 1 
$494 \mathrm{~mm}$ Depth from Surface of Pavement

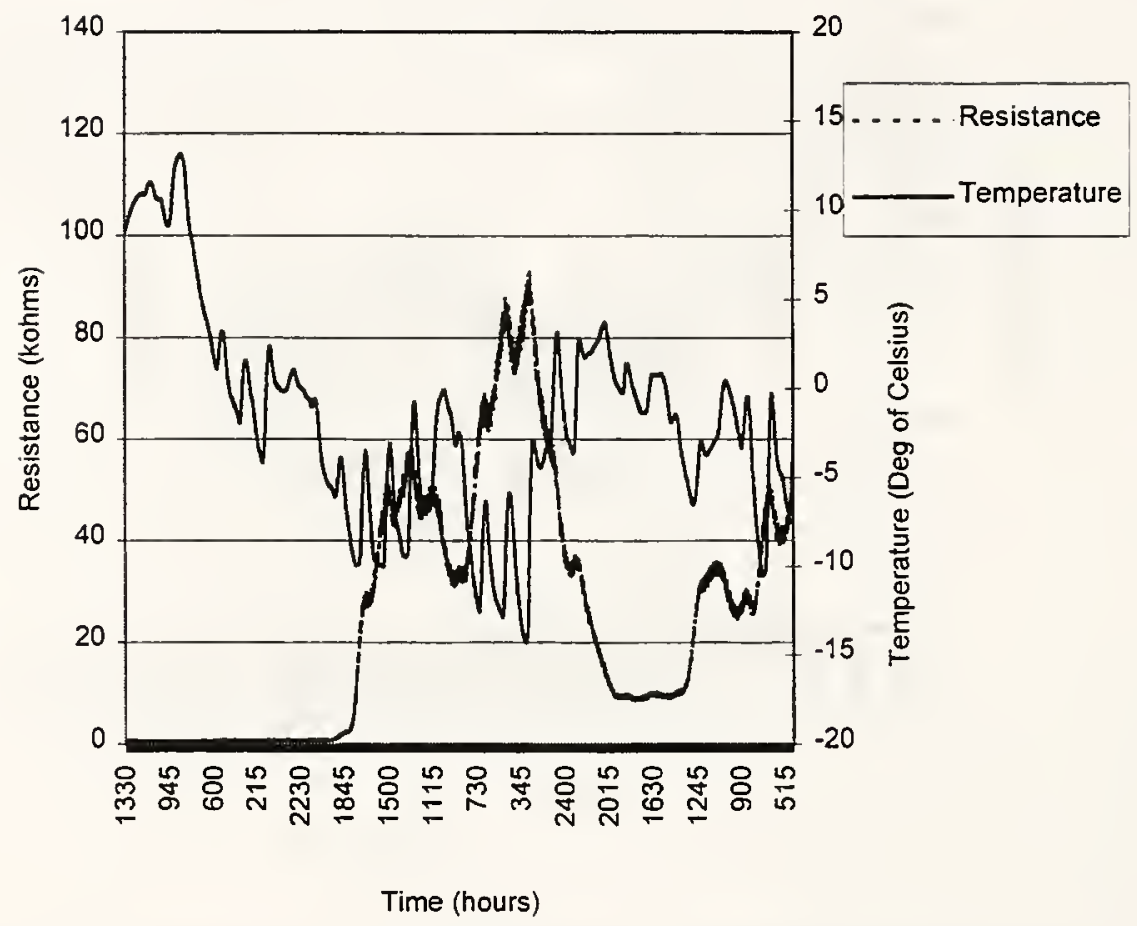

Figure 4.21 Resistance and Temperature in January 1997, Section 1 
$278 \mathrm{~mm}$ Depth from Surface of Pavement

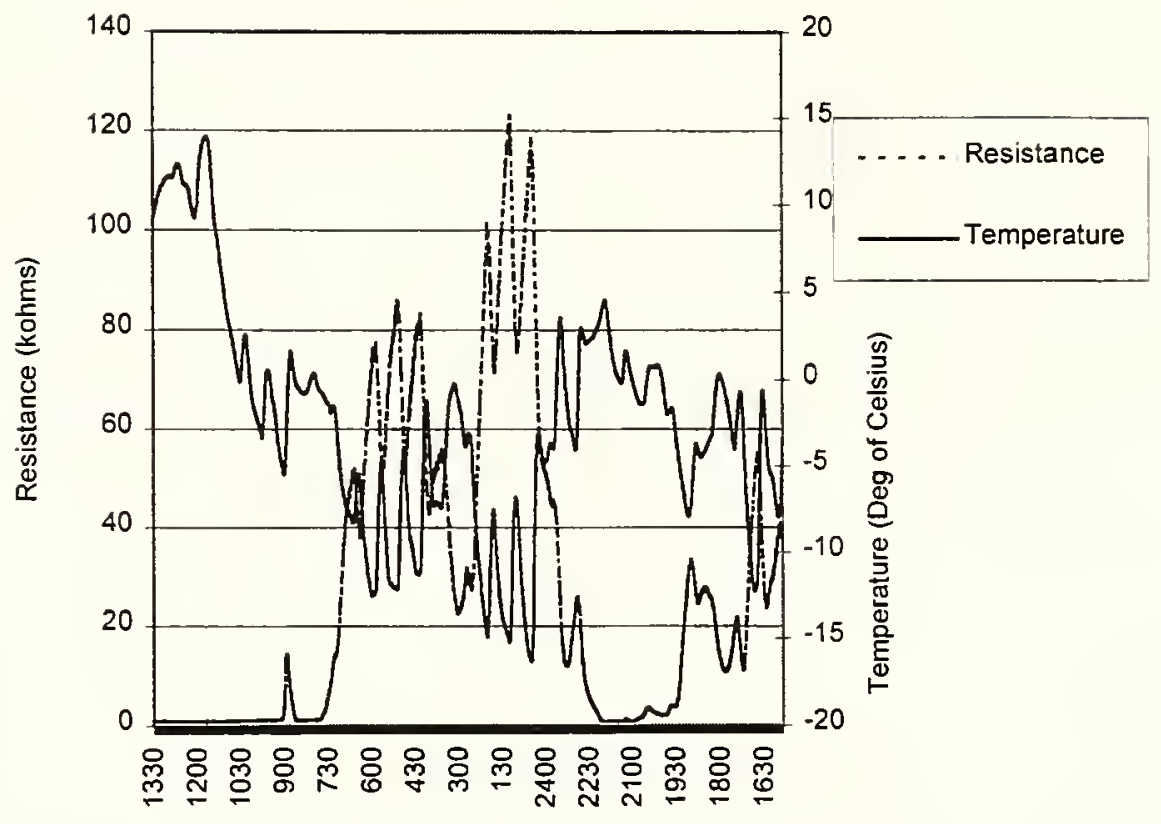

Time (hours)

Figure 4.22 Resistance and Temperature in January 1997, Section 1 
$164 \mathrm{~mm}$ Depth from Surface of Pavement

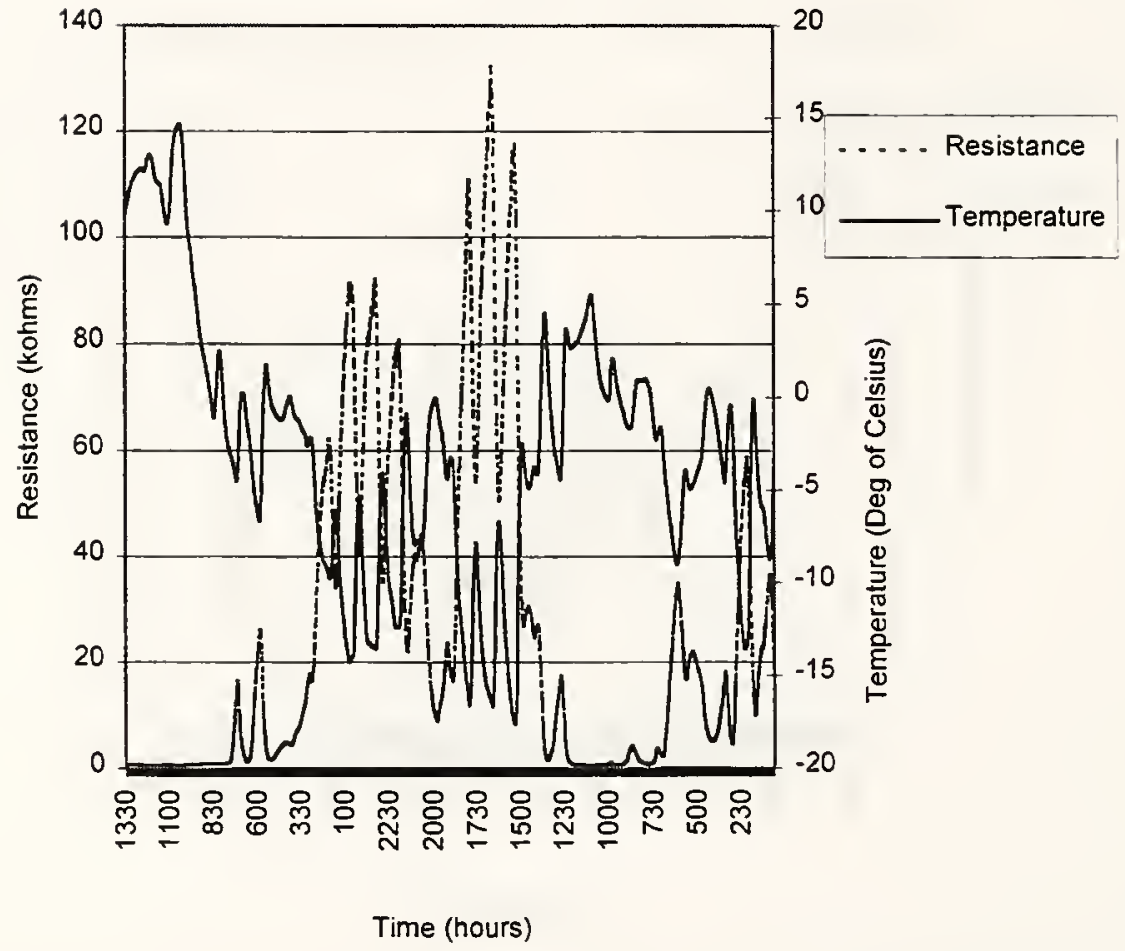

Figure 4.23 Resistance and Temperature in January 1997, Section 1 
The initial resistance before freezing will vary with depth, the maximum and minimum resistance at each depth throughout the winter was determined. The ratio of maximum resistance to minimum resistance is also determined and indicates the depth of frost. Figure 4.24 shows the resistance ratio plot in the winter of 1997. Figure 4.25 shows the resistance ratio for the winter of 1998. In these Figures, there is a low ratio zone, a high ratio zone and a transition zone. From Figure 4.24, the frost penetrations of sections 1,2 , and 3 for 1997 are, respectively, $545,600,565 \mathrm{~mm}$. This roughly equals the mean 30 year frost penetration from the COE method. The frost penetration in 1998 is shown in Figure 4.25. The resistance ratio does not exceed the transition zone. This indicates the pavement was not fully frozen.

\subsection{Rainfall and Outflow Analysis}

A recent rainfall and outflow event is presented for each section to indicate the current drainage performance of the three sections. The rainfall event occurred from 7:00 pm to 10:30 pm on September 20, 1998. Rainfall and outflow are presented in Figures 4.26 to 4.28 for sections 1,2 , and 3 , respectively.

The accumulated intensity of rainfall is multiplied by the area of test section to yield a rainfall volume falling on the pavement. The test section area was estimated by calculating an area with a length equal to the section length and width equal to the lane width $(3650 \mathrm{~mm})$ plus a width of the shoulder up to the outside edge of the trench (600 $\mathrm{mm})$. 


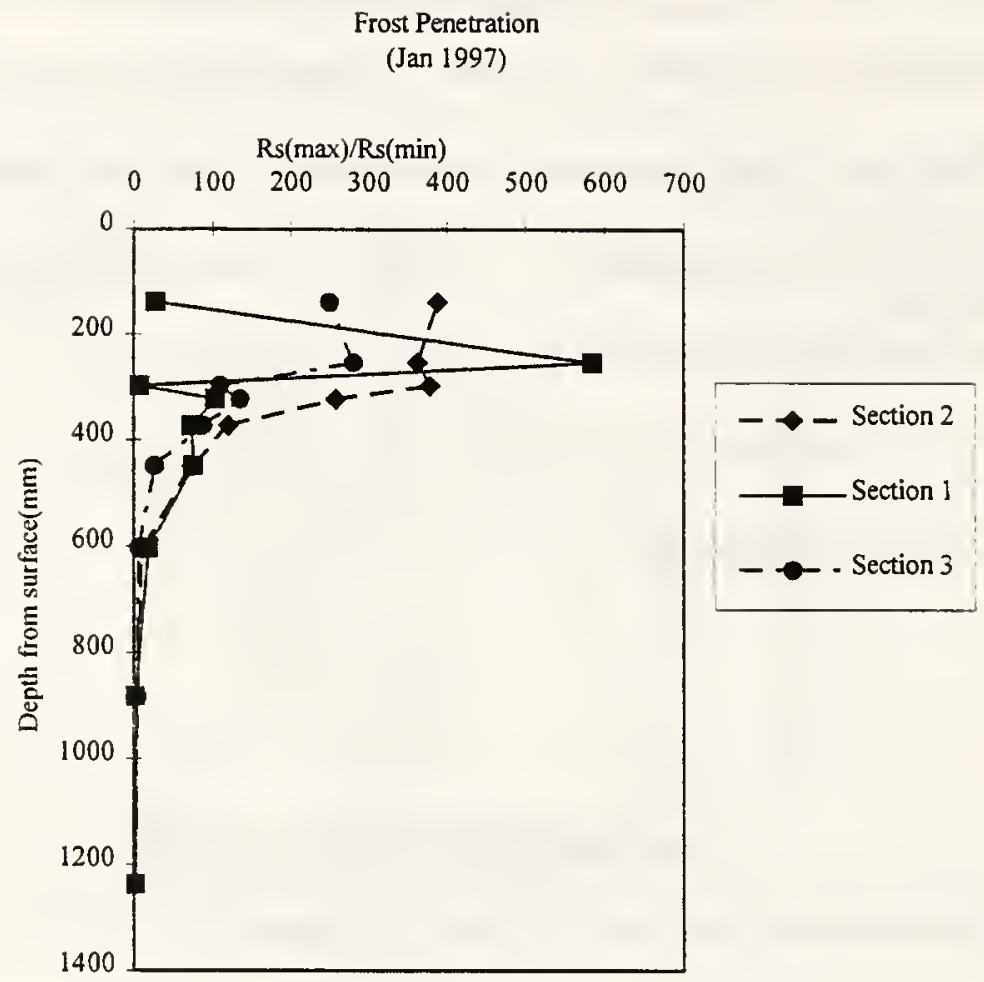

Figure 4.24 Frost Penetration Determination in 1997 
Frost Depth ( Jan 1998)

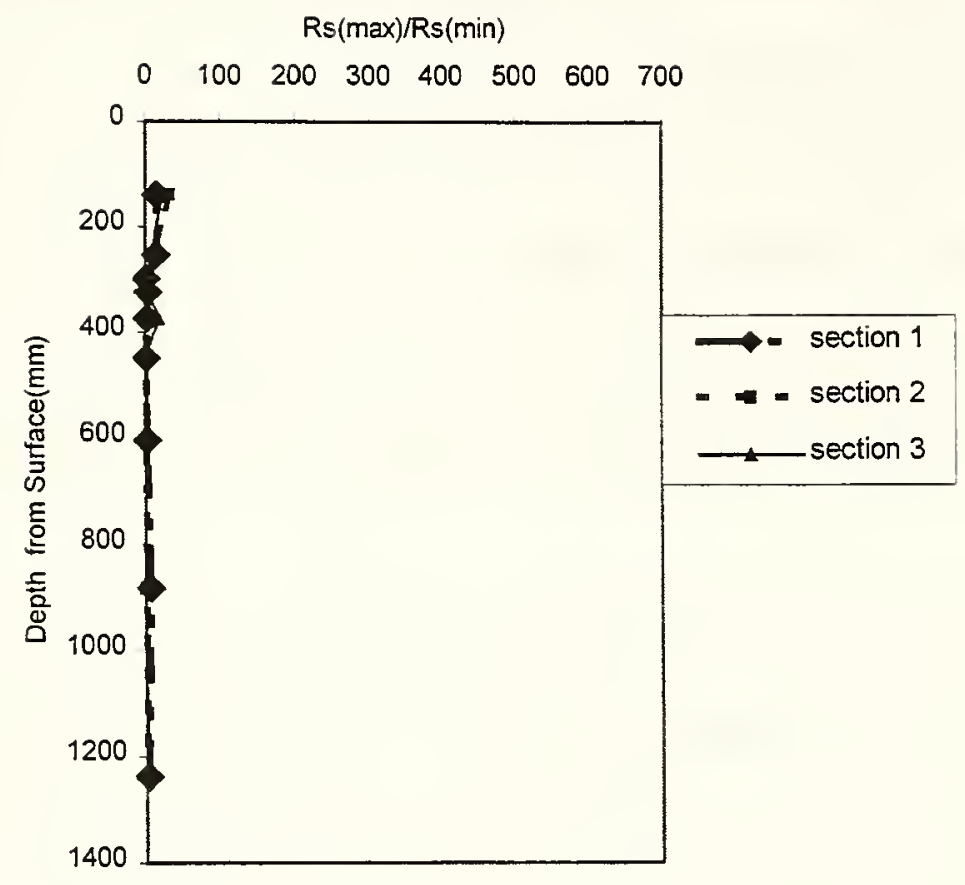

Figure 4.25 Frost Penetration Determination in 1998 
The rainfall and outflow event for section 1 is shown in Figure 4.26. From the figure, drainage occurred over a period of 4 hours. The ratio of outflow from the subdrainage system to total rainfall on the pavement was $7.26 \%$. Figure 4.27 shows the rainfall and flow event for section 2. The drainage period for section 2 was 6.45 hours. Outflow was $7.57 \%$ of the rainfall. Figure 4.28 shows the rainfall and outflow event for section 3 . The section took 7 hours to drain and the outflow was $8.4 \%$ of the rainfall.

For the three test sections, section 1 took significantly less time to drain. This indicates that the drainage performance of section 1 is better than sections 2 and 3 . One reason for this is that the granular filter in sections 2 and 3 stores water and delays drainage.

Over the three years, the infiltration rate into the pavement increased after the first winter (Hossam, 1995). Since then it has decreased. In May 1996, the average infiltration rate was $19 \%$. In October 1996, the infiltration rate was $13.7 \%$. In October 1997, the average infiltration rate was $10.2 \%$. In September 1998 , the average infiltration rate was $7.7 \%$. The drainage time is also shortened dramatically. A reason is that after three years of traffic, the surface and binder are densified and cracks have not occurred yet. Thus, the permeability of the pavement is reduced, and less water enters the pavement. The quicker drainage may result from the fact that less water enters the pavement and the outlet capacity is adequate to drain the water quickly. Overall, the pavement drainage performance is excellent. The drainage performance is summarized in Table 4.5. 
Table 4.5 Summary of Drainage Performance

\begin{tabular}{|c|c|c|}
\hline $\begin{array}{c}\text { Time } \\
(\mathrm{m} / \mathrm{yr})\end{array}$ & $\begin{array}{c}\text { Average Infiltration Ratio } \\
(\%)\end{array}$ & $\begin{array}{c}\text { Average Drainage } \\
\text { Time (Hour) }\end{array}$ \\
\hline $5 / 96$ & 19 & 20 \\
\hline $10 / 96$ & 13.7 & 14 \\
\hline $10 / 97$ & 10.2 & 9 \\
\hline $9 / 98$ & 7.7 & 6 \\
\hline
\end{tabular}

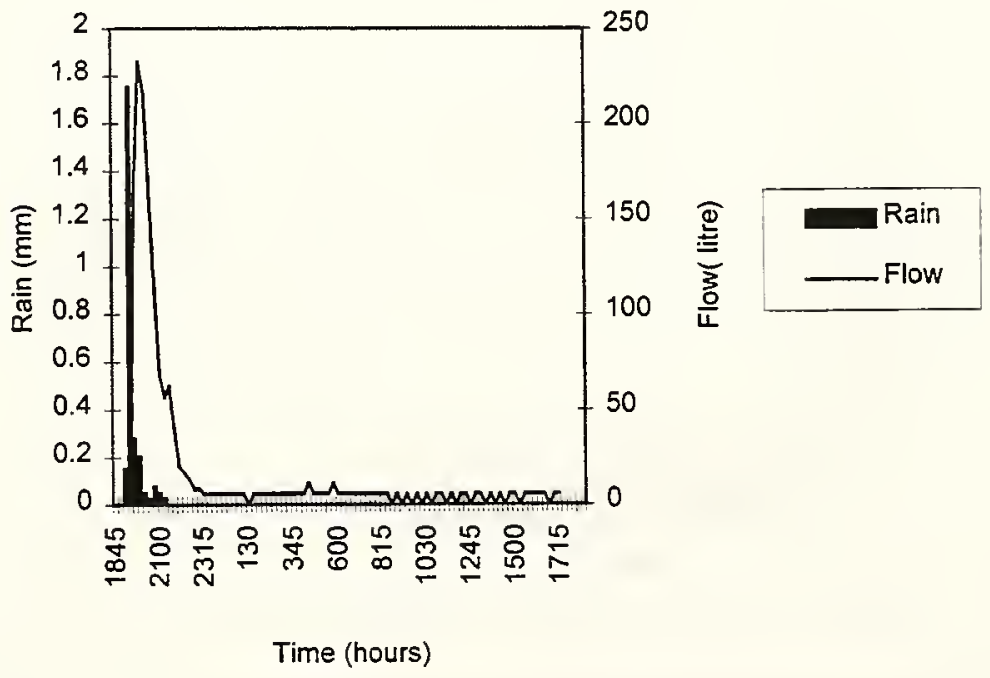

Figure 4.26 Rainfall and Flow Event for Section 1 


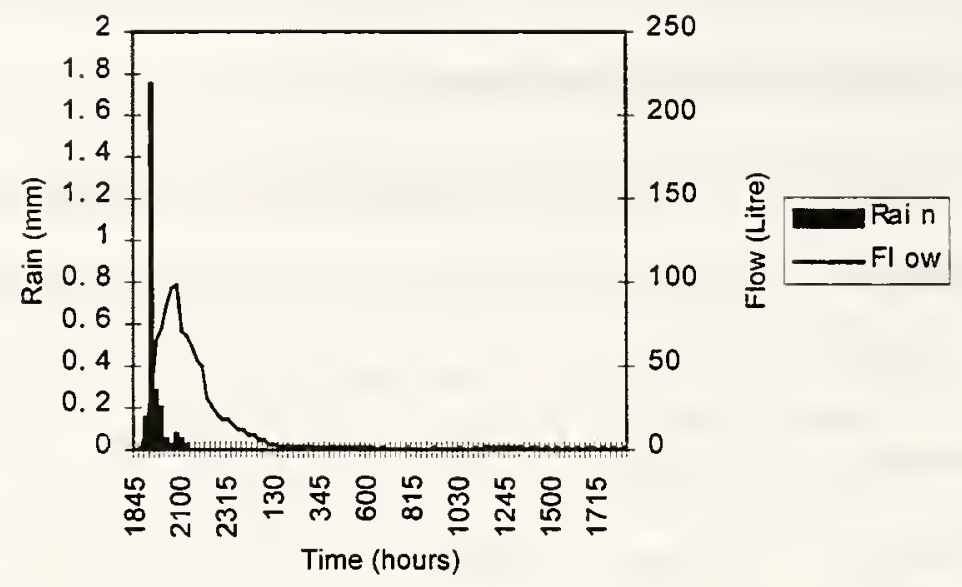

Figure 4.27 Rainfall and Flow Event for Section 2

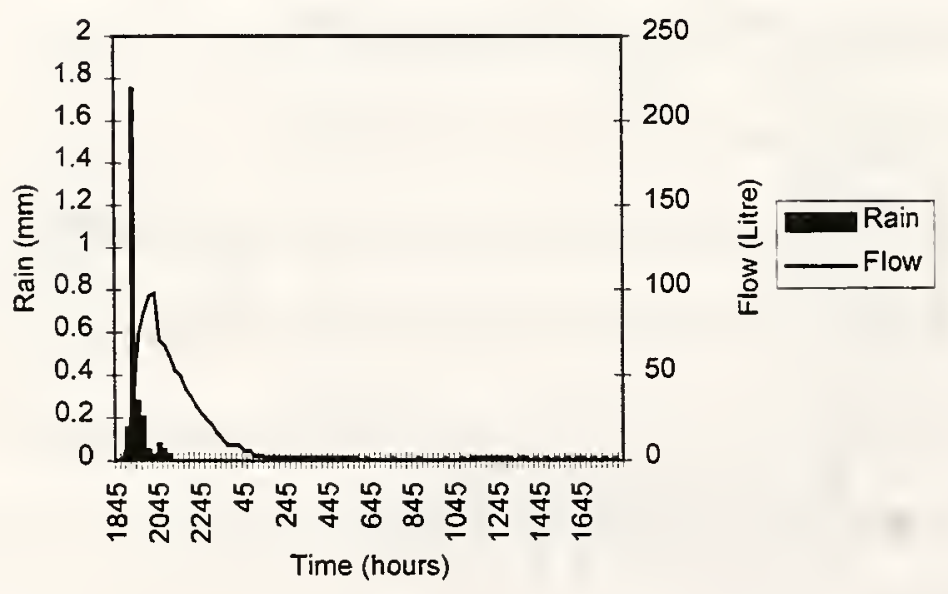

Figure 4.28 Rainfall and Flow for Section 3 


\section{CHAPTER 5 PAVEMENT CONDITION}

The pavement was opened to traffic in October 1995. Pavement condition surveys were conducted in June 1997 and September 1998. Falling Weight Deflector Tests (FWD) were also conducted at these times. The first FWD data was found to be invalid. Two attempts were also made at measuring longitudinal and cross profiles. Data from the first profile survey lacked consistency because the starting point could not be controlled. The equipment malfunctioned during the second survey. As a result, this chapter presents results of the two condition surveys and one series of FWD tests. Data from the first longitudinal profile measurement is presented in Appendix $\mathrm{C}$ for reference.

\section{$\underline{5.1 \text { Condition Survey }}$}

Pavement distress is an indicator of pavement deterioration caused by loading, environmental factors, construction deficiencies or a combination of the factors (Technical Manual Pavement Maintenance Management, TM 5-623, 1982). The condition surveys were conducted in accordance with ASTM D5340-93 "Standard Test Method for Airport Pavement Condition Index Surveys". Pavement condition index $(\mathrm{PCI})$ is a numerical rating of the pavement condition that ranges from 0 to 100 with 0 being the worst possible condition and 100 being the best possible condition.

Traffic control was provided by INDOT for conducting the survey. Both passing and driving lanes were surveyed. Each section was separated into two features (passing 
and driving lane) and 100 percent visual surveys were conducted. The condition survey data is presented in Appendix E.

In general, there is very little distress in the test sections. Distress in section 1 included a small longitudinal construction joint crack between the driving and passing lanes and rutting for a distance of $80 \mathrm{~m}$ along the outer wheel path of the driving lane of less than $1.6 \mathrm{~mm}$. There were three small weathered areas on section 1 . There was also a longitudinal construction joint crack in section 2 approximately $5 \mathrm{~m}$ long. There were two small weathered areas in section 2. Measured rutting was less than $1.6 \mathrm{~mm}$ for about $33 \mathrm{~m}$ in the outside wheel path of the driving lane. There were two locations of a longitudinal construction joint crack in section 3. One was $50 \mathrm{~m}$ long and the other was 6 $\mathrm{m}$ long. There were four longitudinal cracks in the outside shoulder of section 3 with lengths of $50,66,33,33 \mathrm{~m}$. Tables 5.1 and 5.2 show the Pavement Condition Index (PCI) analysis. Condition of all three sections is excellent. The longitudinal construction joint crack is shown in Figure 5.1. Figure 5.2 shows a shoulder crack. Figure 5.3 shows a rutting measurement being made.

Table 5.1 PCI for Condition Survey, June 1997

\begin{tabular}{|c|c|c|c|c|c|c|}
\hline Section & \multicolumn{2}{|c|}{1} & \multicolumn{2}{c|}{2} & \multicolumn{2}{c|}{3} \\
\hline Feature & $\begin{array}{c}\text { Driving } \\
\text { Lane }\end{array}$ & $\begin{array}{c}\text { Passing } \\
\text { Lane }\end{array}$ & $\begin{array}{c}\text { Driving } \\
\text { Lane }\end{array}$ & $\begin{array}{c}\text { Passing } \\
\text { Lane }\end{array}$ & $\begin{array}{c}\text { Driving } \\
\text { Lane }\end{array}$ & $\begin{array}{c}\text { Passing } \\
\text { Lane }\end{array}$ \\
\hline Deduct & 3 & 27 & 0 & 15 & 10 & 10 \\
\hline Total Deduct & 3 & 27 & 0 & 15 & 10 & 10 \\
\hline Corrected & \multicolumn{2}{|c|}{15} & \multicolumn{2}{|c|}{7.5} & \multicolumn{2}{c|}{10} \\
\hline PCI & \multicolumn{2}{|c|}{85} & \multicolumn{2}{c|}{92.5} & \multicolumn{2}{c|}{90} \\
\hline Rating & \multicolumn{2}{|c|}{ Excellent } & \multicolumn{2}{c|}{ Excellent } & \multicolumn{2}{c|}{ Excellent } \\
\hline
\end{tabular}


Table 5.2 PCI for Condition Survey, September 1998

\begin{tabular}{|c|c|c|c|c|c|c|}
\hline Section & \multicolumn{2}{|c|}{1} & \multicolumn{2}{c|}{2} & \multicolumn{2}{c|}{3} \\
\hline Feature & $\begin{array}{c}\text { Passing } \\
\text { Lane }\end{array}$ & $\begin{array}{c}\text { Driving } \\
\text { Lane }\end{array}$ & $\begin{array}{c}\text { Passing } \\
\text { Lane }\end{array}$ & $\begin{array}{c}\text { Driving } \\
\text { Lane }\end{array}$ & $\begin{array}{c}\text { Passing } \\
\text { Lane }\end{array}$ & $\begin{array}{c}\text { Driving } \\
\text { Lane }\end{array}$ \\
\hline Deduct & 4 & 29 & 1 & 17 & 12 & 12 \\
\hline Total & 4 & 29 & 0 & 17 & 12 & 12 \\
\hline Corrected & \multicolumn{2}{|c|}{17} & \multicolumn{2}{|c|}{9} & \multicolumn{2}{c|}{12} \\
\hline PCI & \multicolumn{2}{|c|}{83} & \multicolumn{2}{|c|}{91} & \multicolumn{2}{c|}{88} \\
\hline Rating & \multicolumn{2}{|c|}{ Excellent } & Excellent & \multicolumn{2}{c|}{ Excellent } \\
\hline
\end{tabular}

\subsection{Falling Weight Deflector Test}

Deflection measurements have long been used to evaluate the structural capacity of in situ pavements [Huang, 1993]. They can be used to backcalculate the properties of various pavement components, evaluate load transfer efficiency across joints and cracks in concrete pavements and determine the location and extent of voids under concrete slabs. Falling weight deflectometer application is described in ASTM D 4694, "Deflections with a Falling-Weight-Type Impulse Load Device." 


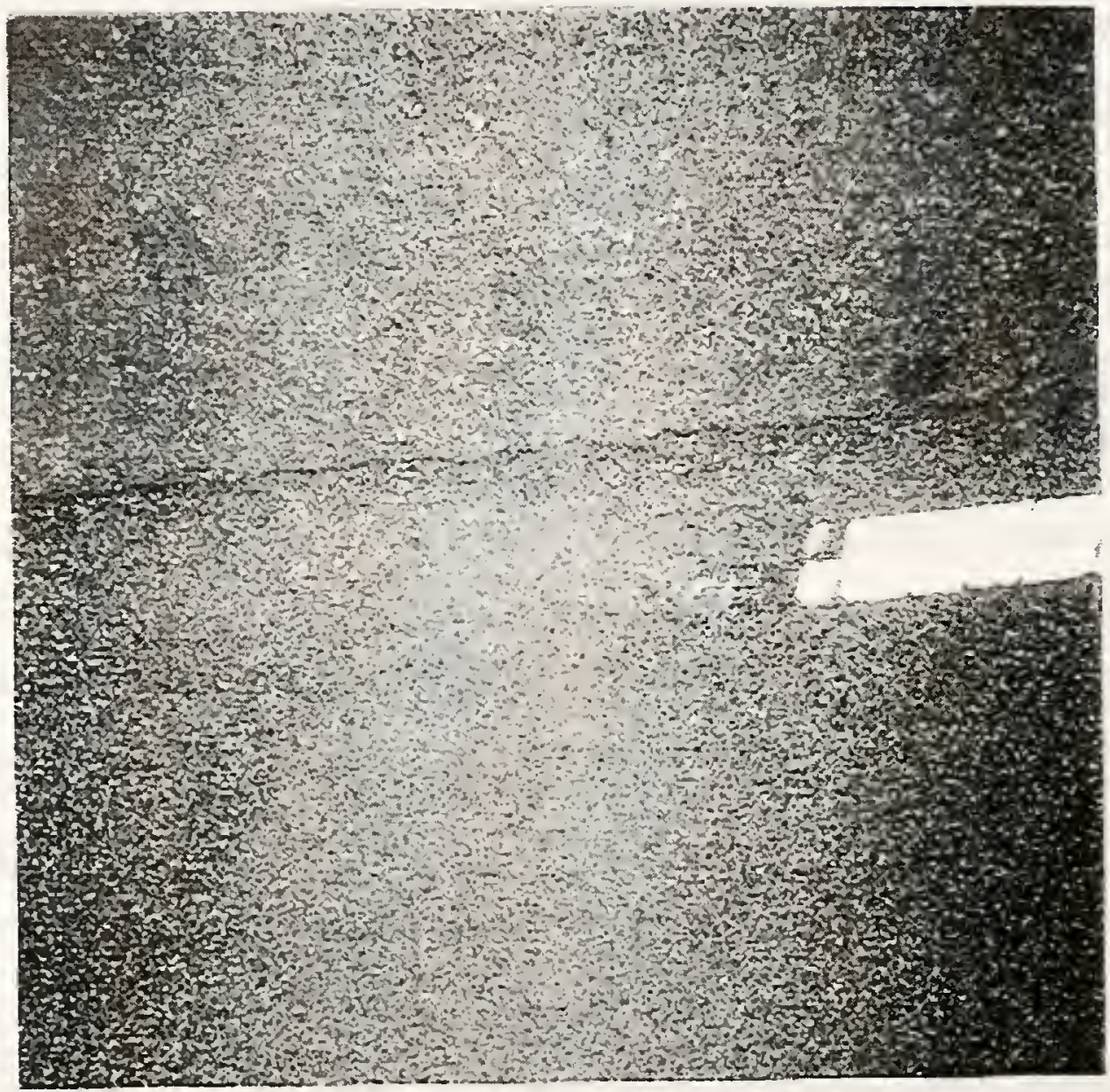

Figure 5.1 Longitudinal Construction Joint Crack 


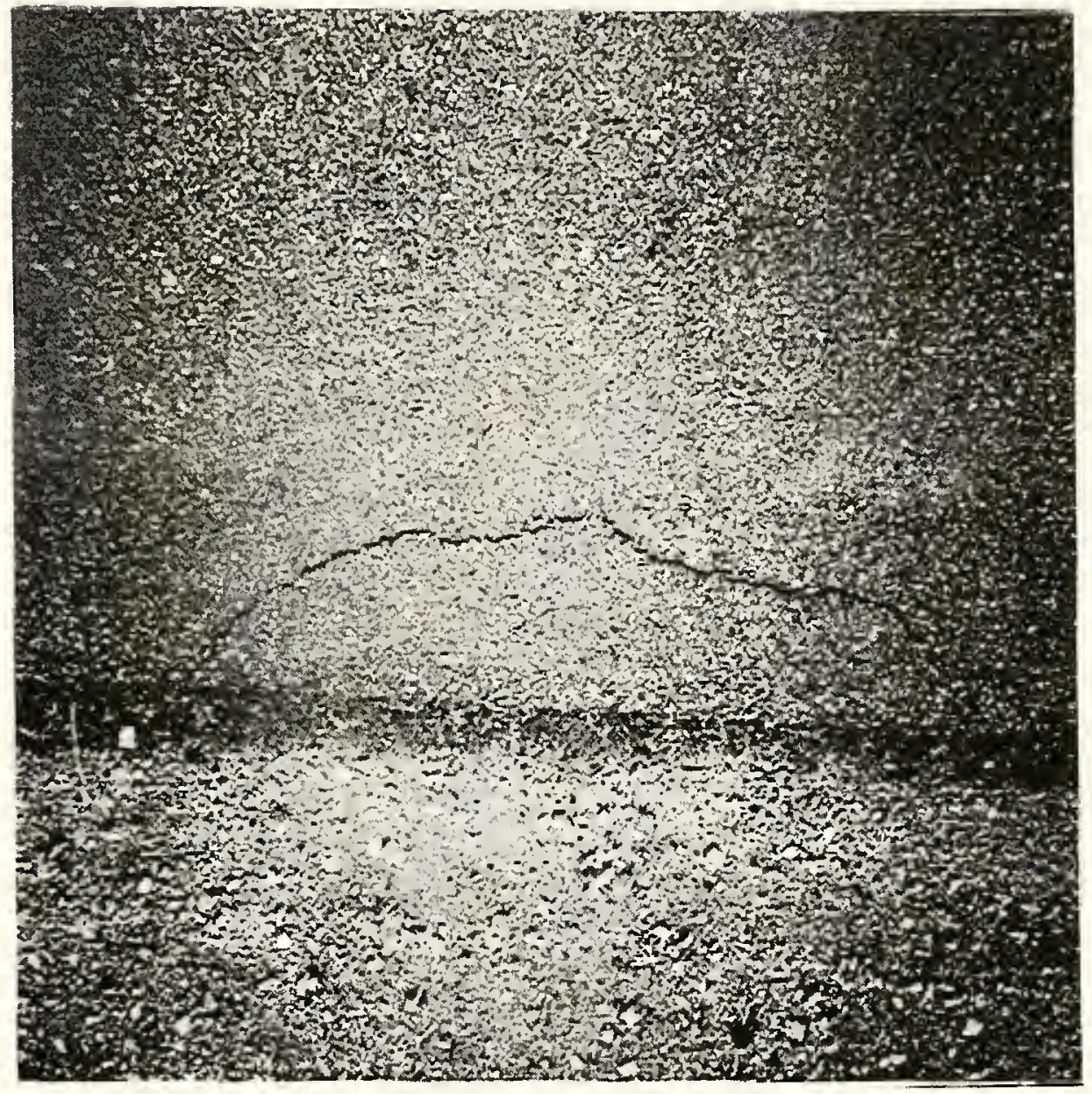

Figure 5.2 Shoulder Crack 


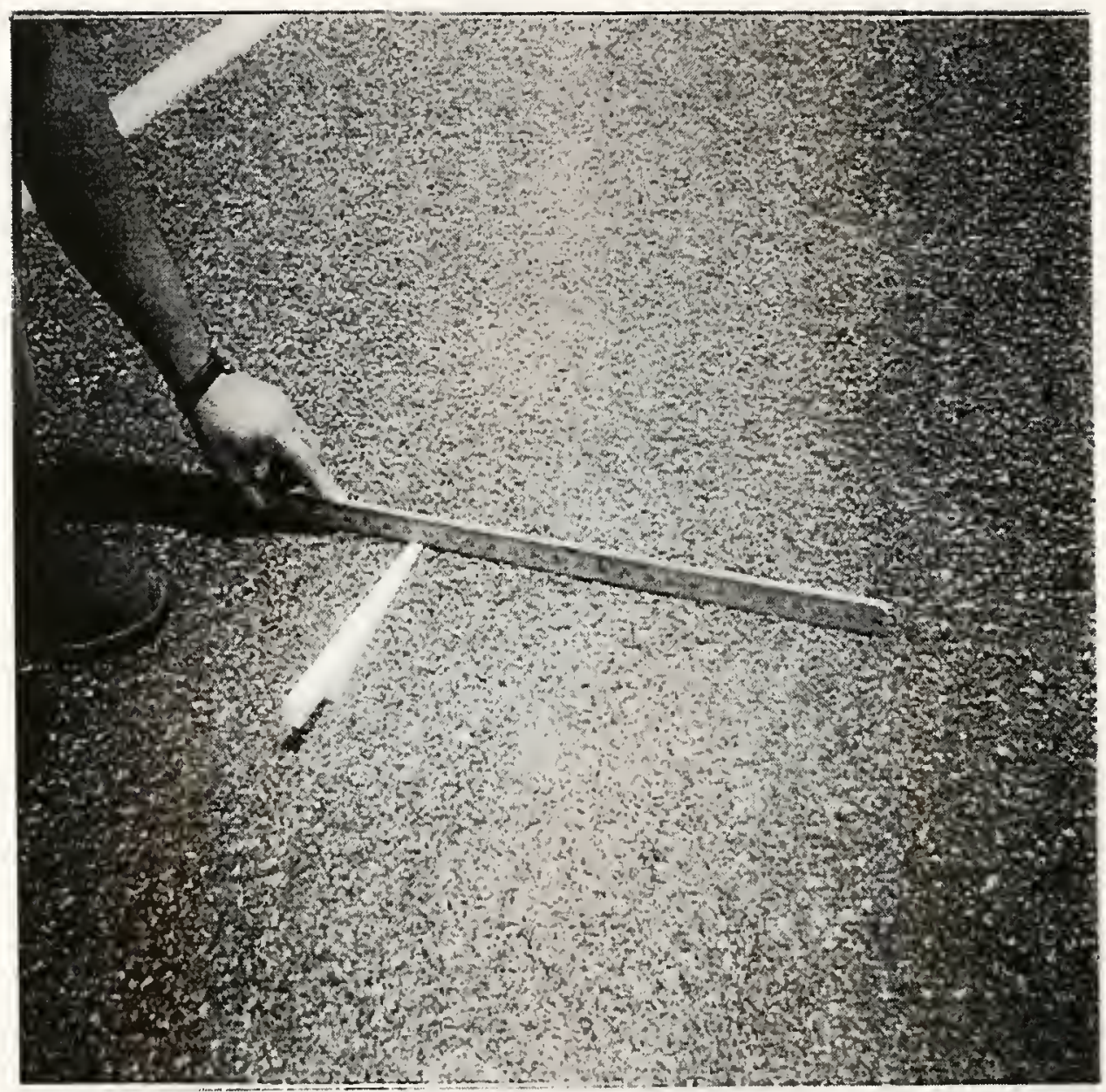

Figure 5.3 Rutting Measurement 
Figure 5.4 shows the FWD sensor test locations. Figures 5.5 and 5.6 show the FWD test positions along the test sections. The load is applied at Dfl. In conducting the tests, the FWD is positioned so that the load plate is at the desired test position. The plate and deflection sensors are lowered to the pavement. A predetermined mass is raised to a height that, when dropped, will impart the desired dynamic force to the pavement. The mass is dropped and the resulting vertical movement or deflection of the pavement surface is measured by the sensors. The force pulse approximates the shape of a haversine or half-sine wave and a peak force of at least $50 \mathrm{KN}$ is recommended. The loading plate is $300 \mathrm{~mm}$ in diameter.

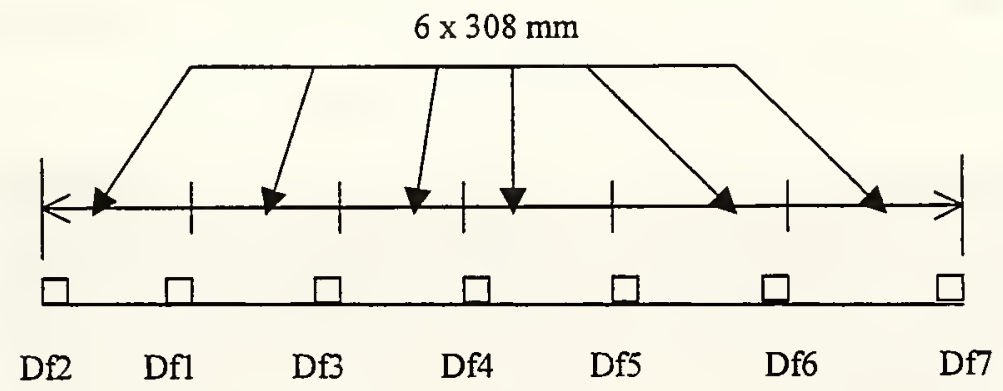

Figure 5.4 Sketch of Sensor Location

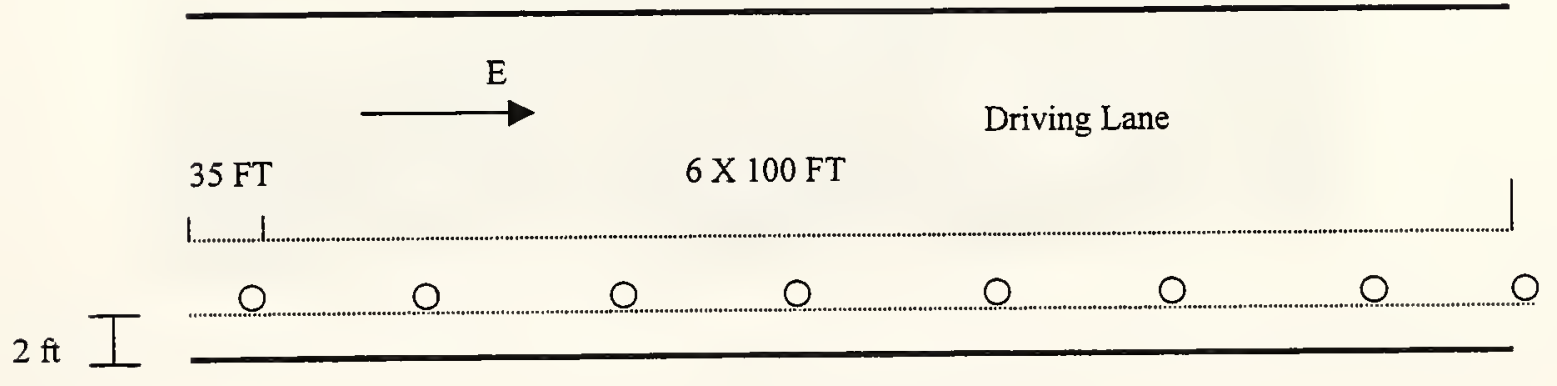

Figure 5.5 FWD Test Location, Section 1 


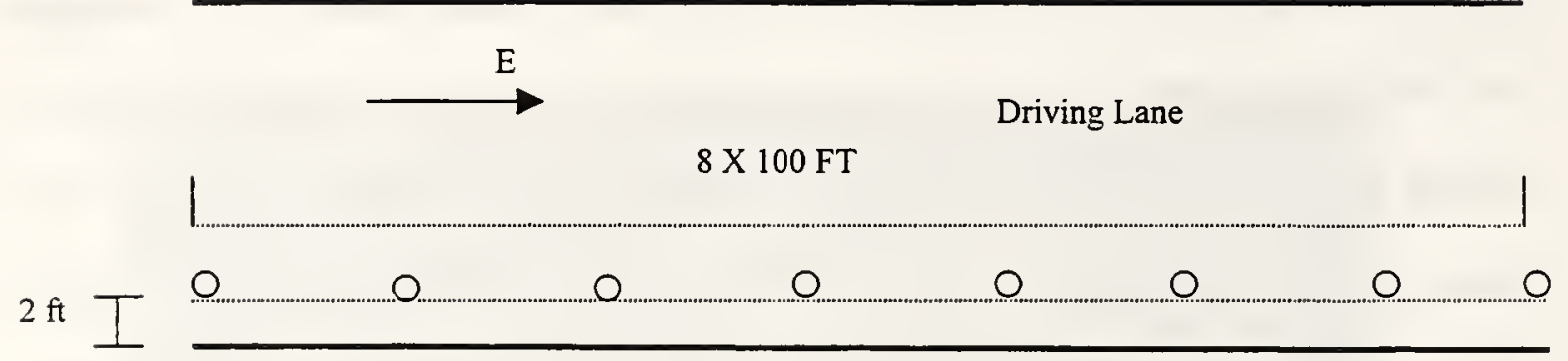

Figure 5.6 FWD Test Location, Sections 2 and 3

Three load levels of $34960,44040,57800 \mathrm{~N}$ were applied for each test position. Figures 5.7 and 5.8 show the overall FWD test equipment and trailer, respectively. Figures 5.9, 5.10, 5.11 show the deformation of Dfl from FWD tests at all locations and for the three load levels. As is usual, the FWD data indicates that the pavement/subgrade stiffness varies. 


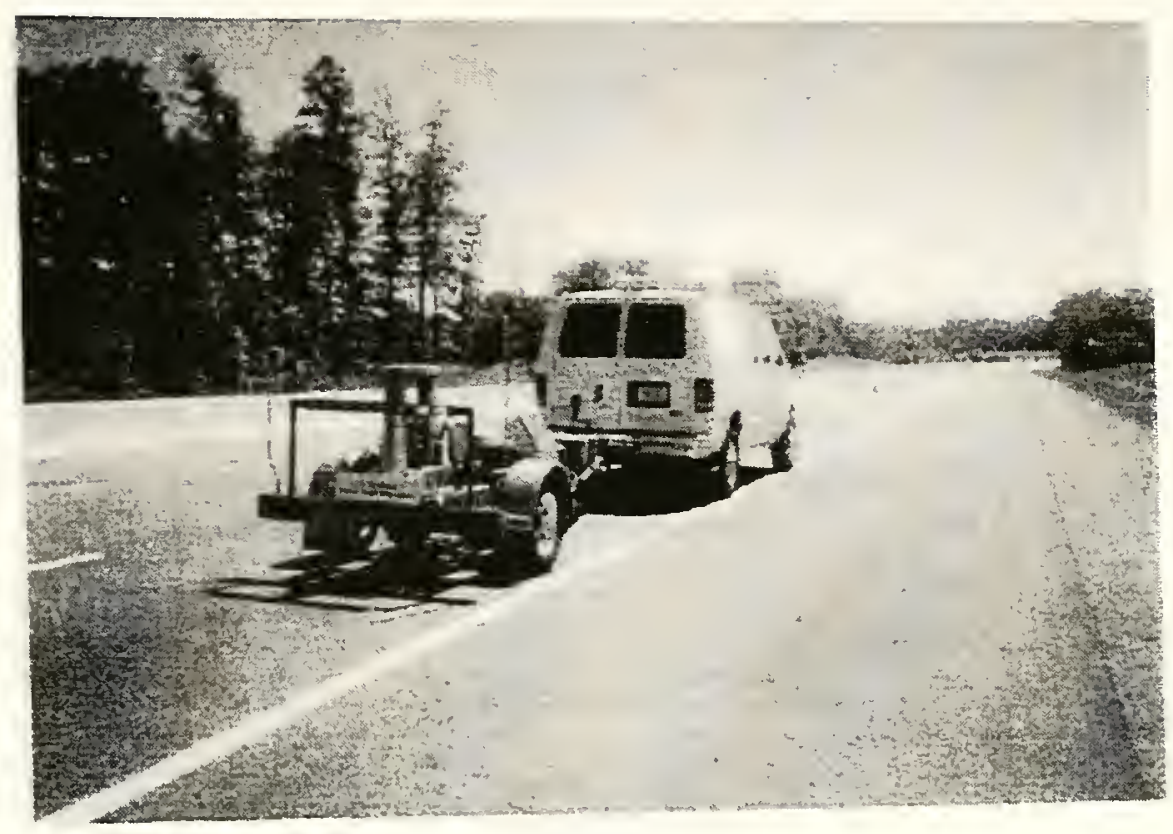

Figure 5.7 FWD Test Equipment

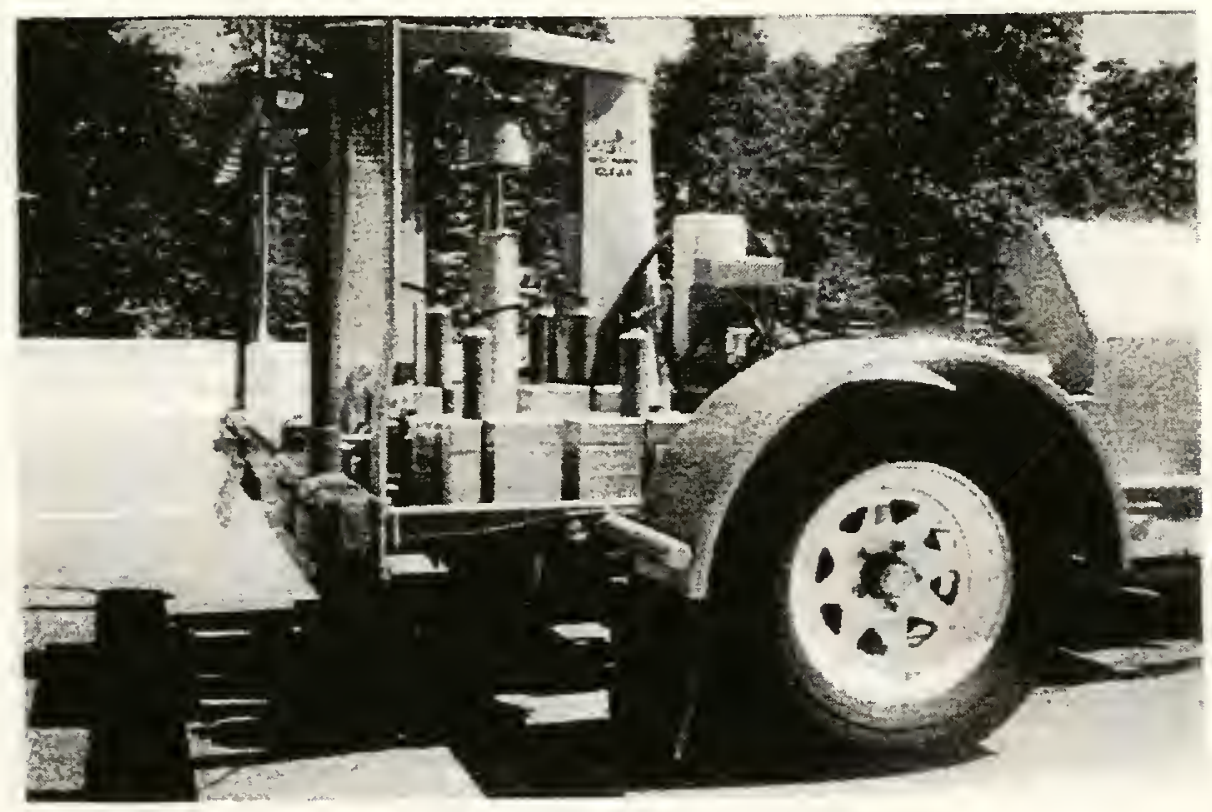

Figure 5.8 FWD Trailer 


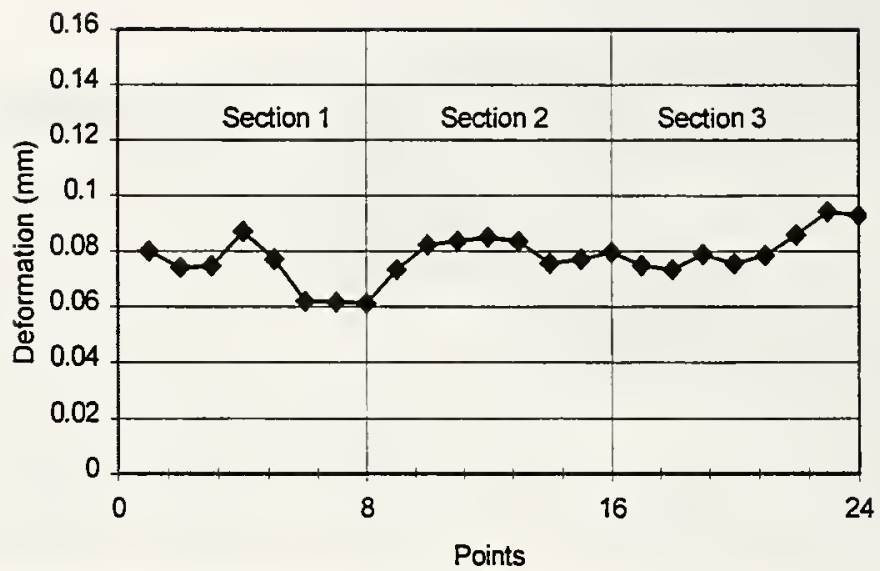

Figure 5.9 FWD Test at All Locations, Level I

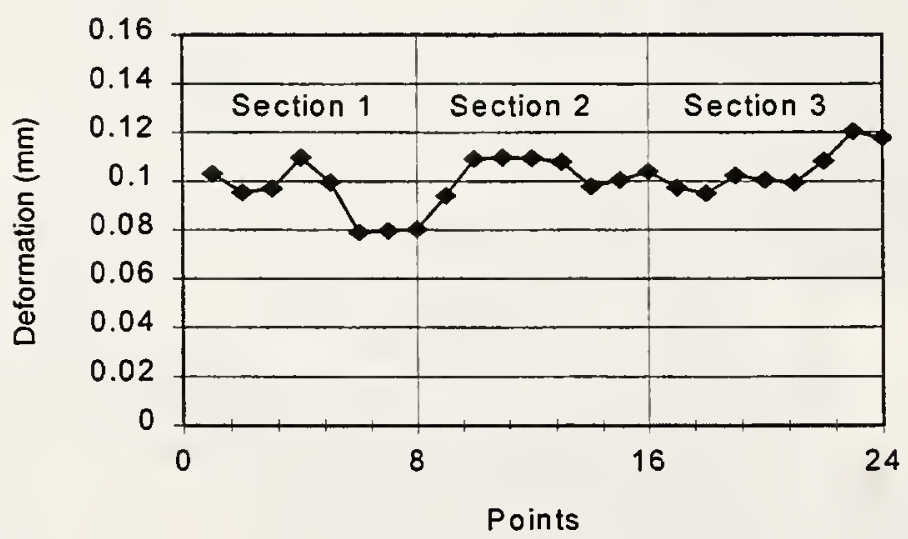

Figure 5.10 FWD Test at All Locations, Level II 


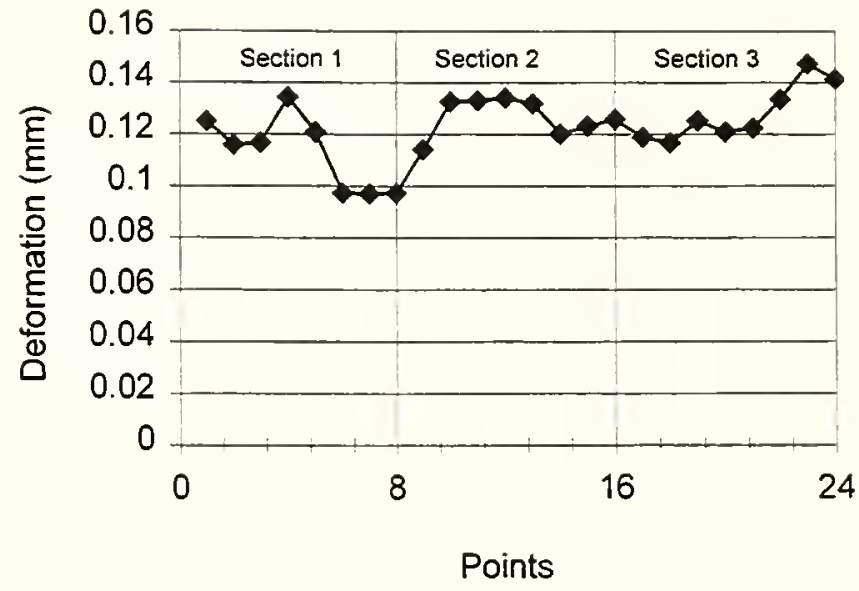

Figure 5.11 FWD Test at All Locations, Level III 


\section{CHAPTER 6 LABORATORY TESTS ON SUBGRADE AND GRANULAR MATERIALS}

One of the goals of this research was to conduct a stability analysis of the drainage layers. This analysis would include a comparison of traffic imposed stresses and available strength and deformation. Triaxial tests were utilized to determine material model parameters for all subgrades, asphalt layers, unbound aggregate layers and trench material. This chapter presents tests and results on subgrades and aggregate materials. Consolidated Undrained (CU) and partially saturated undrained triaxial tests were conducted on the subgrade materials of all three sections. Consolidated undrained and consolidated drained (CD) triaxial test were conducted on the unbound \#53 aggregate filter material and on the \#8 trench aggregate, respectively.

\subsection{Triaxial Test on Subgrade}

\section{$\underline{6.1 .1 \mathrm{CU} \text { Test }}$}

Specimens of subgrade soil from each section was subjected to three different confining pressures. Specimens were compacted at field moisture content and density as described in Chapter 3. Figure 6.1 shows the deviator stress vs. axial strain of the CU test on the subgrade material of section 1. Figure 6.2 shows the corresponding pore pressure vs. axial strain. Figure legends show the corresponding confining pressure. Similarly, 
Figure 6.3 to Figure 6.6 show triaxial results for the subgrade materials of section 2 and section 3.

As would be expected, higher confining pressure produces higher shear strength. Pore pressure increases in the loading process, which indicates that the compacted soil is normally consolidated.

Figures 6.7 to 6.9 show the Mohr circles generated from triaxial tests of the subgrade materials. Figures 6.10 and 6.11 show the relation of initial Young's modulus, yield stress and confining pressure. Both Young's modulus and yield stress increase with increasing confining pressure. Section 1 subgrade is less sensitive to confining pressure. From Figure 6.7, similarly, section 1 subgrade cohesion and friction angle are $11.0 \mathrm{kPa}$ and 29 degrees, respectively. From Figures 6.8 and 6.9, the subgrade cohesion and friction angle for sections 2 and 3 are $27.6 \mathrm{kPa}$ and $10.3 \mathrm{kPa}$, and 23 and 29 degrees, respectively.

The above values of cohesion and angle of internal friction are compared with data reported in the literature for similar materials. The test results are in good agreement to values reported by Hunt [1986], Duncan [1980] and Peterson [1986]. Holtz [1981] stated that "For compacted clays at low stresses, $\mathrm{c}$ ' will be much greater due to prestress caused by compaction."

Janbu [1963] proposed a relationship to estimate an initial Young's modulus:

$$
\mathrm{E}_{\mathrm{i}}=\mathrm{KP}_{\mathrm{a}}\left(\sigma_{3} / \mathrm{P}_{\mathrm{a}}\right)^{\mathrm{N}}
$$

$\mathrm{K}$--- modulus number, related to soil type

$\mathrm{N}$--- modulus exponent

$\mathrm{Pa}$--- atmosphere pressure, $101.4 \mathrm{kPa}$ 
$\sigma_{3}$---- effective confining pressure

Table 6.2 shows the predicted moduli for the subgrades from equation 6.1. The predicted values are higher than the subgrade test values for sections 1 and 3 . However, the predicted values for the section 2 subgrade are in close agreement with the test results.

Table 6.1 Subgrade Triaxial Test Results

\begin{tabular}{|c|c|c|c|c|c|c|c|c|c|}
\hline Test Section & \multicolumn{3}{c|}{1} & \multicolumn{3}{c|}{2} & \multicolumn{3}{c|}{3} \\
\hline Material Type & \multicolumn{3}{c|}{ CL/ML } & \multicolumn{3}{c|}{ CL } & \multicolumn{3}{c|}{ SM/CL/ML } \\
\hline Test & 1 & 2 & 3 & 1 & 2 & 3 & 1 & 2 & 3 \\
\hline$\sigma_{c}^{\prime}$ & 33.1 & 74.4 & 99.9 & 35.4 & 72.3 & 101.3 & 33.2 & 67.2 & 93 \\
\hline $\begin{array}{c}\text { Initial Young's } \\
\text { Modules }(\mathrm{kPa})\end{array}$ & 5696 & 5821 & 6176 & 7399 & 14374 & 16590 & 4361 & 6956 & 11445 \\
\hline $\begin{array}{c}\text { Yield Stress } \\
(\mathrm{kPa})\left(\sigma_{1}-\sigma_{3}\right)\end{array}$ & 29.6 & 39.6 & 47.9 & 66 & 97.7 & 123.7 & 27 & 56.1 & 83.6 \\
\hline $\begin{array}{c}\text { Cohesion c } \\
(\mathrm{kPa})\end{array}$ & 11 & & & 27.6 & & & 10.3 & \\
\hline $\begin{array}{c}\text { Internal } \\
\text { Friction } \phi \\
(\text { degree })\end{array}$ & & & & & 23 & & & & \\
\hline
\end{tabular}

$\left(\sigma_{\mathrm{c}}-\right.$ Effective Confining Pressure, $\left.\mathrm{kPa}\right)$

\section{$\underline{\text { 6.1.2 Partial Saturated Triaxial Test }}$}

As discussed in Chapter 3, partially saturated test specimens were compacted at field moisture and density conditions. Field moisture measurements indicate that subgrades of all three test sections have been partially saturated throughout the reporting period. 
Table 6.2 Young's Modulus Predicted from Janbu Equation

\begin{tabular}{|c|c|c|c|c|c|}
\hline \multicolumn{2}{|c|}{$\begin{array}{c}\text { Section 1 } \\
(\mathrm{K}=120, \mathrm{~N}=0,45)\end{array}$} & \multicolumn{2}{c|}{$\begin{array}{c}\text { Section 2 } \\
(\mathrm{K}=150, \mathrm{~N}=0.45)\end{array}$} & \multicolumn{2}{c|}{$\begin{array}{c}\text { Section 3 } \\
(\mathrm{K}=150, \mathrm{~N}=0.45)\end{array}$} \\
\hline$\sigma_{3}(\mathrm{kPa})$ & $\mathrm{E}_{\mathrm{i}}(\mathrm{kPa})$ & $\sigma_{3}(\mathrm{kPa})$ & $\mathrm{E}_{\mathrm{i}}(\mathrm{kPa})$ & $\sigma_{3}(\mathrm{kPa})$ & $\mathrm{E}_{\mathrm{i}}(\mathrm{kPa})$ \\
\hline 33.1 & 7352 & 35.4 & 9472.5 & 32 & 9203 \\
74.4 & 10585 & 72.2 & 13062 & 67.2 & 12639 \\
99.9 & 12087 & 101.3 & 15203 & 93 & 14630 \\
\hline
\end{tabular}

Figures 6.12 to 6.14 show the stress-strain curves of the partially saturated tests on the three subgrade materials. Figures 6.15 to 6.17 show the resulting Mohr's circles. From Figure 6.15 , the cohesion is determined to be $14 \mathrm{kPa}$, and friction angle is 8 degrees for section 1 subgrade. The Mohr's envelope would be a curve for the section 2 subgrade. As a result, cohesion and friction could not be determined. From Figure 6.17, the cohesion and friction is $40 \mathrm{kPa}$ and 6 degrees, respectively, for section 3 subgrade. Table 6.3 summarizes the test results and Figure 6.18 shows the elastic modulus vs. confining pressure relationship for all of the test sections for partially saturated conditions. As expected, the modulus increases with increased confining pressure. Figure 6.19 shows the relation of yield stress vs. confining pressure for all of the test sections under partially saturated conditions. As expected, the elastic modulus for the unsaturated case is much less than that for the saturated case due to the incompressibility of water. However, the yield stresses for both cases are close. 
Table 6.3 Partial Saturated Triaxial Test Results on Subgrade

\begin{tabular}{|c|c|c|c|c|c|c|c|c|c|}
\hline Test Section & \multicolumn{3}{|c|}{ I } & \multicolumn{3}{c|}{ II } & \multicolumn{3}{c|}{ IIl } \\
\hline Test & 1 & 2 & 3 & 1 & 2 & 3 & 1 & 2 & 3 \\
\hline $\begin{array}{c}\text { Confining } \\
\text { Pressure }(\mathrm{kPa})\end{array}$ & 36.2 & 70 & 102.1 & 36.3 & 69.9 & 137.7 & 34.9 & 69.9 & 137.8 \\
\hline $\begin{array}{c}\text { Initial Young's } \\
\text { Modules }(\mathrm{kPa})\end{array}$ & 1125 & 1676 & 2407 & 2254 & 4104 & 5511 & 2543 & 3661 & 5048 \\
\hline $\begin{array}{c}\text { Yield Stress } \\
(\mathrm{kPa})\left(\sigma_{1}-\sigma_{3}\right)\end{array}$ & 25.2 & 26.9 & 43.1 & 60.5 & 95.6 & 110.2 & 66 & 97.8 & 123.7 \\
\hline
\end{tabular}

Table 6.4 summarizes the relationship of elastic modulus vs. confining pressure and yield stress vs. confining pressure for both the saturated and unsaturated subgrade. Confining pressure is denoted as " $\mathrm{x}$ " in the table. These relations are used in subsequent FEM analysis.

Table 6.4 Analysis on Subgrade

\begin{tabular}{|l|l|l|l|}
\hline \multirow{2}{*}{$\begin{array}{c}\text { Test } \\
\text { Condition }\end{array}$} & Section & \multicolumn{1}{|c|}{ Elastic Modulus $(\mathrm{kPa})$} & \multicolumn{1}{c|}{ Yield Stress $(\mathrm{kPa})$} \\
\cline { 2 - 4 } & & \multicolumn{1}{c|}{$\mathrm{E}_{\mathrm{i}}$} & \multicolumn{1}{c|}{$\mathrm{Y}$} \\
\hline \multirow{2}{*}{$\begin{array}{l}\text { Saturated } \\
\text { CU Test }\end{array}$} & Section 1 & $0.16 \mathrm{x}^{2}-14.5 \mathrm{x}+5996$ & $0.001 \mathrm{x}^{2}+0.11 \mathrm{x}+24.7$ \\
\cline { 2 - 4 } & Section 2 & $-1.7 \mathrm{x}^{2}+373.1 \mathrm{x}-366.6$ & $0.001 \mathrm{x}^{2}+0.8 \mathrm{x}+37$ \\
\cline { 2 - 4 } & Section 3 & $1.6 \mathrm{x}^{2}-86.1 \mathrm{x}+5409$ & $0.004 \mathrm{x}^{2}+0.5 \mathrm{x}+6.4$ \\
\hline \multirow{2}{*}{$\begin{array}{l}\text { Partially } \\
\text { Saturated } \\
\text { Test }\end{array}$} & Section 1 & $0.1 \mathrm{x}^{2}+5.87 \mathrm{x}+783.7$ & $0.007 \mathrm{x}^{2}-0.68 \mathrm{x}+40.9$ \\
\cline { 2 - 4 } & Section 2 & $-0.034 \mathrm{x}^{2}+91 \mathrm{x}-603$ & $-0.008 \mathrm{x}^{2}+1.9 \mathrm{x}+1.8$ \\
\cline { 2 - 4 } & Section 3 & $-0.11 \mathrm{x}^{2}+43.7 \mathrm{x}+1155$ & $-0.005 \mathrm{x}^{2}+1.45 \mathrm{x}+21.8$ \\
\hline
\end{tabular}




\section{$\underline{6.2 \text { Triaxial Test on \#53 Subbase }}$}

The \#53 aggregate is a dense unbound aggregate base material. It is used as the filter and separator layer in sections 2 and 3. Test specimens were prepared at the field average density and moisture conditions as stated in Chapter 3.

\section{$\underline{6.2 .1 \mathrm{CU} \text { Test }}$}

Figure 6.20 shows the stress strain curves for $\mathrm{CU}$ tests of the \#53 dense aggregate base. Figure 6.21 shows the corresponding pore pressure curves.

In the $\mathrm{CU}$ tests of the $\# 53$ dense aggregate base material, the pore pressure increases then decreases. This indicates that the material contracts first and then dilates until failure. From the Mohr's circles in Figure 6.22, the cohesion and friction are estimated to be $10 \mathrm{kPa}$ and 55 degrees, respectively. These values indicate high strength. Results are tabulated in Table 6.5.

Table 6.5 CU Test Results on \#53 Dense Aggregate Base

\begin{tabular}{|c|c|c|c|c|}
\hline $\begin{array}{c}\text { Confining } \\
\text { Pressure }(\mathrm{kPa})\end{array}$ & $\begin{array}{c}\text { Yield Stress } \\
(\mathrm{kPa})\end{array}$ & $\begin{array}{c}\text { Young's } \\
\text { Modulus }(\mathrm{kPa})\end{array}$ & $\begin{array}{c}\text { Friction } \\
(\text { degree })^{1}\end{array}$ & $\begin{array}{c}\text { Cohesion } \\
(\mathrm{kPa})^{1}\end{array}$ \\
\hline 35.4 & 1140 & 24000 & & 55 \\
\cline { 1 - 3 } 68.2 & 1315 & 28470 & & 10 \\
\hline 137 & 1630 & 35456 & & \\
\hline
\end{tabular}




\section{$\underline{6.2 .2 \mathrm{CD} \text { Test }}$}

Figure 6.23 shows the stress-strain curves for the $C D$ tests of the \#53 dense aggregate base. The corresponding volumetric strain vs. axial strain are shown in Figure 6.24. These results also indicate the material contracts first and then dilates until failure. The cohesion and friction angle is obtained from the plot of Mohr's circles in Figure 6.25. Cohesion and friction angle are zero and 53 degrees, respectively. Figure 6.26 shows the relation of elastic modulus and confining pressure and Figure 6.27 shows the relation of yield stress and confining pressure. These results are tabulated in Table 6.6.

Table 6.6 CD Test Results on \#53 Dense Aggregate Base

\begin{tabular}{|c|c|c|c|c|}
\hline $\begin{array}{c}\text { Confining Pressure } \\
(\mathrm{kPa})\end{array}$ & $\begin{array}{c}\text { Yield Stress } \\
(\mathrm{kPa})\end{array}$ & $\begin{array}{c}\text { Young's Modulus } \\
(\mathrm{kPa})\end{array}$ & $\begin{array}{c}\phi \\
(\text { degree })\end{array}$ & $\begin{array}{c}\mathrm{c} \\
(\mathrm{kPa})\end{array}$ \\
\hline 38.8 & 252 & 5857 & \multirow{2}{*}{53} & 0 \\
\cline { 1 - 3 } & 76.7 & 6773 & & \\
\cline { 1 - 3 } & 142 & 15046 & & \\
\hline
\end{tabular}

The friction angle is the same in both $\mathrm{CD}$ and $\mathrm{CU}$ tests. However, the Young's modulus and yield stress in the $\mathrm{CD}$ test is much less than in the CU test. That is because the dilation in the CU test develops a much higher effective confining pressure than in the $\mathrm{CD}$ test.

Table 6.7 shows the quantitative relation between Young's modulus and confining pressure and yield stress and confining pressure. Confining pressure is denoted by " $x$ " in the table. As noted above these equations are used in subsequent FEM analysis. 
Table 6.7 Quantitative Results on \#53 Dense Aggregate Base

\begin{tabular}{|c|c|c|}
\hline & Young's Modulus & Yield Stress \\
\hline $\mathrm{CU}$ & $-0.332 \mathrm{x}^{2}+171.7 \mathrm{x}+18350$ & $-0.007 \mathrm{x}^{2}+6.1 \mathrm{x}+933$ \\
\hline $\mathrm{CD}$ & $0.942 \mathrm{x}^{2}-79.4 \mathrm{x}+7317.9$ & $-0.038 \mathrm{x}^{2}+11.5 \mathrm{x}-134.9$ \\
\hline
\end{tabular}

\subsection{Triaxial Test on \#8 Trench Aggregate}

In field applications, the $\# 8$ trench material is not densely compacted. As a result, in preparing laboratory samples for testing, the material was poured into the mold without compaction. Both $\mathrm{CU}$ and $\mathrm{CD}$ tests were conducted on the $\# 8$ trench material.

\section{$\underline{6.3 .1 \mathrm{CU} \text { Test }}$}

Figure 6.28 shows the stress strain curves for $\mathrm{CU}$ tests of the \#8 trench aggregate. The corresponding pore pressure vs. axial strain results are shown in Figure 6.29. The behavior exhibited by the \#8 trench material is typical of a low density granular material (Holtz, 1991). The material contracts and the pore pressure increases. Mohr's circles for this material are shown in Figure 6.30. The cohesion and friction angle are $11 \mathrm{kPa}$ and 33.5 degrees, respectively. The CU test results are tabulated in Table 6.8.

Table 6.8 CU Test Results on \#8 Trench Aggregate

\begin{tabular}{|c|c|c|c|c|}
\hline $\begin{array}{c}\text { Confining Pressure } \\
(\mathrm{kPa})\end{array}$ & $\begin{array}{c}\text { Yield Stress } \\
(\mathrm{kPa})\end{array}$ & $\begin{array}{c}\text { Young's Modulus } \\
(\mathrm{kPa})\end{array}$ & $\begin{array}{c}\text { Friction } \\
(\text { degree })\end{array}$ & $\begin{array}{c}\text { Cohesion } \\
(\mathrm{kPa})\end{array}$ \\
\cline { 1 - 3 } 37 & 50.6 & 5777 & \multirow{2}{*}{33.5} & 11 \\
\cline { 1 - 3 } & 99 & 10600 & & \\
\hline 14.5 & 37.4 & 13900 & & \\
\hline
\end{tabular}




\section{$\underline{\text { 6.3.2 CD Test }}$}

Stress-strain results for the $\# 8$ trench aggregate are shown in Figure 6.31. Figure 6.32 shows the corresponding volumetric strain vs axial strain results. As in the CU test, the $\# 8$ trench material contracts during loading and subsequently the volume decreases. Mohr's circles for this material are shown in Figure 6.33. The cohesion and friction angle are $11 \mathrm{kPa}$ and 33 degrees, respectively. The CD test results are tabulated in Table 6.9.

Table 6.9 CD Test Results on \#8 Trench Aggregate

\begin{tabular}{|c|c|c|c|c|}
\hline $\begin{array}{c}\text { Confining } \\
\text { Pressure }(\mathrm{kPa})\end{array}$ & $\begin{array}{c}\text { Yield Stress } \\
(\mathrm{kPa})\end{array}$ & $\begin{array}{c}\text { Young's } \\
\text { Modulus }(\mathrm{kPa})\end{array}$ & $\begin{array}{c}\phi \\
(\text { degree })\end{array}$ & $\begin{array}{c}\mathrm{C} \\
(\mathrm{kPa})\end{array}$ \\
\hline 43.6 & 91.9 & 9602 & \multirow{2}{*}{33} & 15 \\
\cline { 1 - 2 } & 105 & 7874 & & \\
\hline 135.3 & 172 & 12332 & & \\
\hline
\end{tabular}

The Young's modulus and confining pressure relations are shown in Figure 6.34. Figure 6.35 shows the relation of yield stress and confining pressure for the \#8 trench aggregate. Equations for these results are given in Table 6.10. As noted above these equations are used in subsequent FEM analysis.

Table 6.10 Quantitative Results on \#8 Trench Aggregate

\begin{tabular}{|c|l|c|}
\hline & Young's Modulus & Yield Stress \\
\hline $\mathrm{CU}$ & $0.89 \mathrm{x}^{2}+235.9 \mathrm{x}-1738.9$ & $-0.0082 \mathrm{x}^{2}+2.29 \mathrm{x}-22.9$ \\
\hline $\mathrm{CD}$ & $1.08 \mathrm{x}^{2}-167.6 \mathrm{x}+14319$ & $0.0055 \mathrm{x}^{2}-0.21 \mathrm{x}+92.3$ \\
\hline
\end{tabular}




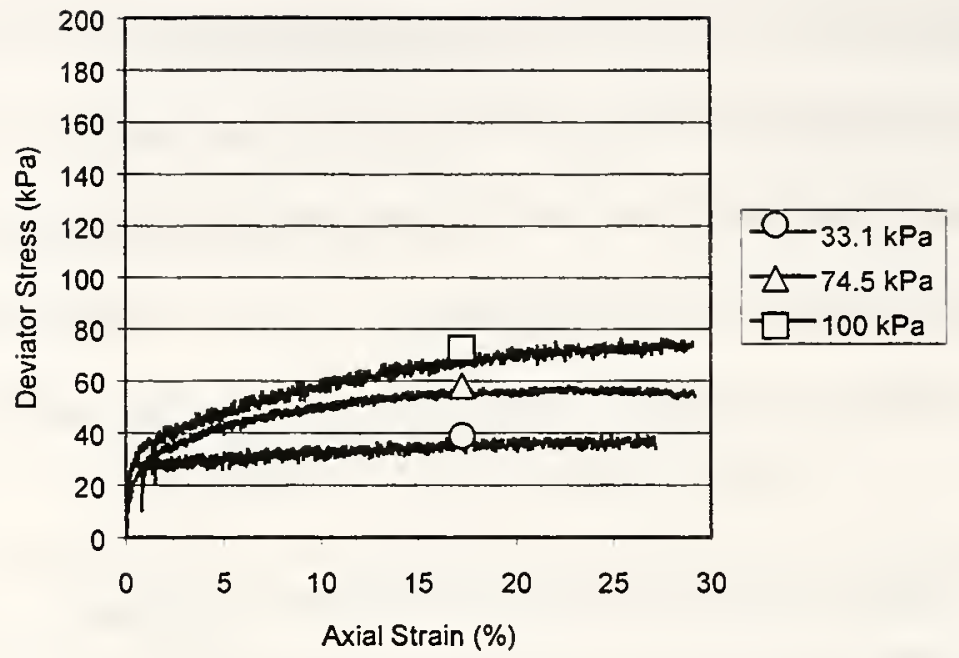

Figure 6.1 Stress-Strain Results for CU Tests on Section 1 Subgrade (Figure Legend Denotes Confining Pressure)

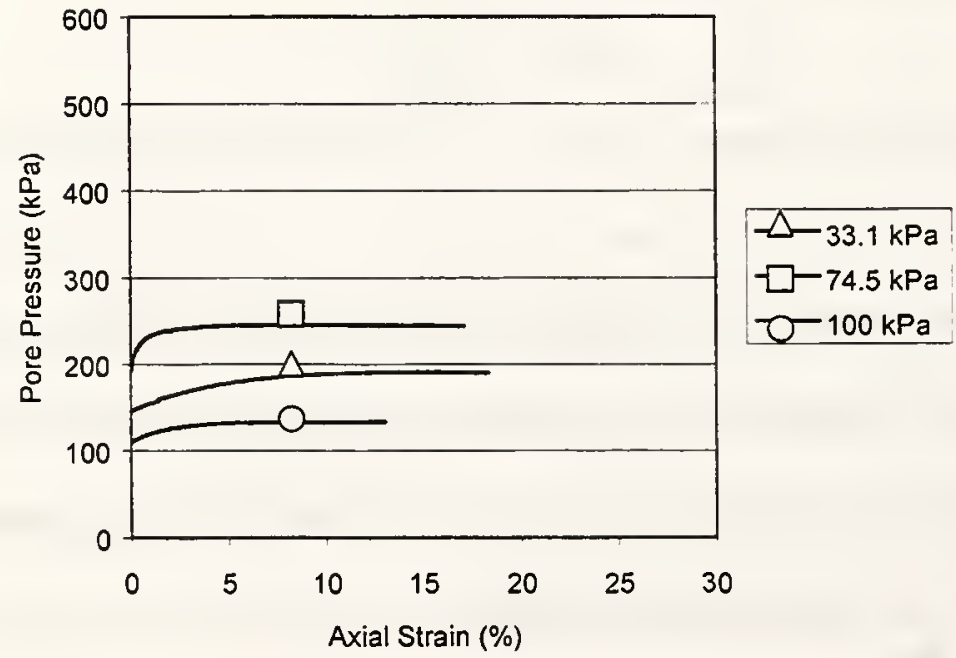

Figure 6.2 Pore Pressure Results for CU Tests on Section 1 Subgrade (Figure Legend Denotes Confining Pressure) 


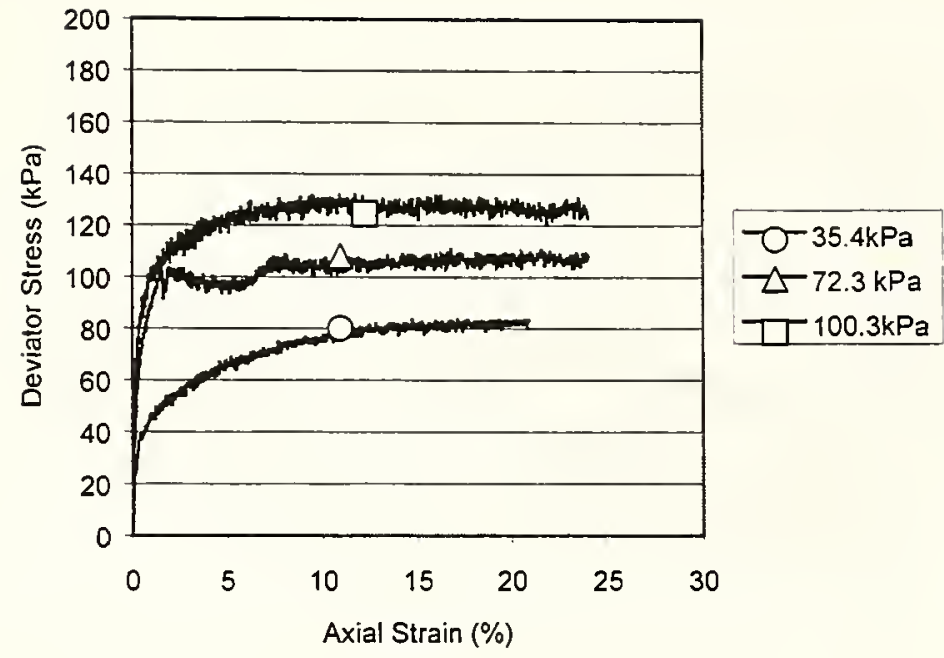

Figure 6.3 Stress-Strain Results for CU Tests on Section 2 Subgrade (Figure Legend Denotes Confining Pressure)

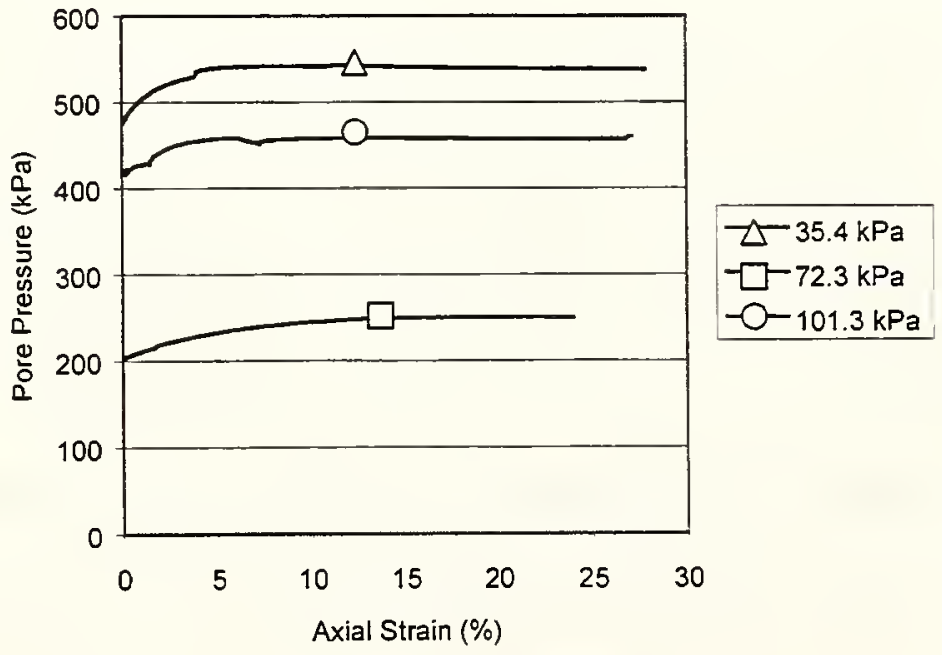

Figure 6.4 Pore Pressure Results for CU Tests on Section 2 Subgrade (Figure Legend Denotes Confining Pressure) 


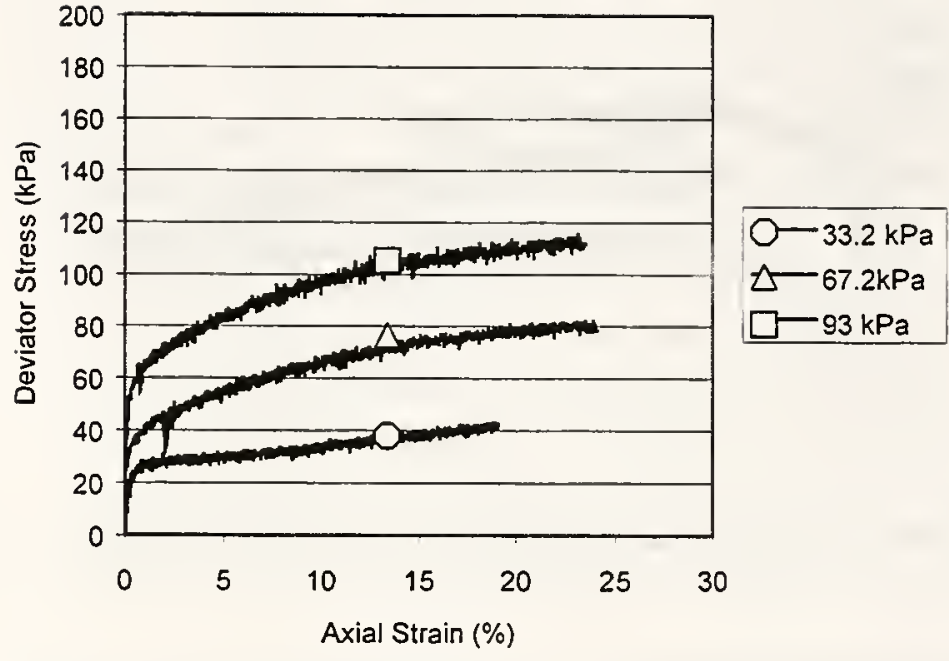

Figure 6.5 Stress-Strain Results for CU Tests on Section 3 Subgrade (Figure Legend Denotes Confining Pressure)

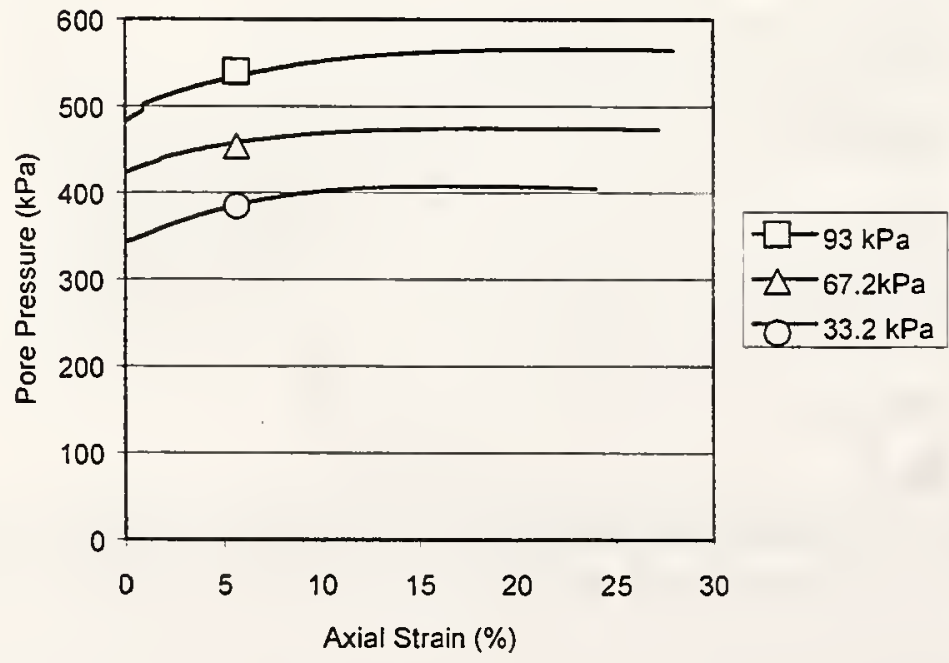

Figure 6.6 Pore Pressure Results for CU Tests on Section 3 Subgrade (Figure Legend Denotes Confining Pressure) 


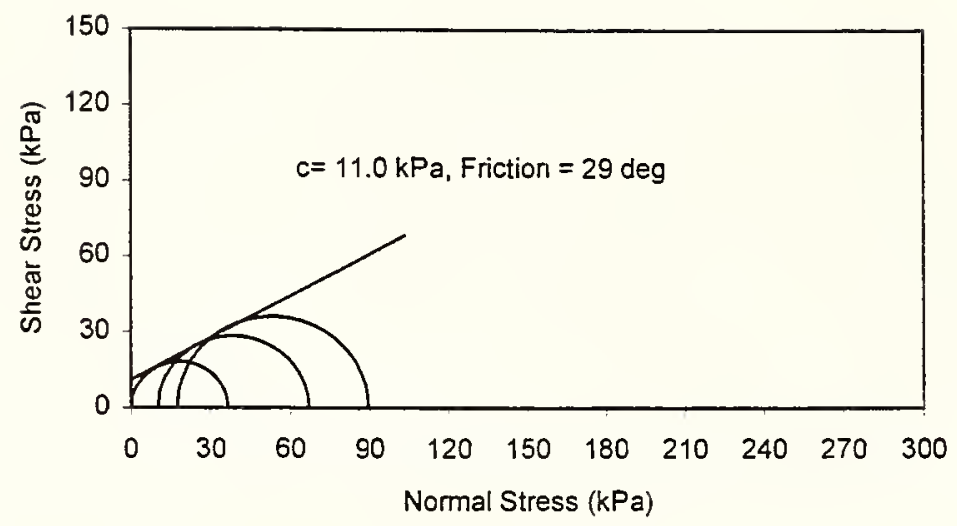

Figure 6.7 Mohr's Circles for Section 1 Subgrade CU Tests

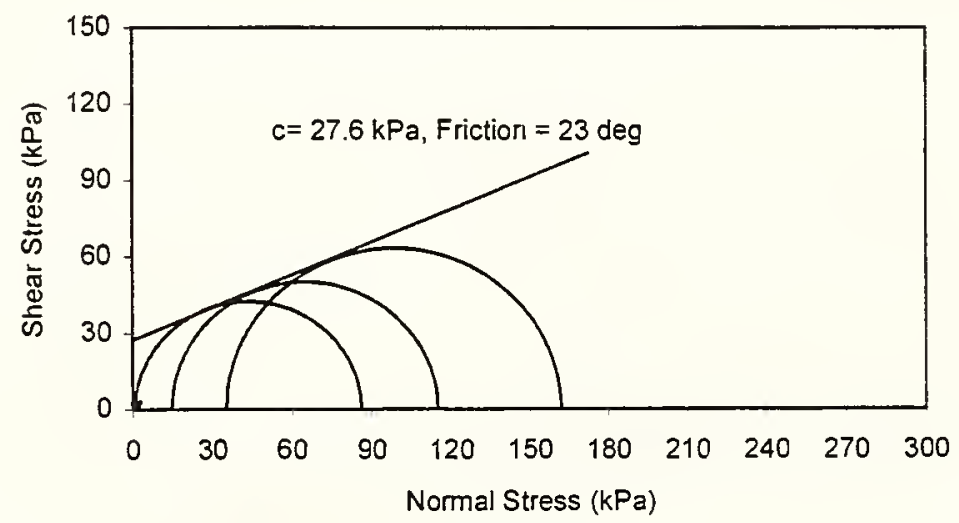

Figure 6.8 Mohr's Circles for Section 2 Subgrade CU Tests 


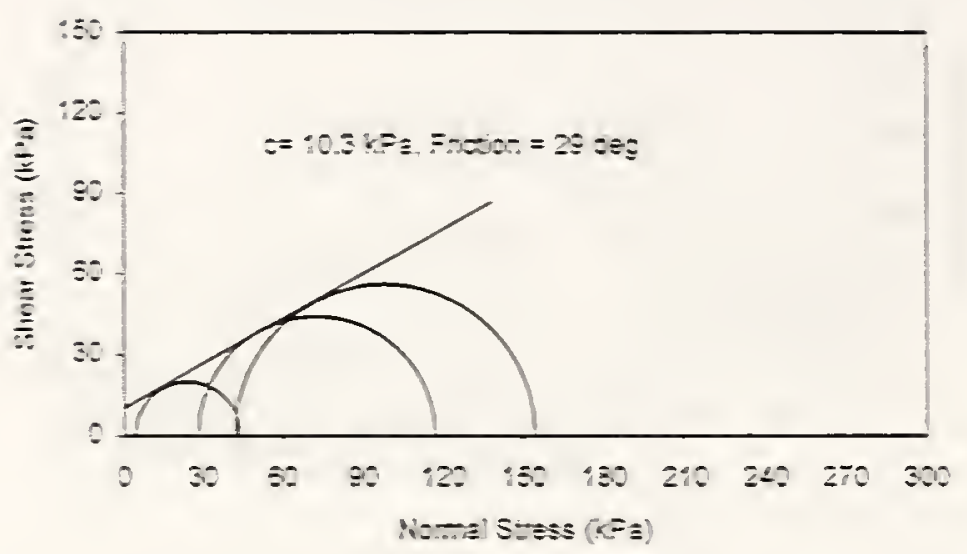

Figure 6.9 Mohr's Circles on Section 3 Suograde CU Test

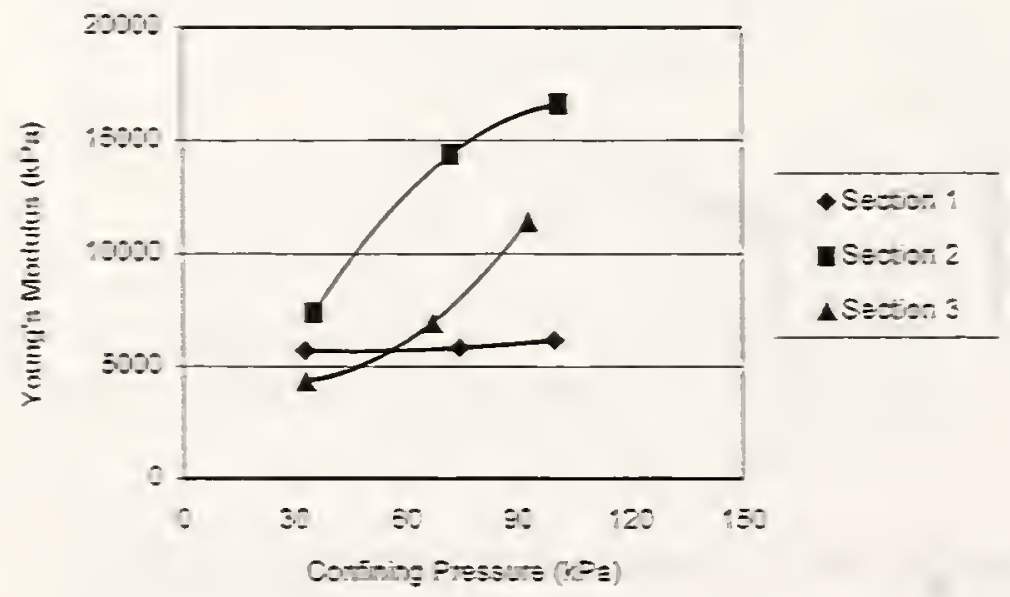

Figure 6.10 Young"s Modulus vs. Confining Pressure (CU Test), Subgrade 


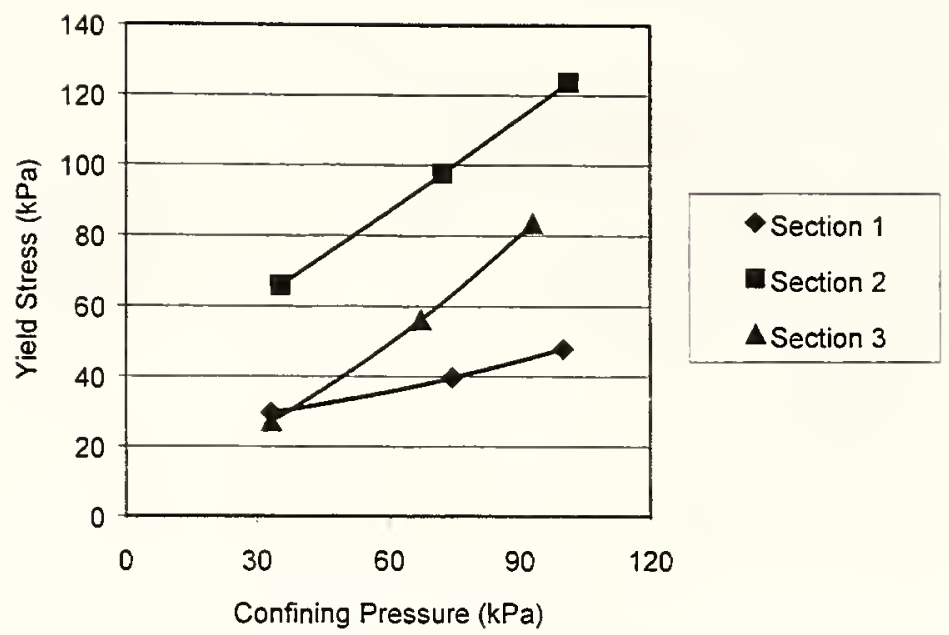

Figure 6.11 Yield Stress vs. Confining Pressure (CU Test), Subgrade

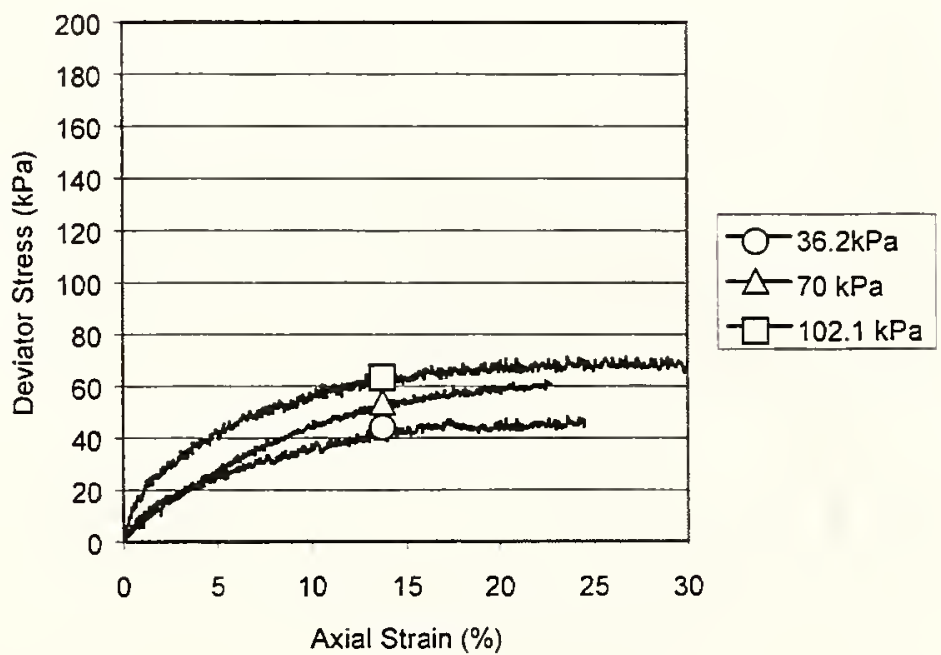

Figure 6.12 Stress-Strain Results for Partially Saturated Test on Section 1 Subgrade (Figure Legend Denotes Confining Pressure) 


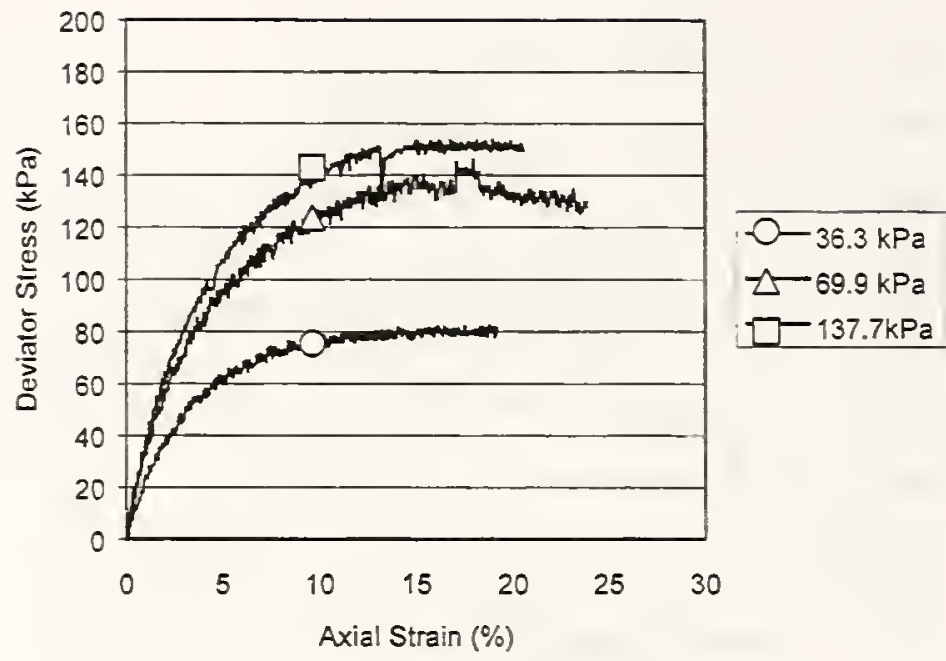

Figure 6.13 Stress-Strain Results for Partially Saturated Tests on Section 2 Subgrade (Figure Legend Denotes Confining Pressure)

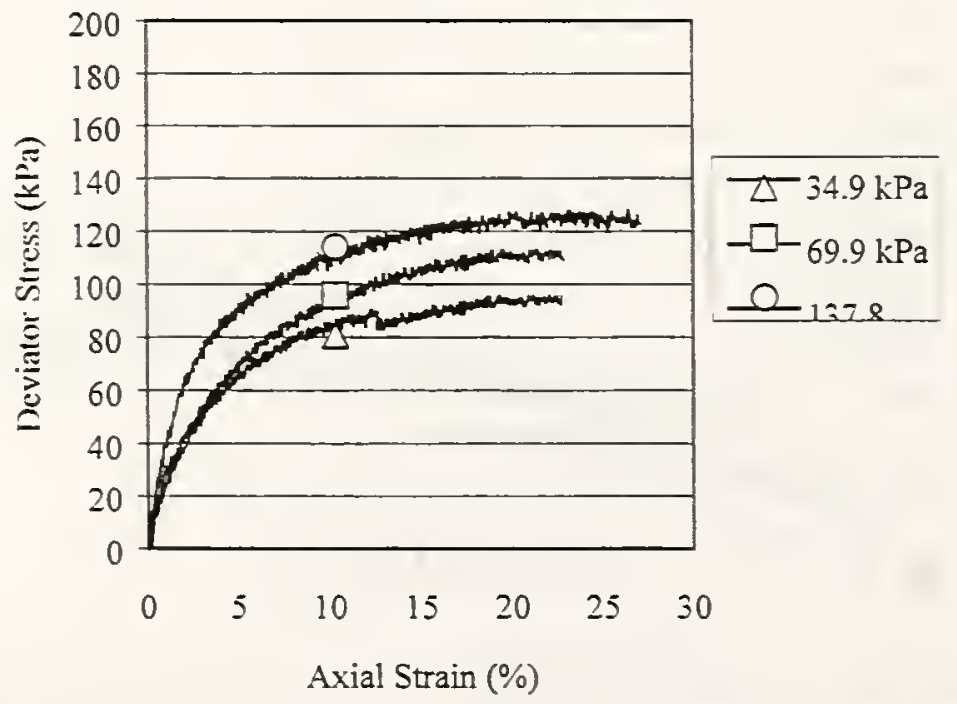

Figure 6.14 Stress-Strain Results for Partially Saturated Test on Section 3 Subgrade (Figure Legend Denotes Confining Pressure) 


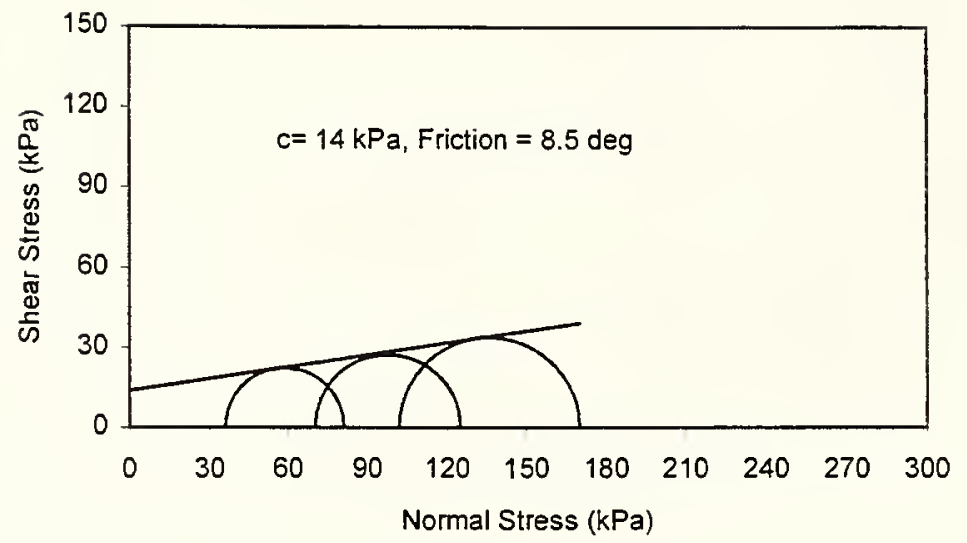

Figure 6.15 Mohr's Circles for Section 1 Partially Saturated Tests

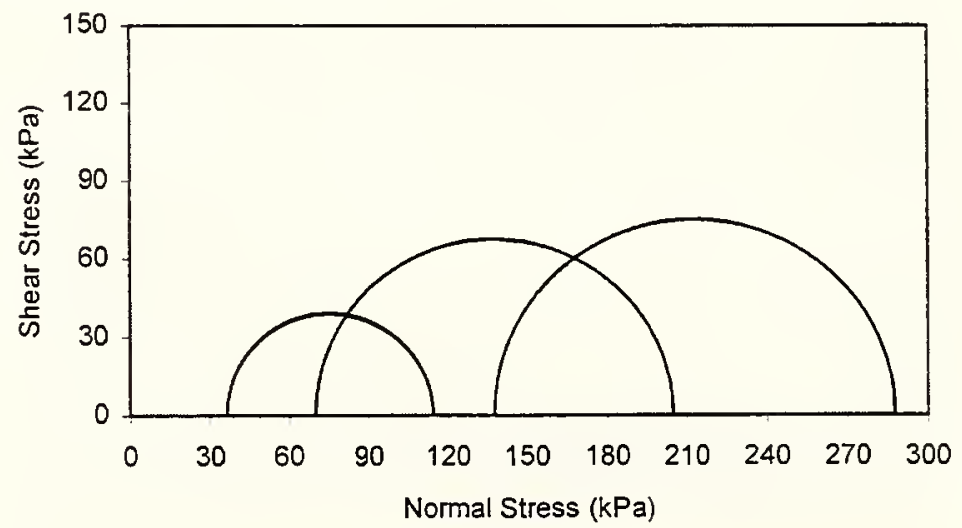

Figure 6.16 Mohr's Circles for Section 2 Partially Saturated Tests 


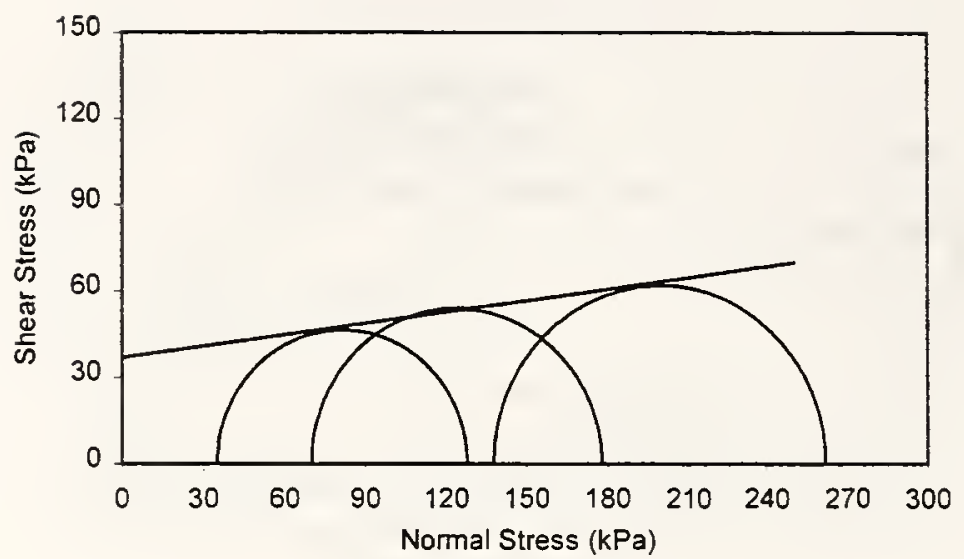

Figure 6.17 Mohr's Circles for Section 3 Partially Saturated Tests

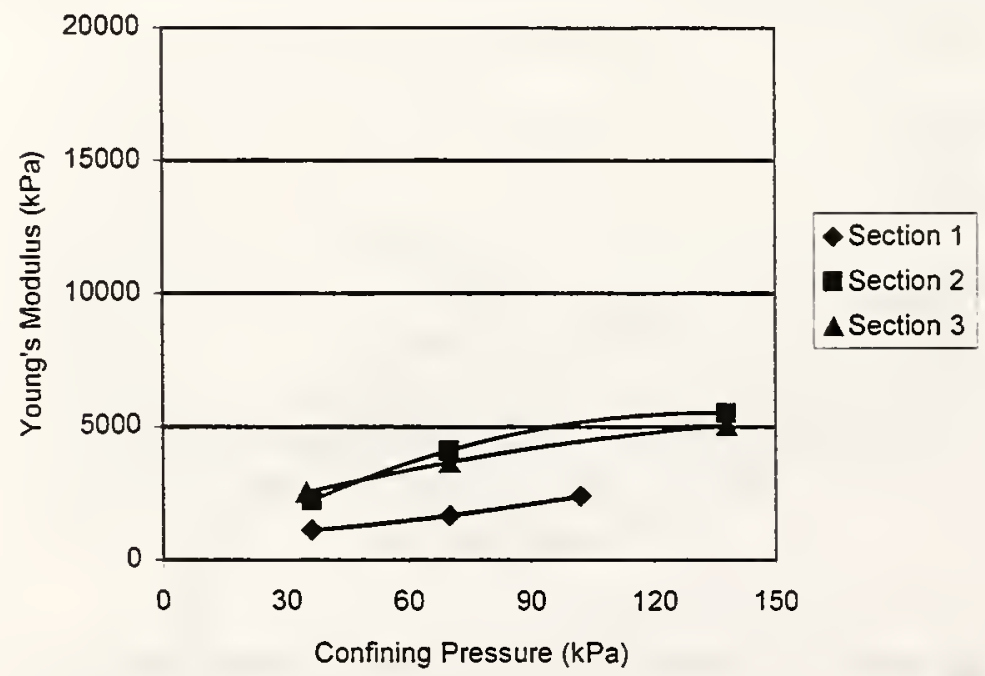

Figure 6.18 Young's Modulus vs. Confining Pressure on Partially Saturated Test, Subgrade 


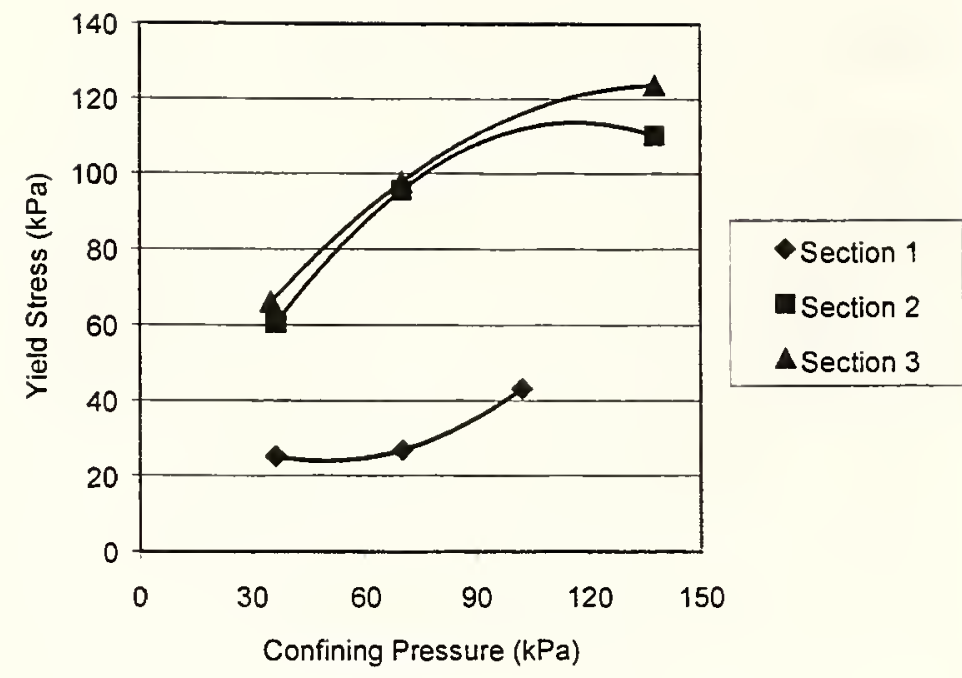

Figure 6.19 Yield Stress vs. Confining Pressure on Partially Saturated Test, Subgrade

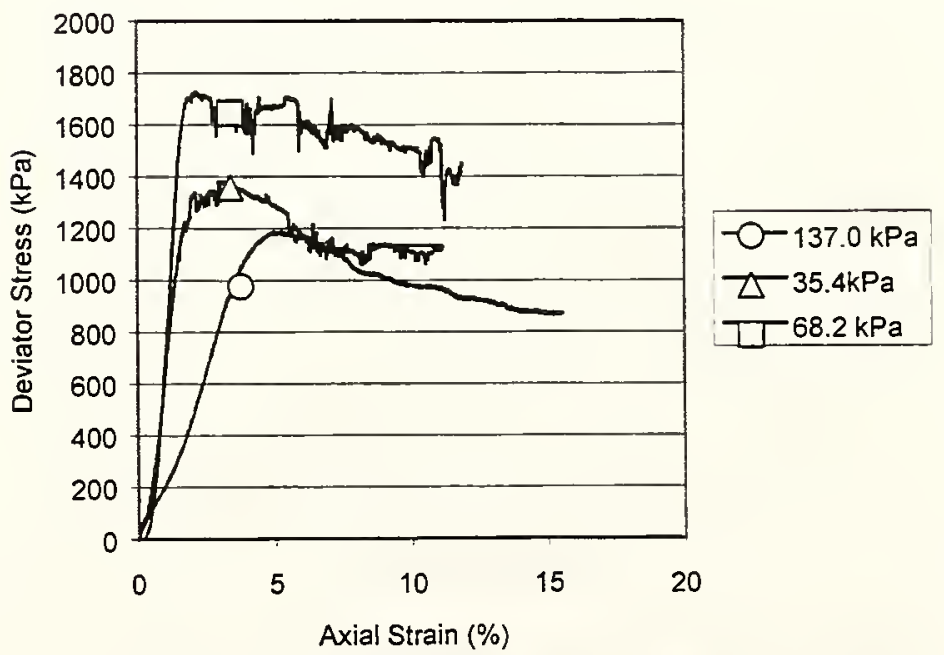

Figure 6.20 Stress-Strain Results the \#53 CU Tests (Figure Legend Denotes Confining Pressure) 


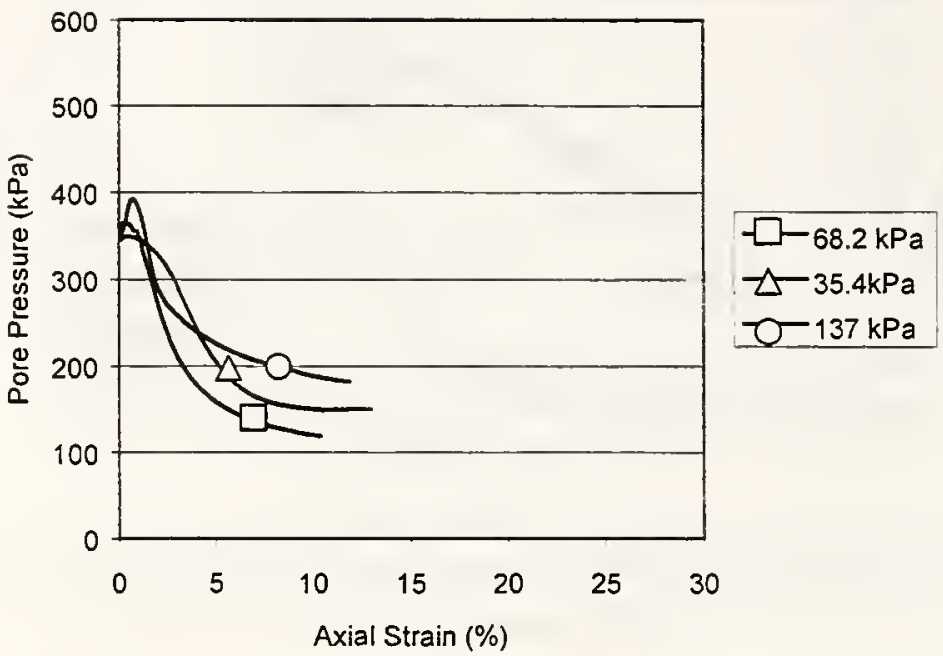

Figure 6.21 Pore Pressure Results the \#53 CU Tests (Figure Legend Denotes Confining Pressure)

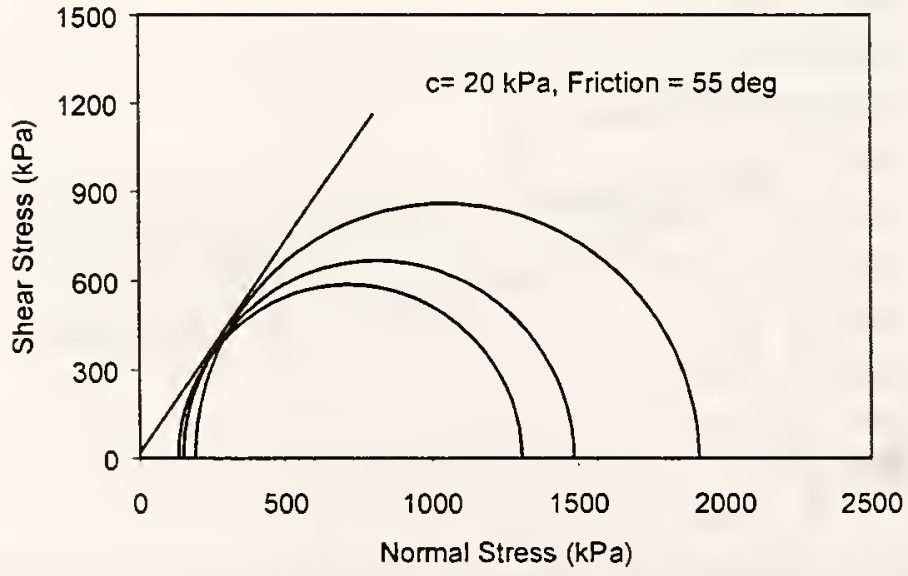

Figure 6.22 Mohr's Circles for the \#53 CU Tests 


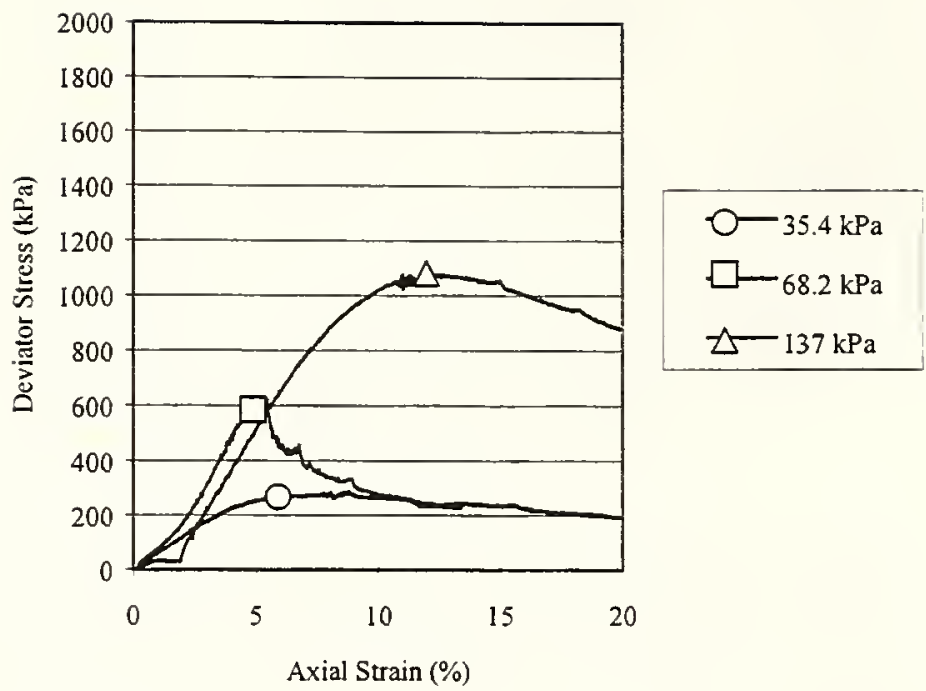

Figure 6.23 Stress - Strain Results for the \#53 CD Tests

(Figure Legend Denotes Confining Pressure)

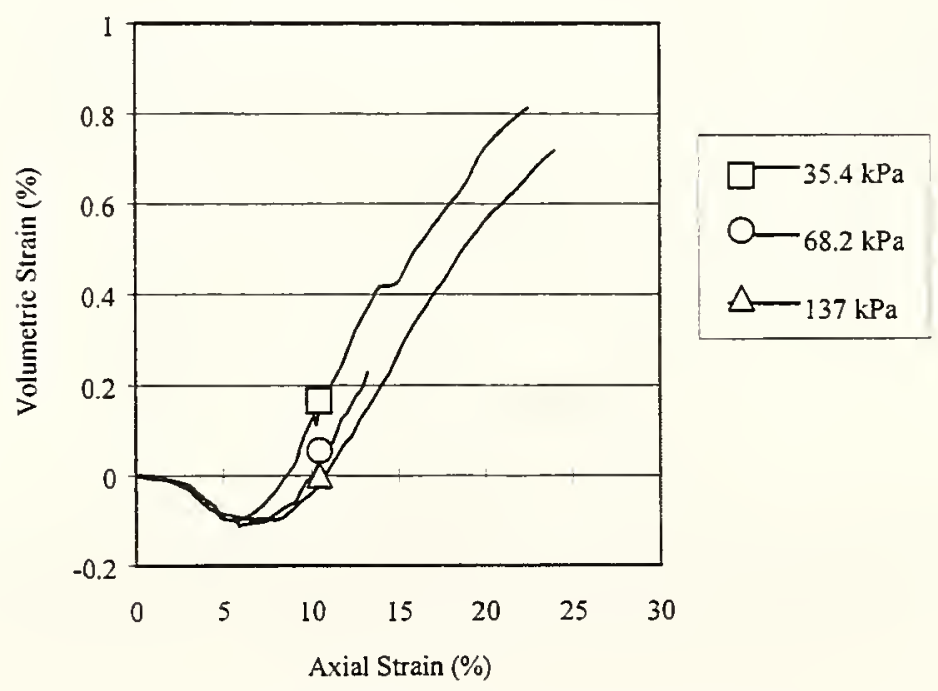

Figure 6.24 Volumetric Strain vs. Axial Strain for the \#53 CD Tests (Figure Legend Denotes Confining Pressure) 


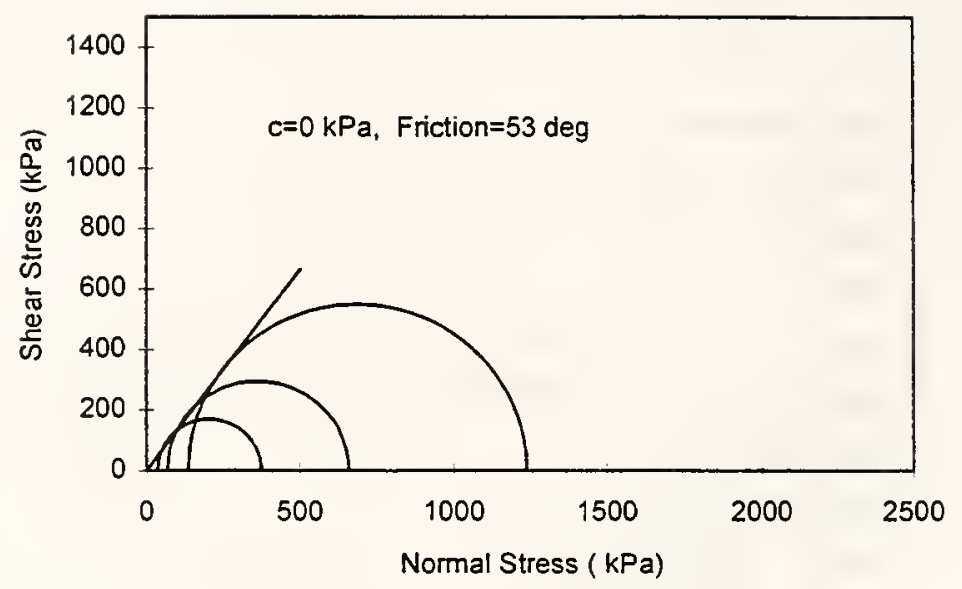

Figure 6.25 Mohr's Circles for the \#53 CD Tests

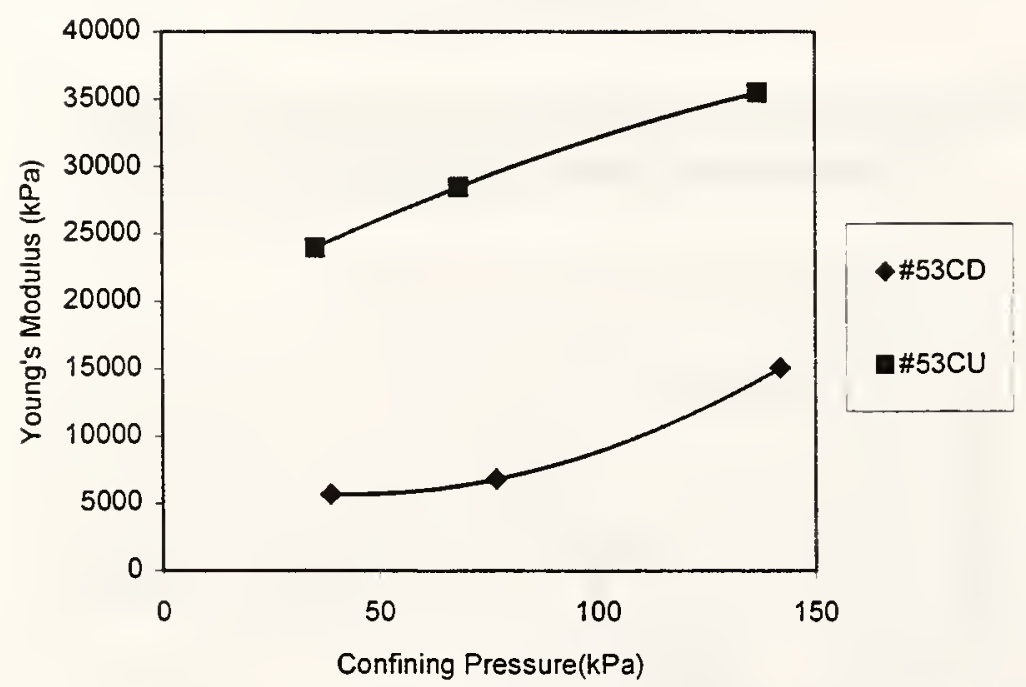

Figure 6.26 Young's Modulus vs. Confining Pressure for the \#53 Tests 


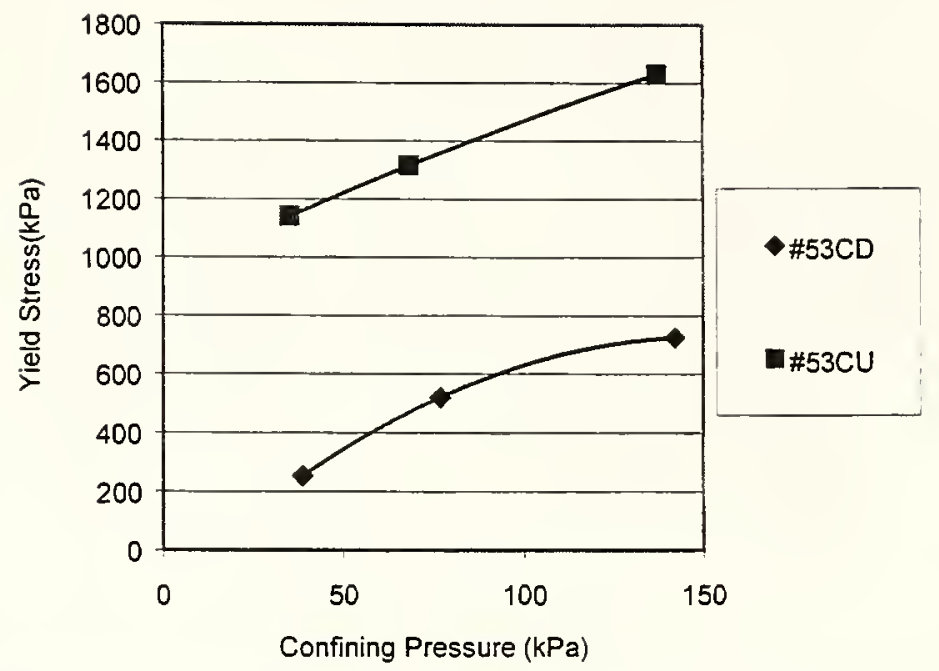

Figure 6.27 Yield Stress vs. Confining Pressure for \#53 Tests

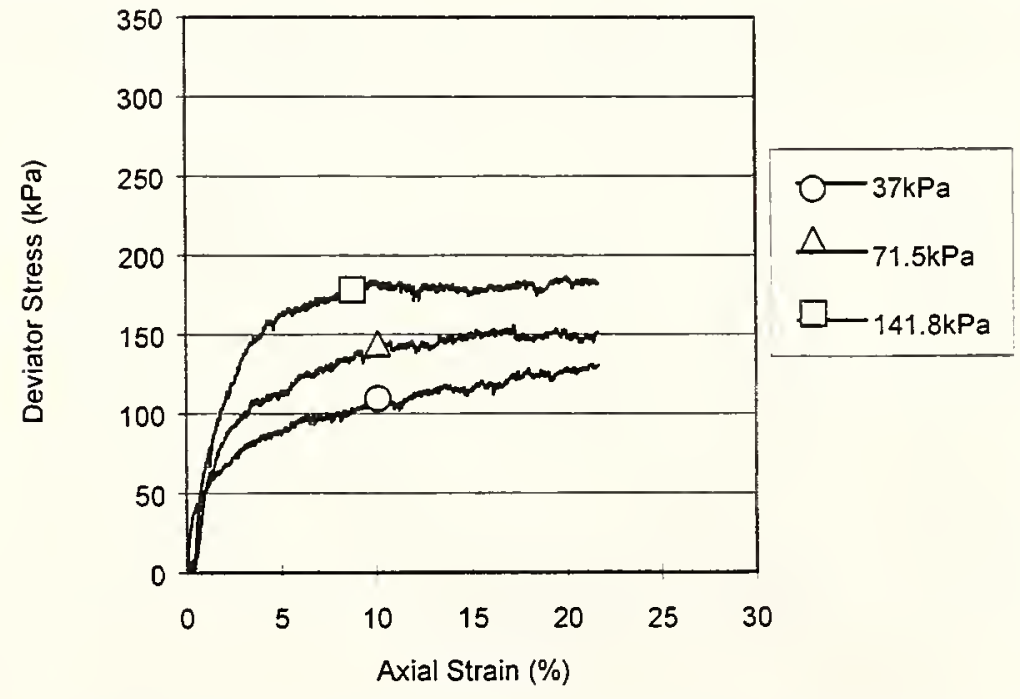

Figure 6.28 Stress-Strain Results for the \#8 Trench Aggregate CU Test (Figure Legend Denotes Confining Pressure) 


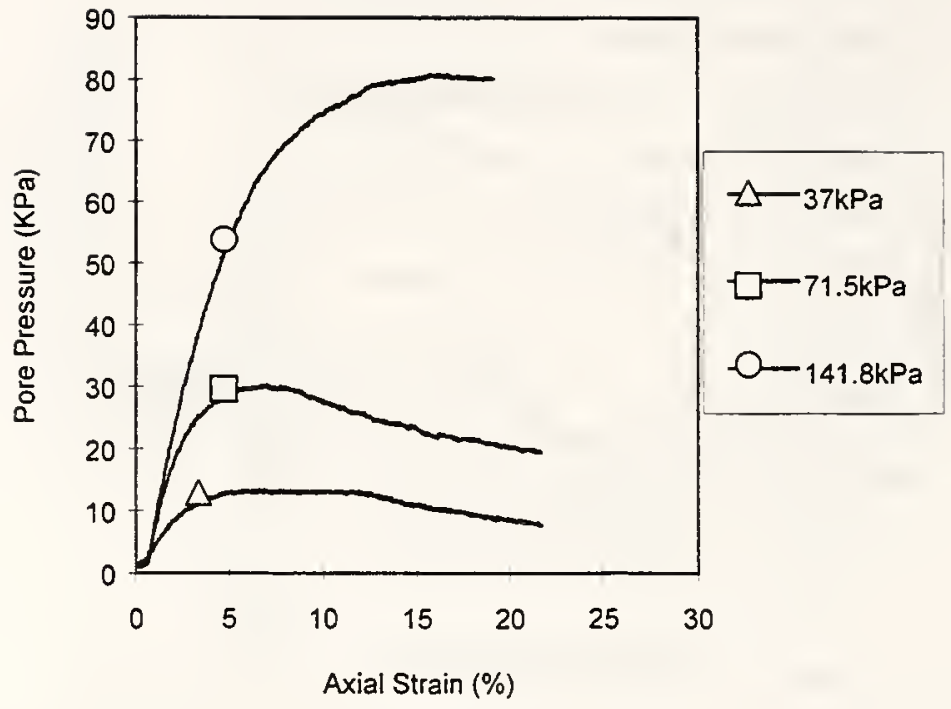

Figure 6.29 Pore Pressure Results for \#8 Trench Aggregate CU Tests (Figure Legend Denotes Confining Pressure)

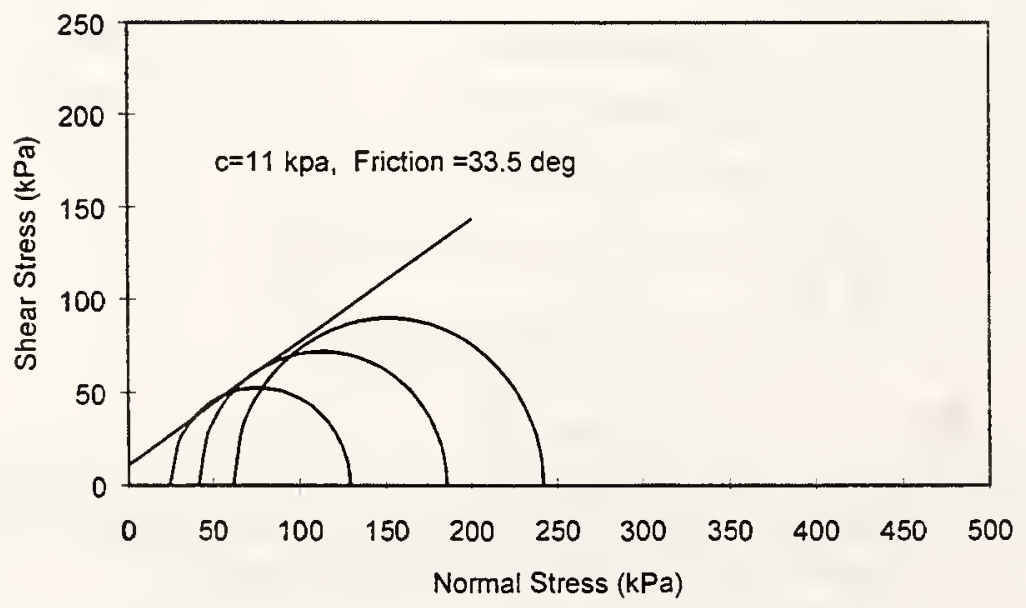

Figure 6.30 Mohr's Circles for \#8 Trench Aggregate CU Tests 


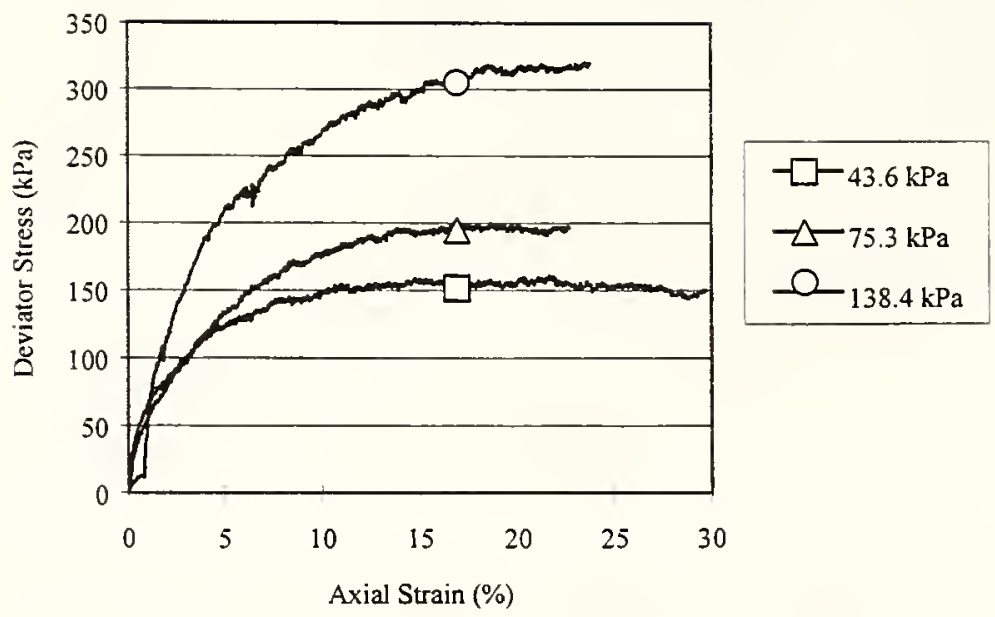

Figure 6.31 Stress-Strain for \#8 Trench Aggregate CD Tests (Figure Legend Denotes Confining Pressure)

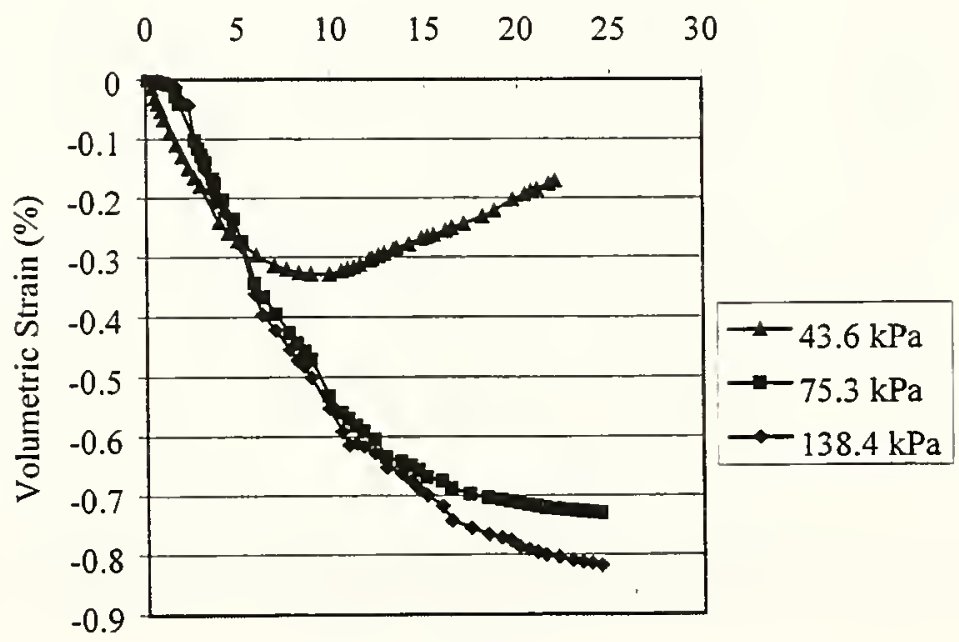

Axial Strain (\%)

Figure 6.32 Volume Change for \#8 Trench Aggregate CD Tests (Figure Legend Denotes Confining Pressure) 


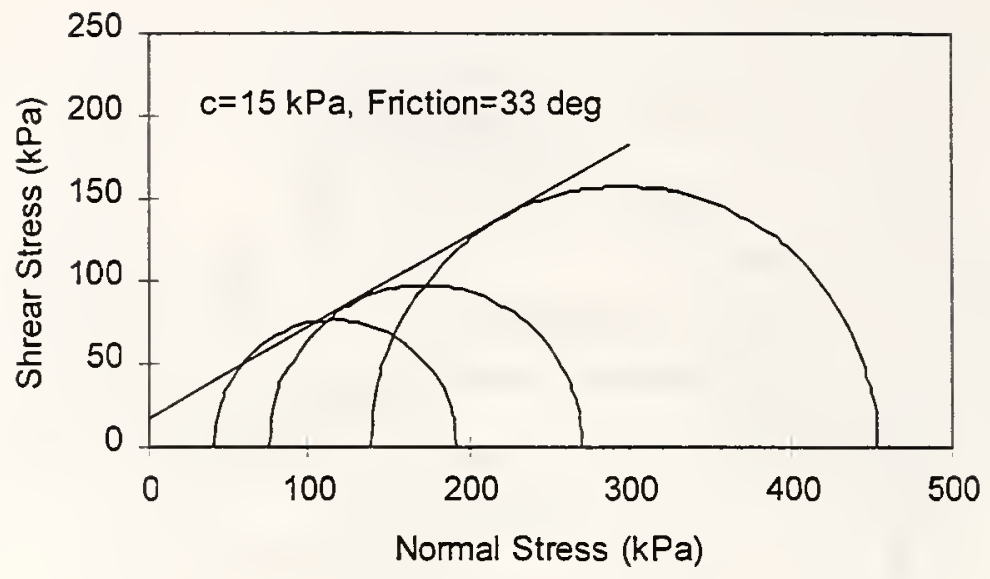

Figure 6.33 Mohr's Circles for \#8 Trench Aggregate CD Tests

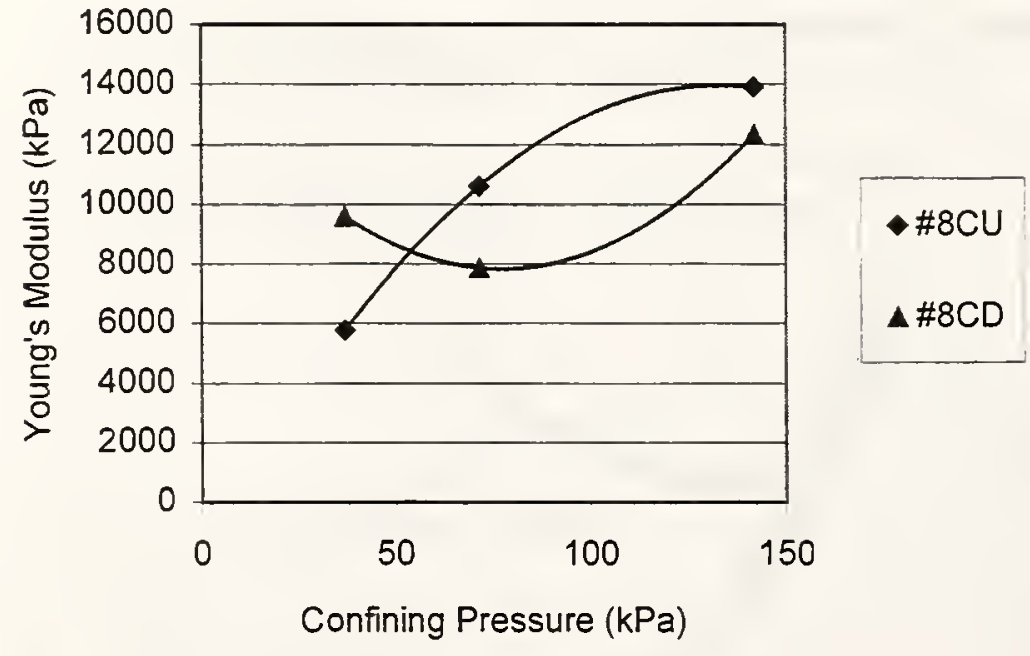

Figure 6.34 Young's Modulus vs. Confining Pressure for \#8 Trench Aggregate 


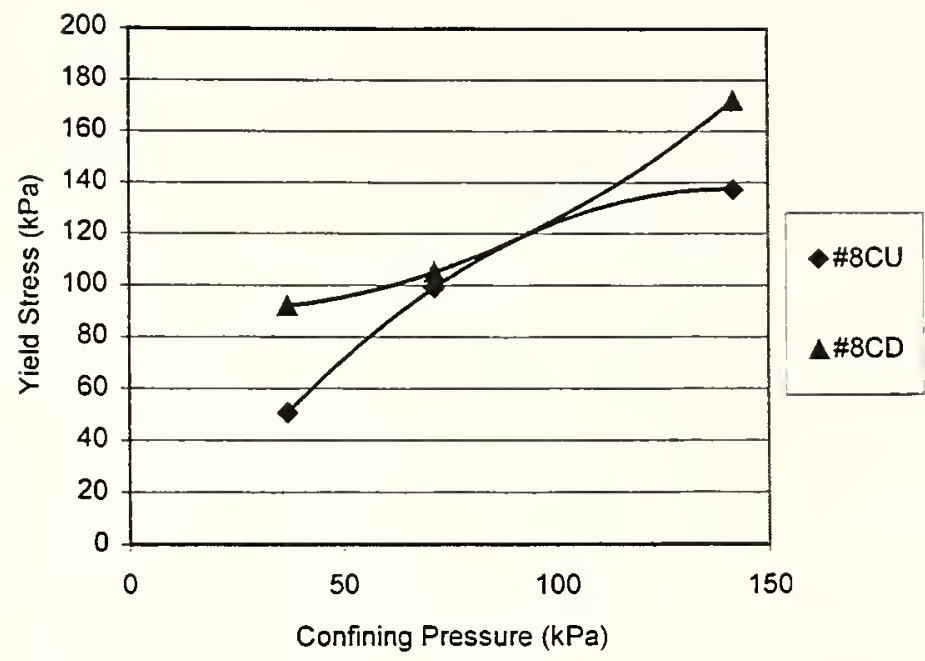

Figure 6.35 Yield Stress vs. Confining Pressure for \#8 Trench Aggregate 


\section{CHAPTER 7 TRIAXIAL TESTS OF ASPHALT MIXTURES}

Triaxial tests were conducted on all asphalt mixtures in the three drainage test sections. Asphalt mixtures included Indiana \#11 surface, \#9 and \#8 binders, \#5C open graded drainage layer, and $\# 5 \mathrm{D}$ and $\# 2$ dense bases. The tests were conducted at the highest recorded seven-day temperature average. This target temperature was selected for its compatibility with Superpave criteria. The confining pressure was selected to bound the expected range of field pavement confining pressures. Consolidated undrained (CU) and dry triaxial tests were conducted on all mixtures at loading speeds of $1.25 \mathrm{~mm} / \mathrm{min}$. and $12.5 \mathrm{~mm} / \mathrm{min}$. The original stress-strain curves, pore pressure change curves for all of the mixtures are presented in Appendix D due to the volume of data. Typically, the exact yield point is difficult to define from the stress strain curve. Therefore, the yield point is taken at the $1 \%$ strain level for the asphalt mixtures. Similarly, Young's modulus is estimated at $0.5 \%$ strain level. Use of the common strain level facilitates comparison of test results for different materials and for the same material tested under different conditions [Holtz and Kovacs, 1981].

The loading capacity of the MTS system at INDOT is $45 \mathrm{kN}$. Due to this limit, sample size, asphalt mixture strength, and maximum confining pressure that could be applied was $140 \mathrm{kPa}$. This test system is designed to use air as the confining medium. The effect of the system load limitation is to restrict the deviator stress and therefore the 
confining pressure of tests on asphalt mixtures. Mohr's circles resulting from these tests are closely spaced. As a result, there is less confidence in the shear strength envelope drawn tangent to these circles. Future research should include use of a higher capacity loading system.

Inspection of the all stress-strain plots indicates the data starts to deviate from a straight line at about the $1 \%$ strain level. Without a distinct yield point, a decision was made to select yield stress at $1 \%$ strain. Similarly, Young's modulus was estimated from a line through zero and a point at $0.5 \%$ strain.

As with the subgrade triaxial tests, there is some concern about the air penetrating the confining membranes. However, there was minimal pore pressure change suggesting that use of air confinement was reasonable.

\subsection{Triaxial Test on \#11 Surface Mixture}

\subsubsection{CU and Dry Tests}

From the plots of the CU tests (Appendix D), the peak in the stress-strain relation for the \#11 surface mixture is not as distinct as in dry test. The \#11 surface mixture exhibits significant high dilation. This is also apparent from the pore pressure curve. The pore pressure increases slightly and then decreases until the specimen fails. The pore pressure increases and then decreases in the $\mathrm{CU}$ test of the \#11 mixture which reflects dense material behavior.

From the plots of the dry tests (Appendix D), there is a distinct peak in the stressstrain relation. The peak for the $12.5 \mathrm{~mm} / \mathrm{min}$. loading is larger than for the $1.25 \mathrm{~mm} / \mathrm{min}$. loading tests. However, the peak becomes less distinct with increasing confining 
pressure. Loading speed has a significant effect on the cohesion but not on the friction angle.

Cohesion increases from $95 \mathrm{kPa}$ to $200 \mathrm{kPa}$ when the loading speed increases from 1.25 to $12.5 \mathrm{~mm} / \mathrm{min}$ in the dry test and increases from $100 \mathrm{kPa}$ to $200 \mathrm{kPa}$ in the wet test. The friction angle in the CU test increases from 41 to 43 degrees when the loading speed is increased from 1.25 to $12.5 \mathrm{~mm} / \mathrm{min}$.

Mohr's circles for the CU tests at 1.25 and $12.5 \mathrm{~mm} / \mathrm{min}$ loadings are shown in Figures 7.1 and 7.2. Figure 7.3 shows the relation of Young's modulus vs. confining pressure, while Figure 7.4 shows the relation of yield stress vs. confining pressure. It is observed that the Young's Modulus and yield stress increase with confining pressure. Results from the CU test for the \#11 surface mixture are summarized in Table 7.1.

Mohr's circles for dry tests of the \#11 surface mixture at loading speeds of 1.25 and $12.5 \mathrm{~mm} / \mathrm{min}$ are shown in Figures 7.5 and 7.6. The Young's modulus and yield stress vs. confining pressure for dry tests are shown in Figures 7.7 and 7.8. Both Young's modulus and yield stress increase with confining pressure and loading speed.

Speed has the same effect on cohesion in the dry test as in CU test. Cohesion increases from $95 \mathrm{kPa}$ to $200 \mathrm{kPa}$ when loading speed increases from $1.25 \mathrm{~mm} / \mathrm{min}$ to $12.5 \mathrm{~mm} / \mathrm{min}$. The friction angle is 40 degrees for both speeds in the dry test. Dry test results for the \#11 surface mixture are summarized in Table 7.2. 
Table 7.1 CU Test Results for \#11 Surface Mixture

\begin{tabular}{|c|c|c|c|c|c|}
\hline \multicolumn{6}{|c|}{ Loading Speed $(\mathrm{mm} / \mathrm{min})$} \\
\hline \multicolumn{3}{|c|}{1.25} & \multicolumn{3}{|c|}{12.5} \\
\hline $\begin{array}{l}\text { Confining } \\
(\mathrm{kPa})\end{array}$ & $\begin{array}{l}\text { Young's } \\
\text { Modulus } \\
(\mathrm{kPa})\end{array}$ & Yield Stress $(\mathrm{kPa})$ & $\begin{array}{c}\text { Confining } \\
\text { Pressure } \\
(\mathrm{kPa}) \\
\end{array}$ & $\begin{array}{l}\text { Young's } \\
\text { Modulus } \\
(\mathrm{kPa})\end{array}$ & Yield Stress $(\mathrm{kPa})$ \\
\hline \multirow[t]{2}{*}{35} & 68299 & 572 & \multirow[t]{2}{*}{35} & 91734 & 855 \\
\hline & 54930 & 472 & & 88911 & 695 \\
\hline \multirow[t]{2}{*}{105} & 94534 & 706 & \multirow[t]{2}{*}{69} & 110283 & 1066 \\
\hline & 101818 & 725 & & 128888 & 1029 \\
\hline \multirow[t]{2}{*}{208} & 124746 & 1024 & \multirow[t]{2}{*}{104} & 135010 & 1167 \\
\hline & 122626 & 984 & & 147304 & 1030 \\
\hline $\begin{array}{c}\text { Cohesion } \\
(\mathrm{kPa})\end{array}$ & & 100 & $\begin{array}{c}\text { Cohesion } \\
(\mathrm{kPa})\end{array}$ & & 200 \\
\hline $\begin{array}{l}\text { Friction } \\
\text { (degree) }\end{array}$ & & 41 & $\begin{array}{l}\text { Friction } \\
\text { (degree) }\end{array}$ & & 41 \\
\hline
\end{tabular}

Table 7.2 Dry Test Results for \#11 Surface Mixture

\begin{tabular}{|c|c|c|c|c|c|}
\hline \multicolumn{6}{|c|}{ Loading Speed $(\mathrm{mm} / \mathrm{min})$} \\
\hline \multicolumn{3}{|c|}{1.25} & \multicolumn{3}{|c|}{12.5} \\
\hline $\begin{array}{c}\text { Confining } \\
(\mathrm{kPa})\end{array}$ & $\begin{array}{l}\text { Young's } \\
\text { Modulus } \\
(\mathrm{kPa})\end{array}$ & $\begin{array}{l}\text { Yield Stress } \\
\quad(\mathrm{kPa})\end{array}$ & $\begin{array}{c}\text { Confining } \\
\text { Pressure } \\
(\mathrm{kPa}) \\
\end{array}$ & $\begin{array}{l}\text { Young's } \\
\text { Modulus } \\
\text { (kPa) }\end{array}$ & Yield Stress (kPa) \\
\hline \multirow[t]{2}{*}{35} & 50485 & 401 & \multirow[t]{2}{*}{35} & 86922 & 703 \\
\hline & 62173 & 448 & & 88330 & 753 \\
\hline \multirow[t]{2}{*}{105} & 64766 & 438 & \multirow[t]{2}{*}{105} & 98783 & 733 \\
\hline & 64770 & 488 & & 110121 & 850 \\
\hline \multirow[t]{2}{*}{208} & 79960 & 648 & \multirow[t]{2}{*}{208} & 169231 & 1227 \\
\hline & 112576 & 799 & & 121616 & 948 \\
\hline $\begin{array}{c}\text { Cohesion } \\
(\mathrm{kPa})\end{array}$ & & & $\begin{array}{c}\text { Cohesion } \\
(\mathrm{kPa})\end{array}$ & & 200 \\
\hline $\begin{array}{l}\text { Friction } \\
\text { (degree) }\end{array}$ & & & $\begin{array}{l}\text { Friction } \\
\text { (degree) }\end{array}$ & & 40 \\
\hline
\end{tabular}




\subsubsection{ANOVA and Regression Analysis}

There appears to be a relation between both Young's modulus and yield stress and confining pressure and loading speed. When confining pressure increases, both yield stress and Young's modulus increase. Also when loading speed increases, Young's modulus and yield stress both increase. Tables 7.3 through 7.6 summarize ANOVA results for the \#11 surface mixture. From the results, the interaction term of speed and confining pressure is not significant for the \#11 surface at the $\alpha=0.05$ level. But the main effects of confining pressure and loading are both significant. In this and subsequent discussions if factors are significant it means that there is a deterministic relation between them. As a result, significant factors can not be ignored in developing predictive relations. If an interaction term is significant then superposition is not valid. Tables 7.7 through 7.10 summarizes the regression analysis results for both $\mathrm{CU}$ and dry tests of the \#11 surface mixture. These regression equations show quantitatively the effect of confining pressure and loading speed.

Table 7.3 ANOVA for \#11 Surface Mixture Young's Modulus in CU Tests

\begin{tabular}{|c|c|c|c|c|c|c|}
\hline Factor & DF & SSE & MSE & F & $\operatorname{Pr}>$ F & R-Square \\
\cline { 1 - 6 } Speed & 1 & 1.01 & 1.01 & 3.23 & 0.1102 & \\
\cline { 1 - 5 } Confining & 1 & 2.43 & 2.43 & 7.77 & 0.0237 & \multirow{2}{*}{0.82} \\
\cline { 1 - 5 } $\begin{array}{c}\text { Speed*Confining } \\
\text { Pressure }\end{array}$ & 1 & 0.353 & 0.353 & 1.13 & 0.3194 & \\
\cline { 1 - 5 } Error & 8 & 2.505 & 0.313 & & & \\
\hline
\end{tabular}


Table 7.4 ANOVA for \#11 Surface Mixture Yield Stress in CU Tests

\begin{tabular}{|c|c|c|c|c|c|c|}
\hline Factor & DF & SSE & MSE & F & $\operatorname{Pr}>$ F & R-Square \\
\hline Speed & 1 & 0.2487 & 0.2487 & 22.23 & 0.0015 & \\
\cline { 1 - 5 } Confining Pressure & 1 & 0.4884 & 0.4884 & 43.66 & 0.0002 & \multirow{2}{*}{0.90} \\
\cline { 1 - 5 } $\begin{array}{c}\text { Speed*Confining } \\
\text { Pressure }\end{array}$ & 1 & 0.05203 & 0.05202 & 4.65 & 0.0631 & \\
\cline { 1 - 5 } Error & 8 & 0.0895 & 0.0112 & & & \\
\hline
\end{tabular}

Table 7.5 ANOVA for \#11 Mixture Surface Young's Modulus in Dry Test

\begin{tabular}{|c|c|c|c|c|c|c|}
\hline Factor & DF & SSE & MSE & F & $\operatorname{Pr}>$ F & R-Square \\
\hline Speed & 1 & 0.596 & 0.596 & 32.36 & 0.0005 & \\
\cline { 1 - 5 } Confining Pressure & 1 & 0.5389 & 0.5389 & 29.26 & 0.0006 & \multirow{2}{*}{0.89} \\
\cline { 1 - 5 } $\begin{array}{c}\text { Speed*Confining } \\
\text { Pressure }\end{array}$ & 1 & 0.00078 & 0.00078 & 0.04 & 0.8418 & \\
\cline { 1 - 5 } Error & 8 & 0.1474 & 0.0184 & & & \\
\hline
\end{tabular}

Table 7.6 ANOVA for \#11 Surface MixtureYield Stress in Dry Test

\begin{tabular}{|c|c|c|c|c|c|c|}
\hline Factor & DF & SSE & MSE & F & $\operatorname{Pr}>$ F & R-Square \\
\hline Speed & 1 & 0.7301 & 0.7301 & 53.63 & 0.0001 & \\
\cline { 1 - 5 } Confining Pressure & 1 & 0.4563 & 0.4563 & 33.51 & 0.0004 & \multirow{2}{*}{0.92} \\
\cline { 1 - 5 } $\begin{array}{c}\text { Speed*Confining } \\
\text { Pressure }\end{array}$ & 1 & 0.0102 & 0.0102 & 0.75 & 0.4117 & \\
\cline { 1 - 5 } Error & 8 & 0.1089 & 0.0136 & & & \\
\hline
\end{tabular}


Table 7.7 Young's Modulus, log (E), Regression Results for \#11 Surface Mixture CU Tests

\begin{tabular}{|c|c|c|c|c|}
\hline Parameter & Estimate & T for $\mathrm{H}_{0}$ & $\operatorname{Pr}>|\mathrm{T}|$ & $\begin{array}{c}\text { Std Err of } \\
\text { Estimate }\end{array}$ \\
\hline Intercept & 10.957 & 22.44 & 0.0001 & 0.4882 \\
\hline Speed & 0.0018 & 0.03 & 0.9742 & 0.055 \\
\hline $\begin{array}{c}\text { Confining } \\
\text { Pressure }\end{array}$ & 0.0034 & 0.94 & 0.3733 & 0.0036 \\
\hline
\end{tabular}

Table 7.8 Yield Stress, log (Y), Regression Results for \#11 Surface Mixture CU Tests

\begin{tabular}{|c|c|c|c|c|}
\hline Parameter & Estimate & $\mathrm{T}$ for $\mathrm{H}_{0}$ & $\operatorname{Pr}>|\mathrm{T}|$ & $\begin{array}{c}\text { Std Err of } \\
\text { Estimate }\end{array}$ \\
\hline Intercept & 6.087 & 65.96 & 0.0001 & 0.0923 \\
\hline Speed & 0.0447 & 4.30 & 0.0026 & 0.010 \\
\hline $\begin{array}{c}\text { Confining } \\
\text { Pressure }\end{array}$ & 0.00399 & 5.85 & 0.0004 & 0.00068 \\
\hline
\end{tabular}

Table 7.9 Young's Modulus, $\log (E)$, Regression Results for \#11 Surface Mixture Dry Tests

\begin{tabular}{|c|c|c|c|c|}
\hline Parameter & Estimate & $\mathrm{T}$ for $\mathrm{H}_{0}$ & $\operatorname{Pr}>|\mathrm{T}|$ & $\begin{array}{c}\text { Std Err of } \\
\text { Estimate }\end{array}$ \\
\hline Intercept & 10.746 & 90.76 & 0.0001 & 0.1184 \\
\hline Speed & 0.042 & 3.15 & 0.0136 & 0.0133 \\
\hline $\begin{array}{c}\text { Confining } \\
\text { Pressure }\end{array}$ & 0.003 & 3.59 & 0.0071 & 0.0088 \\
\hline
\end{tabular}


Table 7.10 Yield Stress, $\log (Y)$, Regression Results for \#11 Surface Mixture Dry Tests

\begin{tabular}{|c|c|c|c|c|}
\hline Parameter & Estimate & $\mathrm{T}$ for $\mathrm{H}_{0}$ & $\mathrm{Pr}>|\mathrm{T}|$ & $\begin{array}{c}\text { Std Err of } \\
\text { Estimate }\end{array}$ \\
\hline Intercept & 5.824 & 57.20 & 0.0001 & 0.1018 \\
\hline Speed & 0.052 & 4.56 & 0.0018 & 0.01146 \\
\hline $\begin{array}{c}\text { Confining } \\
\text { Pressure }\end{array}$ & 0.0033 & 4.34 & 0.0025 & 0.00075 \\
\hline
\end{tabular}

\subsection{Triaxial Test on \# 9 Binder Mixture}

7.2.1 CU Test and Dry Test

As noted above, stress-strain curves for both CU and dry tests for the \#9 binder mixture are presented in appendix D. The pore pressure change curves from the CU test are also shown in appendix D. Mohr's circles for the \#9 binder mixture CU tests at 1.25 and $12.5 \mathrm{~mm} / \mathrm{min}$ are shown in Figures 7.9 and 7.10 , respectively. Figure 7.11 shows the relation of Young's modulus vs. confining pressure, while Figure 7.12 shows the yield stress vs. confining pressure relation. The results are summarized in Table 7.11

The behavior of $\# 9$ binder mixture is similar to that of \#11 surface mixture. There is a peak in the stress-strain relation. The peak is more distinct in the tests of $12.5 \mathrm{~mm} / \mathrm{min}$ than at $1.25 \mathrm{~mm} / \mathrm{min}$ and it becomes less distinct with increase of confining pressure. In the $\mathrm{CU}$ test, the cohesion is increased from $130 \mathrm{kPa}$ to $190 \mathrm{kPa}$ when the speed is increased from 1.25 to $12.5 \mathrm{~mm} / \mathrm{min}$. The friction angle decreases from 42 degrees to 40 degrees. Young's Modulus and yield stress increase with confining pressure. The \#9 binder mixture shows a less distinct peak in the CU test than in the dry test. Pore pressure 
increases slightly and then decreases until failure which indicates the $\# 9$ binder mixture exhibits dense material behavior.

Mohr's circles from the dry tests of the \#9 binder mixture at 1.25 and 12.5 $\mathrm{mm} / \mathrm{min}$ loading speeds are shown in Figures 7.13 and 7.14. Cohesion increases from 120 $\mathrm{kPa}$ to $190 \mathrm{kPa}$ when the loading speed is increased from 1.25 to $12.5 \mathrm{~mm} / \mathrm{min}$. There is no change of friction angle in the dry test at different loading speeds. Figure 7.15 shows the relation of Young's modulus vs. confining pressure, and Figure 7.16 shows the relation of yield stress vs. confining pressure from dry tests. The test results for the \#9 binder mixture in the dry condition are summarized in Table 7.12.

Table 7.11 CU Test Results on \#9 Binder Mixture

\begin{tabular}{|c|c|c|c|c|c|}
\hline \multicolumn{6}{|c|}{ Loading Speed (mm/min) } \\
\hline \multicolumn{3}{|c|}{1.25} & \multicolumn{3}{|c|}{12.5} \\
\hline $\begin{array}{c}\text { Confining } \\
\text { Pressure } \\
(\mathrm{kPa})\end{array}$ & $\begin{array}{l}\text { Young's } \\
\text { Modulus } \\
(\mathrm{kPa})\end{array}$ & $\begin{array}{l}\text { Yield Stress } \\
\qquad(\mathrm{kPa})\end{array}$ & $\begin{array}{c}\text { Confining } \\
\text { Pressure } \\
(\mathrm{kPa})\end{array}$ & $\begin{array}{l}\text { Young's } \\
\text { Modulus } \\
(\mathrm{kPa})\end{array}$ & $\begin{array}{l}\text { Yield Stress } \\
\qquad(\mathrm{kPa})\end{array}$ \\
\hline \multirow[t]{2}{*}{35} & 81855 & 657 & \multirow[t]{2}{*}{35} & 140440 & 1206 \\
\hline & 78266 & 666 & & 142713 & 1140 \\
\hline \multirow[t]{2}{*}{69} & 79675 & 725 & \multirow[t]{2}{*}{69} & 158340 & 1275 \\
\hline & 90970 & 759 & & 161258 & 1369 \\
\hline \multirow[t]{2}{*}{138} & 95335 & 834 & \multirow[t]{2}{*}{138} & 166640 & 1213 \\
\hline & 84413 & 776 & & 181377 & 1417 \\
\hline $\begin{array}{c}\text { Cohesion } \\
(\mathrm{kPa})\end{array}$ & \multicolumn{2}{|c|}{130} & $\begin{array}{c}\text { Cohesion } \\
(\mathrm{kPa})\end{array}$ & \multicolumn{2}{|c|}{190} \\
\hline $\begin{array}{c}\text { Friction } \\
\text { (degree) }\end{array}$ & \multicolumn{2}{|c|}{42} & $\begin{array}{l}\text { Friction } \\
\text { (degree) }\end{array}$ & \multicolumn{2}{|c|}{40} \\
\hline
\end{tabular}


Table 7.12 Dry Test Results on \#9 Binder Mixture

\begin{tabular}{|c|c|c|c|c|c|}
\hline \multicolumn{6}{|c|}{ Loading Speed $(\mathrm{mm} / \mathrm{min})$} \\
\hline \multicolumn{3}{|c|}{1.25} & \multicolumn{3}{|c|}{12.5} \\
\hline $\begin{array}{l}\text { Confining } \\
\text { Pressure } \\
(\mathrm{kPa})\end{array}$ & $\begin{array}{c}\text { Young's } \\
\text { Modulus } \\
(\mathrm{kPa})\end{array}$ & $\begin{array}{l}\text { Yield Stress } \\
\quad(\mathrm{kPa})\end{array}$ & $\begin{array}{c}\text { Confining } \\
\text { Pressure } \\
(\mathrm{kPa})\end{array}$ & $\begin{array}{c}\text { Young's } \\
\text { Modulus } \\
(\mathrm{kPa})\end{array}$ & $\begin{array}{l}\text { Yield Stress } \\
(\mathrm{kPa})\end{array}$ \\
\hline \multirow[t]{2}{*}{35} & 94153 & 571 & \multirow[t]{2}{*}{35} & 96183 & 775 \\
\hline & 70736 & 540 & & 102016 & 782 \\
\hline \multirow[t]{2}{*}{69} & 82485 & 607 & \multirow[t]{2}{*}{69} & 120000 & 914 \\
\hline & 85193 & 611 & & 108283 & 858 \\
\hline \multirow[t]{2}{*}{138} & 117742 & 845 & \multirow[t]{2}{*}{138} & 137742 & 983 \\
\hline & 111111 & 826 & & 126411 & 949 \\
\hline $\begin{array}{c}\text { Cohesion } \\
(\mathrm{kPa})\end{array}$ & \multicolumn{2}{|c|}{120} & $\begin{array}{c}\text { Cohesion } \\
(\mathrm{kPa})\end{array}$ & \multicolumn{2}{|c|}{190} \\
\hline $\begin{array}{c}\text { Friction } \\
\text { (degree) }\end{array}$ & \multicolumn{2}{|c|}{40} & $\begin{array}{l}\text { Friction } \\
\text { (degree) }\end{array}$ & \multicolumn{2}{|c|}{40} \\
\hline
\end{tabular}

\subsubsection{ANOVA and Regression Analysis}

Examination of data from \#9 binder mixture tests indicates that there is a relation between both Young's modulus and yield stress and confining pressure and loading speed. When confining pressure increases, the yield stress and Young's modulus both increases. Yield stress and Young's modulus also increase with increased loading speed. Generally, Young's modulus in the CU test is higher than in the dry test. Table 7.13 through 7.16 show the ANOVA results. It is found that at $\alpha=0.05$ level, the interaction of speed and confining pressure is significant to yield stress in dry tests and Young's modulus in CU tests. Table 7.17 through 7.20 shows the regression analysis results on both dry and wet tests. The interaction of loading speed and confining pressure is not 
significant at $\alpha=0.05$ level. The main effects of confining pressure and loading speed are significant to both Young's modulus and yield stress as shown in the tables.

Table 7.13 ANOVA for \#9 Binder Mixture Young's Modulus in CU Tests

\begin{tabular}{|c|c|c|c|c|c|c|}
\hline Factor & DF & SSE & MSE & F & Pr $>$ F & R-Square \\
\hline Speed & 1 & $1.615 \mathrm{E} 10$ & $1.615 \mathrm{E} 10$ & 399.92 & 0.0001 & \multirow{2}{*}{0.98} \\
\cline { 1 - 5 } Confining Pressure & 1 & $8.376 \mathrm{E} 08$ & $8.376 \mathrm{E} 08$ & 20.74 & 0.0019 & \\
\cline { 1 - 5 } $\begin{array}{c}\text { Speed * Confining } \\
\text { Pressure }\end{array}$ & 1 & $2.382 \mathrm{E} 08$ & $2.382 \mathrm{E} 08$ & 5.90 & 0.0413 & \\
\cline { 1 - 5 } Error & 8 & $3.231 \mathrm{E} 08$ & $4.039 \mathrm{E} 07$ & & & \\
\hline
\end{tabular}

Table 7.14 ANOVA for \#9 Binder Mixture Yield Stress in CU Tests

\begin{tabular}{|c|c|c|c|c|c|c|}
\hline Factor & DF & SSE & MSE & F & $\operatorname{Pr}>$ F & R-Square \\
\cline { 1 - 6 } Speed & 1 & 0.894 & 0.894 & 244.42 & 0.0001 & \\
\cline { 1 - 5 } Confining Pressure & 1 & 0.040 & 0.040 & 10.10 & 0.0130 & \multirow{2}{*}{0.97} \\
\cline { 1 - 5 } $\begin{array}{c}\text { Speed * Confining } \\
\text { Pressure }\end{array}$ & 1 & 0.004 & 0.004 & 1.08 & 0.3286 & \\
\cline { 1 - 5 } Error & 8 & 0.03188 & & & & \\
\hline
\end{tabular}

Table 7.15 ANOVA for \#9 Binder Mixture Young's Modulus in Dry Tests

\begin{tabular}{|c|c|c|c|c|c|c|}
\hline Factor & DF & SSE & MSE & F & $\operatorname{Pr}>$ F & R-Square \\
\hline Speed & 1 & $1.391 \mathrm{E} 09$ & $1.391 \mathrm{E} 09$ & 19.20 & 0.0023 & \multirow{2}{*}{0.86} \\
\cline { 1 - 5 } Confining Pressure & 1 & $2.26 \mathrm{E} 09$ & $2.26 \mathrm{E} 09$ & 31.26 & 0.0005 & \\
\cline { 1 - 5 } $\begin{array}{c}\text { Speed * Confining } \\
\text { Pressure }\end{array}$ & 1 & $1.895 \mathrm{E} 06$ & $1.895 \mathrm{E} 06$ & 0.03 & 0.8755 & \\
\cline { 1 - 5 } Error & 8 & $5.797 \mathrm{E} 08$ & $7.24 \mathrm{E} 07$ & & & \\
\hline
\end{tabular}


Table 7.16 ANOVA for \#9 Binder Mixture Yield Stress in Dry Tests

\begin{tabular}{|c|c|c|c|c|c|c|}
\hline Factor & DF & SSE & MSE & F & $\operatorname{Pr}>$ F & R-Square \\
\cline { 1 - 6 } Speed & 1 & 132510 & 132510 & 142.19 & 0.0001 & \multirow{2}{*}{0.97} \\
\cline { 1 - 5 } Confining Pressure & 1 & 112777 & 112777 & 121.01 & 0.0001 & \\
\cline { 1 - 5 } $\begin{array}{c}\text { Speed*Confining } \\
\text { Pressure }\end{array}$ & 1 & 6390 & 6390 & 6.86 & 0.0307 & \\
\cline { 1 - 5 } Error & 8 & 7455.6 & 931.95 & & \\
\hline
\end{tabular}

Table 7.17 Young's Modulus, E, Regression Results for \#9 Binder Mixture CU Tests

\begin{tabular}{|c|c|c|c|c|}
\hline Parameter & Estimate & $\mathrm{T}$ for $\mathrm{H}_{0}$ & $\operatorname{Pr}>|\mathrm{T}|$ & $\begin{array}{c}\text { Std Err of } \\
\text { Estimate }\end{array}$ \\
\hline Intercept & 71456.7 & 11.57 & 0.0001 & 6175.5 \\
\hline Speed & 5031.1 & 7.24 & 0.0001 & 695.2 \\
\hline Confining Pressure & 67.9 & 1.00 & 0.3447 & 67.6 \\
\hline $\begin{array}{c}\text { Speed*Confining } \\
\text { Pressure }\end{array}$ & 18.5 & 2.43 & 0.0413 & 7.6 \\
\hline
\end{tabular}

Table 7.18 Yield Stress, Y, Regression Results for \#9 Binder Mixture CU Tests

\begin{tabular}{|c|c|c|c|c|}
\hline Parameter & Estimate & $\mathrm{T}$ for $\mathrm{H}_{0}$ & $\operatorname{Pr}>|\mathrm{T}|$ & $\begin{array}{c}\text { Std Err of } \\
\text { Estimate }\end{array}$ \\
\hline lntercept & 6.4 & 104.1 & 0.0001 & 0.06 \\
\hline Speed & 0.05 & 7.95 & 0.0001 & 0.007 \\
\hline $\begin{array}{c}\text { Confining } \\
\text { Pressure }\end{array}$ & 0.002 & 2.82 & 0.0226 & 0.0007 \\
\hline
\end{tabular}


Table 7.19 Young's Modulus, E, Modulus Regression Results for \#9 Binder Mixture Dry Tests

\begin{tabular}{|c|c|c|c|c|}
\hline Parameter & Estimate & $\mathrm{T}$ for $\mathrm{H}_{0}$ & $\operatorname{Pr}>|\mathrm{T}|$ & $\begin{array}{c}\text { Std Err of } \\
\text { Estimate }\end{array}$ \\
\hline Intercept & 64398.1 & 7.79 & 0.0001 & 8271.6 \\
\hline Speed & 2047.3 & 2.20 & 0.0591 & 931.2 \\
\hline $\begin{array}{c}\text { Confining } \\
\text { Pressure }\end{array}$ & 331.97 & 3.67 & 0.0063 & 90.6 \\
\hline
\end{tabular}

Table 7.20 Yield Stress, Y, Regression Results for \#9 Binder Mixture Dry Tests

\begin{tabular}{|c|c|c|c|c|}
\hline Parameter & Estimate & $\mathrm{T}$ for $\mathrm{H}_{0}$ & $\operatorname{Pr}>|\mathrm{T}|$ & $\begin{array}{c}\text { Std Err of } \\
\text { Estimate }\end{array}$ \\
\hline Intercept & 407.7 & 13.74 & 0.0001 & 29.7 \\
\hline Speed & 26.4 & 7.91 & 0.0001 & 3.34 \\
\hline Confining Pressure & 2.9 & 8.99 & 0.0001 & 0.04 \\
\hline $\begin{array}{c}\text { Speed } \\
\text { Confining Presure* }\end{array}$ & -0.096 & -2.62 & 0.031 & 0.037 \\
\hline
\end{tabular}

\subsection{Triaxial Test on \#8 Binder}

\subsubsection{CU and Dry Test}

Stress-strain curves for both dry and wet tests of the \#8 asphalt mixture are shown in Appendix D. The pore pressure curves in the wet test are also shown in Appendix D. Figures 7.17 and 7.18 show Mohr's circles of the $1.25 \mathrm{~mm} / \mathrm{min}$ and $12.5 \mathrm{~mm} / \mathrm{min} \mathrm{CU}$ tests. Figure 7.19 shows Young's modulus vs. confining pressure and Figure 7.20 shows yield stress vs. confining stress for the $\mathrm{CU}$ test of the \#8 binder mixture. The behavior of 
\#8 binder mixture is similar to that of the \#11 surface mixture and the \#9 binder mixture. There is a distinct peak in the stress-strain relation and the peak is higher for tests with a loading speed of $12.5 \mathrm{~mm} / \mathrm{min}$ than for $1.25 \mathrm{~mm} / \mathrm{min}$. The peak becomes less distinct with increasing confining pressure. The loading speed in the $\mathrm{CU}$ test the cohesion. Cohesion increases from $90 \mathrm{kPa}$ to $150 \mathrm{kPa}$ when the loading speed is increased from 1.25 to $12.5 \mathrm{~mm} / \mathrm{min}$. The friction angle decreases from 41 degrees to 40 degrees when the speed increases from 1.25 to $12.5 \mathrm{~mm} / \mathrm{min}$. The CU test results for the $\# 8$ binder are summarized in Table 7.21 .

Young's Modulus and yield stress increase with both confining pressure and loading speed. Pore pressure increases slightly and then decreases until the sample fails. This is the result of the material contracting and then dilating until failure. Young's modulus in CU test is higher than in the dry test.

Table 7.21 CU Test Results on \#8 Binder Mixture

\begin{tabular}{|c|c|c|c|c|c|}
\hline \multicolumn{6}{|c|}{ Loading Speed $(\mathrm{mm} / \mathrm{min})$} \\
\hline \multicolumn{3}{|c|}{1.25} & \multicolumn{3}{|c|}{12.5} \\
\hline $\begin{array}{c}\text { Confining } \\
\text { Pressure } \\
(\mathrm{kPa})\end{array}$ & $\begin{array}{c}\text { Young's } \\
\text { Modulus } \\
(\mathrm{kPa})\end{array}$ & $\begin{array}{l}\text { Yield Stress } \\
\qquad(\mathrm{kPa})\end{array}$ & $\begin{array}{c}\text { Confining } \\
\text { Pressure } \\
(\mathrm{kPa})\end{array}$ & $\begin{array}{c}\text { Young's } \\
\text { Modulus } \\
(\mathrm{kPa})\end{array}$ & $\begin{array}{l}\text { Yield Stress } \\
\qquad(\mathrm{kPa})\end{array}$ \\
\hline \multirow[t]{2}{*}{35} & 76923 & 609 & \multirow[t]{2}{*}{35} & 102424 & 798 \\
\hline & 76875 & 626 & & 92137 & 780 \\
\hline \multirow[t]{2}{*}{69} & 81884 & 614 & \multirow[t]{2}{*}{69} & 99189 & 814 \\
\hline & 85657 & 718 & & 124346 & 991 \\
\hline \multirow[t]{2}{*}{104} & 91532 & 682 & \multirow[t]{2}{*}{104} & 107692 & 808 \\
\hline & 83480 & 763 & & 135282 & 1058 \\
\hline $\begin{array}{c}\text { Cohesion } \\
(\mathrm{kPa})\end{array}$ & \multicolumn{2}{|c|}{90} & $\begin{array}{c}\text { Cohesion } \\
(\mathrm{kPa})\end{array}$ & \multicolumn{2}{|c|}{150} \\
\hline $\begin{array}{r}\text { Friction } \\
\text { (degree) }\end{array}$ & \multicolumn{2}{|c|}{41} & $\begin{array}{l}\text { Friction } \\
\text { (degree) }\end{array}$ & \multicolumn{2}{|c|}{40} \\
\hline
\end{tabular}


Figures 7.21 and 7.22, respectively, show Mohr's circles for the \#8 binder mixture for loading speeds of 1.25 and $12.5 \mathrm{~mm} / \mathrm{min}$. Cohesion increases from $80 \mathrm{kPa}$ to $180 \mathrm{kPa}$ as the speed increases from 1.25 to $12.5 \mathrm{~mm} / \mathrm{min}$. The friction angle is 40 degrees for both speeds. Young's modulus vs. confining pressure and yield stress vs. confining pressure are shown in Figures 7.23 and 7.24 , respectively. Yield stress and Young's modulus both increase with increased confining pressure and speed. The dry test results for the \#8 binder mixture are summarized in Table 7.22. The \#8 binder mixture also exhibits dense material behavior in that material contracts slightly and then dilates to failure.

Table 7.22 Dry Test Results on \#8 Binder

\begin{tabular}{|c|c|c|c|c|c|}
\hline \multicolumn{6}{|c|}{ Loading Speed $(\mathrm{mm} / \mathrm{min})$} \\
\hline \multicolumn{3}{|c|}{1.25} & \multicolumn{3}{|c|}{12.5} \\
\hline $\begin{array}{c}\text { Confining } \\
\text { Pressure } \\
(\mathrm{kPa}) \\
\end{array}$ & $\begin{array}{c}\text { Young's } \\
\text { Modulus } \\
(\mathrm{kPa})\end{array}$ & $\begin{array}{l}\text { Yield Stress } \\
\qquad(\mathrm{kPa})\end{array}$ & $\begin{array}{c}\text { Confining } \\
\text { Pressure } \\
(\mathrm{kPa}) \\
\end{array}$ & $\begin{array}{c}\text { Young's } \\
\text { Modulus } \\
(\mathrm{kPa})\end{array}$ & $\begin{array}{l}\text { Yield Stress } \\
\qquad(\mathrm{kPa})\end{array}$ \\
\hline \multirow[t]{2}{*}{35} & 64505 & 427 & \multirow[t]{2}{*}{35} & 84274 & 666 \\
\hline & 57304 & 423 & & 83030 & 691 \\
\hline \multirow[t]{2}{*}{69} & 69258 & 473 & \multirow[t]{2}{*}{69} & 111201 & 832 \\
\hline & 71864 & 459 & & 111538 & 841 \\
\hline \multirow[t]{2}{*}{138} & 73537 & 571 & \multirow[t]{2}{*}{138} & 130792 & 960 \\
\hline & 78675 & 552 & & 111024 & 924 \\
\hline $\begin{array}{c}\text { Cohesion } \\
(\mathrm{kPa})\end{array}$ & \multicolumn{2}{|c|}{80} & $\begin{array}{c}\text { Cohesion } \\
(\mathrm{kPa})\end{array}$ & \multicolumn{2}{|c|}{180} \\
\hline $\begin{array}{c}\text { Friction } \\
\text { (degree) }\end{array}$ & \multicolumn{2}{|c|}{40} & $\begin{array}{l}\text { Friction } \\
\text { (degree) }\end{array}$ & \multicolumn{2}{|c|}{40} \\
\hline
\end{tabular}




\subsubsection{ANOVA and Regression Analysis}

The \#8 binder mixture shows similar results to those of the other asphalt mixtures. Young's modulus and yield stress increase with increasing confining pressure. Also Young's modulus and yield stress increase with loading speed. Generally, Young's modulus in the $\mathrm{CU}$ test is higher than in the dry test. Tables 7.23 through 7.26 show the ANOVA results. It is found that at the $\alpha=0.05$ level, the interaction of speed and confining pressure is not significant. This means the effects of loading speed and confining pressure can not be superimposed. Tables 7.27 through 30 show the regression analysis results on both dry and CU tests. These relations can be used to estimate Young's Modulus and yield stress. The main effects of confining pressure and loading speed is significant to both Young's modulus and yield stress.

Table 7.23 ANOVA for \#8 Binder Mixture Young's Modulus in CU Test

\begin{tabular}{|c|c|c|c|c|c|c|c|}
\hline & Factor & DF & SSE & MSE & $\mathrm{F}$ & $\operatorname{Pr}>F$ & R-Square \\
\hline \multirow{2}{*}{$\begin{array}{c}1.25 \\
\mathrm{~mm} / \mathrm{min} \text {. }\end{array}$} & Model & 1 & 6.21 & 6.21 & 14.87 & 0.018 & \multirow[t]{2}{*}{0.79} \\
\hline & Error & 4 & 1.67 & 0.417 & & & \\
\hline \multirow{2}{*}{$\begin{array}{c}12.5 \\
\mathrm{~mm} / \mathrm{min}\end{array}$} & Model & 1 & 0.065 & 0.065 & 36.87 & 0.004 & \multirow[t]{2}{*}{0.92} \\
\hline & Error & 4 & 0.007 & 0.002 & & & \\
\hline
\end{tabular}

Table 7.24 ANOVA for \#8 Binder Mixture Yield Stress in CU Test

\begin{tabular}{|c|c|c|c|c|c|c|}
\hline Factor & DF & SSE & MSE & F & $\operatorname{Pr}>$ F & R-Square \\
\hline Speed & 1 & 0.211 & 0.0098 & 21.51 & 0.0017 & \\
\hline $\begin{array}{c}\text { Confining } \\
\text { Pressure }\end{array}$ & 1 & 0.049 & 0.211 & 5.02 & 0.0554 & 0.77 \\
\cline { 1 - 5 } $\begin{array}{c}\text { Speed*Confining } \\
\text { Pressure }\end{array}$ & 1 & 0.000003 & 0.049 & 0.00 & 0.9859 & \\
\cline { 1 - 4 } Error & 8 & 0.078 & 0.000003 & & & \\
\hline
\end{tabular}


Table 7.25 ANOVA for \#8 Binder Mixture Young's Modulus in Dry Tests

\begin{tabular}{|c|c|c|c|c|c|c|}
\hline Factor & DF & SSE & MSE & F & $\operatorname{Pr}>$ F & R-Square \\
\hline Speed & 1 & 0.509 & 0.509 & 61.74 & 0.0001 & \\
\cline { 1 - 5 } Confining Pressure & 1 & 0.149 & 0.149 & 18.13 & 0.0028 & \multirow{2}{*}{0.91} \\
\cline { 1 - 5 } $\begin{array}{c}\text { Speed }{ }^{*} \text { Confining } \\
\text { Pressure }\end{array}$ & 1 & 0.007 & 0.007 & 0.93 & 0.3643 & \\
\cline { 1 - 5 } Error & 8 & 0.066 & 0.008 & & & \\
\hline
\end{tabular}

Table 7.26 ANOVA for \#8 Binder Mixture Yield Stress in Dry Tests

\begin{tabular}{|c|c|c|c|c|c|c|}
\hline Factor & DF & SSE & MSE & F & $\operatorname{Pr}>$ F & R-Square \\
\hline Speed & 1 & 0.822 & 0.822 & 419.22 & 0.0001 & \multirow{2}{*}{0.98} \\
\cline { 1 - 5 } Confining Pressure & 1 & 0.177 & 0.177 & 90.47 & 0.0001 & \\
\cline { 1 - 5 } $\begin{array}{c}\text { Speed*Confining } \\
\text { Pressure }\end{array}$ & 1 & 0.0004 & 0.0004 & 0.20 & 0.6645 & \\
\cline { 1 - 5 } Error & 8 & 0.0157 & 0.002 & & \\
\hline
\end{tabular}

Table 7.27 Young's Modulus, $\log (\mathrm{E})$, Regression Results for \#8 Binder Mixture CU Tests

\begin{tabular}{|c|c|c|c|c|c|}
\hline & Parameter & Estimate & $\mathrm{T}$ for $\mathrm{H}_{0}$ & $\operatorname{Pr}>|\mathrm{T}|$ & $\begin{array}{c}\text { Std Error of } \\
\text { Estimate }\end{array}$ \\
\hline \multirow{2}{*}{$1.25 \mathrm{~mm} / \mathrm{min}$} & Intercept & 9.61 & 13.72 & 0.0002 & 0.701 \\
\cline { 2 - 6 } & $\begin{array}{c}\text { Confining } \\
\text { Pressure }\end{array}$ & 0.036 & 3.86 & 0.0182 & 0.009 \\
\hline $12.5 \mathrm{~mm} / \mathrm{min}$ & Intercept & 11.46 & 252.1 & 0.0001 & 0.0455 \\
\cline { 2 - 6 } & $\begin{array}{c}\text { Confining } \\
\text { Pressure }\end{array}$ & 0.004 & 6.07 & 0.0037 & 0.0006 \\
\hline
\end{tabular}


Table 7.28 Yield Stress, $\log (\mathrm{Y})$, Regression Results for \#9 Binder Mixture CU Tests

\begin{tabular}{|c|c|c|c|c|}
\hline Parameter & Estimate & $\mathrm{T}$ for $\mathrm{H}_{0}$ & $\operatorname{Pr}>|\mathrm{T}|$ & $\begin{array}{c}\text { Std Err of } \\
\text { Estimate }\end{array}$ \\
\hline Intercept & 6.316 & 52.67 & 0.0001 & 0.1199 \\
\hline Speed & 0.023 & 1.73 & 0.1221 & 0.0134 \\
\hline $\begin{array}{c}\text { Confining } \\
\text { Pressure }\end{array}$ & 0.0002 & 1.40 & 0.1977 & 0.0016 \\
\hline
\end{tabular}

Table 7.29 Young's Modulus, $\log (E)$, Regression Results for \#8 Binder Mixture Dry Tests

\begin{tabular}{|c|c|c|c|c|}
\hline Parameter & Estimate & $\mathrm{T}$ for $\mathrm{H}_{0}$ & $\operatorname{Pr}>|\mathrm{T}|$ & $\begin{array}{c}\text { Std Err of } \\
\text { Estimate }\end{array}$ \\
\hline Intercept & 10.9 & 124.01 & 0.0001 & 0.088 \\
\hline Speed & 0.03 & 2.84 & 0.0219 & 0.0099 \\
\hline $\begin{array}{c}\text { Confining } \\
\text { Pressure }\end{array}$ & 0.002 & 1.95 & 0.0867 & 0.00097 \\
\hline
\end{tabular}

Table 7.30 Yield Stress, $\log (Y)$, Regression Results for \#8 Binder Mixture Dry Tests

\begin{tabular}{|c|c|c|c|c|}
\hline Parameter & Estimate & $\mathrm{T}$ for $\mathrm{H}_{0}$ & $\mathrm{Pr}>|\mathrm{T}|$ & $\begin{array}{c}\text { Std Err of } \\
\text { Estimate }\end{array}$ \\
\hline Intercept & 5.90 & 137.18 & 0.0001 & 0.043 \\
\hline Speed & 0.045 & 9.21 & 0.0001 & 0.0048 \\
\hline $\begin{array}{c}\text { Confining } \\
\text { Pressure }\end{array}$ & 0.003 & 5.67 & 0.0005 & 0.0004 \\
\hline
\end{tabular}




\subsection{Triaxial Tests on 5C Open-Graded Mixture}

\section{$\underline{\text { 7.4.1 CU and Dry Tests }}$}

The stress-strain curves of the $\# 5 \mathrm{C}$ open-graded (OG) mixtures for both dry and wet conditions are presented in Appendix D. Pore pressure data are also shown in Appenddix D. Mohr's circles for the \#5C OG Mixture in the CU test at loading speed of $1.25 \mathrm{~mm} / \mathrm{min}$ and $12.5 \mathrm{~mm} / \mathrm{min}$ are shown in Figures 7.25 and 7.26 , respectively. Figure 7.27 shows Young's modulus vs. confining pressure and Figure 7.28 shows the yield stress vs. confining pressure. There is a distinct peak in the stress-strain relation at a loading speed of $12.5 \mathrm{~mm} / \mathrm{min}$. The peak is much less distinct at the $1.25 \mathrm{~mm} / \mathrm{min}$ loading speed. Cohesion is increased from $85 \mathrm{kPa}$ to $120 \mathrm{kPa}$ when the loading speed is increased from 1.25 to $12.5 \mathrm{~mm} / \mathrm{min}$. The friction angle decreases from 41 to 40 degrees when the loading speed increases from 1.25 to $12.5 \mathrm{~mm} / \mathrm{min}$. The CU test results are summarized in Table 7.31

Table 7.31 CU Test Results on \#5C OG Mixture

\begin{tabular}{|c|c|c|c|c|c|}
\hline \multicolumn{6}{|c|}{ Loading Speed $(\mathrm{mm} / \mathrm{min})$} \\
\hline \multicolumn{3}{|c|}{1.25} & \multicolumn{3}{|c|}{12.5} \\
\hline $\begin{array}{c}\text { Confining } \\
\text { Pressure }(\mathrm{kPa})\end{array}$ & $\begin{array}{c}\text { Young's } \\
\text { Modulus (kPa) }\end{array}$ & $\begin{array}{l}\text { Yield Stress } \\
\quad(\mathrm{kPa})\end{array}$ & $\begin{array}{c}\text { Confining } \\
\text { Pressure }(\mathrm{kPa})\end{array}$ & $\begin{array}{c}\text { Young's } \\
\text { Modulus (kPa) }\end{array}$ & $\begin{array}{l}\text { Yield Stress } \\
\quad(\mathrm{kPa})\end{array}$ \\
\hline 35 & 87000 & 586 & \multirow{2}{*}{$\begin{array}{l}35 \\
35\end{array}$} & 141391 & 909 \\
\hline 35 & 86106 & 569 & & 148790 & 898 \\
\hline 69 & 118000 & 755 & \multirow{2}{*}{$\begin{array}{l}69 \\
69\end{array}$} & 161390 & 989 \\
\hline 69 & 111111 & 722 & & 158406 & 1020 \\
\hline 138 & 25296 & 802 & \multirow{2}{*}{$\begin{array}{l}138 \\
138\end{array}$} & 176305 & 1088 \\
\hline 138 & 121210 & 795 & & 180112 & 1069 \\
\hline Cohesion $(\mathrm{kPa})$ & \multicolumn{2}{|c|}{85} & Cohesion $(\mathrm{kPa})$ & \multicolumn{2}{|c|}{120} \\
\hline $\begin{array}{l}\text { Friction } \\
\text { (degree) }\end{array}$ & \multicolumn{2}{|c|}{41} & $\begin{array}{l}\text { Friction } \\
\text { (degree) }\end{array}$ & \multicolumn{2}{|c|}{40} \\
\hline
\end{tabular}


The Young's modulus and yield stress also increase with increased confining pressure. Although the $\# 5 \mathrm{C}$ mixture is an open-graded material, it still exhibits dense material behavior in that the pore pressure increases during test and then decreases.

The dry test results are summarized in Table 7.32. Figure 7.29 and 7.30, respectively, show the \#5C OG mixture Mohr's circles for 1.25 and $12.5 \mathrm{~mm} / \mathrm{min}$ loading speeds. In the dry tests the friction angle increases from 40 to 41 degrees and the cohesion increases from $85 \mathrm{kPa}$ to $130 \mathrm{kPa}$ when the speed increases from 1.25 to 12.5 $\mathrm{mm} / \mathrm{min}$.

Table 7.32 Dry Test Results on \#5C OG Mixture

\begin{tabular}{|c|c|c|c|c|c|}
\hline \multicolumn{3}{|c|}{$1.25 \mathrm{~mm} / \mathrm{min}$} & \multicolumn{3}{c|}{$12.5 \mathrm{~mm} / \mathrm{min}$} \\
\hline $\begin{array}{c}\text { Confining } \\
\text { Pressure } \\
(\mathrm{kPa})\end{array}$ & $\begin{array}{c}\text { Young's } \\
\text { Modulus } \\
(\mathrm{kPa})\end{array}$ & $\begin{array}{c}\text { Yield Stress } \\
(\mathrm{kPa})\end{array}$ & $\begin{array}{c}\text { Confining } \\
\text { Pressure } \\
(\mathrm{kPa})\end{array}$ & $\begin{array}{c}\text { Young's } \\
\text { Modulus } \\
(\mathrm{kPa})\end{array}$ & $\begin{array}{c}\text { Yield Stress } \\
(\mathrm{kPa})\end{array}$ \\
\hline 35 & 62080 & 416.9 & 35 & 112160 & 676.9 \\
\hline 35 & 64560 & 418.7 & 35 & 102160 & 674.5 \\
\hline 69 & 82760 & 542 & 69 & 119800 & 783.6 \\
\hline 69 & 78528 & 517 & 69 & 122177 & 832 \\
\hline 138 & 115808 & 745 & 138 & 149000 & 990 \\
\hline 138 & 113313 & 771.9 & 138 & 146151 & 1054 \\
\hline $\begin{array}{c}\text { Cohesion } \\
(\mathrm{kPa})\end{array}$ & & 85 & Cohesion & & 130 \\
\hline $\begin{array}{c}\text { Friction } \\
(\text { degree })\end{array}$ & & 40 & $\begin{array}{c}\text { Friction } \\
(\text { degree })\end{array}$ & & 41 \\
\hline
\end{tabular}


The Young's modulus vs. confining pressure relation is shown in Figure 7.31 for the \#5C OG mixture dry test. Yield stress vs. confining pressure is shown in Figure 7.32. The relation is similar to those for the other asphalt mixtures.

\subsubsection{ANOVA and Regression Analysis}

The $\# 5 \mathrm{C} \mathrm{OG}$ mixture test data also shows that there is a relation between Young's modulus and yield stress and confining pressure and loading speed. Young's modulus and yield stress increase with increasing confining pressure. Young's modulus and yield stress also increase with loading speed. Generally, Young's modulus in the CU test is higher than in the dry test. Tables 7.33 through 7.36 show the ANOVA results for these factors. Tables 7.37 through 7.40 show the regression analysis results for both dry and wet tests. The confining pressure is significant at the $\alpha=0.05$ level to Young's modulus and both confining pressure and loading speed is significant to the yield stress in the CU test. At the $\alpha=0.05$ level, confining pressure and loading speed are significant to both Young's modulus and yield stress in dry test.

Table 7.33 ANOVA for \#5C OG Mixture Young's Modulus in CU Tests

\begin{tabular}{|c|c|c|c|c|c|c|}
\hline Factor & DF & SSE & MSE & F & $\operatorname{Pr}>$ F & R-Square \\
\cline { 1 - 5 } Speed & 1 & $6.74 \mathrm{E} 08$ & $6.74 \mathrm{E} 08$ & 4.53 & 0.066 & \multirow{2}{*}{0.96} \\
\cline { 1 - 5 } Confining Pressure & 1 & $1.83 \mathrm{E} 10$ & $1.83 \mathrm{E} 10$ & 122.60 & 0.001 & \\
\cline { 1 - 5 } $\begin{array}{c}\text { Speed*Confining } \\
\text { Pressure }\end{array}$ & 1 & $7.85 \mathrm{E} 09$ & $7.85 \mathrm{E} 09$ & 52.72 & 0.0001 & \\
\cline { 1 - 5 } Error & 8 & $1.19 \mathrm{E} 9$ & $1.49 \mathrm{E} 8$ & & \\
\hline
\end{tabular}


Table 7.34 ANOVA for \#5C OG Mixture Yield Stress in CU Tests

\begin{tabular}{|c|c|c|c|c|c|c|}
\hline Factor & DF & SSE & MSE & F & $\operatorname{Pr}>$ F & R-Square \\
\hline Speed & 1 & 253461.3 & 253461.3 & 147.1 & 0.0001 & \\
\cline { 1 - 5 } Confining Pressure & 1 & 70074.6 & 70074.6 & 40.66 & 0.0002 & \multirow{2}{*}{0.96} \\
\cline { 1 - 5 } $\begin{array}{c}\text { Speed*Confining } \\
\text { Pressure }\end{array}$ & 1 & 681.34 & 681.34 & 0.4 & 0.547 & \\
\cline { 1 - 5 } Error & 8 & 13788 & 1723.5 & & & \\
\hline
\end{tabular}

Table 7.35 ANOVA for \#5C OG Mixture Young's Modulus in Dry Tests

\begin{tabular}{|c|c|c|c|c|c|c|}
\hline Factor & DF & SSE & MSE & F & Pr $>$ F & R-Square \\
\hline Speed & 1 & $4.579 \mathrm{E} 09$ & $4.579 \mathrm{E} 09$ & 504.9 & 0.0001 & \\
\cline { 1 - 5 } Confining Pressure & 1 & $4.343 \mathrm{E} 09$ & $4.343 \mathrm{E} 09$ & 478.97 & 0.0001 & \multirow{2}{*}{0.99} \\
\cline { 1 - 5 } $\begin{array}{c}\text { Speed*Confining } \\
\text { Pressure }\end{array}$ & 1 & $6.10 \mathrm{E} 07$ & $6.10 \mathrm{E} 07$ & 6.73 & 0.0319 & \\
\cline { 1 - 5 } Error & 8 & $7.255 \mathrm{E} 07$ & $9.068 \mathrm{E} 06$ & & & \\
\hline
\end{tabular}

Table 7.36 ANOVA for \#5C OG Mixture Yield Stress in Dry Tests

\begin{tabular}{|c|c|c|c|c|c|c|}
\hline Factor & DF & SSE & MSE & F & Pr $>$ F & R-Square \\
\hline Speed & 1 & 213200 & 213200 & 396.19 & 0.0001 & \\
\cline { 1 - 5 } Confining Pressure & 1 & 242387 & 242387 & 450.43 & 0.0001 & \multirow{2}{*}{0.99} \\
\cline { 1 - 5 } $\begin{array}{c}\text { Speed*Confining } \\
\text { Pressure }\end{array}$ & 1 & 1.34 & 1.34 & 0.00 & 0.9614 & \\
\cline { 1 - 5 } Error & 8 & 4305 & 538.1 & & & \\
\hline
\end{tabular}


Table 7.37 Young's Modulus, Log (E), Regression Results for \#5C OG Mixture CU Tests

\begin{tabular}{|c|c|c|c|c|}
\hline Parameter & Estimate & $\mathrm{T}$ for $\mathrm{H}_{0}$ & $\operatorname{Pr}>|\mathrm{T}|$ & $\begin{array}{c}\text { Std Err of } \\
\text { Estimate }\end{array}$ \\
\hline Intercept & 12127 & 1.02 & 0.336 & 11858 \\
\hline Speed & 9893 & 7.41 & 0.0001 & 1334 \\
\hline $\begin{array}{c}\text { Confining } \\
\text { Pressure }\end{array}$ & 1639 & 12.63 & 0.0001 & 129.8 \\
\hline
\end{tabular}

Table 7.38 Yield Stress, Log (Y), Regression Results for \#5C OG Mixture CU Tests

\begin{tabular}{|c|c|c|c|c|}
\hline Parameter & Estimate & $\mathrm{T}$ for $\mathrm{H}_{0}$ & $\operatorname{Pr}>|\mathrm{T}|$ & $\begin{array}{c}\text { Std Err of } \\
\text { Estimate }\end{array}$ \\
\hline Intercept & 511.3 & 12.68 & 0.0001 & 40.3 \\
\hline Speed & 28.4 & 6.24 & 0.0002 & 4.54 \\
\hline $\begin{array}{c}\text { Confining } \\
\text { Pressure }\end{array}$ & 2.0 & 4.52 & 0.0019 & 0.44 \\
\hline
\end{tabular}

Table 7.39 Young's Modulus, Log (E), Regression Results for \#5C OG Mixture Dry Tests

\begin{tabular}{|c|c|c|c|c|}
\hline Parameter & Estimate & T for $\mathrm{H}_{0}$ & $\operatorname{Pr}>|\mathrm{T}|$ & $\begin{array}{c}\text { Std Err of } \\
\text { Estimate }\end{array}$ \\
\hline Intercept & 40830 & 13.95 & 0.0001 & 2926.2 \\
\hline Speed & 4227 & 12.83 & 0.0001 & 329.4 \\
\hline Confining Pressure & 508 & 15.87 & 0.0001 & 32.0 \\
\hline $\begin{array}{c}\text { Speed } \\
\text { Confining Pressure* }\end{array}$ & -9.35 & -2.59 & 0.0319 & 3.61 \\
\hline
\end{tabular}


Table 7.40 Yield Stress, Log (Y), Regression Results for \#5C OG Mixture Dry Tests

\begin{tabular}{|c|c|c|c|c|}
\hline Parameter & Estimate & $\mathrm{T}$ for $\mathrm{H}_{0}$ & $\operatorname{Pr}>|\mathrm{T}|$ & $\begin{array}{c}\text { Std Err of } \\
\text { Estimate }\end{array}$ \\
\hline Intercept & 272.2 & 12.1 & 0.0001 & 22.54 \\
\hline Speed & 23.6 & 9.29 & 0.0001 & 2.54 \\
\hline Confining Pressure & 3.3 & 13.40 & 0.0001 & 0.25 \\
\hline
\end{tabular}

\subsection{Triaxial Test on the \#5D Base Mixture}

\subsubsection{CU and Dry Test}

The wet and dry test stress strain curves for the \#5D base mixture are presented in Appendix D. The pore pressure data is also shown in Appendix D. Figures 7.33 and 7.34 show Mohr's circles from the CU test for loading speeds of 1.25 and $12.5 \mathrm{~mm} / \mathrm{min}$, respectively. There is a distinct peak in the stress-strain test results. The peak is more distinct in the $12.5 \mathrm{~mm} / \mathrm{min}$ test than in the $1.25 \mathrm{~mm} / \mathrm{min}$ test. The peak magnitude decreases with increasing confining pressure. In the CU test, the cohesion increases from $90 \mathrm{kPa}$ to $180 \mathrm{kPa}$ as the loading speed increases from 1.25 to $12.5 \mathrm{~mm} / \mathrm{min}$. The friction angle is 50 degrees for both test speeds. The test results are summarized in Table 7.41. 
Table 7.41 CU Test Results on \#5D Base Mixture

\begin{tabular}{|c|c|c|c|c|c|}
\hline \multicolumn{6}{|c|}{ Loading Speed $(\mathrm{mm} / \mathrm{min})$} \\
\hline \multicolumn{3}{|c|}{1.25} & \multicolumn{3}{|c|}{12.5} \\
\hline $\begin{array}{l}\text { Confining } \\
\text { Pressure } \\
(\mathrm{kPa}) \\
\end{array}$ & $\begin{array}{l}\text { Young's } \\
\text { Modulus } \\
(\mathrm{kPa})\end{array}$ & $\begin{array}{l}\text { Yield Stress } \\
\qquad(\mathrm{kPa})\end{array}$ & $\begin{array}{c}\text { Confining } \\
\text { Pressure } \\
(\mathrm{kPa}) \\
\end{array}$ & $\begin{array}{l}\text { Young's } \\
\text { Modulus } \\
(\mathrm{kPa})\end{array}$ & $\begin{array}{l}\text { Yield Stress } \\
\quad(\mathrm{kPa})\end{array}$ \\
\hline \multirow[t]{2}{*}{35} & 107056 & 1056 & \multirow[t]{2}{*}{35} & 151145 & 1765 \\
\hline & 119006 & 1089 & & 168875 & 1967 \\
\hline \multirow[t]{2}{*}{55} & 123684 & 1119 & \multirow[t]{2}{*}{55} & 195112 & 1782 \\
\hline & 111498 & 929 & & 189439 & 2054 \\
\hline \multirow[t]{2}{*}{69} & 130479 & 1227 & \multirow[t]{2}{*}{69} & 226434 & 2123 \\
\hline & 120505 & 1223 & & 192323 & 2293 \\
\hline $\begin{array}{c}\text { Cohesion } \\
(\mathrm{kPa})\end{array}$ & & 90 & $\begin{array}{c}\text { Cohesion } \\
(\mathrm{kPa})\end{array}$ & & 80 \\
\hline $\begin{array}{l}\text { Friction } \\
\text { (degree) }\end{array}$ & & 50 & $\begin{array}{l}\text { Friction } \\
\text { (degree) }\end{array}$ & & 50 \\
\hline
\end{tabular}

Figure 7.35 shows the Young's modulus vs. confining pressure relation and Figure 7.36 shows the yield stress vs. confining pressure relation from the CU tests of the \#5D base mixture. Both Young's modulus and yield stress increase with increasing confining pressure.

The \#5D base mixture exhibited significant dilation. Under loading, the contracts slightly and then dilates until failure. Consequently, the pore pressure increases slightly and then decreases until failure. The peak in the CU stress-strain relation is less distinct than in dry test. This is a similar result to those for tests of the other asphalt mixture. 
Mohr's circles for dry tests of the \#5D base mixture at $1.25 \mathrm{~mm} / \mathrm{min}$ and 12.5 $\mathrm{mm} / \mathrm{min}$ loading speeds are shown in Figures 7.37 and 7.38 , respectively. Figure 7.39 shows the Young's modulus vs. confining pressure relation and Figure 7.40 shows the yield stress vs. confining pressure relation for the dry test. As expected, the loading speed has a significant effect on cohesion. Cohesion increases from $90 \mathrm{kPa}$ to $190 \mathrm{kPa}$ as the loading speed increases from 1.25 to $12.5 \mathrm{~mm} / \mathrm{min}$. The friction angle is the same as for the CU test and equals 50 degrees. The results are summarized in Table 7.42.

Table 7.42 Dry Test Results on \#5D Base Mixture

\begin{tabular}{|c|c|c|c|c|c|}
\hline \multicolumn{6}{|c|}{ Loading Speed (mm/min) } \\
\hline \multicolumn{3}{|c|}{1.25} & \multicolumn{3}{|c|}{12.5} \\
\hline $\begin{array}{c}\text { Confining } \\
\text { Pressure } \\
(\mathrm{kPa}) \\
\end{array}$ & $\begin{array}{c}\text { Young's } \\
\text { Modulus } \\
(\mathrm{kPa})\end{array}$ & $\begin{array}{l}\text { Yield Stress } \\
\qquad(\mathrm{kPa})\end{array}$ & $\begin{array}{c}\text { Confining } \\
\text { Pressure } \\
(\mathrm{kPa})\end{array}$ & $\begin{array}{c}\text { Young's } \\
\text { Modulus } \\
(\mathrm{kPa})\end{array}$ & $\begin{array}{l}\text { Yield Stress } \\
\quad(\mathrm{kPa})\end{array}$ \\
\hline \multirow[t]{2}{*}{35} & 64600 & 486 & \multirow[t]{2}{*}{35} & 140486 & 1245 \\
\hline & 66304 & 545 & & 157895 & 1135 \\
\hline \multirow[t]{2}{*}{69} & 132258 & 977 & \multirow[t]{2}{*}{69} & 177172 & 1313 \\
\hline & 117864 & 899 & & 169879 & 1220 \\
\hline \multirow[t]{2}{*}{138} & 165927 & 1256 & \multirow[t]{2}{*}{138} & 196721 & 1753 \\
\hline & 153131 & 1154 & & 225767 & 1484 \\
\hline $\begin{array}{c}\text { Cohesion } \\
(\mathrm{kPa})\end{array}$ & & 90 & $\begin{array}{c}\text { Cohesion } \\
(\mathrm{kPa})\end{array}$ & & 90 \\
\hline $\begin{array}{c}\text { Friction } \\
\text { (degree) }\end{array}$ & & 50 & $\begin{array}{l}\text { Friction } \\
\text { (degree) }\end{array}$ & & 50 \\
\hline
\end{tabular}




\subsubsection{ANOVA and Regression Analysis}

For tests of the \#5D base mixture, Young's modulus and yield stress increase with increasing confining pressure. Young's modulus and yield stress also increase with loading speed. Generally, Young's modulus in the CU test is higher than in the dry test. ANOVA of these results are given in Tables 7.43 through 7.46. Tables 7.47 through 7.50 show the regression analyses for both dry and CU tests of the \#5D base mixture. At the $\alpha$ $=0.05$ level, the main effect of loading speed and confining pressure are significant to Young's modulus and yield stress in both the dry and the CU tests.

Table 7.43 ANOVA for \#5D Base Mixture Young's Modulus in CU Tests

\begin{tabular}{|c|c|c|c|c|c|c|}
\hline Factor & DF & SSE & MSE & F & $\operatorname{Pr}>$ F & R-Square \\
\hline Speed & 1 & $1.41 \mathrm{E} 10$ & $1.41 \mathrm{E} 10$ & 115.64 & 0.0001 & \multirow{2}{*}{0.94} \\
\cline { 1 - 6 } Confining Pressure & 1 & $1.93 \mathrm{E} 9$ & $1.93 \mathrm{E} 9$ & 15.89 & 0.004 & \\
\cline { 1 - 5 } $\begin{array}{c}\text { Speed }{ }^{*} \text { Confining } \\
\text { Pressure }\end{array}$ & 1 & $7.14 \mathrm{E} 8$ & $7.14 \mathrm{E} 8$ & 5.87 & 0.0417 & \\
\cline { 1 - 5 } Error & 8 & $9.74 \mathrm{E} 8$ & $1.22 \mathrm{E} 8$ & & & \\
\hline
\end{tabular}

Table 7.44 ANOVA for \#5D Base Mixture Yield Stress in CU Tests

\begin{tabular}{|c|c|c|c|c|c|c|}
\hline Factor & DF & SSE & MSE & F & $\operatorname{Pr}>$ F & R-Square \\
\hline Speed & 1 & 2377190 & 2377190 & 131.14 & 0.0001 & \\
\cline { 1 - 6 } Confining Pressure & 1 & 107381 & 107381 & 5.92 & 0.041 & \multirow{2}{*}{0.95} \\
\cline { 1 - 5 } $\begin{array}{c}\text { Speed*Confining } \\
\text { Pressure }\end{array}$ & 1 & 17897 & 17897 & 0.99 & 0.3495 & \\
\cline { 1 - 5 } Error & 8 & 145019 & 18127 & & & \\
\hline
\end{tabular}


Table 7.45 ANOVA for \#5D Base Mixture Young's Modulus in Dry Tests

\begin{tabular}{|c|c|c|c|c|c|c|}
\hline Factor & DF & SSE & MSE & F & Pr $>$ F & R-Square \\
\hline Speed & 1 & $1.28 \mathrm{E} 10$ & $1.128 \mathrm{E} 10$ & 48.68 & 0.0001 & \\
\cline { 1 - 6 } $\begin{array}{c}\text { Confining } \\
\text { Pressure }\end{array}$ & 1 & $1.154 \mathrm{E} 10$ & $1.154 \mathrm{E} 10$ & 49.82 & 0.0001 & 0.93 \\
\cline { 1 - 5 } $\begin{array}{c}\text { Speed*Confining } \\
\text { Pressure }\end{array}$ & 1 & $3.684 \mathrm{E} 08$ & $3.684 \mathrm{E} 08$ & 1.59 & 0.2428 & \\
\cline { 1 - 5 } Error & 8 & $1.853 \mathrm{E} 10$ & $2.316 \mathrm{E} 08$ & & & \\
\hline
\end{tabular}

Table 7.46 ANOVA for \#5D Base Mixture Yield Stress in Dry Tests

\begin{tabular}{|c|c|c|c|c|c|c|}
\hline Factor & DF & SSE & MSE & F & Pr $>$ F & R-Square \\
\cline { 1 - 6 } Speed & 1 & 336340 & 336340 & 345.66 & 0.0001 & \\
\cline { 1 - 5 } Confining Pressure & 1 & 77122 & 77122 & 79.26 & 0.0001 & \multirow{2}{*}{0.98} \\
\cline { 1 - 5 } $\begin{array}{c}\text { Speed*Confining } \\
\text { Pressure }\end{array}$ & 1 & 6354 & 6354 & 6.53 & 0.0339 & \\
\cline { 1 - 5 } Error & 8 & 7784 & 973.05 & & & \\
\hline
\end{tabular}

Table 7.47 Young's Modulus, Log (E), Regression Results for \#5D Base Mixture CU Tests

\begin{tabular}{|c|c|c|c|c|}
\hline Parameter & Estimate & $\mathrm{T}$ for $\mathrm{H}_{0}$ & $\operatorname{Pr}>|\mathrm{T}|$ & $\begin{array}{c}\text { Std Err of } \\
\text { Estimate }\end{array}$ \\
\hline Intercept & 98683 & 4.99 & 0.0011 & 19761 \\
\hline Speed & 879.7 & 0.40 & 0.7029 & 2224 \\
\hline Confining Pressure & 234 & 0.65 & 0.5343 & 360 \\
\hline $\begin{array}{c}\text { Speed } \\
\text { Confining Pressure* }\end{array}$ & 98.3 & 2.42 & 0.0417 & 40 \\
\hline
\end{tabular}


Table 7.48 Yield Stress, Log (Y), Regression Results for \#5D Base Mixture CU Tests

\begin{tabular}{|c|c|c|c|c|}
\hline Parameter & Estimate & $\mathrm{T}$ for $\mathrm{H}_{0}$ & $\operatorname{Pr}>|\mathrm{T}|$ & $\begin{array}{c}\text { Std Err of } \\
\text { Estimate }\end{array}$ \\
\hline Intercept & 828.2 & 3.44 & 0.089 & 241.1 \\
\hline Speed & 53.05 & 1.95 & 0.0864 & 27.1 \\
\hline $\begin{array}{c}\text { Confining } \\
\text { Pressure }\end{array}$ & 3.4 & 0.77 & 0.462 & 4.4 \\
\hline
\end{tabular}

Table 7.49 Young's Modulus, Log (E), Regression Results for \#5D Base Mixture Dry Tests

\begin{tabular}{|c|c|c|c|c|}
\hline Parameter & Estimate & $\mathrm{T}$ for $\mathrm{H}_{0}$ & $\operatorname{Pr}>|\mathrm{T}|$ & $\begin{array}{c}\text { Std Err of } \\
\text { Estimate }\end{array}$ \\
\hline Intercept & 38751 & 2.62 & 0.0306 & 14788.2 \\
\hline Speed & 7303 & 4.39 & 0.0023 & 1664.8 \\
\hline $\begin{array}{c}\text { Confining } \\
\text { Pressure }\end{array}$ & 881 & 5.45 & 0.0006 & 161.9 \\
\hline
\end{tabular}

Table 7.50 Yield Stress, Log (Y), Regression Results for \#5D Base Mixture Dry Tests

\begin{tabular}{|c|c|c|c|c|}
\hline Parameter & Estimate & T for $\mathrm{H}_{0}$ & $\operatorname{Pr}>|\mathrm{T}|$ & $\begin{array}{c}\text { Std Err of } \\
\text { Estimate }\end{array}$ \\
\hline lntercept & 349 & 11.51 & 0.0001 & 30.31 \\
\hline Speed & 22.1 & 6.47 & 0.0002 & 3.41 \\
\hline Confining Pressure & 1.21 & 3.66 & 0.0064 & 0.33 \\
\hline $\begin{array}{c}\text { Speed } \\
\text { Confining Pressure* }\end{array}$ & 0.1 & 2.56 & 0.0339 & 0.037 \\
\hline
\end{tabular}




\subsection{Triaxial Tests of \#2 Base Mixture}

\subsubsection{CU Test and Dry Test}

Stress-strain curves of $\mathrm{CU}$ and dry tests for the \#2 base mixture are in Appendix D. Pore pressure data is also presented in Appendix D. Figures 7.41 and 7.42 show the Mohr's circles of $\mathrm{CU}$ tests on the \#2 base mixture at 1.25 and $12.5 \mathrm{~mm} / \mathrm{min}$ loading speeds, respectively. As with other asphalt mixtures, there is a peak in the stress-strain relation. The peak becomes less distinct with increasing confining pressure. Figure 7.43 shows the Young's modulus vs. confining pressure relations and Figure 7.44 shows the yield stress vs. confining pressure relations. Young's modulus and yield stress increase with increasing confining pressure. Also, both Young's modulus and yield stress increase with loading speed. Loading speed also has an effect on the cohesion. The cohesion increases from $120 \mathrm{kPa}$ to $160 \mathrm{kPa}$ as the loading speed is increased from 1.25 to 12.5 $\mathrm{mm} / \mathrm{min}$. However, the friction angle decreases from 45 degrees to 41 degrees. The stress-strain curve is not as smooth as for other mixtures because of the \#2 base mixture maximum aggregate particle size. The $\mathrm{CU}$ test results are summarized in Table 7.51.

There is no distinct peak in the CU test for either the 1.25 or $12.5 \mathrm{~mm} / \mathrm{min}$ loading speeds. The \#2 mixture tends to contract slightly and then dilate until failure. The friction angle decreases from 45 to 41 degrees as the loading speed is increased from 1.25 to 12.5 $\mathrm{mm} / \mathrm{min}$. 
Table 7.51 CU Test Results on \#2 Base Mixture

\begin{tabular}{|c|c|c|c|c|c|}
\hline \multicolumn{6}{|c|}{ Loading Speed $(\mathrm{mm} / \mathrm{min})$} \\
\hline \multicolumn{3}{|c|}{1.25} & \multicolumn{3}{|c|}{12.5} \\
\hline $\begin{array}{c}\text { Confining } \\
\text { Pressure } \\
(\mathrm{kPa}) \\
\end{array}$ & $\begin{array}{c}\text { Young's } \\
\text { Modulus } \\
(\mathrm{kPa})\end{array}$ & $\begin{array}{l}\text { Yield Stress } \\
\quad(\mathrm{kPa})\end{array}$ & $\begin{array}{c}\text { Confining } \\
\text { Pressure } \\
(\mathrm{kPa}) \\
\end{array}$ & $\begin{array}{c}\text { Young's } \\
\text { Modulus } \\
(\mathrm{kPa})\end{array}$ & $\begin{array}{l}\text { Yield Stress } \\
\quad(\mathrm{kPa})\end{array}$ \\
\hline \multirow[t]{2}{*}{35} & 86992 & 790 & \multirow[t]{2}{*}{35} & 137400 & 929 \\
\hline & 95565 & 681 & & 135800 & 933 \\
\hline \multirow[t]{2}{*}{69} & 101400 & 883 & \multirow[t]{2}{*}{69} & 166666 & 1027 \\
\hline & 143878 & 820 & & 185598 & 1016 \\
\hline \multirow[t]{2}{*}{138} & 102535 & 896 & \multirow{2}{*}{$\begin{array}{l}138 \\
138\end{array}$} & 265600 & 1131 \\
\hline & 144376 & 1024 & & 230000 & 1095 \\
\hline $\begin{array}{c}\text { Cohesion } \\
(\mathrm{kPa})\end{array}$ & \multicolumn{2}{|c|}{120} & $\begin{array}{c}\text { Cohesion } \\
(\mathrm{kPa})\end{array}$ & \multicolumn{2}{|c|}{160} \\
\hline $\begin{array}{c}\text { Friction } \\
\text { (degree) }\end{array}$ & \multicolumn{2}{|r|}{45} & $\begin{array}{l}\text { Friction } \\
\text { (degree) }\end{array}$ & \multicolumn{2}{|c|}{43} \\
\hline
\end{tabular}

Mohr's circles for dry tests of the \#2 base mixture are shown in Figures 7.45 and Figure 7.46, respectively, for 1.25 and $12.5 \mathrm{~mm} / \mathrm{min}$ loading speeds. Figure 7.47 shows the Young's modulus vs. confining pressure relations and Figure 7.48 shows the yield stress vs. confining pressure relations. The cohesion increases from $80 \mathrm{kPa}$ to $165 \mathrm{kPa}$ when the loading speed is increased from 1.25 to $12.5 \mathrm{~mm} / \mathrm{min}$. The friction angle is 46 and 45 degrees for loading speeds of 1.25 and $12.5 \mathrm{~mm} / \mathrm{min}$, respectively. Young's modulus and yield stress increase with increasing confining pressure. Loading speed has almost the same effect on cohesion in both CU and dry tests. The dry test results are shown in Table 7.52. 
Table 7.52 Dry Test Results on \#2 Base Mixture

\begin{tabular}{|c|c|c|c|c|c|}
\hline \multicolumn{6}{|c|}{ Loading Speed $(\mathrm{mm} / \mathrm{min})$} \\
\hline \multicolumn{3}{|c|}{1.25} & \multicolumn{3}{|c|}{12.5} \\
\hline $\begin{array}{c}\text { Confining } \\
\text { Pressure } \\
(\mathrm{kPa})\end{array}$ & $\begin{array}{c}\text { Young's } \\
\text { Modulus } \\
(\mathrm{kPa})\end{array}$ & $\begin{array}{l}\text { Yield Stress } \\
\quad(\mathrm{kPa})\end{array}$ & $\begin{array}{c}\text { Confining } \\
\text { Pressure } \\
(\mathrm{kPa})\end{array}$ & $\begin{array}{c}\text { Young's } \\
\text { Modulus } \\
(\mathrm{kPa})\end{array}$ & $\begin{array}{l}\text { Yield Stress } \\
\quad(\mathrm{kPa})\end{array}$ \\
\hline \multirow{2}{*}{35} & 57000 & 414 & \multirow{2}{*}{35} & 111000 & 997 \\
\hline & 78600 & 520 & & 135800 & 1008 \\
\hline \multirow{2}{*}{69} & 113100 & 772 & \multirow{2}{*}{69} & 167600 & 1242 \\
\hline & 98000 & 802 & & 184200 & 1215 \\
\hline \multirow{2}{*}{138} & 126600 & 923 & \multirow{2}{*}{138} & 245600 & 1359 \\
\hline & 135000 & 992 & & 210000 & 1403 \\
\hline $\begin{array}{c}\text { Cohesion } \\
(\mathrm{kPa})\end{array}$ & & 0 & $\begin{array}{c}\text { Cohesion } \\
(\mathrm{kPa})\end{array}$ & & 65 \\
\hline $\begin{array}{l}\text { Friction } \\
\text { (degree) }\end{array}$ & & 6 & $\begin{array}{l}\text { Friction } \\
\text { (degree) }\end{array}$ & & 45 \\
\hline
\end{tabular}

\subsubsection{ANOVA and Regression Analysis}

As with previous tests, Young's modulus and yield stress increase with increasing confining pressure. Young's modulus and yield stress also increase with loading speed. Generally, Young's modulus in the CU test is higher than in the dry test. Tables 7.53 through 7.56 show the ANOVA results. Tables 7.57 through 7.60 show the regression analysis results on both $\mathrm{CU}$ and dry tests.

The effect of confining pressure and loading speed on yield stress and Young's modulus is apparent. They both increase with confining pressure. The interaction of the loading speed and confining pressure is not significant at the $\alpha=0.05$ level. The main 
effects of loading speed and confining pressure are significant at $\alpha=0.05$ level to Young's modulus and yield stress for both the CU and dry tests. The above results indicate that both Young's modulus and yield stress depend on confining pressure and loading speed. The total effect from confining pressure and loading speed can be obtained by superimposing the effect of confining pressure and loading speed. The regression equations can be used to estimate Young's modulus and yield stress at the testing temperature and with different loading speeds and confining pressures.

Table 7.53 ANOVA for \#2 Base Mixture Young's Modulus in CU Test

\begin{tabular}{|c|c|c|c|c|c|c|}
\hline Factor & DF & SSE & MSE & F & $\operatorname{Pr}>$ F & R-Square \\
\cline { 1 - 5 } Speed & 1 & $1.66 \mathrm{E} 10$ & $1.66 \mathrm{E} 10$ & 41.62 & 0.0002 & \multirow{2}{*}{0.90} \\
\cline { 1 - 5 } Confining & 1 & $9.92 \mathrm{E} 9$ & $9.92 \mathrm{E} 9$ & 24.88 & 0.0011 & \\
\cline { 1 - 5 } $\begin{array}{c}\text { Speed*Confining } \\
\text { Pressure }\end{array}$ & 1 & $3.57 \mathrm{E} 9$ & $3.57 \mathrm{E} 9$ & 8.95 & 0.0173 & \\
\cline { 1 - 5 } Error & 8 & $3.19 \mathrm{E} 9$ & $3.99 \mathrm{E} 8$ & & & \\
\hline
\end{tabular}

Table 7.54 ANOVA for \#2 Base Mixture Yield Stress in CU Test

\begin{tabular}{|c|c|c|c|c|c|c|}
\hline Factor & DF & SSE & MSE & F & $\operatorname{Pr}>$ F & R-Square \\
\hline Speed & 1 & 89614 & 89614 & 35.36 & 0.0003 & \\
\cline { 1 - 5 } Confining Pressure & 1 & 79271 & 79271 & 31.28 & 0.0005 & \multirow{2}{*}{0.89} \\
\cline { 1 - 5 } $\begin{array}{c}\text { Speed*Confining } \\
\text { Pressure }\end{array}$ & 1 & 830.7 & 830.7 & 0.33 & 0.583 & \\
\cline { 1 - 5 } Error & 8 & 20275 & 2534.4 & & & \\
\hline
\end{tabular}


Table 7.55 ANOVA for \#2 Base Mixture Young's Modulus in Dry Tests

\begin{tabular}{|c|c|c|c|c|c|c|}
\hline Factor & DF & SSE & MSE & F & $\operatorname{Pr}>$ F & R-Square \\
\cline { 1 - 6 } Speed & 1 & $1.657 \mathrm{E} 10$ & $1.657 \mathrm{E} 10$ & 58.96 & 0.0001 & \multirow{2}{*}{0.93} \\
\cline { 1 - 6 } Confining Pressure & 1 & $1.325 \mathrm{E} 10$ & $1.325 \mathrm{E} 10$ & 47.16 & 0.0001 & \\
\cline { 1 - 5 } $\begin{array}{c}\text { Speed*Confining } \\
\text { Pressure }\end{array}$ & 1 & $8.79 \mathrm{E} 8$ & $8.79 \mathrm{E} 8$ & 3.13 & 0.115 & \\
\cline { 1 - 5 } Error & 8 & $2.25 \mathrm{E} 9$ & $2.81 \mathrm{E} 8$ & & \\
\hline
\end{tabular}

Table 7.56 ANOVA for \#2 Base Mixture Yield Stress in Dry Tests

\begin{tabular}{|c|c|c|c|c|c|c|}
\hline Factor & DF & SSE & MSE & F & $\operatorname{Pr}>$ F & R-Square \\
\hline Speed & 1 & 653800 & 653800 & 95.0 & 0.0001 & \\
\cline { 1 - 5 } Confining Pressure & 1 & 342757 & 342757 & 49.8 & 0.0001 & \multirow{2}{*}{0.95} \\
\cline { 1 - 5 } $\begin{array}{c}\text { Speed*Confining } \\
\text { Pressure }\end{array}$ & 1 & 5146 & 5146 & 0.75 & 0.412 & \\
\cline { 1 - 5 } Error & 8 & 55041 & 6880.1 & & & \\
\hline
\end{tabular}

Table 7.57 Young's Modulus, Log (E), Regression Results for \#2 Base Mixture CU Tests

\begin{tabular}{|c|c|c|c|c|}
\hline Parameter & Estimate & $\mathrm{T}$ for $\mathrm{H}_{0}$ & $\operatorname{Pr}>|\mathrm{T}|$ & $\begin{array}{c}\text { Std Err of } \\
\text { Estimate }\end{array}$ \\
\hline Intercept & 89752 & 4.62 & 0.0017 & 19407 \\
\hline Speed & 838.9 & 0.38 & 0.711 & 2184 \\
\hline Confining Pressure & 179.0 & 0.84 & 0.424 & 212 \\
\hline $\begin{array}{c}\text { Speed } \\
\text { Confining Pressure* }\end{array}$ & 71.6 & 2.99 & 0.017 & 23 \\
\hline
\end{tabular}


Table 7.58 Yield Stress, Log (Y), Regression Results for \#2 Base Mixture CU Tests

\begin{tabular}{|c|c|c|c|c|}
\hline Parameter & Estimate & $\mathrm{T}$ for $\mathrm{H}_{0}$ & $\operatorname{Pr}>|\mathrm{T}|$ & $\begin{array}{c}\text { Std Err of } \\
\text { Estimate }\end{array}$ \\
\hline Intercept & 657.7 & 13.44 & 0.0001 & 48.9 \\
\hline Speed & 18.1 & 3.3 & 0.011 & 5.5 \\
\hline $\begin{array}{c}\text { Confining } \\
\text { Pressure }\end{array}$ & 2.13 & 3.98 & 0.004 & 0.54 \\
\hline
\end{tabular}

Table 7.59 Young's Modulus, Log (E), Modulus Regression Results for \#2 Base Mixture Dry Tests

\begin{tabular}{|c|c|c|c|c|}
\hline Parameter & Estimate & $\mathrm{T}$ for $\mathrm{H}_{0}$ & $\operatorname{Pr}>|\mathrm{T}|$ & $\begin{array}{c}\text { Std Err of } \\
\text { Estimate }\end{array}$ \\
\hline Intercept & 50264.6 & 3.09 & 0.015 & 16290 \\
\hline Speed & 3740.3 & 2.04 & 0.076 & 1833 \\
\hline $\begin{array}{c}\text { Confining } \\
\text { Pressure }\end{array}$ & 531.3 & 2.98 & 0.018 & 178 \\
\hline
\end{tabular}

Table 7.60 Yield Stress, Log (Y), Regression Results for \#2 Base Mixture Dry Tests

\begin{tabular}{|c|c|c|c|c|}
\hline Parameter & Estimate & $\mathrm{T}$ for $\mathrm{H}_{0}$ & $\operatorname{Pr}>|\mathrm{T}|$ & $\begin{array}{c}\text { Std Err of } \\
\text { Estimate }\end{array}$ \\
\hline Intercept & 319.5 & 3.96 & 0.0042 & 80.6 \\
\hline Speed & 48.4 & 5.34 & 0.007 & 9.07 \\
\hline $\begin{array}{c}\text { Confining } \\
\text { Pressure }\end{array}$ & 4.5 & 5.14 & 0.0009 & 0.88 \\
\hline
\end{tabular}




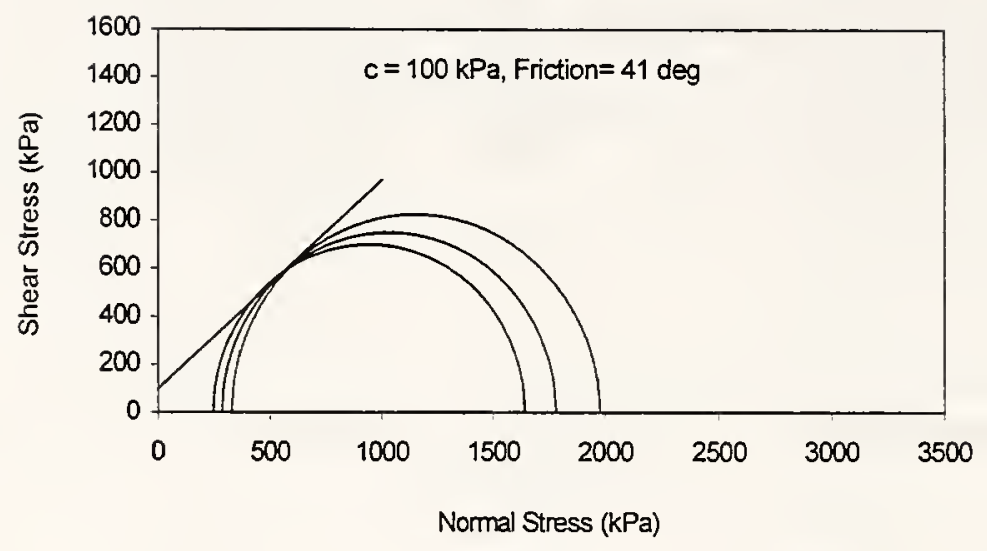

Figure 7.1 Mohr's Circles for the \#11 Surface Mixture CU Tests at Loading Speed of 1.25 $\mathrm{mm} / \mathrm{min}$

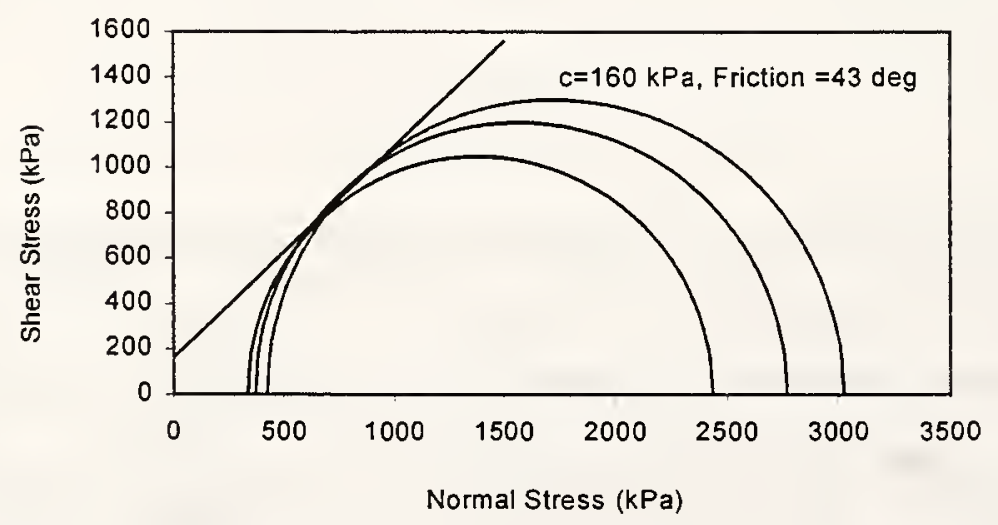

Figure 7.2 Mohr's Circles for the \#11Surface Mixture CU Tests at Loading Speed of 12.5 $\mathrm{mm} / \mathrm{min}$ 


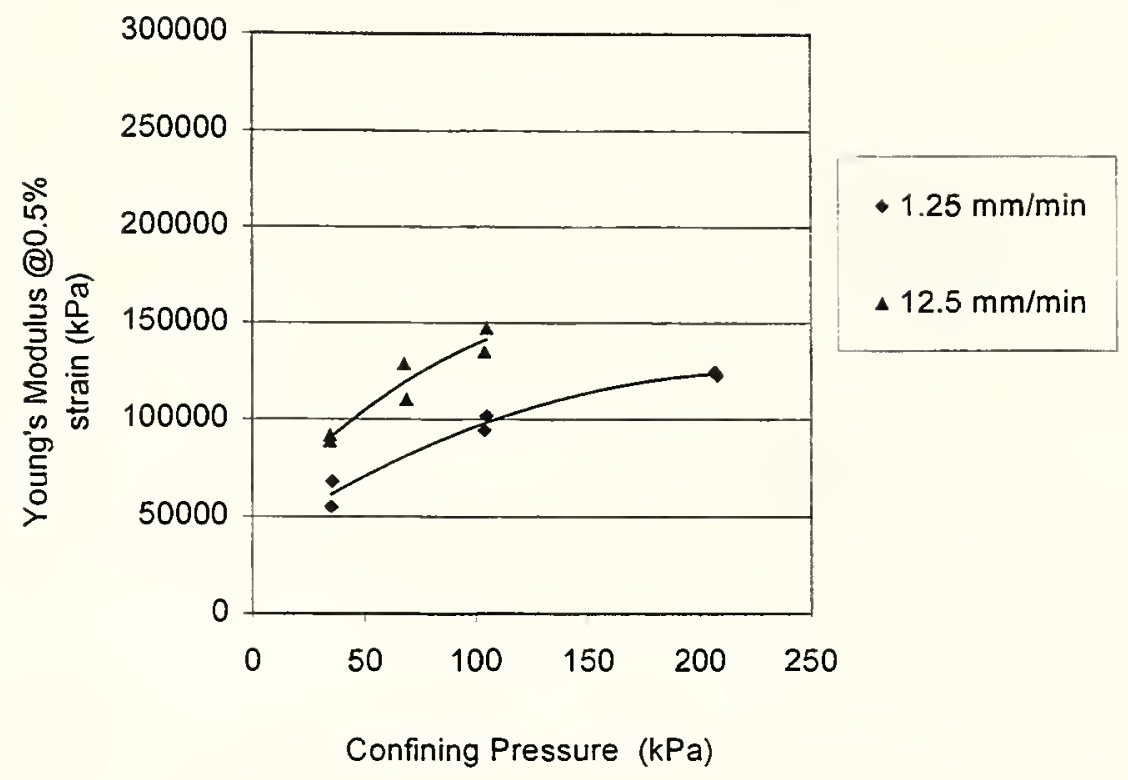

Figure 7.3 Young's Modulus vs. Confining Pressure for the \#11 Surface Mixture CU Tests

(Figure Legend Denotes Loading Speed)

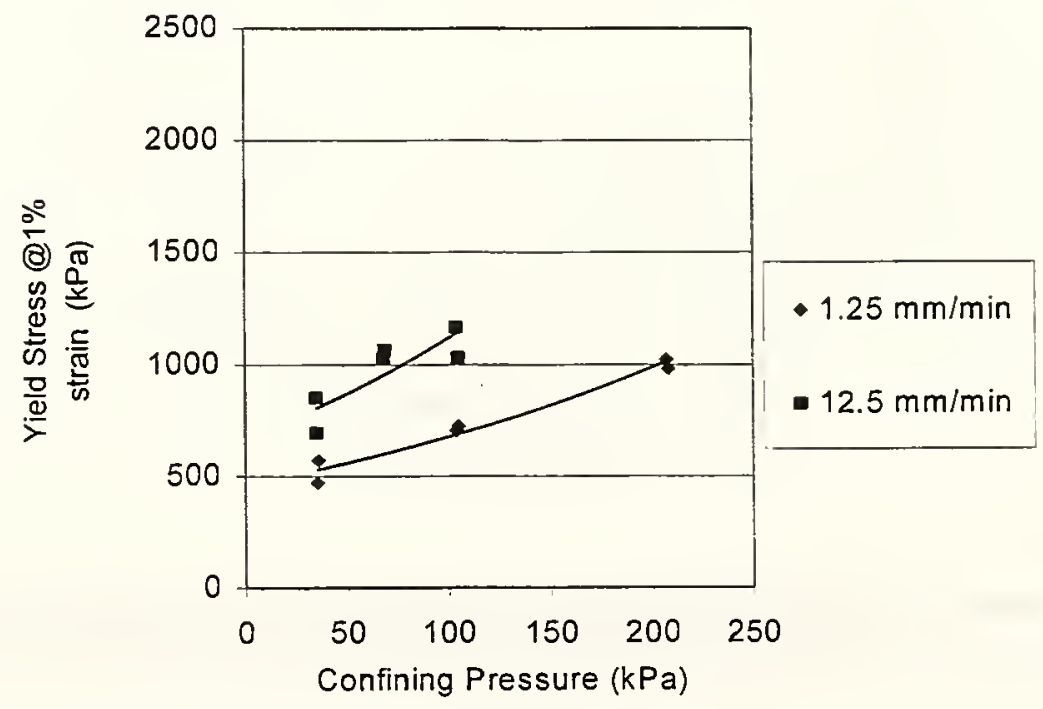

Figure 7.4 Yield Stress vs. Confining Pressure for the \# 11 Surface Mixture CU Tests (Figure Legend Denotes Loading Speed) 


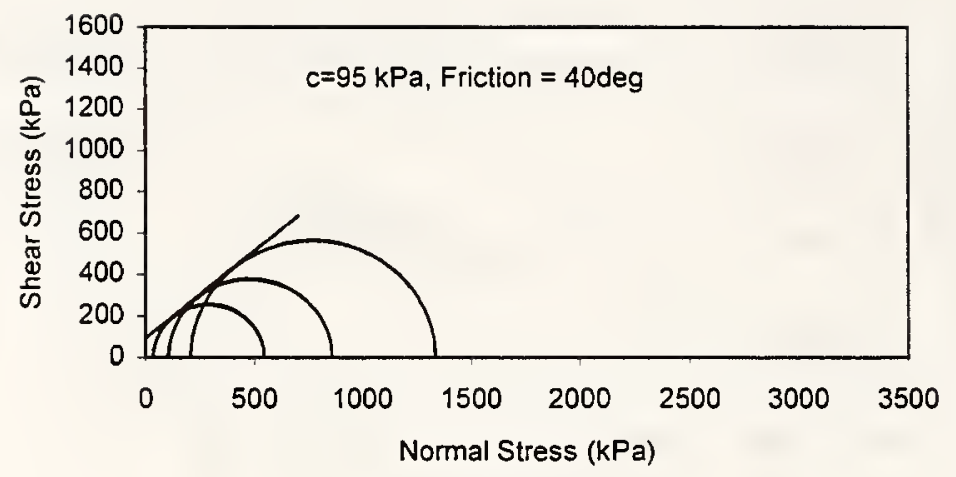

Figure 7.5 Mohr's Circles for \#11 Surface Mixture Dry Tests at Loading Speed of 1.25 $\mathrm{mm} / \mathrm{min}$

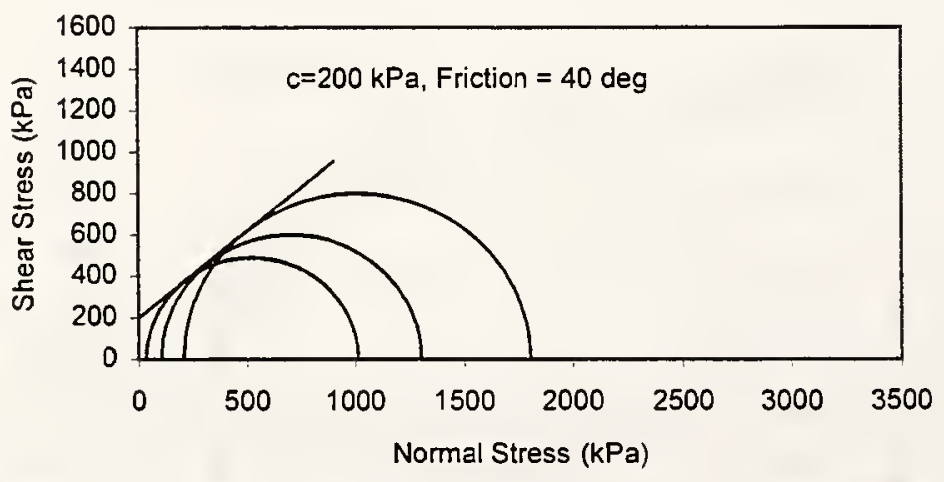

Figure 7.6 Mohr's Circles for \#11 Surface Mixture Dry Tests at Loading Speed of 12.5 $\mathrm{mm} / \mathrm{min}$ 


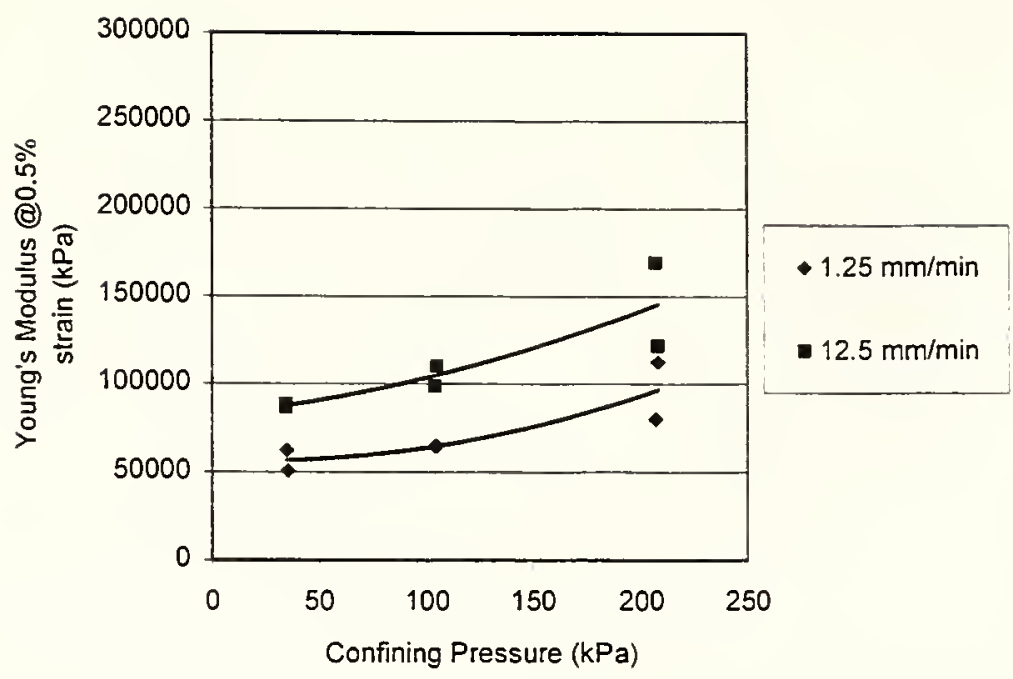

Figure 7.7 Young's Modulus vs. Confining Pressure for the \#11 Surface Mixture Dry Tests (Figure Legend Denotes Loading Speed)

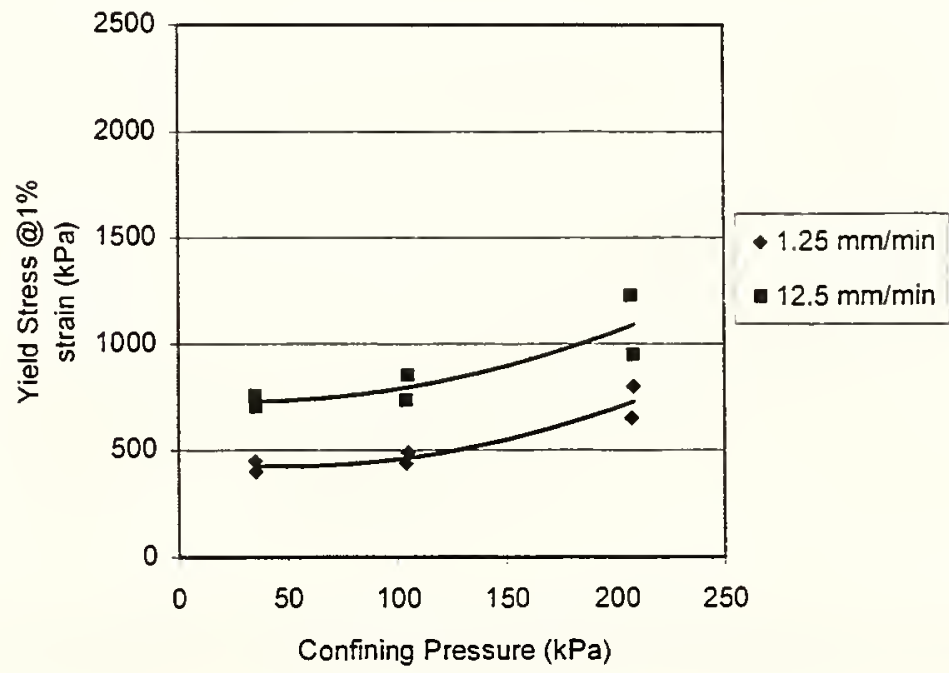

Figure 7.8 Yield Stress vs. Confining Pressure for the \#11 Surface Mixture Dry Tests (Figure Legend Denotes Loading Speed) 


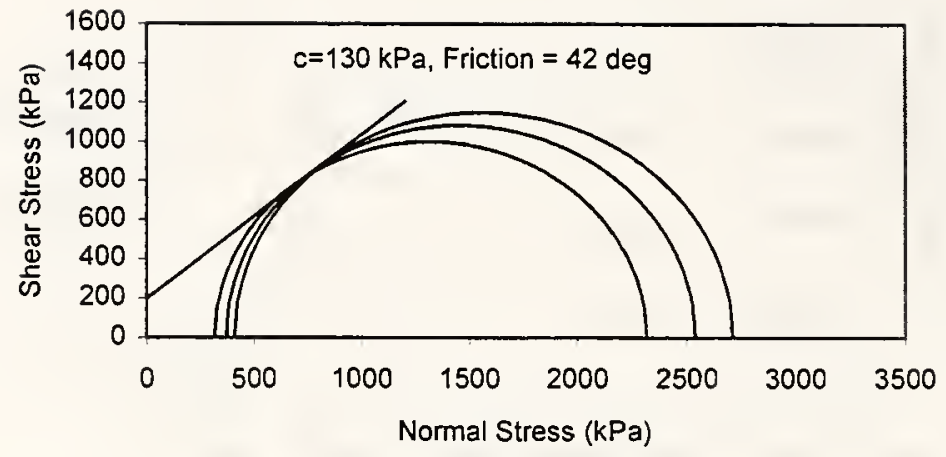

Figure 7.9 Mohr's Circles on \#9 Binder Mixture CU Tests at Loading Speed of 1.25 $\mathrm{mm} / \mathrm{min}$

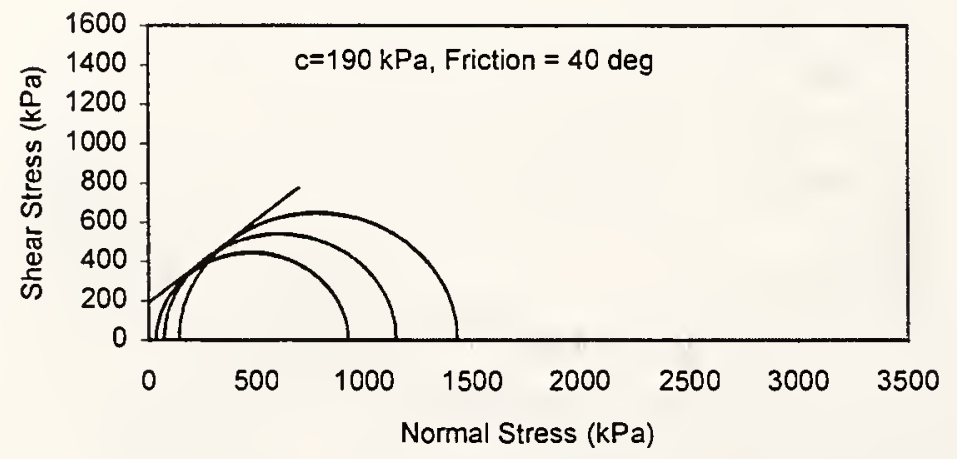

Figure 7.10 Mohr's Circles for \#9 Binder Mixture CU Tests at Loading Speed of 12.5 $\mathrm{mm} / \mathrm{min}$ 


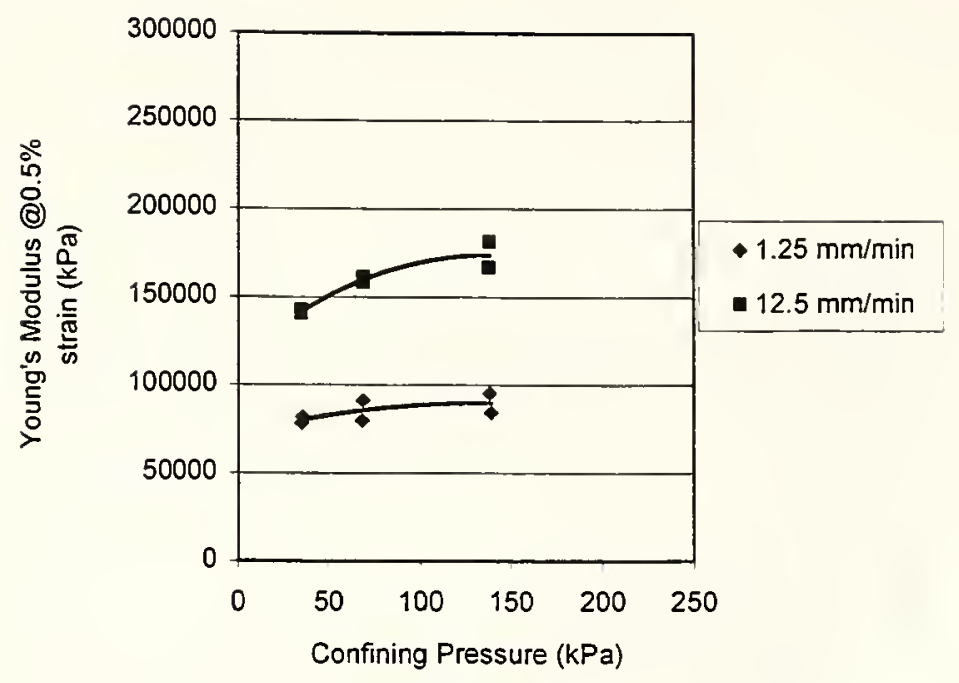

Figure 7.11 Young's Modulus vs. Confining Pressure for the \#9 Binder Mixture CU Tests

(Figure Legend Denotes Loading Speed)

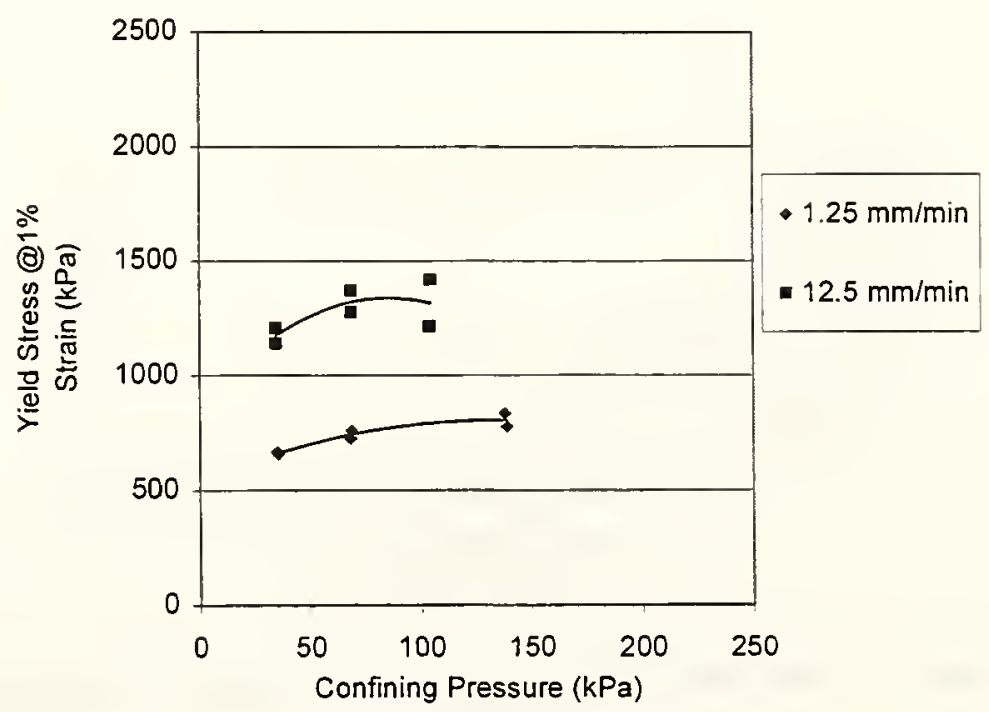

Figure 7.12 Yield Stress vs. Confining Pressure for the \#9 Binder Mixture CU Tests (Figure Legend Denotes Loading Speed) 


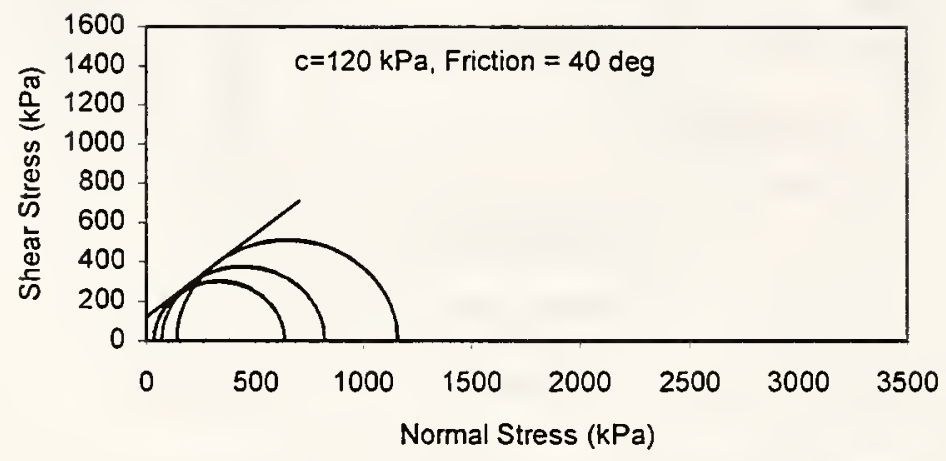

Figure 7.13 Mohr's Circles for \#9 Binder Mixture Dry Tests at Loading Speed of 1.25 $\mathrm{mm} / \mathrm{min}$

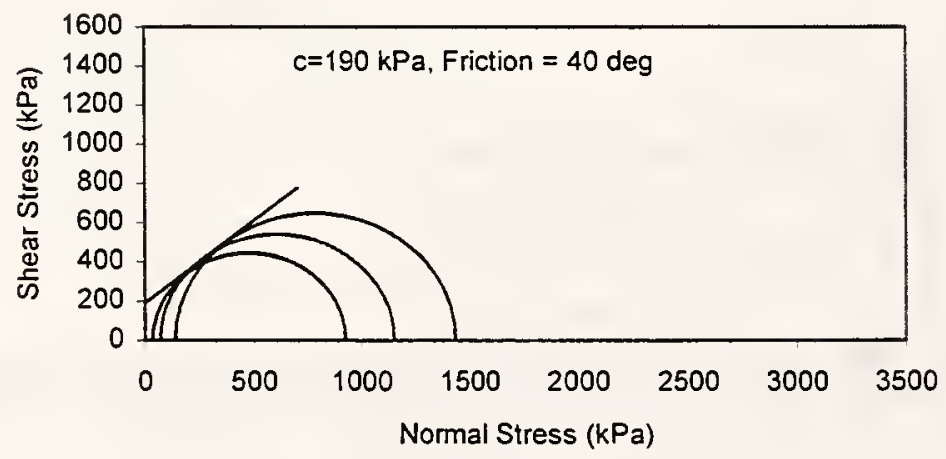

Figure 7.14 Mohr's Circles for \#9 Binder Mixture Dry Tests at Loading Speed of 12.5 $\mathrm{mm} / \mathrm{min}$ 


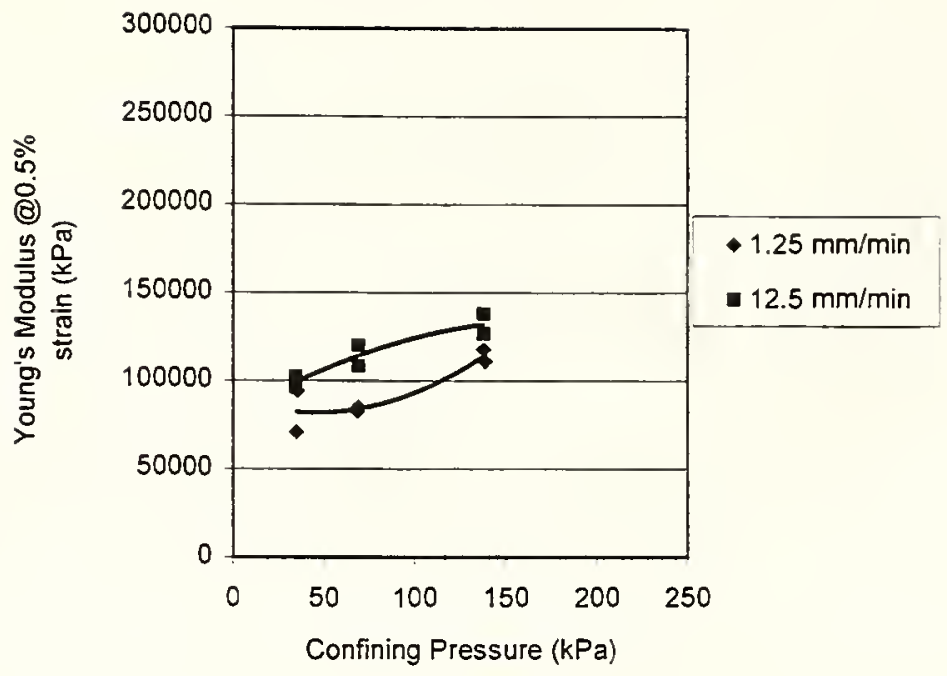

Figure 7.15 Young's Modulus vs. Confining Pressure for the \#9 Binder Mixture Dry Tests

(Figure Legend Denotes Loading Speed)

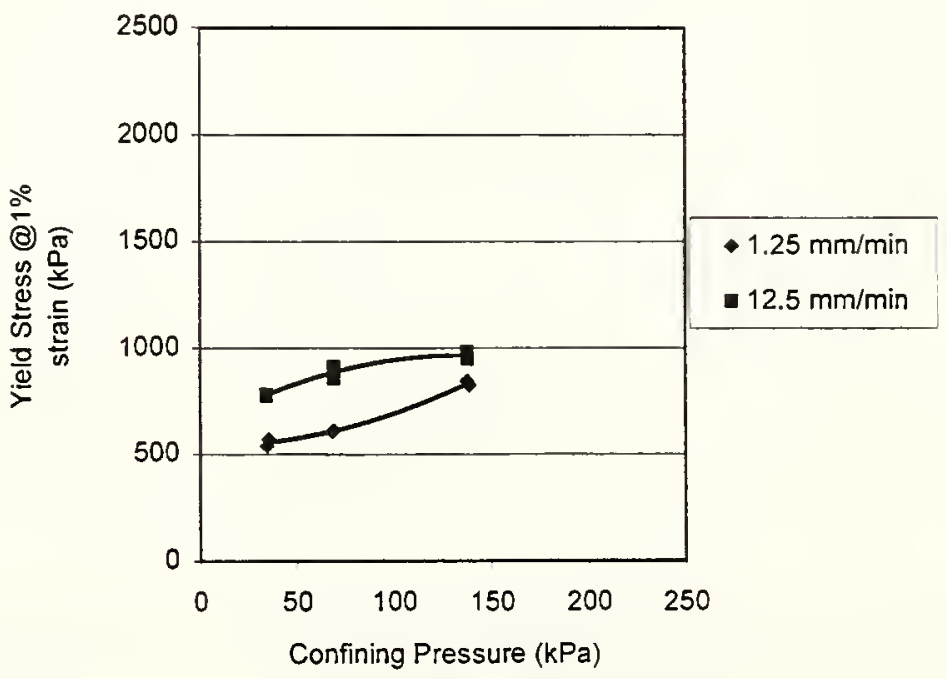

Figure 7.16 Yield Stress vs. Confining Pressure for the \#9 Binder Mixture Dry Tests (Figure Legend Denotes Loading Speed) 


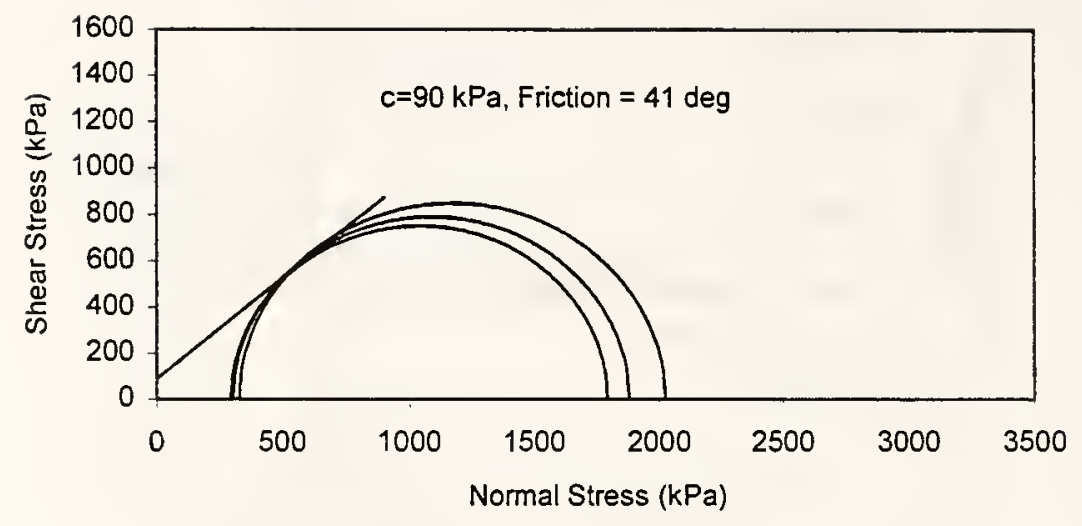

Figure 7.17 Mohr's Circles for \#8 Binder Mixture CU Tests at Loading Speed of 1.25 $\mathrm{mm} / \mathrm{min}$

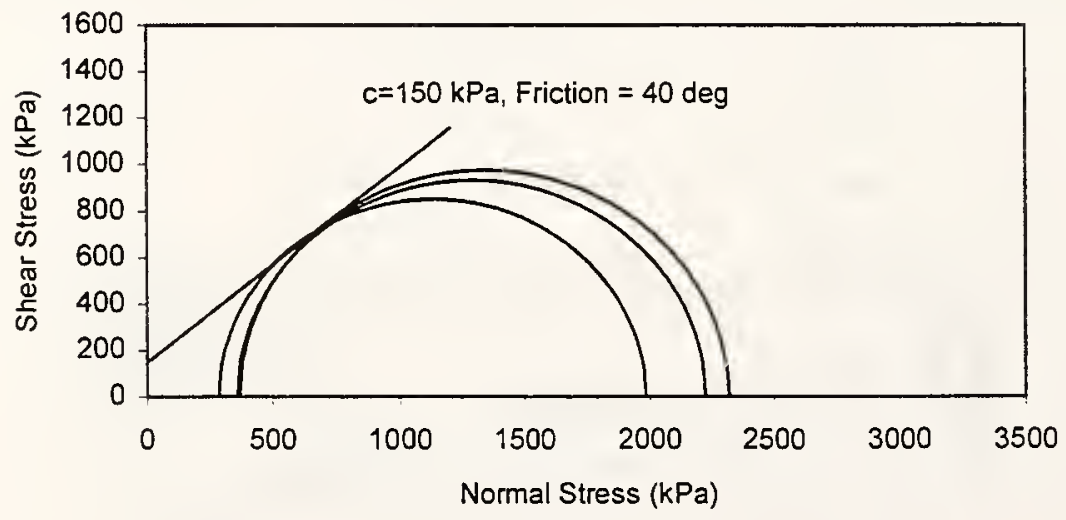

Figure 7.18 Mohr's Circles for \#8 Binder Mixture CU Tests at Loading Speed of 12.5 $\mathrm{mm} / \mathrm{min}$ 


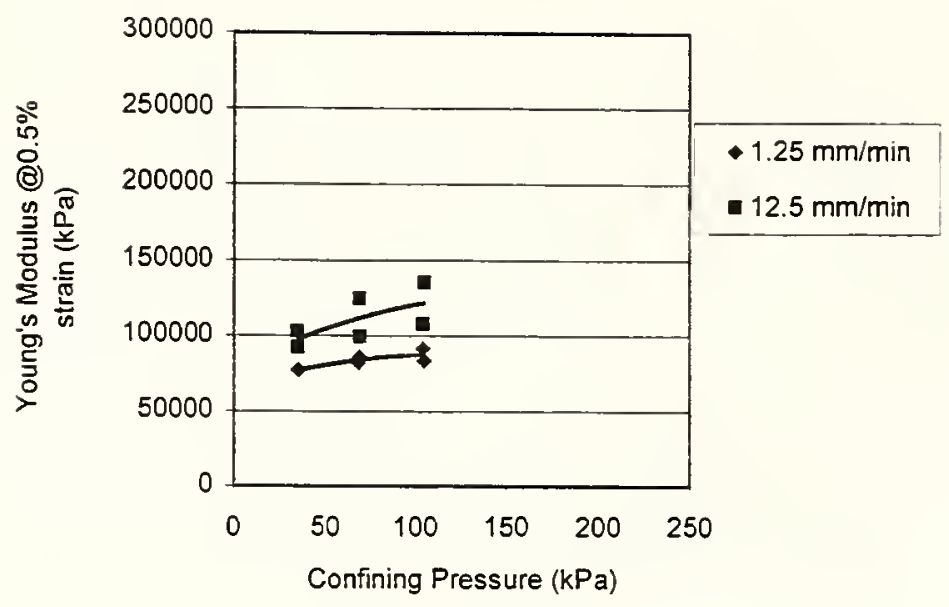

Figure 7.19 Young's Modulus vs. Confining Pressure for the \#8 Binder Mixture CU Tests (Figure Legend Denotes Loading Speed)

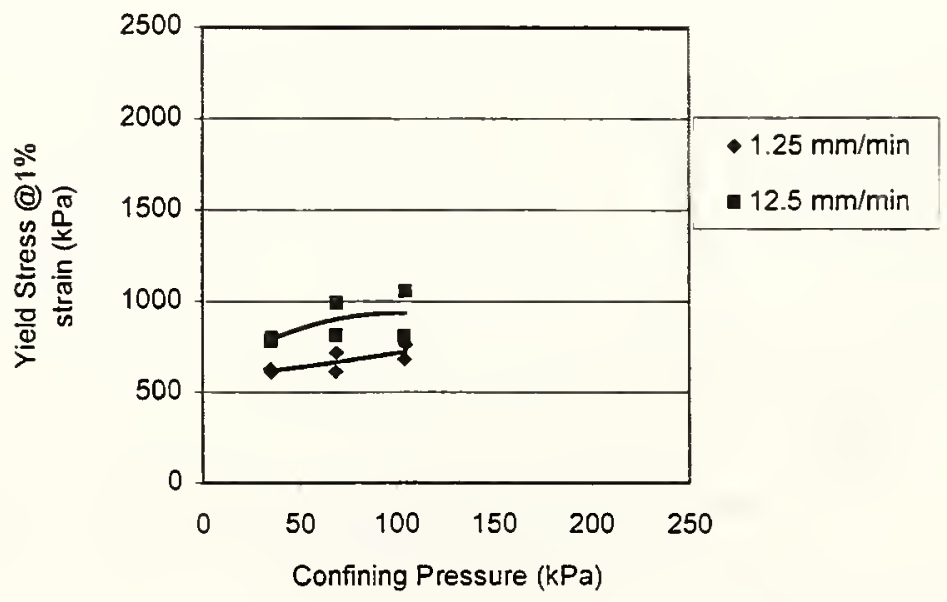

Figure 7.20 Yield Stress vs. Confining Pressure for the \#8 Binder Mixture CU Tests (Figure Legend Denotes Loading Speed) 


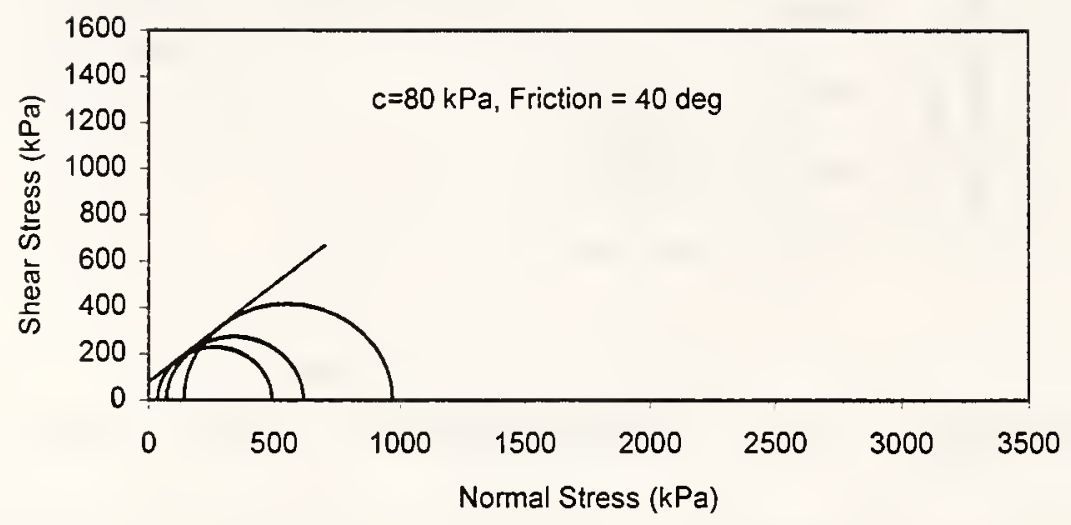

Figure 7.21 Mohr's Circles for \#8 Binder Mixture Dry Tests at Loading Speed of 1.25 $\mathrm{mm} / \mathrm{min}$

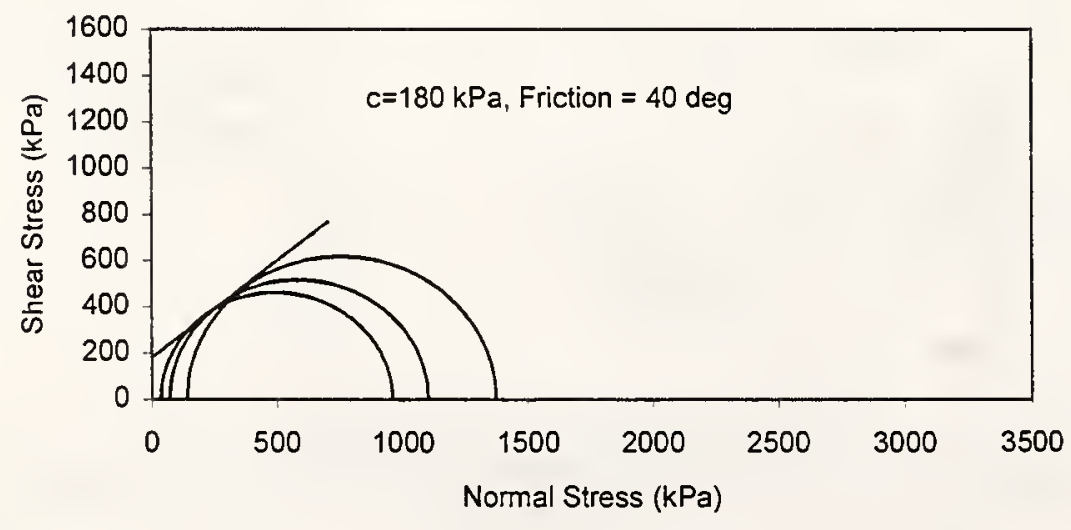

Figure 7.22 Mohr's Circles for \#8 Binder Mixture Dry Tests at Loading Speed of12.5 $\mathrm{mm} / \mathrm{min}$ 


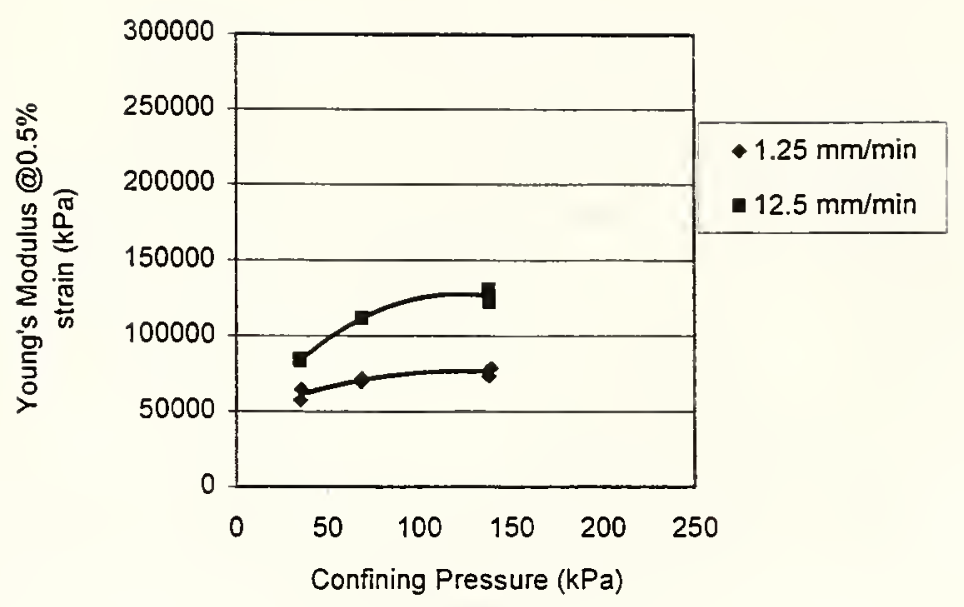

Figure 7.23 Young's Modulus vs. Confining Pressure for the \#8 Binder Mixture Dry Tests (Figure Legend Denotes Loading Speed)

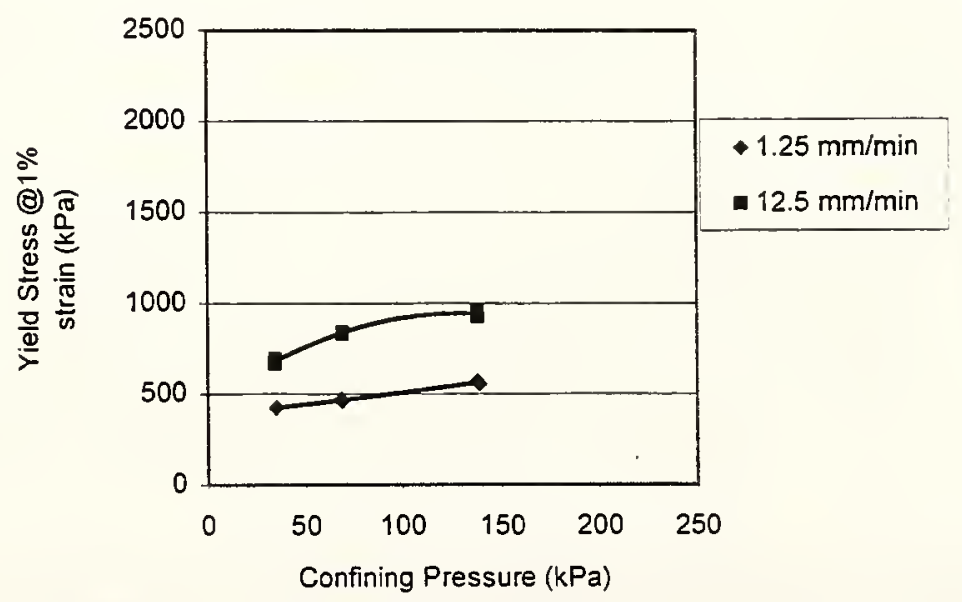

Figure 7.24 Yield Stress vs. Confining Pressure for the \#8 Binder Mixture Dry Tests (Figure Legend Denotes Loading Speed) 


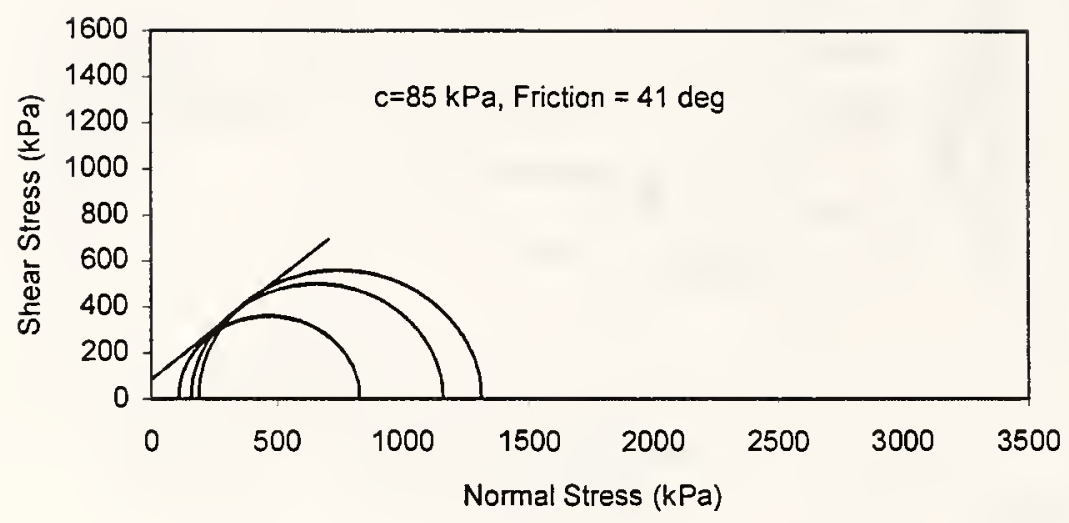

Figure 7.25 Mohr's Circles for \#5C OG Mixture CU Tests at Loading Speed of 1.25 $\mathrm{mm} / \mathrm{min}$

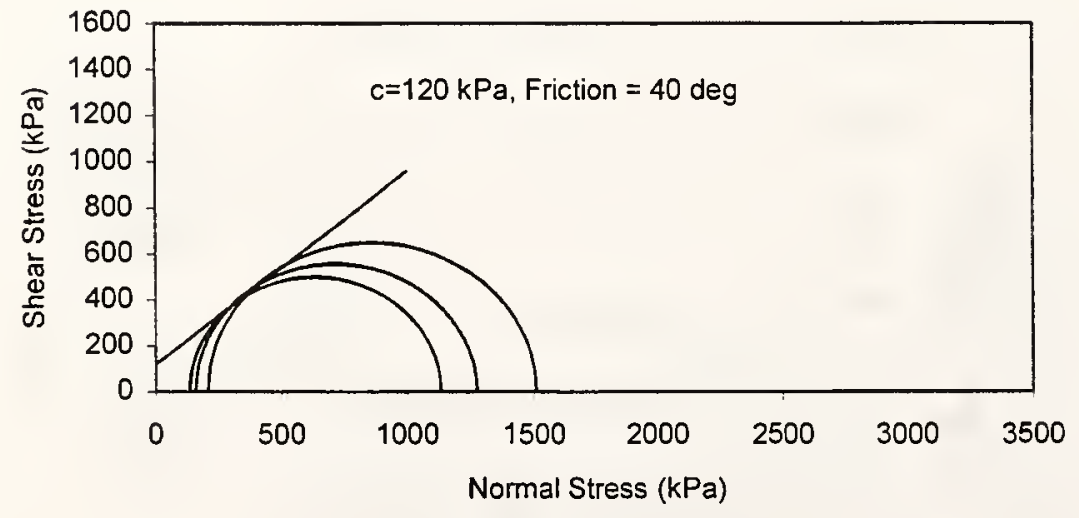

Figure 7.26 Mohr's Circles for \#5C OG Mixture CU Tests at Loading Speed of 12.5 $\mathrm{mm} / \mathrm{min}$ 


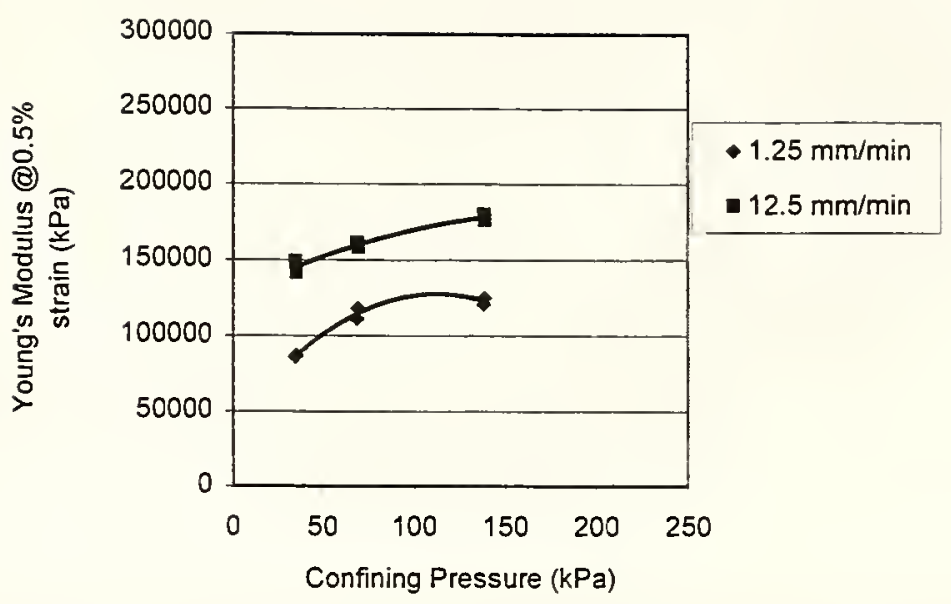

Figure 7.27 Young's Modulus vs. Confining Pressure for the \#5C OG Mixture CU Tests (Figure Legend Denotes Loading Speed)

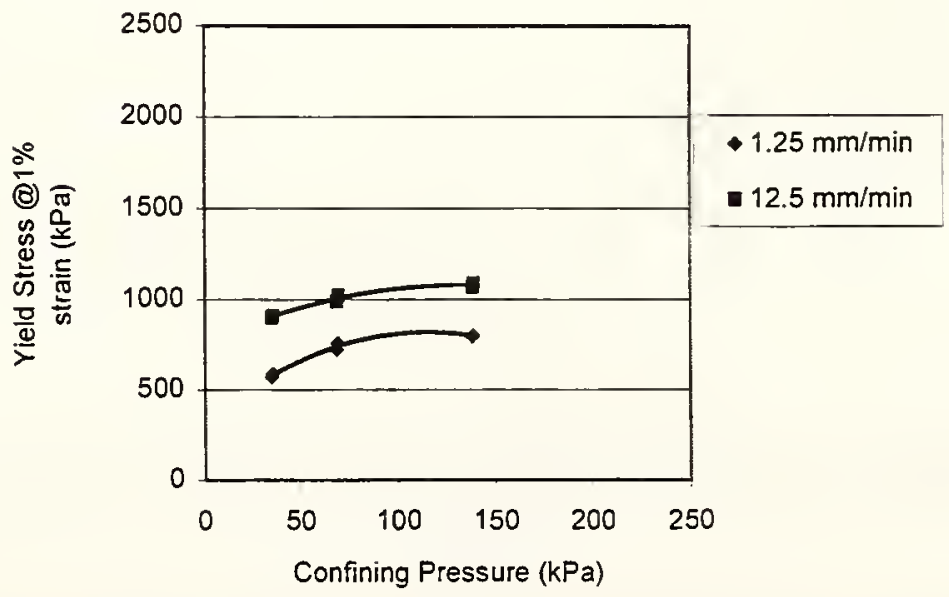

Figure 7.28 Yield Stress vs. Confining Pressure for the \#5C OG Mixture CU Tests (Figure Legend Denotes Loading Speed) 


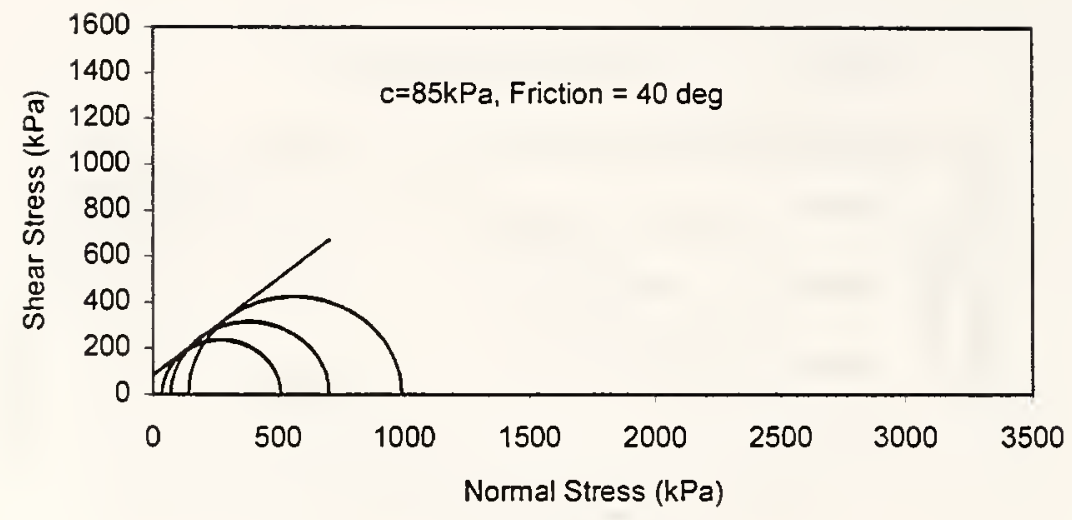

Figure 7.29 Mohr's Circles for \#5C OG Mixture Dry Tests at Loading Speed of 1.25 $\mathrm{mm} / \mathrm{min}$

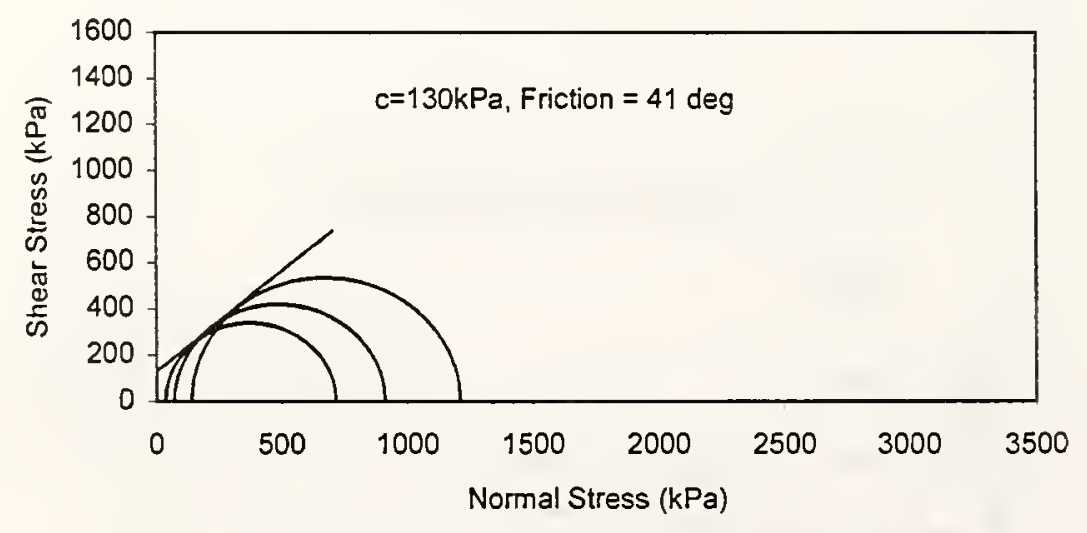

Figure 7.30 Mohr's Circles for \#5C OG Mixture Dry Tests at Loading Speed of 12.5 $\mathrm{mm} / \mathrm{min}$ 


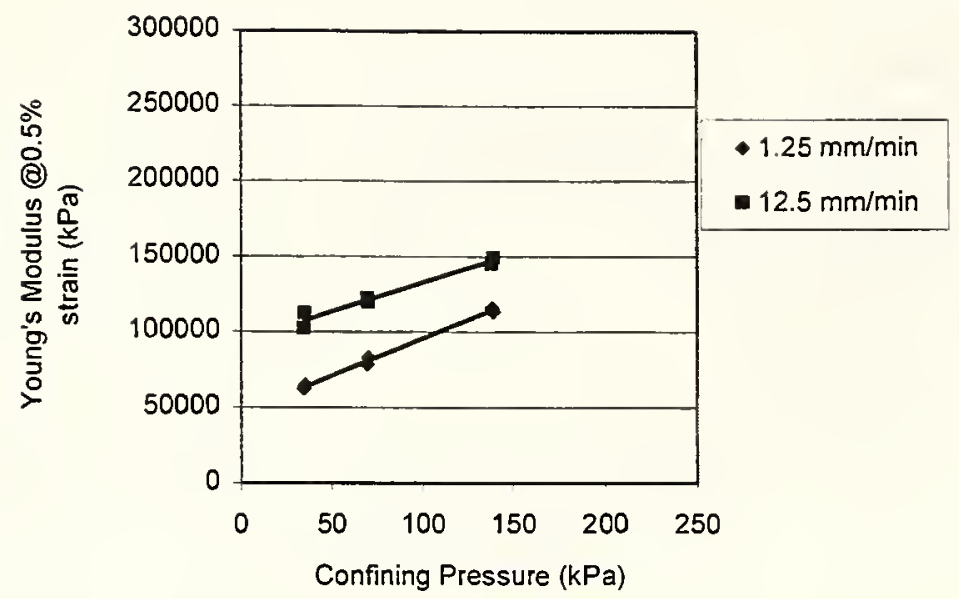

Figure 7.31 Young's Modulus vs. Confining Pressure for the \#5C OG Mixture Dry Tests (Figure Legend Denotes Loading Speed)

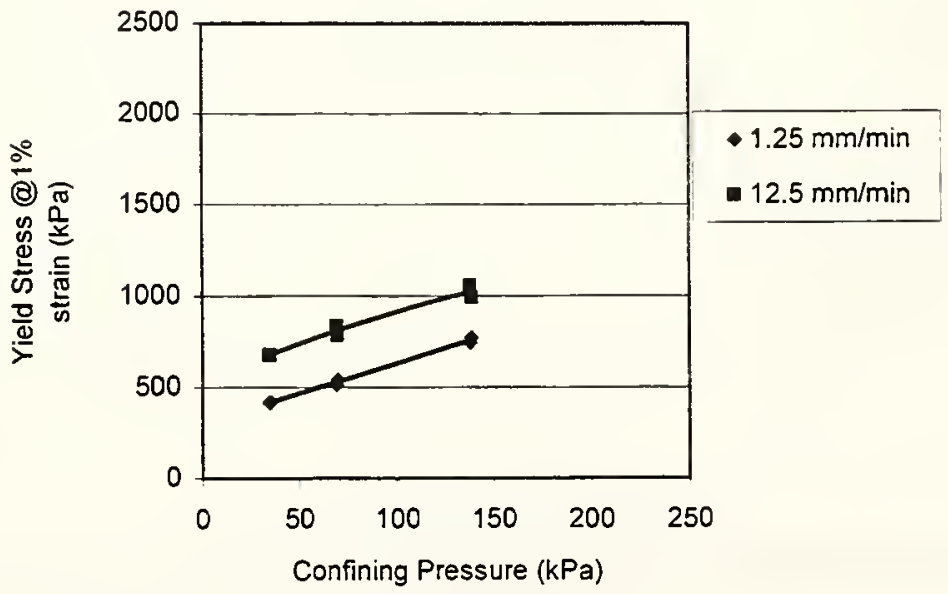

Figure 7.32 Yield Stress vs. Confining Pressure for the \#5C OG Mixture Dry Tests (Figure Legend Denotes Loading Speed) 


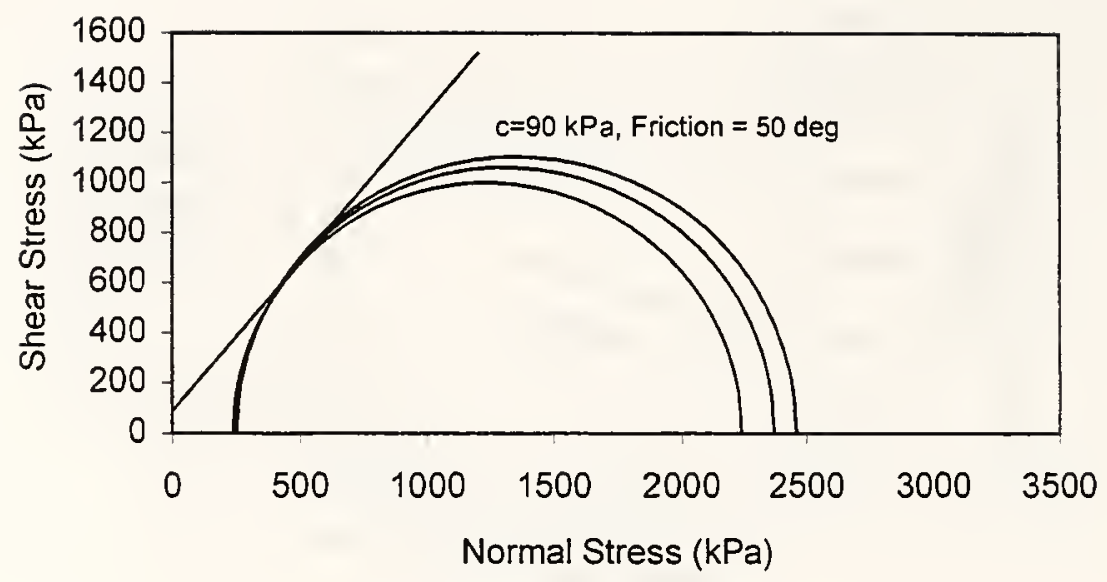

Figure 7.33 Mohr's Circles for \#5D Base Mixture CU Tests at Loading Speed of 1.25 $\mathrm{mm} / \mathrm{min}$

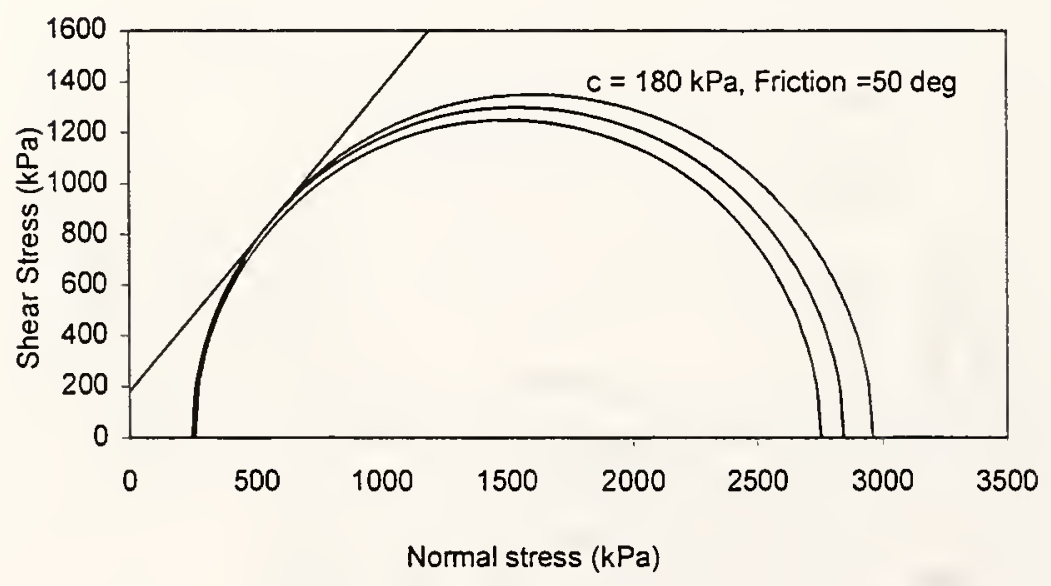

Figure 7.34 Mohr's Circles for \#5D Base Mixture CU Tests at Loading Speed of 12.5 $\mathrm{mm} / \mathrm{min}$ 


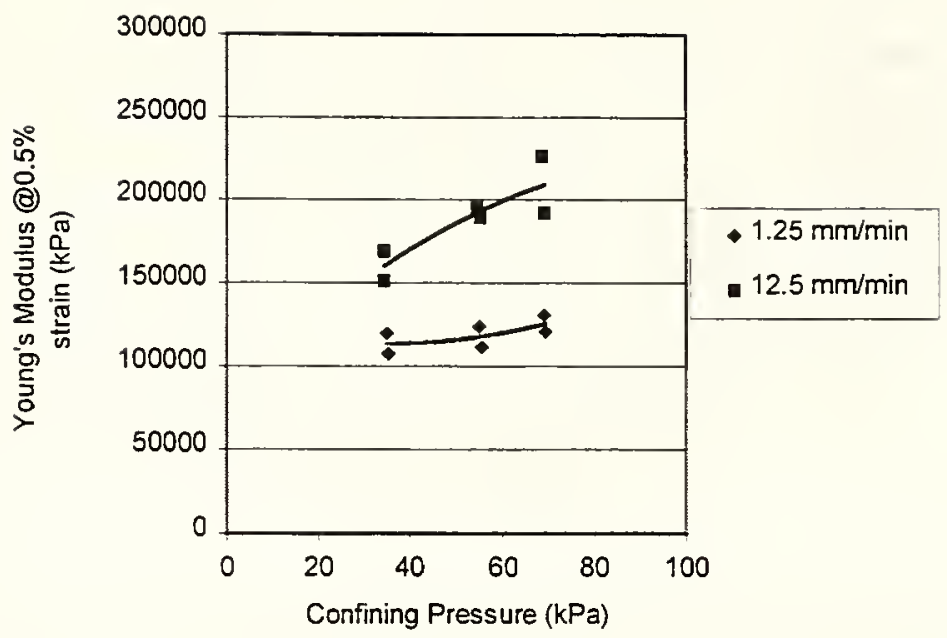

Figure 7.35 Young's Modulus vs. Confining Pressure for the \#5D Base Mixture CU Tests (Figure Legend Denotes Loading Speed)

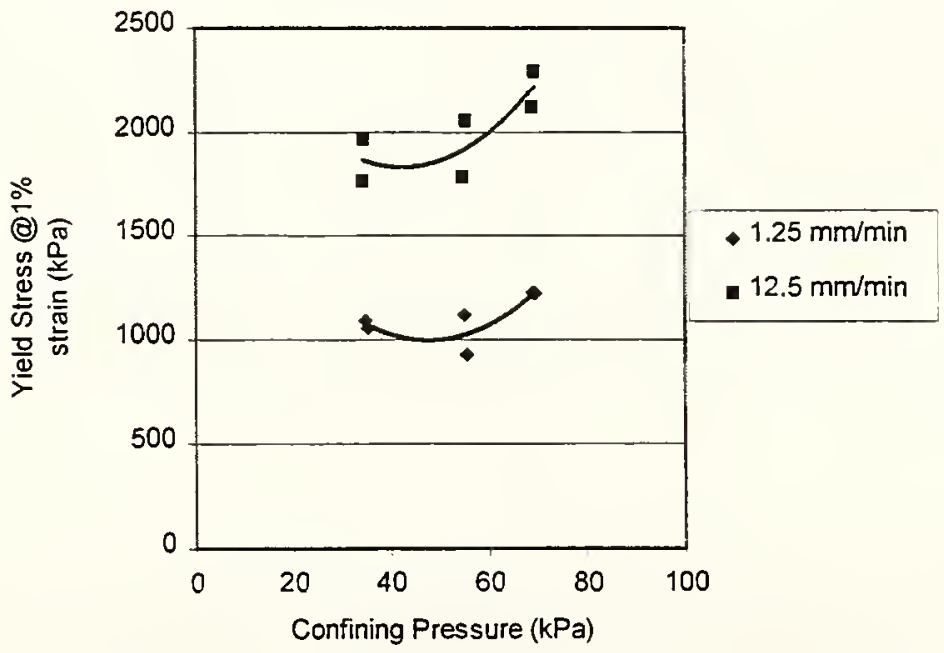

Figure 7.36 Yield Stress vs. Confining Pressure for the \#5D Base Mixture CU Tests (Figure Legend Denotes Loading Speed) 


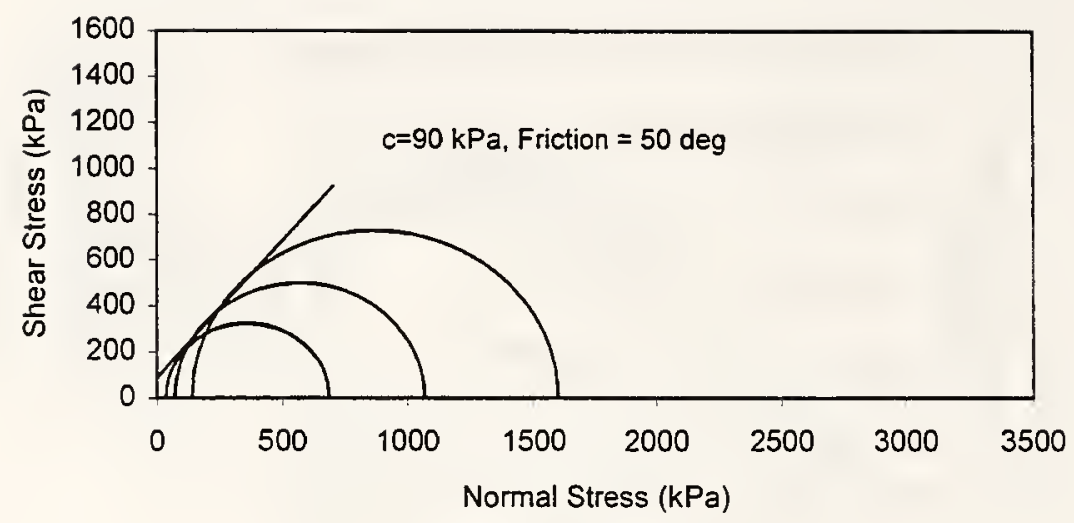

Figure 7.37 Mohr's Circles for \#5D Base Mixture Dry Tests at Loading Speed of 1.25 $\mathrm{mm} / \mathrm{min}$

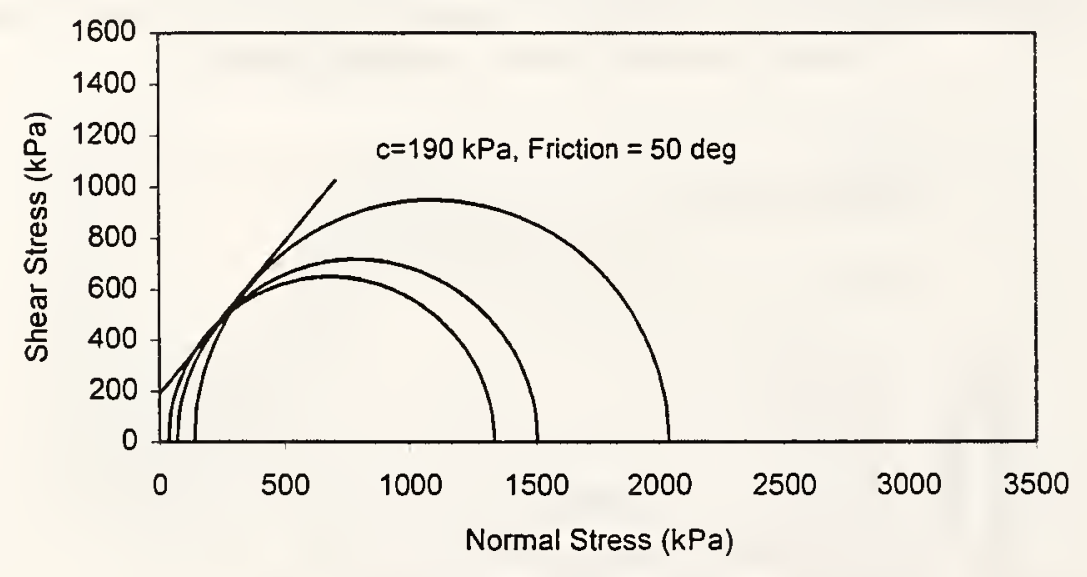

Figure 7.38 Mohr's Circles for \#5D Base Mixture Dry Tests at Loading Speed of 12.5 $\mathrm{mm} / \mathrm{min}$ 


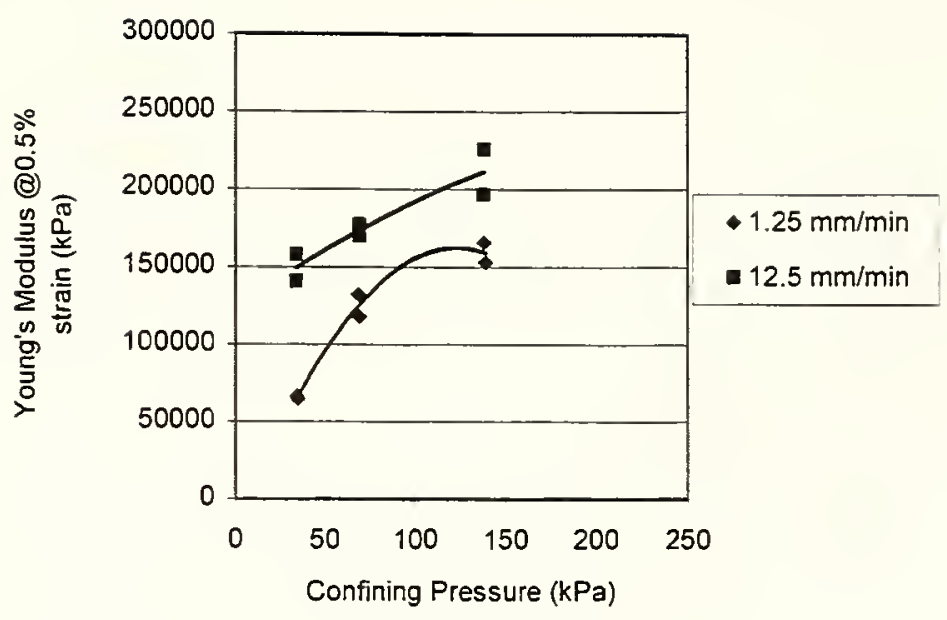

Figure 7.39 Young's Modulus vs. Confining Pressure for the \#5D Base Mixture Dry Tests (Figure Legend Denotes Loading Speed)

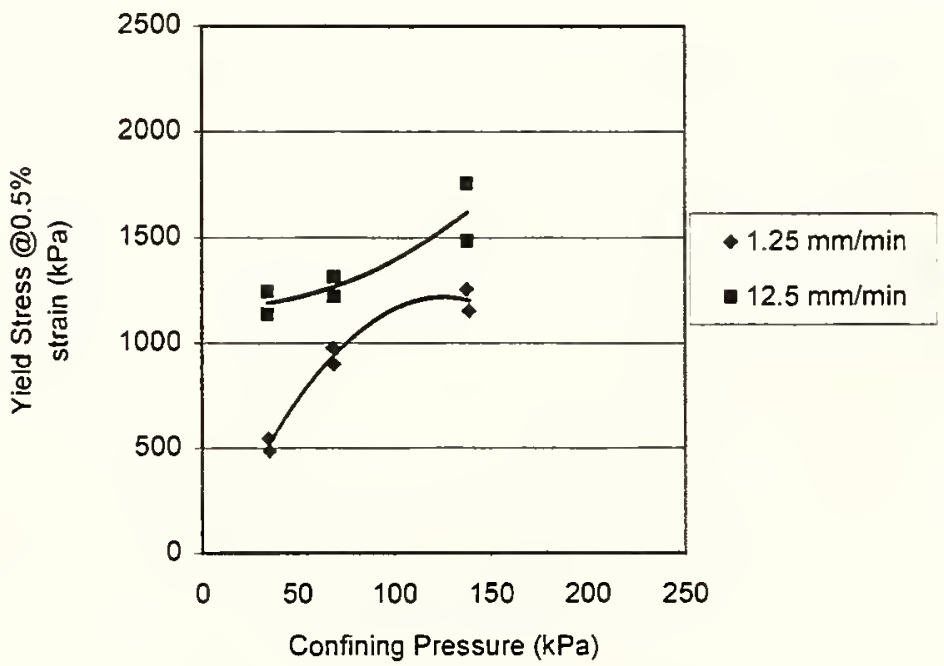

Figure 7.40 Yield Stress vs. Axial Strain for \#5D Base Mixture Dry Tests (Figure Legend Denotes Loading Speed) 


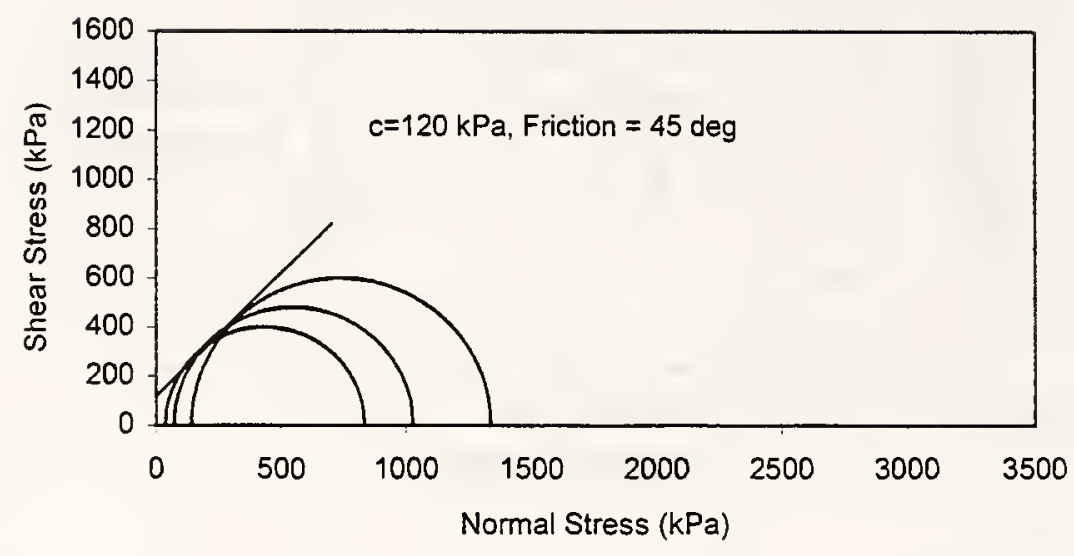

Figure 7.41 Mohr's Circles for \#2 Base Mixture CU Tests at Loading Speed of 1.25 $\mathrm{mm} / \mathrm{min}$

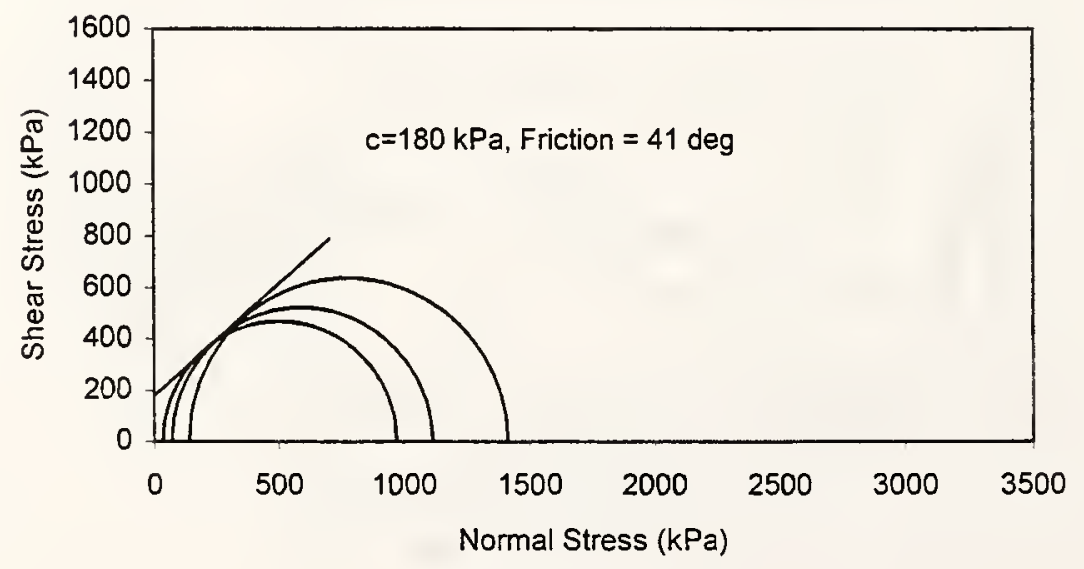

Figure 7.42 Mohr's Circles for \#2 Base Mixture CU Tests at Loading Speed of 12.5 $\mathrm{mm} / \mathrm{min}$ 


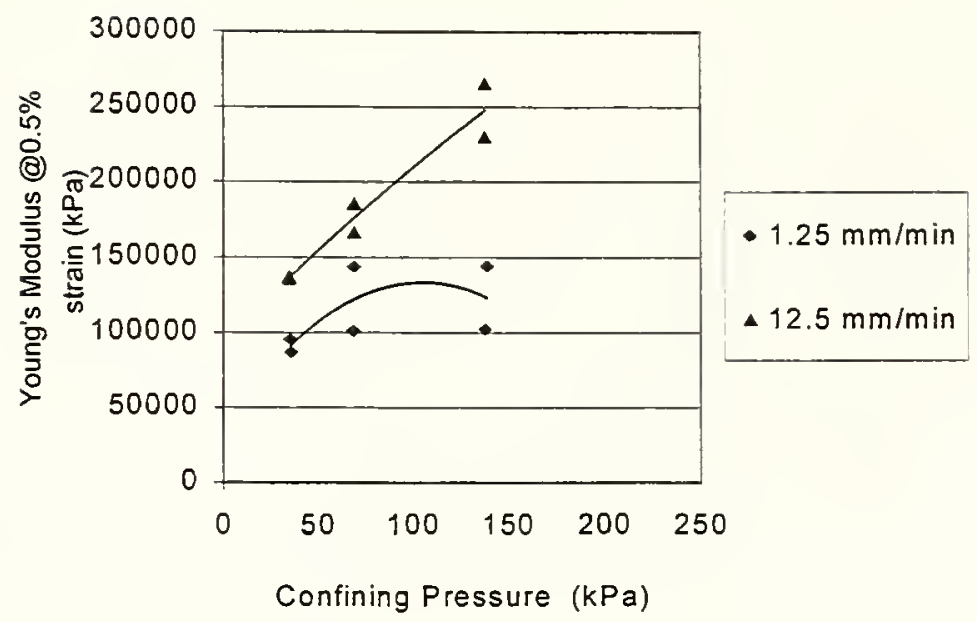

Figure 7.43 Young's Modulus vs. Confining Pressure for \#2 Base Mixture CU Tests (Figure Legend Denotes Loading Speed)

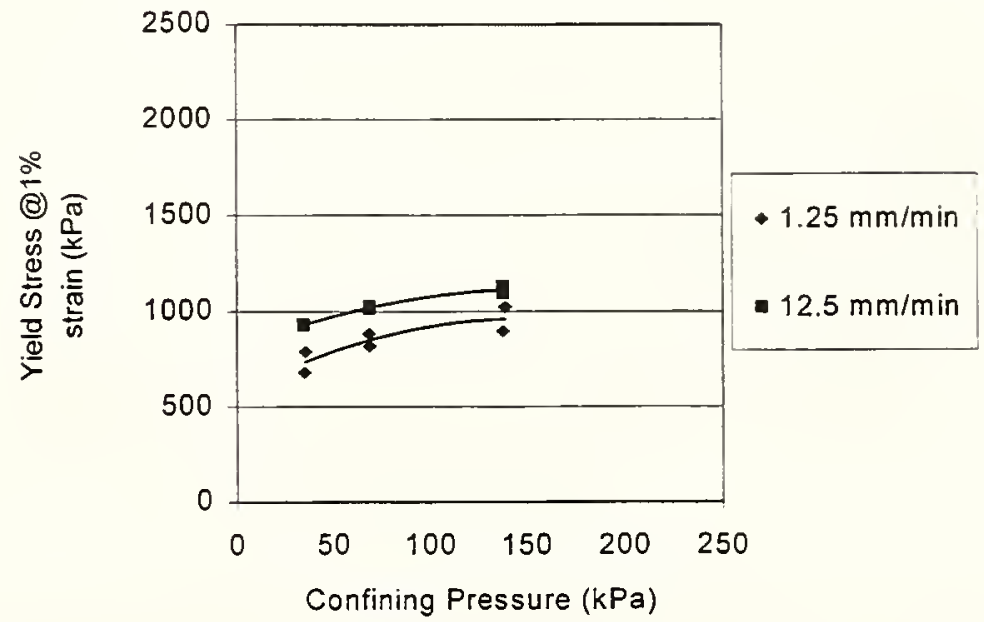

Figure 7.44 Yield Stress vs. Confining Pressure for \#2 Base Mixture CU Tests (Figure Legend Denotes Loading Speed) 


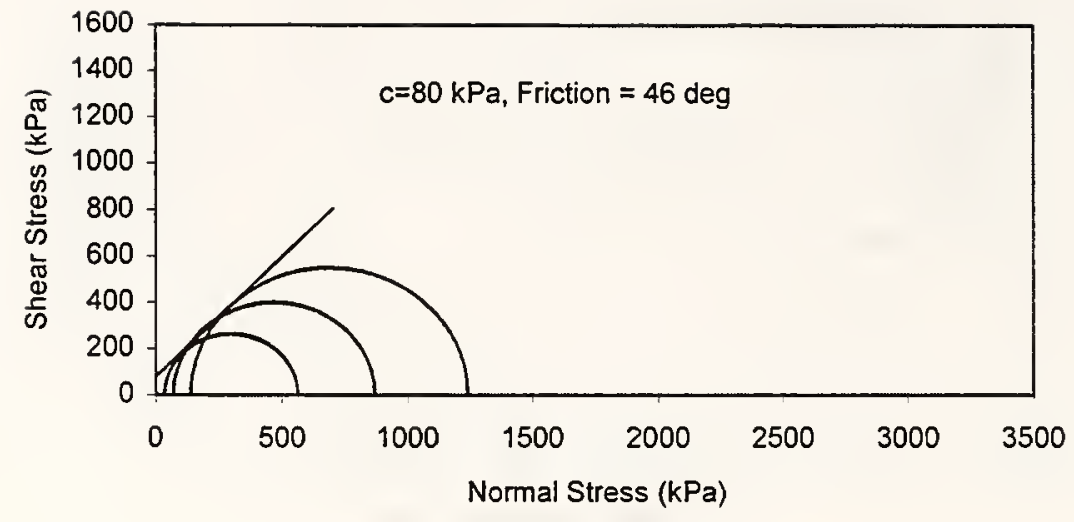

Figure 7.45 Mohr's Circles for \#2 Base Mixture Dry Tests at Loading Speed of 1.25 $\mathrm{mm} / \mathrm{min}$

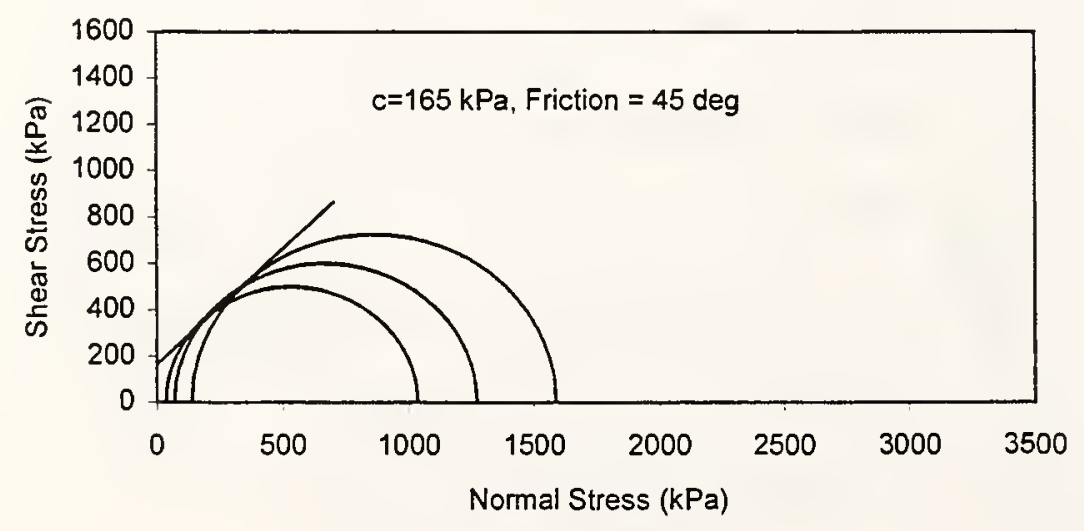

Figure 7.46 Mohr's Circles for \#2 Base Mixture Dry Tests at Loading Speed of 12.5 $\mathrm{mm} / \mathrm{min}$ 


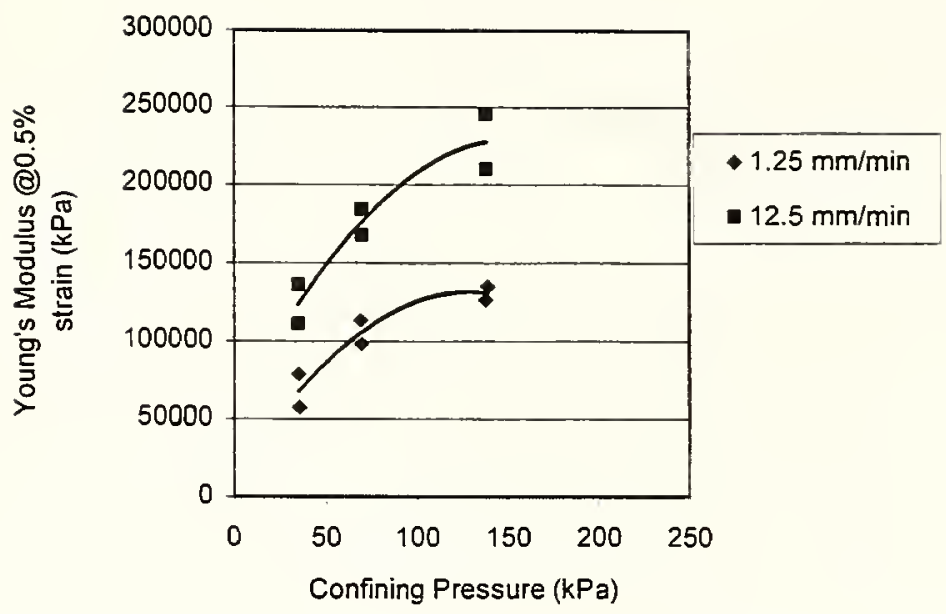

Figure 7.47 Young's Modulus vs. Confining Pressure for \#2 Base Mixture Dry Tests (Figure Legend Denotes Loading Speed)

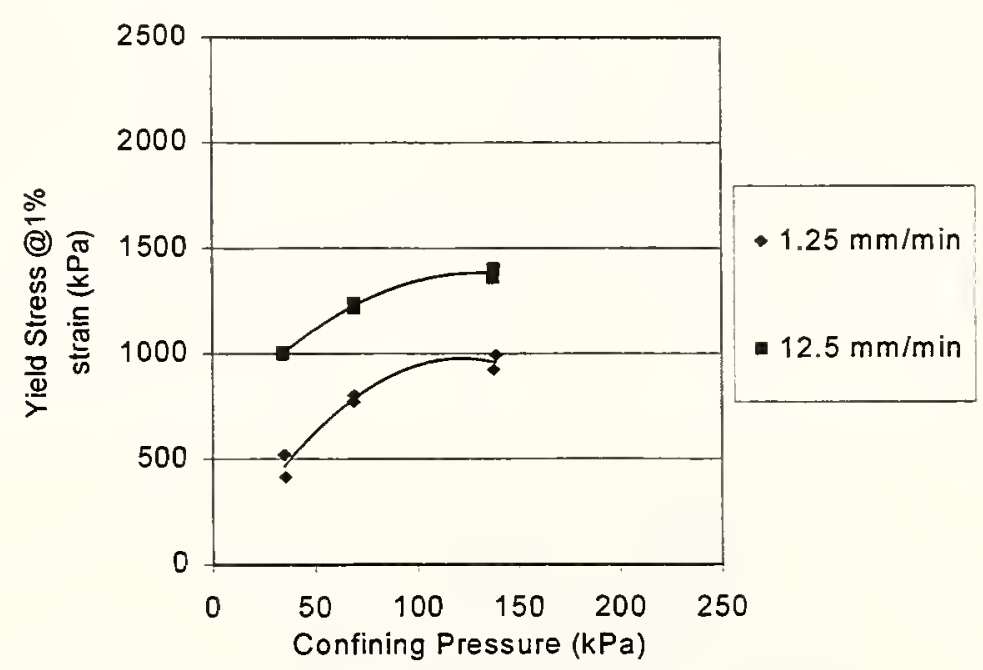

Figure 7.48 Yield Stress vs. Confining Pressure for \#2 Base Mixture Dry Tests (Figure Legend Denotes Loading Speed) 


\section{CHAPTER 8 STABILITY AND DEFORMATION ANALYSIS}

Pavements are a complex system of layers having markedly different material characteristics. Response of the pavement system to loads is affected by these varying material characteristics as well as by interface and boundary conditions. Loads can be moving which cause changing stress conditions. The finite element method (FEM) has proven to be effective in modeling such complex problems. "The finite element method provides a powerful technique for analysis of stresses and movements in earth masses, and it has already been applied to a number of practical problems" [Duncan, 1980]. Previous work by White, et al $[1993,1994]$ has applied FEM to analysis of pavement systems. These studies considered moving wheel loads and FWD impulse loads. As a result, the FEM was utilized in the stability and deformation analysis of the pavement systems studied in this research.

\subsection{Model Geometry and Finite Element Mesh}

Shear flow is one of the major mechanisms of pavement failure. In order to avoid shear flow in all materials and at all depths the pavement should be proportioned and materials specified to maintain the shear strength higher than the imposed shear stresses. The open graded drainage layer and collector trench in these test sections are potentially weak pavement components. A consequence of shear flow is rutting. Several models of 
the pavement system were studied. These models included different geometry and mesh sizes. In a model of the full pavement driving lane, it was found that the stresses and deformations for the inside and outside wheel path are close. As a result, symmetry was assumed about the lane centerline. The subsequent model consists of one half of a driving lane which is $1830 \mathrm{~mm}$ wide and includes $600 \mathrm{~mm}$ of the shoulder. The shoulder width includes the collector pipe trench. Pavement length modeled in the longitudinal direction is $9.76 \mathrm{~m}$. In the center $4.88 \mathrm{~m}$ in the longitudinal direction the pavement materials are modeled in detail. There are $2.44 \mathrm{~m}$ sections on each end that are represented with infinite linear elements.

Figure 8.1 shows a plan view of the model geometry and mesh in the $x-y$ plane. Figure 8.2 shows the geometry and mesh of the model in the $x-z$ plane. Figure 8.3 shows a 3-D view of the FEM model and Figure 8.4 shows the deformed full pavement driving lane model with the shoulder on the right. In this figure the vertical deformation scale is magnified.

The finite element mesh was generated using PATRAN [1997]. PATRAN is a graphical user interface (GUI) for generating FE model mesh. An input file for ABAQUS [1997] can be generated from PATRAN. For analysis, an eight-node solid, brick stressdisplacement element (C3D8) is utilized. Smaller element aspect ratios produce more accurate results. However, there is a trade off because the problem size is limited by computation capacity and time. For this analysis, the mesh generally has an aspect ratio of less than 5. A refined mesh was used in the traffic region. The maximum aspect ratio in this area is 3.9. All of the asphalt layers are modeled as a visco-elastic-plastic material using the extended Drucker-Prager model in ABAQUS. The granular materials are 


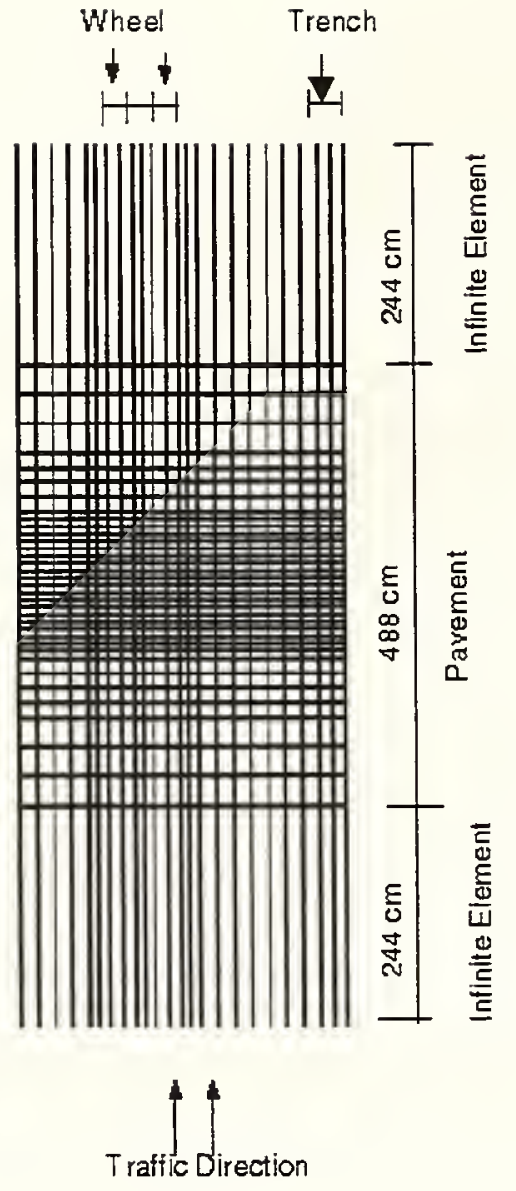

Figure 8.1 Plan View of the Model and FEM Mesh ( $x-y$ Plane $)$ 


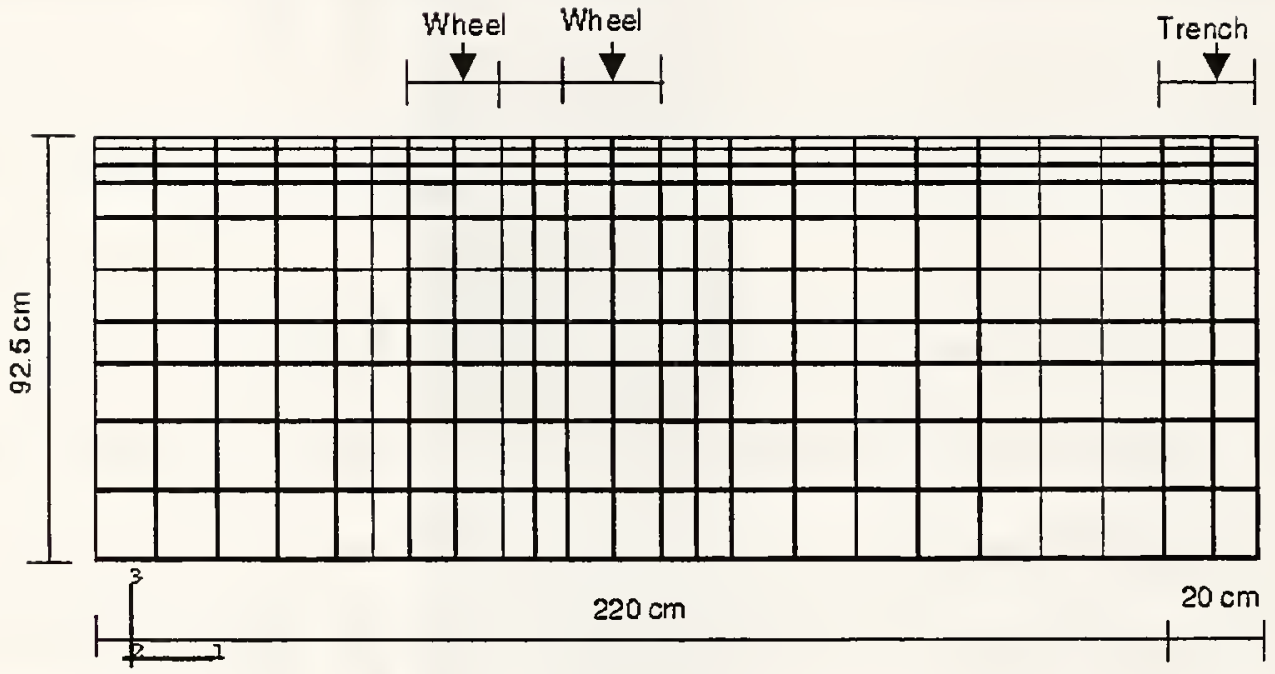

Figure 8.2 Cross Section of the Model and FEM Mesh ( $x$-z Plane) 


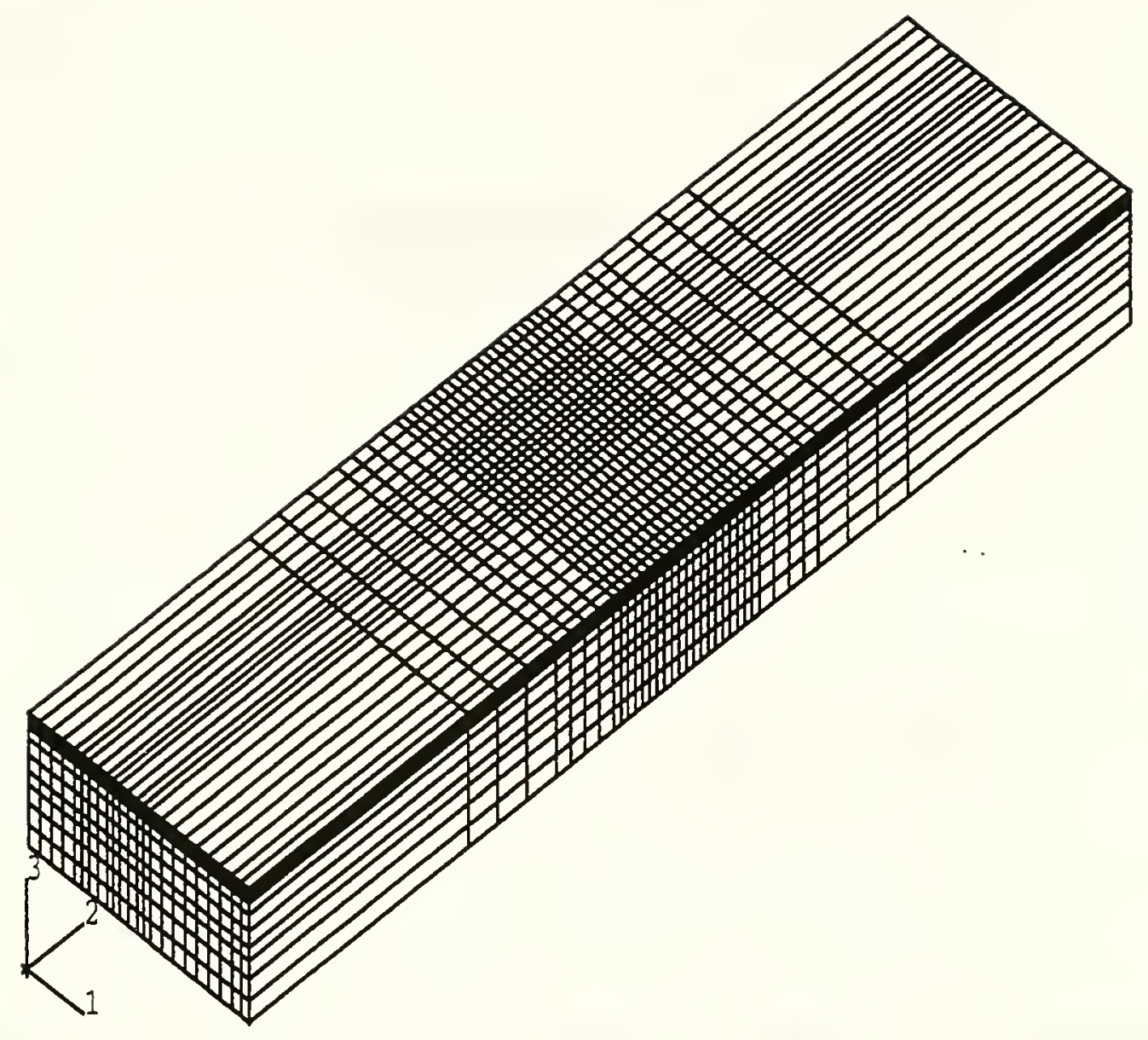

Figure 8.3 Three-D View of the Model and Mesh (x-y-z) 

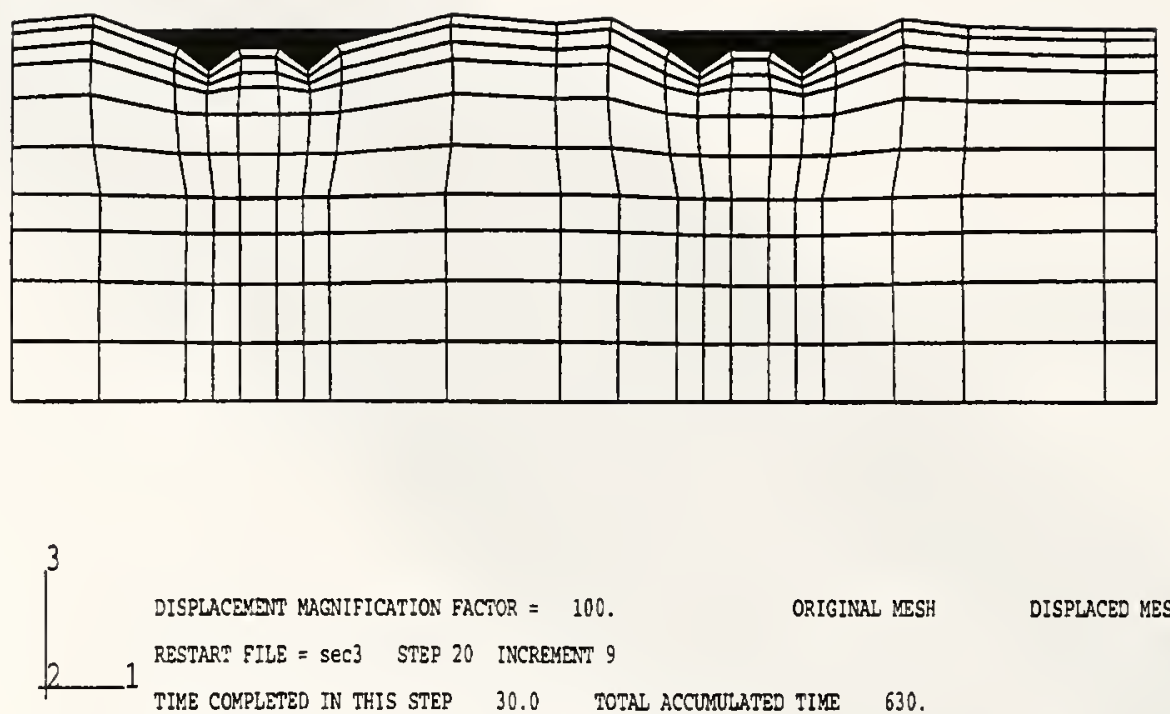

DISPLACEYINT MAGNIFICATION FACTOR $=100$.

ORIGINAL MESH

DISPLACED MESY

RESTAR? FILE $=\sec 3 \quad$ STEP 20 INCREMENT 9

TIME COMPLETED IN THIS STEP 30.0 TOTAL ACCUULATED TIME 630.

ABAQUS VERSION: $5.8-1$ DATE: $12-$ JAN-1999 TTME: $20: 28: 29$

Figure 8.4 Predicted Rutting Profile in the Full Driving Lane Model (Without Wander) 
modeled as an elastic-plastic material based on the extended Drucker-Prager model. Data indicates that the subgrades are predominantly unsaturated. As a result, the subgrades are also modeled as elastic-plastic materials using the extended Drucker-Prager model.

Material properties used in this analysis were obtained from laboratory tests. Properties for the subgrade and the \#53 unbound aggregate were obtained from CU tests. The \#8 unbound aggregate trench material properties are from the CD test. All of the asphalt mixture properties are from dry tests at a loading speed of $1.25 \mathrm{~mm} / \mathrm{min}$ to be conservative. Material properties used in this analysis are summarized in Table 8.1. Values of Poisson's ratio are assumed.

Table 8.1 Material properties for FEM Analysis

\begin{tabular}{|c|c|c|c|c|}
\hline \multicolumn{2}{|c|}{ Material } & $\begin{array}{c}\text { Cohesion } \\
(\mathrm{kPa})\end{array}$ & $\begin{array}{c}\text { Friction } \\
\text { Angle } \\
\text { (Degree) }\end{array}$ & $\begin{array}{c}\text { Poisson } \\
\text { Ratio }\end{array}$ \\
\hline \multicolumn{2}{|c|}{ \#11 Surface } & 95 & 40 & 0.35 \\
\hline \multicolumn{2}{|c|}{ \#9 Binder } & 120 & 40 & 0.35 \\
\hline \multicolumn{2}{|c|}{ \#8 Binder } & 80 & 40 & 0.35 \\
\hline \multicolumn{2}{|c|}{$\# 5 \mathrm{C}$} & 85 & 40 & 0.35 \\
\hline \multicolumn{2}{|c|}{$\# 5 \mathrm{D}$} & 90 & 50 & 0.35 \\
\hline \multicolumn{2}{|c|}{$\# 2$} & 80 & 46 & 0.35 \\
\hline \multicolumn{2}{|c|}{ \#53 Aggregate } & 15 & 53 & 0.3 \\
\hline \multicolumn{2}{|c|}{ \#8 Aggregate } & 15 & 33 & 0.3 \\
\hline \multirow{3}{*}{ Subgrade } & Section 1 & 11 & 29 & 0.3 \\
\hline & Section 2 & 27.6 & 23 & 0.3 \\
\hline & Section 3 & 10.3 & 29 & 0.3 \\
\hline
\end{tabular}


Elastic Moduli are estimated with the equations presented in Chapter 6 and 7 and are based on the actual stress conditions. Yield stress can be calculated from the equations presented in Chapter 2, i.e. $\sigma_{c}^{\circ}$.

\subsection{Boundary Conditions}

The pavement is long in the direction of traffic. Therefore, infinite elastic elements are used for a boundary condition in the longitudinal direction. Infinite elements are assigned the same elastic modulus as the adjoining material. Bottom and side boundaries are taken as elastic foundations. The stiffnesses of these foundations are selected based on FEM peak deformations at offsets where FWD deflections were measured. A description of this process is given in the following section. The lane center line (side) boundary is fixed in the normal direction (x-symmetric boundary).

\section{$\underline{\text { 8.3 FWD Tests and Model Verification }}$}

FWD tests of the three test sections were modeled with the FEM and pavement responses predicted. These predicted responses were compared with FWD test data. Data from the laboratory tests were used for the pavement material properties.

The three sections were tested by INDOT with their FWD in September 1998. The FWD load is modeled as a dynamic load with a duration of $30 \mathrm{~ms}$. Figure 8.5 shows FWD loading and corresponding sensor deflection history [Hua, 1998]. In the analysis, the FWD load is applied to four neighboring elements such that the total area approximates the FWD loading plate area. Data from the tests only include the peak deflection for various offsets from the load. As a result, peak deflection is used as the 
evaluation criteria. The real FWD load varies slightly from test location to test location. As a result, in the model, the load is assumed to be $40860 \mathrm{~N}$ (9000lbs). Measured deformations are normalized based on the difference in actual load and the $40860 \mathrm{~N}$ (9000lbs) load [Hua, 1998]. The mean and standard deviation of deflections are shown for sections 1,2 and 3 in Tables $8.2,8.3$ and 8.4 respectively. Figures 8.6 to 8.8 show the comparison of the peak deflections at offsets at which FWD induced deflections were measured. The peak deflections are usually represented as a "deflection basin" in layered elastic analysis. In fact, the peak deflections occur at different times. "Peak deflections" in this analysis are true predicted values from a dynamic analysis and therefore compare directly to the measured values. Maximum and minimum FWD deflections and predicted deflections for sections 1,2 and 3 are shown in figures 8.6, 8.7, and 8.8, respectively. For all three sections, the FEM predicted peak deflections fall between the measured maximum and minimum deflections.

Table 8.2 Statistical Data for the FWD on Section 1

\begin{tabular}{|c|c|c|c|c|c|c|}
\hline Offset $(\mathrm{mm})$ & 0 & 304.8 & 609.6 & 914.4 & 1219.2 & 1524 \\
\hline $\begin{array}{c}\text { Mean Deflection } \\
\left(\times 10^{-2} \mathrm{~mm}\right)\end{array}$ & 8.66 & 6.35 & 5.09 & 4.11 & 3.23 & 2.55 \\
\hline Standard Deviation & 0.45 & 0.39 & 0.344 & 0.29 & 0.243 & 0.202 \\
\hline
\end{tabular}


Table 8.3 Statistical Data for the FWD on Section 2

\begin{tabular}{|c|c|c|c|c|c|c|}
\hline Offset $(\mathrm{cm})$ & 0 & 304.8 & 609.6 & 914.4 & 1219.2 & 1524 \\
\hline $\begin{array}{c}\text { Mean Deflection } \\
\left(\mathrm{x} 10^{-2} \mathrm{~mm}\right)\end{array}$ & 9.66 & 7.21 & 5.48 & 4.21 & 3.14 & 2.34 \\
\hline Standard Deviation & 0.217 & 0.189 & 0.157 & 0.127 & 0.100 & 0.094 \\
\hline
\end{tabular}

Table 8.4 Statistical Data for the FWD on Section 3

\begin{tabular}{|c|c|c|c|c|c|c|}
\hline Offset $(\mathrm{mm})$ & 0 & 304.8 & 609.6 & 914.4 & 1219.2 & 1524 \\
\hline $\begin{array}{c}\text { Mean Deflection } \\
\left(\mathrm{x} \mathrm{10} 0^{-2} \mathrm{~mm}\right)\end{array}$ & 9.70 & 7.28 & 5.67 & 4.43 & 3.34 & 2.60 \\
\hline $\begin{array}{c}\text { Standard } \\
\text { Deviation }\end{array}$ & 0.345 & 0.391 & 0.341 & 0.295 & 0.242 & 0.204 \\
\hline
\end{tabular}




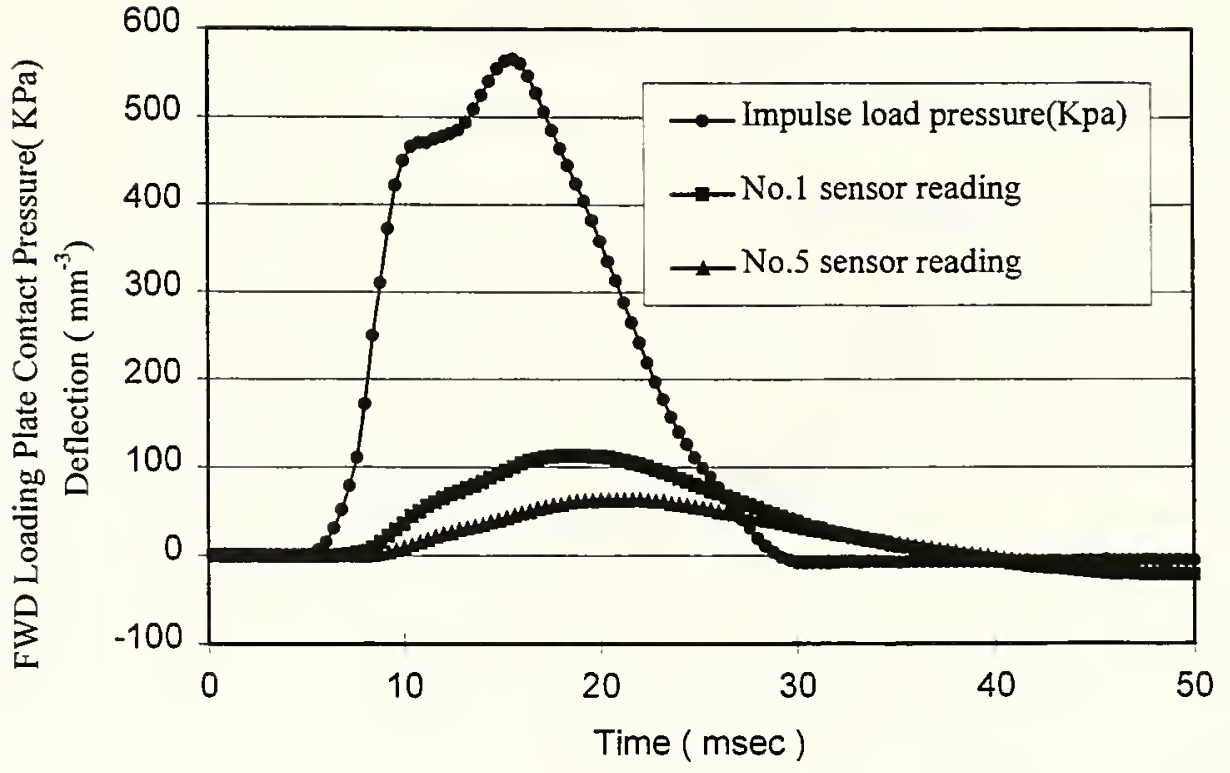

Figure 8.5 A Typical FWD Loading and Sensor Deflection Histories [Hua, 1998]

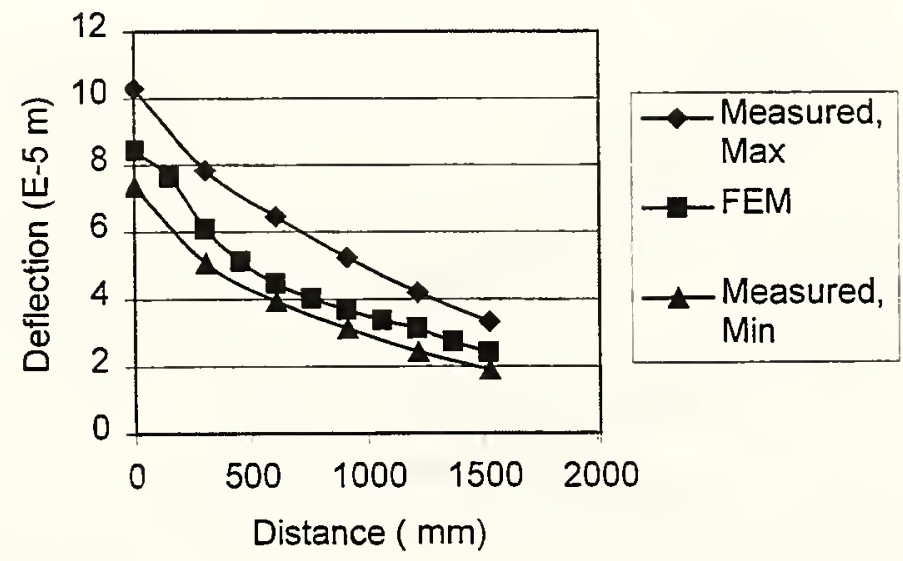

Figure 8.6 Comparison of FWD and Predicted FEM Deflections, Section 1 


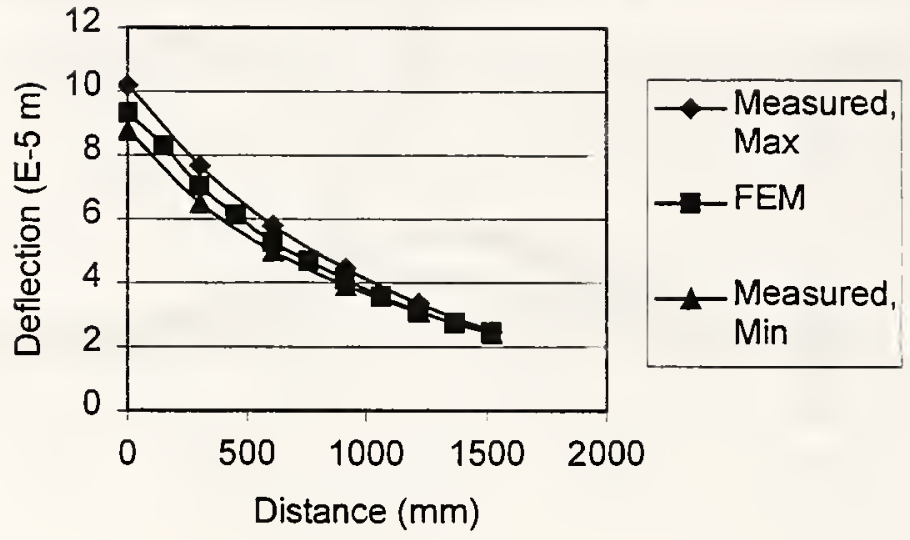

Figure 8.7 Comparison of FWD and Predicted FEM Deflection, Section 2
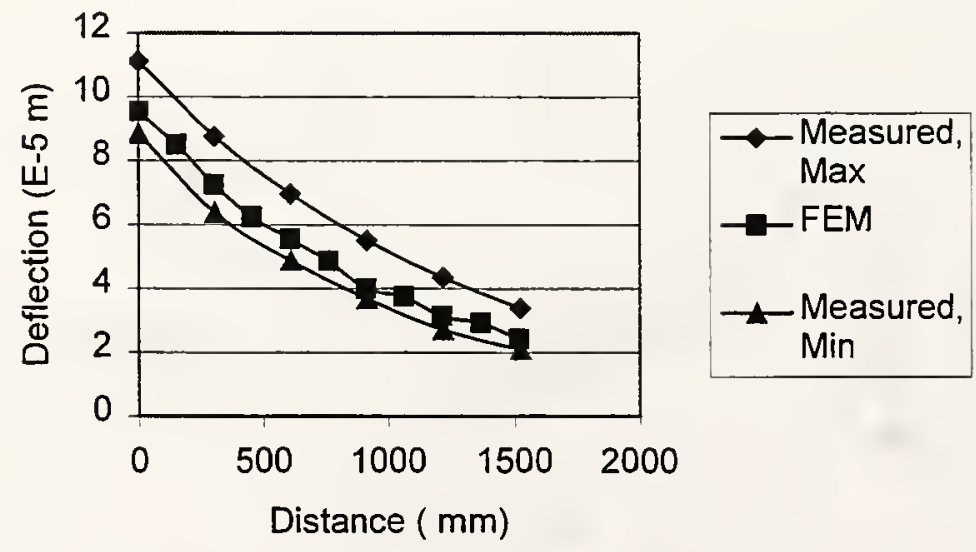

Figure 8.8 Comparison of FWD and predicted FEM Deflection, Section 3 


\subsection{Rutting Prediction}

\subsubsection{Traffic Information}

Rutting of in-service pavements accumulates over time from repeated load applications. Also, the applications occur over a wide range of temperatures. Stiffness of asphalt mixtures and therefore their rutting resistance is directly related to temperature. Both the number of loads and temperature have to be addressed in a rutting analysis.

Traffic data for I-469 were obtained from the INDOT Roadway Management Office. Total eastbound traffic on I-469 is about 8800 vehicles per day, which includes 1700 trucks. Previously a decision was made to conduct all triaxial tests on asphalt samples at a temperature resulting from the measured average seven-day high temperature. The rutting analysis was conducted through the summer of 1998 and for temperatures that would equal or exceed $40{ }^{\circ} \mathrm{C}$. Total time the pavement surface temperature was equal or above $40{ }^{\circ} \mathrm{C}$ was determined by examining the measured temperatures through the summer of 1998 . This time was determined to be 140 hours. Corresponding traffic was obtained by multiplying the hourly truck traffic by the total time. This means that during the three years, loads from approximately 10,000 trucks were applied when the pavement surface temperature was equal to or above $40^{\circ} \mathrm{C}$.

Over seventy percent of the trucks on Indiana highways have five axles. In this analysis loads from the two sets of tandem axles are modeled. The front axle of the truck is neglected. As a result, the 10,000 trucks are represented by 40,000 axle loads in the FEM analysis.

Even with current computer capacity, application of more than a few loads is prohibitive. As a result, a total loading time was determined based on the time for 10,000 
trucks to travel the length of a tire print traveling at a speed $96 \mathrm{~km} /$ hour. This total loading time was used with the creep rate model described in Chapter 2 to predict rutting. Potential transverse wander of traffic was included in the analysis. Wander was assigned to follow a normal distribution. Maximum wander was $127 \mathrm{~mm}$ at each side. Figure 8.9 shows the load distribution in the analysis.

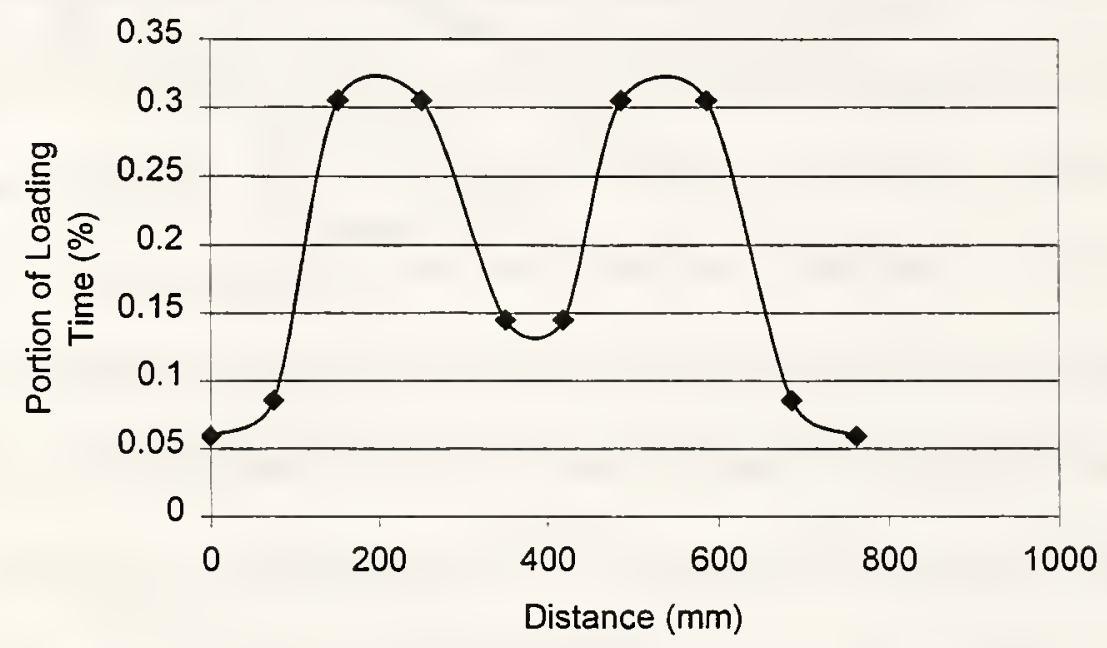

Figure 8.9 Loading Time Distribution of the Dual Tire

\subsubsection{Creep Rate Model Calibration}

Asphalt concrete is a time, temperature and stress dependent material. The elastic properties do not contribute to permanent deformation and can be modeled by modulus of elasticity and Poisson's ratio. The plastic properties contribute to the permanent deformation, which is cumulative under repeated loading. Results of FEM studies show that a creep rate model can successfully model accumulation of asphalt mixture 
permanent deformation. The constitutive equation for the creep rate model used is described in Chapter two.

Before in-service pavement rutting can be predicted using FEM, the creep rate model parameters (A, $m$, and $n$ ) of each asphalt layer must first be determined. Reasonable estimates of the creep rate model parameters for each asphalt mixture used in the in-service pavement sections were obtained from tests with a laboratory wheel test device. The Purdue wheel (PURWheel) test device was designed and fabricated to evaluate the rutting performance of bituminous mixtures [Pan, 1997]. In the device a pneumatic tire is loaded to achieve a gross contact pressure similar to that induced by truck tires on an in-service pavement. The wheel velocity is about $330 \mathrm{~mm} / \mathrm{sec}$. Each specimen (asphalt mixture slab) was subjected to 20,000 wheel passes or until $20.0 \mathrm{~mm}$ of deformation developed. The test data includes number of wheel passes and rut depth. Based on the deformation data from the PURWheel tests, material parameters of the creep model can be backcalculated using a FEM analysis.

Six different asphalt mixtures were used in the in-service pavement sections. All six mixtures were tested in the PURWheel, subsequently the laboratory rutting tests were analyzed to determine values of the creep rate model parameters. The mixtures tested are Indiana \#11 surface, \#9 and \#8 binders, \#5C open-graded base and \#5D and \#2 dense base.

For each asphalt mixture, two PURWheel test slabs were prepared and tested. The widths and lengths of the slabs were $305 \mathrm{~mm}$ by $305 \mathrm{~mm}$. Slab thickness was selected based on the nominal maximum size of the aggregate and ranged from $38 \mathrm{~mm}$ to $76 \mathrm{~mm}$. 
Mixture thickness are shown in Table 8.5. Mixtures for the slab were prepared to match the in-service mixture. Slab and test information are presented in Table 8.5.

Table 8.5 PURWheel Test Information

\begin{tabular}{|c|c|c|c|c|c|c|}
\hline Mixtures & $\begin{array}{c}\text { \#11 } \\
\text { Surface } \\
\text { Mixture }\end{array}$ & $\begin{array}{c}\text { \#9 Binder } \\
\text { Mixture }\end{array}$ & $\begin{array}{c}\text { \#8 Binder } \\
\text { Mixture }\end{array}$ & $\begin{array}{c}\text { \#5C OG } \\
\text { Mixture }\end{array}$ & $\begin{array}{c}\text { \#5D Base } \\
\text { Mixture }\end{array}$ & $\begin{array}{c}\text { \#2 Base } \\
\text { Mixture }\end{array}$ \\
\hline $\begin{array}{c}\text { Nominal } \\
\text { Size (mm) }\end{array}$ & 9.5 & 12.5 & 19 & 12.5 & 19 & 37.5 \\
\hline $\begin{array}{c}\text { Slab } \\
\text { Thickness } \\
(\mathrm{mm})\end{array}$ & 38.1 & 50.8 & 50.8 & 50.8 & 50.8 & 76.2 \\
\hline $\begin{array}{c}\text { Air Void } \\
(\%)\end{array}$ & 14.8 & 17.1 & 17.5 & 22.8 & 8.9 & 14.8 \\
\hline $\begin{array}{c}\text { Temperature } \\
\left({ }^{\circ} \mathrm{C}\right)\end{array}$ & 41.4 & 39.4 & 38.3 & 36.1 & 32.8 & 33.9 \\
\hline
\end{tabular}

A three-dimensional finite element method was used to model the PURWheel. This model represents the tested PURWheel slab in length, width and thickness. In modeling the wheel load, a single step load function was applied. The time of loading is equal to the total loading time of a point on the surface of the slab. The time for one pass is the time for the wheel to travel the length of its contact area at a speed of $330 \mathrm{~mm} / \mathrm{s}$.

The irrecoverable creep strain accumulates under repeated loading and contributes a large portion of the rutting of the asphalt mixture. Each mixture has a unique set of $\mathrm{A}$, $m, n$ which define the creep behavior and hence rutting potential of a mixture. Rut-depth development data from PURWheel tests were used to back-calculate the creep rate model 
parameters for each mixture. Since there were two slabs for each mixture with different air void ratios and hence different densities, the rut-depth accumulation rate varies between the slabs. Back-calculated material parameters for the two slabs will also differ.

A decision was made to determine a best-fit curve for the averaged rut-depth curve of both slabs. The material parameter determinations were then based on this bestfit curve. In the back-calculation procedure, creep rate model parameters were estimated by trial and error. The total predicted rut depth was compared with the measured rut depths at different cumulative time (number of wheel passes). The parameters were estimated when a good match between the predicted rutting and best-fit line of averaged rutting was obtained.

Rut Depth of \#11

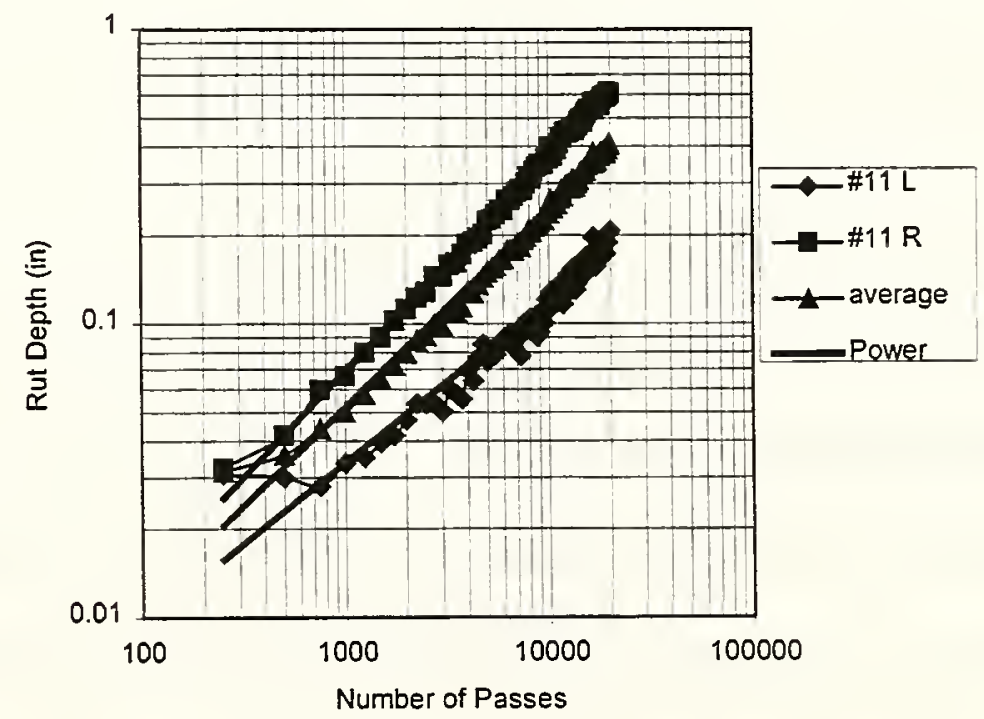

Figure 8.10 Rut Depth vs. Number of Load Passes for PURWheel Test of Indiana \#11 surface mixture 
The creep curve is generally a straight line when drawn on a log-log scale. With other factors being fixed in the creep rate model, an increase in parameter A increases the intercept. The parameter $m$ in the creep rate model defines the slope of the curves. When the $m$ value decreases, the slope decreases and total rut depth decreases. Parameter $n$ defines the stress function in power law form. Rutting magnitude increases as the $n$ value increases.

Since PURWheel tests were conducted at only one fixed tire pressure, no estimate of the stress function was possible. From past experience and the work of Huang [1995], the parameter $n$ was fixed at 0.8 throughout the back-calculation procedures.

Parameter $m$ was estimated first by matching the slope of predicted creep curves with the slope of the averaged best-fit creep curve of that mixture. After parameter $m$ was determined, the A value was estimated by matching the intercept of predicted creep curves with the intercept of the averaged best-fit creep curve. The final back-calculated material parameters of the creep rate model for each mixture are given in Table 8.6.

\subsubsection{Test Section Rutting Analysis}

Using the above backcalculated results a rutting analysis was made for each of the three test sections. The resulting deformed finite element mesh is shown for sections 1,2 and 3 in Figures 8.11, 8.12, and 8.13, respectively. Surface rutting for the three sections is plotted in Figures 8.14, 8.15 and 8.16. A summary of predicted rutting is given in Table 8.7. The measured rutting was less than $1.6 \mathrm{~mm}(1 / 16 \mathrm{inch})$, which was the minimum measurement unit. In conclusion, the measured and predicted rutting are in reasonable agreement. However, future tests should address developing a capability of predicting 
Table 8.6 Back Calculated Creep Rate Model Parameters

\begin{tabular}{|c|c|c|c|}
\hline Mixture & $\mathrm{A}$ & $\mathrm{M}$ & $\mathrm{N}$ \\
\hline $\begin{array}{c}\text { \#11 Surface } \\
\text { Mixture }\end{array}$ & 0.21 & -0.34 & 0.8 \\
\hline $\begin{array}{c}\text { \#9 Binder } \\
\text { Mixture }\end{array}$ & 0.62 & -0.75 & 0.8 \\
\hline $\begin{array}{c}\text { \#8 Binder } \\
\text { Mixture }\end{array}$ & 0.38 & -0.84 & 0.8 \\
\hline $\begin{array}{c}\text { \#5C OG } \\
\text { Mixture }\end{array}$ & 0.38 & -0.91 & 0.8 \\
\hline $\begin{array}{c}\text { \#5D Base } \\
\text { Mixture }\end{array}$ & 0.30 & -0.90 & 0.8 \\
\hline $\begin{array}{c}\text { \#2 Base } \\
\text { Mixture }\end{array}$ & 0.40 & -0.78 & 0.8 \\
\hline
\end{tabular}

rutting over an expected temperature range. Rutting predictions in this analysis allow for relative comparison of the three test sections. Section 1 has slightly higher predicted rutting than sections 2 and 3, which have about the same rutting magnitude. Rutting is greater in section 1 because of the greater total thickness of asphalt layers. Rutting is different in section 2 and 3 because of the different back-calculated creep rate model parameters of $\# 5 \mathrm{C}$ and $\# 2$ mixtures. The minimum predicted rutting is consistent with field measured rutting after three years of traffic. 


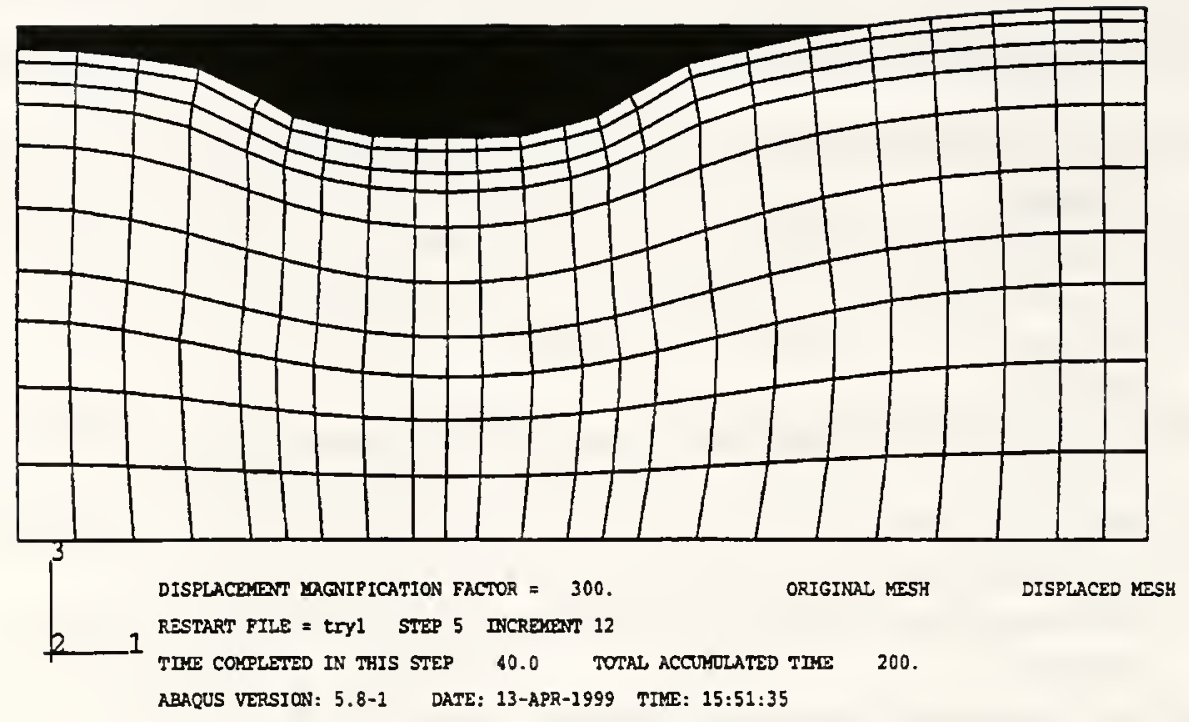

Figure 8.11 Predicted Pavement Cross Section after 3 Years, Section 1 


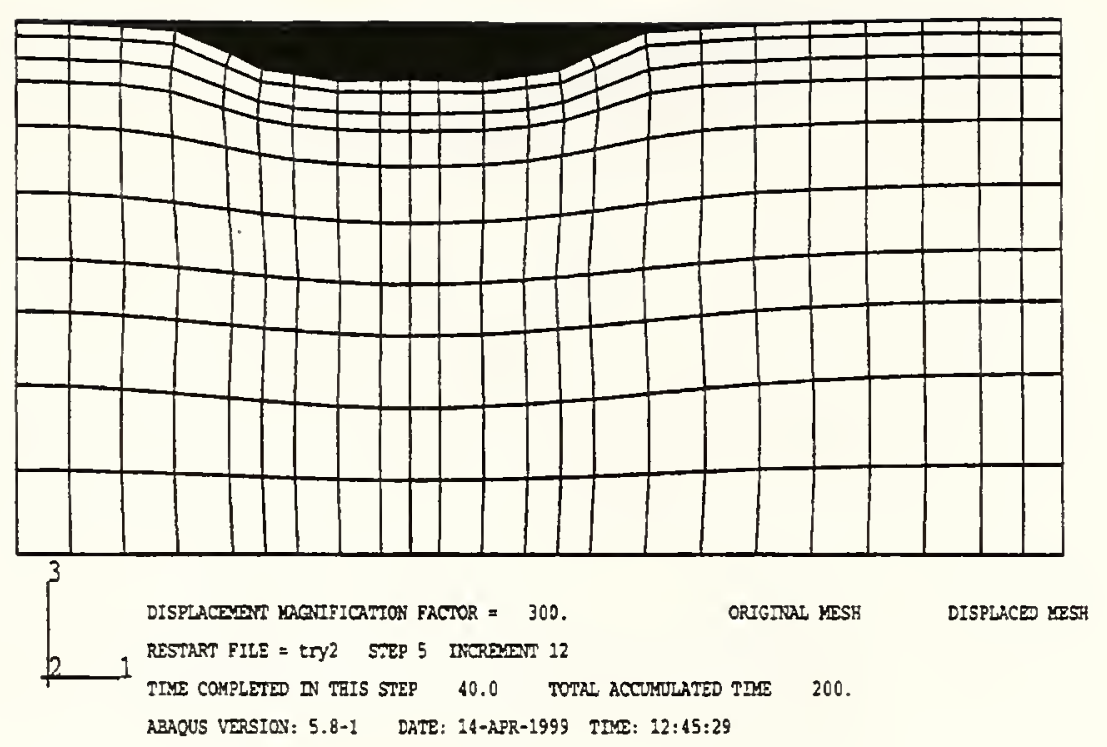

Figure 8.12 Predicted Pavement Cross Section after 3 Years, Section 2 


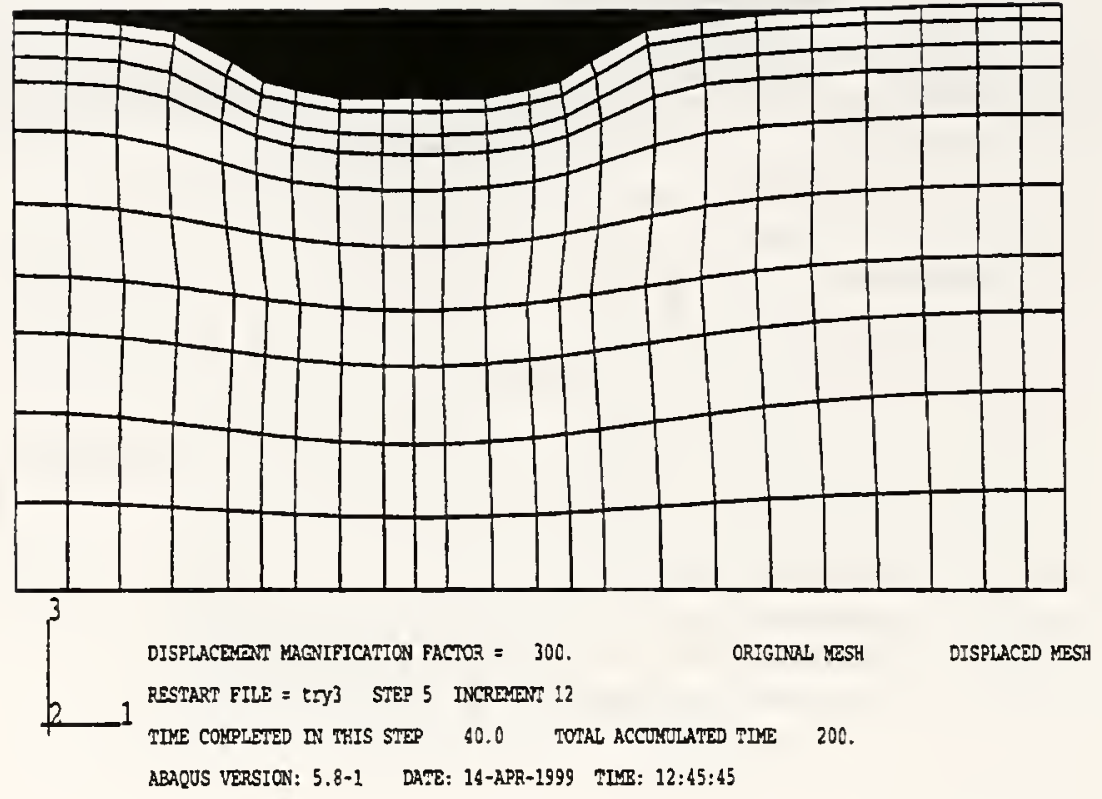

Figure 8.13 Predicted Pavement Cross Section after 3 Years, Section 3 


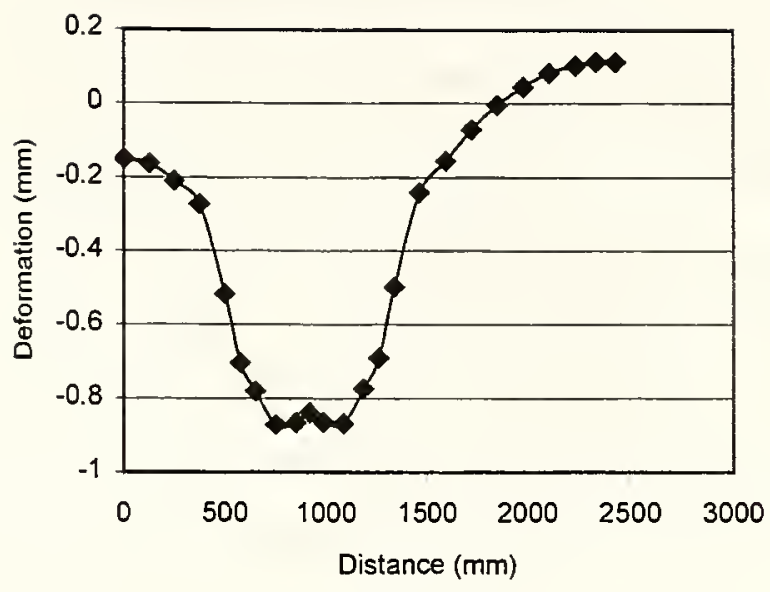

Figure 8.14 Measured Surface Deformation after 10,000 Truck Applications, Section 1

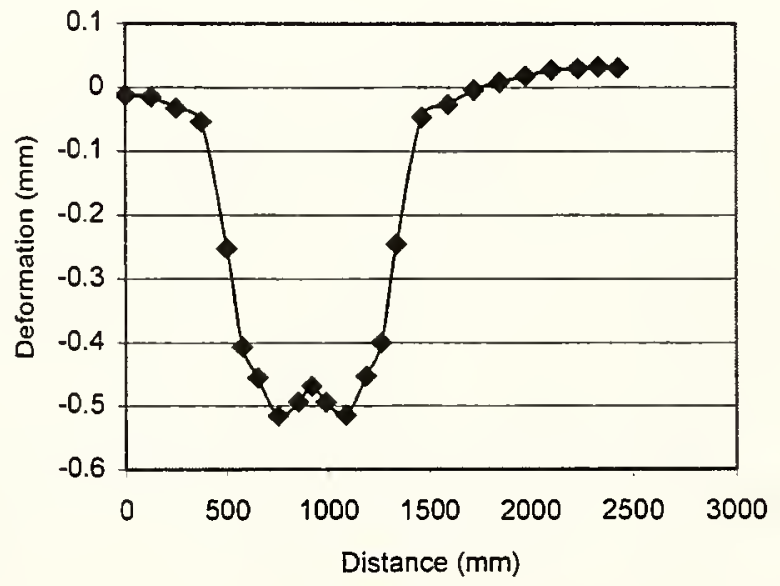

Figure 8.15 Measured Surface Deformation after 10,000 Truck Applications, Section 2 


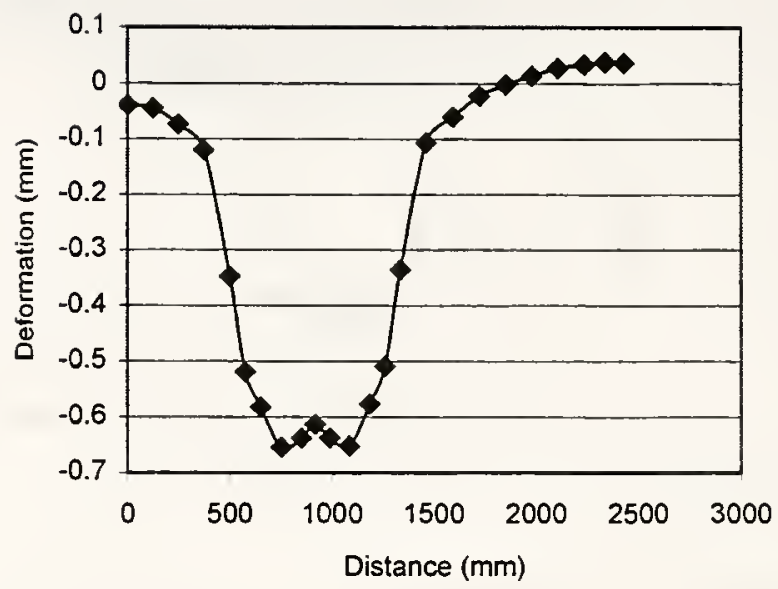

Figure 8.16 Measured Surface Deformation after 10,000 Truck Applications, Section 3

Table 8.7 Predicted Rutting Depth after 10,000 Truck Applications

\begin{tabular}{|c|c|}
\hline Sections & Rutting Depth (mm) \\
\hline Section 1 & 1.0 \\
\hline Section 2 & 0.6 \\
\hline Section 3 & 0.7 \\
\hline
\end{tabular}




\section{$\underline{8.5 \text { Strength and Stability Analysis }}$}

The pavement strength and stability analysis was conducted by modeling a moving load traveling at $96 \mathrm{~km} /$ hour. Shear stress is used as the response factor to evaluate material stability. In this study, the open-graded drainage layer stability is of primary concern. Contact pressure of the moving load was taken as $630 \mathrm{kPa}(90 \mathrm{psi})$ over a contact area of $162.6 \times 198.1 \mathrm{~mm}$. The moving load was modeled by applying the load to a set of elements for a period of time equal to the time that the element area would be loaded at $96 \mathrm{~km} /$ hour. Subsequently, the load is moved to the next set of elements.

Stresses in various pavement layers vary slightly with load repetitions. The stresses appears to stabilize after about three passes. The stress and strength data presented hereafter is for the fifth load repetition. Figure 8.17 shows predicted shear stresses and shear strengths in the surface layer of section 1. Predicted shear stresses and shear strengths at the top of the drainage layer of section 1 are shown in Figure 8.18. Figure 8.19 shows the vertical profile of predicted shear stresses and shear strengths in section 1 under the centerline of the wheel path. Subsequently, Figure 8.20 shows the vertical profile of predicted shear stresses and shear strengths at the outside edge of the trench of section 1. From these analyses, the critical location is at the edge of the wheel. At this location, the shear stress is close to the shear strength. There is some tension stress at the bottom of the $\# 2$ base which is believed to be due to the different stiffness of the $\# 2$ and $\# 5 \mathrm{D}$ asphalt mixtures. There is also some tension at the top of the shoulder. In the test sections, the shoulder is paved with the same material as the pavement. Although this material is strong enough to resist the tension stress, long term repetitive load application could lead to cracking. Pavement thickness appears to be adequate in that the subgrade 
shear strength is greater than the shear stresses. A small zone exists in the \#8 trench aggregate where the shear stress is close to the shear strength. This indicates a potential problem with the trench material. Lack of cohesion in this clean aggregate is the likely source of this problem. An open-graded asphalt mixture would have adequate cohesion and still provide high permeability.

Similar results for section 2 and 3 are presented in Figures 8.21 to 8.24 and 8.25 to 8.28 , respectively. In general, the shear strength exceeds the shear stresses. There is some tension due to the difference in stiffness of the $\# 2$ and \#5D base. The shear strength and shear stress for the $\# 8$ trench aggregate in these sections is marginally stable. 


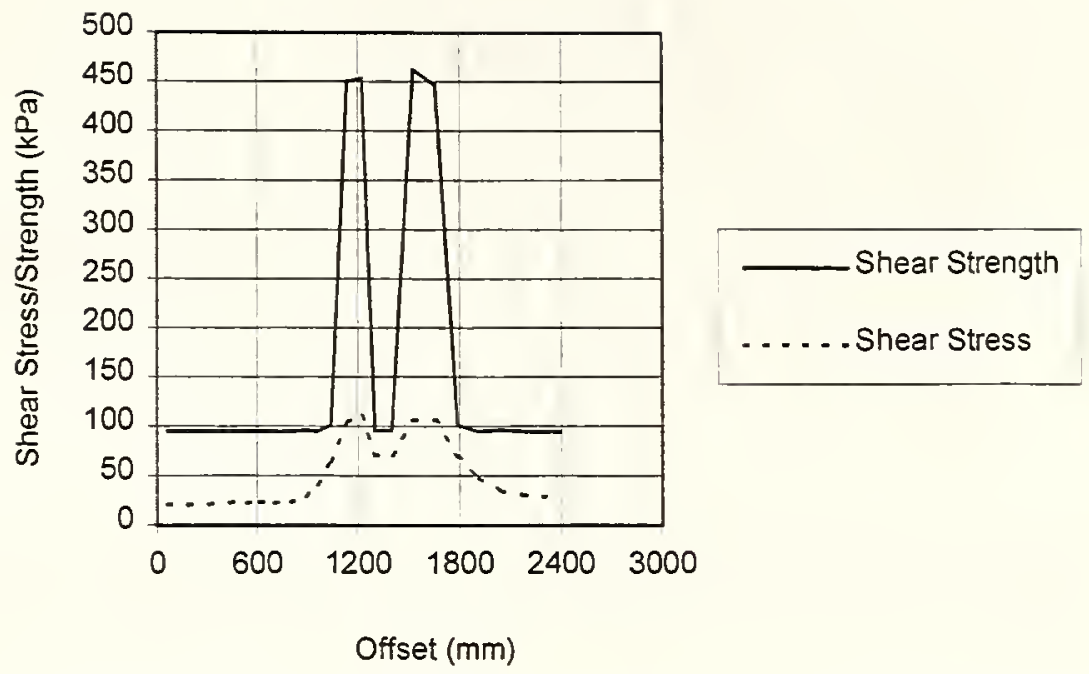

Figure 8.17 Stress and Strength Distribution in Surface Layer, Section 1

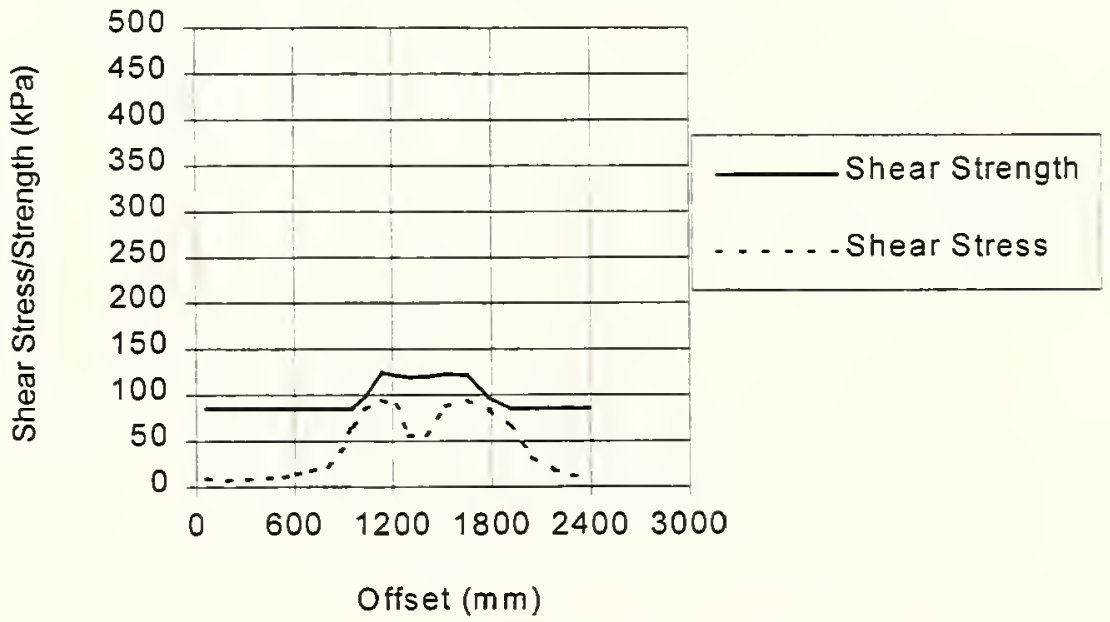

Figure 8.18 Stress and Strength Distribution at the Top of Drainage Layer, Section 1 
Shear Stress/Strength $(\mathrm{kPa})$

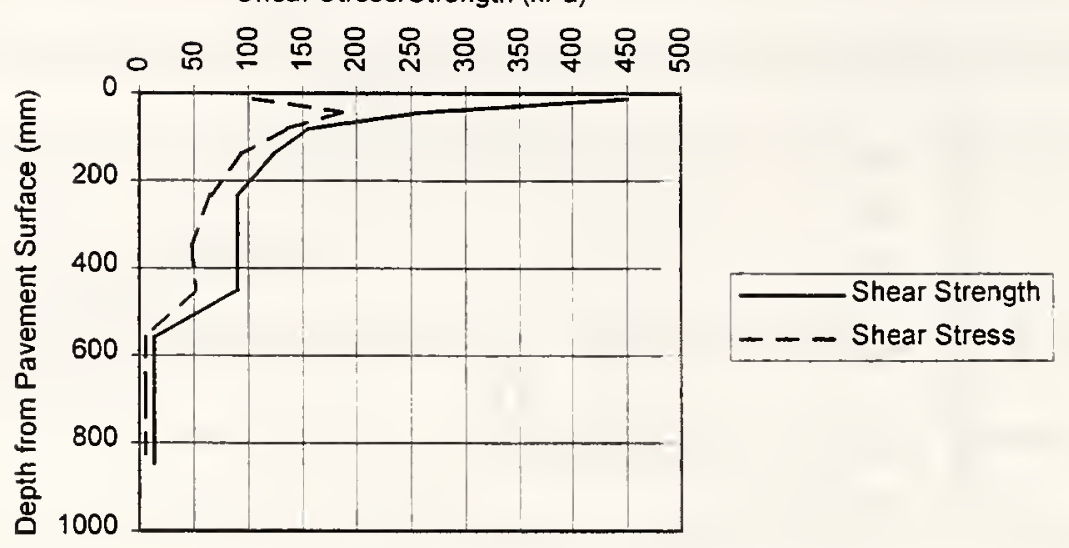

Figure 8.19 Stress and Strength Distribution under Wheel Path, Section 1

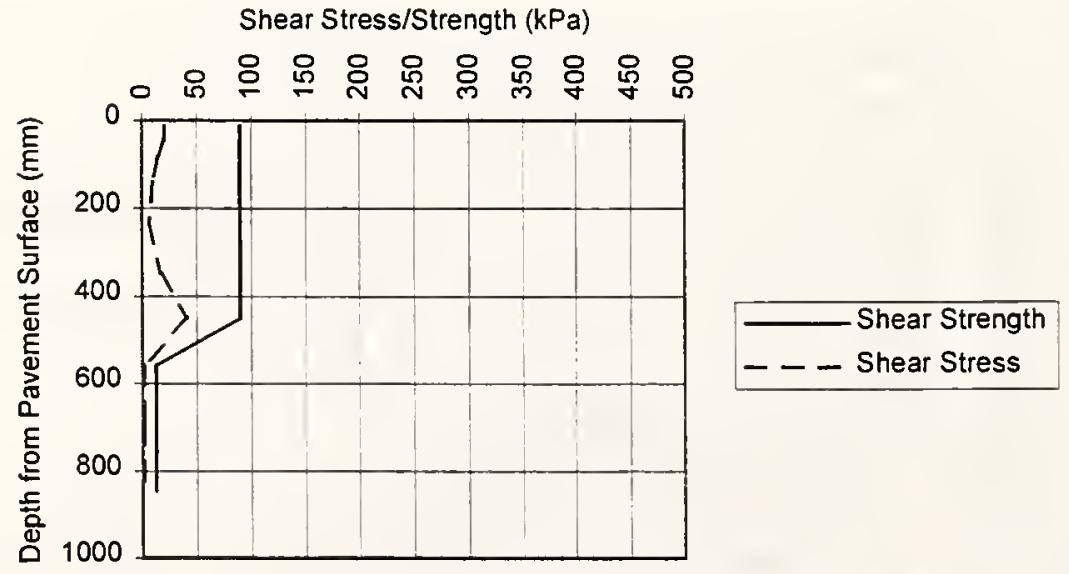

Figure 8.20 Stress and Strength Distribution in Trench, Section 1 


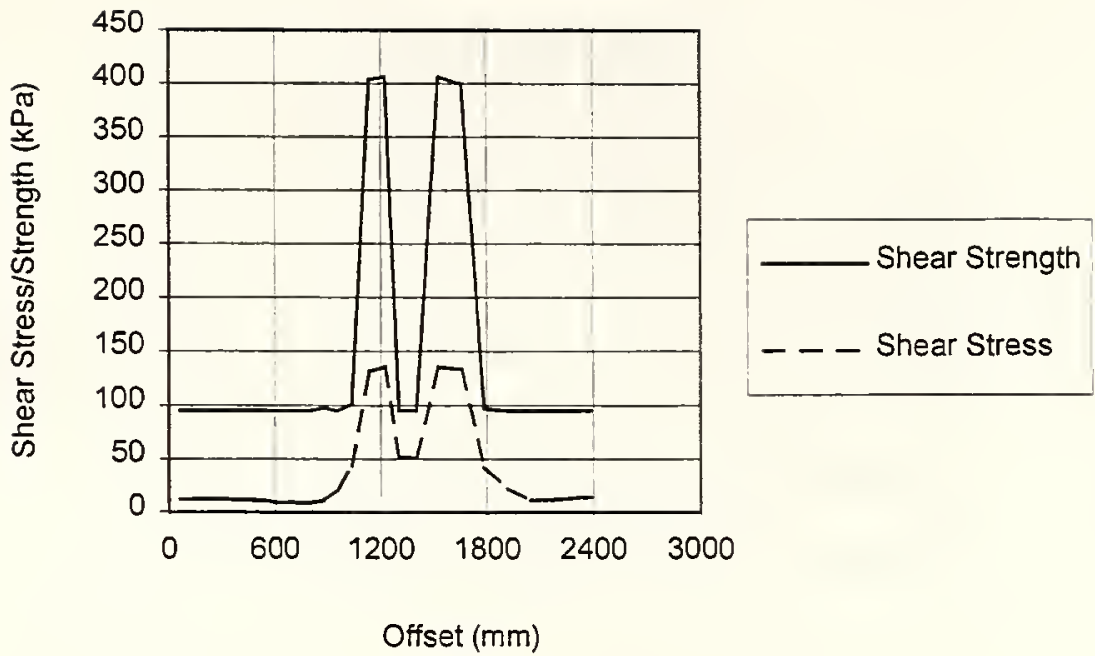

Figure 8.21 Stress and Strength Distribution in Surface Layer, Section 2

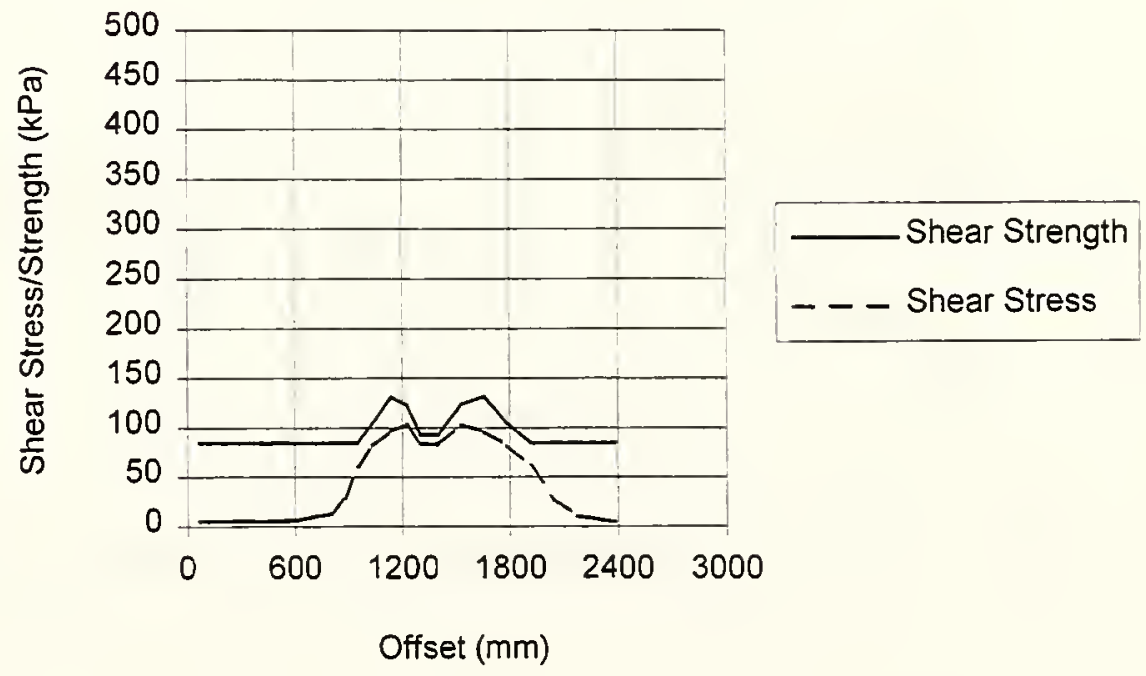

Figure 8.22 Stress and Strength Distribution at Top of Drainage Layer, Section 2 


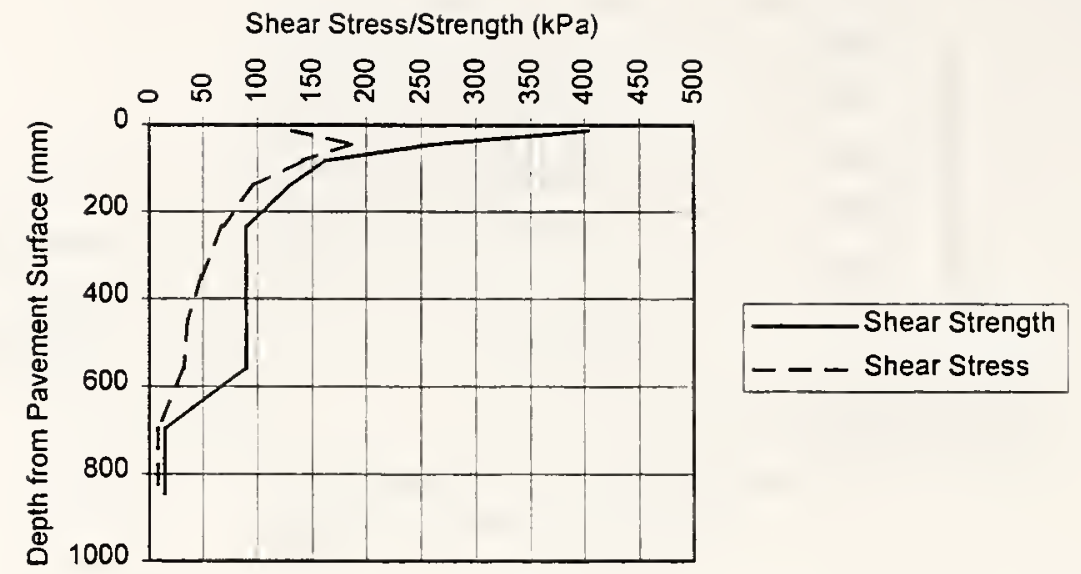

Figure 8.23 Stress and Strength under Wheel Path, Section 2

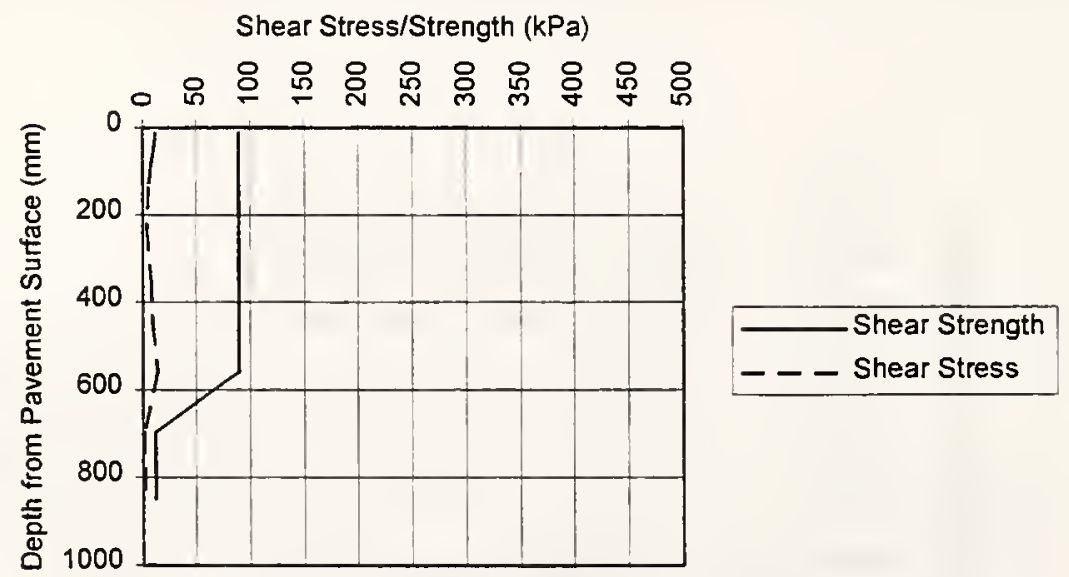

Figure 8.24 Stress and Strength Distribution in the Trench, Section 2 


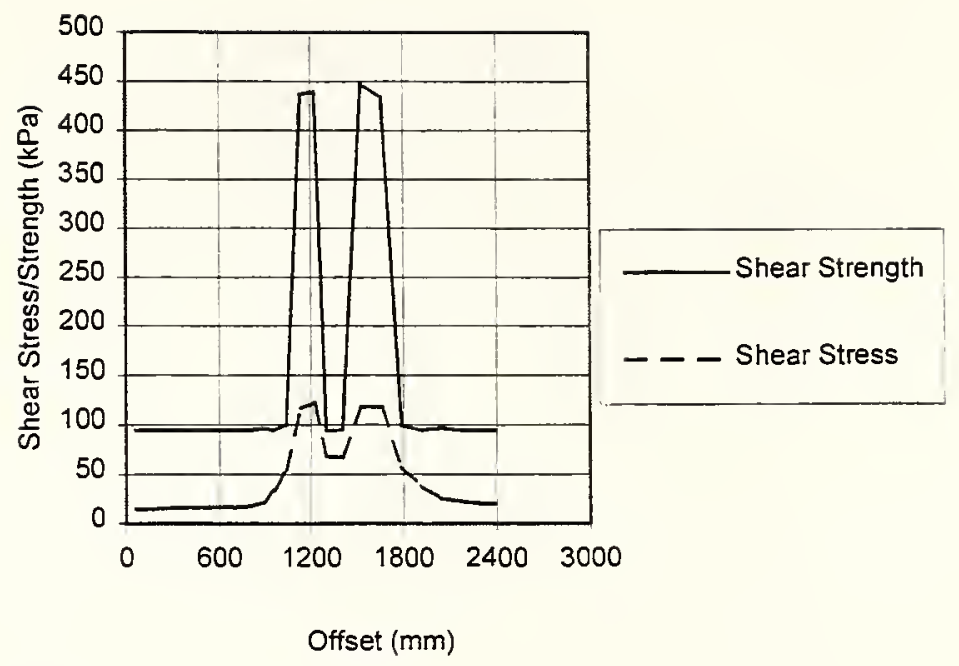

Figure 8.25 Stress and Strength Distribution in the Surface Layer, Section 3

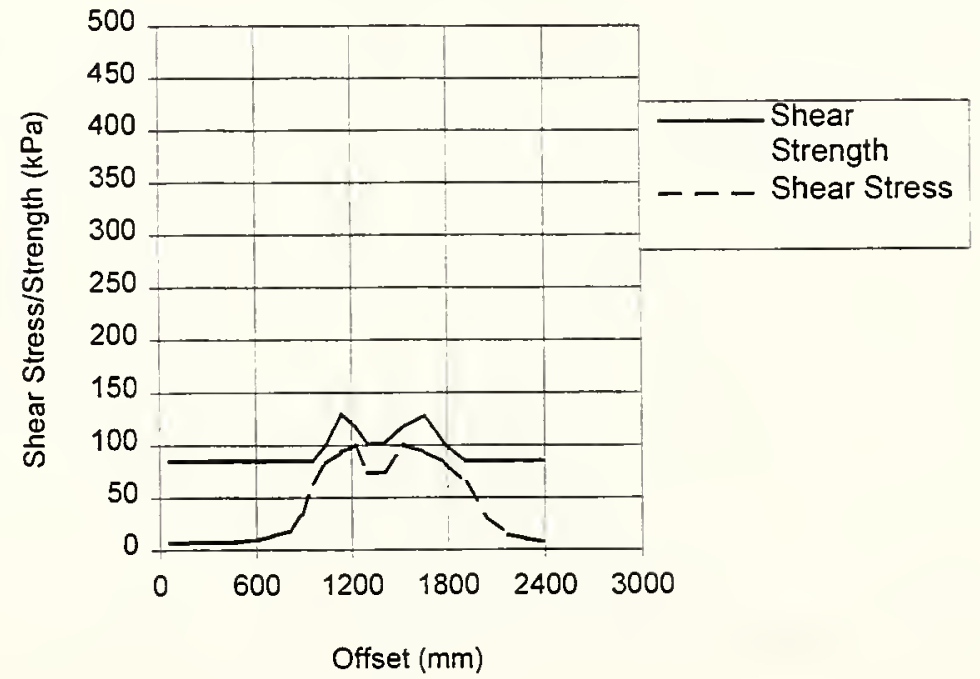

Figure 8.26 Stress and Strength Distribution at Top of Drainage Layer, Section 3 


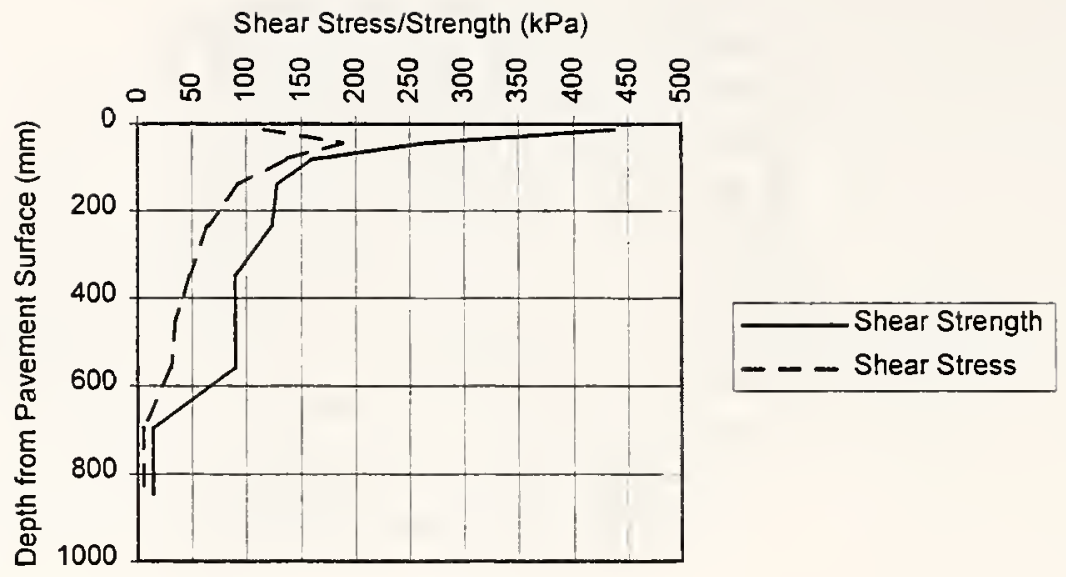

Figure 8.27 Stress and Strength Distribution under Wheel Path, Section 3

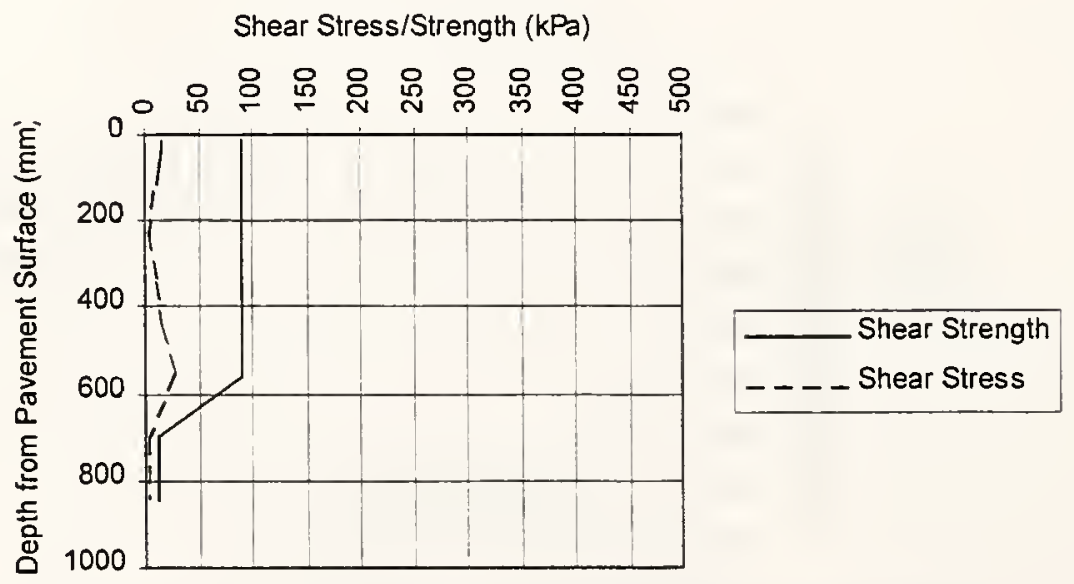

Figure 8.28 Shear Stress and Shear Strength Distribution in Trench, Section 3 


\section{CHAPTER 9 CONCLUSIONS AND RECOMMENDATIONS}

\subsection{Conclusions}

A number of conclusions can be reached based on collected field data, laboratory tests and the finite element analysis.

\subsubsection{Subdrainage Performance and Pavement Condition}

The highway was opened to traffic in October 1995. The subdrainage systems continue to function well. The amount of rainfall falling on the pavement surface and infiltrating the pavement increased over the first winter from about $10 \%$ to about $19 \%$ for the three test sections. The infiltration rate is based on the ratio of measured section outflow to calculated rainfall on the drained pavement surface. In September 1998, the infiltration rate was $7.3 \%, 7.6 \%$, and $8.4 \%$ for sections 1,2 and 3 , respectively. This decrease in infiltration rate is probably due to a combination of densification and clogging of connected air voids by dust and sand. Infiltration is expected to increase when the pavement cracks. The time for all three sections to drain is significantly less than after construction (1995) and in 1996. As shown in Chapter 4, the average drainage time for all sections has decreased from 20 hrs in May 1996 to 6 hrs in September 1998. The shortened drainage time is believed to be due to less surface water infiltrating the 
pavement. The relative efficiencies have remained constant for the three sections, i.e. section 1 remains the most effective drainage section.

Moisture in all pavement layers and the subgrades has stayed relatively constant and shows little variation over the three years of moisture data collection. Also, the temperature sensors initially installed continue to function well. The SHRP equations give very good estimates of pavement temperatures. This conclusion is confined to a normally cold winter. The cold temperature prediction was not good for the unusually warm 1997-98 winter. But this would be expected for an empirical equation.

Frost penetration was estimated from watermark block readings. The frozen depth in the 1996-97 winter was $545,600,565 \mathrm{~mm}$ for section 1,2 , and 3 , respectively. However, as noted, there was no frost penetration in the winter of 1997-98 due to warmer weather.

Two condition surveys were conducted, one in June 1997 and the other in September 1998. The PCI for sections 1,2, and 3 were 83, 91 and 88, respectively, based on the September 1998 condition survey. Very little rutting has developed in the three sections. There is longitudinal construction joint cracking as well as a few shoulder cracks.

\subsubsection{Shear Strength}

The triaxial test is an effective approach for obtaining material model parameters for finite element analysis. Duncan, et al. [1980] showed that all of the material parameters for the "hyperbolic model" could be obtained from triaxial tests. Also, the 
ABAQUS User's Manual states that "Data for geological materials are most commonly available from triaxial compression testing" [ABAQUS, 1997].

Significant shear strength data was obtained for subgrade, unbound aggregate, and asphalt mixture materials. Consolidated, undrained and partially saturated triaxial tests were conducted on the subgrade materials. A summary of these results on the three test section subgrades is given in Table 9.1. Values for these parameters agree with the literature [Hunt, 1986], [Duncan, 1981] and [Peterson, 1986]. Holtz[1983] pointed out that compacted clay will have higher cohesion at low confining stress. With the exception that the cohesion of $27.6 \mathrm{kPa}$ for the section 2 subgrade is slightly higher than Hunt (10$20 \mathrm{kPa})$.

Table 9.1 Summary of Subgrade Triaxial Test Results

\begin{tabular}{|c|c|c|c|c|}
\hline & CU Test & & \multicolumn{2}{c|}{ Partially Saturated Test } \\
\cline { 2 - 5 } & Cohesion (kPa) & Friction (Deg) & Cohesion (kPa) & Friction (Deg) \\
\hline Section 1 & 11 & 29 & 14 & 8.5 \\
\hline Section 2 & 27.6 & 23 & $\mathrm{~N}$ & $\mathrm{~N}$ \\
\hline Section 3 & 10.3 & 29 & 40 & 6 \\
\hline
\end{tabular}

The CU and $C D$ tests were conducted on the \#53 unbound aggregate filter material and the \#8 trench aggregate. The test results for the \#53 and \#8 unbound aggregate are summarized in Table 9.2. The above test results compare with test results for similar materials reported in the literature. 
Table 9.2 Summary of Triaxial Test Results on $\# 53$ and \#8

\begin{tabular}{|c|c|c|c|c|}
\hline \multirow{2}{*}{} & \multicolumn{2}{|c|}{ CU Test } & \multicolumn{2}{c|}{ CD Test } \\
\cline { 2 - 5 } & Cohesion $(\mathrm{kPa})$ & Friction (Deg) & Cohesion (kPa) & Friction (Deg) \\
\hline$\# 53$ & 10 & 55 & 0 & 53 \\
\hline$\# 8$ & 11 & 33.5 & 15 & 33 \\
\hline
\end{tabular}

Both aggregate and asphalt mixture tests were conducted on the MTS system at the INDOT Research Division. The system is setup to use air as confining medium because of exposed data acquisition sensors in the chamber. A higher capacity loading systems is suggested (greater than $45 \mathrm{KN}$ ) to test unbound aggregate and asphalt mixtures. Test results in this research were limited by inadequate load capacity.

Loading speed has a significant effect on the cohesion of asphalt mixtures. When the loading speed is increased from $1.25 \mathrm{~mm} / \mathrm{min}$ to $12.5 \mathrm{~mm} / \mathrm{min}$, the cohesion is almost doubled. However, the friction angle does not vary with the loading speed. Cohesion and angle of internal friction for the various asphalt mixtures are summarized in Table 9.3.

Triaxial testing applied in this research does not simulate all the possible stress paths paving materials may experience when subjected to a moving wheel load. The test does provide the parameters for use with material models applied in FEM analysis. The test is recommended for defining the material model parameters in ABAQUS [ABAQUS, 1997]. 
Table 9.3 Summary of Asphalt Mixture Strength Parameters

\begin{tabular}{|c|c|c|c|c|c|c|c|c|}
\hline & \multicolumn{8}{|c|}{ Loading Speed ( $\mathrm{mm} / \mathrm{min})$} \\
\hline & \multicolumn{4}{|c|}{1.25} & \multicolumn{4}{|c|}{12.5} \\
\hline & \multicolumn{2}{|c|}{$\mathrm{CU}$} & \multicolumn{2}{|c|}{ Dry } & \multicolumn{2}{|c|}{$\mathrm{CU}$} & \multicolumn{2}{|c|}{ Dry } \\
\hline & $\begin{array}{c}\text { Cohesion } \\
\qquad(\mathrm{kPa})\end{array}$ & $\begin{array}{l}\text { Friction } \\
\text { (degrees) }\end{array}$ & $\begin{array}{l}\text { Cohesion } \\
\qquad(\mathrm{kPa})\end{array}$ & $\begin{array}{l}\text { Friction } \\
\text { (degrees) }\end{array}$ & $\begin{array}{l}\text { Cohesion } \\
\qquad(\mathrm{kPa})\end{array}$ & $\begin{array}{l}\text { Friction } \\
\text { (degrees) }\end{array}$ & $\begin{array}{l}\text { Cohesion } \\
\qquad(\mathrm{kPa})\end{array}$ & $\begin{array}{l}\text { Friction } \\
\text { (degrees) }\end{array}$ \\
\hline $\begin{array}{c}\# 11 \\
\text { Surface }\end{array}$ & 100 & 41 & 95 & 40 & 200 & 41 & 160 & 43 \\
\hline $\begin{array}{c}\# 9 \\
\text { Binder }\end{array}$ & 130 & 42 & 120 & 40 & 190 & 40 & 190 & 40 \\
\hline $\begin{array}{c}\# 8 \\
\text { Binder }\end{array}$ & 90 & 41 & 80 & 40 & 150 & 40 & 180 & 40 \\
\hline$\# 5 \mathrm{C}$ & 85 & 41 & 85 & 40 & 120 & 40 & 130 & 41 \\
\hline$\# 5 D$ & 90 & 50 & 90 & 50 & 180 & 50 & 190 & 50 \\
\hline$\# 2$ & 120 & 45 & 80 & 46 & 160 & 43 & 165 & 45 \\
\hline
\end{tabular}

Asphalt mixtures exhibit dilatancy. In the $\mathrm{CU}$ test, asphalt mixtures show significant increase in failure strength due to the increased effective confining pressure. Yield stress and Young's modulus vary with both loading speed and confining pressure. The yield stress and Young's modulus are higher for the higher loading speed. Also, the higher the confining pressure, the higher the yield stress and Young's modulus. Statistical analysis shows that the main effects of loading speed and confining pressure are both significant to Young's modulus and yield stress at the $\alpha=0.05$ level. This means that these factors must be included in developing predictive relations. 


\subsubsection{Pavement Rutting and Stability}

Although there has been concern about loss of pavement stability due to the use of open-graded drainage layers, negligible rutting has developed since the pavement opened to traffic. The predicted rutting is $1.0,0.6,0.7 \mathrm{~mm}$ for sections 1,2 , and 3 , respectively. These values are in close agreement with maximum measured rutting of less than 1.6 $\mathrm{mm}$.

The combination of lowest shear strength and highest shear stress are predicted at the edge of the wheel path. There is some tension predicted at the $\# 2$ and $\# 5 \mathrm{D}$ base interface. However, the shear strength at all levels exceeds the shear stress. There also exists a tension zone at the surface of the shoulder. This confirms the need to use adequate thickness and good quality asphalt mixtures for shoulder pavement. At midheight of the drainage trench, shear stresses are approaching the available shear strength. Lack of cohesion is the reason for this condition developing. The asphalt binder in an open-graded asphalt mixture would have the required cohesion.

\subsection{Recommendations}

The following recommendations result from the study:

1. Use of drainage systems is recommended. Their use will significantly reduce the time moisture is retained in the pavement system. Subdrainage systems also contribute to minimizing moisture changes in pavement layers and subgrades.

2. Additional research should be conducted to evaluate subdrainage system design for "cracked" pavements. 
3. SHRP temperature prediction equations can be used for predicting high and low temperatures for use in the Superpave system.

4. Estimates of frost penetration can be predicted by Corps of Engineers procedures.

5. In application of the triaxial test apparatus, the issue of air permeating the membrane should be examined carefully.

6. Triaxial tests of unbound aggregate and asphalt mixtures require a load system with greater capacity than the one used in this research. It is estimated that the capacity should be at least doubled.

7. Tests on asphalt mixtures should be conducted over a range of temperatures.

8. The FEM provided a means of examining both the rutting potential and stability of the pavement drainage sections. Additional study should be conducted to optimize shear strength relative to shear stress for various thickness.

9. The load model assumes a uniform pressure over the approximate wheel contact area. An analysis is recommended using a more reasonable contact pressure distribution.

10. The FEM has proven effective in modeling FWD dynamic tests. Additional research is recommended using this dynamic analysis. The additional research would provide a basis for formalizing back-calculation of pavement properties.

11. Consideration should be given to developing a test to provide material model parameters for the stress paths pavement materials will experience from moving wheel loads. 



\section{LIST OF REFERENCES}

ABAQUS Standard User Manual, Hibbit, Karlsson \& Sorenson, Inc., Version 5.7, 1997. ABAQUS/Post, User's Manual, Version 5.4-1, Hibbit, Karlsson and Sorenson, Inc., 1994. Asphalt Institute, "Mix Design Methods for Asphalt Concrete and Other Hot-mix Types", Manual Series No. 2 (MS 2), 1988.

Asphalt Institute, "Superpave Asphalt Binder Specification", Superpave Series No. 1 (SP1), Asphalt Institute, Lexington, Kentucky, August, 1995.

ASTM D4767-88, "Standard Test Method for Consolidated Undrained Triaxial Compression Test on Cohesive Soils".

ASTM D5340-93, "Standard Test Method for Airport Pavement Condition Index Surveys".

ASTM D4694, "Standard Test Method for Deflections with a Falling-Weight Type Impulse Load Device".

Bernal, Andres, "Laboratory Study on the Use of Tire Shreds and Rubber-Sand in Backfill and Reinforced Soil Applications", FHWA/TN/JHRP-96/12, 1996.

Bishop, Alan W., Henkel, D. J., The Measurement of Soil Properties in the Triaxial Test, Edward Arnold Publishers LTD, 1957.

Bowles, J. E., Engineering Properties of Soils and Their Measurement, McGraw-Hill, Inc., Fourth Edition, 1994.

Chen, W. F., Han, D. J., Plasticity for Structural Engineers, Springer-Verlag, New York, 1995.

Chisolm, Ed E., "Behavioral Characteristics of Gravelly Sand and Crushed Limestone for Pavement Design", Final Report FAA-RD-74, Soils and Pavements Laboratory, U.S. Army Engineer Waterways Experiment Station, June 1975.

Collop, A. C., Cebon, D., Hardy, M. S. A., "Viscoelastic Approach to Rutting in Flexible Pavements", Journal of Transportation Engineering, Vol. 121, Jan.-Feb. 1995, pp. 82-93. 
Cook, R. D., Malkus, D. S., Plesha, M. E., Concepts and Application of Finite Element Analysis, John Wiley \& Sons, Third Edition, 1989.

Dawley, C. B., Hogewiede, B. L., Anderson, K. O., "Mitigation of Instability Rutting of Asphalt Concrete Pavements in Lethbridge, Alberta, Canada", Proceedings, The Association of Asphalt Paving Technologists, Vol. 59, 1990, pp. 481-508.

Distress Identification Manual for the Long-Term Pavement Performance Project, SHRPP-338.

Duncan, J. M., Byrne, Peter, Wong, Kai S., "Strength, Stress-Strain and Bulk Modulus Parameters for Finite Element Analysis of Stresses and Movements in Soil Masses", College of Engineering, Office of Research Services, University of California Berkeley, California, 1980.

Eisenmann, J. and Hilmer, A., "Influence of Wheel Load and Inflation Pressure on the Rutting Effect at Asphalt-Pavements: Experiments and Theoretical Investigations", Proceedings, The $6^{\text {th }}$ Int. Conf. on the Structural Design of Asphalt Pavements, Univ. of Michigan, Ann Arbor, Michigan, 1987, pp. 392-403.

Endersby, V. A., "The History and Theory of Triaxial Testing, and the Preparation of Realistic Test Specimens - A Report of the Triaxial Institute", Symposium on Triaxial Testing of Soils and Bituminous Mixtures, ASTM STP No. 106, 1951, pp. 5-20.

Fwa, T. F., Tan, S. A., Low, B. H., "Relating Triaxial Test Properties of Asphalt Mixtures to Mix Parameters Determined by Marshall Stability Test", Journal of Testing and Evaluation, Vol. 25, September 1997, pp. 471-478.

Goetz, W. H. and Chen, C. C., "Vacuum Triaxial Technique Applied to BituminousAggregate Mixtures", Proceedings, The Association of Asphalt Paving Technologist, Vol. 19, 1950, pp. 55-81.

Goetz, W. H., "Comparison of Triaxial and Marshall Test Results", Proceedings, The Association of Asphalt Paving Technologists, Vol. 20, 1951, pp. 200-245.

Hank, R. J., "Triaxial Design Adapted to Soils, Flexible, Base, and Foundations, Symposium on Triaxial Testing of Soils and Bituminous Mixtures, ASTM STP No. 106, 1951, pp. 138-151.

Hassan, H. F. and White, T. D., "Locating the Drainage Layer for Flexible Pavements", Final Report, FHWA/IN/JHRP-96/14, December, 1996.

Holtz, R. D., Kovacs, W. D., An Introduction to Geotechnical Engineering, Prentice Hall, 1981. 
Houston, Sandra L. and Wray, Warren, K. (Eds.), Unsaturated Soils, Proceedings, Sessions Sponsored by the Subcommittee on Unsaturated Soils (Committee on Soil Properties) and the Committee on Shallow Foundations of the Geotechnical Engineering Division of the American Society of Civil Engineers in conjunction with the ASCE Convention in Dallas, Texas, October 24-28, 1993.

Hua, Jianfeng, "Dynamic Analysis of Rigid Pavement Response Under Standard Nondestructive Testing Equipment Using a Three Dimensional Finite Element Model by ABAQUS", Master Thesis, Purdue University, 1998.

Huang, Y. H., Pavement Analysis and Design, Prentice Hall, 1993.

Huang, H. M., "Analysis of Accelerated Pavement Tests and Finite Element Modeling of Rutting Phenomenon", Ph.D. Thesis, Purdue University, 1995.

Hunt, R., Geotechnical Investigation Manual, McGraw Hill, 1986.

Huschek, S., "The Deformation Behavior of Asphaltic Concrete Under Triaxial Compression", Proceedings, The Association of Asphalt Paving Technologists, Vol. 54, 1985, pp. 407-431.

Hveem, F. N. and Davis, Harmer, E. "Some Concepts Concerning Triaxial Compression Testing of Asphaltic Paving Mixtures and Subgrade Materials", Symposium on Triaxial Testing of Soils and Bituminous Mixtures, ASTM STP No. 106, 1951, pp. 25-45.

Janbu, Nilmar, "Soil Compressibility as Determined Odemeter and Triaxial Test", Proceedings, European Conference on Soil Mechanics and Foundation Engineering, Wiesbaden, Germany, Vol. 1, 1963, pp. 19-25.

Karim, Ahmed M. K., "Building Highway Embankments of Fly/Bottom Ash Mixtures", FHWA/N/JTRP-97/1, 1997.

Lambe, T. W., Soil Testing for Engineers, John Wiley and Sons, 1951.

Low, B. H., Fwa, T. F., Tan, S. A., "Numerical Analysis of Asphalt Concrete Mixtures with Triaxial Test Properties", Proceedings, The $2^{\text {nd }}$ International Conference on Road \& Airfield Pavement Technology, September 1995, Singapore, pp. 926-934.

McGennis, R. B., Anderson, R. M., Kennedy, T. W., and Solaimanian, "Background of SUPERPAVE Asphalt Mixture Design \& Analysis", National Asphalt Training Center Demonstration Project 101, Publication No. FHWA-SA-95-003, 1995.

McLeod, Norman W., "Application of Triaxial Testing to the Design of Bituminous Pavements", Symposium on Triaxial Testing of Soils and Bituminous Mixtures, ASTM STP No. 106, 1951, pp. 79-111. 
Morris, J., Haas, R.C.G., Reilly, P. and Hignell, E. T., "Permanent Deformation in Asphalt Pavements Can Be Predicted", Proceeding, The Association of Asphalt Paving Technologists, Vol. 43, 1974, pp. 41-76.

MTS, User's Manual, "Pavement Test System Operation", April 1994.

PATRAN3 On-line Help, 1995, MSC/PATRAN Products, MacNeal-Schwendler Corporation.

Roberts, Freddy L., Kandhal, Prithvi S., Brown, E. Ray, Lee, Dah-Yinn, Kennedy, Thomas W., Hot Mix Asphalt Materials, Mixture Design and Construction, $1^{\text {st }}$ Edition, NAPA Education Foundation, Lanham, Maryland, 1991.

SAS, "SAS System for Linear Models", SAS Institute, SAS Campus Drive, Cary, NC, 1991.

Smith, V. R., "Application of the Triaxial Test to Bituminous Mixtures California Research Corporation Method", Symposium on Triaxial Testing of Soils and Bituminous Mixtures, ASTM STP No. 106, 1951, pp. 55-72.

Taylor, Donald W., "A Triaxial Shear Investigation on a Partially Saturated Soil", Symposium on Triaxial Testing of Soils and Bituminous Mixtures, ASTM STP No. 106, 1951, pp. 180-187.

Technical Manual, "Pavement Maintenance Management", TM 5-623, 1982.

Townsend, Frank C., Chisolm, Ed E., "Plastic and Resilient Properties of Heavy Clay Under Repetitive Loadings", Technical Report S-76-16, Soils and Pavements Laboratory, U.S. Army Engineer Waterways Experiment Station, November 1976.

Webster, Steve L., "Geogrid Reinforced Base Courses for Flexible Pavements for Light Aircraft: Test Section Construction, Behavior Under Traffic, Laboratory Tests, and Design Criteria", Geotechnical Laboratory, Dept. of the Army, May 1993.

White, Thomas D., "Measured Pavement Response to Transient Aircraft Loadings", Ph.D. Thesis, Purdue University, 1981.

White, T. D., Zaghloul, S. M., Anderton, G. L. and Smith, D. M., "Pavement Analysis for Moving Aircraft Loads", U.S. Army Corps of Engineers, Waterways Experiment Station, Vicksburg, Mississippi, 1993.

White, T. D., Zaghloul, S., Coree, B. J. and Drnevich, V. P., "Determining Pavement Material Properties from FWD Tests Using a Three Dimensional Dynamic Finite Element Program", ASTM STP 1198, December 1994, pp. 125-138. 
Worley, H. E., "Triaxial Design Correlated with Flexible Pavement Performance in Kansas", Symposium on Triaxial Testing of Soils and Bituminous Mixtures, ASTM STP No. 106, 1951, pp. 112-137.

Wood, Leonard E., "The Stress-Deformation Characteristics of Asphalt Mixtures Under Various Conditions of Loading", Ph.D. Thesis, Purdue University, 1956.

Wood, D., Soil Behavior and Critical State Soil Mechanics, Cambridge University Press, 1990.

Yoder, E. J., Lowrie, C. R., "Triaxial Testing Applied to Design of Flexible Pavements", Proceedings, Highway Research Board, December 1951, pp. 487-499.

Yoder, E. J., Witczak, M. W., Principals of Pavement Design, Second Edition, John Wiley \& Sons, Inc., 1975. 
APPENDICES 
APPENDIX A PAVEMENT TEMPERATURE FOR SECTION 1 
Coldest Days (Jan 27, 28, 29, 1997)

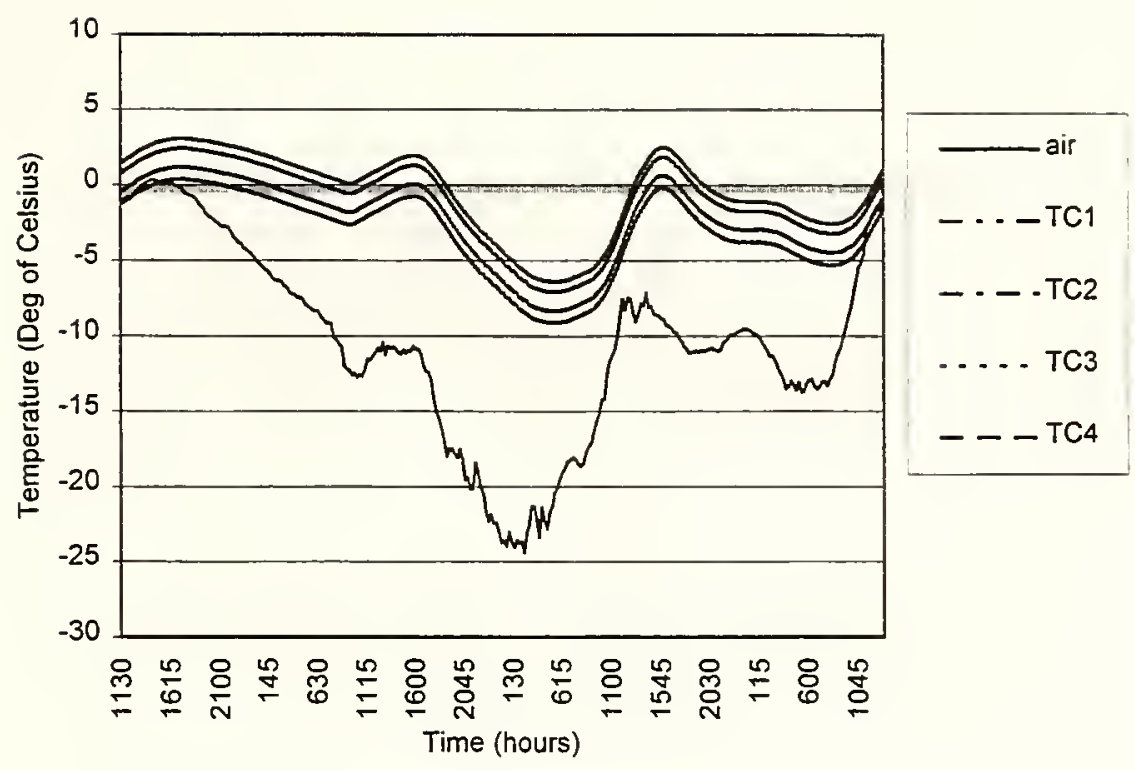

Figure A.1 Coldest Days in 1997, Section 1 
Coldest Days (Jan 27, 28, 29, 1997)

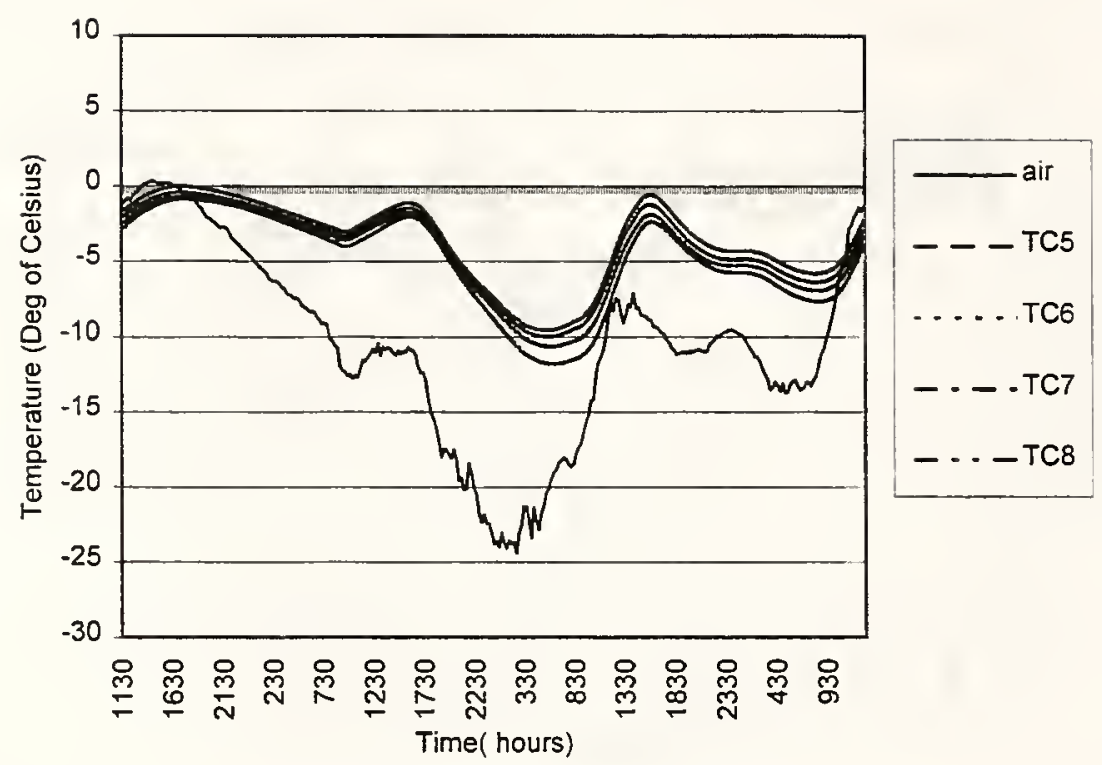

Figure A.2 Coldest Days in 1997, Section 1 
Hottest Days (July 14-21, 1997)

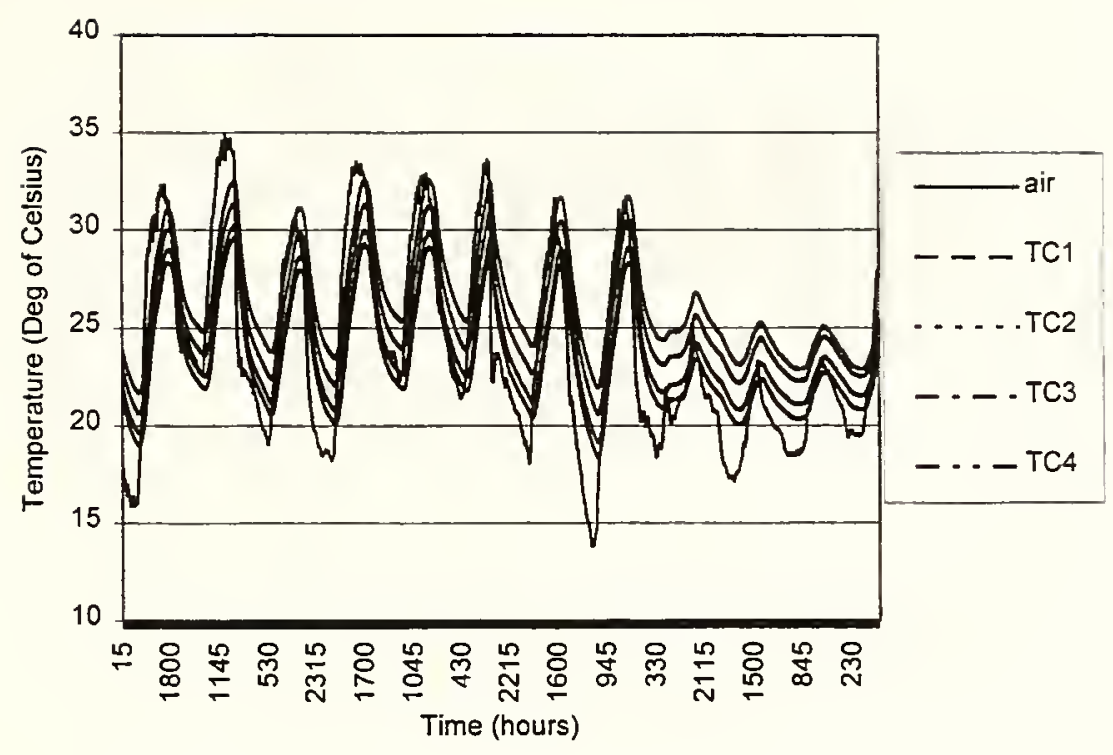

Figure A.3 Hottest Days in 1997, Section 1 
Hottest Days (July 14-21, 1997)

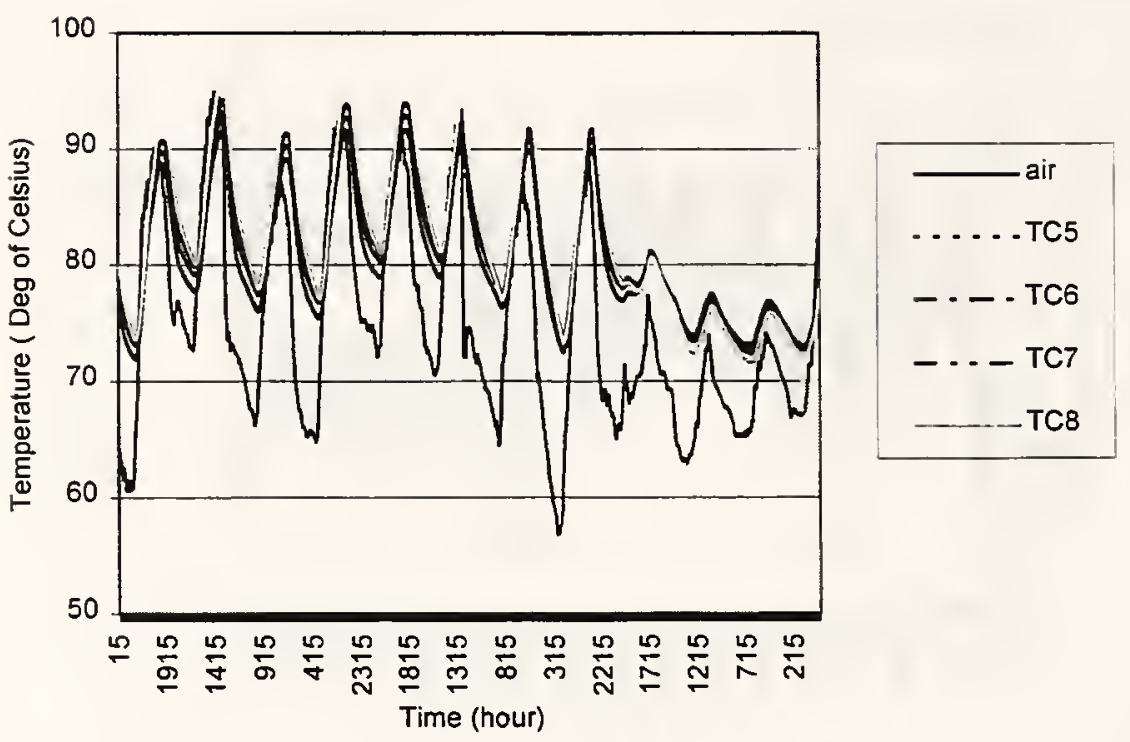

Figure A.4 Hottest Days in 1997, Section 1 
Coldest Days (Jan 11-14, 1998)

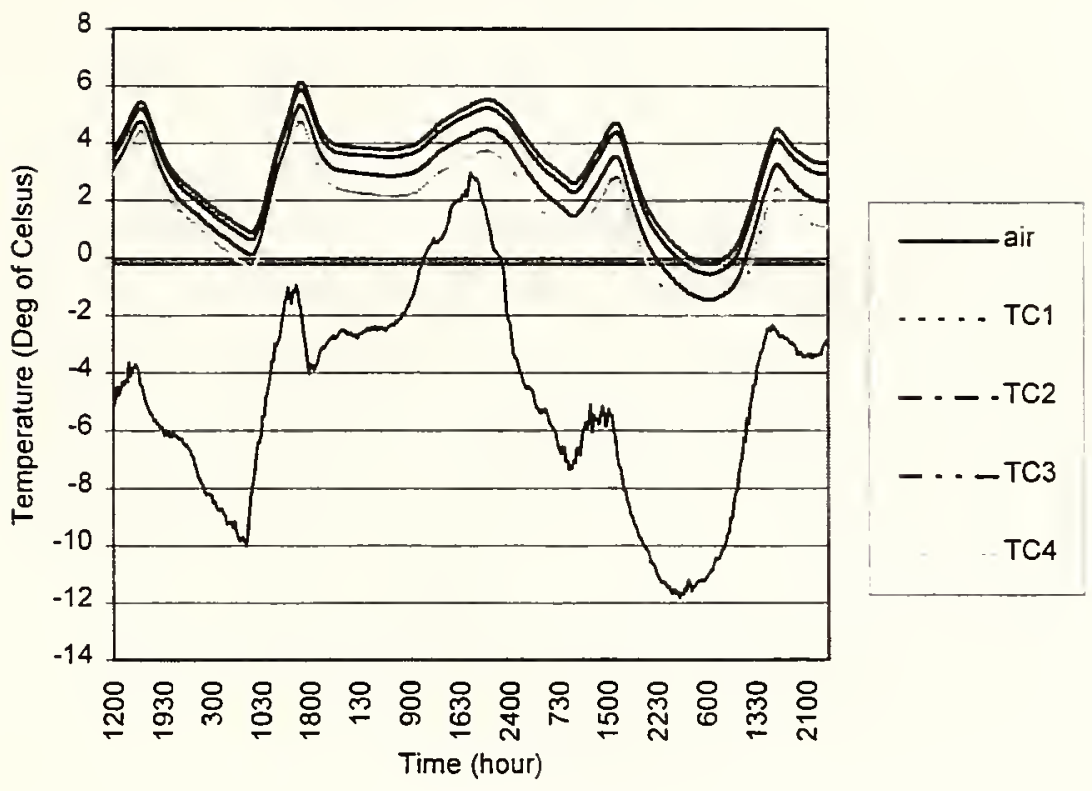

Figure A.5 Coldest Days in 1998, Section 1 
Coldest Days (Jan 11-14, 1998)

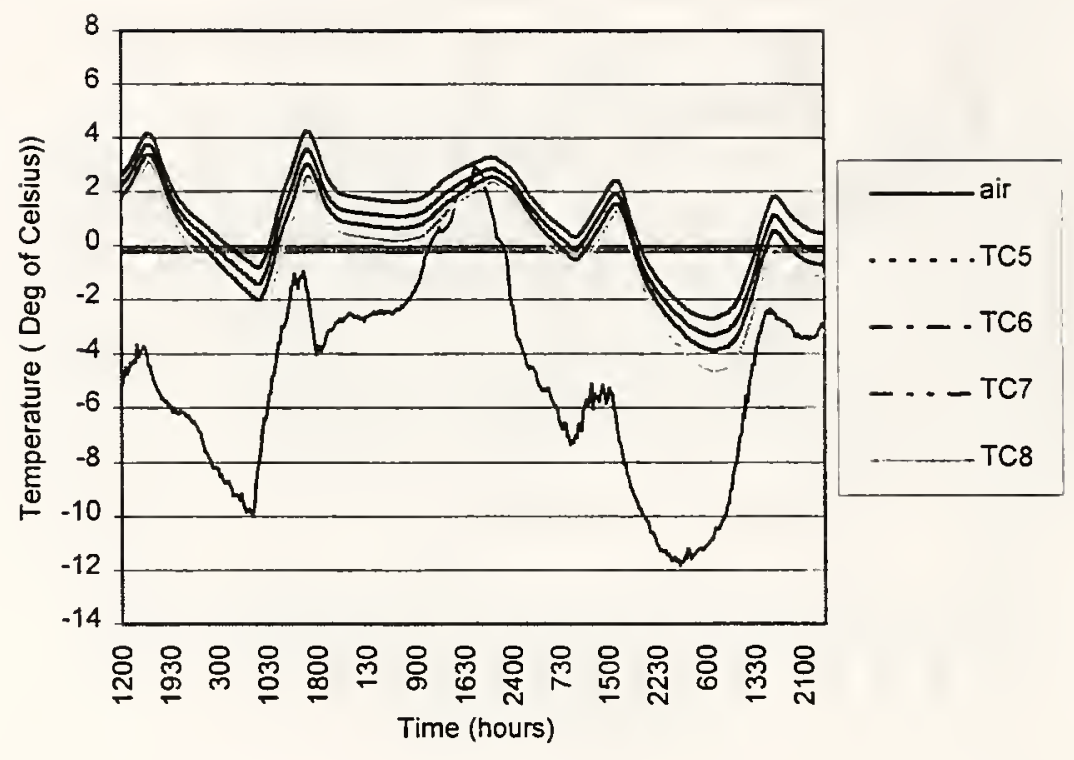

Figure A.6 Coldest Days in 1998, Section 1 
Coldest Days (Jan 11-14, 1998)

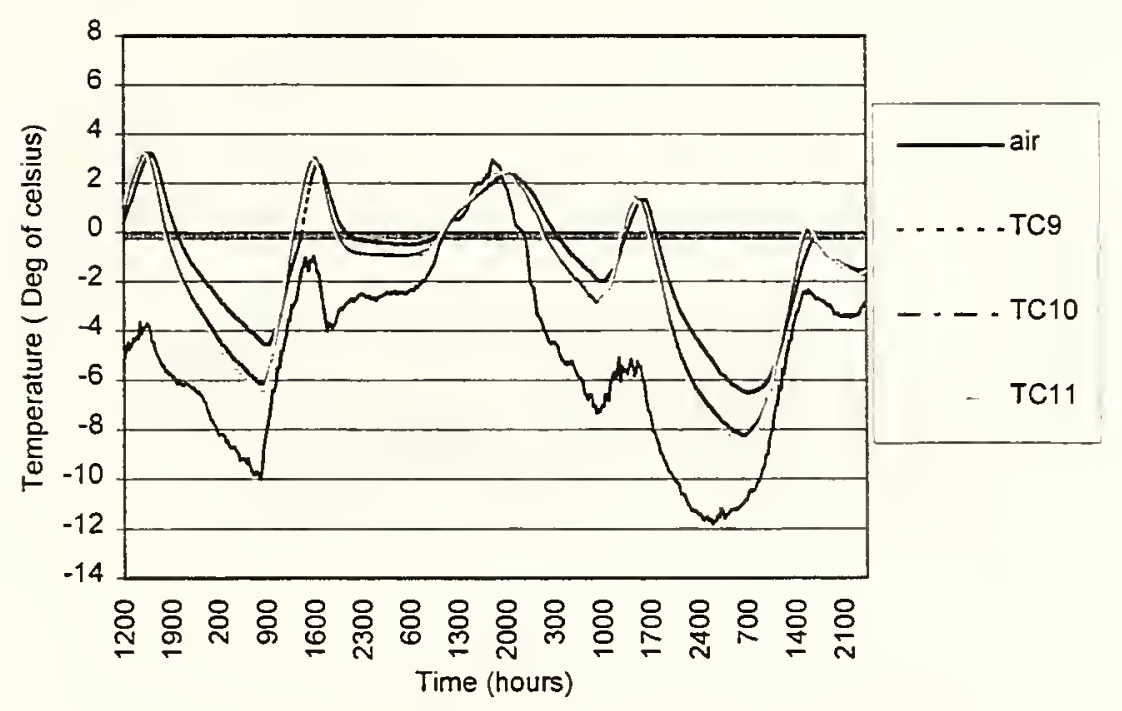

Figure A.7 Coldest Days in 1998, Section 1 
Hottest Days (June 22-28, 1998)

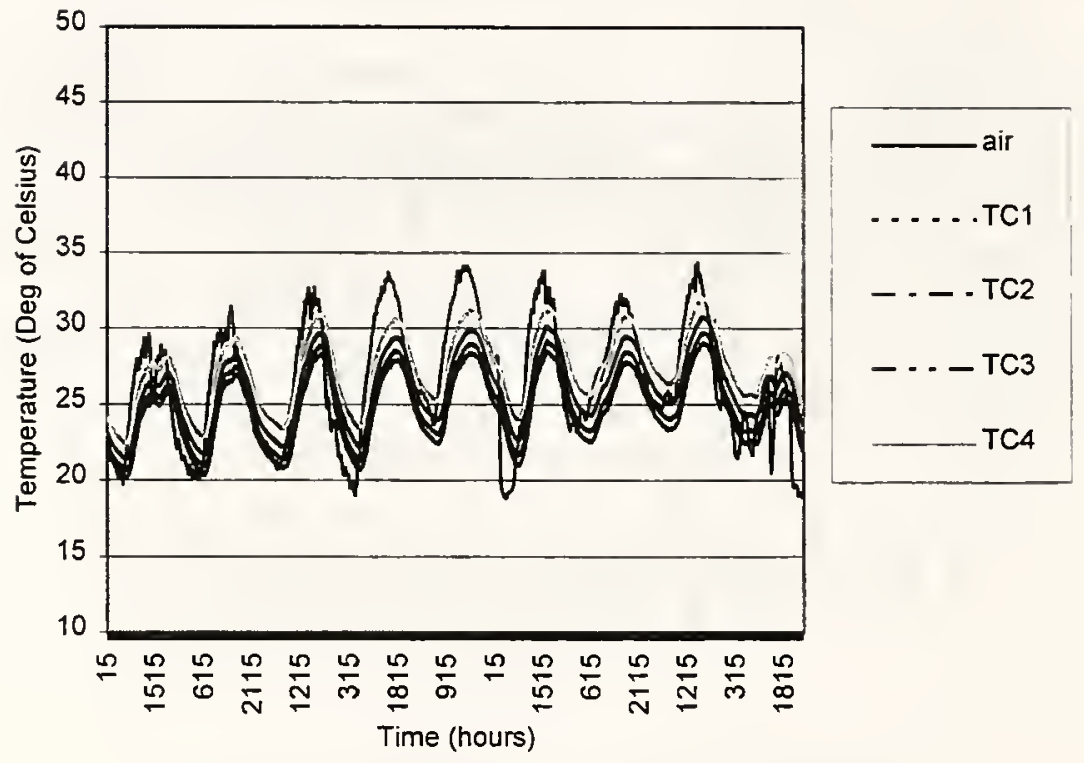

Figure A.8 Hottest Days in 1998, Section 1 
Hottest Days (June 22-28, 1998)

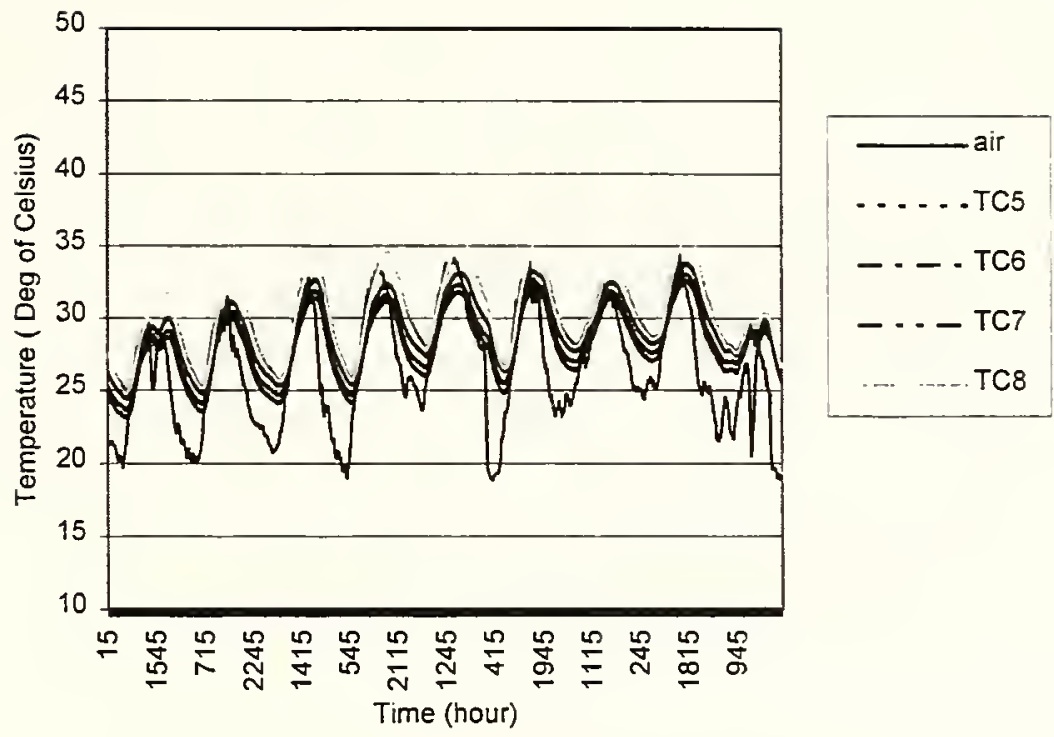

Figure A.9 Hottest Days in 1998, Section 1 
Hottest Days (June 22-28, 1998 )

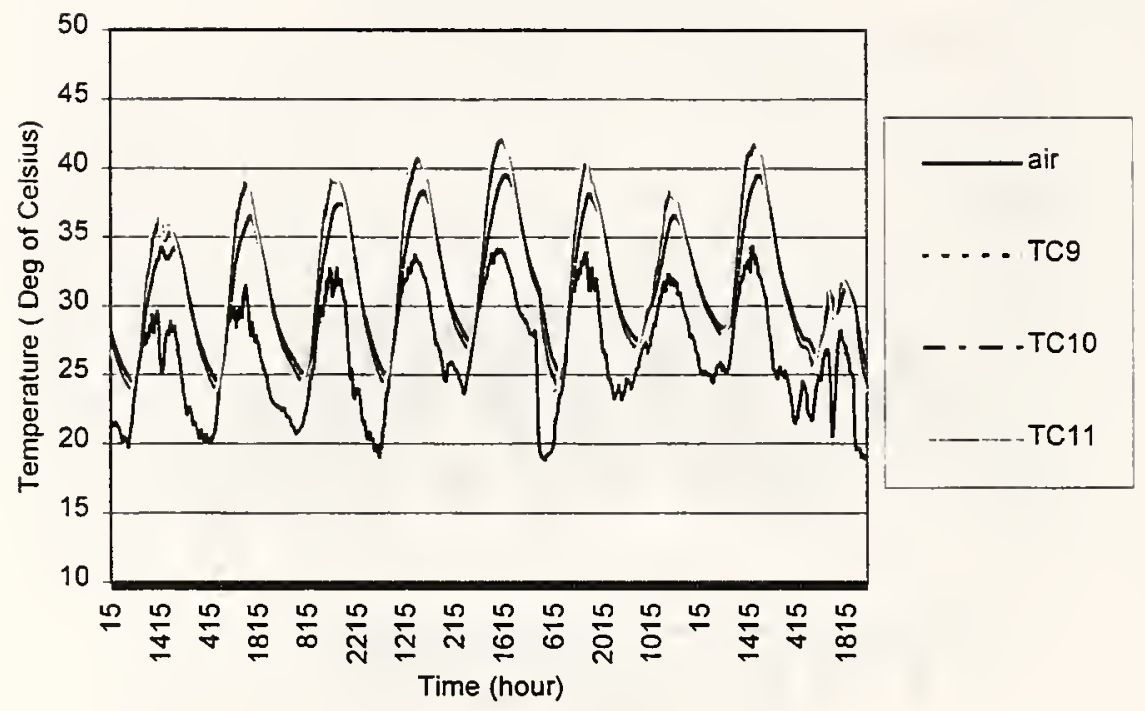

Figure A.10 Hottest Days in 1998, Section 1 
APPENDIX B FWD TEST DATA 
FWD Test

Diameter of Plate: $299.7 \mathrm{~mm}$

$\begin{array}{lllllll}\text { Deflector Distances (mm ) : df1 } & \text { df2 } & \text { df3 } & \text { df4 } & \text { df5 } & \text { df6 } & \text { df7 }\end{array}$

$$
\begin{array}{lllllll}
0 & -304.8 & 304.8 & 609.6 & 914.4 & 1219.2 & 1524
\end{array}
$$

$\underline{\text { Section } 1}$

\begin{tabular}{|r|r|r|r|r|r|r|r|}
\hline Load $(\mathrm{kg})$ & df1 $(\mathrm{cm})$ & df2 $(\mathrm{cm})$ & $d f 3(\mathrm{~cm})$ & $d f 4(\mathrm{~cm})$ & $d f 5(\mathrm{~cm})$ & $d f 6(\mathrm{~cm})$ & $d f 7(\mathrm{~cm})$ \\
\hline 3493.5 & 9.296 & 7.468 & 7.518 & 5.994 & 4.775 & 3.581 & 2.921 \\
\hline 4431.5 & 11.760 & 9.474 & 9.500 & 7.595 & 5.969 & 4.547 & 3.581 \\
\hline 5372.6 & 14.199 & 11.430 & 11.506 & 9.169 & 7.137 & 5.410 & 4.216 \\
\hline & & & & & & & \\
\hline 3486.3 & 9.423 & 7.391 & 7.468 & 5.893 & 4.674 & 3.708 & 2.896 \\
\hline 4407.9 & 12.040 & 9.423 & 9.550 & 7.544 & 5.969 & 4.699 & 3.632 \\
\hline 5376.3 & 14.732 & 11.684 & 11.836 & 9.271 & 7.341 & 5.740 & 4.420 \\
\hline & & & & & & & \\
\hline 3488.1 & 8.585 & 6.274 & 6.325 & 5.029 & 4.064 & 2.972 & 2.388 \\
\hline 4409.7 & 10.820 & 8.052 & 8.179 & 6.401 & 5.156 & 3.810 & 3.124 \\
\hline 5378.1 & 13.360 & 9.931 & 10.033 & 7.925 & 6.325 & 4.826 & 3.835 \\
\hline & & & & & & & \\
\hline 3504.4 & 7.849 & 5.563 & 5.715 & 4.343 & 3.353 & 2.438 & 1.880 \\
\hline 4427.9 & 9.931 & 7.163 & 7.290 & 5.588 & 4.267 & 3.175 & 2.464 \\
\hline 5383.5 & 12.243 & 9.093 & 8.941 & 6.960 & 5.105 & 3.988 & 3.099 \\
\hline & & & & & & & \\
\hline 3482.6 & 7.722 & 5.613 & 5.690 & 4.394 & 3.429 & 2.591 & 1.956 \\
\hline 4398.8 & 9.830 & 7.214 & 7.341 & 5.690 & 4.470 & 3.353 & 2.565 \\
\hline 5363.6 & 12.090 & 8.839 & 8.992 & 6.985 & 5.436 & 4.115 & 3.200 \\
\hline & & & & & & & \\
\hline 3457.2 & 7.899 & 5.690 & 5.791 & 4.369 & 3.378 & 2.591 & 1.854 \\
\hline 4402.4 & 10.236 & 7.290 & 7.391 & 5.639 & 4.318 & 3.251 & 2.438 \\
\hline 5365.4 & 12.522 & 9.119 & 9.195 & 7.061 & 5.410 & 4.140 & 3.124 \\
\hline & & & & & & & \\
\hline 3449.9 & 7.341 & 5.283 & 5.309 & 4.064 & 3.073 & 2.261 & 1.727 \\
\hline 4373.4 & 9.500 & 6.756 & 6.858 & 5.258 & 3.962 & 2.921 & 2.261 \\
\hline 5345.9 & 11.684 & 8.458 & 8.534 & 6.553 & 4.978 & 3.658 & 2.819 \\
\hline & & & & & & & \\
\hline 3464.5 & 7.493 & 5.309 & 5.588 & 4.089 & 3.378 & 2.515 & 1.880 \\
\hline 4395.2 & 9.728 & 7.010 & 6.833 & 5.512 & 4.064 & 3.200 & 2.515 \\
\hline 5340.4 & 11.887 & 8.433 & 8.788 & 6.579 & 5.359 & 4.013 & 3.023 \\
\hline
\end{tabular}

(Deformation unit is: $0.01 \mathrm{~mm}$ ) 
$\underline{\text { Section } 2}$

\begin{tabular}{|c|c|c|c|c|c|c|c|}
\hline Load (kg) & $\mathrm{df1}(\mathrm{cm})$ & $\mathrm{df2}(\mathrm{cm})$ & $\mathrm{df3}(\mathrm{cm})$ & $\mathrm{df4}(\mathrm{cm})$ & $\mathrm{df5}(\mathrm{cm})$ & $\mathrm{df6}(\mathrm{cm})$ & $\mathrm{df7}(\mathrm{cm})$ \\
\hline 3459.0 & 7.976 & 5.588 & 5.690 & 4.242 & 3.200 & 2.388 & 1.727 \\
\hline 4384.3 & 10.389 & 7.188 & 7.290 & 5.486 & 4.140 & 3.073 & 2.362 \\
\hline 5338.6 & 12.573 & 8.941 & 9.042 & 6.833 & 5.182 & 3.861 & 2.921 \\
\hline & & & & & & & \\
\hline 3464.5 & 7.722 & 5.613 & 5.715 & 4.318 & 3.251 & 2.413 & 1.803 \\
\hline 4386.1 & 10.058 & 7.163 & 7.341 & 5.537 & 4.191 & 3.099 & 2.311 \\
\hline 5347.7 & 12.319 & 8.941 & 9.093 & 6.934 & 5.258 & 3.912 & 2.972 \\
\hline & & & & & & & \\
\hline 3459.0 & 7.569 & 5.537 & 5.918 & 4.420 & 3.429 & 2.362 & 1.575 \\
\hline 4371.6 & 9.779 & 7.112 & 7.569 & 5.690 & 4.369 & 3.124 & 2.184 \\
\hline 5340.4 & 12.014 & 8.941 & 9.246 & 7.061 & 5.385 & 3.912 & 2.896 \\
\hline & & & & & & & \\
\hline 3459.0 & 8.357 & 6.223 & 6.350 & 4.902 & 3.734 & 2.819 & 2.134 \\
\hline 4367.9 & 10.795 & 7.874 & 8.052 & 6.198 & 4.724 & 3.556 & 2.692 \\
\hline 5342.2 & 13.183 & 9.931 & 10.033 & 7.747 & 5.944 & 4.496 & 3.378 \\
\hline & & & & & & & \\
\hline 3460.8 & 8.509 & 6.375 & 6.477 & 4.877 & 3.759 & 2.819 & 2.057 \\
\hline 4377.0 & 10.947 & 8.077 & 8.230 & 6.223 & 4.775 & 3.607 & 2.667 \\
\hline 5335.0 & 13.411 & 9.982 & 10.160 & 7.696 & 5.969 & 4.521 & 3.150 \\
\hline & & & & & & & \\
\hline 3466.3 & 8.357 & 6.401 & 6.452 & 5.029 & 3.988 & 2.972 & 2.210 \\
\hline 4373.4 & 10.973 & 8.128 & 8.255 & 6.452 & 5.004 & 3.785 & 2.946 \\
\hline 5344.0 & 13.310 & 10.135 & 10.262 & 8.026 & 6.274 & 4.750 & 3.632 \\
\hline & & & & & & & \\
\hline 3462.7 & 8.230 & 6.299 & 6.426 & 4.775 & 3.683 & 2.667 & 1.930 \\
\hline 4348.4 & 10.922 & 8.077 & 8.204 & 6.198 & 4.775 & 3.429 & 2.515 \\
\hline 5336.8 & 13.259 & 10.033 & 10.109 & 7.722 & 5.867 & 4.318 & 3.200 \\
\hline & & & & & & & \\
\hline 3451.8 & 7.341 & 5.512 & 5.461 & 4.166 & 3.277 & 2.565 & 2.032 \\
\hline 4369.8 & 9.398 & 7.087 & 6.960 & 5.334 & 4.191 & 3.327 & 2.591 \\
\hline 5320.4 & 11.430 & 8.661 & 8.509 & 6.528 & 5.131 & 4.039 & 3.175 \\
\hline
\end{tabular}

(Deformation unit is in: $0.01 \mathrm{~mm}$ ) 
$\underline{\text { Section } 3}$

\begin{tabular}{|r|r|r|r|r|r|r|r|}
\hline Load $(\mathrm{kg})$ & $\mathrm{df} 1(\mathrm{~cm})$ & $\mathrm{df2}(\mathrm{cm})$ & $\mathrm{df3}(\mathrm{cm})$ & $\mathrm{df4}(\mathrm{cm})$ & $\mathrm{df5}(\mathrm{cm})$ & $\mathrm{df6}(\mathrm{cm})$ & $\mathrm{df7}(\mathrm{cm})$ \\
\hline 3459.0 & 6.121 & 4.420 & 4.470 & 3.581 & 2.921 & 2.261 & 1.753 \\
\hline 4387.9 & 8.026 & 5.664 & 5.740 & 4.597 & 3.759 & 2.870 & 2.286 \\
\hline 5335.0 & 9.728 & 7.036 & 7.061 & 5.690 & 4.623 & 3.581 & 2.870 \\
\hline & & & & & & & \\
\hline 3468.1 & 6.172 & 4.191 & 4.267 & 3.302 & 2.642 & 2.007 & 1.575 \\
\hline 4395.2 & 7.976 & 5.359 & 5.436 & 4.242 & 3.378 & 2.642 & 2.057 \\
\hline 5344.0 & 9.703 & 6.629 & 6.756 & 5.258 & 4.216 & 3.327 & 2.591 \\
\hline & & & & & & & \\
\hline 3451.8 & 6.198 & 4.394 & 4.420 & 3.480 & 2.718 & 2.108 & 1.600 \\
\hline 4367.9 & 7.899 & 5.588 & 5.690 & 4.470 & 3.531 & 2.718 & 2.083 \\
\hline 5333.1 & 9.728 & 6.934 & 6.960 & 5.512 & 4.343 & 3.378 & 2.616 \\
\hline & & & & & & & \\
\hline 3457.2 & 7.722 & 5.512 & 5.690 & 4.521 & 3.556 & 2.870 & 2.184 \\
\hline 4380.6 & 9.957 & 7.137 & 7.341 & 5.817 & 4.597 & 3.708 & 2.845 \\
\hline 5313.2 & 12.090 & 8.839 & 8.941 & 7.137 & 5.740 & 4.521 & 3.556 \\
\hline & & & & & & & \\
\hline 3443.1 & 8.712 & 6.375 & 6.502 & 5.334 & 4.318 & 3.454 & 2.692 \\
\hline 4367.9 & 10.973 & 8.357 & 8.433 & 6.960 & 5.639 & 4.496 & 3.607 \\
\hline 5302.3 & 13.437 & 10.135 & 10.312 & 8.509 & 6.934 & 5.512 & 4.343 \\
\hline & & & & & & & \\
\hline 3453.6 & 7.468 & 5.664 & 5.715 & 4.674 & 3.835 & 3.023 & 2.464 \\
\hline 4367.9 & 9.703 & 7.264 & 7.315 & 5.944 & 4.902 & 3.886 & 3.124 \\
\hline 5344.0 & 11.684 & 8.839 & 8.966 & 7.290 & 5.994 & 4.801 & 3.835 \\
\hline & & & & & & & \\
\hline 3434.1 & 7.417 & 5.512 & 5.537 & 4.445 & 3.632 & 2.896 & 2.337 \\
\hline 4361.1 & 9.550 & 7.010 & 7.061 & 5.639 & 4.674 & 3.658 & 2.972 \\
\hline 5304.1 & 11.608 & 8.636 & 8.661 & 7.010 & 5.715 & 4.521 & 3.632 \\
\hline & & & & & & & \\
\hline 3412.3 & 8.001 & 5.740 & 5.867 & 4.623 & 3.734 & 2.921 & 2.261 \\
\hline 4333.9 & 10.312 & 7.341 & 7.442 & 5.969 & 4.801 & 3.759 & 2.921 \\
\hline 5273.7 & 12.497 & 9.068 & 9.195 & 7.417 & 5.969 & 4.648 & 3.683 \\
\hline
\end{tabular}

(Deformation unit is in: $0.01 \mathrm{~mm}$ ) 
APPENDIX C PAVEMENT LONGITUDINAL PROFILE MEASUREMENT 
Longitudinal Profile

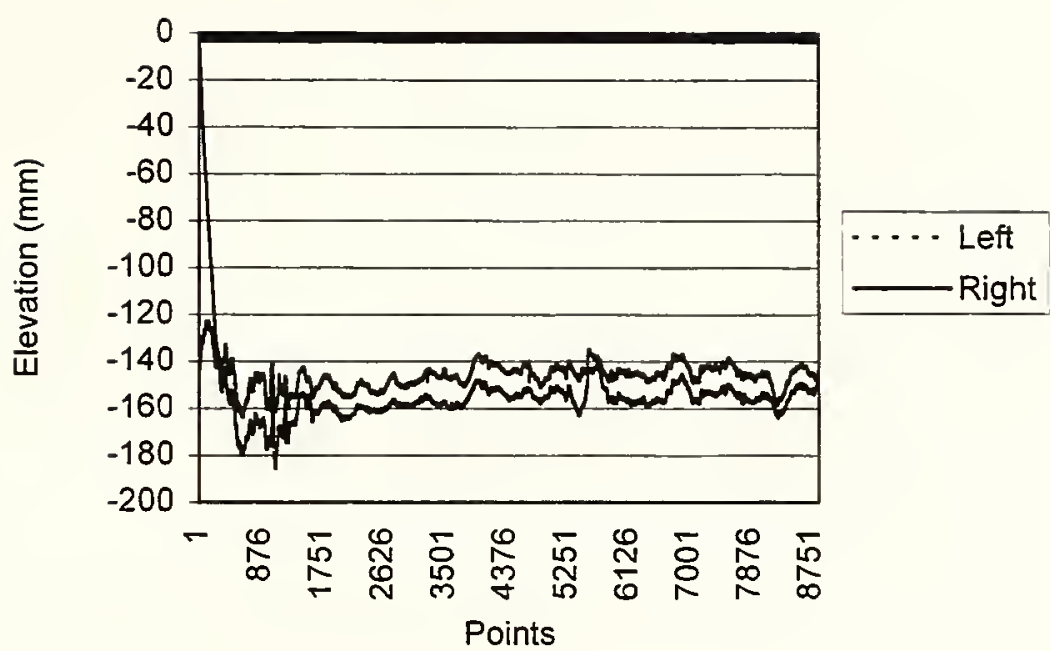

C.1 First Pass (Left, Right-Left, Right Wheel Path)

Longitudinal Profile

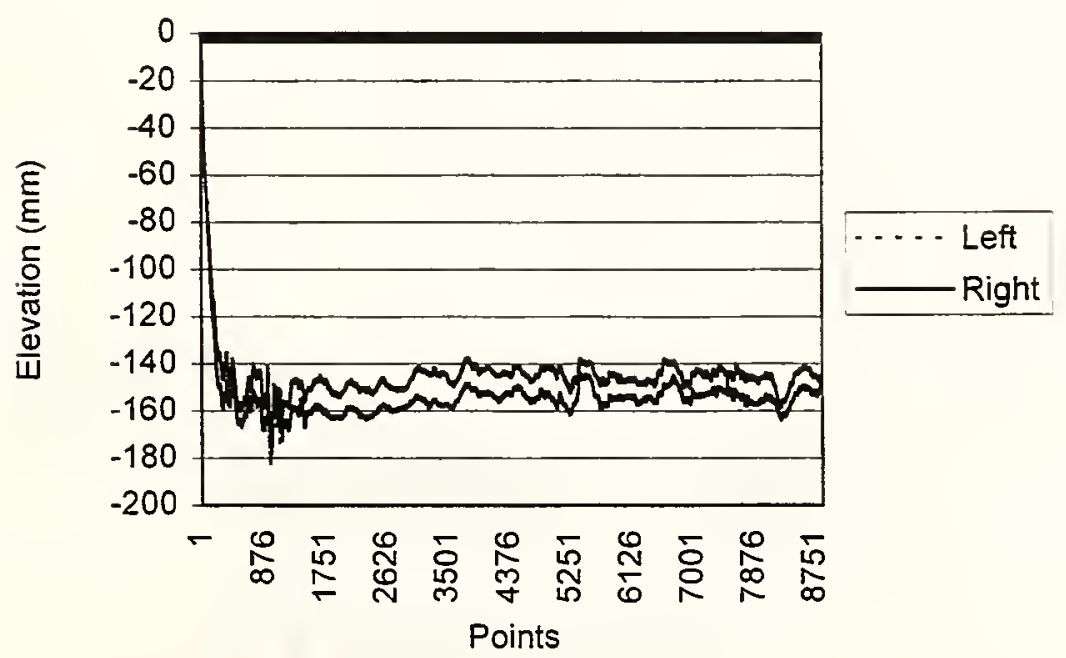

C.2 Second Pass (Left, Right-Left, Right Wheel Path) 
Longitudinal Profile

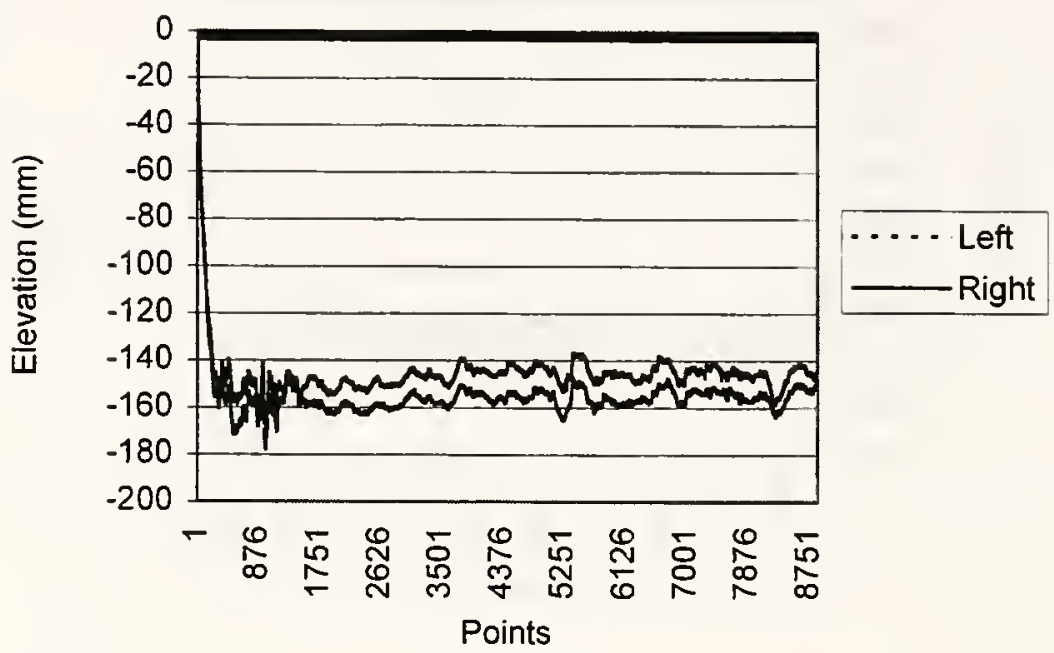

Figure C.3 Third Pass (Left, Right—Left, Right Wheel Path)

Longitudinal Profile

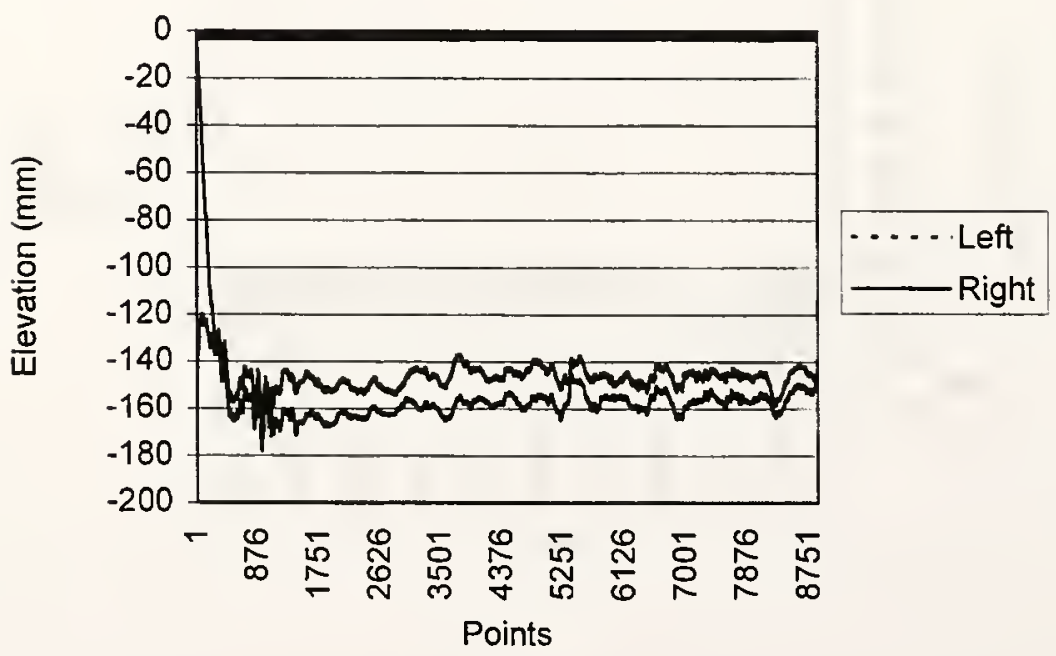

C.4 Fourth Pass (Left, Right—Left, Right Wheel Path) 
APPENDIX D TRIAXIAL TESTS ON ASPHALT MIXTURES 


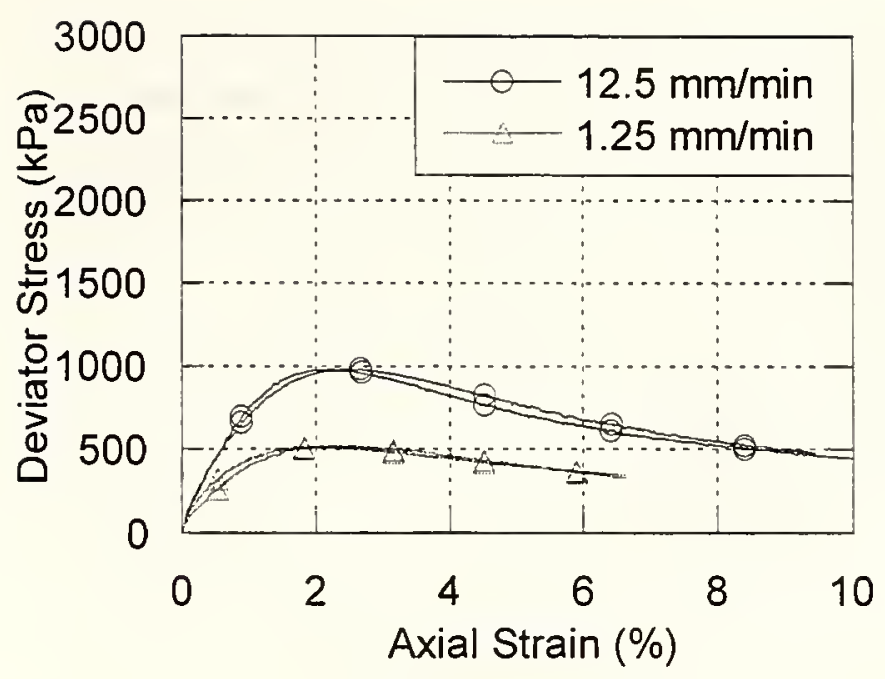

Figure D.1 Stress-Strain on \#11 Surface Mixture Dry Test (35 kPa Confining Pressure)

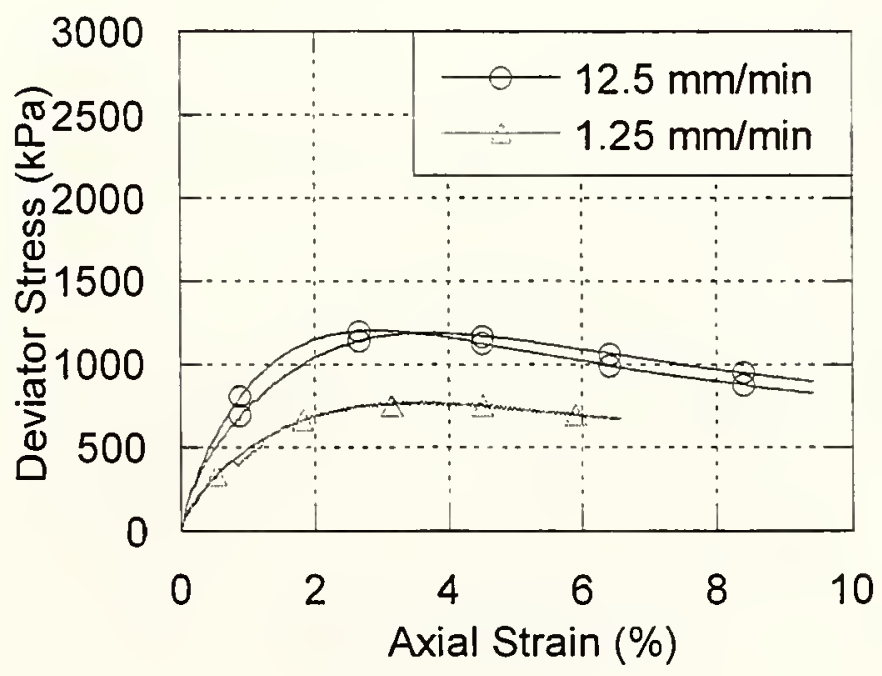

Figure D.2 Stress-Strain on \#11 Surface Mixture Dry Test (104 kPa Confining Pressure) 


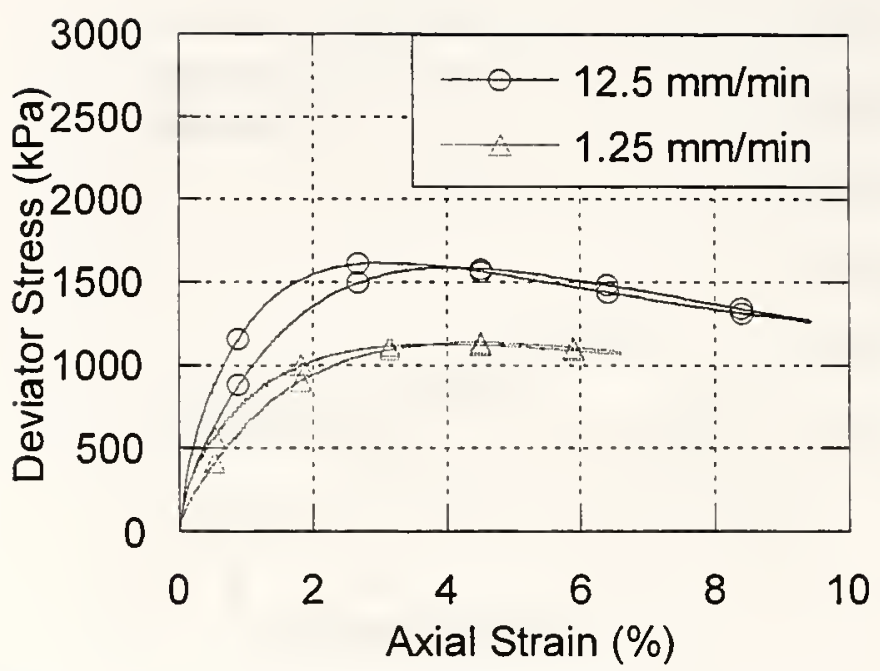

Figure D.3 Stress-Strain on \#11 Surface Mixture Dry Test (208 kPa Confining Pressure)

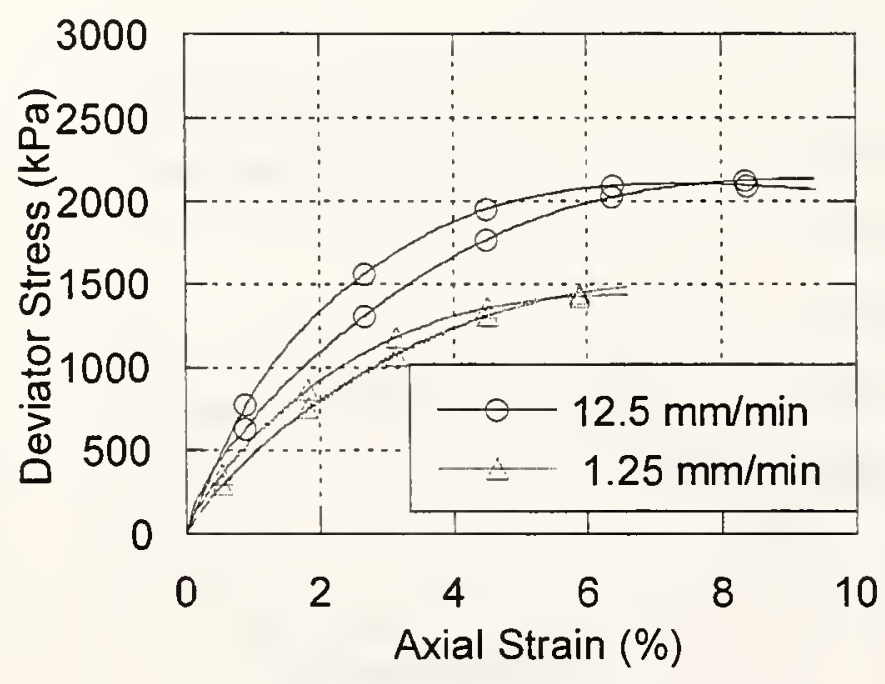

Figure D.4 Stress-Strain on \#11 Surface Mixture CU Test (35 kPa Confining Pressure) 


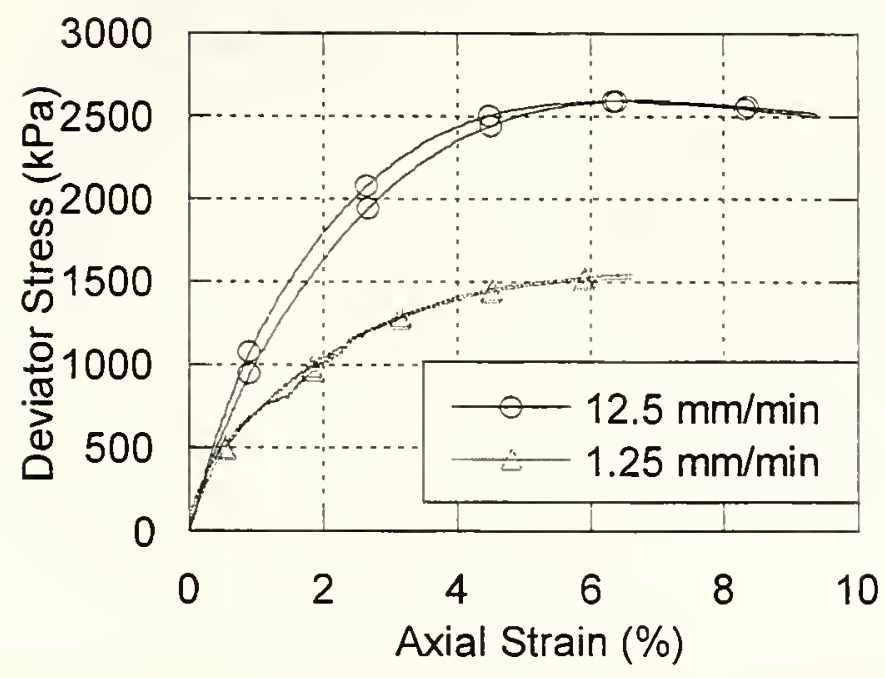

Figure D.5 Stress-Strain on \#11 Surface Mixture CU Test (104 kPa Confining Pressure)

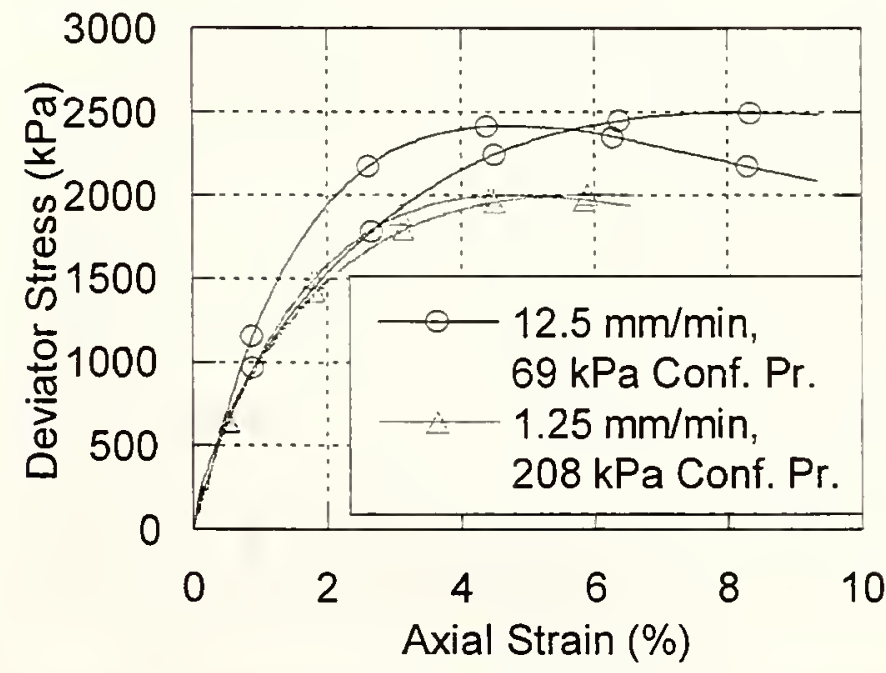

Figure D.6 Stress-Strain on \#11 Surface Mixture CU Test 


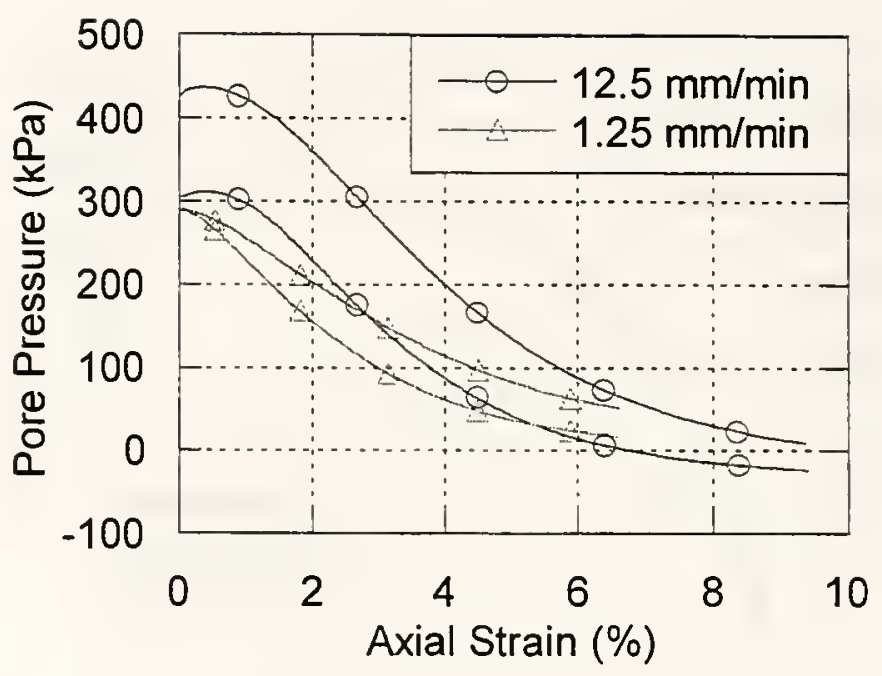

Figure D.7 Pore Pressure vs. Axial Strain on \#11 Surface Mixture CU Test (35 kPa Confining Pressure)

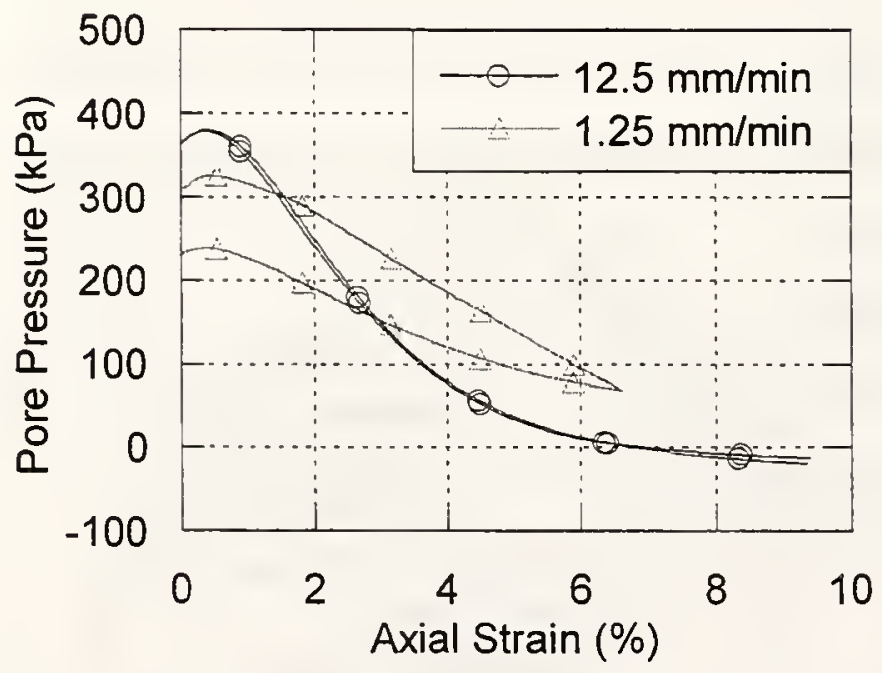

Figure D.8 Pore Pressure vs. Axial Strain on \#11 Surface Mixture CU Test (104 kPa Confining Pressure) 


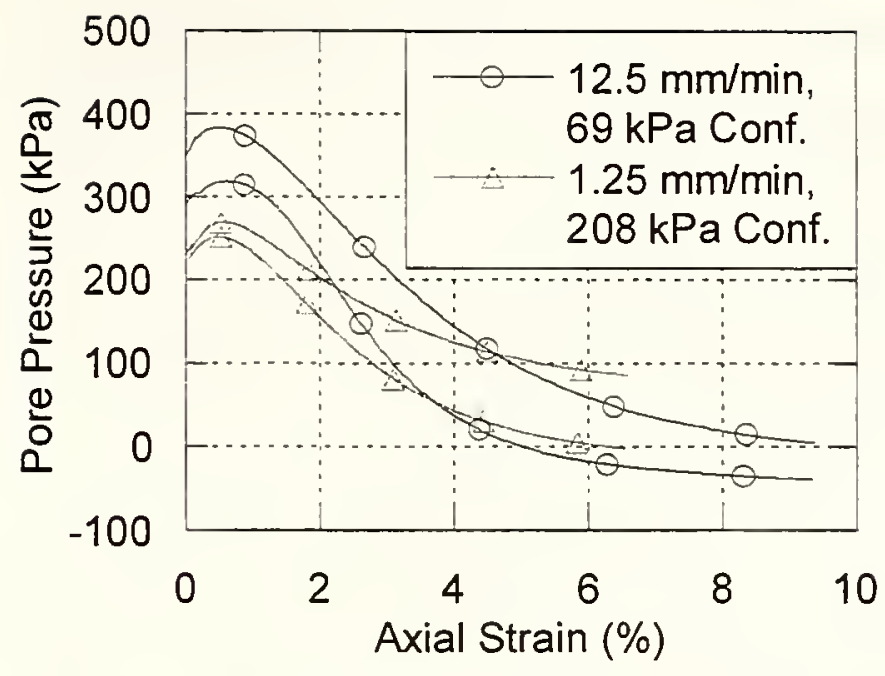

Figure D.9 Pore Pressure vs. Axial Strain on \#11 Surface Mixture CU Test

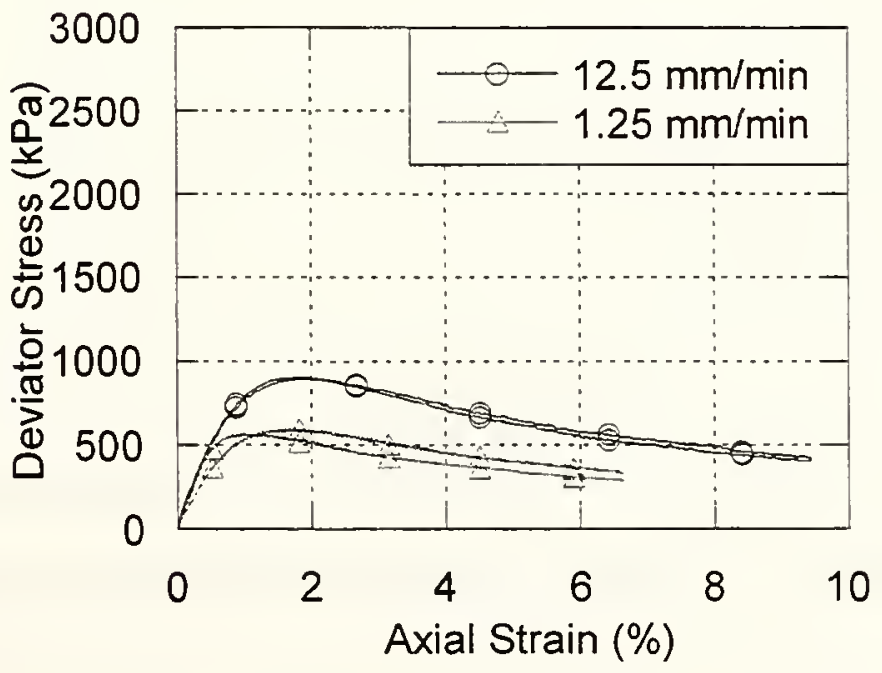

Figure D.10 Stress-Strain on \#9 Binder Mixture Dry Test (35 kPa, Confining Pressure) 


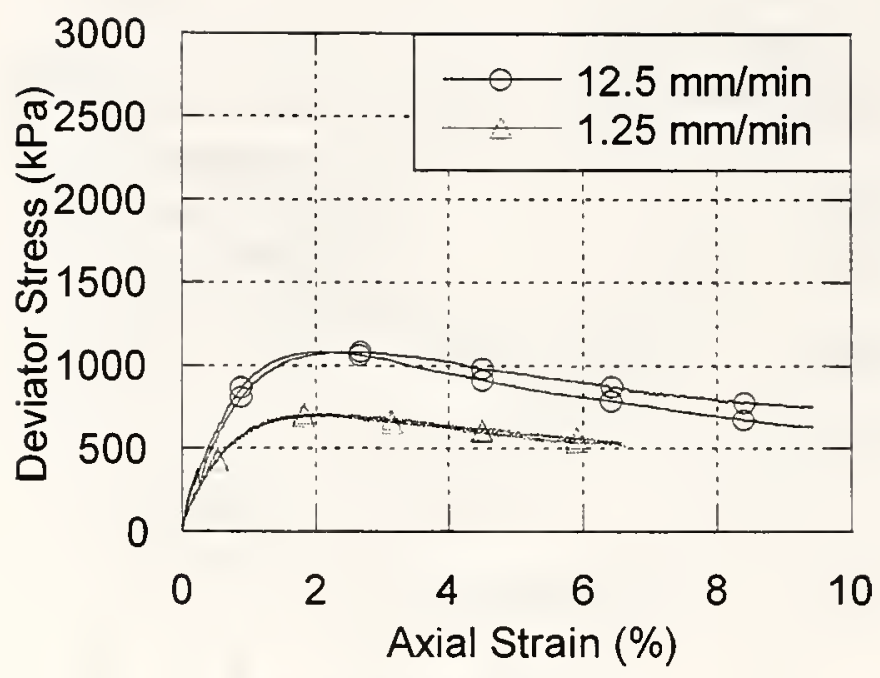

Figure D.11 Stress-Strain on \#9 Binder Mixture Dry Test (69 kPa Confining Pressure)

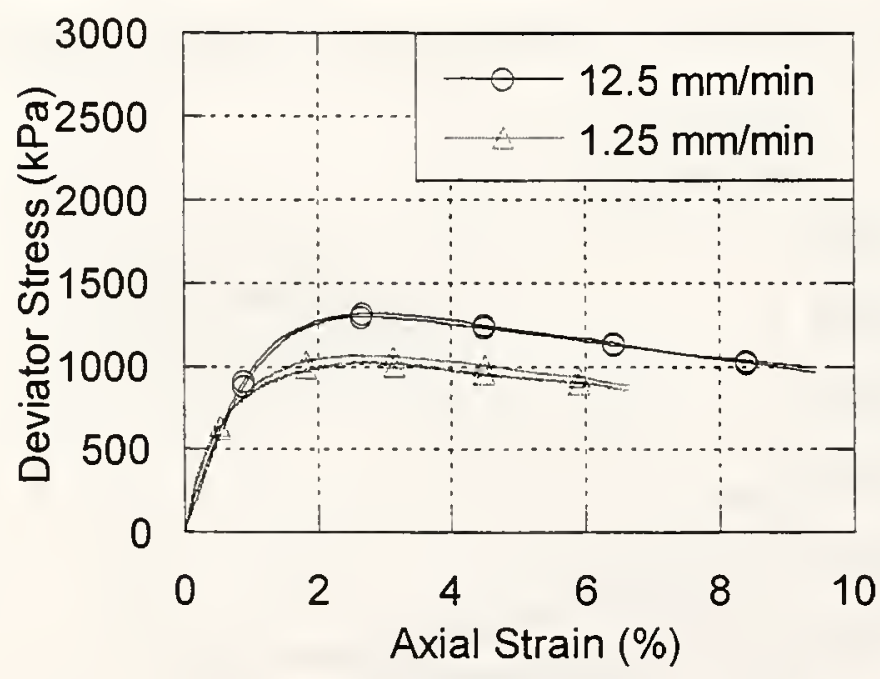

Figure D.12 Stress-Strain on \#9 Binder Mixture Dry Test (138 kPa Confining Pressure) 


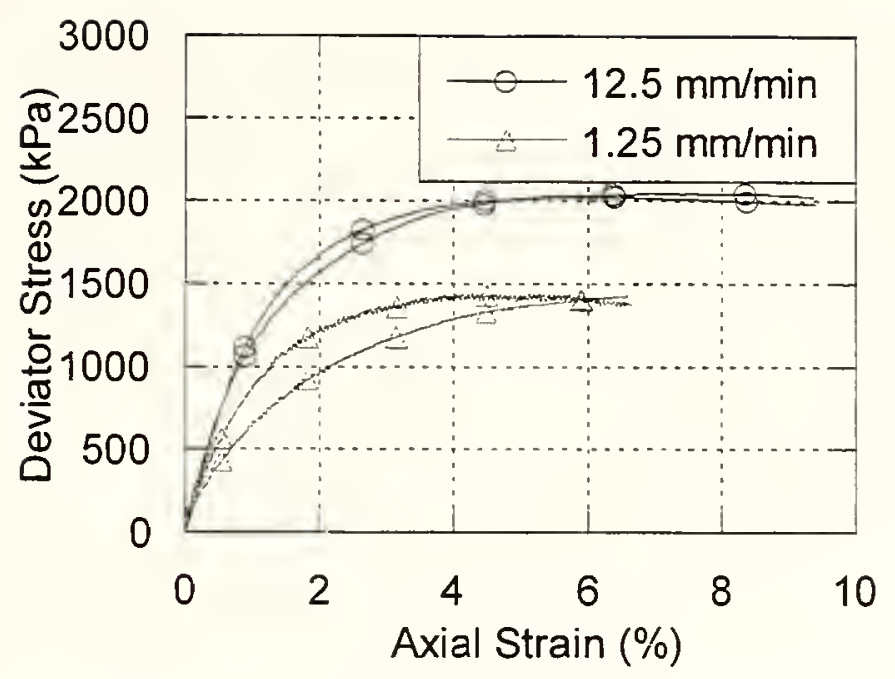

Figure D.13 Stress-Strain on \#9 Binder Mixture CU Test ( $35 \mathrm{kPa}$ Confining Pressure)

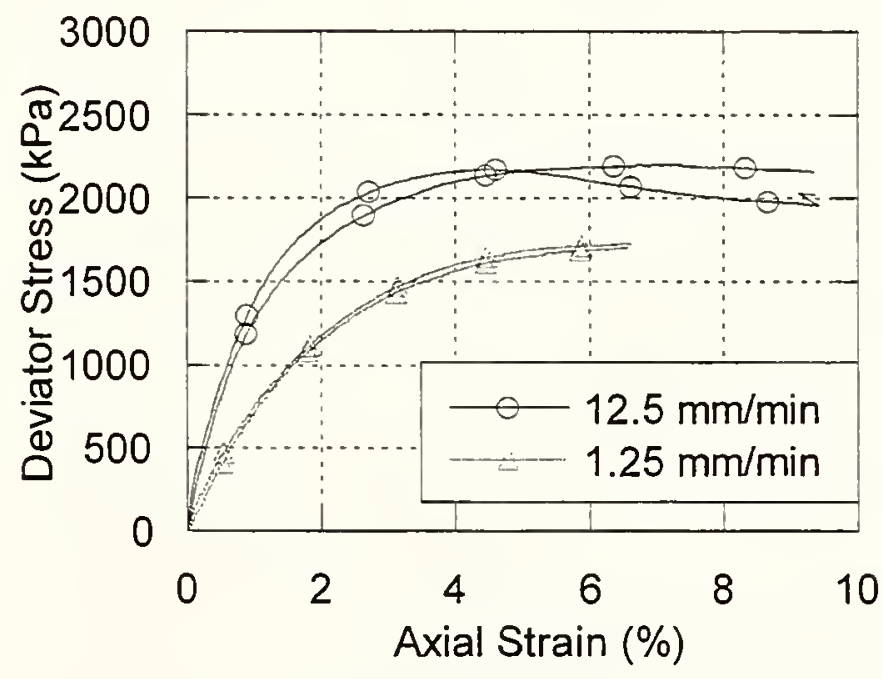

Figure D.14 Stress-Strain on \#9 Binder Mixture CU Test (69 kPa Confining Pressure) 


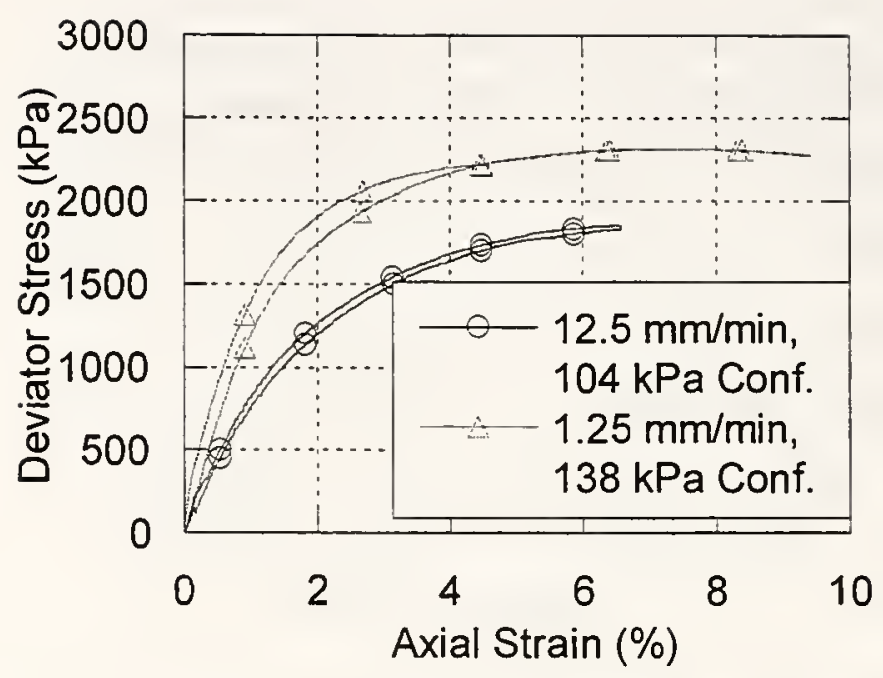

Figure D.15 Stress-Strain on \#9 Binder Mixture CU Test

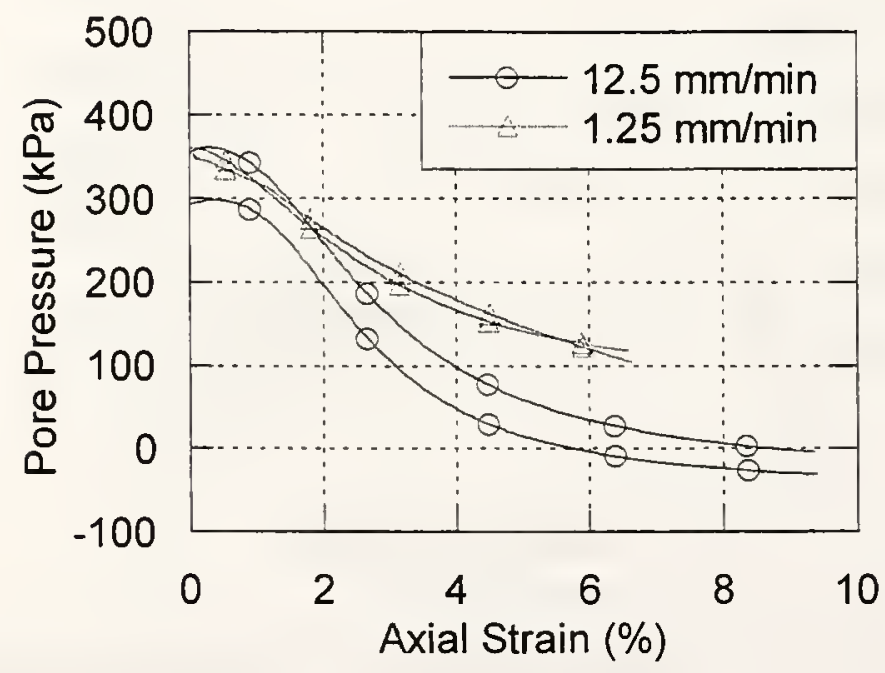

Figure D.16 Pore Pressure vs. Axial Strain on \#9 Binder Mixture CU Test ( $35 \mathrm{kPa}$ Confining Pressure) 


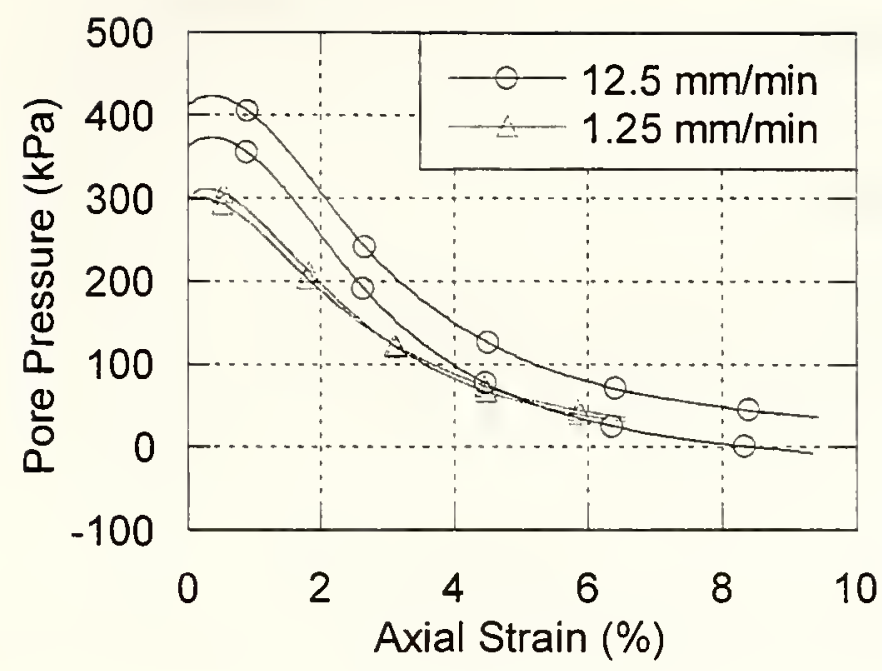

Figure D.17 Pore Pressure vs. Axial Strain on \#9 Binder Mixture CU Test (69 kPa Confining Pressure)

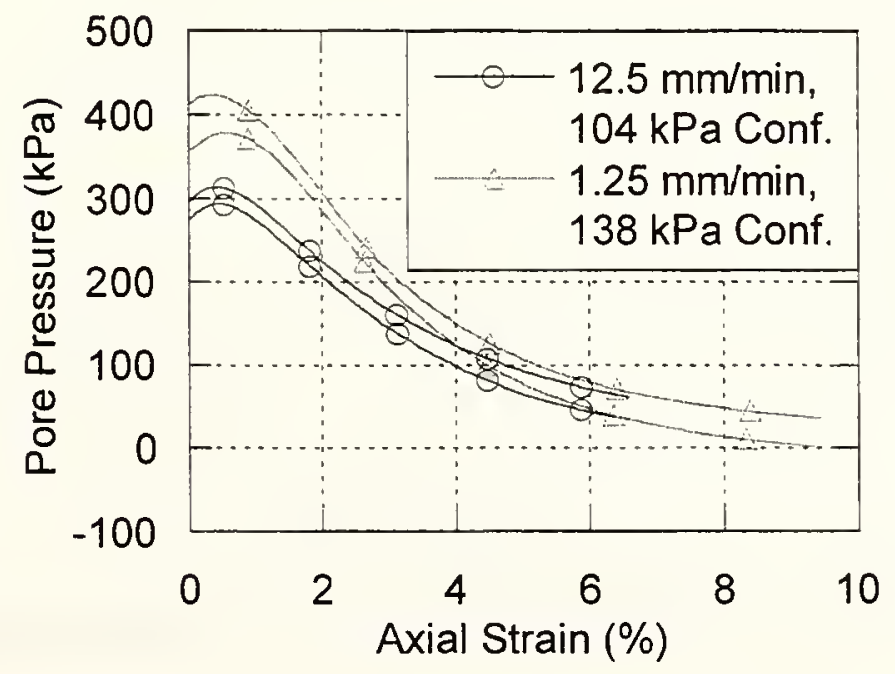

Figure D.18 Pore Pressure vs. Axial Strain on \#9 Binder Mixture CU Test 


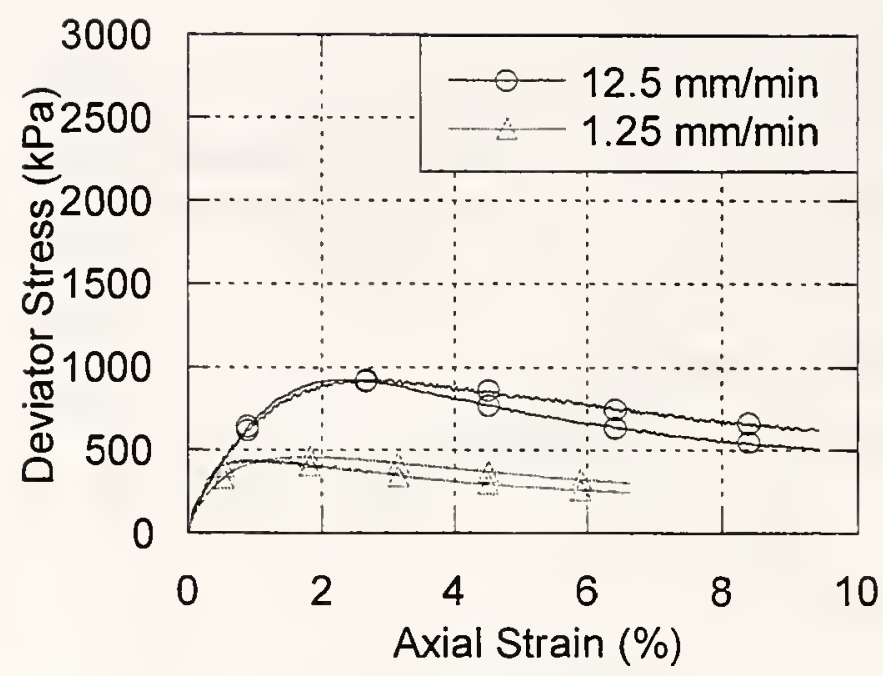

Figure D.19 Stress-Strain on \#8 Binder Mixture Dry Test (35 kPa Confining Pressure)

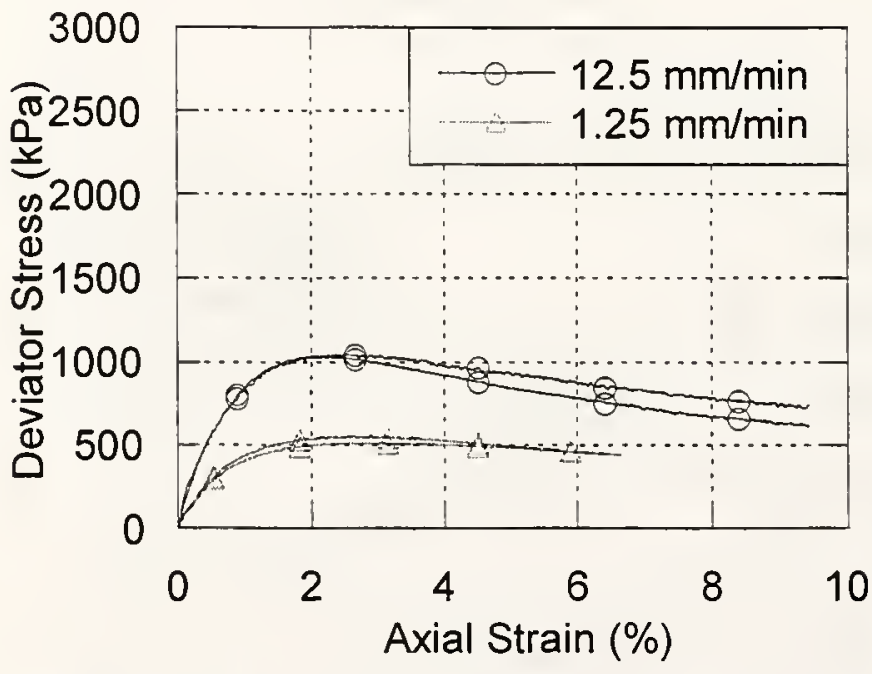

Figure D.20 Stress-Strain on \#8 Binder Mixture Dry Test (69 kPa Confining Pressure) 


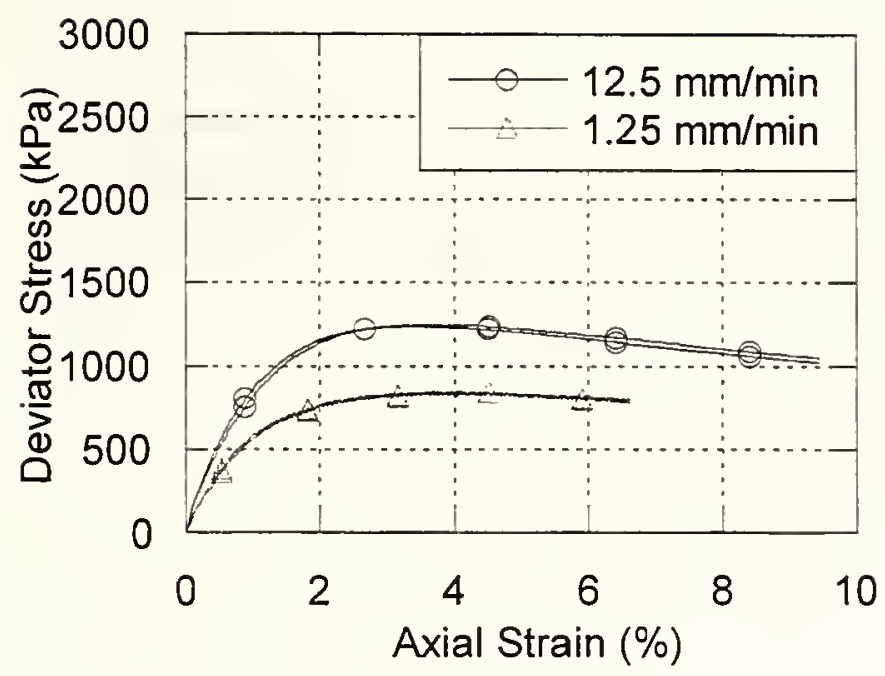

Figure D.21 Stress-Strain on \#8 Binder Mixture Dry Test (138 kPa Confining Pressure)

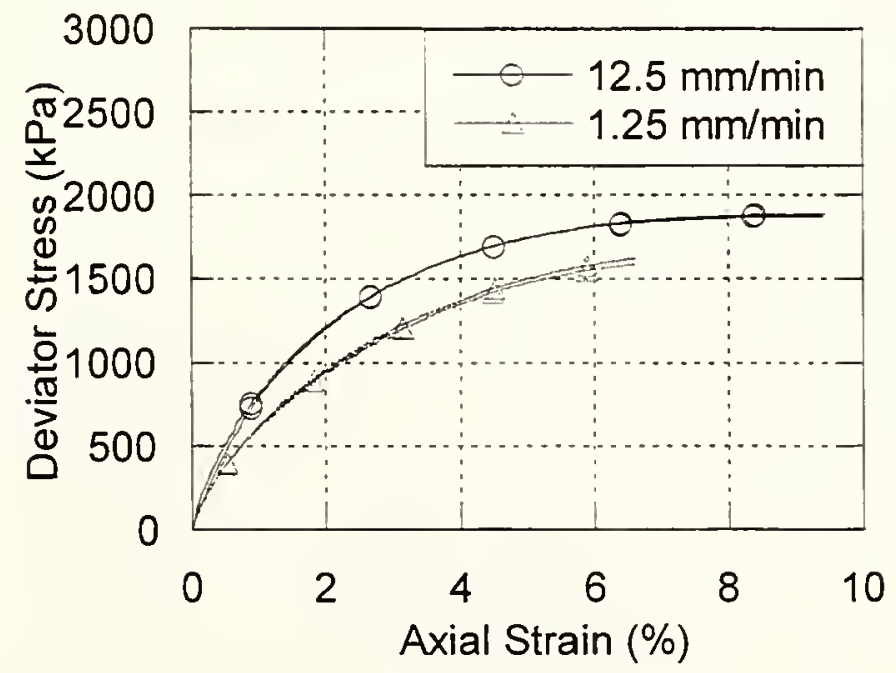

Figure D.22 Stress -Strain on \#8 Binder Mixture CU Test (35 kPa Confining Pressure) 


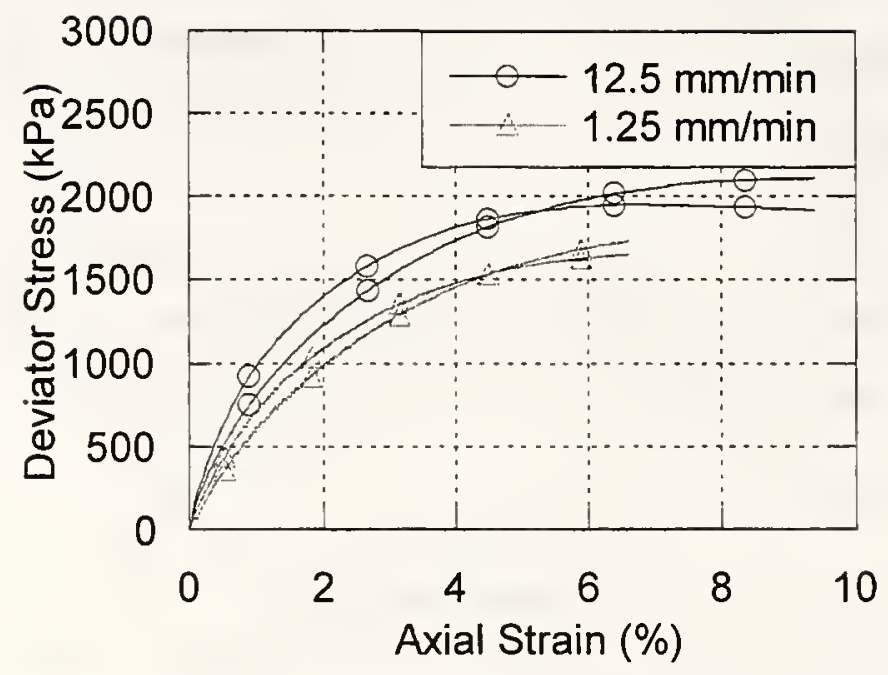

Figure D.23 Stress -Strain on \#8 Binder Mixture CU Test (69 kPa Confining Pressure)

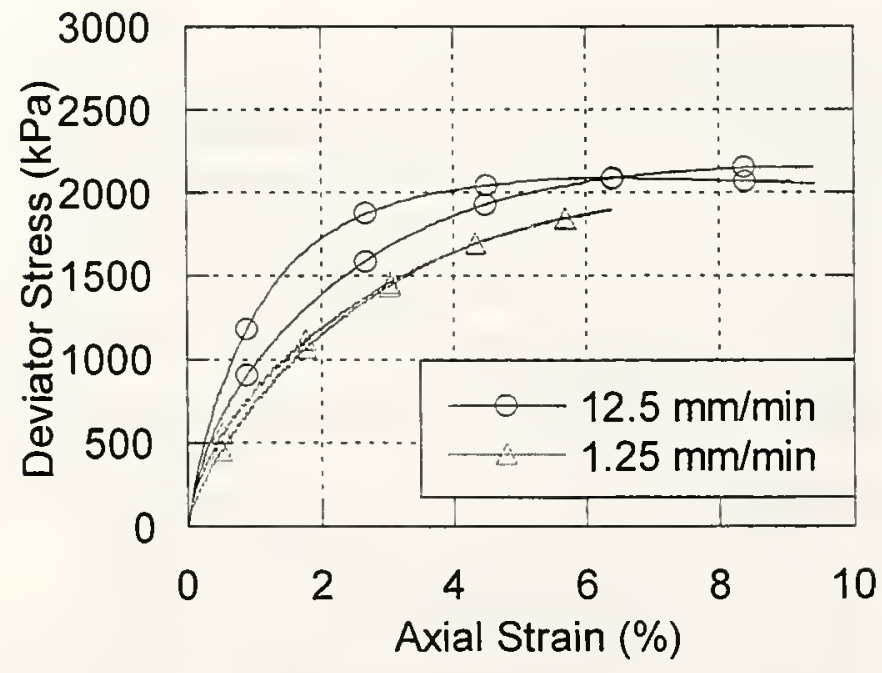

FigureD.24 Stress -Strain on \#8 Binder Mixture CU Test (105 kPa Confining Pressure) 


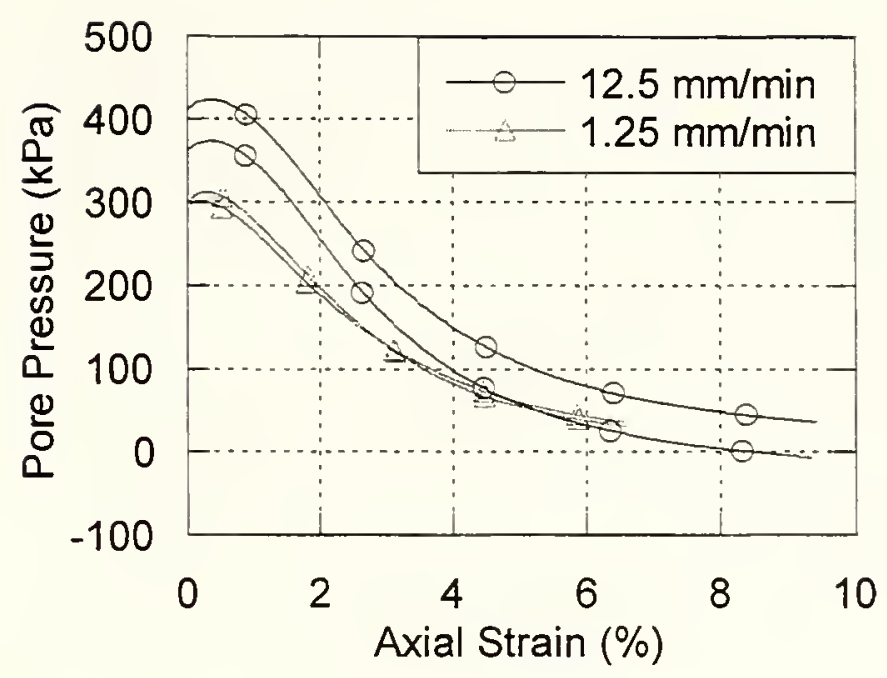

Figure D.25 Pore Pressure vs. Axial Strain on \#8 Binder Mixture CU Test (35 kPa Confining Pressure)

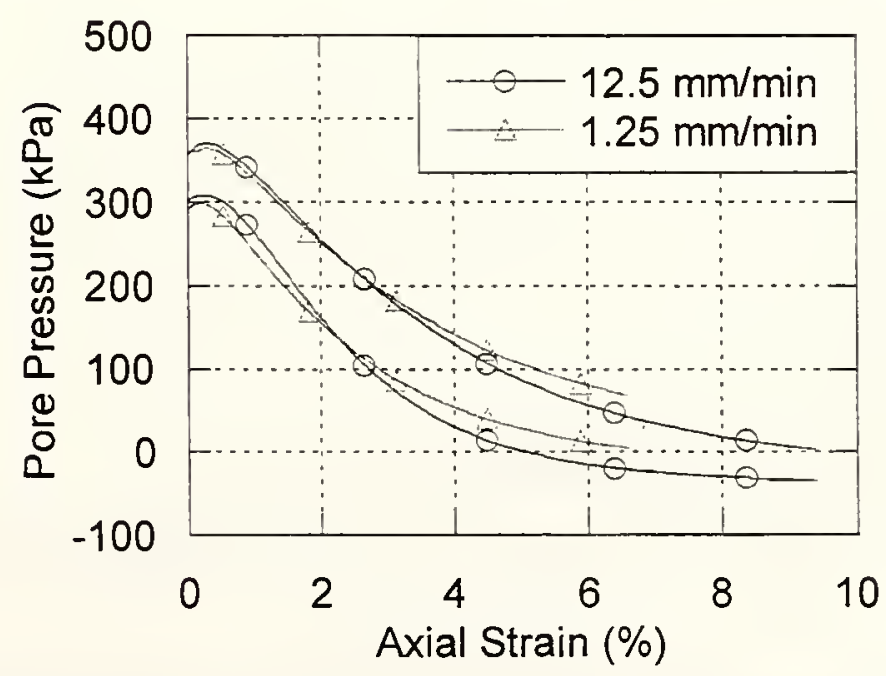

Figure D.26 Pore Pressure vs. Axial Strain on \#8 Binder Mixture CU Test $(69 \mathrm{kPa}$ Confining Pressure) 


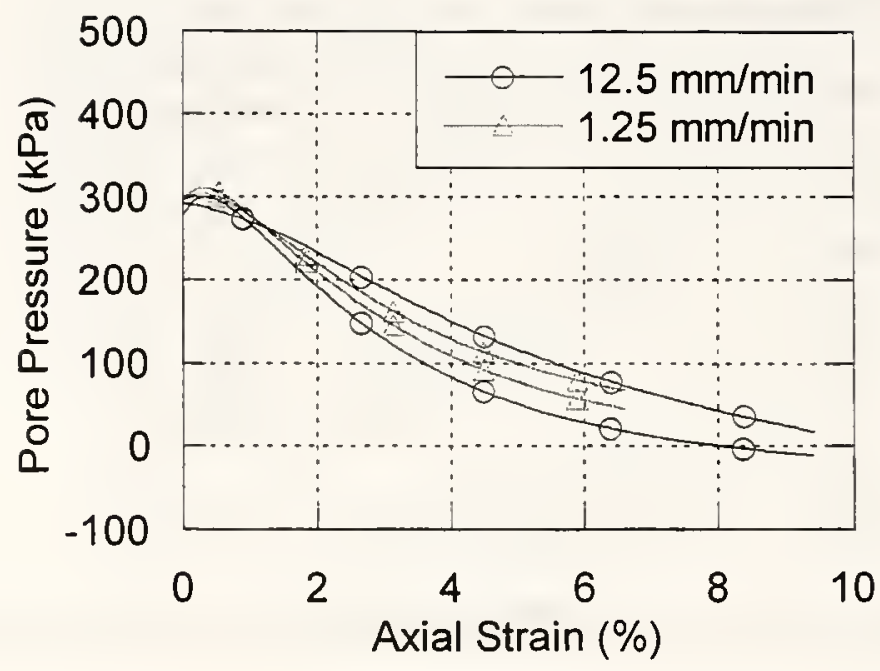

Figure D.27 Pore Pressure vs. Axial Strain on \#8 Binder Mixture CU Test (105 kPa Confining Pressure)

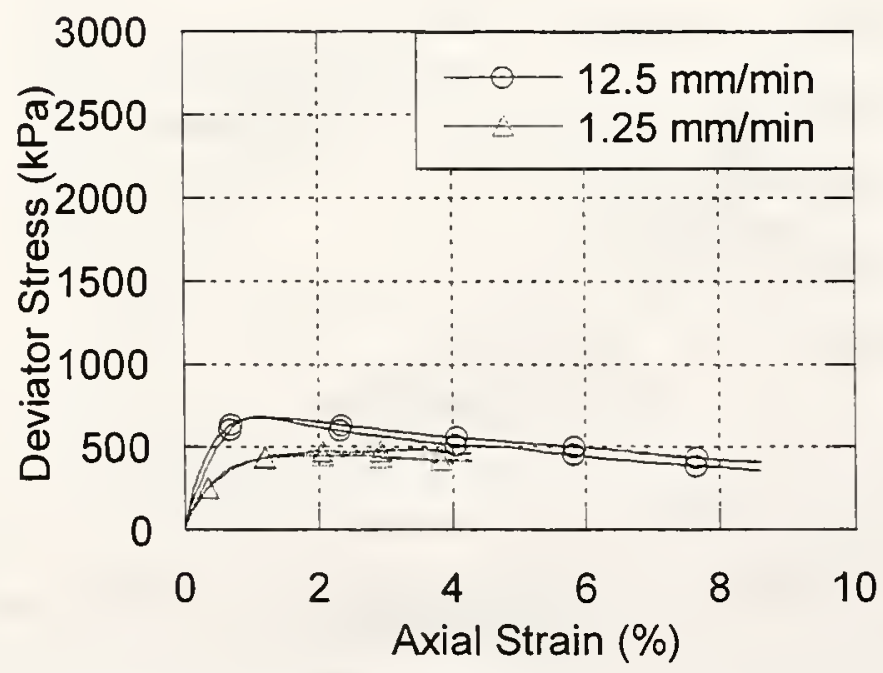

Figure D.28 Stress - Strain on \#5C OG Mixture Dry Test (35 kPa Confining Pressure) 


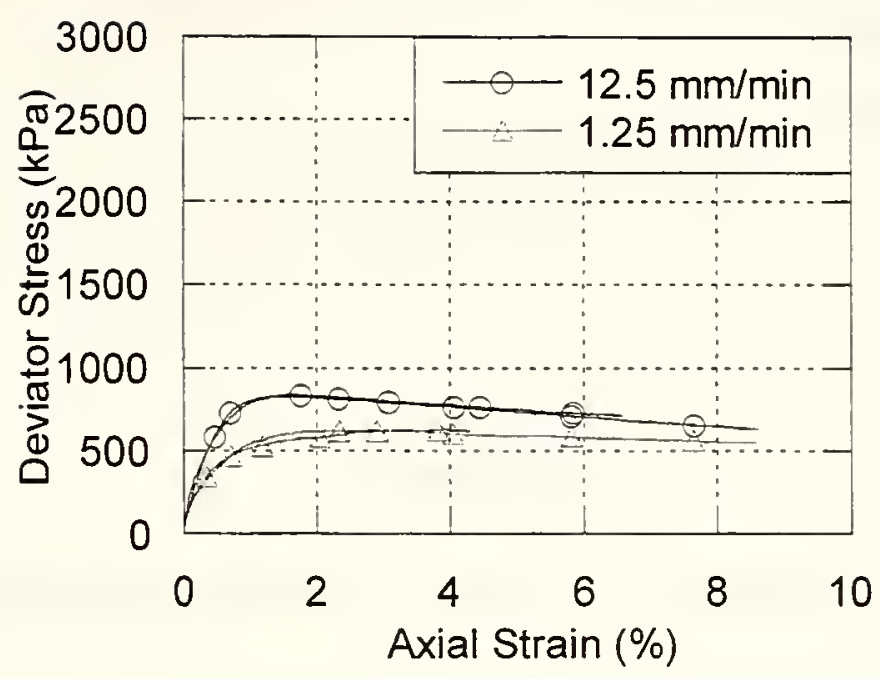

Figure D.29 Stress - Strain on \#5C OG Mixture Dry Test (69 kPa Confining Pressure)

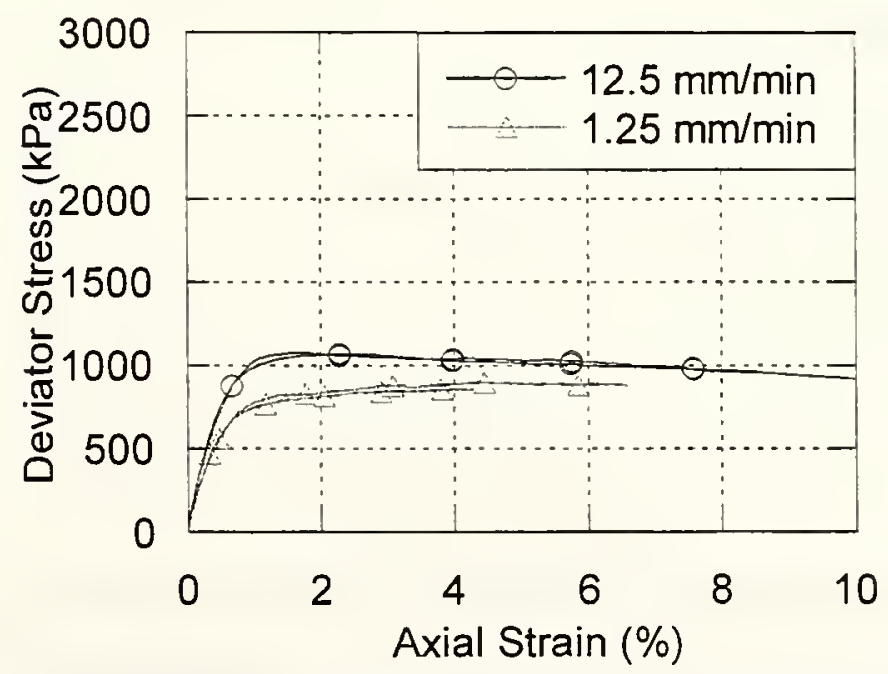

Figure D.30 Stress - Strain on \#5C OG Mixture Dry Test (138 kPa Confining Pressure) 


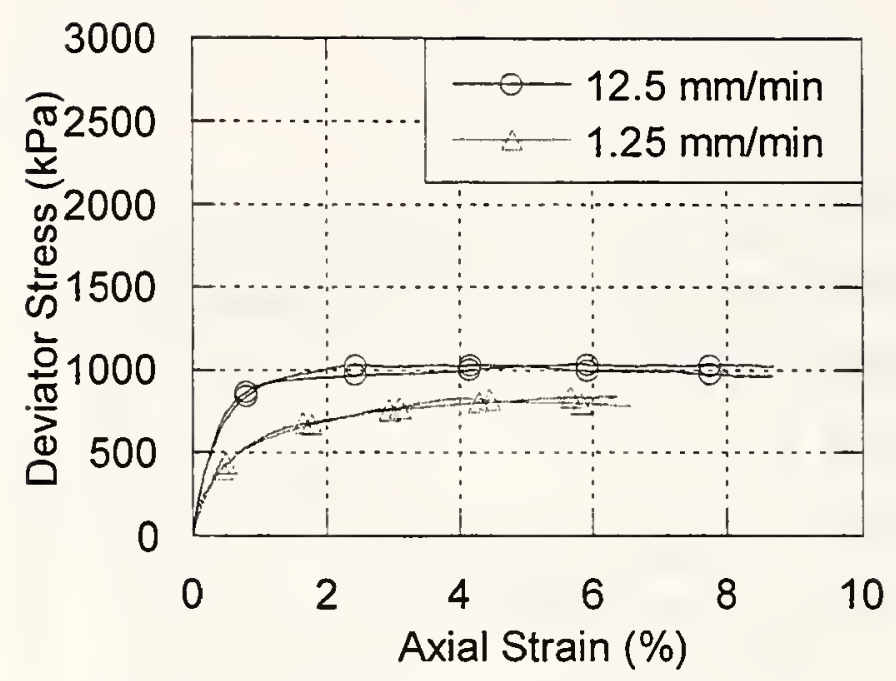

Figure D.31 Stress -Strain on \#5C OG Mixture CU Test (35 kPa Confining Pressure)

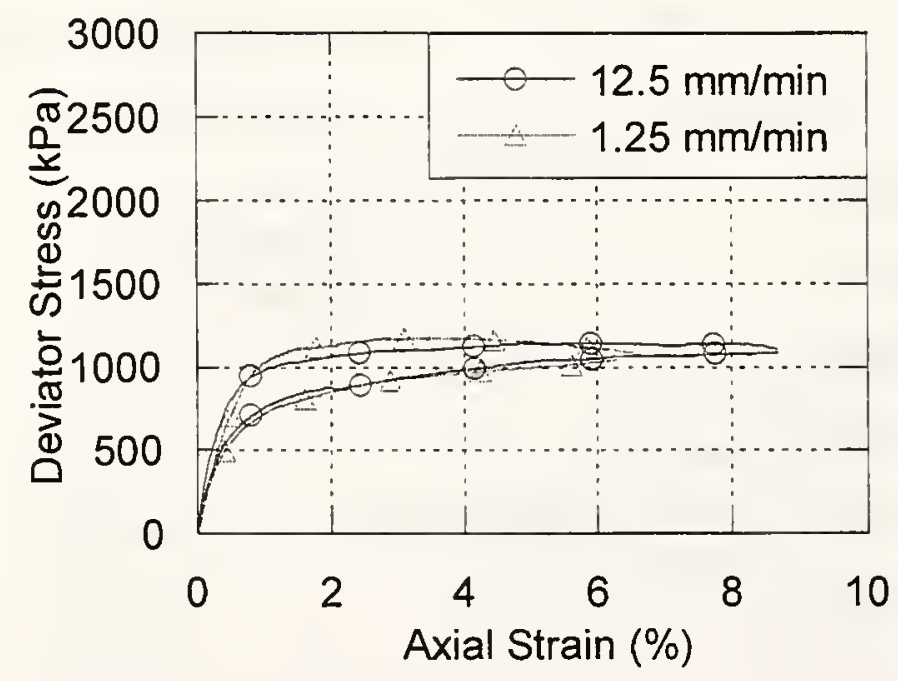

Figure D.32 Stress -Strain on \#5C OG Mixture CU Test (69 kPa Confining Pressure) 


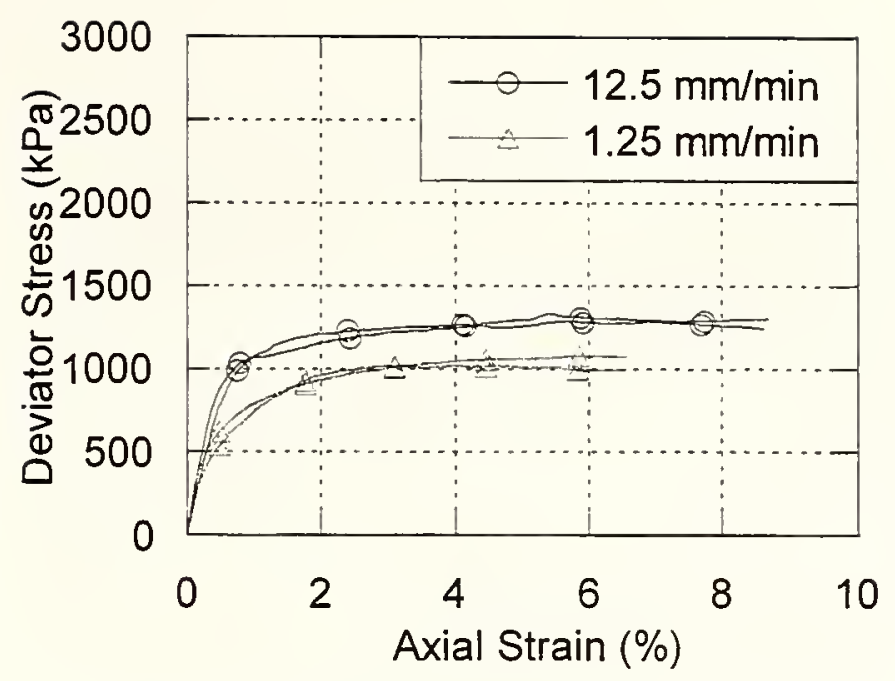

Figure D.33 Stress -Strain on \#5C OG Mixture CU Test (138 kPa Confining Pressure)

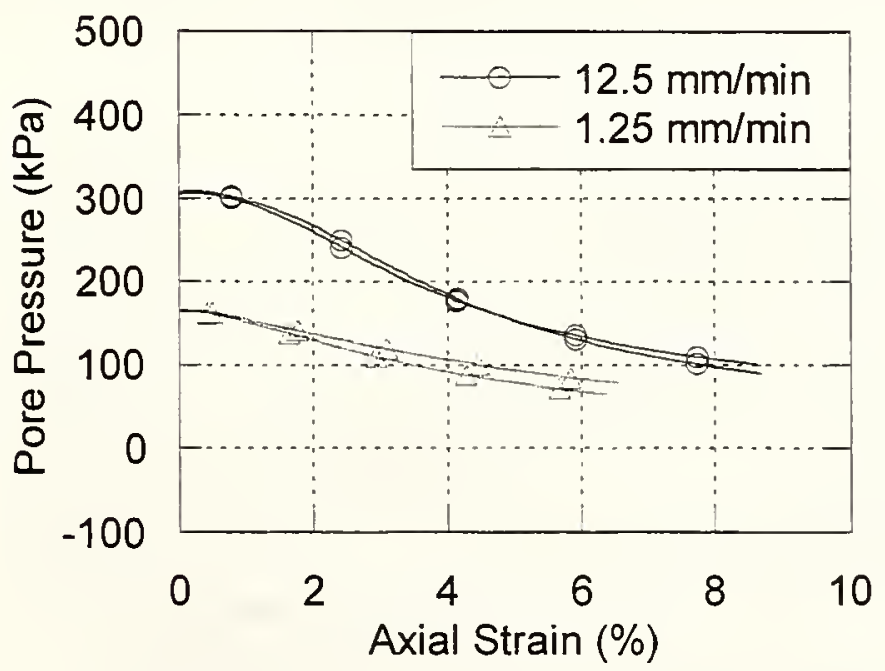

Figure D.34 Pore Pressure vs. Axial Strain on \#5C OG Mixture CU Test (35 kPa Confining Pressure) 


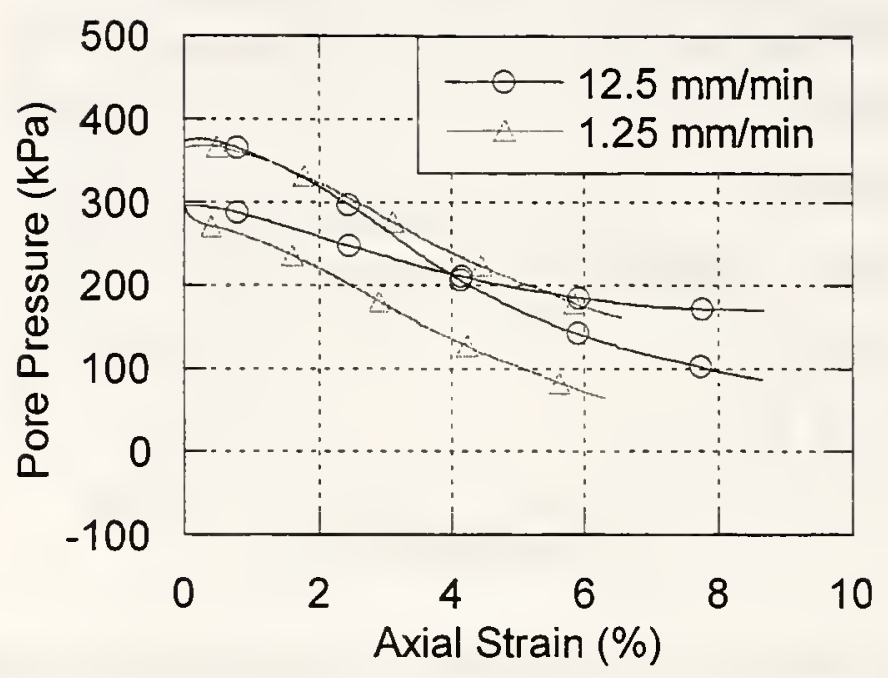

Figure D.35 Pore Pressure vs. Axial Strain on \#5C OG Mixture CU Test (69 kPa Confining Pressure)

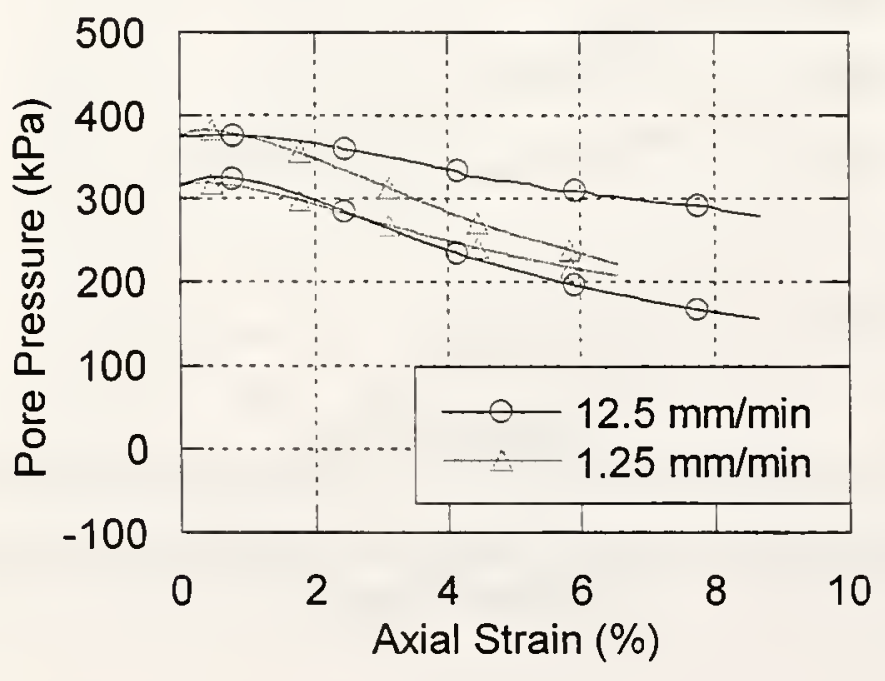

Figure D.36 Pore Pressure vs. Axial Strain on \#5C OG Mixture CU Test (138 kPa Confining Pressure) 


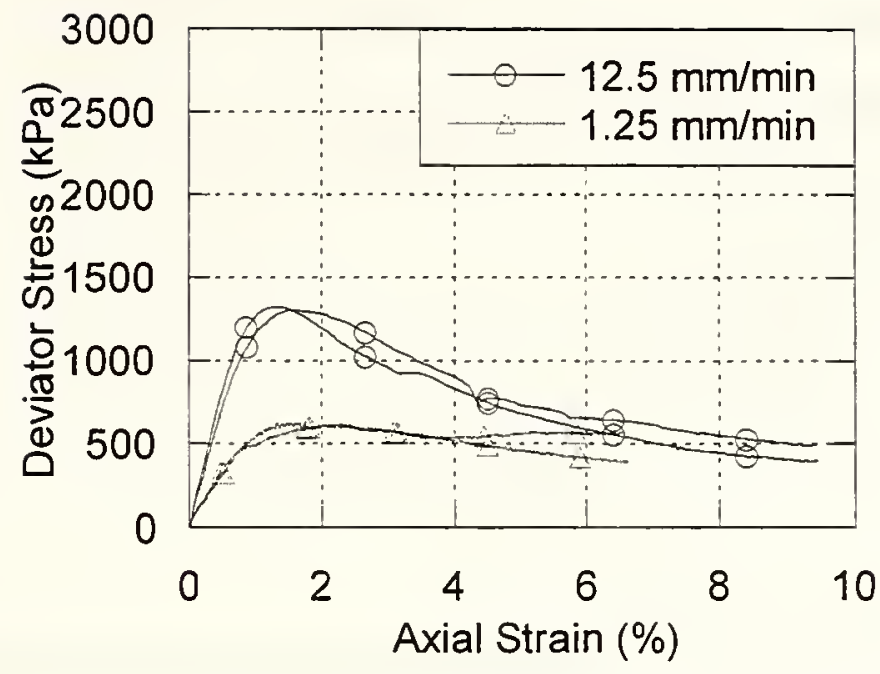

Figure D.37 Stress-Strain on \#5D Base Mixture Dry Test (35 kPa Confining Pressure)

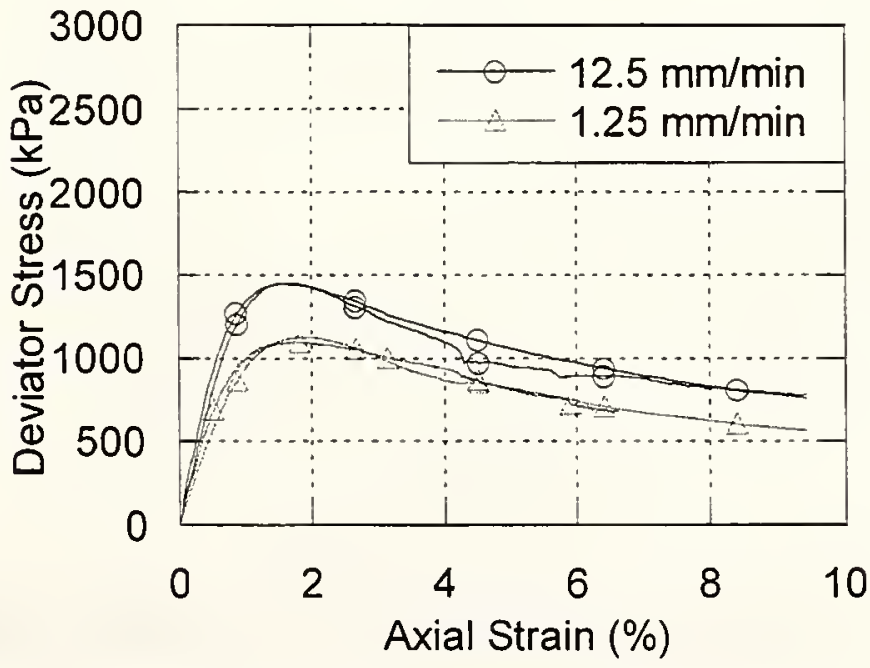

Figure D.38 Stress - Strain on \#5D Base Mixture Dry Test (69 kPa Confining Pressure) 


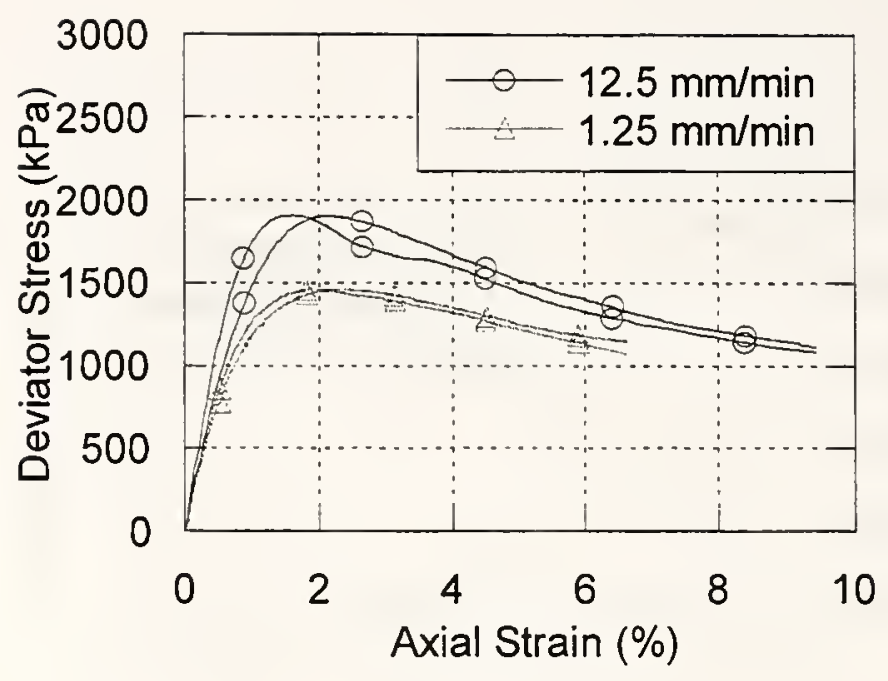

Figure D.39 Stress - Strain on \#5D Base Mixture Dry Test (138 kPa Confining Pressure)

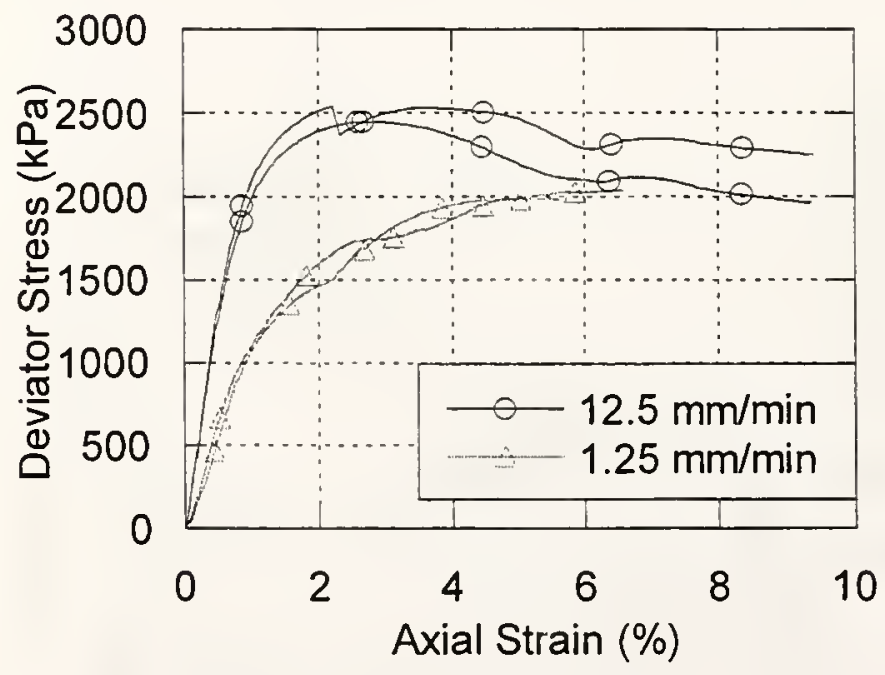

Figure D.40 Stress -Strain on \#5D Base Mixture CU Test (35 kPa Confining Pressure) 


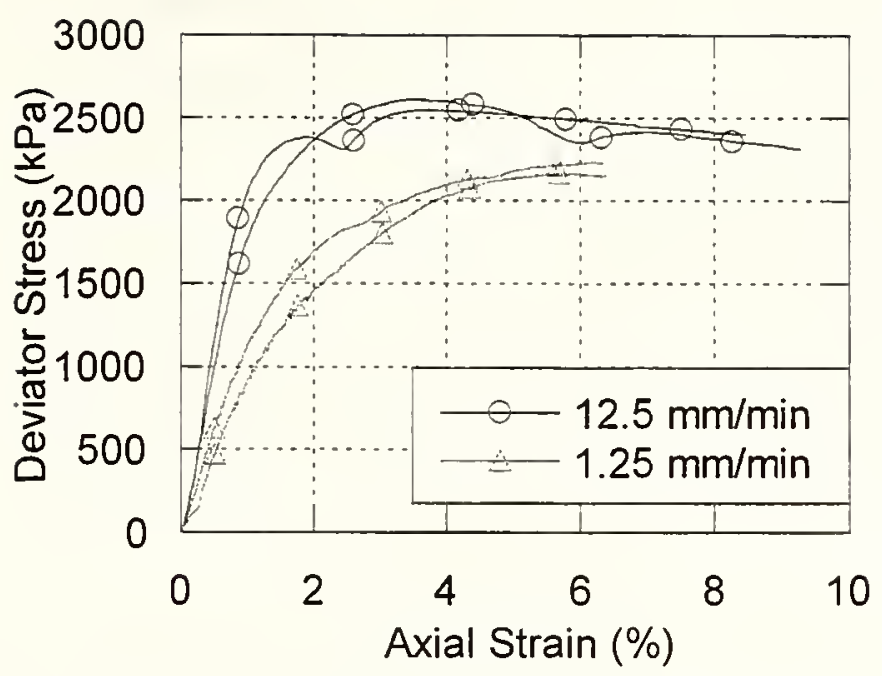

Figure D.41 Stress -Strain on \#5D Base Mixture CU Test (55 kPa Confining Pressure)

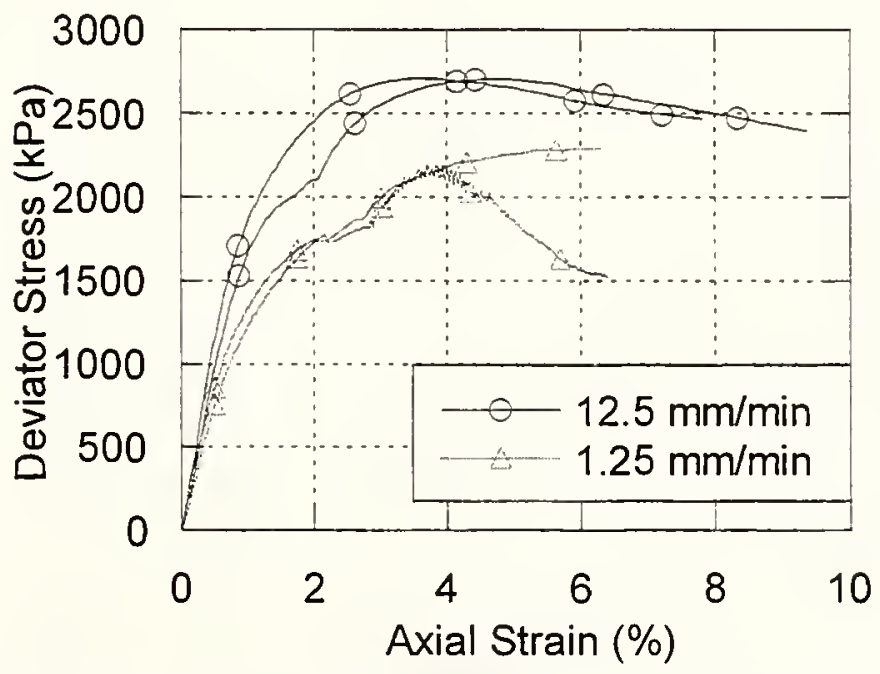

Figure D.42 Stress -Strain on \#5D Base Mixture CU Test (69 kPa Confining Pressure) 


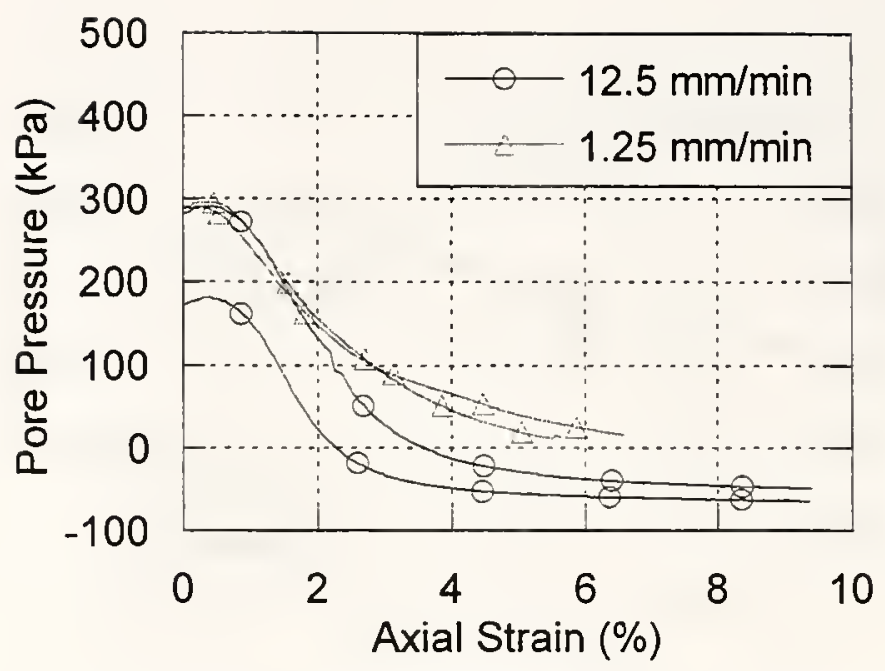

Figure D.43 Pore Pressure vs. Axial Strain on \#5D Base Mixture CU Test ( $35 \mathrm{kPa}$ Confining Pressure)

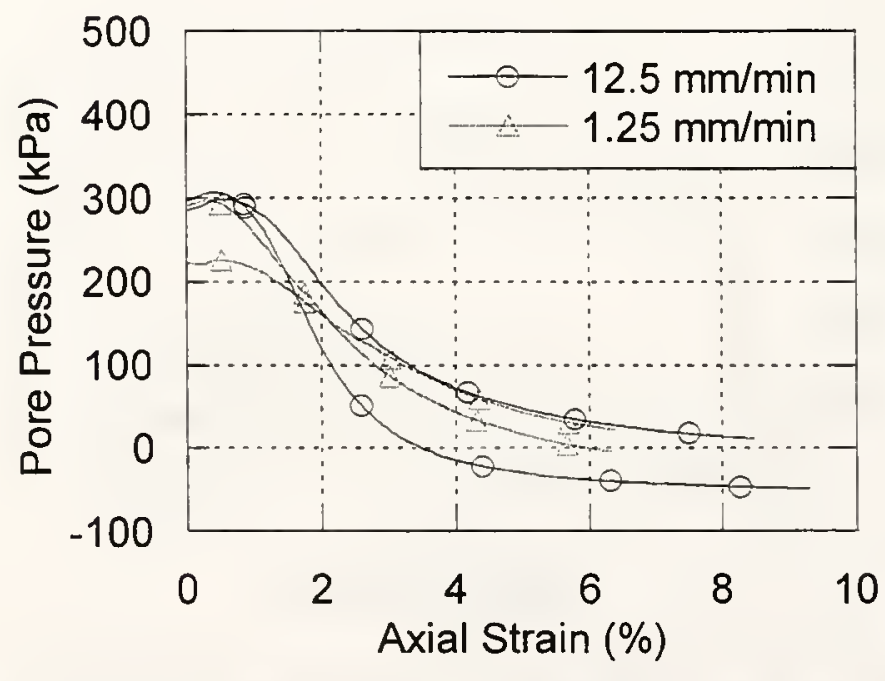

Figure D.44 Pore Pressure vs. Axial Strain on \#5D Base Mixture CU Test (55 kPa Confining Pressure) 


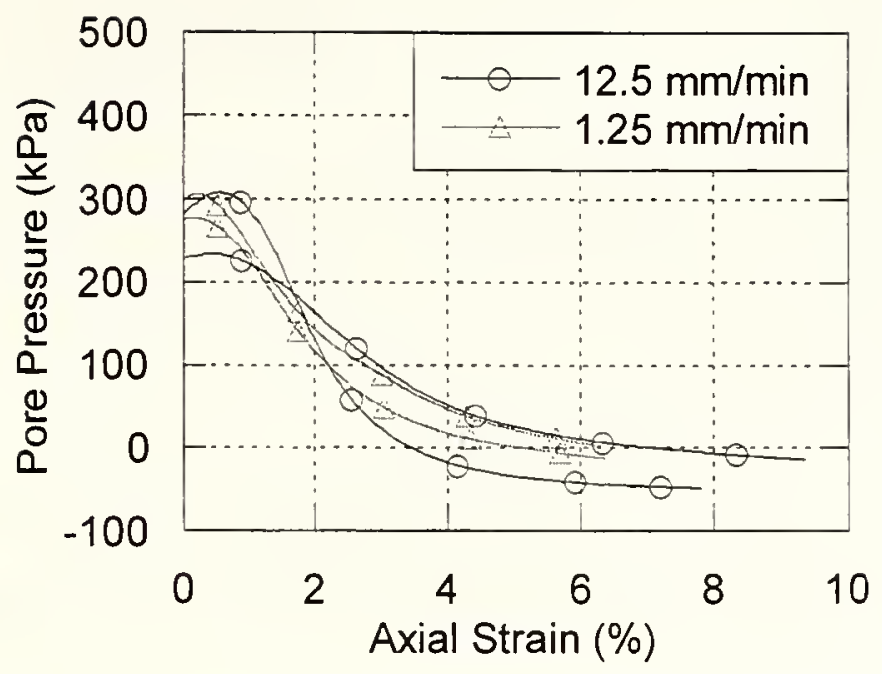

Figure D.45 Pore Pressure vs. Axial Strain on \#5D Base Mixture CU Test (69 kPa Confining Pressure)

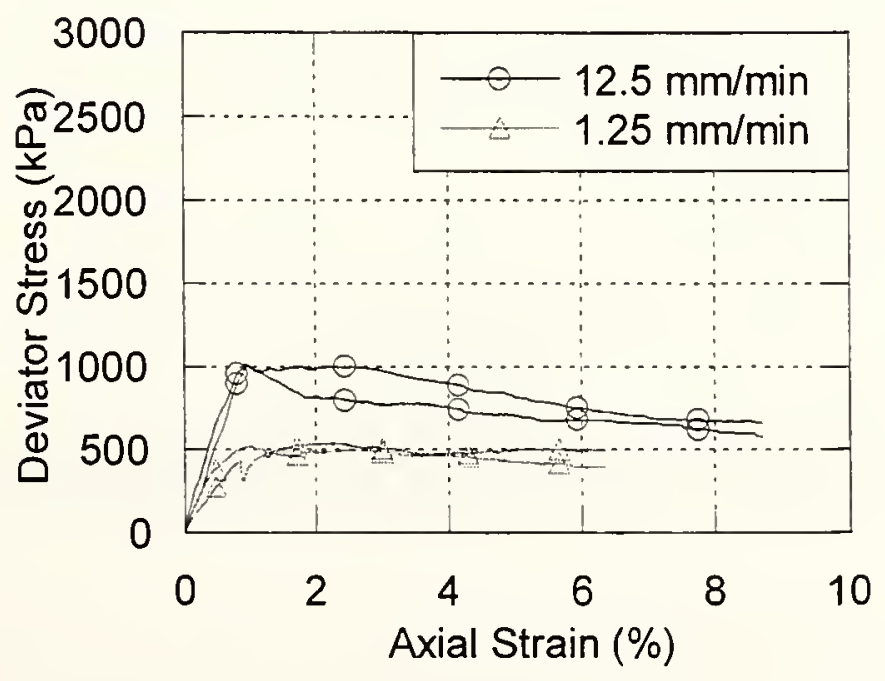

Figure D.46 Stress - Strain on \#2 Base Mixture Dry Test (35 kPa Confining Pressure) 


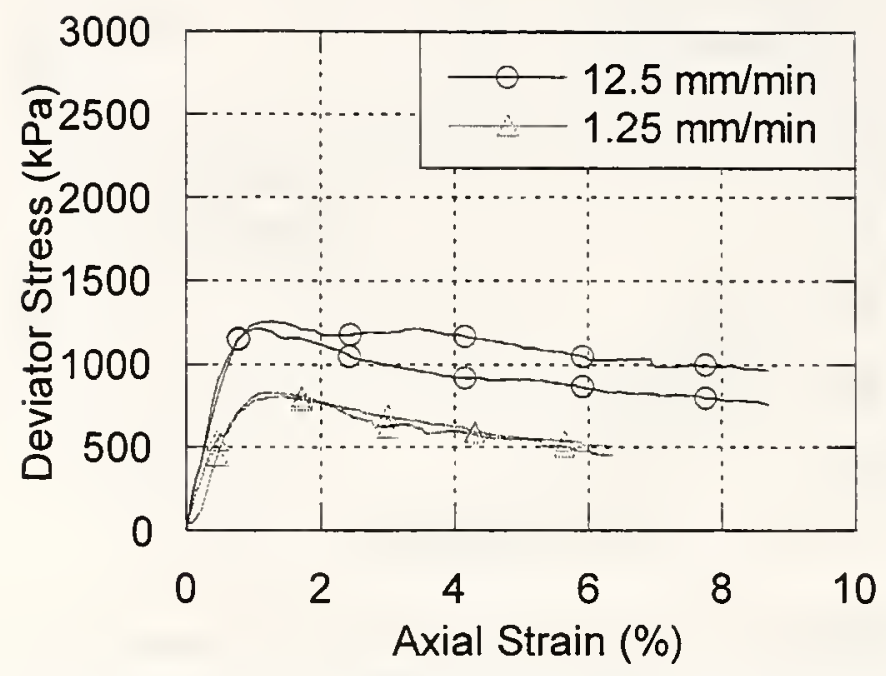

Figure D.47 Stress - Strain on \#2 Base Mixture Dry Test (69 kPa Confining Pressure)

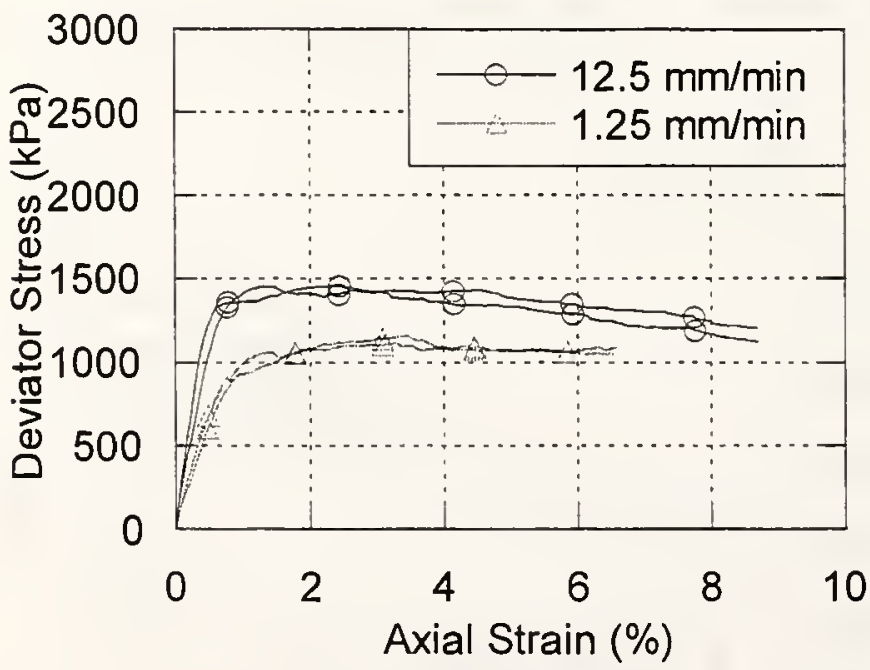

Figure D.48 Stress - Strain on \#2 Base Mixture Dry Test (138 kPa Confining Pressure) 


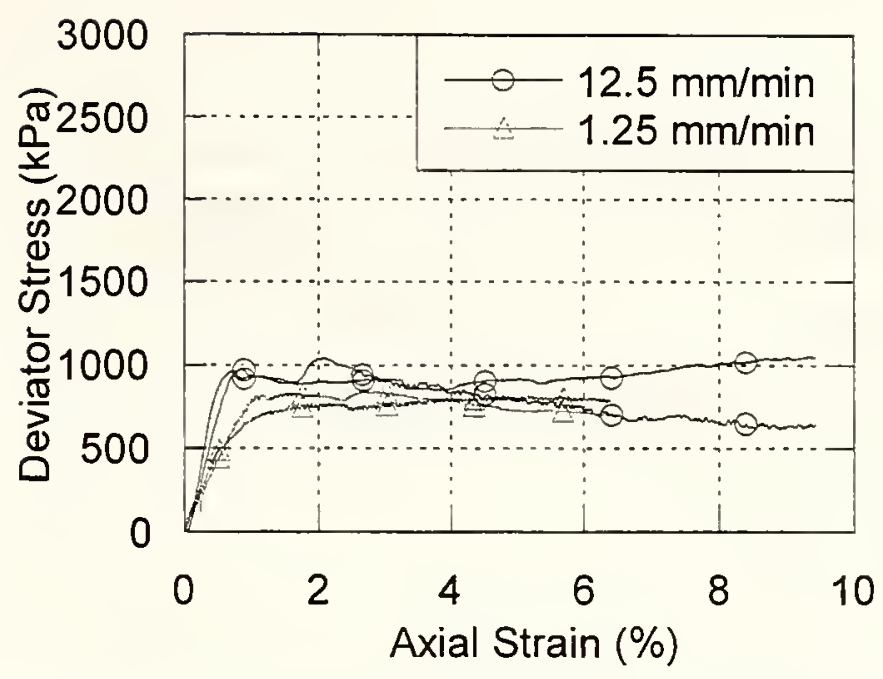

Figure D.49 Stress - Strain on \#2 Base Mixture CU Test (35 kPa Confining Pressure)

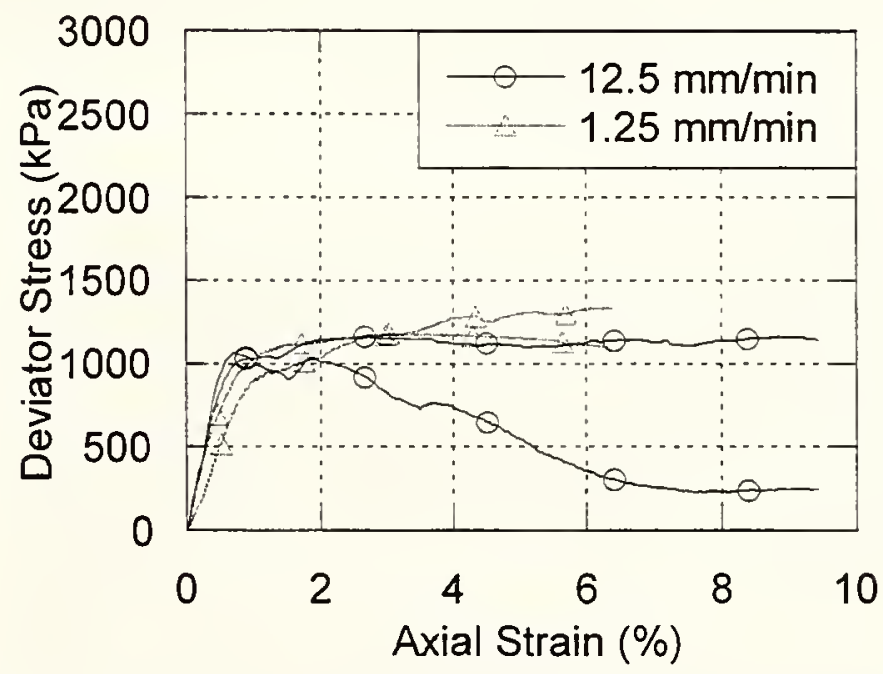

Figure D.50 Stress - Strain on \#2 Base Mixture CU Test (69 kPa Confining Pressure) 


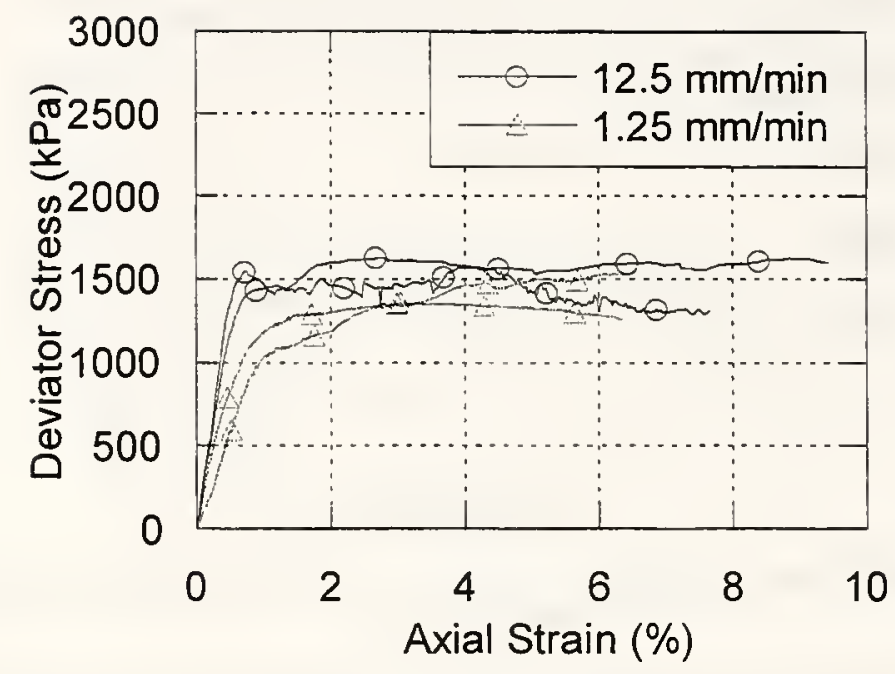

Figure D.51 Stress - Strain on \#2 Base Mixture CU Test (138 kPa Confining Pressure)

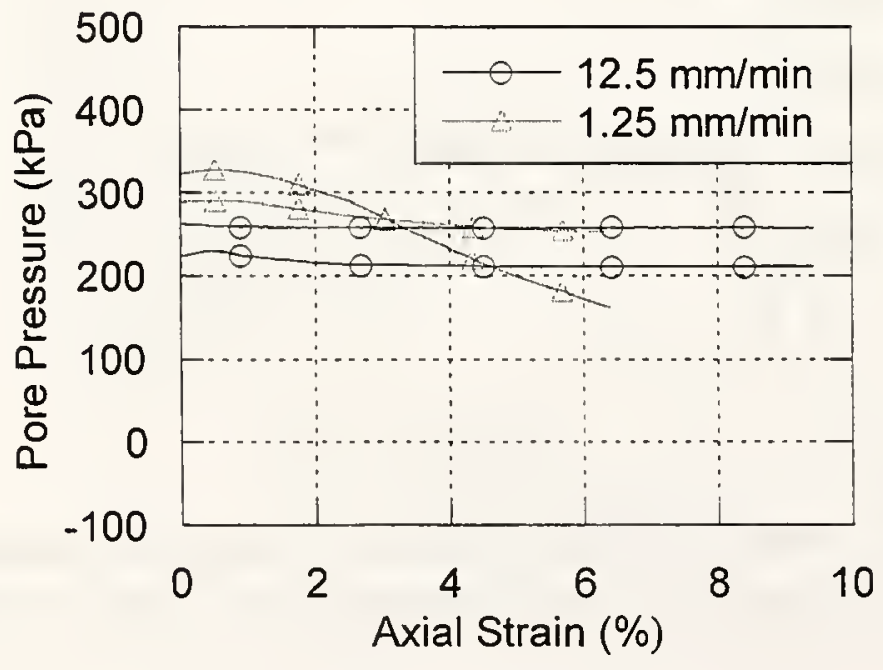

Figure D.52 Pore Pressure vs. Axial Strain on \#2 Base Mixture CU Test (35 kPa Confining Pressure) 


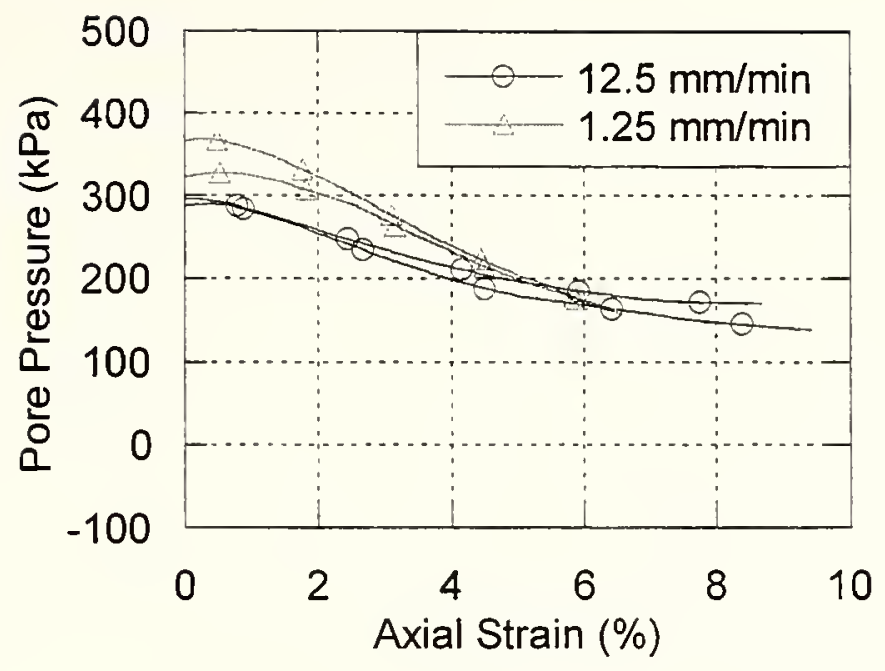

Figure D.53 Pore Pressure vs. Axial Strain on \#2 Base Mixture CU Test (69 kPa Confining Pressure)

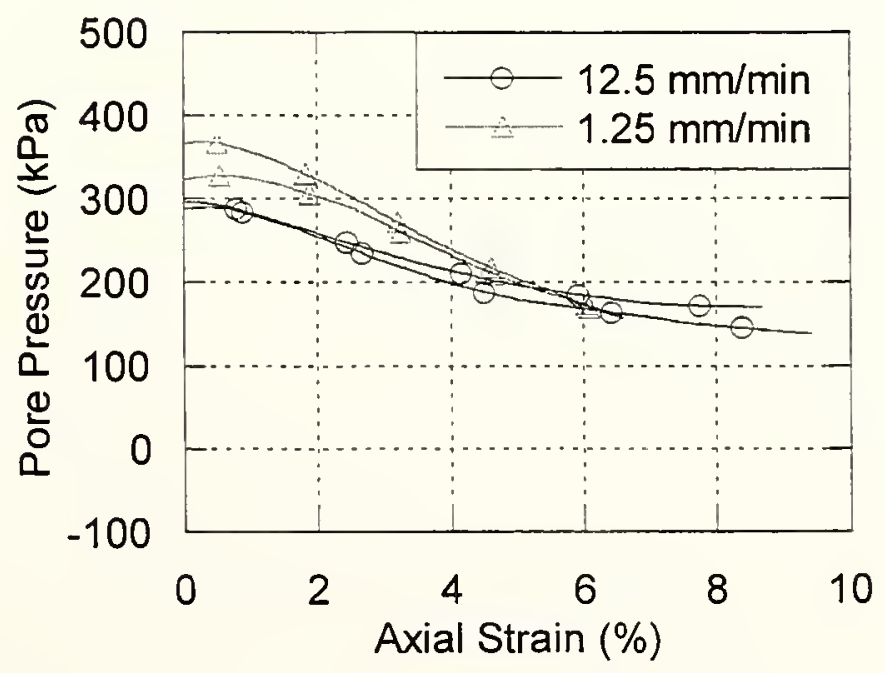

Figure D.54 Pore Pressure vs. Axial Strain on \#2 Base Mixture CU Test (138 kPa Confining Pressure) 
Appendix E Condition Survey Data 
Pavement Distress Types:
1. Alligator Cracking
2. Bleeding
3. Block Cracking
4. Corrugation
5. Depression
6. Jet Blast
7. Jt Reflection (PCC)
8. Long \& Trans. Cracking
9. Shoulder Crack
10. Patching
11. Polished Aggregate
12. Raveling/Weathering
13. Rutting
14. Slippage Cracking
15. Swell

Condition Survey for the Driving Lane of Section 1, June, 1997

\begin{tabular}{|c|c|c|c|c|}
\hline $\begin{array}{c}\text { Distress } \\
\text { Severity }\end{array}$ & Quantity & Total & Density (\%) & Deduct Values \\
\hline $8 \mathrm{~L}$ & 250 & 250 & 2.6 & 4 \\
\hline \multicolumn{3}{|c|}{ Potal Deduct Value } & 4 \\
\hline \multicolumn{2}{|c|}{ PCI } \\
\hline
\end{tabular}

Condition Survey for the Passing Lane of Section 1, June, 1997

\begin{tabular}{|c|c|c|c|c|c|c|}
\hline $\begin{array}{c}\text { Distress } \\
\text { Severity }\end{array}$ & \multicolumn{3}{|c|}{ Quantity } & Total & $\begin{array}{c}\text { Density } \\
(\%)\end{array}$ & $\begin{array}{c}\text { Deduct } \\
\text { Values }\end{array}$ \\
\hline $13 \mathrm{~L}$ & $12^{\prime \prime} \times 400^{\prime}$ & & & 250 & 4.2 & 18 \\
\hline $12 \mathrm{~L}$ & 2 & 1 & & 3 & 0.03 & 0 \\
\hline \multicolumn{6}{|c|}{ Total Deduct Value } & 18 \\
\hline \multicolumn{6}{|c}{ PCI } \\
\hline
\end{tabular}


Condition Survey for the Driving Lane of Section 2, June, 1997

\begin{tabular}{|c|c|c|c|c|}
\hline $\begin{array}{c}\text { Distress } \\
\text { Severity }\end{array}$ & Quantity & Total & Density (\%) & Deduct Values \\
\hline $8 \mathrm{~L}$ & 15 & 15 & 0.15 & 0 \\
\hline \multicolumn{3}{|c|}{ Total Deduct Value } & 0 \\
\hline \multicolumn{2}{|c|}{ PCI } \\
\hline
\end{tabular}

Condition Survey for the Passing Lane of Section 2, June, 1997

\begin{tabular}{|c|c|c|c|c|c|c|}
\hline $\begin{array}{c}\text { Distress } \\
\text { Severity }\end{array}$ & \multicolumn{3}{|c|}{ Quantity } & Total & Density (\%) & $\begin{array}{c}\text { Deduct } \\
\text { Values }\end{array}$ \\
\hline $13 \mathrm{~L}$ & $12 " \times 100^{\prime}$ & & & 100 & 1.0 & 15 \\
\hline $17 \mathrm{~L}$ & $2 \times 1$ & & & 2 & 0.02 & 0 \\
\hline $9 \mathrm{~L}$ & $1 \times 0.5$ & & 0.5 & & 0 \\
\hline \multicolumn{6}{|c|}{ Total Deduct Value } & 15 \\
\hline \multicolumn{6}{|c|}{ PCI } \\
\hline
\end{tabular}

Condition Survey for the Driving Lane of Section 3, June, 1997

\begin{tabular}{|c|c|c|c|c|}
\hline $\begin{array}{c}\text { Distress } \\
\text { Severity }\end{array}$ & Quantity & Total & Density (\%) & Deduct Values \\
\hline $9 \mathrm{~L}$ & 100 & 100 & 1.0 & 3 \\
\hline $11 \mathrm{~L}$ & $1 \times 1$ & & & 0 \\
\hline $8 \mathrm{~L}$ & $15^{\prime}$ & & 0.01 & 0 \\
\hline $12 \mathrm{~L}$ & $1 \times 1$ & 1 & & 3 \\
\hline \multicolumn{5}{|c|}{ PCI } \\
\hline
\end{tabular}


Condition Survey for the Passing Lane of Section 3, June, 1997

\begin{tabular}{|c|c|c|c|c|c|c|}
\hline $\begin{array}{c}\text { Distress } \\
\text { Severity }\end{array}$ & \multicolumn{3}{|c|}{ Quantity } & Total & Density (\%) & $\begin{array}{c}\text { Deduct } \\
\text { Values }\end{array}$ \\
\hline $11 \mathrm{~L}$ & 1 & 1 & 1 & 3 & 0.03 & 0 \\
\hline $8 \mathrm{~L}$ & 150 & & & 150 & 1.6 & 3 \\
\hline 9L & 150 & & & 150 & 1.6 & 3 \\
\hline \multicolumn{7}{|c|}{ Total Deduct Value } \\
\hline \multicolumn{7}{|c|}{ PCI } \\
\hline
\end{tabular}

Condition Survey for the Driving Lane of Section 1, September, 1998

\begin{tabular}{|c|c|c|c|c|}
\hline $\begin{array}{c}\text { Distress } \\
\text { Severity }\end{array}$ & Quantity & Total & Density (\%) & Deduct Values \\
\hline 9L & 200 & 200 & 2.2 & 4 \\
\hline 8L & 250 & 250 & 2.6 & 4 \\
\hline \multicolumn{3}{|c|}{ PCI } & 8 \\
\hline
\end{tabular}

Condition Survey for the Passing Lane of Section 1, September, 1998

\begin{tabular}{|c|c|c|c|c|c|c|}
\hline $\begin{array}{c}\text { Distress } \\
\text { Severity }\end{array}$ & \multicolumn{3}{|c|}{ Quantity } & Total & Density (\%) & $\begin{array}{c}\text { Deduct } \\
\text { Values }\end{array}$ \\
\hline $13 \mathrm{~L}$ & $12^{\prime \prime} \times 500^{\prime}$ & & & 250 & 5.2 & 22 \\
\hline $12 \mathrm{~L}$ & 2 & 1 & & 3 & 0.03 & 0 \\
\hline \multicolumn{6}{|c|}{ Total Deduct Value } & 22 \\
\hline
\end{tabular}


Condition Survey for the Driving Lane of Section 2, September, 1998

\begin{tabular}{|c|c|c|c|c|}
\hline $\begin{array}{c}\text { Distress } \\
\text { Severity }\end{array}$ & Quantity & Total & Density (\%) & Deduct Values \\
\hline $9 \mathrm{~L}$ & 400 & 400 & 4.5 & 6 \\
\hline $8 \mathrm{~L}$ & 15 & 15 & 0.15 & 0 \\
\hline \multicolumn{5}{|c|}{ Total Deduct Value } \\
\hline \multicolumn{3}{|c|}{ PCI } \\
\hline
\end{tabular}

Condition Survey for the Passing Lane of Section 2, September, 1998

\begin{tabular}{|c|c|c|c|c|c|c|}
\hline $\begin{array}{c}\text { Distress } \\
\text { Severity }\end{array}$ & \multicolumn{3}{|c|}{ Quantity } & Total & Density (\%) & $\begin{array}{c}\text { Deduct } \\
\text { Values }\end{array}$ \\
\hline $13 \mathrm{~L}$ & $12^{\prime \prime} \times 130^{\prime}$ & & & 100 & 1.3 & 10 \\
\hline $17 \mathrm{~L}$ & $2 \times 1$ & & & 2 & 0.02 & 0 \\
\hline $9 \mathrm{~L}$ & $1 \times 0.5$ & & & 0.5 & & 0 \\
\hline \multicolumn{6}{|c|}{ Total Deduct Value } \\
\hline \multicolumn{3}{c|}{ PCI } \\
\hline
\end{tabular}


Condition Survey for the Driving Lane of Section 3, September, 1998

\begin{tabular}{|c|c|c|c|c|c|}
\hline $\begin{array}{c}\text { Distress } \\
\text { Severity }\end{array}$ & \multicolumn{2}{|c|}{ Quantity } & Total & Density (\%) & Deduct Values \\
\hline $9 \mathrm{~L}$ & 100 & 300 & 400 & 4.2 & 7 \\
\hline $11 \mathrm{~L}$ & $1 \times 1$ & & & & 0 \\
\hline $8 \mathrm{~L}$ & $15^{\prime}$ & & & & 0 \\
\hline $12 \mathrm{~L}$ & $1 \times 1$ & & 1 & 0.01 & 0 \\
\hline \multicolumn{6}{|c|}{ Total Deduct Value } \\
\hline \multicolumn{3}{|c|}{ PCI } \\
\hline
\end{tabular}

Condition Survey for the Passing Lane of Section 3, September, 1998

\begin{tabular}{|c|c|c|c|c|c|c|}
\hline $\begin{array}{c}\text { Distress } \\
\text { Severity }\end{array}$ & \multicolumn{3}{|c|}{ Quantity } & Total & Density (\%) & $\begin{array}{c}\text { Deduct } \\
\text { Values }\end{array}$ \\
\hline $11 \mathrm{~L}$ & 1 & 1 & 1 & 3 & 0.03 & 0 \\
\hline $8 \mathrm{~L}$ & 160 & & & 150 & 1.7 & 5 \\
\hline 9L & 150 & & 150 & 1.6 & 3 \\
\hline \multicolumn{7}{|c|}{ Total Deduct Value } \\
\hline
\end{tabular}



